\title{
NORTHEAST INDIA
}

\section{A READER}

Edited by

Bhagat Oinam and Dhiren A. Sadokpam 


\section{Northeast India}

Northeast India is a multifaceted and dynamic region that is constantly in focus because of its fragile political landscape characterized by endemic violence and conflicts. One of the first of its kind, this reader on Northeast India examines myriad aspects of the region - its people and its linguistic and cultural diversity.

- The chapters here highlight the key issues confronted by the Northeast in recent times: its history, politics, economy, gender equations, migration, ethnicity, literature and traditional performative practices.

- The book presents interlinkages between a range of socio-cultural issues and armed political violence while covering topics such as federalism, nationality, population, migration and social change.

- It discusses debates on development with a view to comprehensive policies and state intervention.

With its nuanced and wide-ranging overview, this volume makes new contributions to understanding a region that is critical to the future of South Asian geopolitics. The book will be of great interest to scholars and researchers of contemporary Northeast India as well as history, political science, area studies, international relations, sociology and social anthropology. It will also appeal to those interested in public administration, regional literature, cultural studies, population studies, development studies and economics.

Bhagat Oinam is Professor at the Centre for Philosophy at Jawaharlal Nehru University (JNU) and Concurrent Faculty at the Northeast India Studies Programme, JNU, New Delhi, India. He has worked at several institutes including the Indian Institute of Technology (IIT) Bombay, North Eastern Hill University, Centre for the Study of Developing Societies, and Centre for Studies in Civilizations (CSC). He has been a visiting scholar at Freie Universität and Tel Aviv University, among others. In addition to several articles published in journals and anthologies, he has co-edited the volume Perspectives on Manipuri Culture (2017) under the CSC series 'History of Science, Philosophy and Culture in Indian Civilization'.

Dhiren A. Sadokpam is an independent researcher and journalist based in Manipur. He is currently the Executive Editor of Eastern Quarterly, a journal on India's Northeast. Sadokpam was also the editor of the Imphal-based English daily, Hueiyen Lanpao. He has worked both in print and electronic media since 1996 and is currently engaged with independent works on media, culture and the political economy of Northeast India. 
$\because$ Taylor \& Francis

http://taylorandfrancis.com 


\section{Northeast India}

A Reader

\section{Edited by Bhagat Oinam and Dhiren A. Sadokpam}


First published 2018

by Routledge

2 Park Square, Milton Park, Abingdon, Oxon OX14 4RN

and by Routledge

711 Third Avenue, New York, NY 10017

Routledge is an imprint of the Taylor \& Francis Group, an informa business

(C) 2018 selection and editorial matter, Manipur Research

Forum; individual chapters, the contributors.

The right of Bhagat Oinam and Dhiren A. Sadokpam to be identified as the authors of the editorial material, and of the authors for their individual chapters, has been asserted in accordance with sections 77 and 78 of the Copyright, Designs and Patents Act 1988.

With the exception of Chapter 31, no part of this book may be reprinted or reproduced or utilised in any form or by any electronic, mechanical, or other means, now known or hereafter invented, including photocopying and recording, or in any information storage or retrieval system, without permission in writing from the publishers.

Chapter 31 of this book is available for free in PDF format as Open Access from the individual product page at www. routledge.com. It has been made available under a Creative Commons Attribution-Non Commercial-No Derivatives 4.0 license.

Trademark notice: Product or corporate names may be trademarks or registered trademarks, and are used only for identification and explanation without intent to infringe.

British Library Cataloguing-in-Publication Data

A catalogue record for this book is available from the British Library

Library of Congress Cataloging-in-Publication Data

A catalog record has been requested for this book

ISBN: 978-1-138-71657-5 (hbk)

ISBN: 978-0-429-48987-7 (ebk)

Typeset in Sabon

by Apex CoVantage, LLC 


\section{Contents}

List of tables

List of abbreviations

Notes on contributors

$\mathrm{xi}$

Acknowledgements

Introduction

BHAGAT OINAM AND DHIREN A. SADOKPAM

\section{PART I}

Armed political violence

1 Nationalist ideology, militarization and human rights in the Northeast

KAMAL MITRA CHENOY

2 Armed opposition groups in Northeast India:

The splinter scenario

PATRICK HOENIG AND K. KOKHO

\section{PART II}

The extraordinary law and its impact

3 Violence and terror under AFSPA 1958 and the people's movement against it 
vi Contents

PART III

National questions

5 Assamese nationality question SAJAL NAG

6 Challenges and predicaments of Naga nationalism H. SRIKANTH AND C. J. THOMAS

7 Narrating the nation in Manipur: Reproduction of a historical question

A. NONI MEETEI

PART IV

Land and territoriality

8 Land and ethnicity: A study of Manipur and its neighbourhood

LOKENDRA ARAMBAM

9 Politics of land alienation and problem of its restoration in Tripura

KHAKCHANG DEBBARMA

\section{PART V}

Migration and ethnicity

10 Illegal Bangladeshi migration into the Northeast:

Policy making, politics and road blocks

BIBHU PRASAD ROUTRAY

11 Employment, unemployment, job aspiration and migration: Some reflections of Tangkhul migrants to Delhi 
PART VI

Federal politics

12 Salvaging autonomy in India's Northeast: Beyond the Sixth Schedule way

KHAM KHAN SUAN HAUSING

13 Autonomy for tribal communities in India: A study of the Northeastern states

M. AMARJEET SINGH

PART VII

Locating civil society

14 Fast forward or living in a permanent state of nature? SAMIR KUMAR DAS

15 Civil society and democracy: Absence of the sovereign in Northeast India

KAKCHINGTABAM NARESH SHARMA

16 Pang-Sau or redeeming India's Northeast from impoverished constitutionalisms: After-life of an essay PRASENJIT BISWAS

PART VIII

Tradition and modernity

17 Colonial modernity and plight of the receiving communities

BHAGAT OINAM

18 In the name of a flyover: Development, resistance, politics 
viii Contents

\section{PART IX}

Popular culture

19 Music, body and sexuality in Bihu songs of Assam UTPOLA BORAH

20 Problematizing cultural appropriation: Tangkhul folk-blues and socio-political aspirations

DHIREN A. SADOKPAM

21 Poetic discourse in the songs of Tapta

USHAM ROJIO

PART X

Literary trends

22 Manipuri literature in history

THINGNAM KISHAN SINGH

23 The origin and development of Mizo literature LALTLUANGLIANA KHIANGTE

24 Differing resistances: Mediating the Naga struggle in Easterine Iralu's A Terrible Matriarchy and Temsula Ao's These Hills Called Home ASHLEY TELLIS

\section{PART XI}

Women and gender

25 The politics of gendered resistance: Body and agency

26 'We have got things to say': Beyond the nationalizing narrative of the Bodoland movement 
PART XII

State and development policies

27 Building Northeastern futures, looking East

B. G. VERGHESE

28 Preparing the Northeastern economy for the future GULSHAN SACHDEVA

29 Critiquing the development intervention in the Northeast 406 AMAR YUMNAM

\section{PART XIII}

Critiques of development discourse

30 Understanding underdevelopment: State of economy in the Northeast

THINGNAM KISHAN SINGH

31 Re-imagining the Northeast in India, again: Did geography sidestep history in Vision (2020)?

ROHAN D'SOUZA

32 Post-development, democratic discourse and dissensus: A critique of Vision 2020

PRASENJIT BISWAS

Index 


\section{Tables}

10.1 Variation of Muslim population in Assam from 1941 to 2001 (in \%)

10.2 Progress in fencing the Indo-Bangladesh border (length in $\mathrm{km}$ )

10.3 Identification and deportation of illegal migrants

11.1 Distribution (\%) of employment in organized sector in Manipur/India

11.2 Branch-wise distribution (\%) of employment in organized sector in Manipur/India

11.3 UPS unemployment rates (\%) and educated unemployment rates for $15+$ years $(\%)$ in Manipur/India

11.4 Distribution (\%) of reasons of migration for migrants (by POLR with all-duration of residence) from Manipur to Delhi (NCT)

28.1 Economic growth in the Northeast, 1992-2017

28.2 Net state domestic product (NSDP) in the Northeast, \% growth (2004-5 to 2013-14) 


\section{Abbreviations}

$\begin{array}{ll}\text { AASU } & \text { All Assam Students Union } \\ \text { AATWF } & \text { All Assam Tribal Women's Federation } \\ \text { ABSU } & \text { All Bodo Students' Union } \\ \text { ABWWF } & \text { All Bodo Women's Welfare Federation } \\ \text { ADC } & \text { Autonomous District Council } \\ \text { AFSPA } & \text { Armed Forces Special Powers Act } \\ \text { AGP } & \text { Asom Gana Parishad } \\ \text { AIPRF } & \text { All India Peoples Resistance Forum } \\ \text { AMUCO } & \text { All Manipur United Clubs Organisations } \\ \text { APCC } & \text { Assam Pradesh Congress Committee } \\ \text { APHLC } & \text { All Party Hill Leaders' Conference } \\ \text { APRSU } & \text { Andhra Pradesh Radical Students Union } \\ \text { AR } & \text { Assam Rifles } \\ \text { ASS } & \text { Assam Sahitya Sabha } \\ \text { BIMSTEC } & \text { Bay of Bengal Initiative for Multi-sectoral Technical } \\ & \text { and Economic Cooperation } \\ \text { BJP } & \text { Bharatiya Janata Party } \\ \text { BLT } & \text { Bodoland Liberation Tiger } \\ \text { BPAC } & \text { Bodo Peoples' Action Committee } \\ \text { BSF } & \text { Border Security Force } \\ \text { CAD } & \text { Constituent Assembly Debates } \\ \text { CCS } & \text { Cabinet Committee on Security } \\ \text { CGPI } & \text { Communist Ghadar Party of India } \\ \text { CONSOCOM } & \text { Consolidation Committee of Manipur } \\ \text { CRPF } & \text { Central Reserve Police Force } \\ \text { DGET } & \text { Directorate General of Employment and Training } \\ \text { FACG } & \text { Folk Art and Cultural Guild } \\ \text { GPRN } & \text { Government of People's Republic of Nagalim/ } \\ & \text { Nagaland } \\ \text { GoI } & \text { Government of India } \\ \text { HADP } & \text { Hill Area Development Plan }\end{array}$


IBRF

ICCPR

IMDT

INC

JAC

KCP

KHADC

KNA

KNO

KYKL

LEP

MASS

MDoNER

MDU

MEA

MNF

NCERT

NCR

NDA

NDC

NDFB

NEC

NEFA

NEPED

NGO

NMA

NNC

NPC

NPMHR

NSAB

$\mathrm{NSCN}(\mathrm{IM})$

$\mathrm{NSCN}(\mathrm{K})$

NSDP

NSS

PCG

PLA

PANMYL

POB/POLR
Indo-Burma Revolutionary Front

International Covenant on Civil and Political Rights

Illegal Migrants (Determination by Tribunals) Act

Indian National Congress

Joint Action Committee

Kangleipak Communist Party

Khasi Hills Autonomous District Council

Kuki National Army

Kuki National Organization

Kanglei Yayol Kanna Lup

Look East Policy

Manab Adhikar Sangram Samiti

Ministry of Development of North Eastern Region

Manipur Dramatic Union

Ministry of External Affairs

Mizo National Front

National Council of Educational Research and

Training

National Capital Region

National Democratic Alliance

National Development Council

National Democratic Front of Bodoland

North East Council

North East Frontier Agency

Nagaland Empowerment of People through

Economic Development

Non-governmental Organization

Naga Mothers Association

Naga National Council

Naga People's Convention

Naga Peoples Movement for Human Rights

National Security Advisory Board

National Socialist Council of Nagalim, Isak-Muivah faction

National Socialist Council of Nagaland, Khaplang faction

Net State Domestic Product

National Sample Survey

People's Consultative Group

People's Liberation Army

Pan Manipuri Youth League

Place of Birth/Place of Last Residence 
PREPAK

PTCA

RGM

RPF

SCS

SDP

ST

TADA

TKADC

TKLD

TNV

TSF

TSR

TUJS

UCM

UCPN

UKJH

ULFA

UN

UNLF

UNUPR

UPA

WESEA

WPR

ZRO
People's Revolutionary Party of Kangleipak

Plains Tribal Council of Assam

Revolutionary Government of Manipur

Revolutionary People's Front

Senior Citizens for Society

State Domestic Product

Scheduled Tribe

Terrorist and Disruptive Activities (Prevention) Act

Thengal Kachari Autonomous Demand Committee

Tangkhul Katamnao Long Delhi

Tripura National Volunteers

Tripura Students' Federation

Tripura State Rifles

Tripura Upajati Juba Samity

United Committee Manipur

United Communist Party of Nepal

United Khasi and Jaintia Hills

United National Liberation Front of Asom

United Nations

United National Liberation Front of Manipur

United Nations Universal Periodic Review

United Progressive Alliance

Western South East Asia

Workforce Participation Rate

Zomi Revolutionary Organisation 


\section{Contributors}

Lokendra Arambam is a scholar, theatre director and critic, and recipient of the Sangeet Natak Academy Award for theatre direction (2004). He was former head of department of the Audio Visual Research Centre (AVRC), Manipur University, Canchipur.

Amrapali Basumatary teaches English at Kirori Mal College, University of Delhi. She works on gender issues in addition to nationalist discourses in Assam.

Anjuman Ara Begum is a freelance journalist, blogger and human rights activist from Northeast India. She is currently based in Kathmandu, advocating human rights initiatives for FORUM-ASIA as South Asia Programme Officer.

Sukalpa Bhattacharjee teaches English at North-Eastern Hill University, Shillong. Her publications include Society, Representations and Textuality: The Critical Interface (2012) and Postcolonial Literatures: Essays on Gender, Theory and Genres (2004).

Prasenjit Biswas teaches philosophy at North-Eastern Hill University, Shillong. His publications include Ethnic Life-World(s) in NorthEast India (2008) and Between Philosophy and Anthropology: Aporias of Language, Thought and Consciousness (2017).

Utpola Borah is an ethnomusicologist, educationist, folklorist, cultural archivist and performer of Hindustani classical music. She is currently working for the Columbus Metropolitan Library, USA, and Teaching Artist/Artist in Residence, Ohio Arts Council, USA. She is also research scholar for the Advancing Interdisciplinary Research in Singing (AIRS) project in University of Prince Edward Island, Canada.

Kamal Mitra Chenoy is Professor at the Centre for Comparative Politics and Political Theory, School of International Studies, Jawaharlal 
Nehru University, New Delhi. He has extensively published on contesting nationalisms and armed conflicts.

Samir Kumar Das, former vice chancellor of North Bengal University, is Professor at the Department of Political Science, Calcutta University, Kolkata.

Khakchang Debbarma is Professor and Head of the Department of Political Science, North-Eastern Hill University, Shillong. He specializes on politics of migration, development administration and human rights.

Rohan D'Souza is Associate Professor at Graduate School of Asian and African Area Studies, Kyoto University, Kyoto. He has extensively written on environmental history, technology studies, climate change and environmental politics.

Kham Khan Suan Hausing is Professor in the Department of Political Science, University of Hyderabad, Hyderabad. He specializes on federalism and autonomy issues in India and has written several scholarly articles on these themes.

Patrick Hoenig was with the Academy of Third World Studies, Jamia Millia Islamia, New Delhi. Currently, he is researcher at Hamburg Foundation for the Promotion of Science and Culture, based in Germany.

Yengkhom Jilangamba is Chairperson of the Centre for Peace and Conflict Studies at Tata Institute of Social Sciences, Guwahati Campus. He is interested in the areas of territoriality, development, violence and indigeneity.

Laltluangliana Khiangte is Professor at the Department of Mizo, Mizoram University, Aizawl. He is a recipient of the Padma Shri Award for his contribution to Indian literature.

K. Kokho is Assistant Professor at the Centre for Northeast Studies and Policy Research, Jamia Milia Islamia, New Delhi.

Reimeingam Marchang is Assistant Professor at the Centre for Study of Social Change and Development, Institute for Social and Economic Change, Bengaluru. He specializes in labour, migration, education, economy and development.

A. Noni Meetei teaches political science at Moirang College, Manipur. He is Associate Editor of Alternative Perspectives, and co-authored Colonialism and Resistance: Society and State in Manipur (2015).

Sajal Nag is Professor in the Department of History at Assam University, Silchar. He was Netaji Subhash Chandra Bose Distinguished 
Chair Professor in Social Sciences at Presidency University, Kolkata. He specializes in the history of modern Northeast India.

Malem Ningthouja received MPhil and PhD degrees in history from the University of Delhi and was a Fellow at the Indian Institute of Advanced Study, Shimla. He has extensively published on nationalism, insurgency movements, human rights and democracy.

Bhagat Oinam is Professor at the Centre for Philosophy at Jawaharlal Nehru University (JNU) and Concurrent Faculty at Northeast India Studies Programme, JNU, New Delhi, India.

Usham Rojio received MPhil and $\mathrm{PhD}$ degrees in theatre and performance studies at the School of Arts and Aesthetics, Jawaharlal Nehru University, New Delhi.

Bibhu Prasad Routray served as Deputy Director in India's National Security Council Secretariat, New Delhi. He was also Director of the Institute for Conflict Management, Guwahati.

Gulshan Sachdeva is Professor at Centre for European Studies, School of International Studies, Jawaharlal Nehru University, New Delhi. Currently, he is Jean Monnet Chair in European Economic Integration \& Energy Security, awarded by the European Commission.

Dhiren A. Sadokpam is an independent researcher and journalist based in Manipur. He is currently the Executive Editor of Eastern Quarterly, a journal on India's Northeast.

Kakchingtabam Naresh Sharma is an independent researcher. He has an MPhil degree from the Special Centre for Law and Governance, Jawaharlal Nehru University, New Delhi.

M. Amarjeet Singh is Professor at the Centre for Northeast Studies and Policy Research, Jamia Millia Islamia, New Delhi. He has extensively worked on conflict studies, identity politics and migration studies.

Thingnam Kishan Singh was an MCS officer in the Government of Manipur. Earlier, he taught English at the Department English, Manipur University, Canchipur.

H. Srikanth is Professor at the Department of Political Science, NorthEastern Hill University, Shillong. He was awarded the Canadian Studies Faculty Fellowship in 2005 and has authored and edited several books on ethnicity, nationalism and democracy.

Ashley Tellis is a rights activist, and was Panos Media Fellow at Guwahati (2007-08). He has taught at Eastern Illinois University and 
City University of New York, University of Delhi, and O. P. Jindal University.

C. J. Thomas is Deputy Director, Indian Council of Social Science Research - Northeast Regional Centre, Shillong.

B. G. Verghese was recipient of the Magsaysay Award for Journalism (1975). He was a member of the Shukla Commission (1997) that reported on 'Transforming the Northeast', and was on the World Bank and ADB team on Northeast development.

Amar Yumnam is Professor at the Department of Economics, Manipur University, Imphal. He specializes in development economics, institutional economics and new economic geography dimensions of development issues in the Northeastern Region of India. 


\section{Acknowledgements}

This Reader is the fruit of hours of collective anxiety, arguments and debates within a group of individuals hailing from Manipur. These individuals were deeply concerned with the turn of events in their homeland and the Northeastern region of India in the early part of this millinium. As a response to the collective anxiety, they formed a body and named it Manipur Research Forum (MRF). One of the first initiatives of MRF was to launch a quarterly journal besides organising seminars, talks and conferences to address any issues which had social, economic, political and cultural ramifications.

MRF's journal Eastern Quarterly eventually took up the task of disseminating factually accurate information in addition to analysis on Northeast India - the region and its people. The journal as it is published today highlights and encourages plurality of methodologies and perspectives. In fact, it attempts to set a platform for debate and discussion among concerned individuals and groups cutting across disciplinary and ideological predilections. Over a period of time, a number of papers with insightful perspectives were published by Eastern Quarterly. Each issue of this journal is thematically planned. The collection in this Reader is a compilation of select papers on the basis of themes that appeared in the journal and which the editors thought would truly benefit academics, scholars and researchers besides helping laypersons equip with certain information and worldviews about the region called Northeast India.

First of all, without naming them, the editors express deep gratitude to all the members of the editorial team of Eastern Quarterly whose relentless service with commitment enabled reaching out to a large section of scholars to come to a platform for debate and deliberation.

We are also grateful to the contributors for their efforts in shaping and reshaping the papers so as to be part of this Reader. We also 
respect the freedom of thought and expression of each of the contributors who come from different beliefs and predilections.

The editors also express a deep sense of indebtedness to Taylor \& Francis India for accepting the collection for publication. Without the full assistance of editors, copy editors, managers and those who worked on the production and publication of this Reader, it would have been an impossible dream. This Reader represents voices from the margins, not in terms of contributors' social and cultural positions, but in terms of their representing multiple voices within the margins. We thank you all for your patience and understanding.

The editors of this Reader once again thank each and every one who had rendered their valuable services to this humble effort. Specifically, we cannot miss acknowledging the assistance provided by Usham Rojio. We truly believe and acknowledge that this Reader would not have been published without the help and support provided by you all.

Bhagat Oinam Dhiren A. Sadokpam 
$\because$ Taylor \& Francis

http://taylorandfrancis.com 


\section{Introduction}

\section{Bhagat Oinam and Dhiren A. Sadokpam}

Northeast India, as understood in the administrative, geographic and academic sense in contemporary India, comprises eight states: Assam, Arunachal Pradesh, Manipur, Meghalaya, Mizoram, Nagaland, Tripura and Sikkim. Though there are diverse ethnic, cultural, linguistic and racial groups in the present geographical area understood as Northeast India, the region has been more or less looked upon as a homogenous entity. In recent times, the region is no more 'a strange or a distant land' to the average educated Indians. From a state of tabula rasa, Northeast India has now become a mosaic of multiple impressions. However, it is to be noted that many of these impressions are hinged on stereotypical imageries. One popular conception of the region in contemporary times has been based on the region's violent political history. It has been conveniently believed that armed insurgent activities and their impact as reported by the media have brought the region into the country's psychological map. Though this is too simplistic a reading, it is also a fact that insurgency has not yet been permanently resolved. It still impacts the reading of the region in certain ways and hence, the imagination of the Northeast as a 'violenceridden' if not always 'backward' and 'tribal' area.

Northeast India has become a site of eager interests amongst academics, scholars and also independent researchers. In the postglobalization and liberalization period, many have made attempts to understand the region from their respective geo-political contexts. Given its strategic geographical location, the economies of the West and East have begun exhibiting interests in recent times. From the Indian context, the Northeast region has most of the time been understood from the development deficit discourse and exotic cultural traditions. While discussing the Northeast as distinct from mainland India, the dominant discourse in contemporary times has been centred on the region's physical distance and a psychological barrier between the two. 


\section{Bhagat Oinam and Dhiren A. Sadokpam}

Factors that have brought the region closer to India's political and academic discourses are not one but many. The number of research works on the region as well as creative writings in various languages have increased manifold in the last couple of decades. The spurt in research interests also has linkages with the political and administrative compulsions of India. The effort, after all, is a remarkable journey - from 'unknown land' to 'land with enormous attention'.

The present volume is a collection of essays from the journal Eastern Quarterly that has been running over a decade. The journal in its unique capacity brings out theme-related essays for each published issue. These are framed keeping in mind the larger problems that the region has been facing during the last several decades while tracking both the significance as well as immediacy of the problems. Sections in this reader are based on the themes articulated by Eastern Quarterly and are composed of diverse themes on the region.

\section{Representations}

Historians trace the concept to the 'north-east of then British Bengal' mainly addressing to then undivided Assam and few adjoining areas. However as mentioned earlier, the idea of the Northeast comprising the eight states has become a political reality today (Oinam 2009). Against this backdrop, the present volume is being prepared to make sense of the region and the idea. It is also being acknowledged that comprehending the region is a complicated affair and requires nuanced reading of the region. The present reader, while taking cognizance of political division of the region, is not strictly bound by the given federal administrative structure. Rather, priority has been given to those visible and compelling issues that the region in general is faced with.

The volume begins with an entry point, from the story of crisis. The presence of the region is felt, though unfortunately, through violence witnessed over the last six decades - violence between the state and the non-state actors, among the non-state actors themselves, ethnic violence, religious antagonism, inter-state conflicts - the list is not only long but overlapping. There are not only layers of conflict, but even a conflict between two parties is marked by more than one issue of contention. Further, an event of violence need not necessarily result from conflict of interests exclusively between two parties; at times the same conflicting parties join hands to counter a common enemy at another site of contestation. Thus, conflicts turn multi-cornered and overlapping. Shifting triangular relationship amongst the Meiteis, Nagas and Kukis in recent times highlight this dynamic. 
There are historical reasons behind seeing Northeast India through the prism of conflict. The region (and the people) except for the lower Brahmaputra valley and the Barak valley are late entrants to the nationalist politics in the Indian subcontinent. These two valleys were perhaps the only sites where the Indian national freedom struggle could reach its arms. The third site, the Imphal valley, is dubious by its peculiarity as a historical site of nationalism. Though there are traces of Indic cultural sites in the region as early as the fifth and sixth centuries, ${ }^{1}$ that itself did not make the Northeast the site of political agitation against British colonial rule as well as a resultant nationalist imagination. This therefore has created complications in the post-independence period where the Indian state, which derives legitimacy, to a large measure, from the anti-colonial struggle, finds a slightly weak ground in the region. While Nagas continue to claim that they are not Indians and that they declared independence one day before India did, voices in Manipur are divided on merger/annexation of the then Manipur kingdom into India on 15 October 1949. ${ }^{2}$ Many other smaller ethnic communities could exercise very little their political choices at the time of India's freedom struggle and subsequent formation of India. Their entry into the collective nationalist consciousness of India is still in the making with diverse layers and commitments. Take the case of the Mizos. Till the signing of Mizo Accord in 1986 and the subsequent creation of Mizoram as a separate state, Mizos were struggling to determine an independent future of their own (Pachuau 2014). They were in the same 'fraternity club' with the Nagas till then. Overall, the entry of these ethnic communities into mainstream consciousness has not been smooth and the passage has been largely marked by violence. The task of this volume is also to map this entry.

While the region's entry to the collective imagination of India is still in the making, an equally hazardous challenge is the making of Northeast India and the communities therein. Not that the community identities in the region were absent earlier, but the larger text of Indian nation making presents an altogether altered context. Multiple identity articulations are the most dynamic aspect of the region's contemporary political and cultural history. They also define the contours of the representative institutional politics and civil society movements. Whether it is the Seng Khasi movement of Meghalaya, Donyi Polo of Arunachal Pradesh, the Sanamahi movement of Manipur, Naga Hoho in Nagaland or the Young Mizo Association in Mizoram, different modes of cultural and political representations are visible in each of these assertions. The representations take place not merely as unilinear self-projection but through constant interaction and creation of the 


\section{Bhagat Oinam and Dhiren A. Sadokpam}

self and the other (as binary). In this quest for self-definition, the idea and the motifs of the Indian nation quite often present themselves as the 'other'. The modernity of the politico-economic institutions and processes that brought in the process also add to the apprehensions and fear of losing one's political and cultural moorings. Scholarly writings as well as community politics express these apprehensions. Many resort to recovering the lost memory, often vis-à-vis an 'aggressive other'. This therefore spawns writings (and politics) on the issues of indigenous identity, land and territoriality, and in recent times, on illegal migration. In some cases, the construction and re-construction of the 'origin myth' are generated through traditional practices of identifying geographical areas that are of significance to the communities. Along with the generation of 'origin myth', communities have also been engaged in 'sanctification' of these spatial demarcations and converting them as representations of revered deities. For instance, the Meiteis over the ages have attached cultural and religious significance to two mountain peaks: Koubru and Thangjing. In their cosmogony, the two peaks have been depicted as prime deities indicating control over marked territory. Such narratives have been seen as one of the many ways to legitimize 'historical' claims over lands despite emerging territorial contestations.

Representation through civil society initiatives is yet another site. There has been a rise of dissenting voices to the state power. Civil society protests show various forms of spectacle through which people show representation of dissent. Many of these civil society initiatives, be it Meira Paibis, Naga Hoho, United Committee Manipur, Young Mizo Association or Naga Mothers Association, have shown peoples' contrary stands to the state functioning. In addition, there are peoples' movements against the construction of dams and environmental degradation. One of the highlights is the works of Krishak Mukti Sangram Samiti (KMSS) led by Akhil Gogoi, along with Takam Mising Porin Kebang (TMPK), Asom Jatiyatabadi Yuba Chatra Parishad (AJYCP) and All Assam Students' Union (AASU). These organizations have led strong rallies across the state of Assam protesting the construction of the mega-dams at lower Subansiri. Similar such protests came up against construction of the Tipaipukh Dam project planned for construction over the Barak River.

Writers in Assamese, Manipuri, Mizo and English literatures have shown the richness of these experiences. These Hills Called Home, Temsula Ao's poetry collection, for example, expresses her love for the land which is being shattered by waves of unending violence. One may also witness cynicism in such representations in 'I want to die with 
Indian bullet' (Thangjam Ibopishak). The poem shows the irony of the people of Manipur where 'love' for India is so intense that the poet wants to die with the bullet made in India, for death does not have to wait for its natural course in the state. It comes 'man-made'. The poem highlights the overarching presence of the Indian military and in whose trigger-ridden fingers lay the fate of the Manipuri people.

While representations of the region are taking place through different mediums and modes, one lacks a comprehensive reading of the region. The parallel narratives of national security on one hand and that of self-determination on the other have created two quite often irreconcilable sites of political articulation. This in turn presents to us the challenge to innovate ways in transcending the boundaries of existing limitations and comprehend the states of affair in the region afresh. There is, therefore, an urgent need to study the strength and weaknesses of the existing perspectives and discourses. This takes us to the core issues of (mode of) reading the region.

\section{Methodological issues}

Northeast India has often been qualified by a twin impression of being 'unique' and 'exceptional'. Uniqueness shows being incomparable, and also being exceptionally distinct. Exceptionality shows that what is the case is beyond any set of rule/norm. The two are twin terms. Today, although there is a great deal of discussion on the region, this discussion is largely on seeing the region very differently from understanding the rest of the country. This reading is constructed with a structural divide that while the Indian state and its people are seen as 'normal', the region and the people are seen as an 'exception'. Setting the Northeast beyond the purview of any comparative framework, and also beyond any rule/norm, closes down the possibility of any sharable reflection on the region.

Let us begin with a set of questions. Are such qualifiers (as mentioned above) the means to carve a different epistemic framework? Or is it to show that the region is incomparable? Why is it that the very utterance of the word 'Northeast' gives a strange image of a phenomenon? Does it have to do with the people about whom the study is conducted, or has it to do with the people who study them? Perhaps addressing to these questions will help in handling the 'mystery'. While one of the images on the region shows it as inhabited by 'dancing and singing' people (as naïe and/or 'peace-loving'), the other image is of strange and violent peoples - thus showing contrasting imageries. This is not so strange if put into perspective. A closer reading may reveal 
that these images represent our vocabulary to fill up the gap created by our failure to sufficiently comprehend the region and its people.

To make sense of the failure and the success of comprehension, it is important to go back in time (or in history) on how the region and its people were addressed. It is not so far away that the region was mapped out as a 'borderland', the term very popularly used today by historians and political anthropologists. This vocabulary is being used to make sense of the region as understood by the colonial ethnographers and the administrators on how the region was seen as buffer zone between the colonial powers. Representations made by these ethnographers, officers and also the Christian missionaries were the beginning of marking the region as part of a global politics. But this should not give the impression that there were no records made on the lives of the people prior to the colonial interventions, as if the region were a tabula rasa. There were practices of writing royal chronicles at four different kingdoms (Ahom, Manipuri, Tripuri and Koch Rajbongshis). These records not only narrate the achievements of the respective kingdoms but also their relationships with neighbouring kingdoms and communities. There were also practices of counter narratives (in Manipur) where people who do not agree with the kings and royalty wrote counter chronicles (e.g. Larei Lathup). Apart from the written texts, folk narratives depict the rich oral traditions of different ethnic communities. But colonial ethnographers and British administrators had preconceived readings about these communities. They had not only disciplinary biases but also carried a specific political agenda. Historically, use of the idea of exceptionality is often traced to the writings of colonial ethnographers like Sir Edward Gait, for whom lack of a reference point makes Assam, and its rulers the Ahoms, an exception to the mainstream historiography on India. While such a reading may be purely about methodological considerations, it also conveys at the same time inability of the historians to put the region within a conceptually comprehensible framework and create connections. There are also epistemic understandings that show the region as 'exception' with negative connotation. Tracing from colonial time to the free India, mention can be made of Christoph von Fürer-Haimendorf's 'Naked Nagas', and H. Onderson Mawrie describing the Khasis as 'promiscuous hordes', and J. H. Lorrain's (Pu Buanga) statement that Mizos don't take baths. These highly contemptuous remarks explain the inability of these scholars to understand the people of the region and their ways of life. The stereotype they carried shaped their understanding of the people in the region as the 'other'. The rich ethical concepts (like 'kaenyue' by the Angamis) and normative traditions (like 
'chainarol' among the Meiteis) do not find mention in the works by colonial ethnographers or even by mainstream Indian scholars. This opens up the possibility of studying the region in cultural and religious terms, striking a depth of difference with the mainstream and the existing body of knowledge, which are produced as a 'homogenized' frame of knowledge. The current volume broadens up the immanent frame of understanding the region not just by opening up its inner diversity and difference of cognitive and epistemic methods, but by throwing up distinctive categories and concept-metaphors that shape the local imagination of lived realities.

Scholarship emerging from the region in the last few decades, in contrast to the mainstream scholarship (Amalendu Guha, Hiren Gohain etc.), largely looks at rediscovery or invention of the community self. To them, 'Indian nation building' or 'state consolidation' gets a secondary space. The narrative of an anxious 'communal' subject becomes the hallmark. Scholars like Apurba Baruah, Gangmumei Kamei, Milton S. Sangma, Mamoni R. Goswami, Naorem Sanajaoba, Sanjib Baruah, Tiplut Nongbri, Udayon Mishra and several others echo the search for self-identity and assertion by the communities of the region. The search for identity is seen through different forms of collective praxis. It starts from the armed political struggle to the autonomy claims for self-governance, and further to the agitations against 'illegal' migration, or even in kinship and livelihood studies. These issues are picked up from the concerns of the local communities. These studies undoubtedly look at the strength and weaknesses of collective claims of the marginal communities. This is in spite of not only fulfilling the methodological compulsions but also driving with richer and newer findings. Udayon Mishra's study of Naga nationalism with all its objectivity narrates the Naga story that challenges the idea of India, the inherent contradictions between the two. Even those who do not engage with conflict studies and take recourse to 'neutral' studies in history, sociology or literature, the stories are also about the people of the region - about their story of memory and aspirations (written or unwritten).

These concerns mentioned above can be seen in concrete form in the functioning of civil societies, too. Nature and character of civil societies in the region are definitely very different from what is globally understood by the term. ${ }^{3}$ These are highly 'communal' in the community sense of the term. The civil society organizations continue to assert and claim their community interest, be it on human rights violations, gender violence or anti-drug or anti-alcohol movements. Often in the process, the ethical stance and the issue-based consideration of the movement get jeopardized. This point has been made by Samir Kumar 
Das in several of his writings on the region. But one may also see if such 'confusion' is comparable with what has happened with 'secularism' in India. Can it be argued that as much as 'secularism' though borrowed from the West has gone through redefinition in India, is it the same with 'civil society' in the Northeast? This calls for further deliberation.

Objectivity of a study has to be seen in the light of the standpoint from which the researcher addresses the problem. Objectivity in terms of truth and falsity of knowledge claim are something that is being cross-checked by the methodological verifications. But there still lies issues beyond the purview of the validity of knowledge, for all statements are not about verification. There are several data of information produced on the region. The cultural and ritualistic practices of the communities and tribes are being recorded (for instance, in the PeOple of India series). Narrations of armed movement and subsequent agreements/settlements are being recorded. A corpus of knowledge on the region is slowly being built. But the question still remains if we have sufficiently understood the region. Statements of understanding are not statements of verification.

The discussion boils down to the issue of care. The quantum of work on the region in the last couple of decades is surprisingly large, perhaps more than the volume of works done before put together. The reasons are few. One of the reasons lies in the increase in the quantum of research on the region conducted during these decades. Most of these works tend to get published as number of publishers venturing on the region has increased in unimaginable scale. While it is encouraging to see that Northeast India is increasingly becoming visible through the volumes of works and publications, this is no guarantee to a 'caring' engagement with the subject. It is in this context that we may highlight the conceptual distinction between 'knowing' and 'understanding'. It is a well-known distinction, yet let us revisit the concepts to make a methodologically relevant point. The former is necessarily devoid of the latter, whereas the latter is added on to the former. Knowing is epistemic, quite obviously dealing with how information are gathered and perspectives set as we make sense of the world around us. Knowledge is systematic and objective. The latter, on the other hand, involves internalizing what we experience - not merely relying on what is being known but by capturing those between the objective knowledge. Reading Northeast India requires more than what one perceives as knowledge about the region and its people. It is a moral imperative of the subject (researcher) to traverse between the perceptions, between information and objectivities. Understanding the region is the greatest challenge faced today, more so when the region is 
seen at the margins of a larger national discourse and when the margin itself is faced with acute crises, not only of its making but also by the forces outside its making. There is perhaps a need to make sense of 'understanding' as a philosophical concept. ${ }^{4}$

It is not to make a claim that this book comes out of an understanding of the region. That would be a self-aggrandizing statement. It cannot be denied that with the quantum of works expanding on the region there is also certain rise in good quality research works. This is not to do with number and information, but more about insight. The foremost attempt of the volume is to aim at reaching towards that. The attempt is to generate a platform where different points of views are played out for the readers to arrive at an understanding of the region. In that sense this reader is an invitation to participate in an engagement with several issues and problems. Questions are set, and answers attempted. Yet many more questions may arise, hence ever increasing answers. Understanding does not foreclose; it discloses. It is a revealing act. Understanding the region can therefore be achieved through deep concern for the region. Focus of this book is to come closer to this 'concern' of the region, more than mere knowledge of the politics and culture about the region.

\section{Diversity and the challenges}

General reading on diversity of the region is focused on multitude of ethnic and linguistic diversity. This calls for a closer look. Diversity in exteriority is a fact of reality; there is nothing so unique about it. Diversity of ethnicity and language is a fact about Northeast India. It is not so significant a perception to see the region with many variations. Those are facts of reality. Diversity as a matter of givenness is a fact of life. What is significant is the way we see those as opposed or conflicting. Diversity of the region, more than the ethnic and linguistic plurality, is marked by contesting interface of people and their collective claims. Those are the real challenges the region is faced with. The issue is about how constituent agents of this diversity look at their relationships. Diversity of the region has to be understood in the light of these complexities and not merely on the givenness of things. The challenge before us is more about shaping up the diversity into coherence. Understanding the Northeast is an ethical challenge - and not to reduce the region as a stark object of study.

A closer look reveals that the region is a replica of the Indian subcontinent, perhaps a miniature India. If India's diversity is marked by cultural and linguistic differences from the north (Dogri, Kashmiri 


\section{Bhagat Oinam and Dhiren A. Sadokpam}

and Ladakhi) to the south (Malayalee, Kannada and Tamil), and from the west (Gujarati and Marwari) to the east (Bengalee, Assamese and Manipuri); equally matched diversity can be found in Assam (Axomiya, Bengalee, Bodo, Rajbongsi, Miri, etc.) and Manipur (Meitei, Tangkhul, Rongmei, Thadou, etc.) and Arunachal Pradesh (Adi, Aptani, Mishing, etc.). The number of ethnic communities and languages numbering over 200 shows fluidity in capturing the region as a given whole. Positively, it is a good site to experiment with democratic politics, for there is neither an absolute majority community nor a major language to serve as a lingua franca. The region in the true sense is unsettled; it is fairly fluid to take an enduring shape. To contextualize this point, identity politics could serve as a good example. Most of the nationality claims by the ethnic communities are extremely fragile. It is not merely because the idea of nation that these claimants (ethnic groups) aspire is a modern concept, but also that there is a lively exercise of ethnic groups re-identifying themselves in the light of several new categories and relationships. Since national aspiration is a modern ethos, the ethnic groups are constantly struggling to adapt and own the spirit of nationalism of their own community, and even at times expand it - all these in the backdrop of a traditional and/or tribal worldviews and ways of life. It is a practical problem of nation making (many terms it as 'sub-national') in the region. ${ }^{5}$ Naga identity, for instance, is a very lively category constantly being worked upon in the light of shaping a national identity. Take even relatively complex categories such as 'Ahom', 'Assamese', 'Ahomiya' and 'Axomiya'. These are not merely differences in spelling, but each term carries certain political overtone or 'point of view' of how a group of people should be known. Each of these terms carries different senses/meanings.

These exercises have become a good site of phenomenological reading of how identity formation is always in the becoming. Identities are not fixed and final; finality lies only in the aspiration of the claimants. Fixity of identity lies only where it is seen as a projected goal, say in what a community projects itself as. It is when identity politics starts operating that the fixity turns into life, into fluidity. Fluidity is the mark of being alive. While this is a general phenomenon witnessed in every nationality claim, the region displays deeper complexity. The region witnesses sharp contestation of projected identities. Conflicts are witnessed among multiple ways of life and identity projections of each of these communities/tribes. Most of the communities continue with shifting projection of identities. When even bigger communities like the Assamese continue with multiple projection of self-identity, the smaller ethnic communities show much fragility in such projections. 
Change as a form of 'becoming' so far as a community projects its identity is conceptually an act of interiorization. Even when such an exercise happens, it is not so much an issue to worry about. Change and diversification is part of not only individual life but of the community. The real issue arises when claim or assertion of one community is opposed and contested by another community. The dynamics of diversity arises when such a situation comes to the fore. What is significant in the above illustration is that the region's 'unsettling diversity' lies on the kind of contestations and conflicting claims these ethnic communities are engaged in. Conflict highlights the unsettling of diverse views and ways of life. Northeast India is unfortunately a site of this unsettling diversity.

Conflicts in the region, as also being discussed in the previous section (on representation), shows dual existence of exteriority and interiority. While the former is overtly visible often associated with physical violence, the latter happens at the individual and intra-community domain. Conflicts of exteriority and interiority are not completely divorced from each other; both are closely woven. On one hand, interethnic or inter-tribe rivalry/contestations as conflict of exteriority are clearly visible, be it between Bodos and Bangladeshi migrants, Nagas and Kukis, Nagas and Meiteis, and so forth. On the other hand, conflict of interiority happens at subtle forms, say on different ideas of what should be called to the people of Assam, or the constant tussle within the Meitei society on their cultural identities (on Vaisnava and pre-Vaisnava ways of life). The conflicts of interiority and exteriority apparently look mutually exclusive. But a closer look reveals that what is self-articulation or projection is not an isolated act. Several external factors compel these ethnic communities to shape their identity in particular ways. To still go to the grassroots, challenges faced by the Paites, Anals, Moyon, Monsang, Khoibu and so forth on their self-identification are highly complex and vary for each tribe, compelled by diverse and shifting factors. Even the so-called internal conflicts among the Meiteis are compelled by several external factors. To be precise, the shaping and reshaping of community identities cannot altogether be an isolated affair as an intra-group level exercise. Though it seems like an internal exercise, that of interiority, these have deeper relationship with external factors, what can be called 'shaped by exteriority'.

To understand the intra- and inter-ethnic conflicts in concrete terms, the major site of conflict is found between the Indian state and the insurgent organizations. 'National claims' and 'struggle for selfdetermination' come in direct confrontation with 'national security'. 


\section{Bhagat Oinam and Dhiren A. Sadokpam}

The latter has not only been heightened but aggressively followed by the Indian state in recent times. Each of the insurgent groups that take up arms represents the concerns of one community or the other. There is no pan-regional insurgent organization that talks of the Northeast as a whole. Even though there have been attempts made by several insurgents groups to come at one common platform, those are highly pragmatic and do not bear signs of aiming at Northeast India as a national project. So these groups both in composition as well as in aspiration are highly diverse and confined to smaller national aspirations.

Complexity emerges when this contestation becomes murky and multi-cornered. Take Assam as a case. The long-standing armed resistance by the United Liberation Front of Asom (ULFA) with ruptured and added crises created by emergence of surrendered ULFA cadres, also known as SULFA, is a big story. It re-enacts at our time the old story of the revolutionary and the renegade. Several lives have been lost whose memory is hard to erase. Sporadic violence by the insurgents in the form of bomb blasts at crowded places has caused enormous loss of innocent lives and properties, thus showing lack of direction of a proclaimed revolution. ${ }^{6}$ On the other hand, state violence and statesponsored violence have been far reaching, with many cases of blatant violation of human rights, all in the name of national security. Human rights abuse and legitimization of the same drawn from constitutional enactments raise doubt on the very practice of democracy in the region. Trauma of the surviving victim and mindset of the perpetrators of violence shows complex nature of the crises (Hoenig and Singh 2014). Distinctly connected is the ongoing crisis of ethnic conflicts involving Bangladeshi Muslims, Assamese, Bodos, tribes in tea garden (popularly called 'tea tribes') and a few more. These conflicts are connected and cross over different parties and issues. Sporadic armed confrontations among different tribes (Karbis and Dimasas, for instance) have led to loss of several lives. Crises though sporadic violence still continue as if these are part of a historical project.

Manipur, too, shows a picture of "embodied violence" that are fairly pronounced and diverse. Multiple conflicts starting from the Indian state versus the insurgent organizations, to warring among different insurgent organizations, further to factional ${ }^{8}$ and fratricidal ${ }^{9}$ infightings - the list is long. These shifts in the nature of conflicts inform a murkier form of political contestations - where criss-crossing of conflicts shows each player as both a victim and perpetrator at the same time. Communal and ethnic tensions flaring up with the involvement of insurgent organizations that are based on ethnic loyalty across the region is the highlight of the said articulation, Bodo-Muslim clash in Assam as a case in 
point (Kimura 2013). Ethnic conflict dates back to the days of British colonial administration, not to mention the pre-colonial inter-tribe rivalry and conquests. Language of claim and nature of contestations have also changed over the period. Take for instance, the conflict that existed between Naga and Kuki villages, or Naga villages with the Meitei kings, during the pre-colonial period. Civil society agitation against the state also has a long-standing history (Singh 1998; Nag 1990). Several women's agitations (Nupi Lan) continue till date. The 'naked protest' by elderly Manipuri women on 15 July 2004 is seen by many as another form of Nupilan in our time. Thus, conflicts have taken different avatars.

Conflict in the region still pervades; the only difference is that while in some places it is overtly visible, in some others it is latent. It is a matter of time until it explodes (Oinam 2014). Political scientists of varied interests have worked on the political volatility of the region. To see Northeast India as a troubled region, it is at best to see the region as mini-India in terms of the multiple layers of troubles, reflections of which are manifestly visible in everyday life. Trouble with the region is manifold, though the most visible is the violence generated by armed conflict. Armed conflicts, starting from armed political movements to claim for autonomous administrative arrangements, work over wide and multi-layered conflict zones.

Contradictions among the ethnic groups are also a social reality. It is built on the conflict of interests on issues of land, territory, resources and opportunities. There are several cases of contestations: between the majority Bengalees and the Tripuris in Tripura, between the majority Assamese and the smaller ethnic communities like Bodos, and also between Bengalee Hindus and the Assameses in Assam, between the Meiteis and the Nagas in Manipur, or between the majority Meiteis and the Meitei Pangals. Protests in the form of economic blockades and non-cooperation are languages of conflict. In Assam, claim for Bodoland as an autonomous region (consisting four districts of Assam) is a prelude to a claim for a full-fledged state where Bodos will be the majority. The struggle by the native Tripuris to mark and protect tribal lands from further infringement by the majority Bengali is very much alive. What is significant from such demands is the increasing awareness of 'land as capital'. There is major shift taking place in peoples' perception of land from the traditional worldview to the modern conception. The traditional views look at land as site of habitation. It is also seen as extension of the body-self of the communities. That is why many of the tribes dream of dying at the land where they belong. But more significant 


\section{Bhagat Oinam and Dhiren A. Sadokpam}

development today is of seeing the land as capital, where the land is seen not only for agriculture (subsistence economy) but also as major resources for generating capital, be it of minerals (Meghalaya and Nagaland), forest-based industries (Tripura and Mizoram), or growing cash crops (Manipur and Tripura).

Contestation over land takes violent overtone (both in collective assertion and actions) with the alarming scale of migration. Tripura is no more the lone case, but the phenomenon is becoming alarming in Assam, Nagaland and Manipur. The issue of Bangladeshi migrants in Assam is becoming alarmingly complex, and has been used in electoral politics for few decades now. Migration is slowly changing the population landscape of Assam where political representation takes a complex turn. This has further complicated with twofold vocabularies of 'illegal migrant' and 'refugee', the former addressing the Bangladeshi Muslims and the latter the Bangladeshi Hindus. Migration is a global phenomenon. From the earliest human settlement across the globe moving of people from one place to another, looking out for greener pastures is a fact of collective life well documented in the human history of migration. It is in a nation state's project of having clearly marked boundaries keeping restriction to human migration and adhering to exclusive relationship of 'land as territory' with 'people as citizen' has made migration a major site of contestation. Today migration in the region has complicated inter-community relationships to a great extent. Like the rest of the world, migration is not a new phenomenon in the region. Many of these communities carry memories of their ancestry to places far away from the present Northeast to places like northern Thailand and southern China. Ahoms are the interesting examples of a group of warrior ethnic groups from Thailand who invaded, settled and ruled Assam, and slowly absorbed into the Assamese community, so much so that till recently an Ahom chief minister was acceptable as a better ruler in the heart of democratic politics in Assam. There are also other smaller ethnic communities who believe in the myth of the cave, ${ }^{10}$ from where many tribes are supposed to have emerged. These caves, mythical and otherwise, are located in places within the region. While this is not an argument to push for dividing the region between the original inhabitant and the migrant, there are genuine concerns raised by those who are already settled and who feel threatened. Increase of population over a period of time has led to the shrinking of land use. That the land cannot expand as the population does, the ethnic conflict has emerged as a consequence. Conflicts start on the community line. 


\section{Emerging changes: Inseparable interiority and exteriority}

Conflicts in interiority are as important as that of the conflicts in exteriority. This point was briefly made in the previous section. The close linkages may reveal that what is visible in exteriority is grounded in deep-rooted problems of interiority, or vice versa. A closer reading of the conflicts discussed above can be explained through the perspective of tradition versus modernity debate. This is not to provide prescription towards conflict resolution. But there are sufficient grounds to accord those conflicts witnessed in the region to this debate. The idea of conflict within is a well-discussed idea. Also the idea of India and Bharat is a classic illustration of the divide in visible exteriority between a modern form of life and traditional form of life respectively. This of course is a stereotypical divide between tradition and modernity. The problem calls for a deeper reading than merely seeing the two as opposite binaries. The puritan traditionalist and radical modernists often fail to see the grey areas as social change and transformation takes place through constant interaction and not in opposite binaries.

Nearly a century back Mahatma Gandhi saw and explained in his Hind Swaraj that the problem of the enslaved India had deeper causes of troubles it faced in the contestation between tradition and modernity. More than the evils of a foreign rule (the British), destruction of the (collective) self (swa) by the onslaught of modernity (stark form of capitalism) was the major cause of enslavement of India. Gandhi's thesis was to acknowledge the enemy in one's own self, in the inner weaknesses. Nandy has further worked this out in his idea of the 'intimate enemy', in the inner conflict one finds oneself with the appropriated identities that comes from exteriority (Nandy 1983/2002). The paradox is that what is being appropriated and yet questioned is already part of one's own being. When one questions and challenges colonialism and its worldviews, one ends up challenging one's own being. What Northeast India faces today in terms of conflicts in exteriority has close connecting links with the conflict of interiority. This connection is better comprehended in the tradition-modernity debate. Tradition and modernity as exemplified in historical developments and interfaces are of visible conflicts of exteriority. But it also has the other side; the conflicts within one's own self - in the conflict of identity. This is the conflict of interiority. These issues have been deliberated in details by scholars in the book. Two articles are included in the section on 'Tradition and Modernity', which not only try to problematize the theoretical issues of tradition and modernity in the region, but also pick up concrete case study that addresses the larger issues. 


\section{Bhagat Oinam and Dhiren A. Sadokpam}

There are several avenues where tradition modernity interface is played out, both in the state/institutional domain as well as in the individual/cultural domain. Experiment with democracy has been a major challenge in the region. But this problem is not peculiar to the region. Challenges thrown up by the practice of democracy in the developing world where traditional worldview dominates the everyday life of the community are alarmingly large. Centrality of individual choice of what is good for one comes into constant conflict with collective good and traditional values. Be it on the dress code, marital choice or right to dissent, restriction on the democratic values is alarming. While these form the domain of the individual-society conflict guided by ideological influences, there are other domains where conflict of exteriority is very pronounced. Electoral behaviour in the practice of democratic politics shows some naked truths. While exercises of voting rights are hallmark in the practice of democracy, this is more often violated where people engage in self-defeating practices. In most part of the Northeast, electoral politics is not so much about choosing representative based on issues of policy, governance and reason. While these values may not completely be absent, the priority of choice is most often built on ethnic identity and clan loyalty. These values are certainly pre-modern. The latter is not about absence of reason but about absence of modern rationality.

Federal politics and autonomy claims also show some intriguing cobweb of political practices. Traditionally communities in the region lived with certain sense of self-sufficiency with some degrees of isolation. This was more so in the hills, where difficult terrain kept the ethnic communities in isolated pockets. Lack of engaged interaction failed to develop a lingua franca for the villages living side by side. The difficulty as mentioned earlier is not so much in diversity. People lived independently and separately with few restricted contacts as well. Diversity per se is not the issue. Trouble lies in the diverse conflicts that have come up in the last few decades. These have emerged not without any substantive reasons. What was traditionally left to the ethnic communities without interventions by the colonial powers (through the policy of non-intervention) was changed with the birth of independent India. The formation of states to govern different regions and the people in the country led to the creation of larger administrative units and led to consolidation of the Northeast as a unit. Masked by the new idioms of modern institutions, the ethnic communities want land and administrative mechanisms to serve their own community interests. Several autonomy movements came up from 1970s onwards to carve out new states, union territories and autonomous district councils. These movements have their stories of success and failure and points 
of negotiation. Today attempts are being made to initiate division of administrative institutions and citizens' privileges on ethnic line across the region. This is turning out to be a never-ending story.

Along with autonomy demand, which is more of a soft version of self-rule, the region has also seen mushrooming of identity assertions. While one may see ethnic assertions as positive search for subjecthood, the inter-ethnic conflicts take us towards a different understanding. Often these conflicts arise out of control over land: each of the communities requires not only to claim as their own but also to have governing mechanism in operation. While larger communities take to consolidating their hegemonic presence in the region, the smaller communities are constantly in alliance and in the process of re-negotiating their identities. While these renegotiations/reconfigurations may be towards larger process of political formations, at few places there are instances of communities succumbing to pressure abandoning their traditional identities. This may be seen as a product of constant tussle between tradition and modernity. Modern forms of political institutions and their compulsions have pushed the ethnic communities to negotiate between traditional values and ways of life on the one hand and democratic politics and individual aspirations on the other. This may be seen as the plight of the 'receiving communities', as conceptualized by Bhagat Oinam in the present volume. The receiving communities are the receivers of new forms of changes coming from outside which are not of their own making but which they have to 'own' as their own while making constant adjustment with the forces of change. There was a time when modernity was better understood by juxtaposing it in complete contrast to tradition. With the 'giver' of modern institutions and the 'receiver' having contrasting, if not 'non-reconcilable', understanding of what was or is being transacted, the generation of meanings has multifarious, if not fused, layers. Be it politics or economy, these fused layers find resonance in the everyday cultural and political articulations of a society, making it even more difficult to understand them from the conventional positionality of the 'binaries'. The idea of the receiving communities here implies a replacement of not just the traditional institutions with modern ones but also a shift in the value system. When a community grapples with the theory and praxis of institutions which are tailored in line with modern democratic values, there is also a state of disruption, at least at the transition period. The trouble seeps in seemingly undetected while roots of fractured impact are planted over the prolonged years of integrative nuances. The prolonging of the transition in the Northeast region is most of the time characterized by turmoil. Much of the 


\section{Bhagat Oinam and Dhiren A. Sadokpam}

conflicts that have been witnessed in the society and polity have bases in the tension between forces of tradition and modernity.

\section{Way forward: Peace and/or development?}

In the midst of the push and pull of highly 'communal'11 life in the region, with ruptured violence and uncertainty, a blueprint is perhaps needed to bring peace and development. Peace deficit is certainly a stark reality, but it is equally important to highlight that 'peace' and 'development' are not unqualified concepts. These are highly loaded. At times there could be violent peace, where peace is brought through fear that compels subjugation. Development in our time has seen unevenness of violent faces. It is not altogether out of place to ask the kind of peace and development one envisages in the blueprint.

Two political perspectives have emerged with contesting priorities. One group of political pundits is of the view that insurgency has to be contained first so that development and peace initiatives could be successfully taken up. They further argue that unless insurgency is contained, development initiatives will be misused and derailed by the insurgent organizations. So violence has to be totally curbed so that peace could prevail. It is not only one-sided articulation but also highly statist. This articulation comes from state officials and highly nationalist political leadership. On the contrary, there are others who highlight the need to initiate development programmes that can generate employment for the youth so that they are not attracted towards insurgency movements. Both the articulations come from state perspective, the former as hard state perspective and the latter as the soft one. Another difference is that while the former stands firmly for national security, the latter seems to be ambivalent of its stand towards the debate on national security versus human security.

There is a third perspective that is statist in nature, but challenges the very nature of the nation that is in existence. Armed opposition movements in the region invoke the 'right to self determination' to counter the idea of Indian nation as well as the existence of the Indian state. While these movements (initiated by NNC, NSCN, UNLF, PLA, ULFA and MNF) stood at one time or the other in complete opposition to the Indian nation state, their opposition is directed to the content than to the form. Even though the political aspiration is of 'self-determination', this self is not about the ordinary mundane self. It is about an imagined people who are supposed to be tight together with an organic bond. This self is highly political and has all the potential to be synonymized with the state at certain point of its making. 
This self is in political transition from a (collective) people to becoming a state. So all these perspectives, including those who demand selfdetermination, (except for degrees) are state-centric. Aspiration and destiny of the ordinary people is structurally, and therefore politically, subsumed within the state-centric perspective.

The challenge lies in inventing discourses where priority is truly given to the individual subject. This initiative has to come from the people living their everyday existence - from their needs and aspirations. These may not be structured and articulate, but fragmented and even arbitrary. That is what human aspirations are all about. Northeast India must have that space free from extreme political positions and where average individual citizen comes out with their own grievances of peace and development. This has to begin with close examination of the existing state policies. The volume looks into this aspect of development policies, particularly the Look East Policy (also called Act East). Two separate sections have been devoted to study development from different intellectual discourses.

\section{The concrete plan}

The present reader comprises thirteen sections and thirty-two chapters. These sections have been shaped to comprehend different issues involved with the region, namely armed opposition movements, autonomy claims, migration, cultural lives, literary expressions, gender issues, development challenges and so forth. These are not exhaustive but representative in terms of priority.

The reader begins with Part I on armed political violence. Kamal Mitra Chenoy's chapter titled 'Nationalist ideology, militarization and human rights in the Northeast' initiates the study, wherein the author questions the mode of Indian state's engagements with different minority nationalities. The author sees political violence as the state's failure to negotiate between India's imagination of a national project vis-à-vis alternate national projects of different national minority communities. Interestingly in the last few couple of decades, with the mushrooming of several armed organizations and their internal contradictions, the Indian state is no more the lone target; the contest is multi-cornered now. Patrick Hoenig and K. Kokho in the chapter 'Armed opposition groups in Northeast India: The splinter scenario' map this trend and show the new dynamics where the government is an arbitrator of peace negotiations more than being a party to conflicts.

Part II is devoted to the extraordinary law and state impunity on its exercise. In the third chapter, Malem Ningthouja studies AFSPA 
as a highly programmed nationalist Act with structural limitation in recognizing alternate voices, thus creating a 'state of exceptions' in the political space. He further studies the resistance movements initiated by the common people against the Act. This is followed by a chapter titled 'People's conversation on truth, justice and reparation', where author Anjuman Ara Begam gives a detailed account of the legal and social repercussions of such an over-empowered law in practice.

To address the complex nationality claims in the region, Part III is devoted to national questions. Sajal Nag's chapter, 'Assamese nationality question', gives a transparent account of nationality issues in Assam - the socio-ideological dynamics behind the Assamese nationality movement, the dilemmas of the Bengalis in Assam, and further the responses of the tribal communities to a pan-Assamese identity. Further highlighting the contradictions that lie with nationality claims, H. Srikanth and C. J. Thomas make a critical review of the Naga national movement, the rough terrains it has moved and the further challenges ahead. A. Noni Meetei's chapter, 'Narrating the nation in Manipur: Reproduction of a historical question', further problematizes the nationality issue where different ethnically based political groups make contesting nationality claims, thus showing limitations in arriving at a meaningful solution.

The question of nationality and identity claims is closely linked with community claims over land, the subject of Part IV. Lokendra Arambam in 'Land and ethnicity: A study of Manipur and its neighbourhood' makes a close reading of how land is inseparably linked with the body politics of the region. Highlighting the case of Manipur, Arambam sees how land is linked to nationalist imaginations and has been a site of contestation among the ethnos. In the next chapter, Khakchang Debbarma makes a concrete report of how unchecked migration of a dominant population not only changes the demographic composition of Tripura but also how the original inhabitants are minoritized and marginalized in their 'own' land.

Migration and ethnicity are major issues linked to land and territoriality. Often nationality claims coincide with fear of ethnic groups being marginalized and outnumbered by huge waves of migrations, both internal as well as external. Thus Part V is devoted to migration and ethnicity. Bibhu Prasad Routray, in his chapter 'Illegal Bangladeshi migration into the Northeast: Policymaking, politics and road blocks', highlights the fear of demographic change with unfazed waves of Bangladeshi migration. While migration from outside the country is well accepted as a national concern, internal migration is a complicated affair. Reimeingam Marchang's chapter moves away from the usual 
reading of internal migration into the Northeast, and takes up a study of migration from the Northeast to the metropolis, showing a newer dynamics of push and pull.

Federal politics, the subject of Part VI, is yet another major issue. Political violence of self-determination finds root not only in the sovereignty, but also in the autonomy movements. Kham Khan Suan Hausing takes up the constitutional provision of the Sixth Schedule and deals with the claims for autonomy by smaller ethnic groups in the region against the so-called exclusivist majoritarian administrations. M. Amarjeet Singh takes the debate further and critically evaluates the Sixth Schedule provisions and the politics of autonomy claims in the region.

Part VII on civil society movement has been included in this reader. Civil society bodies in the region are often communally defined, and quite different from the general understanding of civil society. This raises the question whether 'civil societies' in the region are civil society in the true sense. Samir Kumar Das, in his chapter 'Fast forward or living in a permanent state of nature?' takes up this issue and raises some pertinent questions on the nature of civil society in the region. This is followed by another critical review by Kakchingtabam Naresh Sharma. He evaluates the role of civil society in the trouble-torn parts of the region where the state ceases to perform its governmental roles, reducing its own presence to near-absence. Prasenjit Biswas further brings out the challenges faced by the civil societies in the region on how they respond to the enormous forces of the state and the market.

Part VIII of the reader focuses on the varied problems of tradition and modernity. In his chapter 'Colonial modernity and plight of the receiving communities', Bhagat Oinam discusses the layers of contradictions faced by the 'receiving community' as existent templates of modernity are still being introduced into the region. Meanwhile Yengkhom Jilangamba's chapter titled 'In the name of a flyover: Development, resistance, politics' engages with one of the modernist templates characterized by the spectacle of gigantic infrastructural edifices. The author gives a critical evaluation of such modernist escapades.

Part IX on Popular Culture includes three articles, one on traditional folk dance and music and the other two on new genres of adaptation and synchronized music. Utpola Borah in 'Music, body and sexuality in Bihu songs of Assam' exposes the popular folk content of sexuality and merrymaking in the songs and rhythms of Bihu dance. Dhiren A. Sadokpam highlights the adaptation of Western rock music and blues in the traditional Tangkhul music. Tangkhul musician Rewben Mashangva's musical journey has been captured to show representation 
of a larger social change based on adaptation, inclusion and empowerment. Usham Rojio highlights the power of poetry, the text and the mode of communication through the songs of Tapta, which has not only succeeded in transforming the traditional media perceptions but also breaks the monopoly of letters in understanding the language of poetry.

The literature of Northeast India is fairly wide-ranging, which initially can be divided into oral and written practices, followed by richness of variety in terms of having large speech communities. Three chapters cannot be fully representative of the literary traditions in the region, but Part X is planned within this limitation. The late Thingnam Kishan Singh gives an overview of the history of Manipuri literature from the earlier oral tradition to the emergence of written texts and further to the modern literary trend in the nineteenth century. This is followed by an overview on Mizo literature by Laltluangliana Khiangte, who highlights the role of Christian missionaries in bringing about Mizo literature in public discourse. Ashley Tellis's chapter highlights a new trend of English writings in the region. Tellis evaluates the English writings of two Naga littérateurs highlighting women's voices in the trouble-torn patriarchy practices of violence (of both the state and non-state forces).

Part XI on women and gender has been devoted not only to represent the fact that women in the region play formidable role in everyday public life, but also to show some inherent contradictions that goes with many of these perceptions. Sukalpa Bhattacharjee, in her chapter 'The politics of gendered resistance: Body and agency', shows how women's social movements use body and emotion and in turn challenge the traditional values of patriarchy. Illustrations from Meira Paibis endorse this argument further. Amrapali Basumatary also highlights the deep-rooted patriarchy values in play in the political movements that claim to bring emancipation of the marginalized peoples and dreams of an egalitarian society. Based on her study of Bodoland movement, Basumatary brings threadbare the inner contradictions in these movements.

The last two parts of the reader are devoted to development policies and political economy. As addressed in the beginning, political violence and social unrest in the region is often shown as caused by unemployment and under development. Developing the region, as reiterated by the new political regime, is shown as the mantra through which many ills are expected to be cured - hence a broad discussion. In Part XII on state policies on development, the late B. G. Verghese takes a look at how new concrete steps could be taken up for the development of the 
region. Gulshan Sachdeva, in 'Preparing the Northeastern economy for the future', argues against the 'neglect theory' as often articulated on the Northeast economy, and emphasizes the need to overcome the inappropriate socio-economic policy framework. Further, Amar Yumnam gives a critical review of the centre's development policies on the region. Part XIII is devoted to the issues related to political economy to raise larger questions on development paradigm set for the region in the last sixty years of India's independence. While the late Thingnam Kishan Singh makes a critique of the politics of underdevelopment, Rohan D'Souza and Prasenjit Biswas critically review the NER Vision 2020 document. D'Souza shows the difficulty of setting a development agenda based on premises and principles that ignored the historical dynamics of the region. Prasenjit Biswas, while reviewing the Vision 2020 document and Look East Policy, critiques the development discourse based on 'periphery' and 'lack'. Overall the volume ends with a critical review, not with an aim to provide a pessimistic picture but towards having a guarded movement.

This new way of conceptualizing the dialectics between existing statist paradigms of development and its possible alternatives emanating from a complicated sense of lack and loss that engulfed the region has no easy solution. The volume brings it out with a stroke of argument and imagination by closely following the categories of thinking that engage people of the region in a parallel home-grown development discourse of their own constituted by claims and paths carved by political and economic imagination by the concerned people themselves. Such an imagination has both conflictual and collaborative dimensions rendering strategies into forces of political and economic struggle and possibly by opening up a way to overcome the dualities and dichotomies of political economy of development.

Overall the volume aims at touching upon the key areas that represent the significant presence of the region as a socio-political entity. The chapters contained herein are not supposed to provide finished understanding about the region, but will certainly provide a site with contesting and complementing views through which readers can gain some authentic understanding about the region called Northeast.

\section{Notes}

1 This reference is to the antiquities found at Dah Parvatiya village, an archeological site located to the west of Tezpur. Historians trace it to the period before Bhaskarverman.

2 The terms 'merger' and 'annexation' represent two standpoints quite different, if not contesting. Those who see that Manipur's becoming part of India 


\section{Bhagat Oinam and Dhiren A. Sadokpam}

was an inevitable political process use the term 'merger'. For obvious reason, the document is known as 'Manipur Merger Agreement'. From within Manipur, the Manipur Congress and its supporters wanted the merger of Manipur into India with its critical opposition to the Maharaja. On the other hand, those who see that the Maharaja was arm-twisted into signing the Agreement term it as an 'annexation'. For details, see Singh (2004/2005). The voices of protest have steadily increased from the days the document was signed. Since the 1980s, valley-based insurgent organizations call bandh on every 15 October. One may also see that those who supported the 'merger' subsequently joined the mainstream democratic practices, and their presence can be seen in the national and local electoral politics.

3 This articulation has been made by scholars like Samir Das over several writings. For instance see Das (2010: 87-94).

4 The sense conveyed by the word 'understanding' carries a philosophically deeper meaning - of an act of internalizing our knowledge about the world. It is to go beyond seeing the world as an object, given for dissection and illustration. It is about seeing the world as it unfolds. It is not only the world that unfolds but also that the subject (agent) located in the world is himself/herself evolving. This understanding that object of knowledge and subject of knowledge are not separate is what is to be seen as 'care'. This is clearly explained in the philosophy of Heidegger. For details, see Heidegger (1953/2010).

5 For those who believe in India as a multi-nation accommodates different nationalities terming those as sub-nations within the larger rubric of India as a multi-nation.

6 In a way Assam takes the lead in the region for others to follow, be it on a bomb blast in crowded markets causing maximum casualty to the ordinary citizens or be it student movements against foreigners, only to end up as climbing the ladder of electoral politics.

7 By embodied violence I am implying to a life deeply entranced in violence in its everyday form.

8 The break-up of UNLF into UNLF and KYKL, KCP into several factions like KCP (VP), KCP (Pro), KCP (N) and so forth are cases of factionalism infighting.

9 Fratricidal conflict between Nagas and Kukis, and tensions between the Meiteis and the Nagas, are clear cases of conflict based on ethnicity and tribe line.

10 These beliefs are spread over several ethnic communities like Kabui, Thangal, Maram and so forth.

11 The term 'communal' refers to its original meaning of a highly closed community life. In the Northeast, ethnicity plays a significant role in determining this communal life. The usage of the term here drastically differentiates itself from contemporary conception of inter-religious conflict prominently etched with the dawn of Indian nation building project and subcontinental articulation of religious animosity.

\section{References}

Das, Samir. 2010. 'Fast Forward or Living in a Permanent State of Nature?', Eastern Quarterly, 6(3).

Gandhi, M. K. 1938. Hind Swaraj. Ahmedabad: Navajivan Publishing House. 
Heidegger, Martin. 1953/2010. Being and Time, trans. Joan Stambaugh. Albany: State University of New York Press.

Hoenig, Patrick and Navsharan Singh (eds.). 2014. Landscapes of Fear: Understanding Impunity in India. New Delhi: Zubaan.

Kimura, Makiko. 2013. The Nellie Massacre of 1983. New Delhi: Sage Publications.

Nag, Sajal. 1990. Roots of Ethnic Conflict: Nationality Question in Northeast India. New Delhi: Manohar.

Nandy, Ashis. 1983/2002. The Intimate Enemy. New Delhi: Oxford University Press.

Oinam, Bhagat. 2009. 'Preparing for a Cohesive Northeast: Problems of Discourse', in Sanjib Baruah (ed.), Beyond Counter-Insurgency: Breaking the Impasse in Northeast India. New Delhi: Oxford University Press.

Oinam, Bhagat. 2014. 'Impunty, Violence: A Tale from Manipur', in Patrick Hoenig and Navsharan Singh (eds.), Landscapes of Fear: Understanding Impunity in India. New Delhi: Zubaan.

Pachuau, Joy L. K. 2014. Being Mizo: Identity and Belonging in Northeast India. New Delhi: Oxford University Press.

Singh, M. Anandamohan. 2004/2005. Shillong 1949 (in Manipuri). Imphal: M. Akshayakumar Singh.

Singh, N. Lokendra. 1998. Unquiet Valley. New Delhi: Mittal Publications. 
$\because$ Taylor \& Francis

http://taylorandfrancis.com 


\section{Part I}

Armed political violence 
$\because$ Taylor \& Francis

http://taylorandfrancis.com 


\title{
1 Nationalist ideology, militarization and human rights in the Northeast ${ }^{1}$
}

\author{
Kamal Mitra Chenoy
}

The intervention by the armed forces in Northeast India is longstanding, and the facts are fairly well known. These will not be the focus of this chapter. Instead, this chapter will seek to raise, in a very preliminary form, some basic issues that arise from the militarization of the Northeast. The history of human rights violations in these states will not be the focus of enquiry, though the interaction between militarization and human rights violations in the Northeast will be examined. But certain ideological, political and legal issues, which may also be of relevance to other countries in South Asia, will be sought to be raised.

\section{India and ethnic minorities}

The dominant nationalist ideology does not accept the concept of 'ethnic minority' as relevant for India. Attempts to use this term in the Indian context have always been officially rebuffed. It has repeatedly been argued that in India, there are linguistic and religious minorities, but no ethnic minorities. Partly as a reaction to British imperialist propaganda, the dominant nationalist discourse is also profoundly homogenizing. Though cultural variations are recognized, and within limits celebrated, there is a notion of a 'composite culture' incorporating strands from India's diverse cultures. Instead of recognizing the existence of a multiplicity of cultures, a composite culture which implies a process of homogenization is theorized. But, within this composite whole there is a privileging of the elite Hindu tradition.

To cite just one instance of this cultural elitism, we can look at the constitutional basis of India's linguistic policy. Though a number of regional languages have been listed in the Eighth Schedule, and 
Article 350A guarantees adequate facilities for instruction in the mother tongue for linguistic minorities, Article 351 stipulates that the Union

promote the spread of the Hindi language . . . as a medium of expression for all the elements of the composite culture . . . by drawing, wherever necessary or desirable, for its vocabulary, primarily on Sanskrit and secondarily on other languages.

Thus Sanskrit, an ancient language, which was traditionally restricted to a tiny Brahminical elite, is privileged as the primary source for the medium of expression of the composite culture.

Minority cultural assertions are like minority political assertions therefore subordinated to elitist, upper caste/class ideologies. Such instances could be multiplied and discussed at much greater length, but this is not the focus of this chapter. Here we would merely seek to indicate that these ideological features shape the Indian state's response to movements for autonomy or self-determination. The use of the armed forces in the Northeast and the dominant national media's response to popular assertions which are perceived as threatening India's integrity are shaped by this same nationalist ideology. There is therefore a cultural and ideological basis to Indian militarism which makes the phenomenon so pervasive and resilient.

\section{Ideological patterns, self-determination movements and the judiciary}

The legitimation of various repressive laws and their judicial sanction are based on similar movements being defined as anti-national, terrorist and disruptive. Thus a statist understanding of national interest governs the judicial scrutiny of such laws. The judicial judgments on such draconian laws invoked the alleged threats to sovereignty and national security, which was evidently accepted as widespread. Thus, for instance, the areas notified under the erstwhile Terrorist and Disruptive Activities (Prevention) Act, 1985 (TADA) as terrorist affected were expanded from the original four states and two union territories to cover almost all the states in the country (PUDR 1994).

The major act that governs military action in the Northeast is the Armed Forces (Special Powers) Act, 1958 (as amended in 1972) or AFSPA, which confers special powers upon members of the Armed Forces in the disturbed areas in the states of Arunachal Pradesh, Assam, Manipur, Meghalaya, Mizoram, Nagaland and Tripura. The Act gives no definition of 'disturbed area'. The declaration of any area as 'disturbed' under Section 3 of the Act is the prerogative of the 
governor of the state, or the administrator of the union territory, or the central government. The state legislature has absolutely no jurisdiction, though under the Indian Constitution (Entry 1, List 2 Seventh Schedule), 'public order' is a state subject.

Under Section 4(a) of the Act, any armed forces officer, warrant officer, non-commissioned officer or any person of equivalent rank may 'if he is of the opinion that it is necessary to do so for maintenance of public order, after giving such due warning as he may consider necessary, fire upon or otherwise use force, even to the causing of death' of persons not only disobeying any law, but even those disobeying orders prohibiting the assembly of five or more persons or carrying of weapons or 'of things capable of being used as weapons'. This gives very wide discretion to even junior officers, as the necessity to use force including lethal means is left to their 'opinion', as is the nature of the 'due warning'. Further, 'things capable of being used as weapons' can include objects like stones, bricks and so forth. Moreover, five people can assemble for innocuous purposes like a religious ceremony, family gathering or visit to an ailing relative.

Similarly, Section 4(b) of the Act allows such military personnel to destroy any shelter from which, in his opinion, armed attacks 'are likely to be made' or which has been utilized as a hideout by absconders 'wanted for any offence'. This latitude would permit the destruction of any shelter or structure, including in several instances, places of worship like churches, apart from educational institutions like schools and colleges. Section 4 (c) permits the arrest without a warrant, with whatever 'force as may be necessary' of any person against whom 'a reasonable suspicion exist that he is about to commit a cognizable offence'. This has provided the basis of indiscriminate arrests, and the use of brutal force including firing against innocent civilians.

Section 4(d) of this special law authorizes the entry and search without warrant of any premises to make arrest as sanctioned under Section 4(c), or to recover any person 'believed to be wrongfully restrained or confined' or any property 'reasonably suspected' to be stolen property or any arms, ammunitions or explosive substances 'believed to be unlawfully kept in such premises'. For this purpose also, all 'force as may be necessary' is authorized. For military personnel operating in a culturally alien terrain, beliefs and reasonable suspicions are often wholly unfounded, leading to horrendous abuses as we shall see below.

Though Section 5 explicitly states that 'Any person arrested and taken into custody under this Act shall be made over to the officer in charge of the nearest police station with the least possible delay', this has been repeatedly violated. Apart from all these caveats, Section 6 (the last section of this short Act) rules that 'No prosecution, suit or 


\section{Kamal Mitra Chenoy}

legal proceeding shall be instituted, excepts with the previous sanction of the Central Government against any person in respect of anything done or purported to be done in exercise of powers conferred by this Act'. The exemption from prosecution is not only for what is done under this Act, but also for what is 'purported to be done'.

This Act therefore provides the legal cover for the militarization of the Northeast and the consequent terrorization of the civilian population. Experts in the UN Human Rights Committee which met in Geneva in March 1991 were categorical that this Act is violative of several articles in the International Covenant on Civil and Political Rights, as well as of the Indian Constitution. Article 2(1) lays down that each state party will ensure to all individuals (not only citizens) the rights laid down in the Covenant. Article 2(3)(a) directs the state to ensure that any person whose rights have been violated 'shall have an effective remedy, notwithstanding that the violation has been committed by persons acting in an official capacity'. Article 26 talks of the equality before the law, the equal protection of the law and the fact that the equal protection of the law itself shall prohibit any discrimination in the rights guaranteed to all persons in the Covenant. All these articles have been violated by the Armed Forces (Special Powers) Act.

Article 4(1) permits state parties to take measures derogating from their obligations under the Covenant in the time of national emergency. But Article 4(3) lays down that any state party availing itself of the right of derogation must inform other state parties through the secretary-general of the UN. The Indian government made no such communication. In any case, as an expert in the UN Human Rights Committee pointed out, such an emergency must be a temporary measure and cannot continue for decades as the Armed Forces (Special Powers) Act has. Further, Article 4(2) stipulates that no derogation from various articles including Article 6 (right to life) may be made under this provision. But Section 4 of the Act empowers firing which may result in death merely on the basis of a relatively junior officer's opinion of suspicion. This violates Article 6(1) which inter alia states that 'No one shall be arbitrarily deprived of his life'.

This Act, like the erstwhile TADA, is violative of Articles 14 and 21 of the Indian Constitution and is a derogation from Entry 1, List II of the Seventh Schedule. The Act also infringes Article 13 which voids all laws inconsistent with the fundamental rights. Article 19 which protects the freedoms of speech and expression, of peaceful assembly, and the right to form associations and unions is also violated. However, though various civil liberties groups and others challenged the constitutionality of this law in the Supreme Court in 1982, the matter has not yet come up for hearing. 
The Punjab Security of State Act, 1953 came into force in Manipur on 26 January 1971. This Act also has draconian features similar to those analysed above. For example, the Act debars any court from requiring production of documents or particulars contained in any correspondence between the lieutenant governor of Manipur and his advisory council set up under the Act. Any speech, statement, rumour or report which undermines friendly relations with foreign states, decency and morality, apart from more serious charges, is punishable with three years' imprisonment. The Act provides for collective fines to be levied on the order of a district magistrate. All offences are non-bailable.

Section 13(1) rules out all legal proceedings against any person 'for anything which is in good faith done or intended to be one under, or in pursuance of this Act'. Section 13(2) provides for similar immunity for the central government and the lieutenant governor of Manipur.

\section{Militarization and violation of human rights}

Any discussion of the role of the Indian armed forces in the Northeast should begin with an introduction to the specificities of this region and its dissimilarities to the rest of the country. More than 220 hill tribes live in the $250,000 \mathrm{~km}^{2}$ region of Northeast India comprising the seven states of Arunachal Pradesh, Assam, Manipur, Meghalaya, Mizoram, Nagaland and Tripura. They feel ethnically, economically, socially and culturally quite different from the rest of India. These perceived differences along with feelings of exploitation and oppression have fuelled movements of autonomy and independence, some of which have resulted in armed struggle (Arambam 2007).

As early as 1929 , some Naga representatives made a plea for selfrule when the reorganization of India was being discussed. Nagas led by the Naga National Council (NNC) asserted their demand for independence, which they declared on 14 August 1947. In 1951, the NNC claimed 100 per cent support for independence in a plebiscite. The Indian state reacted strongly. In 1953, the Assam Maintenance of Public Order (Autonomous District) Act, 1953 was enacted. In April that year, armed police from Assam entered the Naga Hills to arrest NNC leaders. In 1954, a special army officered force, the Assam Rifles, entered the Naga Hills. On 27 November that year, Chingmei village was bombed. In 1955, the Assam Disturbed Areas Act was introduced. On 2 April 1956, the Naga Hills and Tuensang were handed over to the army, and the commander of the armed forces set up the headquarters in Kohima. In 1958, the Armed Forces (Special Powers) 


\section{Kamal Mitra Chenoy}

Regulation was introduced, which on 11 September was converted into an Act (NPMHR 1990, 1991, 1993, 1994).

In Mizoram too, militarization occurred in the mid-1950s, and villages were strafed and bombed. The pattern in Assam and Tripura was different. Militarization in the Northeast Frontier Agency, which later became Arunachal Pradesh, was initially directed against an external threat, China. But there are commonalities in the manner in which the armed forces tackled the civilian population in Arunachal Pradesh, Assam, Manipur, Mizoram, Nagaland and Tripura.

\section{Armed forces and human rights}

The Indian armed forces in Arunachal Pradesh, Assam, Manipur, Mizoram, Nagaland and Tripura appeared to have little knowledge or acquaintance with the customs and culture of the local people. This, given the Hindi-Sanskrit-centrism of dominant nationalist culture, briefly indicated above, was to be expected. Intelligence was poor, and the counter-insurgency forces had problems of communication with the people. With these forces armed with sweeping powers, often without civilian control, with sympathetic governments and an uncritical media, there was in the initial decades in the Naga Hills and Mizoram little check on excesses by the armed forces. Thus Prime Minister Nehru could report to the Lok Sabha on 5 September 1959 that between December 1958 and July 1959, Nagas had suffered 1,568 casualties compared to 334 casualties for the armed forces.

Repeatedly in affected districts in this region, armed forces personnel have violated even the extensive powers granted them under the special laws in their search for an elusive enemy. Civilians have been detained illegally and tortured. In other instances, they have been handed over to the local police and then taken into illegal army custody again. The Gauhati High Court repeatedly directed the army during Operation Rhino and other counter-insurgency campaigns not to interrogate detained civilians after their arrest under the Armed Forces (Special Powers) Act, and not to take into custody such persons after they were handed over to civilian authorities.

The patterns of human rights violations have been fairly consistent (Amnesty International India 1990). In Nagaland and Manipur these have included:

1 Extra-judicial killings.

2 Extra-judicial deprivation of the liberty of people especially in villages due to (a) grouping of villagers and villages; (b) illegal 
imposition of curfew; (c) detention for long periods at army posts and campuses; (d) use of churches and schools as detention or interrogation centres.

3 Rape, molestation and sexual harassment of women.

4 Mode of violence includes (a) hitting with rifle butts, kicking with boots and striking with blunt weapons; (b) giving electric shocks; (c) depriving persons of food, water and sleep; (d) hanging persons upside down and beating the soles of their feet; and (e) threats to shoot, interrogation at gunpoint with the weapon placed against the forehead and inside the mouth.

5 Desecration of churches.

6 Forced labour.

7 Large-scale looting of homes and granaries.

There are, of course, differences in the specificities in human rights violations in different regions. For example, in Assam, forms of torture also included (1) burying persons in the ground up to the neck and covering the head with a bucket; (2) anal penetration with a lathi smeared with chilli powder and petrol; (3) tying persons spread-eagle to a vertical rectangular wooden frame; (4) dunking the head of a person in a drum/bucket of water; (5) continuously pouring water over the mouth and nose of a person immobilized on the ground; (6) pulling out hair from the roots; and (7) inflicting burns with cigarette butts (Manav Adhikar Sangram Samity 1991, 1993).

Very often despite torture, no alleged hard-core insurgents were apprehended or any hard evidence obtained. Because of the strangeness of the local language and culture, army personnel tortured persons for no reason. For instance, during Operation Rhino, Dr. Rudra Gogoi, assistant professor of radiology, Assam Medical College, Dibrugarh, was repeatedly asked, 'Why are you so popular, why does everyone address you as “da"?' The army personnel, not knowing that 'da', an honorific denoting 'elder brother', is commonly used in Assam, tortured Dr. Gogoi for three days. Similarly, Assamese youth who did not speak Hindi were suspected of being United Liberation Front of Asom (ULFA) supporters and tortured. But so were those who spoke Hindi, who were suspected for that reason.

There have been numerous instances of armed forces personnel trying to destroy, diminish or impugn evidence of human rights violations. Witnesses have been threatened, tortured or detained in order to ensure that they do not level charges or provide evidence against the armed forces.

Generally, senior army officials dismiss human rights activists as naïve busybodies at best and agents of anti-national forces at worst. Armed 


\section{Kamal Mitra Chenoy}

forces spokesmen have repeatedly denied reports of human rights violations as 'unfounded', 'baseless' or 'highly exaggerated'. These reports are usually put down to pro-insurgent propaganda and are often accused of being 'foreign inspired'. Using nationalist sentiment of the most chauvinist variety, official spokespersons have almost invariably questioned the patriotism of critics of militarism and human rights violations.

For instance, in a press conference in New Delhi on 10 January 1995, the then additional director-general of military operations, Maj. Gen. A. B. Masih, referred to counter-insurgency operations being carried out in various parts of the country, including Assam, Manipur, Nagaland, parts of Arunachal Pradesh and Mizoram. He revealed that a total of twenty-three columns were called out four times in Assam, and three columns once in Sikkim. He was particularly vocal on the human rights issue.

Maj. Gen. Masih alleged that 'We seem to be buckling under human rights, a Western rights concept. There are far more human rights violations in the West'. He claimed that the Indian Army had an enviable and impeccable record despite performing under duress and provocation. Equating human rights violations with breaking traffic rules, the senior officer regretted that the media never highlighted violations of traffic rules the way it allegedly blows up an aberration of an army jawan under extreme provocation (Times of India 11 January 1995). This statement reveals various elements of the militarist ideology. Patriotism was invoked and the army lauded. Foreign intervention was criticized and shown as hypocritical. And human rights violations were trivialized by equating them with traffic violations. And all this was used in an attempt to question the credentials of the media and to pressurize it not to report human rights violations. As we shall see below, such pressures have been remarkably effective.

In few cases, the armed forces have taken action against their personnel for human rights violations. In August 1988, an army lieutenant was sentenced to life imprisonment for the murder of a woman in Ngaimu village, Manipur, in January 1986. Often, the action taken is minimal. For instance, two army soldiers were dismissed from service and given one year's imprisonment for raping a minor girl in Sibsagar district, Assam.

\section{Militarization and gender}

Women amongst the Manipuri communities especially amongst the Meiteis have a history of struggle including clashes with the colonial British rulers. In the late nineteenth century there was a massive uprising by the Manipuri women against the inordinate increase in the price of rice. They protested fearlessly, undeterred by warning shots 
and later firing. This is popularly known as 'Nupi Lan'. In more recent years women have formed groups often accompanied by a few men which have tried to deter drug abuse and drunkenness. A number of times erring men were taken to the police station or to the locality where the rowdy men came from. But the most important recent incident was after an ex-terrorist Manorma Devi was taken into custody and then raped (The Sangai Express 11 July 2004). The army's claim that she had run away from soldiers is highly unlikely. How would a woman in a phanek (sarong) outrun male soldiers wearing trousers? Moreover, she was shot in the groin area, which would make the determination of rape impossible. In response to this, Manipuri women marched on the Assam Rifles headquarters and took off their phaneks, showing their bodies to the paramilitary with signs and slogans 'rape us' (Times of India 11 January 1995). This agitation succeeded in the long-standing Manipuri claim for the return of the palace Kangla Fort that had been taken over by the Assam Rifles.

It is well known that in counter-insurgency operations women are often targeted. The other troubled state of Kashmir has had numerous such instances. A common pattern is that this is denied by the army and paramilitary, who in any case are protected by AFSPA. In some instances, the right of habeus corpus is stalled by the judiciary for months, judicial intervention in contrast to peaceful areas is highly insufficient and dilatory. The national media often tends to ignore these events or reproduce official versions. A systematic analysis of the role of the media in reporting such events needs to be evaluated on a more massive scale. For example, the Supreme Court constitution bench, while ruling the AFSPA valid, laid down dos and don'ts to guide the actions of the security forces. Within a couple of years a smaller Supreme Court bench dropped the dos and don'ts.

Militarization biases the state apparatus and penetrates all areas of society and events. Importantly it negatively shapes societal relations including gender rights. It increases violent tendencies and factors exacerbating gendered violence. Women in Manipur have resisted by forming collectives of Meira Paibi. These collectives form the basis of collective security at the community/local level. These groups, however, cannot be a substitute for legal-based state protection.

\section{Militarization of civilians}

The armed forces have also tried to inflame ancient tribal hatreds and pit 'loyal' tribes and communities against allegedly 'anti-national' ones. For instance, the army and other state agencies, allegedly motivated, 


\section{8}

armed, trained and protected Kukis to attack supposed Naga supporters of the National Socialist Council of Nagalim (NSCN) in Chandel district in Manipur. Reports have cited that rapes in the villages of Purbung and Lungthulian in Manipur (Chhakchhuak 22 July 2006) were a consequence of ethnic division by the Hmar tribes against the UNLF. Both communities back their own versions and denials divided the communities and women's movements. This is a tactic that the British colonial regime also used against Naga insurgents. But the impact had been far-reaching. Hundreds, both Kuki and Naga, had been killed, and thousands were rendered homeless, especially in the hill districts of Manipur. During the Kuki-Naga clashes, villagers had set up armed self-defence squads demonstrating the militarization of the civil society and ensuring its perpetuation even if state agencies stop their activities. This has been represented in detail by Solidarity Group in Support of the Restoration of Civil and Democratic Rights in the Northeast (1994).

\section{Judiciary and human rights}

As shown above, the judiciary has also been affected by militarist ideology. Since a number of groups in the Northeast are secessionist, virtually all dissent has been characterized as 'anti-national', often 'foreign inspired'. Ideological-political pressures have thus resulted in judicial delays and unfavourable judgements, with the benefit of the doubt often going to state agencies.

On some occasions the judiciary, particularly at the higher levels, has intervened. During Operations Rhino and Bajrang, the Gauhati High Court (Assam) repeatedly pulled up the army for the torture, arrest and harassment of civilians. In July 1991, the Supreme Court ordered that army officers making arrests of women under the Armed Forces (Special Powers) Act, 1958 should follow procedures laid down for police officers under the Code of Criminal Procedure, which guarantee various rights and protections to women and children.

In April 1984, the Supreme Court ordered the payment of 200,000 rupees to the widows of a pastor C. Paul and a school teacher C. Daniel who had been picked up from their villages in Ukhrul district, Manipur, in March 1982 and were never seen again. In August 1991, the Supreme Court ordered the union government to pay compensation of 150,000 rupees each to the mothers of two youths from the valley who were picked up by the army in October 1980 and had been missing since (Manav Adhikar Sangram Samity 1991, 1993). 


\section{Militarization, human rights and the media}

Though the media has often highlighted human rights violations, its reporting is often highly tendentious. A study of the reportage on the Naga-Kuki clashes in major Indian dailies, in both English and Hindi, between 1 January and 10 April 1992 found the gaps and silences in otherwise detailed reports to be linked to the counter-insurgency concerns of the Government of India. This has been brought out by analysing the shifts and quality of reporting in three phases during this period.

The study concludes that 'the media has acted as a willing conniver in the Centre's (central government's) plan for military integration of (the) Northeast. This fascination of media to capitulate to the central authority augurs ill for the future of Indian democracy' (Singh, n.d.).

\section{Conclusion}

The militarization of the Northeast has led to a substantial deterioration of the lives of the common people there. But the costs of militarization are both local, national and international. Armed forces brutalized by such experiences retain little respect for democracy, civilian rule or international commitments. For them, human rights violations become equivalent to breaking traffic rules. Militarist ideology legitimizes authoritarian measures including the suppression of democratic institutions and rights. This weakens political society including the judicial system, fractures civil society and relaxes the rule of law by the rule of force, including in interpersonal relations and in ethnic relations. Militarist measures accentuate the alienation of affected peoples. This alienation is taken to justify even harsher punitive action resulting in greater mass alienation threatening national unity and stability (Chenoy and Chenoy 2010).

The opportunity costs of militarism are also very large. Scarce and vitally needed resources for development are squandered in military expenditures in counter-insurgency and pacification campaigns. A mass psychology of chauvinism and hostility to minorities, the underprivileged and foreigners is built up. These factors cumulatively undermine democratic institutions and processes, and render development efforts unsustainable. Since the 'foreign hand' is seen as instrumental in a number of movements in the Northeast, militarist ideology and policies also run counter to all genuinely popular attempts at peaceful cooperation between India and her neighbours. 
In multi-ethnic and multi-cultural societies in South Asia that are marked by social pluralities, militarism can only be profoundly destabilizing. Militarization in any region has profoundly negative consequences. More so because the militarization of one country often serves as justification for that by others. Thus the struggle against militarism became a national as well as an international imperative.

\section{Note}

1 This is a revised version of the paper 'Nationalist Ideology, Militarisation and Human Rights in the Northeast', Eastern Quarterly, 3(1): 20-30, 2005.

\section{References}

Amnesty International India. 1990. 'Operation Bluebird': A Case Study of Torture and Extrajudicial Executions in Manipur. October. AI Index: ASA 20/17/90.

Arambam, Lokendra. 2007. 'Land and Territoriality', Eastern Quarterly, 4(2).

Chenoy, A. M. and K. M. Chenoy. 2010. Maoist and Other Armed Conflicts. New Delhi: Penguin.

Chhakchhuak, Linda. 2006. 'Women in Line of Fire', India Together, 22 July.

International Covenant on Civil and Political Rights adopted by the UN General Assembly in resolution 2200 A (XXI) of 16 December 1996, and entered into force on 23 March 1976.

Manav Adhikar Sangram Samity. 1991. A Report on Human Rights Violations \& State Terrorism in Assam during Operation Rhino, September. Guwahati: MASS.

Manav Adhikar Sangram Samity. 1993. The Terrorist State Unmasked: The State as the Abductor. Guwahati: MASS.

NPMHR. 1990. A Question of Human Rights. New Delhi: NPMHR.

NPMHR. 1991. Naga People's Movement for Human Rights Goes to United Nations, November. Imphal: NPMHR.

NPMHR. 1993. Know Your Rights, June. Imphal: NPMHR.

NPMHR. 1994. 'Submission of the Naga People Movement for Human Rights', Presented at the 12th Session of UNWGIP, Geneva, 25-29 July.

People's Union for Democratic Rights (PUDR). 1994. TADA Judgement: A Critique, July. New Delhi: PUDR.

Singh, Sanjay Kumar. Undated. A Reportage on the Naga-Kuki Clash: A Prose in Counter-Insurgency. New Delhi: Solidarity Group in Support of the Restoration of Civil and Democratic Rights in the North East.

Solidarity Group in Support of the Restoration of Civil and Democratic Rights in the Northeast. 1994. An Introduction to the Ethnic Problem in Manipur \& A Reportage on the Naga-Kuki Clash, Solidarity Group, January. New Delhi. 'Cannot fool all, all the time', Editorial, The Sangai Express, 11 July 2004. The Times of India, 11 January 1995. New Delhi. 


\title{
2 Armed opposition groups in Northeast India \\ The splinter scenario ${ }^{1}$
}

\author{
Patrick Hoenig and K. Kokho
}

From Northern Ireland to Mozambique, and from Colombia to Palestine, the results of efforts aimed at dispute settlement have been mixed. Peace brokers routinely caution against excessive expectations from peace talks in protracted conflict situations. They point out that it takes time for negotiations to develop traction and for peace processes to become irreversible. Many of the peace initiatives in Northeast India are considered to have reached a safe landing from where a lasting accord is only a short distance away. And, yet, an editorial published in the Statesman (Kolkata 18 December 2008: 6) warned that a number of militant groups in Karbi Anglong, the North Cachar Hills, Boroland and the Garo Hills as well as Tripura, Manipur and Nagaland, after agreeing to a truce with the Centre or a temporary suspension of operations, were becoming increasingly frustrated and indignant about the absence of any 'next step' to a logical conclusion.

A cascading collapse of ceasefire agreements in the Northeast may not be likely, irrespective of the growing resentment among militants. This is for three reasons. First, the military odds are heavily stacked against the armed opposition groups, and they know it. Virtually no insurgent group can convincingly claim to possess the striking power to dislodge the Indian state from 'its' territory. In the current scenario, guerrilla warfare, at best, offers an opportunity of enhancing one's own bargaining position vis-à-vis the state or rival groups. Second, it has become increasingly difficult for armed opposition groups to claim the moral high ground in a global arena where an obsession with 'terrorists' has diminished the prospects of promoting armed struggle as a solution to political problems. Third, militant groups in the Northeast, where they control territory, have usurped functions normally exercised by the state, such as policing, taxing and dispensing justice. Developing into a quasi-state, it is doubtful that they have the stomach for returning to war. 
However, with the peace talks going nowhere fast, something else is in the cards: a further splintering of the armed opposition, along clear-cut ethno-political lines, and the emergence of mini rebel power centres that will not immediately challenge the Indian state but slowly unravel its fabric. In the process, rule of law, secularism and federalism will be torn up in factional fighting and disappear in the shadow of the Indian security apparatus.

\section{The fickleness of negotiations}

The sticky point in negotiations between armed opposition groups in the Northeast and the central government in New Delhi is the Indian Constitution. Both sides agree that defining the relationship of the peoples of the Northeast to the constitution lies at the heart of any solution. Groups with separatist leanings take exception to the notion that they are secessionist. The Indian Constitution, they argue, does not apply to the people they claim to represent as the political entities established in their respective homelands never effectively acceded to the union. Manipuri groups hold that the 1949 instrument of accession, signed by Maharaja Bodh Chandra Singh, was never legally valid. Naga outfits maintain that the outcome of the 1951 plebiscite clearly indicated the Naga preference for independence. Separatists in Assam make the point that Ahom has always been an entity distinct from India. On this, no compromise is possible. The Indian government, on the other hand, qualifies any calling into doubt of the applicability of the constitution to any part of the Northeast, or any other region of 'India' for that matter, as seditious, an assault on the very notion of the Indian nation. This is not a position unique to the administration led by the Bharatiya Janata Party, currently in power at the Centre. A cursory review of the history of peace talks in the Northeast reveals that the approach of governments may have varied over time but the red line has always been the territorial integrity of India, or more mundanely, the retention of territory by the union. All that the Indian government ever was prepared to discuss were solutions within the four corners of the Indian Constitution. What was on the table never went significantly beyond the possibility of upgrading the autonomous status of a territory, creating a new state within the Indian Union and/or adjusting the boundaries of an already existent state, all of which are remedies readily available in the constitution.

The paradoxical nature of the peace talks in the Northeast is illustrated by an anecdote that Samir Kumar Das relates in an article on 'ethnic accords' in Northeast India (Das 2005: 128-9). When the 
Naga leader-in-exile Angami Zapu Phizo went to meet the Indian Prime Minister Morarji Desai in 1977, two years after the signing of the Shillong Accord, he opened the meeting, according to the transcript done on the conversation taped by Phizo, as follows: 'I have come to meet [you] because my people have been suffering for a long time'. Desai immediately challenged Phizo on the grounds that, first, he had no standing in the Naga case as he was a 'foreigner' and 'staying in a foreign country' and, second, he had no knowledge of the ground situation ('I have all the reports and there is no problem. I know everything. I am the Prime Minister of India'). In the account of the meeting provided by Das, Phizo tried to raise the issue of Naga suffering no fewer than five times, and each time, he was interrupted by Desai telling him that he was not prepared to listen ('[I]f you want to talk only about Naga Independence, I won't talk to you'). Das points to a 'strange dilemma' emerging from the way the meeting unfolded: 'You want to talk because there is a problem; but you are not allowed to talk if you bring in the problem'.

The way negotiations presently go in the Northeast indicates that the balance of power is dramatically shifting in favour of the state. It seems possible now more than at any given stage in the history of freedom movements in the Northeast that the state will be able to reach political settlements more or less on its terms. 'The peace process may seem interminable', a serving Indian army officer wrote with respect to the talks between the government of India and the Isak-Muivah faction of the National Socialist Council of Nagalim (NSCN-IM), which started in 1997 and are painfully slow to unfold, '[b]ut sometimes the lion must roar, just to remind the horse of his fear' (Arya 2007: 591). Retaining the use of force as an option, this military expert reasons, is all the more opportune as a sharp decline in discipline with most armed opposition group cadres has been observed. There is thus hope for 'the weakening of the insurgents' ability to fight the security forces after a prolonged ceasefire.

Operation Green Hunt, the codeword for a military adventure, which was launched in 2009 with the aim of stamping out the naxal movement in central India, was seen by many as a test run for alternate ways of dealing with political dissent. The doctrine of a 'new realism' attracts ever-greater attention in a world of shrinking resources. The bottom line is this: we live in a 'changed, hard-headed world' where 'national interest' is the 'primary impulse of that conglomerate of powerful, individual nation-states known as the international community' (Joshi 2009: 7). The time for niceties is over. 'Talks for the sake of talks serve no useful purpose, not even in earning diplomatic brownie 
points as New Delhi thought it did in decades past'. Confidencebuilding measures used to be considered a way of shoring up goodwill, which in turn was seen as a means of creating stakeholders in peace. This is no longer the case. Now it is argued that

$[\mathrm{u}]$ nless New Delhi does a better job providing security to its own people and to the people of its smaller regional partners against rebels, secessionists, drug runners and arms traffickers, it will not be able to generate much confidence in the capitals of surrounding nations.

(Maitra 2008: 35)

Maitra further states that the goal is for India to become a power with Asian reach, not just reach within the Indian Ocean. So maybe, in the long run, the gloves will come off. The 'forces of progress' will claim that the writ of the state has to run and it has to run deep.

\section{No-peace-no-war limbo}

Not all observers agree with the foregrounding of security in policy making in the Northeast. Nishal Pandey for one has pointed out that, for any effort to jumpstart the development of the region to succeed, 'regional and sub-regional economic cooperation' will have to take 'precedence over the build-up of security personnel' (2008: 108). There is nothing inherently wrong with such a line of arguing, except that it appears to be rooted in the commonly held notion of economic deprivation being at the heart of armed insurrection against the state. However, the grievances of the 'seven sister states', contrary to the Centre's perception, are not of economic nature alone. Nagaland, for instance, receives four times as much from the central government in terms of grants than it pays over in revenue charges (Dent 2004: 64). And yet, the security situation remains precarious.

Besides, development schemes more often than not reflect the interests of particular groups rather than the public at large. Sanjay Barbora considers legal regimes to have been 'as dispensable a commodity for the early British planters as they are today for international funding institutions and public sector hydro-electric [power plants] in India' (Barbora 2008: 15). The prevailing situation in the Northeast presumably suits the Indian government for it allows a continuation in its pursuit of mega-development projects, with no real debate and democratic challenge, and the opening of commercial windows on Southeast Asia, beautifully packaged in the concept of 'Look East', which 
is empty in political terms, except for the implicit understanding that connectivity to mainland India is non-negotiable. Armed opposition groups, on the other hand, are struggling to build up parallel government structures, some of them with home, finance and crime control departments.

On a more general note, it seems that power, in its dual manifestation as state-making and resistance to it, generates its own dynamics and possibilities of abuse as well as synergies. Sanjib Baruah has argued that the gradual militarization of the Northeast, coupled with development-related investment, 'cosmetic federalism' and demographic shifts, is creating 'stakeholders in the pan-Indian dispensation' and 'a political counter-weight to pro-independence rebellions' (2005: 57). The binary of pro- and anti-state has become entangled in a knot of power structures where everything is wired with everything else. Asked in an interview whether he acknowledged that there was a 'nexus between politicians, police and militants' in his state, Manipuri Chief Minister Okram Ibobi Singh stated: 'Earlier it did. We have arrested some underground militants from official bungalows'. Question: 'It is not happening anymore?' Answer: 'We hope so' (Mittal 2009: 3). However, if hope becomes the basis of governance, it is clear we need to fear that all reason is lost.

\section{'Solutions'}

In the previous sections we discussed the parameters of the discourse shaping the structure and dynamics of negotiations - but what is the substance of peace talks in the Northeast? Earlier, talks seemed to be centred on creating breathing space for people finding their feet in a messy post-colonial world. The 'Hydari Agreement' or 'Nine-Point Agreement' of 1948 is seen as a skilfully negotiated document for giving the Naga people a ten-year period in which to assess the situation (Kumar and Murthy 2002: 44). The agreement also was flexible enough to allow for both sides to claim it in support of their respective position. The Nagas insisted they had retained the right to 'opt out' of their relationship with India, while the Indian government maintained that any new arrangement would have to be negotiated on the basis of the constitution. In contrast, the negotiations currently underway between the Indian government and the NSCN (IM) are essentially addressing the problems that were created by setting up the state of Nagaland in the first place. The much-touted NSCN (IM) ' 31 Points Draft' revolved around the integration of adjoining Naga-inhabited areas into Nagaland, a 'special' federal relationship with India and a 
separate constitution for Nagaland. The Indian government has given no hint that it is prepared to accommodate the NSCN (IM) on any of their core demands, but even if it met all of them, the arrangement would translate into nothing more (and nothing less) than Nagaland being placed on an equal footing with Jammu \& Kashmir, which from the Indian government standpoint is an integral part of India.

Today the ceasefire is extended only for six months at a stretch, and in early 2009, after the killing of young civil servant Thingnam Kishan Singh, along with two companions, in the Manipur hill district of Senapati, it briefly looked as if it would collapse altogether. Contrary to initial concerns, the peace talks were not called off. Kishan was reported to have fallen victim to an unauthorized killing by a member of the NSCN (IM) whom he had rubbed the wrong way. ${ }^{2}$ However, the execution-style killing triggered large-scale protests throughout Manipur against the law and order situation in the state. It also served as a stark reminder of what can happen in present-day Manipur to anyone outspoken, thoughtful and visionary, even though Kishan thought of himself as a moderate, a pragmatist. The writing on the wall is clear. In the time that is remaining, how do we open up space for peace talks?

Sanjoy Hazarika ${ }^{3}$ has observed that the continued use of the Armed Forces Special Powers Act (AFSPA) in various parts of the Northeast constitutes 'a bar to negotiations; repealing it can open up political space for discussion at various levels' (2008: 94). It goes without saying that an atmosphere conducive for peace talks will require respect for the rule of law, upholding of human rights standards and openness for reconciliation in justice. Ranabir Samaddar holds that a dialogue to 'find out truth' even though it cannot 'erase asymmetries of power' becomes a 'necessary mechanic' for turning a system of injustice, with sprinkles of retributive justice, into a system of restorative justice based on the recognition of past injustices (Samaddar 2005: 39). If disagreement on political positions were to be accompanied by mutual respect and a certain amount of goodwill, the ceasefire agreements in place in the Northeast could be seen as a crucial first step to break the dynamics of violence and mistrust.

Unfortunately, this is not the case. Local groups have sometimes been listened to, and sometimes not, but they are yet to make a decisive difference in the way peace initiatives unfold. In May 2007, twentyone months before his untimely death, Kishan, then assistant professor at the Manipur University and editor of the quarterly journal Alternative Perspective, spoke with one of the authors of this article about the political situation in Manipur. He did not mince words. In the course of the conversation, he termed the political leaders in Imphal 'agents 
of the Indian state', condemned pervasive corruption and restrictions on the freedom of speech, deplored the lack of spending on education and the fragmentation of civil society and warned that with AFSPA in place and political grievances continuing to go unaddressed, militancy in Manipur was yet to peak. In spite of the bleak picture he painted of the overall situation, Kishan held out hope that the young generation would be able to open up new space for the political discourse to yield meaningful results. No doubt, the Northeast is a place where new tactics are being created, the 'politics of whisper' and 'kitchen politics', the baring of bodies as a plea for rights, Irom Sharmila's fast against force. Civil society groups, such as the Naga Mothers Organisation, Naga Hoho, Apunba Lup, Meira Paibi, student organizations and churches have been active to reconcile warring factions and promote peaceful conflict resolution. But the unified human rights movement that activist Binayak $\mathrm{Sen}^{4}$ had called for in his first meeting since his release on bail from Raipur jail is yet to find its voice.

Indications are that the space for civil society is shrinking, partly because of a growing disconnect between the centre and the periphery. The political discourse in India has become fragmented. What one means to say depends not only on where one stands politically but also, literally, on one's location. Asked about the meaning of national holidays, a friend from Imphal shared how she remembers her family returning from a visit to Delhi when she was a child, bringing back pictures of the 'real Republic Day', with balloons, cheering crowds and the 'proud Indian flag' (her parents still have the pictures at home, she says). As she grew up, however, Republic Day began to be etched in her memory as a 'black day', a day 'when we had to stay in'. She finally recounted an episode from Republic Day a few years ago:

A friend called up from Delhi asking if I wanted anything since she would be shopping the next day, which was Republic Day. I said there was nothing I wanted she could get for me from Delhi and then quickly added, 'Isn't there a bandh tomorrow? Shops won't be open'. She said, 'Well, I'm in Delhi!'

\section{The endgame: Leaders versus people}

Armed opposition groups in the Northeast, in pursuit of their own vision for forms of social and political organization, have resisted the British Empire and the Indian state. Ironically, the more they managed to mould their behaviour in a way that made them look 'state-like', the more they became a 'respectable' negotiating partner for the state, 


\section{Patrick Hoenig and K. Kokho}

the less they seemed aligned to principles they set out to defend and in touch with people they claimed to represent. In the final stages of the peace talks in Mizoram, Pu Laldenga, the leader of the Mizoram National Front, insisted that he could only be expected to bring the armed struggle to an end if he were to be appointed chief minister of the newly created state first (Pudaite 2007: 443). This demand proved a major stumbling block for as long as the People's Conference, a regional party, wielded power. The sitting chief minister made it clear that he would not give up office unless defeated in elections. It was only when the Indian National Congress won the Assembly elections in 1984 that the Centre, under the leadership of Indira, then Rajiv Gandhi, was in a position to force the hand of the state government. The incoming Chief Minister Lal Thanhawla offered to step down if it was felt that his resignation would facilitate the peace process. It turned out that it did. The Memorandum of Settlement ending the insurgency, the so-called Mizo Peace Accord, was signed in June 1986; Laldenga was appointed chief minister shortly thereafter, without a ballot being cast in his favour. ${ }^{5}$ Laldenga's rise to power may serve as an example of how endurance and perseverance have their place in prevailing over political opponents. But his story hardly reinforces the notion that leaders of popular movements represent the people for whom they purport to be speaking more legitimately than the political establishment.

In Seeing Like a State, James Scott argues that 'formal order' tends to be 'parasitic on informal processes, which the formal scheme does not recognize, without which it could not exist, and which it alone cannot create or maintain' (1998: 310). But if we shift the focus from the state to those fighting it, we will find that the same process happens in the reverse. Insurgencies have a tendency to incorporate elements from the state, turning into a quasi-government, with all the potential of corruption, collusion and complacency. The price for institutionalizing informal processes oftentimes is alienation. The following story from the hill tracts of Manipur illustrates this point. A middle-aged man lived with his wife and three children in Tamenglong, a hill district of Manipur. Carving out a meagre living with farming, the man took to supplementing his earnings by fishing in the river. One day he decided to increase his catch by inserting poison into the river. However, he miscalculated the amount and killed many more fish than was acceptable to the villagers. When reported to the militant group in control of the village, he ran away to escape punishment. But soon he realized there was no getting away from the long arm of the militants. In his desperation, he joined a rival militant faction where he received 
a hero's welcome. We do not want to push our point too far, but it seems that the contemporary 'Naga nationalist', wrapped in various layers of coercion and cooption, more often than not is the product of fear. What is more, evidence is mounting that the scaffolding of the peace talks, 'being like a state', does not support a solution conducive to meeting the political aspirations and economic needs of the civilian population. And precisely because they have lost support of the local population, the armed opposition groups, in the twisted logic of the state, are no longer considered insurgents but 'terrorists', with whom one can have no dialogue.

No-talk factions in the Northeast, for their part, maintain that there is no point in negotiating with the state as it merely exists to oppress. Such thinking is rooted in anti-colonial traditions of resistance to state power. Frantz Fanon (1925-61), a psychiatrist born in Martinique, a fighter for the independence of Algeria and a stout anti-colonialist, pointed in his book The Wretched of the Earth (1961) to the impossibility of the colonizer and the colonized finding common ground. ${ }^{6}$ While the colonizer was busy making sure that the colonized found it impossible to do as much as dream of freedom, the colonized, on the other hand, was occupied with exploring even the remotest possibility of overthrowing the colonizer. The notion of the indigenous being 'bad in absolute terms' had found its mirror-image, according to Fanon, in the idea of the colonizer being 'bad in absolute terms'. In Fanon's days, the dichotomy of perceptions could not be overcome. The creation of the homme neuf, the new man, with a skin not black or white but sensitive to the notion of justice, remained a utopian idea, a goal unattained.

Whether it is appropriate to frame the relationship between the Indian state and the peoples of the Northeast in (post-)colonial terms is beyond the scope of this chapter. However, it is interesting to note that while talks are on, the prospects for peace have become ever more elusive in the Northeast. The bipolar character of the struggle for independence has given way to a complex web of actions and reactions, increasingly blurring the line between black and white and bringing to the fore, if anything, a new post-Fanon species, the grey man. What is getting crushed in the battle of the elements, inevitably, is people's empowerment and participation in political processes. The state slicing up the Northeast for investment and exploitation of natural resources marginalizes, but does not eliminate, armed opposition groups. Militancy has started to feed on itself, and we feel that what may be in store for the region is an increasingly acrimonious struggle between the political and military leaderships of armed opposition groups for 
the crumbs falling from the table. The brunt will be borne by the cadres and the population at large. But with the periphery turning into a perpetual danger zone, what will happen to democracy and selfdetermination? There is an old Meitei proverb: when the fish decided to speak and opened his mouth, the water choked him.

\section{Notes}

1 This is a revised version of the paper 'Armed Opposition Groups in Northeast India: The Splinter Scenario', Eastern Quarterly, 6(1/2): 49-58, 2010.

2 The suspected perpetrator, an NSCN (IM) 'officer' of the rank of 'colonel', was initially arrested and detained on orders from his own hierarchy, then, in a surprising move, handed over to the Indian authorities and made to stand trial in Delhi High Court.

3 Hazarika was a member of the AFSPA Review Committee (Reddy Committee), which in 2005 submitted its (unpublished but leaked) report to the Indian government recommending the repeal of AFSPA, but also arguing for legislation, which, in Hazarika's words, 'enables emergency duty for security forces'.

4 Dr. Sen was arrested in May 2007 on charges of aiding and abetting the naxals. He was held in detention for two years, on flimsy evidence, under provisions of the Chhattisgarh Special Public Security Act 2005 and the Unlawful Activities (Prevention) Act 1967. The Supreme Court of India granted him bail in May 2009.

5 It is true that Assembly elections held in 1987 confirmed Laldenga in office (before he was eventually ousted by the imposition of president rule the following year), but the point is that he agreed to holding elections only after donning the mantle of chief minister.

6 Frantz Fanon, Les damnés de la terre, Paris: La Découverte, 2002. For a readable analysis of 'Wretched of the Earth', see Alice Cherki, Frantz Fanon: A Portrait, Ithaca and London: Cornell University Press, 2006, pp. 170-84.

\section{References}

Arya, Major Shailender Singh. 2007. 'Nagaland - the Uneasy Ceasefire', U.S.I. Journal, 137(570), New Delhi.

Barbora, Sanjay. 2008. 'Under the Invisibility Cloak', Biblio: A Review of Books, 13(5/6), New Delhi.

Baruah, Sanjib. 2005. Durable Disorder: Understanding the Politics of Northeast India. New Delhi: Oxford University Press.

Cherki, Alice. 2006. Frantz Fanon: A Portrait. Ithaca and London: Cornell University Press.

Das, Samir Kumar. 2005. 'Nobody’s Communiqué: Ethnic Accords in Northeast India', in Samir Kumar Das (ed.), Peace Processes and Peace Accords. New Delhi: Sage Publications.

Dent, Martin J. 2004. Identity Politics: Filling the Gap between Federalism and Independence. Hants (England) and Burlington (Vermont): Ashgate Publishing. 
Editorial of The Statesman, Kolkata, 18 December 2008.

Fanon, Frantz. 2002. Les damnés de la terre. Paris: La Découverte.

Hazarika, Sanjoy. 2008. 'Legalised Anarchy', The Little Magazine, 7(3/4), New Delhi.

Joshi, Ishan. 2009. 'Fortress India', The Statesman, 7 December.

Kumar, Ram Narayan and Laxmi Murthy. 2002. Four Years of the Ceasefire Agreement between the Government of India and the National Socialist Council of Nagalim: Promises and Pitfalls. New Delhi: Civil Society Initiatives on the Naga Peace Process and Other Media Communications.

Maitra, Ramtanu. 2008. 'Incorporating Security in India's Look East Policy', AAKROSH: Asian Journal on Terrorism and International Conflict, 11(39), April.

Mittal, Tusha. 2009. 'In Cold Blood: "Education Is More Important Than Right to Life"', Tehelka, 5 December, New Delhi.

Pandey, Nishal N. 2008. India's North-Eastern Region: Insurgency, Economic Development and Linkages with South-East Asia. New Delhi: Manohar, in Association with the Institute of South Asian Studies, National University of Singapore.

Pudaite, L. T. 2007. 'Peace and Development in Mizoram: A Perspective', in Anuradha Dutta and Ratna Bhuyan (eds.), Genesis of Conflict and Peace: Understanding Northeast India: Views and Reviews, Vol. 2. New Delhi: Akansha Publishing House.

Samaddar, Ranabir. 2005. 'The Politics of Understanding', in Samir Kumar Das (ed.), Peace Processes and Peace Accords. New Delhi: Sage Publications. Scott, James. 1998. Seeing Like a State: How Certain Schemes to Improve the Human Condition Have Failed. New Haven: Yale University Press. 
$\because$ Taylor \& Francis

http://taylorandfrancis.com 


\section{Part II}

\section{The extraordinary law and its impact}


$\because$ Taylor \& Francis

http://taylorandfrancis.com 


\title{
3 Violence and terror under AFSPA 1958 and the people's movement against it $^{1}$
}

\author{
Malem Ningthouja
}

The Armed Forces Special Powers Act, which replicates the British colonial Armed Forces Special Powers Ordinance 1942, has been a controversial legislation in India. Historically, in 1947, to deal with the situation of communal unrest and riots on account of the 'partition' the then governor general issued four repressive ordinances, ${ }^{2}$ which were continued by the then Dominion of India. In 1948 the four repressive ordinances were replaced with the Armed Forces (Special Powers) Act, 1947. On 14 December 1955, the governor of Assam gave assent to the controversial Assam Disturbed Areas Act, 1955, which resembled the AFSPA. It had draconian provisions that empowered either civil officer magistrate or police officer or officer of the Assam Rifles to kill on the pretext of maintaining public order, and they were protected from legal prosecution unless with the previous sanction of the state government. The original AFSPA was repealed in 1957. But in early 1958, a regulation known as the Armed Forces (Special Powers) Regulation, 1958 was promulgated by the President of India. This was followed by an ordinance known as the Armed Forces (Assam \& Manipur) Special Power Ordinance 1958, passed on 22 May 1958, which was aimed at suppressing the liberation movement spearheaded by Naga National Council in the Naga Hills areas of Assam, parts of the then North Eastern Frontier Agency and Manipur. It became an Act on 11 September 1958. In 1972 the title of the Act and certain clauses were amended in order to encapsulate newly demarcated administrative regions in the Northeast. The new government that was formed after the emergency repealed the controversial Clauses 2 to 4 of the AFPSA on 26 November 1978. The repealed provisions were restored after nine years by the Act 19 of 1988. Meanwhile, in 1983 a version of the Act entitled the Armed Forces (Punjab and Chandigarh) Special Powers Act 1983 was enacted to suppress Khalistan movement in Punjab. In 1990 the Armed Forces (Jammu \& 
Kashmir) Special Powers Act, Act No. 21 of 1990, was enacted to deal with the Kashmir question.

This chapter deals with the violent experiences faced by the people in Manipur under the regime of the Armed Forces (Special Powers) Act (AFSPA). ${ }^{3}$ It analyses various ways and means adopted by people's movements against the Act. There is a perception that there is simultaneity of violence perpetrated with impunity under the regime of the Act (henceforth violence) and protest against it; each respectively representing 'policy of governance' and 'people's response' against such policy. Although this understanding remains uncontested, protest against the intension of violence, if not raison d'être of violence embodied in the Act, preceded ${ }^{4}$ violence. The 1958 protest in parliament $^{5}$ was a harbinger of subsequent protracted movement against violence. The intention of violence was rooted in a fabricated national exigency, that is a demand factor, thereby construed violence as justified means to defend an imagined Indian nationhood. ${ }^{6}$ It framed a law and order discourse to act as propaganda surrogate to cover up the capital interest of the policy makers in the weak spots. ${ }^{7}$ The argument is that the objective of AFSPA and its implication are to be interpreted from perspectives beyond the legal paradigm. This chapter analyses the issue in two sections. The first deals with violence and the second deals with the people's movement against AFSPA.

\section{Experiences of violence}

AFSPA is widely condemned in Manipur and beyond for unrestrained violence. Protagonists of the Act, that is the clique of policy makers, defended the Act. The Supreme Court of India in $1997^{\circ}$ upheld it, for 'deployment of the armed forces" ${ }^{9}$ of the Union shall be for the purpose of enabling the civil power in the State to deal with the situation affecting maintenance of public order which has necessitated the deployment of the armed forces in the State'. ${ }^{10}$ The Court, to uphold human rights, prescribed a set of 'dos and don'ts' for the armed forces, which in no practical sense do away with the impunity provisions of the Act. Violence continued. Despite protest for decades, the former Home Minister Shivarj Patil's 'brothers, men and officers of the Armed Forces .... (who are) involved in countering insurgency"11 resented amendment or repealing of the Act because 'we (soldiers) function under orders and hence our interests need to be protected'. ${ }^{12}$ To cover up the violence, they have adopted military civic action program, for example gifting and hosting tours and sports events for civilians. Although these measures attract few beneficiaries, in the long run they 
perpetuate militarization of the social service sector, thereby undermining the role of civil administration, and do not ensure immunity of the people from violence.

Violence continues because Section 3 empowers any responsible official to declare any area as disturbed (which is a precondition for deployment of troops in the area), and impunity provisions became operative. Section 4 empowers any commissioned officer, warrant officer, non-commissioned officer or any other person of the equivalent rank in the armed forces in the disturbed area(s) to carry out brutal and arbitrary policing, ${ }^{13}$ which often leads to unrestrained collateral damage or pogrom upon civilians. Section 6 defends guilty personnel, as 'No prosecution, suit or legal proceeding shall be instituted, except with the previous sanction of the Central Government against any person in respect of anything done or purported to be done in exercise of the powers conferred by this Act'. Reports and complaints suggest that guilty personnel were hardly convicted through delaying investigations, tampering of evidences and intimidating victims. In this scenario, therefore, suspension of the fundamental constitutional rights and violation of the United Nations' prescribed humanitarian norms ${ }^{14}$ get to be the order of the day.

Interference by the armed forces in the civil administration, politics and judiciary are repeatedly reported. For instance, in 1988 a major of the Assam Rifles (henceforth AR) barged into the room where a team of the Planning Commission was meeting and disrupted the meeting with abusive tone: 'The norms of decency followed by us here are different from those in Delhi'. ${ }^{15}$ Legislatures could be debarred from moving beyond lines drawn by the armed forces. Instead of aiding civil administration, they at times operated without a request from the state government (Navlakha 1995: 2228-9), and interfered in legal proceedings and politics. For instance, when the then Chief Minister Rishang Keishing protested against violence in Oinam village, Senapati District in 1987, he was promptly removed from the post due to the pressure of the AR. ${ }^{16}$ In 1988, the AR prevented the registrar (judicial) of the Gauhati High Court from interviewing women victims of rape. Pressurized by the AR, the then Home Minister of Manipur Tombok Singh went to Oinam village on 11 April the same year to tell the villagers to withdraw their writ petition. ${ }^{17}$ In 1989 , every day at the sessions court in Imphal, the AR personnel who were facing a case carried a table and a pair of chairs to the court room on the plea that the ordinary benches used by the public were not good enough for them. When the judge ordered that there must be equality before the law and treatment given to the petitioners and respondents must be alike and same, the AR 


\section{8}

went to the Gauhati High Court challenging the order. ${ }^{18}$ As if a norm, lawyers and democratic rights activists were routinely given a taste of the bared fangs of the armed forces (Bose 1989: 214). Officials of the state government - both magistrates and police officers - could be detained and their offices raided by the armed forces. ${ }^{19}$

In summary, violence and its aftermath experienced by the people include cold-blooded fake encounters, massacre, torture, harassment,$^{20}$ illegal detention, forced disappearance, killing as a result of 'mistaken identity', ${ }^{21}$ rape, molestation, sodomy, post-traumatic stress disorder ${ }^{22}$ and destruction of property. ${ }^{23}$ The UN acknowledged the scale of violence and observed in 1991 that there were number of fields in which legislation and practice in India were not compatible with the terms of the ICCPR 1966, such as the implementation of the Covenant in 'disturbed areas', arbitrary killings and arrests in some states, the excessive powers granted to the security forces, and the failure to bring proceedings against police offenders. ${ }^{24}$ Individuals and organizations published accounts of violence, namely MiniEmergencies to Suppress the Poor (Ram 1978: 1880), Use of Coercive Power (Mathur 1992: 337-49), Obstructing Justice, ${ }^{25}$ Official sanction for killings, ${ }^{26}$ National Security tyranny, ${ }^{27}$ Hard Option, ${ }^{28}$ Where Peacekeepers Have Declared War ${ }^{29}$ and so forth. In 2005, the Report of the Committee to Review the Armed Forces (Special Powers) Act, 1958, Ministry of Home Affairs, ${ }^{30}$ noted that AFSPA had promoted violence and recommended that the Government of India (GoI) repeal the Act. The recommendations of the Second Administrative Reform Commission $^{31}$ and the UN UPR 2012 sought for repealing of the Act. On 20 November 2012, the National Security Advisory Board (NSAB) stated to include recommendation for 'repeal' or 'amend' of the Armed Forces Special Powers Act (AFSPA) in the Northeast in its proposed report to the Government of India. ${ }^{32}$

Unrestrained violence has drawn the attention of critics who shift the interpretation of the Act from a legal perspective/law and order discourse to anti-colonial perspective, that is AFSPA as manifesting colonial implication. ${ }^{33}$ If we go by the statements of the Indian left democratic forces such as the $\mathrm{CGPI}^{34}$ and the AIPRF, ${ }^{35}$ violence was an inevitable course adopted by the GoI. The left interpretation, if not the propaganda literature of insurgent organizations in Manipur, ${ }^{36}$ suggests that AFSPA was a legal camouflage to cover up Indian expansionism, that is a term used by the United Communist Party of Nepal (UCPN) in the context of Nepal. ${ }^{37}$ Such interpretation may sound polemical. However, the AFSPA debate of 1958 informs that the Act was enacted primarily to suppress national liberation movement in 
Northeast, later on in Kashmir. Geographical coverage under AFSPA would indicate that the GoI has adopted military option while dealing with the vexed national question (sic. political issue) raised by the community of suspects, that is people of 'virile" 38 character, with different ideological and racial ${ }^{39}$ loyalties as referred to by the first generation of post-colonial Indian policy makers. The pretext and context of the Act and its material implication appear to cast in the mould of what Neville Maxwell had termed as Nehru's 'forward policy'. ${ }^{40}$ The Act undermines democratic rights and perpetuates 'the predicted' alarming situation, that is undeclared martial law or emergency. ${ }^{41}$ The Act, which also reinforces other repressive legislations such as the Unlawful Activities Prevention Act, National Security Act, Prevention of Terrorism Activities Act, ${ }^{42}$ Prevention of Seditious Meetings Act and so forth converted Manipur into a permanent state of siege, that is 'State of Exception' according to Agamben for a similar situation (Agamben 2004: 11-22). In other words, if there is severe violence as a result of 'war on people', ${ }^{43}$ violence under the regime of AFSPA is self-illustrative. Brutal and repressive tactics to suppress people's movement against AFSPA produce a vicious cycle of state-sponsored reign of terror and perpetuates violence. This begs the questions, for whom is the Indian nation state constructed, and whose security and peace are we talking about?

\section{Ways and means of protest}

The violence has inflicted different degrees of pains on several individuals and groups in different ways, circumstances, spaces and times. There is no village or hamlet or locality or residential colony that has not been wounded, either physically or psychologically. The physical wound to an individual or a group might have recovered with the lapse of time; the trauma and memory of pains remain long lasting, through generating or to generate the process that Maurice Halbwachs might have termed 'collective memory' (Coser 1992). Amongst those who are being tortured, the 'capable' usually raise up in pain as a mark of protest and for justice. These are expressed in organized forms in the visually manifested individual or collective, passive or active, spontaneous or organized, sporadic or simultaneous, sectarian or coordinated protests and agitations against torture and AFSPA. These reverberated individual or social pains, often expressed in the aftermath of immediate torturous assaults on individuals and properties, are either subsumed into or become essential ingredients of constituting a larger social framework that Ron Eyerman had termed 'cultural 
trauma' (Eyerman 2004: 1-2). The objective of such expressive pain is to create what Halbwachs had termed 'collective mind', to use as a technique that infuses the psychology of pain among the 'citizens', to achieve social solidarity and a correspondence between thoughts, sentiments and acts in the fight against AFSPA. Chronologically, the protest was registered as early as 1958 in the parliament. However, organized attempt to make the movement broad-based have not taken place till 1970s for various reasons: (1) the Act was imposed in piecemeal/sporadic manner, ${ }^{44}(2)$ there was communal interpretation on the implication of the Act; ${ }^{45}$ (3) there was lack of consciousness for democratic rights and common democratic goal; (4) there were other sensitive and overlapping issues ${ }^{46}$ that diverted attention away from violence, (5) there were repressions against protest and so forth.

In the early 1970s, the Kanglei League, a party that wanted to raise issues through electoral politics, initiated a campaign against AFSPA (Laba 2010: 5). At the individual level, a reported suicide was committed by a Tangkhul woman named Rose Ningshen, reportedly committed suicide on 6 March 1974 after being gang raped by $95 \mathrm{Bn}$ BSF personnel two days earlier. ${ }^{47}$ The author was informed that the suicide had inspired the birth of Tangkhul Shanou Long (Tangkhul Women's Association). On 10 May 1974, the East District Women's Association of Manipur submitted a memorandum to the then prime minister of India demanding action against the BSF personnel responsible for the crime. From 1978 onwards, Naga People's Movement for Human Rights raised the issue of violence. Human Rights Forum, Manipur, since 1979 began international campaign and took up legal challenges. ${ }^{48}$ In 1980, in the aftermath of widespread protest against violence by the Central Reserve Police Force at Patsoi Langjing, Imphal, the women's Meira Paibee movement emerged. ${ }^{49}$ By September 1980, Amnesty International sent a letter to Human Rights Forum, Imphal, stating that it was 'keen to receive any reliable reports of political imprisonment, detention, torture, and the death penalty in India'. ${ }^{50}$ In 1983, the Civil Liberties and Human Rights Organization was formed by lawyers to fight in the courts against violence. In 1993, the Committee on Human Rights was formed with the objectives to create awareness and to build up mass movement against violence. Coincidently various interplaying factors such as the introduction of the Indian Human Rights Bill 1993; establishment of National or State Human Rights Commissions; establishment of Office of the United Nations High Commissioner for Human Rights; ${ }^{51}$ intensification of national liberation movement and expansion of its mass fronts contributed towards human rights movement picking up momentum. 
Civil societies and scores of what Bayly would term 'assertive intelligentsia' (2002: 148) took up the initiative to carry forward series of individual $^{52}$ and collective protests against AFSPA. During the 2004 course of intensified protest against AFSPA, ${ }^{53}$ about a dozen women, raising the chants 'Indian Army Rape Us' and 'Indian Army Take Our Flesh' stripped themselves in front of the Assam Rifles Headquarter Gate on 15 July. On 15 August, Mr. Pebam Chittaranjan committed self-immolation in protest against the AFSPA. A conglomeration of thirty-two organizations under the banner called Apunba Lup ${ }^{54}$ carried out what they called (1) meepal tangdaba khongiang (self-reliance movement that began with boycotting cold drinks and mineral waters manufactured outside the geographical area of the Northeast states); (2) leingak loisang saruk yadaba khongjang (non-cooperation movement that began with mass boycotting of government offices and institutions); and (3) wakat khongiang (protest movement). Agitators used bricks, stones, sticks and catapult and fought several pitched battles against the repressive machineries in several parts of Manipur. Movement against AFSPA continues.

People's movement illustrate various interplaying and reinforcing means and ways such as submission of memoranda, ${ }^{55}$ legal challenges for justice, circulation of campaign/propaganda literature, publication of reports, street plays, attending or organizing seminars, conferences, meetings, sit-in protests, rally hunger strikes, rallies, road blockades, closing of offices and institutions, non-cooperation movement, photo exhibitions, installation of memorials, ${ }^{56}$ observation $^{57}$ or commemoration of events, ${ }^{58}$ fighting pitched battles with repressive machineries and so forth. All these produce holistic effect in terms of (1) documenting and registering protest at various levels, (2) propaganda against AFSPA, (3) winning solidarity statements and support from peoples and organizations beyond Manipur, (4) organizing and motivating the people for unity and struggle, (5) keeping the spirit of democratic movement alive and so forth. The dominant theme or demand of the movement, although tendency of incorporating the demand for right to self-determination including right to secession could be seen in some instances, is largely confined to the demand for right to life and justice, thereby within the framework of the Indian Constitution and internationally recognized humanitarian norms, that is a yardstick for measuring the degree of violence and buttressing legitimacy of the demand. Therefore, the movement per se is confined in the domesticity created by the Indian policy makers.

People's movements reflect organizational efforts where every individual by default constitutes a crucial ingredient at the individual 
capacity or at various leikai (residential area or colony), Manipur, India, and international levels. At the bottom line there are units/ locals in every leikai, for example club, meira paibee, committees and other collectives, which may come together and constitute an ad hoc Joint Action Committee. At the higher levels, there are civil societies called NGOs or fronts that eulogize themselves as apex or Manipur level. Each of them may have branches or units or allies in the leikais. They may come together under common banners for ad hoc coordination, and may have links with other organizations in other states, or with India level or international level organizations. Functionally, the initiatives by the apexes are largely concentrated on coordinating the units or locals or allies within Manipur and beyond. They are largely responsible for carrying out the means and ways of movement as mentioned in the preceding paragraph. At the local level, apart from the JACs that are active in course of specific issues, the women meira paibees play crucial roles. They not only act as vanguards of the movement by keeping vigil vis-à-vis the armed forces, but also continuously keep alive the spirit of the movement through organizing periodical torch march and quick response against violence. In short analysis, inasmuch as the locals responded to the coordination by the apexes and vice versa, there is crisscrossing dialectic between spontaneity and organization. The tendency of spontaneity is dominantly seen at the local level when locals rise up instantly against sudden violence. In such instances the concerned locals develop a climax of protest, which may be followed by a relatively coordinated and organized response from the neighbouring locals or state level apexes. The spontaneity at the local is either merged with or subsumed within the long drawn-out strategy of coordinated movement at the higher level planned by the apex(es). The modus operandi of the movement continues.

Indian policy makers' seeming commitment to democracy framed within the framework of the propaganda that articulated for India as a democratic nation has produced two contradictory situations in Manipur. On the one hand, the conscious effort to erase any mark of difference through guaranteeing constitutional rights in principle allows the people of Manipur to politically bargain for realizing the rights. On the other hand, the forward policy of sending in troops to occupy the region and the unrestrained violence in the name of defending Indian national security prevent the people from enjoying peace and progressive democratic order. If one would agree with Partha Chatterjee that India is marked by bringing together into the political arena the two domains - one of sovereignty and the other of governmentality, corresponding respectively to a discourse of rights and a discourse of policy 
(Chatterjee 1999: 16) - then the people of Manipur appropriated/ adopted the former in juxtaposition against the latter discourse. Constitutional rights to form association and organization accorded to the people have made easier the task of carrying out movement for democratic rights since disparate assertive intelligentsia could openly form civil societies and took leadership role of the movement.

However, the movement against AFSPA has not been fully successful for various reasons. For example (1) there is heavy repression and psychological propaganda by the government to suppress the movement; (2) authorities could bribe the family of the victims to silence their voice ${ }^{59}$ and drive many into frustration; (3) there is lack of coordination among civil societies and common platform cutting across communal and regional boundaries; (4) there is communal and regional colouring of the area coverage under AFSPA, having corresponding communal stereotyping of protest and crowd composition; (5) there is overlapping of several other sensitive issues; (6) party politics, alleged opportunism and sectarianism among the leaders and apexes frustrated several locals; (7) people largely organized around short-lived sentiment and emotion lack regular ideological and orientation course for consistent and protracted democratic struggle; (8) tactics adopted in protest that would affect the economic livelihood of the majority who are impoverished rendered a particular course of protest suicidal and self-defeating and so forth.

\section{Conclusion}

AFSPA had symbolic significance for the government as it upholds the morale of the Indian 'security forces'. Statements by the concerned union ministers and military officers substantiate the point. Practically, although there were certain degree of collateral damages to the armed insurgents the purpose of AFSPA to wipe out insurgency has failed. The prolonged imposition of AFSPA, which exhibits either the lack of the will or the 'poverty of perception' ${ }^{\prime 60}$ to create a situation that would make rebellion purposeless, has been keeping the troops perpetually acculturated with AFSPA that made many criminals out of them, which subsequently disgrace a battalion or a regiment or the defence establishment in its entirety. In other words AFSPA, by creating a coterie of 'armed personnel', who in their own discretion exceeded the limit that Kelman had termed as the 'crime of obedience' (Kelman 1995: 21), promotes a culture of impunity and perpetuates state terrorism.

On 23 November 2012 the Supreme Court of India had expressed shock over the attitude and orientation of the affidavit filed by the Government of Manipur on case of extrajudicial executions by the 
government forces. A two-member bench asked the counsel of Manipur Government, "How can a State Government files an affidavit stating that they are killing "us" and so we are killing "them." ... Are we in a state of war? . . . Are you trying to make the National Human Rights Commission an alibi to all the killing?' 61 The Supreme Court of India Judgement, dated 8 July 2016, acknowledged the alleged trends of fake encounters perpetrated by the law enforcing forces and reiterated that the use of excessive force or retaliatory force by the law enforcing forces was not permissible even in an area declared as a disturbed area under AFSPA. ${ }^{62}$ Against this backdrop, the feeling of being inflicted upon with violence entails the feeling of being acted upon; thereby, violence became the subject of the shared political discourse of the democratic dissents and produces the visibility of the torturer and the political regime they represented. Indeed, the violence under AFSPA is deeply structured in the system of the regime that subscribes to certain dogmatic concepts of nationhood, national sovereignty and security, which are also being used as jargon that camouflaged certain ruthless objectives of subjugation, exploitation and oppression in the name of peace and security. The official intention to continue with violence is being illustrative as the regimes deliberately desist from enacting an act to prevent torture. ${ }^{63} \mathrm{Will}$ the regime continue to function in this manner, in the name of peace and security, and at what price?

\section{Notes}

1 This is a revised version of the paper titled 'Violence as AFSPA 1958 and People's Movement Against It', Eastern Quarterly, 6(4): 145-55, 2010.

2 (1) The Bengal Disturbed Areas (Special Powers of Armed forces) Ordinance, 1947 (11 of 1947); (2) The Assam Disturbed Areas (Special Powers of Armed Forces) Ordinance, 1947 (14 of 1947); (3) The East Punjab and Delhi Disturbed Areas (Special Powers of Armed Forces) Ordinance, 1947 (17 of 1947); and (4) the United Provinces Disturbed Areas (Special Powers of Armed Forces) Ordinance, 1947 (22 of 1947).

3 Act 28 of 1958, passed by the Indian Parliament on 11 September 1958.

4 Parliamentary debate on AFSPA 1958 on 18 August 1958 is recorded in the Lok Sabha Debates, Second Series, Volume XVIII, 1958.

5 Parliamentary representatives from Manipur Shri L. Achaw Singh (Inner Manipur) and Shri Rungsung Suisa (Outer Manipur) vehemently protested AFSPA.

6 AFSPA was enacted in the name of suppressing Naga rebellion and potential rebellion by others.

7 'Northeast comprising Manipur; Sardar Patel's letter to Jawaharlal Nehru', 7 November 1950; reproduced in Karunakar Gupta, Spotlight on SinoIndian Frontiers, Calcutta: Friendship Publications, 1983. 
8 After ten years of legal pursuit initiated by the NPMHR.

9 Armed forces would mean the military forces and the air forces operating as land forces, and includes any other armed forces of the Government of India so operating. The author uses the term 'armed forces' to mean the army and paramilitary forces interchangeably.

10 Supreme Court of India Judgment, dated 27 November 1997 against Writ Petition (Crl) 550 of 1982 with Writ Petition (C) Nos. 5328/80, 922930/82, Civil Appeals Nos. 721 to 724 of 1985, 2173-76/1991, 2551/81 and Writ Petition (C) Nos. 13644-45/84. Published in (1998) All India Reporter: Supreme Court of India, 463-464.

11 Statement of the former Minister of Home Affairs Shivraj V. Patil on Law and Order Situation in Manipur; Lok Sabha, Tuesday, 17 August 2004.

12 'AFSPA must continue in NE: DG AR'; Hueiyen News Service, Guwahati/ Shillong, 27 February 2010.

13 Search, arrest, detain, torture and so forth without issuing a warrant.

14 Please read the Submission of Committee on Human Rights (COHR), Manipur, On Human Rights Situation in Manipur (India) to OHCHR, Concerning the Universal Periodic Review of the Government of India, At the UN Human Rights Council in April 2008.

15 'Different Norms', Economic and Political Weekly, 23(34): 1713-14, 20 August 1988.

16 Ibid.

17 Ibid.

18 'Army vs Civil Administration', Economic and Political Weekly, 24(6): 273-4, Mumbai, 11 February 1989.

19 'Army Rule', Economic and Political Weekly, 22(40): 1670-1, 3 October 1987.

20 'Army Terror Unleashed Again in Kachai', People's Democratic Movement, 1 May 1991, Imphal.

21 'Guarding the Guards', Economic and Political Weekly, 25(23): 1228, 9 June 1990.

22 'Damaged in Body and Mind Source', Economic and Political Weekly, 25(37): 2025, 15 September 1990.

23 'Operation Loktak', Report of Joint Fact Finding Team, prepared by the Committee on Human Rights, Manipur, March 1999.

24 Concluding Observations of the UN Human Rights Committee 1991, India; UN Ref: CCPR/C/37/Add.13.

25 'Obstructing Justice ...,', p. 214.

26 'Official Sanction for Killings in Manipur', Amnesty International, AI INDEX: ASA 20/014/1997, 1 April 1997, India.

27 'A Study in National Security Tyranny Armed Forces Special Powers Act', South Asia Human Rights Documentation Centre, New Delhi. www.hrdc. net/sahrdc/resources/armed_forces.htm. Accessed on November 2008.

28 'Disturbing Option', Economic and Political Weekly, 25(40): 2225, 6 October 1990.

29 Where Peacekeepers Have Declared War, Report on Violations of Democratic Rights by Security Forces and the Impact of the Armed Forces Special Powers Act on Civilian Life in the Seven States of the Northeast, New Delhi: National Campaign Committee Against Militarisation and Repeal of Armed Forces Special Powers Act, 1997. 


\section{Malem Ningthouja}

30 The Government of India set up the Committee. See Ministry of Home Affairs Office Order No. 11011/97/2004-NE-III dated 19 November 2004. The committee submitted its report to the Government of India on 6 June 2005.

31 Fifth Report of the Second Administrative Reforms Commission, June 2007.

32 National Security Advisory Board (NSAB) for repealing AFSPA, Hueiyen News Service/Newmai News Network, Shillong, 20 November 2012.

33 A replica of the Armed Forces Special Powers Ordinance 1942, imposed by the British to suppress Indian freedom movement.

34 'Human Rights and National Oppression in Northeast India', paper presented by Representative of Communist Ghadar Party of India at the Human Rights Conference in Imphal, 8-9 December 1994.

35 'Nationality Question in India', paper presented by Shiv Sunder, Executive Committee Member of All India Peoples Resistance Forum, at the International Seminar on Nationality Question, held at New Delhi, 16-19 February 1996.

36 Memorandum of the Revolutionary People's Front, Manipur submitted to United Nations, 2nd edn., 1999.

37 'We Have Not Abandoned the Revolutionary Path', interview with the UCPN's Baburam Bhattarai, 26 October 2009. http://links.org.au/node/ 1331, accessed on November 2009.

38 Letter to Vallabhbhai Patel, dated 10 May 1949, from Debeshwar Sarmah, president of the Assam Provincial Congress Committee, in Das (ed.), Sardar Patel's Correspondence 1949-50; Vol. 8, 1973, pp. 318-19.

39 'Sardar Patel's letter to Jawaharlal Nehru', 7 November 1950, reproduced in Gupta, Spotlight on Sino-Indian Frontiers.

40 See Neville Maxwell, India's China War, Bombay: Jaico Publishing House, 1970. Military intervention and bureaucratic control are seen as preemptive measures to defeat any potential threat to Indian geo-political interest in the Northeast.

41 Statements of Shri Mahanty (Dhenkanal), and Shri Warlor (Trissur) in Parliamentary Debate on AFSPA 1958, on 18 August 1958, Lok Sabha Debates, Second Series, Volume XVIII, 1958 (11-22 August 1958).

42 Repealed on Thursday, 9 December 2004.

43 (1) Refers to the Operation Green Hunt against the naxalite rebels. (2) Resolution of the All India Convention against War on People, 4 December 2009, New Delhi.

44 The 7 October 1960 declaration of Ukhrul Subdivision, a disturbed area, was followed by piecemeal declaration till the entire Manipur became a disturbed area in 1980. In 2004 AFSPA was repealed from seven assembly constituencies in Greater Imphal areas.

45 It is logical that when the Act was imposed in those areas dominantly inhabited by the Nagas, peoples, those who did support the NNC project of integrating the proposed Naga inhabited areas would not encourage to protest government policy to impose AFSPA to suppress the NNC.

46 The Naga leaders were engaged more with the peace mission in 1960s.

47 Rose's suicide note was translated into Manipuri and published in Bharatki Loilam Manipur by Pan Manipur Youth League in 1993. 
48 Yambem Laba, 'Human Rights: Issues at Stake in Manipur', paper presented at the National Seminar on Human Rights at the Gandhi Memorial Hall, Imphal, Manipur, 8-9 December 1994.

49 'Eikhoigee wakat' (Our complaint), a pamphlet circulated against the AFSPA, 1958 by the Apunba Manipur Nupee Kanglup (All Manipur women's organization) on 27 May 1980, document reproduced in NRCM edn., Meira Paibee, Imphal: National Research Centre Manipur, 1999.

50 Facsimile of a signed letter by Wolfgang Heinz, Asia Research Department, Amnesty International, 10 Southampton Street, London: WC2E 7HF, England, addressed to Yambem Laba, 24 September 1980.

51 The office was established by the UN General Assembly on 20 December 1993.

52 (1) On 4 October 2003 Miss Nandeibam Sanjita (fifteen) of Jiri committed suicide in protest against rape by the Indian paramilitary force. (2) Miss Irom Sharmila, humiliated by the Malom Massacre on 2 November 2000, had been on hunger strike since 5 November demanding the repealing of AFSPA.

53 When people rose up for several months against the custodial rape and killing of a thirty-two-year-old woman in Manipur, Thangjam Manorama, by the personnel of the 17th Assam Rifles on 12 July.

54 The Apunba Lup still exists today, and yet its composition remains fluctuating in tune with party politics of shifting alliance and changes in coordination.

55 Submitted to the Manipur government, Government of India and other international bodies.

56 For example Heirangoithong Massacre Memorial Pillar, RIMS Massacre Memorial Pillar, Malom Massacre Memorial Complex and so forth.

57 On 12 April 2009 Nupi Khunnai Meira Paibi Liwa Bokul Makhong, a local Meira Paibee organization in Imphal, organized the Meira Paibee Martyrs' Memorial Day. On that occasion a statue of Meira Paibee was unveiled and the observers paid floral tributes to it.

58 Meira Paibee day on 28 May organized by Poirei Leimarol; International Human Rights Day on 10 December and so forth.

59 Many are being forced to reconcile with torture and remain silent so that the culprits are not exposed. To cite a few examples:

(i) The family of Miss Rose Ningshen of Ngaprum Khullen village in the East District (now Ukhrul), who committed suicide on 6 March 1974 following a gang rape in the night of 4 March 1974 by ninetyfive personnel of the Border Security Force, was silenced through torture, intimidation and payment of 6,000 rupees as a token of compromise. Based on interview with Prangam Ningshen on 14 January 2015 at Kumram.

(ii) The protest against the killing of three women at Saitu Village on 5 May 2005 by fourteen Assam Rifles personnel was silenced by intimidation and payment of customary fine amounting to 1.4 lakh rupees.

(iii) The illegal abduction and torture on Ahanthem Nandakishor alias Naoba of Lei-Ingkhol village on 7 May 2014 by the Assam Rifles post at Chingmeirong was covered up. Naoba was released on the condition that he must neither go for medical treatment to any hospital nor approach the media and police to expose the matter. 


\section{Malem Ningthouja}

60 Absence of positive outlook and strategies to effectively deal the intricate economic and political questions.

61 'Is there a war going on? SC asks Manipur Govt', Hueiyen News Service, Imphal, 23 November 2012.

62 Supreme Court of India Judgement against the Original Jurisdiction Writ Petition (Criminal) No. 129 of 2012.

63 India had not ratified although signed the Convention against Torture and Other Cruel, Inhuman or Degrading Treatment or Punishment on 14 October 1997. The Prevention of Torture Bill 2010, introduced in the Lok Sabha and revised following criticism, was lapsed.

\section{References}

Agamben, Giorgio. 2004. 'A Brief History of the State of Exception', in Giorgio Agamben (ed.), State of Exception. Chicago: University of Chicago Press.

Bayly, Susan. 2002. Caste, Society and Politics in India from the Eighteenth Century to the Modern Age. New Delhi: Cambridge University Press.

Bose, Tapan. 1989. 'Obstructing Justice', Economic and Political Weekly, 24(5), 4 February, Mumbai.

Chatterjee, Partha. (ed.). 1999. Wages of Freedom. New Delhi: Oxford University Press.

Coser, Lewis A. (ed.). 1992. Maurice Halbwachs on Collective Memory. Chicago: University of Chicago Press.

Eyerman, Ron. 2004. Cultural Trauma: Slavery and the Formation of African American Identity. London: Cambridge University Press.

Kelman, Herbert C. 1995. 'The Social Context of Torture: Policy Process and Authority Structure', in Ronald D. Crelinsten and Alex P. Schmid (eds.), The Politics of Pain: Torturers and Their Masters. Oxford: Westview Press.

Laba, Yambem. 2010. A Human Rights Story in Manipur. Imphal: Just Peace Foundation.

Mathur, Kuldeep. 1992. 'The State and the Use of Coercive Power in India', Asian Survey, 32(4): 337-49.

Maxwell, Neville. 1970. India's China War. Bombay: Jaico Publishing House.

Navlakha, Gautam. 1995. 'Growing Indo-US Military', Economic and Political Weekly, 30(36), 9 September, Mumbai.

Pan Manipuri Youth League. 1993. Bharatki Loilam Manipur. Imphal: PANMYL, 115-117.

Ram, Mohan. 1978. 'Mini-Emergencies to Suppress the Poor', Economic and Political Weekly, 13(46): 1880. 


\title{
4 People's conversation on truth, justice and reparation ${ }^{1}$
}

\author{
Anjuman Ara Begum
}

The present chapter discusses the daily conversation among people in Northeast India on violence, suffering and denial of justice. This conversation takes place as a result of fifty-six years of continuous armed conflicts in the region between the state and non-state actors. This conversation is not going to be merely on the grasping of knowledge, articulation and understanding of a subject matter on self and violence. It is a daily conversation of a different kind on the life and death of people in the region.

It is also a conversation on the bitter truths of the politics of counterinsurgency and impossibility of letting that truth exposed and making the state accountable. In a region where the state legislates exceptional laws (e.g. the infamous Armed Forces Special Powers Act 1958) in view of an extraordinary situation, like external incursion or internal rebellion, everyday life conversation among people is going to be very different. The conversation reflects citizens' helplessness, fear, trauma and denial of their democratic rights. Armed conflict of fifty long years is responsible for such a conversation. This daily experience is an important source to understand how the "rule of law'" is suspended and the 'state of democracy' is existing on the ground. To understand suspension of rule of law and democracy, we consider that daily conversations constitute the narratives of defenseless people.

Every narrative is an expression of violence experienced by a victim/ survivor or family and friends of victims. Nevertheless, narratives of this kind are illuminating expressions of despair, helplessness, trauma and desire to know the truth behind violence and crime. Further, these narratives share the same structure of violence though they apparently differ from place to place, person to person, family to family. We also consider that these narratives revolve around the following key parameters: innocence, urge to know truths about the violence, justice and healings. 


\section{'Innocence' of death and arbitrary reason of the state}

On 5 February 2006, Ajit Mahanta, a thirty-year-old man who lived at Dirak Gosaigaon, Pengeri police station, was picked up by army personnel in civilian dress from Dirak Kakopathar, Tinsukia district, Assam. Following day, the army personnel left his dead body in a gunny bag in Dibrugarh Medical College hospital. Family and villagers refused to accept the dead body. On the next day, Kakopathar police officials along with a magistrate tried to hand over the dead body to the family but it was not accepted. But on the third day, family and villagers accepted the dead body and last rites were performed. A procession was organized on 10 February 2006 to condemn the killing. About 20,000 people took part in the protest march held in Kakopathar. During the procession protestors became violent towards the CRPF personnel who were deployed to maintain law and order. A commotion took place in which protestors beat one CRPF personnel to death. CRPF fired to control the protestors and nine persons including six women were killed in the firing and about twelve became handicapped.

Subsequently, the Government of Assam announced compensation of a sum of 5 lakh rupees and a 4th grade job for the widow of Ajit. Further, a sum of 3 lakh rupees and a government job was also announced to the relatives of each of the protestors killed in the firing. Initial demand for bringing under custody guilty army personnel was somehow silenced by this sort of compensation, yet Ajit's family felt that justice was not delivered. The government claims that 'the case' was resolved in fifteen days, but the demand for punishing the guilty army personnel was put in cold storage. Ajit's mother, when asked, replied,

No. This is not justice because he [Ajit] was innocent, everyone [in the village] knows about him. How can someone kill him on false accusation? If he was a thief or robber, they should have informed me first as I am his mother. He [Ajit] did nothing like that. He only worked and earned for the family. We got money [compensation by the state] but we can't get back him alive again.

While the state has its own reason to carry out violence as counterinsurgency strategy, for the family members and villagers, it is seen as a reason arbitrarily developed and understood by the state only: no one knows who would be considered as one included or excluded in the 'insurgent' movement against the state; only the state decides whom to be killed or sacrificed. 
In another of extra-judicial killing, the victim was considered as 'Taliban' and the act of killing was apparently justified on the ground that there is a global war against the Taliban; something like all the 'Talibans' and 'Taliban-like Muslims' are threats to national security. A Muslim boy named Sameer Khan was killed at Guwahati on 1 November 2001. Sameer Khan was a young college going boy of the age of 23, 'bright, shy, religious and homely in nature', according to his father. Sammer's story is as follows:

On that day Sameer Khan went for namaz at the nearest mosque at our Birubari residence (Guwahati) around $8 \mathrm{pm}$. After completing his namaz Sameer along with eleven other friends from the same locality decided to go for a tour to some of the prominent masjids in the city of Guwahati. The group started at around 9:30 pm. They were in bikes and scooters. After visiting the Athgaon masjid, Ulubari masjid, Hatigaon masjid, etc. at around 00:30 am, they were on their way to Burah masjid, one of the oldest and prominent masjid in Guwahati. His scooter was stopped at Zoo Tiniali, about one $\mathrm{km}$ away from Burah Masjid. Security persons posted at Zoo Tiniali asked the group to halt. Sameer stopped his scooter. A young kid named Fazal, ten years old, was the pillion rider. CRPF personnel Venteshwaram who was heavily drunk, reached kurta-pajama clad Sammer and put the gun at his belly. Sameer was frightened and requested the official to remove it. Sammer could hardly come to know why he was asked to stop, Venteshwaram shouted, 'you are all talibans' and pumped bullets in his abdomen. Sameer fell down from the scooter and said, 'Uncle you really shot me?' Sameer's other friends who were waiting for him in an around the shooting site were too frightened to utter a word. A vigilant mobile vehicle of Assam Police reached the spot and arranged for hospitalization of bleeding Sameer after half an hour. Sameer was taken to the hospital after two hours and the doctors couldn't save him.

This case is different from that of Ajit Mahanta because Sameer was a Muslim. The narrative of innocence for Sameer, unlike Ajit to some extent at least, apparently carries the extra burden of defending a Muslim as non-threat to state. Narration of offering namaz to Masjids as a way of life for an ordinary God-fearing Muslim is perhaps to be shown as opposed to those engaged in anti-state activity. Further, for Siraj Khan his son was innocent because he was not a criminal.

Arbitrariness to the killing took place soon after the 11 September 2001 attack on the World Trade Center in New York, and there is the 
influence of the global 'war against terrorism' on local daily life; the Taliban in Afghanistan has come to the major attention of national security. This percolates to the mindset of the CRPF personnel who committed the crime. For them, Sameer was none but a 'Taliban', and that itself was enough and an adequate excuse for shooting him. The incident triggered huge public outcry and became headlines for the local newspapers the next day.

The state constituted an enquiry commission under the Commissions of Enquiry Act 1952. The commission was ordered to submit a report within fifteen days. After nine years, Sameer's parents are yet to know the findings of the enquiry commission. Sameer's father says, 'For me, there is no justice in sight. Justice is denied to us because we are Muslims'. In a petition titled 'most urgent' filed by Siraj Khan to the Chairman, Minority cell, APCC, Rajib Bhavan, Guwahati (dated 2009), wrote, 'the petty amount of 10 thousand given as compensation is unjustified and is a kind of insult to a member of minority community. We have no relation with Talibans but we are treated as Talibans'. The case is now completely erased from the public memory and the authorities do not care to look into the issues of accountability and prosecution.

Incidents of 'involuntary' or 'enforced' disappearances of person are another form of deprivation of people's life. Here, the narrative of innocence revolves around the desire to know the truth of disappearance, the whereabouts of a person suddenly missing, wanting to know those who are responsible. This case gives a different picture of the politics of counter-insurgency that refuses the common people to know any source of such politics; perhaps it may be an instance where there is more soul-searching than those instances of killings, where one at least knows who killed a person.

A classic example is the disappearance of Sanamacha, a seventeenyear-old boy. He was, as reported later on, picked up by some seventeen personnel of Raj Rifles deployed in the State of Manipur from Angtha village in Thoubal district of Manipur on 12 February $1998 .{ }^{3}$ The only witness was the victim's sister-in-law, Jati. Since then Sanamacha involuntarily disappeared. Coming under the pressure of a public agitation against the alleged disappearance of Y. Sanamacha Singh, the Government of Manipur constituted a Commission of Enquiry to determine the sequence of events leading to the disappearance of the boy. However, the central government challenged the constitution of the Commission and filed petition to the Gauhati High Court. The High Court held ${ }^{4}$ that the Commission of Enquiry is not a court but a fact-finding body that attempts to conduct its inquiry on the basis of the material and the evidence available even in the absence of either party or their advocates. The terms of reference do not require the 
Commission to investigate the powers and functions, jurisdiction and privileges of the members of the armed forces under the Union of India. The work of the Commission falls within the purview of 'public order', which is a state subject, and since the disappearance has assumed the character of public importance, the state government has not committed any illegality by appointing a Commission of Enquiry to determine the facts about disappearance and make recommendations to prevent the recurrence of such incidents. With this judgment the Commission continued to investigate and submitted report to the Manipur government. However, report is still not made public.

For Jati, the sole witness of Sanamacha's abduction and subsequent disappearance, the government and army have not done justice. High Court gave (ordered) interim relief of 3 lakh rupees [US\$5000 approx.] from the army. The case lasted for four years and after completion, she received the amount. However, she feels that monetary compensation is not justice or an official apology; when an innocent person is killed in an arbitrary manner, the killer deserves to be prosecuted and punished. Monetary compensation does not correct the wrongs done and cannot bring back the life of Sanamacha: 'we cannot compare Sanamacha with money'. Jati decides not to give up fighting for justice. She filed a writ petition before the Gauhati High Court in 2005 demanding the prosecution of the guilty army officer, Major Mahindra. The case is sub judice.

There have been never-ending cases of killing and involuntary disappearance. The following are some of the utterances of despair from the victims and relatives:

My husband was kidnapped at mid night and I came to know after a day that he was murdered. I want to know the truth behind his death.

My husband was travelling in a Tata Sumo. Fellow travelers saw him being stopped at a point by Armed Forces for interrogation. They took him along. He never came back. We are still fighting for his case before the Judiciary.

He was about 55 years old. They came mid-night. They dug our courtyard in search of arms and ammunition. They found nothing and then took away my husband for interrogation. He never came back. Ten years now ... I still put vermilion on my forehand and waiting for his return.

I was serving tea to my guest and asked my son to get some snacks from the nearby market. After few hours I came to know that my son was killed in an encounter. 
Three army personnel raped me in the midnight, medical report was negative, I heard. I am suffering from skin diseases since then. I am denied a copy of the medical report.

They arrested my husband, took him along with them. Ten years now. My husband never returned.

CRPF killed my son mercilessly and I was given a pittance of 10 thousand rupees after two years as compensation. I felt insulted and humiliated. My son was innocent.

These narratives long for truth, to know the truth behind the disappearance and violence. Everyday conversation generally means talking about one's daily life, problems, studies, foods, office matters or leisure. But this becomes an expression of violence, injustice, anguish and longing for truth and justice when the near and dear ones are killed or forced to disappear.

Legally speaking, 'right to truth' would mean the right to know what happened to the victim and how it happened. Part of the right to truth is the right to a proper investigation carried out by a court of law (Hoenig and Singh 2015). This includes implementation of all possible forensic procedures and analyses to identify the remains, and to provide information about the cause and the manner of death. The first step towards the right to truth is initiation of investigation. The state has a duty to implement all possible means to find out the truth. Right of access to information, contained within the right to 'seek, receive and impart information', is guaranteed by preamble of the International Convention for the Protection of All Persons from Enforced Disappearance 2002. The inalienable right to know the truth in India is mostly reflected in Commission of Enquiry Act 1952, Right to Information Act 2005, fundamental rights under Article 19 of the Constitution and so forth, also not available to the victims of those areas where AFSPA is in force. State government ritually appoints Enquiry Commissions under the Commission of Enquiry 1952 whose reports never see the light of day.

In Argentina, 'truth trials' are often conducted to extract truth. Truth trials are courtrooms dedicated to the investigation and documentation of human rights abuses committed during the last military government without the possibility of prosecution. In these 'trials', victims and perpetrators are brought together face-to-face and 'the truth' is 'exposed'. While truth trials do not have prosecutorial capacities in relation to the crimes covered under the amnesty laws, they may and do prosecute for contempt of court. ${ }^{5}$ Therefore, such crimes as false testimony and failure to appear before the court have resulted in the detention of at 
least eight military and fifty-five police personnel involved in cases of torture during the dictatorship. Several truth commissions in Africa, the Russell Tribunal in Vietnam and other countries were successful enough to bring out the truth and satisfied the victim's families to know what happened to their beloved ones. However, the practices of 'truth trials' have not developed in India. Though the investigations by 'enquiry commissions' under the Commissions of Enquiry Act 1952 (under the Government of Assam) can be treated a sort of state-sponsored 'truth trials', these commissions couldn't achieve any success as most of the reports are yet to become public.

Legal system has permitted extrajudicial executions, arbitrary detention, disappearances, custodial deaths, custodial rapes and so forth rather than protecting civilians, as reflected in the narratives. Under Section 4 of AFSPA, any commissioned officer, warrant officer, non-commissioned officer or any other person of equivalent rank in the armed forces may use 'special force' to the extent of causing death.

An important Commission of Enquiry, constituted by the Supreme Court of India, as an outcome of Writ Petition (Criminal) 129 of $2012^{6}$ and Writ Petition (Civil) 445 of $2012^{7}$ filed its report to the Court on 30 March 2013. This investigation by the Commission was chaired by Justice N. Santhosh Hegde (retired judge of the Supreme Court and former solicitor general of India) along with Mr. J. M. Lyngdoh (former chief election commissioner of India) and Dr. Ajai Kumar Singh (former director general of police, Karnataka state) as members. This inquiry highlights the practice of false encounter killings by security forces in six sample cases investigated in Manipur. This petition has presented 1,528 cases of alleged false encounter killings committed by security forces in Manipur and demanded a proper investigation. The court has also called for inquiry commission reports of another thirtythree cases, however final judgment is still pending.

\section{Longing for justice, healing through reparation}

Parvati Debbarma, a sixty-year-old woman, along with her children of Kutnabari village in Tripura survived trauma and loss of assets when her village was attacked by state forces on 6 November 1996. Members of the Tripura State Rifles (TSR) put the whole village aflame, and Parvati witnessed the whole episode of burning down her house. About 40,000 rupees in cash was reduced to ashes. In Parvati's own words:

suddenly I heard sounds of firing, people running around, hue and cry, fire etc. a group of school student came running towards my 
house and asked to close all the four doors and windows of the house. As soon as I finished closing the windows and doors, I saw members of TSR loitering here and there and shooting in all directions. They shot at Mohan Chandra's house, my neighbour. TSR members entered my premises and broke open the door. Myself and my daughter Lily ran away from the behind door to save our live.

Parvati fell down in a pit and was unconscious for a long time. She doesn't remember how long she was unconscious, but her part-time servant Rana Debbarma saved her by pulling her out of the pit. Still, she couldn't take rest or sit for a while. TSR personnel directed all the villagers to gather at the school compound. Parvati had to rush there. She was still unconscious when brought to the school compound. From there she was immediately rushed to her maternal house and from there she was taken to local hospital. Later she was referred to G. B. Hospital, Agaratala as her condition was critical. She ended up in the hospital for four to five days.

It was announced that those who want compensation for their house must stay at their respective ruined house. Parvati came back from hospital and stayed in the place of her house in order to avail the compensation amount. She had three beds, 45,000-50,000 rupees in cash, furniture, utensils, dining table and so forth - all burnt and nothing left in the house. Compared to the loss, compensation of 30,000 rupees was a mere pittance. It was reported in the media that an enquiry commission was constituted after the incident. The report of the commission is not available. With all her sufferings and deep anguish in mind, Parvati still hopes for adequate compensation and justice.

Justice is the concept of moral rightness based on ethics, rationality, law, religion, fairness or equity. ${ }^{8}$ Justice concerns itself with the proper ordering of things and people within a society. John Rawls, for instance, claims 'Justice is the first virtue of social institutions, as truth is of systems of thought' (Rawls 1999: 3). Right to justice cannot be separated from the 'rule of law' as formulated by A. V. Dicey. If justice is to be seen as done, then, in cases of human rights, the state will have certain duties to perform.

These obligations are best reflected in the Inter-American Court of Human Rights judgment in the case of Velásquez Rodríguez v. Honduras. ${ }^{9}$ The court found that all states have four fundamental obligations in the area of human rights. These are (1) to take reasonable steps to prevent human rights violations; (2) to conduct a serious investigation 
of violations when they occur; (3) to impose suitable sanctions on those responsible for the violations; and (4) to ensure reparation for the victims of the violations. States have a duty to ensure reparation for the victims of human rights violations. Article 2(3) of the International Covenant on Civil and Political Rights (ICCPR) has echoed the same version, saying that state parties to the Covenant have an obligation to provide an effective remedy in case of a violation of the human rights protected in the Covenant and that individuals have a concomitant right. This obligation includes three elements: (1) truth: establishing the facts about violations of human rights that occurred in the past; (2) justice: investigating past violations and, if enough admissible evidence is gathered, prosecute the suspected perpetrators; and (3) reparation: providing full and effective reparation to the victims and their families, in its five forms: restitution, compensation, rehabilitation, satisfaction and guarantees of non-repetition.

The Theo van Boven/Bassiouni principles $(2005)^{10}$ adopted by the UN General Assembly (GA, 60/147) set out the forms of reparation restitution, compensation, rehabilitation, satisfaction and guarantees of non-repetition. Victims of human rights violations in Northeast India generally approach the judiciary and/or human rights commissions for 'adequate compensation'. In some cases, 'compensation' or 'ex gratia' is awarded by the Court or Human Rights Commission to the victims. The amount of 'compensation' as observed is probably an innovation by the judges taking into consideration of the minimum wages fixed by the state, victim's age and life expectancy. Norms of the transitional justice system are hardly considered. The doctrine of strict liability was invoked by the Supreme Court of India in 1993 in Smt. Nilabati Behera $v$. State of Orissa. ${ }^{11}$ It was held that

it is now well-accepted . . . that monetary or pecuniary compensation is an appropriate and indeed an effective and sometimes perhaps the only suitable remedy for redressal of the established infringement of the fundamental right to life of a citizen by the public servants and the State is vicariously liable for their acts.

The obligations and principles of compensation which the Supreme Court invoked under the strict liability doctrine are a far cry from the international standards. The 'right to compensation' as stipulated by Article 14 of the Convention against Torture is not recognized in India.

In several judgments pronounced by the Gauhati High Court, the armed forces were held guilty of violating human rights in the name of curbing insurgency, and ordered compensation. Paying compensation 
by a party itself is the conclusive proof that violations have taken place. Not only ordering compensation, in several cases, the Gauhati High Court ordered for initiating prosecutions as well. What happened about the prosecution aspects is not known to public. With all probability, it can be concluded that no one was punished despite the court's order. Compensation amount varies from case to case depending upon the age, employment and family status of the victim. For cases of disappearances and extrajudicial killings, it is found that the amount of compensation varies from 80,000 to 4 lakh. In most of the cases compensation was received only as a result of the court's verdict. Families are of the opinion that the amount of compensation cannot replace a human life and cannot rebuild life.

\section{Conclusion}

People's narrative and conversation are not confined to the sequence of the incidents but it reflects the 'state of democracy'. Narratives are multi-scalar; it can relate to belonging on a national, political scale, represent locality dynamics, more small-scale, personal experiences, or stories of significance. Narratives and conversation show that like nuclear fission reaction, culture of impunity is widespread in Northeast India and the process has become almost irreversible. Conversation and narrative of sufferings remain alive in the mind even after years. The Oinam massacre of 1987, Nellie massacre of 1983, Ujanmaidan mass rape case of 1988 , several disappearances, extra-judicial executions and secret killings remained unaccounted for decades, but these are still alive in public memory. Sometimes it remains dormant, but at times comes out once provoked. Memory like this is unhealthy for a democratic state as it leads to further violence and suffering.

It is observed that in cases of human rights violation in Northeast India, victims have little access to information and to know the truth. Justice is denied through the denial of information. Due to the existence of a wide range of 'immunity laws', ${ }^{12}$ legal proceedings against armed forces require mandatory sanction from the state government. Hence a culture of impunity came into existence and over the period of time has become the norm, not the exception. The inalienable right to know the truth about violations is also not available to the victims of those areas where the AFSPA is in force. State government usually appoints enquiry commissions under the Commission of Enquiry Act 1952, an agency quite similar to truth commissions, as a response to the public outcry for justice. What is unfortunate is that the reports of the enquiry commissions were never made public. Given such 
situations, peoples' longing for justice itself depicts the true picture of the 'state of democracy' in the country.

The right to know the truth and get justice is not a privilege but a fundamental human right. Conversations and narratives suggest that there is a desire to know the truth. Hence 'truth trials' can be considered. Wounds must be healed with respect to the citizen's fundamental rights and not to be treated as a burden to the state. Concepts like 'compensation', 'ex gratia' and 'damages' should be updated and principles of reparation must be incorporated. Citizen's rights should not be infringed at all.

\section{Notes}

1 This is a revised version of the paper titled 'People's Conversation on Truth, Justice and Reparation: A Case of Northeast India', Eastern Quarterly, 6(4): 164-72, 2010.

2 Rule of law, according to A. V. Dicey, demands total absence of arbitrary powers and equality before law. The basic postulate of the rule of law is that 'justice should not only be done but it must also be seen to be done'.

3 On 13 February 1998 along with a written report, which resulted in the registration of an FIR No. 15(2)/1998, YPK PS, U/S 13 UA (P) Act and 25 I-B Arms Act at Yairipok Police Station and interview with the family on 30 June 2008 at Angtha village, Manipur, are the source of information.

4 Gauhati High Court case Union of India and Ors v. State of Manipur and Ors 1998 (4) GLT 391, decided on 8 May 1998.

5 Right to Truth, http://eaaf.typepad.com/pdf/2002/17RightToTruth.pdf, accessed on 21 February 2011.

6 Extra Judicial Execution Victims Families' Association and Another (petitioners) against Union of India and Others (respondents).

7 Suresh Singh (petitioner) against Union of India and Others (respondents).

8 http://en.wikipedia.org/wiki/Justice, accessed on 17 March 2010.

9 www.corteidh.or.cr/docs/casos/articulos/seriec_04_ing.pdf, accessed on 19 March 2010.

10 The Theo van Boven/Bassiouni principles, adopted and proclaimed by UN General Assembly resolution 60/147 of 16 December 2005. www2.ohchr. org/english/issues/remedy/principles.htm, www2.ohchr.org/english/law/ remedy.htm, accessed on 19 March 2010.

Article 11 of the principles is ' 11 . Remedies for gross violations of international human rights law and serious violations of international humanitarian law include the victim's right to the following as provided for under international law: (a) Equal and effective access to justice; (b) Adequate, effective and prompt reparation for harm suffered; (c) Access to relevant information concerning violations and reparation mechanisms'.

11 Nilabati Bahera v. State of Orissa (1993) 2 SCC 746.

12 In response to growing armed resistance in the state (now Nagaland), the Government of India imposed the Assam Disturbed Areas Act in 1955; the Assam Maintenance of Public Order Act, 1953, amended in 1968 and 1971; the Nagaland Security Regulations, 1962; the Unlawful 


\section{Anjuman Ara Begum}

Activities (Prevention) Act, 1967, amended in 2004; the National Security Act, 1980; and the Armed Forces Special Powers Act 1958, amended in 1972. Most of these Acts contain 'immunity clauses' leading to the culture of impunity. 'Prior sanction' is mandatory for legal proceedings against alleged violation of human rights. Section 45, 32, 197 of the Code of Criminal Procedure, Sections 125, 126 of the Army Act, 1950, section 6 of the Armed Forces Special Powers Act and Section 45 of the Unlawful Activities (Prevention) Act etc. provide that no court shall take cognizance of any offence under the Act unless 'prior sanction' is granted by the appropriate government. Statistics available show that till date about 50,000 people were killed in armed conflict-related incidents in Northeast India. Official records (which have a tendency to understate casualty figures) show that civilian deaths outnumber casualties among militants and security personnel.

\section{References}

Hoenig, Patrick and Navsharan Singh (eds.). 2015. Landscapes of Fear: Understanding Impunity in India. New Delhi: Zubaan Books.

Rawls, John. 1999. A Theory of Justice, revised edn. Oxford: Oxford University Press. 


\section{Part III}

\section{National questions}


$\because$ Taylor \& Francis

http://taylorandfrancis.com 


\title{
5 Assamese nationality question ${ }^{1}$
}

\author{
Sajal Nag
}

Until very recently the making of an Indian was seen as a unilinear, mono-dimensional process manifesting itself in the Indian national movement. The sole objective of the national movement was to rally all the Indians together to combat British colonialism and establish itself as a 'nation'. ${ }^{2}$ The only diversion in this process came from the separatist attitude of the Muslims who played into the 'divide and rule' manoeuvres of the colonial administrators and brought about the partition of the country.

One of the foremost challenges to this historiography came when the Indian national movement was refused to be seen as a 'hallowed and blemish-less' movement. It was pointed out that Indian national movement failed to channelize the currents of national and the social discontents into one single anti-colonial, anti-feudal revolution - a lapse that was described as 'tragic' (Sarkar 1973: 512-16). This movement also failed to ensure 'prefect mobilisation' (Pandey 1978), which happened due to its bourgeois character (Dutt 1949; Desai 1966). This radical historiography also pointed out that there has been a tendency of the 'elitist' historiography to concentrate on the Gandhian uprisings as 'abnormal outgrowth' peripheral to the study of the development of Indian nationhood (Pandey 1978: 217). ${ }^{3}$ These critics depicted that it was a distortion of the reality. The Congress-led movement and the popular upsurges in various parts of the country were coeval processes. In fact, often, at opportune times, the Congress leadership attempted to seize control of the latter so as to curb the outburst of any undesirable militancy. The third challenge disputed the theory that the achievement of Indian freedom was solely the work of the Indian National Congress. It brought to light vast new materials to show that the British attempted to retain the 'jewel of the crown' until the last moment (Gupta 1987), but it was the immense panic created by the widespread revolt throughout the country that prompted the war-devastated Britain to make a hasty withdrawal from India (Sarkar 1983: 414-46; 


\section{Sajal Nag}

Gupta 1987). The fourth dimension of the Indian nation making process was discovered by another group of historians who rejected the notion that India was already a nation. It brought to light the fact that colonial India experienced two streams of coeval processes as far as its nationality question was concerned. One was based on its pan-Indian identity and the other on its regional linguistic-cultural identity. While the former stimulated fight against the colonial rule, the latter at the same time worked towards self-assertion (Guha 1982: 2-12; Guha 1979: 355-458; Guha 1983; Chandra 1982: 1282-6; Rao 1973; Mohanti 1982; Nag 1990; Ram 1979: 377-402).

This school rejected the pre-conceived one-nation-one-nationalmovement theory and formulated that considering the diverse and multiple linguistic, cultural and even racial communities that India consisted of, who are all advancing towards a nation-like entity, India can be described as a multi-nationality and multi-ethnic country (Habib 1987: 17-25; Nag 1990). India is, therefore, a country that contained a number of nationalities, both nascent and consolidated, which is at various historical stages of development. None of these, however, theoretically speaking, yet by themselves forms a nation. Together they form the Indian nation-in-the-making (Guha 1982). The nationalist aspirations of self-rule of these entities are either satisfied or neutralized by the federal structure of the union. The period of Indian freedom struggle coincided with the period of awakening of these nationalities. These awakenings manifested themselves in the form of agitations and movements for recognition to their respective vernaculars, formation of unilingual provinces and separation from the dominant nationalities. These movements based on regional identities have been variously termed as 'little nationalism' (Guha 1979), 'regionalism' (Guha 1983; Chandra 1982; Majeed 1984; Wallace 1985; Hargopal 1987: 360-90; Mishra 1988), 'sub-nationalism' (Sharma 1990: 370-81) and even full-fledged 'nationalism' (Shah and Munshi). ${ }^{4}$ In general, historically speaking these movements flowed under the shadow of the anticolonial movement during the colonial period and did not oppose the interest of the latter. In fact, these were not isolated movements but an integral part of the nation-making process itself. But after independence, these movements occurred with more frequency and intensity as recognition to regional identities and regional autonomy was a promised nationalist agenda. It, therefore, often had to fight against the post-colonial state itself as it went back on its promises and failed to recognize the urgency of reorganization of the colonial policy ( $\mathrm{Nag}$ 1993: 1521-32). These struggles and the response to it by the colonial state thus form an important chapter of the history of modern 
India. Unfortunately, the textbooks of modern Indian history do not include these processes. Although the resurgence of radical schools of Indian historiography in recent times has forced the entry of peasants, workers, tribals and dalits into the textbooks of modern Indian history (Sarkar 1983) which so far were 'elitist' and 'politics' oriented, ethnic and nationality movements still remain excluded. But the developments that post-colonial India have experienced have made it amply clear that without the inclusion of these streams any understanding of the making of Indian nation would be inadequate.

In India, the nationality formation process hastened with the advent of British capitalism in colonial form. The new mode of production required a homogeneous market, unified political territory and a common language. The British, therefore, administratively unified the country. In the process, among the groups which first came into contact with the British, the language of the major group was designated the official language of the area, indirectly recognizing the group as the major nationality. This resulted in suppression of small nationalities whose language was not developed or who were yet to come into contact with the British. Their linguistic-cultural claims were brushed aside. The big nationalities flourished while the small ones remained subdued. The big nationalities spread their social and economic domination (Seal 1968: 345-6) by controlling the employment sector owing to the head start they had in the new education system. To assert their nationality status, the small groups had to break the domination of the big groups and reinstate their own language and culture in their rightful place. In this nationality formation process, language played a crucial role. It became a rallying point and a symbol of crusade. In Assam, Bengali was introduced as the official language, overlooking the claims of the Assamese. The Assamese strongly resented this. The situation was aggravated by the dominance of Bengalees in the employment sector and suppression of Assamese culture. Complaints were voiced in Orissa also about the unequal status of Oriya vis-à-vis the Bengali language. The situation here was similar to that of Assam. The Oriyas lamented that

the Bengalees assert that Oriya is merely a dialect of Bengali and has no claim to be considered as an independent language (though) at a period when Oriya was already a fixed and settled language, Bengali did not even exist.

(Beams 1966: 117-19)

To this were added other issues which further strained the relationship between the two groups. 'The new education system was dominated 


\section{Sajal Nag}

by the Bengalees. There was a movement in progress to replace Oriya by Bengali in administration and education' (Kluyev; Manisha cited in Nagendra 1959: 464). The movement for the separation of Bihar from Bengal was Bihar's first effort to 'assert its own regional identity' (Shaibal Gupta). Bihar was tagged to Bengal during pre-British times. This slowed its political and economic development. The emergence of British power sealed Bihar's fate for another century. On the one hand, the official language of Bihar - 'Hindi' - was not the mother tongue of any major population group (Brass 1974: 69). On the other, Bihar had to grow under the cultural shadow of Bengal. Bengalees were also the preponderant group in education and jobs. Thus, the agitation for separation of Bihar from Bengal was essentially an anti-Bengalee movement (Shaibal Gupta). In Madras Presidency, the Telegus outnumbered the Tamils, but because the Tamils were educationally advanced, they dominated government service, which was then the most important employment sector. This incited jealousy between the two communities (Slater 1936: 312). Such conflicts between communities in India, though often violent and a source of destabilization, were signs of development of nationalities (Dasgupta 1970: 1-30, 225-70).

\section{Formation of the Assamese nationality}

The pre-colonial Assamese were settled in a clearly demarcated geographical territory. The Indo-Aryan Assamese language emerged as the lingua franca for groups residing within the boundary including the ruling Ahoms who gave up their language in favour of Assamese. There was corresponding development in literature and culture also. While state intervention helped institutionalize folk culture, the rise of the bhakti movement enriched literature. As a result it became easier to distinguish the Assamese as a separate entity. State control of the production process brought about uniformity in the economic life of the people. The geography of the state and royal policies bred insularity, and consequently dislike for outsiders. A greater Assamese community was emerging on the basis of common language, territory, economic life and mental outlook (Nag 1990). The community, however, was not stable because the members of the community, represented distinguishable cultural types; it was not unilingual in spite of Assamese being the lingua franca because the Indo-Mongoloid groups retained their languages for conversation; and the concept of a motherland did not extend beyond the local geographical unit and operated only during external attacks. Inner contradictions surfaced owing to the advancement of a feudal mode of production, resulting in the 
Moamaria peasant uprising in religious garb followed by a fratricidal war of succession. In the internecine power struggle the Ahom royalty threw open the insular society and sought British and Burmese help. The Burmese entered and devastated the structure followed by the British who stayed on to annex the province.

The advent of British rule disrupted the social formation. To render it responsive to the requirements of British capitalism, the existing structure of Assam was transformed by force. The ownership of the means of production was changed and the self-sufficiency of the economy was destroyed. Production for satisfaction of needs was replaced by production for trade. A new revenue system along with its superstructure was introduced. An extensive administrative set-up along with a new judicial system made their appearance. The new means of subsistence and functioning changed the value system. The cumulative result was the gradual impoverishment of Assamese peasants, the disappearance of the medieval gentry and the emergence of modern social classes.

A number of Bengalee functionaries entered Assam along with the British. They were the functionaries through whom the changes were effected. A new geographical territory was imposed on the Assamese by attaching them to Bengal. The British rule halted the centuries-old process of amalgamation and homogenization in Assam.

When, in the interest of tea plantations and trade, the British separated Assam from Bengal and created a separate Assam Chief Commissionerate, Bengali was introduced as the official language of Assam. This was a setback for the Assamese. Missionaries preaching Christianity through the medium of the local tongue were also affected. Together they started an agitation to compel change in the policy. The government retaliated by saying that Assamese could not be the medium of instruction since it was a mere Bengali patois. The Assamese middle class and missionaries made serious efforts to disprove the theory. The British, meanwhile, were supported by prominent Bengalees. Assamese was finally declared the official language.

While the subjugation of Assamese was viewed as an attack on the Assamese nationality, the employment of Bengalees was considered to be an attack on the economic rights of the Assamese. In a situation where the traditional means of subsistence were fast disappearing, avenues open to the Assamese were the white-collar jobs. However, they lost these jobs to competing Bengalees who had better access to modern education and were often preferred by the British. Economic frustration gave birth to ethnic ideas and resentment.

Ethnic polarization also permeated the social relations between the two groups. Being the functionaries of the British, the Bengalees 


\section{Sajal Nag}

identified themselves with the ruling class. Their cultural advancement bred ethnocentrism which led them to flaunt their advancement. Bengali cultural activities, therefore, flourished in the Brahmaputra valley. In contrast, Assamese culture was subdued. Attracted by the advancement of the Bengalees, a section of the Assamese delinked themselves from the Assamese community and adopted Bengali culture and openly stated that they were proud of doing so. This resulted in partial acculturation. The societal bi-culturalism hampered the development of the Assamese nationality.

The most serious threat to the Assamese came from the increase in the numerical strength of the Bengalees through continuous immigration. Immigration was not confined to job-seeking Bengalees only. It comprised the land-seeking farm settlers also. The massive immigration continued unabated despite protests from the Assamese because the economy needed these immigrants. From a small immigrant community, the Bengalees became a dominating force. The enlargement of their sphere of influence enabled the Bengalees to lay claim to the resources of the province hitherto considered the exclusive preserve of the Assamese. The Bengalees also demanded and won a share in local self-government and state politics. They challenged the Assamese by demanding that some schools should have Bengali as the medium of instruction. Since they were numerically strong, the government acceded to their demand. The establishment of Bengali (medium of instruction) schools in the Brahmaputra Valley was another setback to the aspirations of the Assamese nationality.

To counter the Bengalee dominance the Assamese had to accomplish a number of arduous tasks. One was to curb the growth of Bengalee population. Since immigration was partially government sponsored, their appeals and protests fell on deaf ears. The immigrants, who happened to be Bengalees, along with the Bengalees of Surma valley were already in a position to be declared as the majority community of the province. Since the existence of the Assamese nationality now depended on the reduction of the number of the Bengalees in the province, it was sought to be achieved by transferring Sylhet to Bengal and assimilating the immigrant Bengalee farm settlers.

Meanwhile, the continuing settlement of Bengalee Muslim immigrants destroyed the homogeneity of Assamese society. The immigrants with an alien religion, different languages, social attitudes and behavioural patterns were regarded as pollutants by the Assamese rural folk who valued their ethnic, linguistic and religious affiliations. The prosperity of the immigrant peasants fuelled the Assamese-Bengalee peasant conflict. 
The middle-class leadership of Assam, taking note of the threats and challenges faced by the Assamese nationality and the ethnic conflict, was involved in responding to the situation. They established Assamese literature by contributing copiously to it and unearthing its past glory. They also successfully demolished the theory that Assamese was a dialect of the Bengali language and affirmed its separate identity. Through a process of meticulous politicization and socialization, they channelled the fears and aspirations of the emerging Assamese nationality into a social movement.

The movement for the development of the Assamese nationality attracted participation of all classes of society. Reduction of the numerical strength of the Bengalees was taken up as the most urgent task by the Assamese at the social level. They joined the Bengalees of Sylhet in their demand that Sylhet be transferred back to Bengal. The Assamese now forced the government to stop further immigration and evict the existing immigrants. The unrestricted immigration also increased the percentage of the Muslim population in Assam since a large number of the immigrant Bengalees were Muslim. This led the Muslim League to demand that Assam be transferred to the proposed state of Pakistan. The grouping plan of the Cabinet Mission which bracketed Assam with Bengal was a simultaneous threat. While the former proposal meant that the Assamese would lose their identity in the proposed Islamic State of Pakistan, the latter proposal meant that they would be absorbed in Bengal. Both were considered equally perilous for the survival of the Assamese nationality, which found itself cornered both on linguistic and religious grounds. To fight these threats, the entire Assamese society fought as a unified group. Eventually, the Assamese leadership succeeded in thwarting the grouping plan. Soon Sylhet too was transferred to Pakistan.

The Assamese-Bengalee ethnic conflict, thus, was an integral part of the process of the development of the Assamese nationality. By the fourth decade of the twentieth century, the Indo-Mongoloid groups like the Bodos and Ahoms who had hitherto formed a part of the Assamese nationality also began to show signs of secession, which the Assamese leadership failed to perceive. With its newfound chauvinism, the Assamese nationality not only ignored the grievances of such groups, but it even brushed aside their cultural aspirations.

Again, though the numerical strength of the Bengalees was reduced after the transfer of Sylhet to Pakistan, a few lakhs of Bengalee Hindus entered Assam as refugees in successive waves. They added to the existing Bengalee population. But the potential source of danger was the immigrants who declared themselves as Assamese in the census 
reports without actually going through the assimilation process. In a political structure where 'numbers' could make or break a nationality, this turned out to become a major issue of concern. The perpetual fear that the Assamese faced then onwards was that at any time these immigrants might resume calling themselves Bengalees, thereby tilting the balance again in favour of the Bengalees.

The rise and development of the ethnic conflict in Assam had Assamese nationality formation as its backdrop, either of these was not an isolated process. In fact, the ethnic conflict and Assamese nationality formation were inextricable parts of the same process: the development of Assamese nationality.

\section{Post-independence crisis}

After independence ethno-nationality issues began to surface endemically. The outbreak of a strong and violent ethnic conflict after 1947 was perhaps nowhere as prominent as in Assam. The ethnic conflict in Assam had its making during the colonial period. In that period there was no violent clash between the Bengalees and the Assamese. The Assamese wanted to remove the Bengalees from their social unit. The transfer of Sylhet to Pakistan and eviction of immigrants substantially reduced the Bengalee and Muslim population in the Assam valley. This reduced the threat to the political aspirations of the Assamese. However, the preponderant Bengali culture in the valley worried the Assamese. The influx of refugees from the then Pakistan again increased the Bengalee population of Assam. The tension surfaced again. Soon after independence an open clash broke out in 1948 between the two communities. In major towns of Assam valley, Bengalees were assaulted on the streets and Bengali signboards were pulled down. The assaulters were drawn from the student community. The social base of the movement was becoming wider and its manifestation more violent.

The year 1948 also ushered in a new phase in the movement. So far the Assamese had viewed expulsion of the Bengalees as a means of reducing the threat to their aspirations. They now found that a thorough Assamesization of the province would reduce the fear of Bengali acculturation. The pulling down of Bengali signboards and the demand to use Assamese on signboards was one device. The violent outbursts that took place in 1954, 1955 and 1960 were a continuation of the 1948 phase. While in 1954 and 1955, the Assamesization efforts were more extensive, in 1960 a bolder step was taken. Assamese was sought to be introduced as the official language of Assam. The political leaders of the province also supported the demand and 
the government took necessary steps to implement it. The Bengalees, mainly in the Cachar valley and the hill tribes, offered massive resistance to the move. Violent disturbances took place in various parts of the state in protest against the forcible imposition of the Assamese language. Looting, arson, assaults, injuries and deaths (for a detailed account of 1960 disturbances, see Barua 1961; Assam Sahitya Sabha 1960; Barua 1960; N. Choudhury 1963; A. Choudhury 1961) were followed by the hill peoples' demand for separation from Assam.

The move to impose Assamese proved to be both a disaster and a revelation for the Assamese. It showed that the time was not yet ripe for such an attempt and that the Assamese were not the undisputed dominant community in Assam. The resistance offered by the Bengalees showed that they were also a force to reckon with within Assam. It also revealed that the Assamese did not have an economic foothold in their own state. The Marwari trading community virtually controlled the economy. Hence, in 1968 a movement was launched against the Marwaris wherein they were asked to quit Assam.

The 1970 and 1972 outbursts were pre- and post-census (1971) attempts at Assamesization. In 1970, it was an attempt to terrorize Bengalees to declare Assamese as their mother tongue in the census. In 1972 , it was a reaction to the increase in the Bengalee population. It was suspected that many refugees who entered Assam in the wake of the Bangladesh War (1971) stayed back illegally and registered themselves as regular Indian citizens in the census, which further increased the Bengalee population.

The Assamese achieved no significant success in these movements. Hence, in 1979-80, the anti-foreign national movements were launched. It was a renewed attempt to reduce the numerical strength of Bengalees in Assam. It grew into a social upheaval and continued for an incredibly long duration, unleashing a reign of terror, violence and genocide of a magnitude unknown in Assam. It initiated a constitutional crisis. The professed demand was detection and deportation of illegal Bengalee foreign nationals resident in the state. However, the events in the movements showed that it was really an attempt by the Assamese to expel Bengalees from Assam to retain Assamese hegemony in the state and realize their political aspirations. The development and recognition of Assamese as a full-fledged nationality was sought to be achieved by reducing the numerical strength of Bengalees in Assam. But the move proved disastrous, as it not only failed to detect and deport the so-called foreign nationals, it also alienated other groups of the composite Assamese nationality. The major secessionist movement was launched by the Bodos - the largest tribal community of 


\section{Sajal Nag}

the Brahmaputra valley. They declared themselves as a full-fledged nationality, demanded complete autonomy by dividing Assam 'fiftyfifty' and launched a violent movement for self-rule. The arrogance and chauvinism of the caste Hindu Assamese also led the Ahoms to break away from the parent community and search for an alternate identity. They were followed by the Tiwas, Karbis, Dimasas and so on, all of whom demanded self-rule outside the Assamese hegemony. The grant of autonomous councils has temporarily calmed some of these tribes while others still have launched violent insurgency to achieve their objective.

\section{Notes}

1 This chapter was first published in Eastern Quarterly, 3(4): 251-61, 2006.

2 This has been the general perspective of the historiographical school categorized as 'nationalist'.

3 An entire school of historiography subsequently emerged which launched a crusade against the elitist historiography and highlighted this aspect of Indian national movement. See the series entitled Subaltern Studies edited by Ranajit Guha.

4 Also see Surjit Hans, 'Punjabi Nationalism', 1989. Also see articles by Udayan Mishra on the Nagas, V. Anai Muthu on the Tamils, Shankar Guha Niyogi on Chhattisgarh, in Andhra Pradesh Radical Students Union, Nationality Question in India, Hyderabad: Peace Book Centre, 1982. Prof. Javed Alam called the anti-colonial movement for independence in India as a supra-nationality nationalism and the various national movement of the people belonging to different national groups remained subsumed under it, notwithstanding the demand for Pakistan. See Javed Alam, 'Class, Political and National Dimensions of State Autonomy Movements in India', 1987.

\section{References}

Alam, Javed. 1987. 'Class, Political and National Dimensions of State Autonomy Movements in India', in TDSS, Nationality Question in India. Pune: TDSS.

Assam Sahitya Sabha. 1960. Assam's State Language. Jorhat.

Barua, H. C. 1961. A Glimpse of Assam Disturbances. Gauhati.

Barua, K. C. 1960. Assam: Her People and Language. Shillong.

Beams, John. 1966. A Comparative Grammar of Modern Aryan Languages of India. Delhi: Munshiram Manoharlal.

Brass, Paul R. 1974. Language, Religion and Politics in Northern India. Cambridge: Cambridge University Press.

Chandra, Sudhir. 1982. 'Regional Consciousness in 19th Century India: A Preliminary Note', Economic and Political Weekly, 17 August.

Choudhury, Amitabh. 1961. Mukher Bhasha Buker Rudhir (in Bengali). Calcutta: Grantha Prakash. 
Choudhury, Narayan. 1963. Asamer Bhasha Danga (in Bengali). Calcutta.

Dasgupta, Jyotindra. 1970. Language Conflict and National Development. Berkeley: University of California Press.

Desai, A. R. 1947/1966. Social Background of Indian Nationalism. Bombay: Popular Prakashan.

Dutt, Rajni Palme. 1949. India Today. New Delhi: People's Publishing House.

Guha, Amalendu. 1979. 'Great Nationalism, Little Nationalism and Problem of National Integration: A Tentative View', Economic and Political Weekly, 14, Annual, February.

Guha, Amalendu. 1982. 'Indian National Question: A Conceptual Framework', Economic and Political Weekly, 17, Special Number, 31 July.

Guha, Amalendu. 1983. 'Nationalism: Pan-Indian and Regional in Historical Perspective', Presidential Address, Modern India Section, Indian History Congress, 44th Session, Burdwan.

Guha, Ranajit. Subaltern Studies, Series. New Delhi: Oxford University Press. Gupta, Partha Sarathi. 1987. 'Imperial Strategy and the Transfer of Power 1939-51', in Amit Kumar Gupta (ed.), Myth and Reality: The Struggle for Freedom in India 1945-47. New Delhi: Manohar.

Gupta, Shaibal. 1981. 'Non-Development of Bihar: A Case of Retarded Sub-Nationalism', Economic and Political Weekly, 16(37): 1496-502, 12 September.

Habib, Irfan. 1987. 'Emergence of Nationalities', in TDSS, Nationality Question in India. Pune: TDSS.

Hans, Surjit. 1989. 'Punjabi Nationalism', paper presented in a seminar on 'Nationalism: Problems and Challenges', organised by K.M. Munshi Centenary Committee and Government of Gujarat, Centre for Social Studies, Surat.

Hargopal, G. 1987. 'Dimension of Regionalism, Nationality Question in Andhra Pradesh', in TDSS, Nationality Question in India. Pune: TDSS.

Majeed, Akhtar (ed.). 1984. Regionalism: Developmental Tension in India. New Delhi: Cosmo.

Mishra, M. 1988. Politics of Regionalism in India with Special Reference to Punjab. New Delhi: Deep and Deep.

Mohanti, Nivedita. 1982. Oriya Nationalism. New Delhi: Manohar.

Nag, Sajal. 1990. Roots of Ethnic Conflict: Nationality Question in Northeast India. New Delhi: Manohar.

Nag, Sajal. 1993. 'Multiplication of Nations? Political Economy of SubNationalism in India', Economic and Political Weekly, 17-24 July.

Nagendra, V. (ed.). 1959. Indian Literature. Agra: Lakshmi Narain Agarwal.

Pandey, Gyanendra. 1978. The Ascendancy of the Congress in Uttar Pradesh: A Study in Imperfect Mobilisation. New Delhi: Oxford University Press.

Ram, N. 1979. 'Dravida Movement in Pre-Independence Phase', Economic and Political Weekly, 14(78), February.

Rao, K. Narayana and G. Dasaradha. 1973. The Emergence of Andhra Pradesh. Bombay: Popular Prakashan.

Sarkar, Sumit. 1973. Swadeshi Movement in Bengal. New Delhi: People's Publishing House. 


\section{Sajal Nag}

Sarkar, Sumit. 1983. Modern India, 1885-1947. New Delhi: Macmillan. Seal, Anil. 1968. Emergence of Indian Nationalism: Competition and Collaboration in the 19th Century. Cambridge: Cambridge University Press.

Shah, Ghanshyam and K. M. Munshi. 'Gujarat and Indian Nationalism', paper presented in a seminar on 'Nationalism: Problems and Challenges', Centre for Social Studies, Surat.

Sharma, K. L. 1990. 'Jharkhand Movement: The Questions of Identity and Sub-Nationality', Social Action, 40(4).

Slater, Hilbert. 1936. Southern India: Its Political and Economic Problem. London: G. Allen \& Unwin.

Wallace, Paul (ed.). 1985. Region and Nation in India. New Delhi: Oxford and IBH. 


\title{
6 Challenges and predicaments of Naga nationalism ${ }^{1}$
}

\author{
H. Srikanth and C. J. Thomas
}

Inspired by classical Marxist understanding of nationality and national movements, several scholars and activists in India have examined the colonial and pre-colonial roots of nationalities and studied the impact of the development of nationalities on Indian politics. The debate on the nationality question that started during the anti-colonial struggle threw light on distinct trajectories of development of different nationalities in India (Jacob 1988; A.P.R.S.U. 1982; AIPRF 1996; TDSS 1987). Still, the discourse on nationality remains inconclusive. Questions as to whether post-colonial India is a sovereign nation state or a dependent multi-nationality state continue to bother many scholars even today. Furthermore, generalizations on nationalities in India are based primarily on the experiences of dominant nationalities in mainland India. Not much work has been done to comprehend the emergence of nationalities in peripheral regions of Northeast India.

Understanding the nationality question in Northeast India is difficult because of the complex history and social composition of the region. In the Northeast, in addition to socially and culturally advanced communities, one also comes across several communities officially designated as scheduled tribes (ST). Like the Assamese and Meiteis, some of the ST communities are also asserting themselves as distinct nations and leading movements for political autonomy or independence. The Naga resistance movement is the first struggle of such a kind in the history of post-colonial India. The civil disobedience movement of the Nagas that later took the form of insurgency has shown the way to several other ethnic insurgencies in the Northeast. Over six decades of movement of the Nagas for self-determination questions the conventional understanding of the development of nationalities. It does pose a challenge to the practice of civic nationalism and casts doubts on the possibilities of multi-nationality nations. A critical study of the nature and dynamics of the Naga national movement, therefore, becomes a necessity for both theoretical and practical reasons. 


\section{Scholarship on nations and national movements}

In academics we come across several competing perspectives of nationality, nationalism and national movements. Based on certain observations of the phenomena, each perspective projects a set of elements or factors as the core determinants of nationality or national movements. Scholars like Steven Grosby (2005: 56-78) and L. van den Berghe (2005: 113-18), who presented evolutionary biological perspective, underscore nations' linkages with religion and ethnics. Contradicting the scholars like Berghe, who consider modern nations as extension of ethnics, Marxists and other modernist scholars view nations as historical entities bound with territory and state. According to classical Marxist understanding, nationalities emerge at comparatively more advanced stages of development of human society, after the communities reach the stage of settled agriculture and develop common language, cultural symbols and practices that could bind all the members of the community. Marx and Lenin showed how the imperatives of capitalist development gave further boost to consolidation of nations and facilitated the formation of nation states with national markets and centralized state structures (Marx and Engels 1974; Lenin 1986). Asserting that a nation is not a racial or tribal, Joseph Stalin defines nation as a historically constituted, stable community of people, formed on the basis of a common language, territory, economic life and psychological make-up manifested in a common culture (Stalin 1913). Ernst Gellner also argues that the growth of nations becomes possible in economically specialized, occupationally mobile, highly technical, meritocratic industrial societies with shared medium of communication, literacy and education (Gellner 1981: 753-76). Benedict Anderson, who looked at nations as imagined communities, considers the development of print capitalism that contributes to the spread of literacy and literature in a newly standardized language of the educated elite, as essential condition for the raise of nationalism (Anderson 1991). Although these modernist scholars differ in their identification, essential material conditions for the development of nations, they all emphasize on territorial nature of the nations and view nations and nationalities as something more than ethnics. Anthony D. Smith, who advocated 'Ethno-Symbolism', accepts nations as modern phenomena, but calls attention to the importance of real or imagined ethnic roots and the role of culture - symbols, beliefs, myths and values - in infusing emotions and forging national unity (Smith 1991, 2009). Walker Connor believes that nationalism has ethnic core even if it is presented in civic guise (Connor 1994).

There is a tendency among a section of the scholars to generalize the history of origins of nations based on the experience of classic 
examples of nations in the Europe. But the reality is that the development of nations did take different routes in different parts of the globe. Even in the Europe, the experience of nation formation in Eastern and Southern Europe is different from Western Europe. Similarly, the formation of nations in colonies and semi-colonies is very different from the experience of the colonizing nations. Marx and Lenin were aware of different trajectories in the development of nationalities. They took note of the facts that apart from the classic instances of nationalities developing into independent nation states, there were instances of immature national movements and examples of different ethnic communities/smaller nationalities merging and assimilating together to form bigger nations or new nation states (Lenin n.d.: 25-30). Marxists insisted on understanding the class character of the national elite before certifying the national movements as progressive or reactionary. Further, Marxists never advocated the ideas that every nation should have its own state. They recognize both the possibility and desirability of nations coming together voluntarily to form multi-nationality states based on the principles of equality and mutual respect (Ibid, 173). The existence of multi-nationality nation states is recognized by scholars of different ideological persuasions - liberal, Marxist, post-Marxist, post-colonial and even primordialists (Bhabha1990; Chakrabarty 2007; Rex 1996; Berghe 2005). Not only the USA, the UK and Switzerland, even those cited as classic examples of one-nation - one state, such as France, Germany and Italy are increasingly becoming multicultural, multi-ethnic and multi-national. Similarly, most ex-colonies and semi-colonies in Asia, Africa and Latin America which got liberated from the colonial yoke are multi-ethnic and multi-national in composition. Despite the resurgence of ethnic nationalism in recent decades, pure nation state with only single ethnic or single nationality is hardly visible in the world. Supra-nation consciousness as citizens of America, Canada, France, Switzerland, and so on can coexist with ethnic or nationality consciousness as Hispanic, Jewish, German, Chinese, Indians, and so on within the multi-ethnic and multi-nationality nation states.

\section{National question in India}

The nature and form of nationality formation and national consciousness in the Indian subcontinent were conditioned by the British rule. Although there was cultural and civilizational unity, India as a whole never existed as a single political entity in history prior to colonization of the Indian subcontinent by the British. It was the British rule 
which integrated different nationalities and regions under a common political and economic regime. The shared historical experiences of subjugation and exploitation under the colonial rule gave birth to Indian national consciousness and brought different nationalities on a common platform to fight for independence. By facilitating development of regional languages and literatures, the colonial rule also gave birth to nationality consciousness as Tamils, Bengalis, Oriyas and so on. However, due to the impact of the Indian nationalist movement, the nationalities in mainland India instead of thinking in terms of forming separate independent states felt the need to come together for giving shape to a sovereign multi-nationality nation state (Srikanth 1991: 1-12). These nationalities, of course, aspired and agitated for political autonomy and equal status within the Indian union but never seriously demanded separate national status. Some ultra-left scholars and activists in India often mistook the right to self-determination as something synonymous with right to secession. They do not realize that self-determination of nations may also take the form of seeking political autonomy and entering to federal relations with other nationalities to form multinationality nation states.

While acknowledging that in the mainland India supranational consciousness as 'Indians' grew alongside particular nationality consciousness, it is also necessary to admit that in Kashmir and in India's Northeastern region, wherein the Indian national movement had little influence, national consciousness developed somewhat unevenly and differently. After independence certain regions and sections of the people within the Northeast who were influenced by India's freedom struggle were favourably inclined to join the Indian Union. But others, specially the communities living in the fully excluded hill areas of the Northeast and also in the princely state of Manipur, wherein the people were not directly touched by the Indian nationalist movement, were sceptical of their future in the post-colonial India. Despite their reservations, eventually most of these communities were persuaded or coerced to join the Indian Union. The manner in which the reluctant communities and regions within the Northeast were forced to become a part of the Indian Union has been one of the reasons for the rise of insurgent movements in Northeast India. The Nagas were the first to declare themselves as a distinct nation and expressed their desire not to become a part of the Indian Union.

\section{Background to the Naga movement}

The name 'Naga' is a generic term that refers to a group of over thirty tribes inhabiting not only in Nagaland, but also in the Northeastern 
states of Assam, Manipur and Arunachal Pradesh. Some Naga tribes are found in the northwestern parts of Myanmar bordering India as well. Each Naga tribe has its own language and traditional social and political institutions. Till the arrival of the British, most of these communities depended on hunting, food gathering and shifting cultivations for their livelihood. Except among a few of comparatively advanced Naga tribes such as the Angami, Sema and Tangkhul, who practised wet rice cultivation, the institution of private property had not developed among the Nagas before the arrival of the British (Nag 2002: 28-30). The traditional political institutions of the Nagas were decentralized. Each tribe lived in their respective villages under their chiefs, and inter-tribal and inter-village conflicts were common (Jacobs 1990: 69-76). Although the tribes were living in their present areas of inhabitation for centuries, their tribal background did not permit state formation in the modern sense of the term.

Though Naga tribes had confrontations with neighbouring kings and tribal chiefs, by and large they lived autonomous lives with little interference from outsiders. They felt a potential threat to their existence only when the British started developing tea plantations along the foothills and encroached into the areas which the Nagas considered as their natural traditional territories. The Nagas reacted to the British advance by raiding and plundering the villages in the plains under the control of the British. To establish peace along the borders and to make peace with the Nagas, the British tried several methods. Initially, they unsuccessfully tried to use the rulers of Manipur and Cachar to check the Naga raids and pitted the Kuki tribes against the Nagas. When such indirect methods failed to yield positive results, the British sent several punitive expeditions against the Nagas till 1880 to suppress the Naga rebellion. The colonial authorities introduced Inner Line Policy Regulations in 1872-73, seeking to stop further encroachment of tribal lands by tea planters and monitor the entry of traders and other plainsmen into the hill areas inhabited by wild tribes (Mackenzie 1994: 55-6). Apart from this, the colonial authorities consciously encouraged the Christian missionaries to work among the Naga tribes to educate and civilize them. The British constituted Naga Hills District and gradually brought different Naga-inhabited areas under their control. But the British realized that these territories had little economic relevance for them. Hence they chose not to waste their resources for creating elaborate administrative set-up in the hills. Instead they chose to administer the Naga-inhabited areas with the help of the traditional chiefs (Sema 1991). No conscious efforts were made to bring about radical changes in the economic and social structure of the Nagas. 
However, certain unintended changes did take place with administrative unification of several Naga-inhabited areas and with establishment of peace and order in the hills. The missionaries' role in spreading education and Christianity helped in mitigating the anti-British feelings among the Nagas. Certain new ideas, professions and practices hitherto unknown to the traditional tribal societies began to take root within the Naga society. Educational institutions and churches brought Nagas belonging to different tribes together on same platforms. From within the Naga society there emerged a new class of educated and baptized elite (Nag 2002: 9), who rose above tribal loyalties and dreamt of uniting all Nagas. Unlike in the Lushai Hills, wherein the newly emerging educated elite openly confronted with the oppressive traditional chiefs, no such confrontations took place in the Naga Hills between the traditional tribal chiefs and the emerging educated elite. The traditional Naga chiefs, being more democratic and openminded, continued to command respect from all, including the emerging educated elite. Voluntary participation of thousands of Nagas in the First and Second World Wars enabled them to expose themselves to modern ideas of patriotism and nation state. The British administrative policy of keeping the frontier areas aloof from the rest of India kept the Nagas away from the influence of Indian nationalist movement. On their part, the British officers and the missionaries made the Nagas feel that they were racially, culturally and historically different from the plainsmen and that they had nothing to do with mainland India and Indians. The fears nurtured by the British against the plainsmen found its initial political expression in the form of memorandum submitted by the Naga Club to the Simon Commission requesting the British to keep the Nagas out of the proposed constitutional reforms (Nuh 2002: 111-12).

\section{Naga nationalist movement}

Even during the British rule, the Nagas enjoyed considerable autonomy in the so-called backward tracts, un-administered areas and fully excluded areas, with little or virtually no interaction with the people living in the plains. It was hence natural that the Nagas became apprehensive of their future when the British chose to withdraw from the Indian subcontinent. During this transition period, the Naga Hill District Tribal Council transformed itself into the Naga National Council (NNC). The Naga leaders appealed to the British authorities to grant them independence. They began to argue that, since the Nagas were historically, racially and culturally different from Indians and were 
never occupied by the Indian rulers, the Nagas should be granted freedom as a sovereign country once the British rule comes to an end (Nuh 2002: 30, 51, 65-6). They also approached the Indian leaders and expressed their concerns and wishes. After several rounds of negotiations, the moderate leaders of the newly formed NNC signed in June 1947 a Nine-Point Agreement with Akbar Hydari, the then governor of Assam, wherein it was agreed that ten years after the agreement 'the Nagas will be free to decide their future' (Nuh 2002: 67-8).

In subsequent years this agreement became a subject of controversy among the Nagas and also between the Naga leaders and the succeeding Indian governments. Militant leaders like Zapu Phizo began to interpret the clause to mean that the Nagas had the right to become politically independent after ten years. The Constitution Assembly overlooked the Hydari Agreement. Enraged by the Indian leaders' disregard for the Nine-Point Agreement, the NNC proclaimed independence on 14 August 1947, one day before India was officially declared independent, and intimated the same to the Government of India and to the United Nations. The Naga leaders refused to join the Bordoloi Sub-committee constituted by the Constitutional Assembly to make recommendations for accommodating the aspirations of the hill tribes of Assam. Subsequently, they discarded the Sixth Schedule of the Indian Constitution, which made provision for an Autonomous District Council for the hill communities. With militant leaders like Phizo taking over the leadership, NNC persisted on its demand for independence. Responding to the call of their leaders, the Nagas in the Naga Hills District voted en masse for Naga independence in the 'referendum' organized by NNC. Inspired by their leaders, the Nagas boycotted the first general elections for the parliament and assembly in 1952 and started a civil disobedience movement against the Indian officials and government.

At this point of time the Naga revolt was basically confined to the tribes inhabiting the Naga Hills District of Assam. Although the demand for independence was articulated by the educated Nagas, it had the support of Naga tribal chiefs as well. But from the documents of NNC, it becomes clear that its goal was not to re-establish the precolonial authority of the tribal chiefs. Although the speeches and writings of the then Naga leaders romanticized the tribal background of the Nagas and projected the Indians as personifications of all ills and negative qualities, one can understand from the kind of state that they sought to establish that the leaders wanted the Nagas to move ahead, not backwards. ${ }^{2}$ The Indian nationalist leaders should have appreciated the dilemmas and fears of the Nagas who had little knowledge of 
India and the Indians. They should have handled the Naga resistance with patience and maturity. Instead, the nascent Indian state took the Naga revolt as an affront and started using repressive measures to suppress the Naga movement. The Government of India enacted several black acts and empowered the armed forces with enormous powers to undertake arrest and suppress the leaders and people supporting the Naga movement. Far from solving the problem, the bureaucratic and repressive measures drove the Naga activists to take up arms against the Indian state. The state repression gave moral justification to the logic of the militant Naga leaders and helped in marginalizing the moderate leaders within the NNC. The stories of repression and violation of human rights hurt the sentiments of all Nagas and helped in the spread of militancy to other Naga-inhabited areas in the Northeast.

\section{Accords and negotiations}

Since 1950s the Naga movement took different twists and turns. Realizing the futility of armed solution, Jawaharlal Nehru's government favourably responded to the Sixteen Point proposal put forward by the Naga People's Convention (NPC) and entered into an agreement with it in 1960. Following the agreement, Nagaland came into existence as a separate state by merging the Naga Hills District and Tuensang Area. The agreement assured that no Act or law passed by the Union Parliament affecting the Naga religious or social practices, their customary law and procedures, civil and criminal justice and the ownership and transfer of land and resources, would have any legal force in Nagaland unless accepted by a majority vote of the Nagaland Legislative Assembly. The Indian government accepted NPC's proposals concerning local self-government, administration of justice and continuation of the Inner Line Regulation rules. The Indian government approved the proposal to place Nagaland under the Ministry of External Affairs of the Government of India. However, no commitment was given with regard to the proposal for inclusion of the contiguous areas inhabited by the Nagas as a part of the state of Nagaland (Srikanth and Thomas 2005: 65).

The outcome of the Sixteen Point agreement satisfied the moderate Nagas, who began participating in the Assembly and parliamentary elections since then. However, the militants denounced the agreement as a compromise and continued insurgency. In the 1960s, a ceasefire agreement was negotiated and several rounds of negotiations took place between NNC leaders and the Indian government. But the negotiations failed to bring peace to the region, as the parties involved stuck to their 
stated positions and refused to compromise. The failure of peace talks led to renewal of insurgency and counter-insurgency operations. A section of NNC leaders who sought to escape the state repression entered into negotiations with the Indian government and signed the Shillong Accord in 1975. They agreed to give up arms and seek solutions for the Naga problems within the parameters of the Indian Constitution. The treaty apparently concluded with the consent of Phizo, who was by then in exile, hurt the sentiments of militant leaders within NNC. Leaders like Isak Chishi Swu, Thuingaleng Muivah and Khaplang, who considered the Shillong Accord as a sellout, formed the National Socialist Council of Nagaland (NSCN) in 1980. NSCN extended its hold to distant areas inhabited by the Nagas. Despite the progress it made within a limited time, because of personality clashes and tribal animosities the NSCN split into two factions in 1988 - the NSCN (IM) and NSCN (K). After the split, the NSCN (IM) led by Isak Chishi Swu and Thuingaleng Muivah emerged as a powerful Naga insurgent group and soon established its supremacy over other insurgent groups in the region (GPRN 1995: 172-99). Because of its hold over the Naga movement, the Government of India rightly thought that no solution to the Naga problem could emerge without engaging the NSCN (IM).

Ever since the Indian government entered into a ceasefire agreement in 1997, several rounds of negotiations have taken place at highest levels both in India and abroad. Although all peace-loving people Nagas as well as non-Nagas - expected the peace talks to succeed, nothing positive and concrete has emerged out of the negotiations yet. Compared to the peace talks that took place in the 1960 s, where the parties refused to budge from their stated positions and expected the other party to fall in line with the solution suggested by it, the negotiations taking place now are, however, far more open and reciprocal. The NSCN (IM) is not persisting with its demand for independence and, for its part, the Government of India also is not insisting on acceptance of the Indian Constitution as a pre-condition for talks. Despite the sincerity of the parties concerned, if the negotiations have not succeeded in finding an amicable solution, one needs to probe the complexity of the Naga national question and see whether the very nature of the Naga national movement itself eludes acceptable solution to the decades-long Naga problem.

\section{Naga movement: Tribal or national?}

At one time the British projected the Nagas as wild, savage tribes. After independence the Indian government officially recognized them 
as scheduled tribes. On their part, the Naga leaders also accepted such colonial and post-colonial representations and asserted their distinct identity asserting the Nagas as an emerging nation. That they did not see any contradiction between tribal and national identities becomes evident from the renaming of Naga Tribal Council as Naga National Council. But this association of tribe with nation should not make one blind to the changes that have taken place in the Naga-inhabited areas during the British rule and thereafter. Referring to political developments in Manipur, Bhagat Oinam rightly points out that many larger tribes are moving out of tribal identity to that of ethnic community (Oinam 2005). This is true of the Nagas as well. Factors like the growth of Christianity, spread of modern education, establishment of new political institutions, penetration of market mechanisms, expansion of transport and communication network, disintegration of communal ownership, development of the institution of private property and so forth have considerably weakened the economic and social base of traditional Naga society. New classes and groups unknown to the tribal societies have begun to play important roles in awakening Naga social and political consciousness. But for these changes, the Naga movement could not have achieved the character of ethnic nationalism. Indeed the Nagas, who were treated as primitive and savage tribes not long ago, have now become an ethnic community aspiring for national status.

While acknowledging the Naga movement as a movement of an emerging nationality, one should not become blind to the vestiges of tribalism obstructing the development of Naga nationality. Despite the glorification of the virtues of tribal life, the Naga leaders knew that tribal identities do come in the way of Naga unity. The church in Nagaland made persistent efforts to encourage the Nagas to think and act, rising above the tribal loyalties (Nuh 2002: 435-6). The NSCN (IM) used Christianity as an effective tool to unite different Naga tribes. However, mutual suspicions and animosities among the Naga tribes continue to affect the organization and leadership of the Naga national movement. The continuing rivalries are adversely affecting the Naga cause. With each Naga insurgent group projecting itself as the real national force and criticizing the others as traitors, the much-aspired unity of all Nagas still remain a distant reality. The Nagas themselves admit that number of Nagas killed in inter-tribal and inter-group clashes far exceed the number of militants killed by the Indian Army. Persistence of inter-tribal and inter-group rivalries stand in the way of coming out with a meaningful solution acceptable to all sections of the Naga society (Srikanth and Thomas 2005: 77-80). Of course, 
in recent years the church and the Naga Hohos are making efforts in this direction.

\section{Civic nationalism or ethnic nationalism}

Some scholars who have made intensive study of several national movements across the world make a distinction between civic nationalism and ethnic nationalism. Although some critics hold the view that these two forms of nationalism are not mutually exclusive, one can still distinguish between civic and ethnic nationalism on the basis of emphasis on territory or ethnic identity. ${ }^{3}$ Civic nationalism is born out of the composite civic and historical experiences of different communities living in a particular territory and subjected to common economic and political life. Civic identities, by their very nature, are multi-ethnic and multi-cultural. Where identities are based on civic nationalism, one can see more than one ethnic group identifying with it. Civic nationalism, as such, cannot be reduced to the interests and roles of any particular dominant ethnic community inhabiting the territory (Reed 2014). In contrast, ethnic nationalism calls for unity of all members belonging to that particular ethnic community, irrespective of the political territory to which they belong. Since its emphasis is on ethnic unity, ethnic nationalism by its very nature excludes other ethnic communities living in the same territory. Ethnic nationalism appeals to beliefs in common ancestry, in common myths of origin and kinship ties to unite and mobilize the people. Very often ethnic nationalism invokes the principle of indigeneity to exclude other communities. In territories where they have to share space with other ethnic communities, ethnic nationalism excludes all those communities which are viewed as non-indigenous and expects other communities to vacate the land or live there by paying taxes and accept the supremacy of those communities who claim to be the original inhabitants of the land (Baruah 2010; Eriksen 2002).

In Northeast India, one can see the advocates of Assamese and Manipuri nationalism invoking civic identities. Both Assam and Manipur are multi-ethnic and multi-cultural states. The Ahom rule in Assam and the Meitei rule in Manipur brought together different tribal communities under their hold. Before the British colonization, the Assamese language in the Ahom kingdom and Meitei language in Manipuri state developed as lingua franca of different communities inhabiting these territories. In both kingdoms, several non-ruling communities also began to identify themselves with the language, culture and traditions of the ruling regimes. There were material conditions ripe for the 
emergence of both Assamese and Meitei distinct homogenous nationalities. However, the process of nationality formation in both the territories was marred by the British colonization. The colonial policies of encouraging immigration in Assam and of pitting the hill communities against the valley people in Manipur created ethnic tensions and obstructed the process of integration of the communities along civic and territorial lines. Some smaller ethnic communities began to assert their own ethnic identities and disassociated themselves from the civic nationalism that was emerging. The fear of domination by the 'outsiders' partly diluted the civic nationalism of the dominant community advocating them and compelled them to take a parochial and chauvinist stand. As such in Assam as well as in Manipur, one comes across two processes of nationality formation - one appealing to civic and territorial loyalty and the other invoking ethnic identities. To make a clear-cut distinction between civic and ethnic nationalisms is difficult, as one can observe the communities invoking civic nationalism and advocating unity of different ethnic communities, at times appealing to ethnic sentiments to unite one group of peoples against its adversaries. ${ }^{4}$ Despite these complexities, one can still say that in Assam and Manipur, civic nationalism preponderates ethnic nationalism.

In contrast, one comes across the predominance of ethnic nationalism in the hill areas of the Northeast. Naga nationalism is indeed a classic example of ethnic nationalism. Although the Naga movement started in the Naga Hills district, it did not confine itself to the district. The movement appealed not only to the people of Nagaland state, but also to the Nagas inhabiting in the neighbouring states of Assam, Manipur and Arunachal Pradesh, and for that matter, even to the Nagas living in Myanmar. The ethnic nationalist demand for integration of all Naga-inhabited areas is blind to the concerns of other communities presently inhabiting in those territories. They claim different territories outside Nagaland not because the territories are inhabited exclusively by the Nagas, or that the Nagas are in majority in those territories, but because the Naga militants believe that the Nagas were the original inhabitants and hence the territories belong to them even if they are inhabited now by other ethnic communities as well. It is this ethnic logic that drives the Naga militant organizations to issue quit notices to the non-Nagas and pit the Nagas against the Kukis, the Meiteis and the Assamese. The Nagas' demand for integration materializes only by disintegrating the existing states of Assam, Manipur and Arunachal Pradesh. The solution of such a kind will not be acceptable to Assam and Manipur, which have come into existence emphasizing the civic national identities. The ethnic nationalism of 
the Nagas, which succeeded in uniting different Naga tribes in the Northeast, finds itself clueless as to how it could make the people and governments of Assam and Manipur accept the ethnic demands of the Naga movement (Misra 2003). The divergence in perceptions is in a way the outcome of the conflict between ethnic nationalism and civic nationalism.

\section{Self-determination and sovereignty}

In the world of nations, every emerging nationality has the right to determine its future. This internationally accepted principle of selfdetermination is often mistakenly identified with the aspiration to establish a sovereign nation state. It is true that many an oppressed nationality in the world chose to form independent states of their own to escape feudal or colonial domination and subjugation. But it is also equally true that in their own interest quite a few nationalities across the globe voluntarily came together to form federations and at times accepted to become a part of bigger nations. Even in mainland India, we come across several nationalities which joined the Indian Union on their own volition and sought autonomy within the federal set-up to protect their culture, language and other interests. In the nationalist discourse, one often fails to acknowledge that such nationalities have also exercised the right to self-determination as much as the ones who chose to secede and form independent states. History shows that the principle of self-determination of nations took varied forms in different countries, and seeking sovereign status is only one form of assertion of right to self-determination (Srikanth 2005: 20-8).

As an emerging nationality, the Nagas have the right to selfdetermination. But a problem arises when the right to self-determination is identified as something synonymous with political independence. It is true that the Naga militants have always insisted on independence from the Indian Union, and its non-compromising stand on the issue of sovereignty resulted in the failure of peace negotiations in 1960s and led to splits in NNC. The fear of compromise on the question of sovereignty caused a split even in NSCN. But this militant position is not shared by all Nagas. Back in the 1950s there were moderates among the Nagas who were ready to join the Indian Union, provided India assured them of considerable autonomy. The Sixteen Point agreement of 1960, which led to the birth of Nagaland, could not have materialized without the support of some sections of the Nagas. The years of forced or voluntary association with the Indian state did create certain classes and groups of people among the Nagas who are 
quite comfortable being a part of India. The militants may brand them as traitors, but the fact of the matter is that there are quite a few Nagas who do not share the militants' view that the Nagas have a better future if only they secede from the Indian Union.

It is also necessary to acknowledge that the response of Naga tribes to the militant Naga movement is not uniform. While anti-Indian feelings are indeed strong among those Naga communities, which suffered considerably due to anti-insurgency operations, the Nagas living in Assam and Arunachal Pradesh do not appear to be so keen on the demand for a sovereign Nagalim. It appears that even the NSCN (IM) leaders realize that in any future arrangements the Nagas cannot totally remain independent of India. However, it needs to be seen whether NSCN (IM) would be able to communicate and convince the Nagas who are under the influence of other Naga insurgent groups about the need to be pragmatic in their demand for sovereignty. The civilian protest in Dimapur, Kohima, Makokchung, Zunheboto and Wokha against the extortion by the militants (The Telegraph 8 May 2014) and the growing demand for Eastern Nagaland (Sangtam 2011) shows that the whole of the Naga militants is gradually diminishing. Hence they need to negotiate an amicable agreement with the Indian government in their own interest.

\section{Role of the Indian state}

Following the retreat of socialist movement and anti-colonial struggles in recent decades, today there are remote possibilities of Nagas achieving independence through armed rebellion. Withdrawal of material and moral support by the big powers has considerably affected the insurgent outfits. In the changed international context, the insurgent movements are compelled to negotiate with their respective states to find solution through other means. The NSCN (IM) has only responded to the needs of the time when it chose to accept ceasefire and started negotiations with the Indian state. At this juncture, what form the Naga national movement takes in future depends considerably on what the Indian state chooses to do or fails to do.

The Look East (now the Act East) Policy pursued by the Indian government compels the policy makers in India to explore the ways and means to restore peace in the region. India has thus reasons and compulsions to engage the Naga insurgent groups in peace talks and seek early solution to the Naga problem. Having said this, it is necessary to acknowledge that despite its own compulsions to seek peace, the Indian state may find it difficult to concede to the demands of the 
Naga national movement. Although the hill areas inhabited by the Nagas have no economic relevance for India, the Indian state cannot afford to grant independence to the Nagas because of political and strategic considerations. Similarly, the Indian government will not be able take any decision to integrate all the Naga-inhabited areas in the Northeast without the consent of the people and governments of the affected neighbouring states.

\section{Conclusion}

Militant tribal movements are not new to India. Many a tribal community in the mainland India waged heroic struggles against the landlords and the British government. But the Naga struggle is unique in the sense that it is the first organized resistance movement against the post-colonial Indian state with the aim of establishing an independent nation state of their own and struggled for over five decades facing all odds and obstacles.

The structural changes that took place in the region over the years did facilitate interactions among different Naga tribes and brought them together as an ethnic community. Common struggle that they waged did help in transforming the Naga tribes living in different parts of the Northeast and speaking diverse languages into a distinct nationality. No doubt inter-tribal and inter-group rivalries obstruct the pace of development of the Naga nationality. But the existence of the Naga nationality is no more in doubt. What really concerns us today is the consequences of the nature and development of Naga nationalism.

The ethnic nature of Naga nationalism has come to pose a serious challenge to India's idea of a multi-nationality nation. Yet there is no way that the Naga national movement achieves its objectives without negotiating simultaneously with the Indian state and with the neighbouring nationalities upholding the idea of civic nationalism. In the given situation, what would be the future of Naga nationalism depends on how the Indian government and the Naga leadership handles opposing concerns and competing interests in the region, and finds a solution that is acceptable to all parties which have stakes in the problem.

\section{Notes}

1 This is a revised version of the paper 'Challenges and Predicaments of Naga Nationalism', Eastern Quarterly, 3(4): 262-74, 2006.

2 See the Constitution of Naga National Council (NNC) and also Phizo's address on the eve of the plebiscite organized by NNC. 
3 For understanding the relationship between civic and ethnic nationalism, refer to Ignatieff (1993), Nikolas (1999) and Brown (2010).

4 For understanding these complex and competing processes of civic and ethnic nationalisms in Assam and Manipur, refer to Bora (1991), Misra (1982: 899-900), Guha (1977), Oinam (2003), Akoijam (2001) and Nag (2002).

\section{References}

Akoijam, A. Bimol. 2001. 'Manipur: How History Repeats Itself', Economic and Political Weekly, 36(30), 28 July.

All India People's Resistance Forum. 1996. Symphony of Freedom: Papers on Nationality Question. Hyderabad: All India Peoples Resistance Forum.

Anderson, Benedict. 1991. Imagined Communities: Reflection on the Origin and Spread of Nationalism. London: Verso.

Andhra Pradesh Radical Students Union. 1982. Nationality Question in India: Seminar Papers. Hyderabad: Andhra Pradesh Radical Students Union.

Baruah, Sanjib (ed.). 2010. Ethnonationalism in India: A Reader. New Delhi: Oxford University Press.

Berghe, Pierre L. van den. 2005. 'Ethnies and Nations: Genealogy Indeed', in Atsuko Ichijo and Gordana Uzelac (eds.), When Is the Nation: Towards an Understanding of Theories of Nationalism. London: Routledge.

Bhabha, Homi K. 1990. Nation and Narration. London: Routledge.

Bora, Phani. 1991. 'Development and National Question in North Eastern Region', in Girin Phukan (ed.), Nation Building and Development in Northeast India. Guwahati: Purbanchal Prakash.

Brown, David. 2010. Contemporary Nationalism: Civic, Ethnocultural and Multicultural Politics. London and New York: Routledge.

Chakrabarty, Dipesh. 2007. Provincializing Europe: Postcolonial Thought and Historical Difference. Princeton: Princeton University Press.

Connor, Walker. 1994. Ethnonationalism: The Quest for Understanding. Princeton, NJ: Princeton University Press.

Eriksen, Thomas Hylland. 2002. Ethnicity and Nationalism: Anthropological Perspectives. London: Pluto Press.

Gellner, E. 1981. 'Nationalism', Theory and Society, 10(6), November.

GPRN. 1995. The Shepoumaramth in the Naga National Movement. Shepoumaramth Region.

Grosby, Steven. 2005. 'The Primordial, Kinship and Nationality', in Atsuko Ichijo and Gordana Uzelac (eds.), When Is the Nation: Towards an Understand of Theories of Nationalism. London: Routledge.

Guha, Amalendu. 1977. Planter Raj to Swaraj: Freedom Struggle and Electoral Politics in Assam, 1896-1947. New Delhi: ICHR.

Handique, Maitreyee. 2015. 'Nagaland: Post Accord, a Revolt Rises East of the Sun', The Quint. www.thequint.com/opinion/2015/09/21/nagaland-postaccord-a-revolt-rises-east-of-the-sun

Ignatieff, Michael. 1993. Blood and Belonging: Journeys into the New Nationalism. New York: Farrar, Strauss and Giroux. 
Jacob, T. G. (ed.). 1988. Nationality Question in India: CPI Documents 1942-47. New Delhi: Odyssey.

Jacobs, Julian. 1990. The Nagas: Society, Culture and Colonial Encounter. London: Thames and Hudson.

Lenin, V. I. 1986 reprint. On National Liberation and Social Emancipation. Moscow: Progress Publishers.

Lenin, V. I. n.d. Collected Works, Vol. 20. Moscow: Progress Publishers.

Mackenzie, A. 1994. The Northeast Frontier of India. New Delhi: Mittal Publications.

Marx, Karl and Friedrich Engels. 1974 reprint. The Communist Manifesto. Moscow: Progress Publishers.

Misra, Udayon. 1982. 'Culture and Politics: Asom Sahitya Sabha', Economic and Political Weekly, 17(22), 29 May.

Misra, Udayon. 2003. 'Naga Peace Talks: High Hopes and Hard Realities', Economic and Political Weekly, 15 February.

Nag, Sajal. 2002. Contesting Marginality: Ethnicity, Insurgency and SubNationalism in Northeast India. New Delhi: Manohar.

Nikolas, Margareta Mary. 1999. 'False Opposites in Nationalism: An Examination of the Dichotomy of Civic Nationalism and Ethnic Nationalism in Modern Europe', 11 March. www.nationalismproject.org/articles/nikolas/ title.html

Nuh, V. K. (ed.). 2002. The Naga Chronicle. New Delhi: Regency Publications. Oinam, Bhagat. 2003. 'Patterns of Ethnic Conflict in the North-East', Economic and Political Weekly, 38(21), 24 May.

Oinam, Bhagat. 2005. 'Dynamics of Ethnic Conflict in Manipur', in Monirul Hussain (ed.), Coming Out of Violence: Essays on Ethnicity, Conflict Resolution and Peace Process in Northeast India. New Delhi: Regency Publications.

Reed, David. 2014. 'Scottish Independence and Civic Nationalism', The Guardian, 23 April. www.theguardian.com/politics/2014/apr/23/scottishindependence-civic-nationalism

Rex, John. 1996. 'National Identity in the Democratic Multi-Cultural State', Sociological Research Online, 1(2).

Sangtam, Yanglikhum. 2011. 'Why ENPO Demands Drontier Nagaland', The Morung Express, 30 January. http://morungexpress.com/why-enpo-demandsfrontier-nagaland/

Sema, Piketo. 1991. British Policy and Administration in Nagaland 18811947. New Delhi: Scholars Publishing House.

Smith, Anthony D. 1999. Myths and Memories of the Nation. Oxford: Oxford University Press.

Smith, Anthony D. 2009. Ethno-Symbolism and Nationalism: A Cultural Approach. London: Routledge.

Srikanth, H. 1991. 'Nationality Question in India: A Critique of Traditional Indian Marxist Interpretations', Teaching Politics, 17(3\&4).

Srikanth, H. 2005. 'Insurgency and Counter-Insurgency: Agenda for Peace in India's Northeast', in C. Joshua Thomas (ed.), Polity and Economy: Agenda for India's Northeast. New Delhi: Regency Publications. 


\section{H. Srikanth and C. J. Thomas}

Srikanth, H. and C. J. Thomas. 2005. 'Naga Resistance Movement and the Peace Process in Northeast India', Peace and Democracy in South Asia, 1(2). Stalin, Joseph. 1913. Marxism and the National Question. www.marxists.org/ reference/archive/stalin/works/1913/03a.htm

TDSS. 1987. Nationality Question in India. Pune: Training for Development Scholarship Society.

The Telegraph (Northeast Edition), 8 May 2014. www.telegraphindia.com/ 1140508/jsp/northeast/story_18317106.jsp\#.VwZ2Efl97IU 


\section{Narrating the nation in Manipur}

\section{Reproduction of a historical question $^{1}$}

\section{A. Noni Meetei}

\section{The context}

Post-colonial validation of India and invalidation of the same by dissenting Manipuri nationalism raises some pertinent questions, such as how a nation is reproduced as a tool of dominance and how this politics generate an antithetical historical consciousness vis-à-vis the tendencies of dominance. The anxiety of implanting an Indian nation, however, finds itself in a relational confrontation with several realities of nationalisms that had its own energies of dissenting what they generally prefer to level as 'alien' encroachments. Narrating the nationality question of Manipur reflects a similar case in point. An inherent character of an evolving modern Indian self was its constant struggle to consolidate a politics that ironically failed to come out of the confines of an over-anxious attempt to enforce a linear historiography of its nationhood. As a result, the nationalist project of assembling a larger nationalized territoriality in India made it imminent to resort to a selective amnesia. The amnesia strategically helped in overrunning realities and memories of differences that finally propelled the nationalists to deny the autonomy of historically significant polities. Significant polities, on the other hand, continue to move on to consolidate its autonomy, simultaneity and historicity. ${ }^{2}$ The historical national aspirants in its dissenting form continue to raise questions over the nature of nation states in the post-European imperial era.

The chapter enquires into the imageries of nationalizing the state in India on the one hand, and narrates how Manipur gradually emerged to constitute into a nationality particularly marked by an advanced democratic experimentation and absorption on the other. The seeding of national imageries in multiple forms also underscored prospect of confrontations amongst forms and contents of nationalisms. Such is the relational nature of national India and the form of Manipuri nationality. The interface between the historically simultaneous and 
often largely non-intersecting polities in the subsequent encounters gets reduced to a hierarchized relationship - dominant and dissenting. The contestation between the two raises a politics that generates an antithetical historical consciousness, which remains insolvent against the tendency of producing nation as a tool of dominance. A constant questioning and reference to such dominant nationalist construct becomes one of the most fertile grounds where the 'nationalist worldview' of the 'dissenting nationalisms' are being played out.

The form of 'nationalist worldview' is employed here in an attempt to grapple with the dynamics of nationalist projects which generally struggle to overcome discomfort of the constituents. Such a burden is not only typical of the dominant nationalists' projects but also of the dissenting nationalisms when it collapses to the idioms and language of the dominant. Probing into this aspect of nationalism in Manipur can reveal the dynamics of nationality politics and nature of its reproductions.

\section{Reproduction of a historical time}

An undeniable character of historically moot question is its ability to reproduce itself at any given point of time. Here, the historical time is treated as a companion of modernity that insulates socio-economic, cultural and political identities which embarked upon the idea that the political end and the national unit should be congruent (Gellner 1987: 1 ) and founded on the basis of a communion. The form of 'national Manipur' is posed through its historical investments made towards a territoriality and a kingdom (state) and a nation. The investment towards a Manipuri self is spaced as an associate precondition of becoming an independent (nation) state. The Manipuri narrative is reasoned against certain historical experiences of denial and coercion that trickled down from the hegemonic spacing created by the Indian nationalist project. It is this experience of denial and coercion that marked a historical moment of contestation in Manipur resulting in a reproduction of a dissenting nationalism. A constant reproduction of the historical time has been further aggravated by contemporary experiences of being oppressed, parasitic, decline of its self-reliance and growing internalization of inter-community relations.

The 'national' of Manipur seem to render energies of its own historicity rather than a mere stepping into the shoes of post-enlightenment European model which Partha Chatterjee calls a 'derivative discourse', whereby the nationalisms in the non-Western (Third World) societies operate more as a copy of European post-enlightenment discourse 
(Chatterjee 1993: 42) searching for its most modern sense of collective political self. However, there is some truth in claim that the newly contrived European nation-ness successfully transplanted itself to a variety of desperate terrains. The cumulative historical congregation towards a 'nation' proved an invention impossible to patent (Anderson 1991: 67), which resulted in the 'nationalist standardization' of the idea of India. As the premise of nationalism in India dominantly cast a centrist and rightist form, it indispensably objectified a will of 'creating national ceremonies, language of official communication and symbols' (Tamir 1998: 102) and so forth. The monologue of the postcolonial Indian state discourse of elevating the differences of identities to a common subjecthood within a hegemonic space is a source of dissent, resistance and protest from the margins (Swain 1996: 83). The monologue resulted in the production of dominant national suspicion which is best exemplified by the letter written by Sardar Vallabhbhai Patel, India's first home minister, to Jawaharlal Nehru in 1950 during the incorporation of the Northeast region, which reads in part:

Our northern or northeastern approaches consist of Nepal, Bhutan, Sikkim, Darjeeling and Tribal Areas of Assam. From the point of view of communication they are weak spots.... The contact of these areas with us is by no means close and intimate. The people inhabiting these portions have no established loyalty or devotion to India. Even Darjeeling and Kalimpong areas are not free from pro mongoloid prejudices.

(Subba 1996: 97)

From the above passage, it is obvious that the production of India in the Northeast amplifies a historical absence in the region whose 'official nationalism' inherits its form and content from the fallen region, the British Empire, whose presence was marked by deficiency of legitimacy.

\section{Absence, denial and nationhood}

Manipur represents a theatre of a 'national' dialectics that was played out immediately along with the departure of the British colonialism in the form of combination of binary relations. For example, the resistance of the prince(s) to the idea of joining Indian dominion coexisted with the demand for a responsible government. Another binary relation is the emergence of a political class favouring the idea of a united India challenged by a contesting mobilization for independence 
or autonomy or restoration of pre-British India status. These companion leanings were detrimental to various historical complexities. The desire of mass politics to remain as independent and autonomous dies in its embryonic form for three reasons. First, the Indian response disallowed any prolongation of princely state resistance and representation. To cite an example, responding to a letter written by the Maharaja of Manipur on 14 May 1947 asking for separate representation for Manipur in the Constituent Assembly on the basis of 'peculiar geographical and topographical' considerations, Jawaharlal Nehru (256) replied:

I think your suggestion . . . has some force . . ., unfortunately we have to function within the limits of certain rules laid down for us. These rules are based chiefly on population ... the Negotiating Committee had not done so [to include Manipur in the Constituent Assembly].

The response of Jawaharlal Nehru signified the limited choices and representation that the Indian state had allowed to its supposedly constitutive parts at the outset of its national imagining. In contrast, the Maharaja of Manipur was ceding ground to the democratic stirrings of an increasingly assertive political mass by convening an Interim Council consisting of four officials, one representative of the maharaja and five non-official representatives of the hills and the valley. The council drafted the Manipur State Constitution Act of 1947 (Sarin 1998: 112). In 1948, Manipur became an independent constitutional monarchy with a legislative assembly consisting of fifty-three members including eighteen from the hill areas. The question of Manipur's integration with India was one main issue in this election. The Manipur state Congress Unit formed in 1946 as an extension of the Indian National Congress (INC), which had advocated integration could manage to win only thirteen out of fifty-three seats in the 1948 elections (Joykumar Singh 1995: 108). The following months had, in fact, indicated much sharper perspectives on the integration as well as a larger political consolidation of mass polity in Manipur. On 18 September 1948, a large public meeting was held in which all the leaders of both hills and plains strongly opposed the proposal of State Congress Party (Joykumar Singh 1995). The representatives of Tangkhul Long, Kuki National Assembly, Kabui Association, Khul Union, Mizo Union and Praja Samiti, Manipur Krishak Sabha, Meitei Marup and Nongpok Apunba Marup had a joint meeting at MDU Hall, Imphal, in November 1947. The meeting resolved to constitute a front called 
United Front of Manipur under the leadership of H. Irabot Singh. The United Front fought for a responsible government and non-merger of Manipur (Dena 1995: 113).

The assertive mass polity surfaced in opposition to significant moments that evolved in the aftermath of 1947, when Manipur became a pioneering state to hold an independent election based on adult franchise in 1948 (Narahari 2002: 153) in the Asiatic region. The celebration of democracy proved to be short-lived, for in 1949 V. P. Menon, a senior representative of the Government of India, invited the King of Manipur to a meeting in Shillong on the pretext of discussing the deteriorating law and order situation in Manipur. Consequently, the king was allegedly made to sign the merger agreement 'under duress' (Nag 2002: 204) on 21 September 1949 at Shillong. The letters written by the maharaja while he was under house arrest in Shillong reflects what actually happened in the making of India. One of the letters written by the titular king, dated 18 September 1949, reads:

now that the sovereignty of the State has been vested in the people, it would be in the fitness of things to hear the people's voice and learn their sentiments so that the line of action may not in any case be unconstitutional. ${ }^{3}$

The maharaja further wrote:

I consider that I have a guardian in the person of your Excellency who guides and helps me in my endeavour towards ameliorating the welfare of my people. The only thing is that this being a great change it should be done constitutionally and democratically with an eye to the will of the people whose co-operation I confidently hope we will secure.

(Nag 2002: 110)

It was in response to this discomfort of the raja that the Government of India asked the then governor of Assam, Sri Prakasha, 'whether he (the Governor) did not a have a Brigadier in Shillong' (Rustomji 1973: 109). The nature of integration marks the point that the nonconsented consensus authored in Shillong marked the entry point of independent India into Manipur; but the dubious processes employed left a question mark on the legitimacy of the very presence. The Indian nationalists' way of authoring its national dominant self in Manipur replicated a Machiavellian way that celebrated brutalizing of democratic aspirations. In the words of Sanjib Baruah, the process of Indian 
integration began with an 'authoritarian accent' (Baruah 2001: 12), thereby producing a historical time.

\section{Expansionism and alterations}

Soon after it suffered the negation of its constitutional status in Shillong, Manipur yet again became a victim of the emerging expansionism and scramble frontier security amongst Asian powers. India and Burma haggled over Kabaw valley, India and East Pakistan over Chittagong Hill Tracts, and India and China over the North-East Frontier Agency (NEFA), present-day Arunachal Pradesh. The competing expansionism produced wider political implications for Manipur and its territoriality. As a result, Kabaw valley was handed over to Burma. Further humiliation was in store for Manipur as on 26 January 1950, with the enactment of the Constitution of India, Manipur was downgraded to a Part ' $\mathrm{C}$ ' state. Subsequently, the Part 'C' States (Laws) Act was replaced by the Union Territories Act in 1956, and Manipur became a union territory, much against the popular wish. The sharpest opposition came from the movement led by the communist leader, Hijam Irabot. Along with Hijam Irabot's nationalist peasant mobilizations, the demand for a responsible government and full statehood came from many quarters. Irabot's wholesome object was to launch a revolutionary movement in the Northeastern region of today's India and Manipur in particular with an aim of establishing an 'independent peasant republic'. ${ }^{4}$ The ideological mooring of communism in Manipur as a response to the question of 'merger' widely opened the debates on the political status of Manipur. The debate paved the way for stronger nationalist narration and subsequent armed struggles. The history of armed struggle in Manipur dates back to the transition times of 1947 when the European imperialism formally began to recede (Naorem 1988: 246). However, the actual legacy of a radicalized struggle became possible only with the ever-growing politicization of the masses with the formation of Nikhil Manipur Mahasabha in the 1930s. The Mahasabha came to play the role of crucial political platform for consolidation of mass polity in Manipur and even went on to generate grounds for garnering diaspora solidarity.

\section{The continuity}

The communist movement in Manipur was a strategic companion of a national liberation project in South Asia (also in Myanmar) that was shaped during the anti-colonial struggle of the twentieth century. Hijam 
Irabot's armed resistance bore intense correspondence to insurgency movements in Myanmar for secession like that of the Shan, Karen, Kachin and so forth. In the footprints of the communist legacy, several party politics emerged in Manipur. The All Manipur National Union, led by Yangmasho Saiza and Sogalsem Indramani, took up the question of 'merger' in the late 1950s and early 1960s, while reposing the historicity of Manipur's political status. A speedy renewal of a new phase of armed resistance began in Manipur with the objective of 'liberating' Manipur from India. The formation of the United National Liberation Front of Manipur (UNLF) in November 1964 deepened the issues concerning Manipur-India conflict (Mangang 1997: 53). The UNLF in the first phase of its mobilization manifested itself in an unarmed mass campaign. On the other hand, there were other activists like Oinam Sudhir Kumar and Nameirakpam Bisheshwor, who believed in the immediate launch of an armed struggle (Mangang 1997). This led to irreconcilable differences within the organization and shift in the 'liberation' movement in Manipur. As a result, the Sudhir Kumar faction formed the Consolidation Committee of Manipur (CONSOCOM) (Phanjoubam 1996: 59) in 1968, which subsequently led to the formation of Revolutionary Government of Manipur (RGM). On the other hand, the Pan Manipur Youth League joined the Manipuri nationalistic mobilizations on 28 December 1968 and started its campaigns through its journals called Lamyanba and Resistance.

The main focus of the Pan Manipur was to generate mass consciousness and awakening issues such as corruption, freedom and territorial integrity of Manipur (Constantine 1981: 89-90). The foregoing details are an attempt to map out the ideological moorings and the objective conditions of armed trajectories as dissenting nationalisms and to locate the competitive dynamics within the dissenting nationalisms. I propose to situate the shifts in the nature of dissenting nationalisms whereby the communities have become apparently competitive and non-communicative units of polity.

\section{Statehood, rebounds and trajectories}

Two different sub-strands of consciousness entered into the politics of the 1960s with the historic Chaklam Khongchat (Hunger Marchers' Day $)^{5}$ in 1965 on one hand, and the continuing demand for statehood on the other hand. In 1972 Manipur attained statehood, which was followed by the declaration of amnesty for the armed rebels. The delayed statehood to Manipur gave rise to a popular perception that it was violence and 'secessionist' manifestations that brought statehood 
to Manipur. The amnesty led to the surrendering of many insurgents which was perceived by the state as a crucial way to end the armed dissent. Ironically, statehood to Manipur failed to wean away dissenting nationalist formations in Manipur from the armed path. Throughout 1970s, armed organizations mushroomed with objectives to restore 'pre-merger' independent status of Manipur. The post-statehood period saw an intensified phase of armed dissent and splits within. Nameirakpam Bisheswor, who founded the People's Liberation Army (PLA) in 1978 with nineteen other associates, brought a new ideological leavening to the armed dissents in Manipur. The main ideology, in its wider connotations, stressed on democratic centralism and liberating India, especially the working classes, who are considered allies in the final analysis (Gopalkrishnan 1995: 82).

The communist ideological leanings of PLA focused on the exploitation of Manipur and conversion of the Northeast into a 'captive market'. At the same time, it also argues its struggle as something strongly antithetical to the capitalist mode of production. The communist ideological mooring of PLA can be seen in the context of the political traditions left by revolutionary Hijam Irabot. The Manipuri nationalists' formation grew more vocal along with the formation of new revolutionary organizations. The People's Revoultionary Party of Kangleipak (PREPAK) was formed on 9 October 1977 and the erstwhile Meitei State Committee (formed in 1967) was transformed into the Kangleipak Communist Party (KCP) on 20 August 1979, raising similar trajectories of political mobilization for independence. ${ }^{6}$ Much later, another organization called Kanglei Yayol Kanna Lup (KYKL) was formed in mid-1994. The mushrooming mobilization, though confined to the valley area, is premised on the image of organic 'wholeness'.

Over the past decades, the historicity of the dissenting Manipuri national self has, however, found strange bedfellows in opposing trajectories and competing identities. Emergence of 'competing identities' ${ }^{7}$ within the Manipuri national site indicates an emerging contradiction that requires a constant engagement for the nationality question. The emergence of identities in Manipur seeks to supplant the non-exclusive spaces inherent in a collective political imagination. The case for this argument is best seen in the inter-community positioning which has veered towards erecting 'hardened boundaries' reinforced by playing upon suspicion and perceived grudges. Both the erection of these 'hardened boundaries' and the mushrooming of armed formations and fragmentation of social movements in Manipur are a recent phenomenon which is inimical towards the fusion of a Manipuri self.

The causal aspects of increasing fragmentation on the identitarian trajectories are founded on varying grounds. In the context of Manipur, 
some have emerged due to inter-ethnic conflicts as protective community forces demanding 'safer' exclusive homelands. Some validate themselves on a transcendent projection of enmity against a community, and some a hegemonic pursuit of nationhood over the others on grounds of culture and historicity. However, both display and harp upon an arrogant immunity to the 'wholesome' nationalist imageries. The first equation has been seen in the case of Zomi Revolutionary Organisation (ZRO) that emerged in the wake of escalating ethnic violence between the Kukis and Paites in the Churachandpur district of Manipur. The second equation is a recent tendency among the struggling peoples once consolidated under the roof of a common historical experience. Transcendence has occurred resulting in the shift of the very language of authoring the dissenting nationals. The case of National Socialist Council of Nagaland - Issac-Muivah (NSCN-IM) and its project of 'Greater Nagaland' that crosses the territoriality of many neighbouring states exemplify the shift and its relationships. The shift has become a critical proposition in Manipur as it appears to have constructed closed meanings of historicity and thereby failing to identify a common historical antagonist. The equations for imagining a self is played out often in absurd pantomime as the communities and identities seek to arrogate a 'national self', producing the wildest dreams of a 'nation' on exclusive terms. The Northeast has seen enough of these exclusivities sliding into blind alleys of 'quite notices', ethnic cleansing, impositions of majoritarian symbols and sentiments as state holidays and pitting territorialities against each other over issues belonging to federal jurisdictions and so forth. The complex imagining of a 'national self' on exclusive terms in Manipur is the site of a failed collective amongst historically interdependent communities and lived experiences of our times.

In the light of such a complex web, it is a challenge on the part of Manipuri dissenting self whether it is potentially capable of locating itself beyond such perennial infection of exclusivity, which is the precondition for a common ideological mooring. A further explication of the above proposition can be best seen in the context of present-day Manipuri dissenting nationalists' search for its selfhood, where each ethnic community invests more of its political capital on constructing fragile boundaries that disowns the nationalist worldviews of a collectivized Manipur. Historically, the armed nationalists' formation in the Northeast region began along a common trajectory. But in the late 1980s, sharp fissures were noticed with the growing factionalism and regrouping of armed organizations which, at the Northeast level, did not have representation of all the groups.

The late 1970s and early 1980s witnessed an increase in the armed struggle with the regrouping of several armed parties. It was during 


\section{A. Noni Meetei}

this time that the valley areas of Manipur had been tagged as a disturbed area, which paved the way for invoking the Armed Forces (Special Powers) Act 1958 (AFSPA) in September 1980. The enforcement of AFSPA marked the beginning of a new era in the history of counterinsurgency measures followed by India's diminishing respect for human rights. The insurgency, however, re-emerged in force towards the end of the 1980s. In an important development, the PLA reorganized itself and formed a political wing called the Revolutionary People's Front (RPF) in 1989 and established a government-in-exile. Attempts to float a common platform for armed revolutionary parties in the region had been made at several stages. The armed parties prefer to identify themselves as a region belonging to Western South East Asia (WESEA) rather than being identified as Northeast to subcontinental South Asian regional identity of India. For instance, mention can be made of the regrouping of armed parties in the likes of Indo-Burma Revolutionary Front (IBRF) on 22 May 1990 consisting of United National Liberation Front (UNLF), United Liberation Front of Asom (ULFA) and National Socialist Council of Nagaland led by SS Khaplang or the NSCN (K) and Kuki National Army (KNA) (Sinha 2007: 116). IBRF was established with an objective to consolidate a pro-mongoloid solidarity and 'to build a united struggle for the independence of IndoMyanmar'. There have been many more such attempts to forge unified platforms for armed groups such as Manipur People's Liberation Front and Co-ordination Committee of several armed parties belonging to Manipur, popularly known by its acronym CorCom.

\section{The future ahead}

It can be said that the features of nationalists spacing is played around a continuing confrontation between the dominant nationalists' enforcements and historical contenders for nations. Nationalization of territorial units in modern times has been commonplace with the receding of European imperialism and democratization of societies in the nonEuropean world, as nations cannot remain a collective space sans opportunities of options. Options exemplify the scope of legitimacy thereby ensuring a liberating core to the ideas of political associations. When such pre-conditions are overridden, a nation becomes the site of prolonged dissent to its own self. The contradiction between Manipur and the process of constituting India is also the result of such a denied historical process. As said above, it can be concluded that similar contradictions would emerge in Manipur if the spacing of the Manipur self, consciously or sub-consciously, is premised on the hegemonic tendencies as an associate force of its validation. The historical dialectics 
between the dominant and its contesting versions occupies a centrality in the lives of contemporary 'nation states'. The contemporary realm of nationalist space at both the levels, 'centre' and 'periphery', remains fragile due to the pursuit of all identities to operate its collectivity only through a nationalized space. It remains to be seen whether the dissenting nationalism is able to rebuild and reinvent its historical resources with the intimations of elements and motifs compatible with a meaningful collectivization of its national rationality. Collectivized national rationality could perhaps preempt internally insulated competitiveness amongst peoples who otherwise share similar historicity of being interdependent and commonality of economic and social lineages.

\section{Notes}

1 This is a revised version of the paper titled 'Multiple Nationalisms in Manipur: A Historical Time and Its Reproduction', Eastern Quarterly, 3(4): 240-50, 2006.

2 The nature of nationalist narratives in Manipur and elsewhere is largely premised on the ground that they (historically) were never 'part' (or 'similar') of the idea of India in terms of culture, look and territoriality. Thus, the narration of having been an independent kingdom state and preceding India in terms of constitutional enactment in 1947 and first election in the region in 1948 are all what can be called simultaneity of history.

3 Resistance, 25 September 1975, Imphal.

4 See Boro (1981: 15). Cited in Kshetri Rajendra Singh, 'Social Movements in Manipur: A Study of Two Movements among the Meitheis', unpublished $\mathrm{PhD}$ thesis, Manipur University, undated, p. 41.

5 In 1965 students were in arms against the government in Manipur. There was a repeat of the infamous 1939 incident, more popularly known as Nupi Lan, artificial shortages of food grains in Manipur. The students led a demonstration demanding 'we are starving, give us rice'. During the rally four students were killed on 27 August 1965 in police firing. The All Manipur Students' Union commemorates the incident as Chaklam Khongchat (Hunger Marcher's Day) every year till date.

6 A Report on Special Convention of Kangleipak Communist Party, 13 August 1994.

7 'Competing identities' can be defined as those identities that have undergone a process through which certain consciousnesses are created defining the nature of relationship that it has to maintain vis-à-vis the other ethnic/ community/nationality and so forth.

\section{References}

Anderson, B. 1991. Imagined Communities: Reflections on the Origin and Spread of Nationalism. London: Verso.

Baruah, Sanjib. 2001. 'General as the Parallel Political System', HIMAL, 14(6), June. 
Boro, Th. 1981. 'Manipurda Communist Party Amasung Khutlai Paiba Lalhou', in Neengshing Chephong - 85th Anniversary of Irabot Commemorative Publications (in Manipuri). Imphal: Irabot Bhawan.

Chatterjee, Partha. 1993. Nationalist Thought and the Colonial World: A Derivative Discourse, 2nd edn. London: Zed Books.

Constantine, R. 1981 reprint. Manipur: Maid of Mountains. New Delhi: Mittal Publications.

Dena, Lal. 1995. Annexation of Manipur 1949. Imphal: PDM.

Gellner, Ernest. 1987. Nations and Nationalism. New York: Cornell University Press.

Gopalkrishnan, R. 1995. Insurgent North Eastern Region of India. New Delhi: Vikas Publishing House.

Joykumar Singh, N. 1995. 'The Merger of Manipur into India and the Manipur State Congress', in Annexation of Manipur 1949. Imphal: People's Democratic Movement.

Mangang, Paonam Labango. 1997. Kangleipakta Revolution (in Manipuri). Imphal.

Nag, Sajal. 2002. Contesting Marginality: Ethnicity, Insurgency and Subnationalism in North-East India. New Delhi: Manohar.

Naorem, Sanajoaba. 1988. 'The Genesis of Insurgency', in Naorem Sanajaoba (ed.), Manipur: Past and Present, Vol. 1. New Delhi: Mittal Publications.

Narahari, N. S. 2002. Security Threats to Northeast India: Socio-Ethnic Tensions. New Delhi: Manas.

Nehru, Jawaharlal. Undated. Selected Works, Second Series, Vol. 2. New Delhi: Jawaharlal Nehru Memorial Fund.

Phanjoubam, Tarapot. 1996. Insurgency Movement in the North Eastern India. New Delhi: Vikas Publishing House.

Rajendra Singh, Kshetri. Undated. 'Social Movements in Manipur: A Study of Two Movements among the Meitheis'. Unpublished Ph.D. thesis, Manipur University.

Rustomji, Nari. 1973. The Enchanted Frontiers. New Delhi: Oxford University Press.

Sarin, V.I.K. 1998. India's Northeast in Flames. New Delhi: Vikas.

Sinha, S. P. 2007. Lost Opportunities: 50 Years of Insurgency in Northeast and India's Response. New Delhi: Lancer Publishers and Distributors.

Subba, T. B. 1996. 'Ethnicity, Culture and Nationalism in North-East: A Conspectus', in M. M. Agrawal (ed.), Ethnicity, Culture and Nationalism in North-East India. New Delhi: Indus.

Swain, Nirmal Kumar. 1996. 'The Post-Colonial Indian State', in M. M. Agrawal (ed.), Ethnicity, Culture and Nationalism in North-East India. New Delhi: Indus.

Tamir, Yael. 1998. 'Minority Culture and the Nation-State', in Gurpreet Mahajan (ed.), Democracy, Difference and Social Justice. New Delhi: Oxford University Press. 


\section{Part IV}

\section{Land and territoriality}


$\because$ Taylor \& Francis

http://taylorandfrancis.com 


\title{
8 Land and ethnicity \\ A study of Manipur and its neighbourhood ${ }^{1}$
}

\author{
Lokendra Arambam
}

The month of June 2007, at Moreh, about 120 miles to the southeast of Imphal at the international border adjoining Myanmar, marked yet another rupture in the chequered history of pluralism in Manipur. For the first time, two ethnic communities - the Meitei and Kuki who shared an age-old history of friendship and amity were locked in armed violence. Eleven people were killed during those events. Moreh, incidentally, became a hyper-active centre of human activity since international trade and commerce had been formally opened between the Governments of India (GoI) and Myanmar in 1994-95. This small hill township has a diverse population including Tamils, Malayalees along with Manipur's ethnic indigenes, notably the Nagas, Kukis and Meiteis.

There had been political movements based on ethno-national ideologies. For example, the Nagas claimed the district of Tengnoupal, wherein Moreh was a major economic and political centre, as the ancestral domain of the Nagas. On the other side of the ideological spectrum, the Kuki ethnic communities, ranging from various clans of the indigenous variety to kith and kin from across the border in Myanmar, had been actively pursuing the political goal of Zale'n-gam, the abode of the Kukis, which include Moreh. A significant number of Meitei settled in Moreh completes the overall ethnic balance of this border town.

The incident at Moreh which nearly sparked off a communal bloodbath between the Meitei and Kuki communities had been assuaged temporarily through the combined efforts of various civil societies and the government. But the enmity between two militant outfits, the UNLF (United National Liberation Front) and the KNA/KNO (Kuki National Army/Kuki National Organization), which lies at the root of the incident, continued to simmer in the backdrop. The press releases of the two militant outfits remind us of conflictual perceptions on 


\section{Lokendra Arambam}

issues of land and territory. The KNO believed that the unfortunate events of 9 June 2007 at Moreh, in which eleven people died, were a direct consequence of UNLF's 'intrusive presence in Kuki territory', and urged 'the UNLF to confine their revolutionary activities, ideologically and physically, to the valley called Manipur, which had been their abode from time immemorial'. The UNLF, on the other hand, charged the KNA of targeting the Meitei people indiscriminately with the sole agenda of whipping up communal tension in Moreh. The UNLF also reiterated that it had nothing against the Kukis, but it would deal with the KNA/KNO firmly for allowing itself to be used as a weapon by the Indian Army against the liberation struggle and against the UNLF. Tussle between the two has been going on since 1990s (E-pao, 11 June 2007). Incidentally, the Naga civil society groups who support the implicit claims of the Naga ancestral domain which include Moreh proffered friendship to the Kuki community. Incidentally, the Nagas and Kukis were involved in a no-holds-barred mutual ethnic cleansing campaign in 1992-98, which began from the struggle to control Moreh and its economic underbelly.

\section{Naga lebensraum and the Meitei}

Since the late 1960s, the Naga ethno-national movement had been propagating integration of contiguous portions of Manipur, Assam and Arunachal Pradesh into Greater Nagalim. They also had been insinuating that the Meitei independence struggle against the Indian Union is that of and for the valley (consisting of some 700 square miles) alone. The KNA/KNO also claims that the Meitei independence struggle is of the Meiteis alone for the valley. The Meitei non-state actors in the valley, however, have a spatial imagination of their independence encompassing the organic topography of the hills and the valley along with ethnic populations as in pre-colonial times which gave formal shape and features to the polity of Manipur. Ethnic insurgencies in the Northeast in the course of their prolonged struggle against the powerful Indian state seem to be losing their original character of ethnic unity and harmony. It is hard to say whether the heightening tensions and sharper accentuation of social boundaries between/among these communities were caused by the internal dynamic of struggle for power and resources in conflictual growth processes, or that these relationships were being manipulated by exogenous factors like the counter-insurgent forces, or that these symptoms were the surface manifestation of internal intrigue and behind-the-scene manoeuvres of elite stakeholders in the identity project. 
The hardening perceptions of the divide between the 'we-self' and the 'other' are portents of latent social conflict. The formulation of separate entities and the spatial dichotomization of the imaginative geographies between the hills and plains in terms of ethnicity and ethnicization of social relations and networks are deeper issues afflicting the plural order in the era of insurgency. The politics of insurgency and counter-insurgency, variegated responses by the awakened ethnicities in the changing dynamics of life, and the development of selfconsciousness and subjectivity in ethnic formations in the emerging discourse on land and territoriality are matters of deep import.

How does the issue of land and territoriality then inflect the changing dimensions of ethnic strife? Or are these proclamations and media handouts reflections of the self-appropriation of people's voice in the subaltern margins of visibility by strident political elites in the stream of insurgent history? What is the reality behind insurgency and counterinsurgency which form conflicting discourses? A brief history of contemporary insurgency would throw light on the patterns of political and social violence afflicting ethnic relations in the state.

The assertion of Naga nationhood has 'legitimate' claims to territorialization of substantial portions of Northeast India's geography through claims of land-people relationship and concepts of the ancestral domain. Territoriality is not a simple occupation of a sizable piece of the earth's surface. Territoriality, according to Robert D. Sack,

is the attempt by an individual or group to affect, influence or control people, phenomena and relationships, by delimiting and asserting control over geographic area. ... It is not an instinct or drive, but rather a complex strategy . . . and the device through which people construct and maintain spatial organization.

(Winichakul 1994)

The Nagalim concept also features ardent pursuance of a geographic boundary, which is linear where vertical interfaces between 'state sovereignty' intersect the surface of the earth (Muir 2000). As vertical interfaces, boundaries have no horizontal extent. This modern concept of territorialization therefore is being processed as against the nonboundedness of the human geography of pre-colonial times.

In the words of Winnichakul, territoriality involves three basic human behaviours: a form of classification by area, a form of communication by boundary and an attempt at 'enforcing'. The third factor was what forced the use of aggressive spate of hate Meitei campaigns and various democratic agitations, economic blockades and all other 
forms to effect enforcement. The event of 18 June 2001 where eighteen valley people lost their lives was a result of such profound measures to officialize the enforcement. The NSCN (IM) stated over and over again that it does not believe in Manipur's integrity, that the present Manipur state is a temporary phenomenon, and that the NSCN (IM) is 'not greedy about land and will never take even an inch of Meitei's territory, nor will it part with what is theirs'. On the other hand, the Meitei national movement that surfaced in the valley of Manipur professed relations of respect and mutual support to the Naga insurgency in the late seventies and early eighties.

The Meitei concept of territoriality was also of a different cultural vintage. The hills and valleys, which constituted the geo-body of the pre-colonial nation state, were homologous with the body of a human organism. When the Meitei developed its polity in the eighteenth century, they had incorporated all the hills and plains as vital limbs of the human body that symbolized the geography of the land. Mythic beliefs were incorporated into their visions of land, people and cultures as an organic, moving national consciousness. The Meitei believed the hills of Koubru in the Northwestern sector as the head of the organism. The Lamphel marshes in the valley were regarded as the breasts. The Kangla (Imphal the Capital) was the navel of the organism, which gave intelligence and nourishment to the body. Loktak Lake in the Southwestern plains was regarded as the bowels and pelvic zone of the geo-body. The Imphal River at its rear-end and before it fell into the Chindwin in Myanmar was regarded as the rectum. The hills were the arms and legs of the organism.

The people of the highlands were brought into the body of the polity through a traditional concept of ritual sovereignty when the denizens of the hills were sensuously integrated into the pre-colonial polity as tribute-giving citizens. This ensured their right of occupancy of the hill regions at a small cost of ritual obedience to the state's annual contribution of the hills' produce as a token. It provided protection by the state of their internal autonomy and fundamental freedoms. They were never dispossessed of their lands in any period of the nation's history. The contrary was reported by the Nagas in their submission to Indian government during the current negotiations of the Indo-Naga political settlement. The traditional polity of Manipur gave protection to the inhabitants of the hills and plains together, and they fought the nation's wars against the Burmese in the eighteenth century and against the British in the nineteenth century. A symbolic sharing of this relationship was celebrated ritually by mutual wining and dining with sports and revelry known as Mera Hao-chongba (the dance of 
the hill-men) every year in the auspicious October months. This ritual celebration of brotherhood between the hills and plains were begun in the tenth century.

All these traditional worldviews, cosmologies of statecraft and anthropomorphic practice of polity were shattered through colonial defeat at the hands of the British Empire in the nineteenth century. The Indian state continued the British policies of hills and plains divide to perpetuate their hold over the land and people of Manipur since the middle of the twentieth century. Their notion of territoriality that incorporated the entire Northeast was the reason behind their practice of the four principles of Kautilyan statecraft - Sham (reconciliation), Dam (inducement), Dand (force) and Vedh (split) - in their dealings with contemporary ethnoses. The Meiteis in the plains, who had experienced deep traditions of polity governance and maintenance of community equilibrium in their erstwhile history, had been ruthlessly exposed to the gradual crumbling of their national life through rapid ethnicization in the overall counter-insurgency designs.

In the course of the armed conflict between instruments of Indian state and non-state Meitei actors, we witnessed a critical stage of armed strike by the valley insurgents in the late seventies and the resultant counter-insurgency operations by the Indian state with intensive intrusions into the domestic lives of the citizens. During the eighties, the violent engagements of armed conflict were rather confined to major geographical locations in the villages of the plains where the Indian military had a distinctive advantage. Even though the urban insurgency started by the PLA (People's Liberation Army) was one of the finest in Asia - second only to that of Saigon (presently Ho Chi Minh City), as observed by Yambem $\mathrm{Laba}^{2}$ - the spatial organization of military engagements was however effectively controlled by the superior military power of the Indian state. It was only when the surrounding hills became an active site of military confrontation between the Meitei non-state actors and the Indian army in the 1990s that urgent policy shifts became essential in counter-insurgency operations. Ethnicity became an ardent ploy as the best and effective means of using the hill populations against the Meitei non-state actors who had substantial control of major spaces in the hill terrain. The art of mountain warfare cultivated by the Meitei nationalists could be countered by strategic, methodical approaches for military presence in the hills and unprecedented civic action programmes to 'convert' the local populations. The Assam Rifles became a friend of the hill people in the post-1990s when the mother of all insurgencies, the NSCN (IM), agreed to sit at the negotiating table in 1997 and enter 
into political dialogue with the Centre. The prolongation of armed resistance by the Meitei armed opposition groups could be countered by meticulous weaning of tribal groups and communities away from the logic of ethnic unity. For contemporary developmental interventions by systems of predation cultivated by politicians, bureaucrats, police and tribal elites lent itself to manipulation as an overall picture of discrimination and exploitation of the marginal hill regions.

The twenty-first century saw the emergence of India as a strong Asiatic power vis-à-vis China. And the Look East Policy and Act East Policy, which were propelled by the logic of globalization, would have induced a culture of de-territorialization in the civic processes of intense economic interaction. But realistic statecraft emphasized the permanent 'occupation' of the development frontier by the defence establishments in view of the fragile national security scenario. For significant populations of Mongoloid racial categories were still unassimilated into the pan-Indian nationhood and active presence of armed opposition groups in the difficult mountain terrain should have to be permanently neutralized. This could only be achieved through meticulous cultivation of ethnic jealousies, prejudices and primordial passions through a system of calculated interventions by predatory capitalism and pitting of ethnic leaderships in the partaking of pleasure and profit from the relationship with the Indian state. Those who have abjured the principle of armed violence could now be projected as genuine leaders of the people. And people like Zoramthanga, the chief minister of Mizoram, and Thuingaleng Muivah, the protagonist of Nagalim, had been icons of peace-loving people of the Northeast!

\section{Zale'n-gam or Kuki homeland}

The issue of the Kuki Zale'n-gam (Haokip 1998) movement, however, draws less attention in the Indian media than that of Nagalim. Because of intrinsic migratory habits of the slash-and-burn cultivators of yore, these cognate Kuki-Chin communities straddled across various regional habitats in Myanmar, Manipur, North Cachar Hills (Assam), Mizoram, Tripura, Bangladesh and so forth. A stable resource base, which would facilitate development of a modern political movement, was therefore lacking amongst these tribes. The concept of Zaie'n-gam or the Kuki nation also seems to have had certain anomalies regarding united political aspirations amongst the Kuki clans and other cognate tribes. The Chin tribes in Myanmar envisaged freedom from the political domination of the Myanmarese, while their brethren in India 
sought a 'homeland' or Kuki state within the Indian Union. Though not much information is available about their political activities in the neighbouring Chin Hills of Myanmar, the national imageries of these people in India were developed from the intense experiences of sacrifices and defeat at the hands of the British imperial forces in the Anglo-Kuki War of 1917-19. The sacrifices and exemplary activities of chieftains like Chenjapao Doungel, Lhukhomang Haokip, Tintong Haokip, Enjakhup Kholhou, and Khotingthang Sitlhou in that war provided inspiring memories for the development of narratives of the Kuki independence struggle. In fact, tales of their experiences of migration and settlement amidst other communities, and confrontations with the British imperial forces since the middle of the nineteenth century, as well as the stories of their participation in the Indian National Army of Netaji Subhas Chandra Bose during World War II offered vivid testimony to the freedom-loving spirit of the Kuki people.

The confrontation with the Naga 'national' movement and tragic experiences of the 'ethnic-cleansing' in 1992-98 made the Kukis in Manipur dependent on the Indian political and military establishment for succour and help. This violent engagement within ethnic communities of Manipur led to progressive militarization of ethnic relations and development of ultra-militant ambitions amongst younger generations. Overall, armed movements in the Northeast were also fuelled by the Indian state, which extended support of arms and money to mutually contentious groups for defence of the ethnic selves from violent aggressions from the ethnic 'other'. The recent rise and spread of the Kuki National Army, hitherto confined to Myanmar, in Manipur and other neighbouring regions were an outcome of militarization of ethnicity in the Northeast, where the Indian state played a vital role. Kuki-Chin aspirations for identities, though varied and diverse due to clan and group loyalties, were however strident since the end of World War II as the 1950s ushered in a completely changed environment for ethnic self-consciousness, assertion and mobilization, where propagation of homeland with armed resources was an inevitable result.

Not all political movements amongst the Kukis were associated with armed violence. In fact, democratic aspirations and practice was the path followed by the tribal elites during the 1960s. In a momentous meeting at Thingkhanphai in Churachandpur district during 19-22 January 1960, the elders of the erstwhile Kuki National Assembly (established in 1946) raised the issue of Kuki homeland in Manipur. Thereafter, Kuki chiefs and elders submitted a memorandum to the then Prime Minister Pandit Jawaharlal Nehru on 24 March 1960. The memorandum pleaded for immediate establishment of Kuki state, 
and unification of all contiguous areas now under the habitation of the Kukis in India under the proposed Kuki state (Gangte 2006).

This democratic aspiration for a homeland, consisting of spaces in Manipur's hill districts of Churachandpur, Senapati, Ukhrul and Tamenglong, were however mired in controversies as the Kuki habitations were spread through mixed settlements with other communities, and the Nagas themselves nursed primordial grievances against them, since they regarded the Kukis as outsiders and migrants who were deliberately settled by the British authorities and Meitei rulers since the nineteenth century. The desire for the Kuki people to raise the Sadar Hills in the northern part of Manipur as a revenue district was strongly objected to by the Nagas, who claimed these areas as part of their ancestral domain. The Sadar Hills in the Senapati district continued to haunt ethnic relations for quite long, with things likely to get complicated with the creation of seven new districts in December 2016, in which Kangpokpi district fulfils the long desire of the Kukis to make Sadar Hills a separate revenue district.

An aborted attempt was made to partition the hill regions of Manipur during the crisis of three bills passed by the Manipur State Legislative Assembly in August 2015. The ethnic implosion in the southwestern hills of Manipur due to the passing of the Manipur Peoples Protection Bill, 2015 and two others was provoked by deep tribal discontent over supposed hegemonistic attitude and practice by the majority Meitei community on the issues of land alienation and suspected invasion into tribal rights over their lands. Nine hill denizens were killed through state violence in repressing the violent agitation where the dead bodies lay for more than one and a half years in the morgue of the district hospital. ${ }^{3}$ During the height of this intense agitation the Kuki National Organization was reported to have suggested to the NSCN (IM) to partition the surrounding hill regions of Manipur into the proposed lands of Nagalim (for the Nagas), and Zale'n-gam (for the Kukis) in August 2015. It perhaps didn't materialize probably due to the re-arousal of their ancient animosities through memories of the ethnic cleansing in 1992-98, in which the Government of India was suspected to have played significant roles to enhance the conflict.

\section{Development frontier to disturbed area, economic bridgehead and beyond!}

To India, the Northeast as a region was a development frontier in the Nehruvian imagery. By the time his daughter Indira Gandhi came to power, the Northeast became a disturbed area, and by the time of 
Prime Ministers Narasimha Rao to Manmohan Singh, the Northeast became an economic bridgehead, where predatory capitalism would have a field day. The Look East Policy and drive towards global economic integration via the Northeast would be processed under the auspices of the World Bank, the Asian Development Bank, the Japanese Bank of International Co-operation and so forth.

The influence of speculative intrusion of financial capital in international economy which inhibits growth by creating an environment of low wages, low growth and strangulation of simple innocent work forces had a disastrous impact in a corrupt society like Manipur, where there were little opportunities for productive investment and honest returns. The system of predation in which corrupt business, political, police and bureaucratic classes, or government officials entered into a wanton race for grabbing of plots/businesses in Imphal, Jiri or Moreh towns, parking of unaccounted wealth in the form of assets and/or bank accounts in Indian cities and elsewhere by the nouveau riche politicians, contractors or other enriched classes are all part of a general spectrum of corruption. The race for periodic control over government purses therefore became a driver of the electoral processes for government formation. All these activities were interlaced with rising insurgent violence as well, with its increasing propensity to devour its own children. Manipur had not witnessed a sane public life.

Heavily politicized ethnic relations in the era of insurgency therefore are not perhaps the result of endogenous conflictual growth of vertical social boundaries alone, but rather an end product of intensification of networks of exogenous relationships able to create this effect. Meiteis occupying major portions in the valley are now under 'siege' from aroused ambitions of ethnic assertion and territorializing ethno-national formations all around the once natural and organic physiographic landscapes. This transformation of organic geographic spaces of hill and plains as alienated political entities is the product of intense dynamics of Manipur's post-merger history.

\section{The new historical challenges}

How does the Meitei community as a whole see and interpret this 'reality'? This community has its origins from intense interactions in blood and kin relationships with the surrounding ethnoses in its primal life. The community itself has adapted faster to the vagaries of the environment to form an organized political order, utilized its human and material resources to develop an original Asiatic civilization, with collective memory of a once proud martial nation with a pluralistic 


\section{Lokendra Arambam}

social order. The hills and plains were organic, vital limbs in the geobody of the nation. Its boundaries in the pre-colonial periods as the state 'Meckley' in the early nineteenth century reached as far as the banks of Brahmaputra in the north, the Kabaw valley in the east, and the Badarpur Thana in Cachar in the west. The concept of boundaries understood by the ethnogens was of an interaction of peoples, cultures and spaces, without interference in domestic life. Mutual economic and social relationship through an indigenous Ngai (bond) system prevailed.

All these quotidian complexes had altered drastically during the last hundred years. A brief stint with British colonialism has seen slow and gradual divide between the hills and valley polity. Unfortunately the trend continued even after India's independence. Those who are struggling for the 'restoration of Manipur's independence' are as equally divided as other ethnogens of the state. They seem as overwhelmed by predatory capital as the democratic representatives of India's political order. Their medieval passions and prejudices as are observed in their subterranean dealings with officials, institutional representatives or others in the social milieu reflect personal manifestations of desperation and/or wantonness in a hostile environment of corruption, distrust, intimidation and coercion. The prolonged resistance, the perpetuation of political conflict, the intense hit-and-run engagements in the valley, and stubborn confrontation with India's military might in the Indo-Myanmar borderlands had been suppressed in the contemporary discourse of political conflict. Nor do they seem to inform the structures and dynamic of the ethnic societies' painful ascent to modernity.

Over the last fifteen years or so, the military engagements of the Indian security forces with the Meitei non-state armed opposition groups had revealed a pattern of progressive linkages between armed conflict and politics of ethnicity. Since the end of 2003, the thrust to secure the Manipur hills to restore civil administration and exercise area domination over the western ranges of the Manipur state, there were slow, periodic, inch-by-inch, yard-by-yard occupations of strategic mountain villages, the flushing-out of Meitei insurgent outfits who had earlier entrenched themselves in the rugged mountain terrains, mingling with the 'neglected' and 'marginalized' hill people. Earlier stories of mutual support between the ethnic populations of the hills and the valley, stories of help in arms and equipment, and training of ethnic brothers by valley insurgents, stories of development interventions by militant cadres in areas where state presence was negligible all these were suddenly transformed into chapters of spite and hate campaigns over the valley people by the hill civil society organizations. 
The turmoil in the lives of ethnic populations caused by these unfortunate incidents of armed conflict between the instruments of state and non-state actors were suddenly catapulted into chaotic disequilibrium and massive uprooting of life's rhythm. Stories of displacement, collective exodus into neighbouring hill townships and villages, incidents of physical harm and decapitation in landmine explosions, charges of rape and criminal assaults over the bodies of tribal women - all these concomitant agonies were brought into the public sphere in a confusing amalgam of doubt, distrust and heightening ethnic differences over perceptions on truth and reality. The earlier balance between ethnic brotherhood were substantially damaged. For the Indian state, the operations against the Manipur militants in Operation All Clear (2004), Operation Tornado (2005), Operation Dragnet (2006) and so forth were meant to clear the western ranges of the Manipur hills for restoration of civil administration as well as the destruction of 'Meitei hegemony over the hill people'. The highland ethnic psyche was thus aroused to see the lowlander valley people as oppressive others.

The landslide victory of the Bharatiya Janata Party (BJP) in the national elections of 2014 and the aggressive campaign for Hindutva had also contributed to the complexification of the Northeast regions relationship with the national polity and conflictual concepts on territoriality. Earlier the Congress regime, complacent with the feeling of loyalty by the Northeastern peoples, had treated the Northeasterners with a little disdain coloured with a tinge of liberalism, but now under the increasing success of the Hindutva brigades under the supervision of the Rashtriya Swayamsevak Sangh (RSS), a major epistemic change is taking place in the ideological penetration into the vulnerable ethnic minds of the Northeast. Also the vital principles of national integration and national security could be cloaked under the disguise of demands for poverty alleviation, women's empowerment and quality education, along with the utilization of the Adivasi (aboriginal) consciousness to include tribal cultures of the Northeast regions, so as to encourage, and later transform the indigenous identities into a greater inclusive Hindutva consciousness which could absorb religions and ethnicities.

The valley Meitei as indigenous community therefore stands at a critical threshold of the state's modern history. The heavy politicization of ethnicity and ethnic differences signal unease, anxiety and instabilities, which portend ruptures, fissures and unimagined arousals over its contemporary status as a distinct civilizational entity inherited from the past. In addition to the Indian state's pervasive design marked by political and military power, the developmental interventions of sheer global economic processes, ruthless violence over the natural 
geographies - on roads, rivers, waters, forests and so forth - portend a system of life where territoriality and exclusivity of ownership of the earth's surface through ethnic rights may even be forced to wither away, which is as yet not happening. The Northeast is also now inevitably drawn into a vortex of intense geo-economic and geo-strategic compulsions of the Indian state which ethnic indigenes should either challenge with newer insights of trans-ethnic Northeastern nationalism or consociational imagination of the native peoples capable of overriding the marginalizing tendencies of 'racial others' of India's Asian ambitions. The placid, pre-modern, tribalistic self-centredness which had withstood the forces of change shall not stand the test of time.

\section{Notes}

1 This is a revised version of the paper titled 'Land and Territory in the Northeast: Politics of Ethnicity and Armed Violence in Manipur', Eastern Quarterly, 4(2): 79-90, 2007.

2 Cited along with the observation of Clive Schofield, in Nepram (2002).

3 On 1 September 2015, nine people were shot dead in police firing to contain a violent mob who came to torch the house of a local MLA. With civil society bodies refusing to bury the bodies till the controversial bill was withdrawn, and the state government refusing to do so for the fear of a backlash, eight out of the nine bodies remained in the Churachandpur district hospital morgue for one year and eight months. With the signing of an agreement between the BJP-led coalition government and Joint Action Committee, the bodies were finally put to rest with church rituals on 24 May 2017.

\section{References}

E-pao. 2007. 'Teach KNA a Lesson: UNLF to Kukis', E-pao News Report from The Sangai Express. 11 June. http://www.e-pao.net/GP.asp?src=5.110607. jun07. Accessed on 22 March 2018.

Gangte, T. S. 2006. 'Reflections on the Struggle for Identity among the Hill People of Manipur', paper presented at the national conference on Folklore, Identity and Performance, organized by Forum for Laboratory Theatres of Manipur, 23 May.

Haokip, P. S. 1998. Zale'n-gam. Kuki National Organization.

Muir, Richard. 2000. The New Reading the Landscape: Fieldwork in Landscape History. Exeter: University of Exeter Press.

Nepram, Binalakshmi. 2002. South Asia's Fractured Frontier. New Delhi: Mittal Publications.

Phanjoubam, Tarapot. 2007. Bleeding Manipur. New Delhi: Har Anand Publications.

Winichakul, Thongchai. 1994. Siam Mapped: A History of the Geo-Body of a Nation. Hawaii: University of Hawaii Press. 


\title{
9 Politics of land alienation and problem of its restoration in Tripura ${ }^{1}$
}

\author{
Khakchang Debbarma
}

While owning land can be a source of productivity and prosperity, losing the same could be source of ethnic conflict and a human rights violation. The state of Tripura in the Northeastern region of India represents a glaring example where this problem is visibly and distinctively witnessed. Pursuing this problem, the chapter proposes to address the following questions: Who are the indigenous people in Tripura? Have these historical communities in the state been dispossessed of their land? How did they eventually lose their land? How the increasing immigration is resulting in the alienation of indigenous people's land? And what are the consequences?

Tripura has been facing distinct socio-economic, political and ethnic problems, which are essentially driven by long spell of immigration from across the international border. The state covers an area of $10,491.69 \mathrm{~km}^{2}$ and shares a border with Bangladesh in the north, west and south, and Assam and Mizoram in the east. The economy of the state is predominantly dependent on agriculture. Tripura has a unique history in the country where the original inhabitants - the indigenous peoples called the Boroks of Mongoloid origin - have been outnumbered by the influx of immigrants from across the international border of erstwhile East Pakistan, now Bangladesh (Adhikari 1982: 1). To a great extent, the socio-economic and political problems in the state are related to one crucial process that has been happening unabated: the land alienation of the indigenous people.

Tripura has a history of being ruled by as many as 184 kings belonging to the Boroks. It is the homeland of about nineteen sub-clans of indigenous peoples who share common features and identity as Borok peoples. The Boroks comprise many sub-clans namely Debbarma (Tipra of Tipperah), Reang, Jamatia, Koloi, Noatia, Rupini, Halam, Hrangkhawl, Ranglong, Kaipeng, Tripura, Morasing, Molsom, Darlong, Mog, Bongcher, Chorai, Uchoi and the like. Except one or two of 
these sub-clans, all of them speak a common language called the Kokborok. In fact, the name 'Tripura' is a corrupted form and is derived from Kokborok word, 'Twipra'. The name 'Twipra' is a combination of two Kokborok words - Twi (water) and Bupra (tributaries). It is widely consented that the Boroks migrated from parts of China, and in the process reached the present territory, which was not occupied by any ethnic group or people, and started settling nearby the areas where plenty of water was available. So the word 'Twipra' indicates the Boroks as the indigenous peoples, owners, first occupants and sons of the soil of the state. The Boroks were known to have practiced shifting cultivation as the main traditional source of economy and means of their livelihood (Das Gupta 1994: 147-63). Misra, in his book Socio-Economic Adjustment of Tribals, referred them as jhumias, which applies to those indigenous peoples who practice shifting cultivation like other tribes of Northeast India and Chittagong hill tracts of Bangladesh (1976: 1-8).

To speak about the political history of Tripura, it had been a princely state until it was completely merged to the Indian Union on 15 October 1949, after which it went through a series of political status - it first became a Territorial Council in 1956, then a Union Territory in 1963, and attained statehood on 21 January 1972. Today, the largest threat to indigenous population comes from the unabated influx of peoples mainly from across the Bangladesh border. The beginning of this influx can be linked to the time of India's partition, when the Indian state showed indifference to the idea of protecting the territorial integrity and identity of the indigenous Tripuris. This historical blunder reduced the indigenous peoples into a minority in the land and territory of their own.

In Tripura, the growth of population has been so phenomenal that over a decade following the partition of India, the territory registered more than a twentyfold increase in its population (Misra 1976). After the partition, in the decade from 1949 to 1959 alone the total number of influx of refugees from across the international border figured 373,500 , and in the year 1964-65 itself 100,304 refugees migrated to Tripura. The total number of recorded or registered refugees within the period from 1947 to 1971 was 609,998 (Bhattacharyya 1988: 7). As a result, the immigrants began to outnumber the Boroks since 1960 s thereby reducing the latter into a minority. The Boroks, whose population were once more than 95 per cent, now constitute only about 30 per cent of the total population of the state. Today, the immigrants not only outnumber the Boroks but also marginalize them and dominate over the economic, political, administrative and social 
spheres of the state. This process naturally makes the Boroks insecure, creating a sense of discontentment and denial of their basic rights to self-determination.

Traditionally, the Boroks practised jhuming or shifting cultivation because not only the technique of settled cultivation was unfamiliar and contrary to their tradition, but also they found the hill slopes unsuitable for plough cultivation (Das Gupta 1994: 148). Gradually, influx of population and scarcity of space compelled the Boroks to shift from shifting cultivation to settled cultivation. At the same time, the latter was prominently emphasized as a desirable practice in India's post-independent period (Misra 1976: 5-6). The scarcity of land was largely created by the unchecked large-scale immigration. Such a form of immigration had significantly affected the Borok's economy. This led to the Borok people's alienation over their own land and also to the non-tribal immigrants in the state. Some people identify alienation of land as the root cause of socio-economic problems, political unrest and ethnic conflicts in the state. The unceasing influx of 'foreign nationals' had deprived the indigenous peoples' rights over the lands and employment opportunities (Baroah 1984: 287-300). The settlement of large number of immigrants in both the plains and hills of the state has led to (1) displacement of the Boroks, (2) non-availability of land for rehabilitation to jhumias and (3) non-availability of land for distribution among landless local peoples.

Going by the tradition of shifting cultivation, land was owned collectively by the community, and the rights of ownership enjoyed by an individual local person over a particular area of shifting cultivable land was neither permanent nor alienable nor transferable to any person nor inheritable from any person (Misra 1976: 75-6). Prior to the partition of India, as the density of population was very low in Tripura, the foodstuff required by the Boroks was minimal and could be met easily from shifting cultivation. As such the issue of transfer of lands did not arise (Das Gupta 1991: 2113), and therefore, the problem over land alienation was non-existent.

Each Borok family had huge area of wetland under its possession. Although they were not using those lands all the time, the same were used from time to time for jhuming. To induce his subject (Boroks) to settled cultivation and to increase state's revenue, King Bir Bikram Kishore Manikya (1923-47) reserved for the Boroks a large area of fertile cultivable lands by order in 1931 and 1943 covering the areas of 110 square miles and 1,950 square miles, respectively (Chakravarty 1994: 126). Thus, technically speaking, all the fertile cultivable lands were made reserved for the king's subjects and many families were 


\section{Khakchang Debbarma}

settled in reserved areas and taken to settled cultivation by the $1940 \mathrm{~s}$ (Bhattacharyya 1991: 55-6). Further, as a measure to protect his subjects the last King of Tripura declared that no land in the reserved areas could be transferred to others without the permission of the government. But despite this declaration and safeguard, the reserved areas lost their balance, mainly after the partition of India (1947) and Tripura's merger with the Indian Union. Thereafter, the rate of inflow of the immigrant population increased sharply, forcing the state authorities to utilize the reserved areas for building refugee colonies.

Describing the impact of large-scale of immigration in the state, Malabika Das Gupta opines that ' $[w]$ hile there has been a general lack of economic development in the state, by and large, the tribal people of Tripura have been the worse sufferers as a result of this phenomenon' (Das Gupta 1993: 309). The massive influx of refugees into the state, which had made the indigenous people into a minority in the land of their own, has added fuel to the fire and accentuated the alienation of the Borok people's land despite legislative measures to prevent the same (Das Gupta 1991: 2113). Besides, the immigrants claim to have brought with them the superior agricultural technology of plough cultivation. Though a handful of Boroks had tried to adopt plough cultivation, the majority of them lost their plains lands to the non-tribal immigrants and were compelled to retreat into interior hills and forests of the state. Many of the Bengali immigrants had taken to trading and moneylending, and steadily the Boroks came under the exploitative influence of the immigrant moneylenders and traders (Das Gupta 1993: 308-17).

The failure of the jhum products and revenue to meet the growing needs of the Boroks in a way led to their dependence on non-tribal moneylenders and businessmen for loans used to buy necessary items they could not produce. Loans with interests to be repaid within fixed periods of time were given to the Boroks only against the mortgage of their plains cultivable lands. Meanwhile the moneylenders could use mortgaged lands for cultivation. Mortgaging of cultivable land led to dwindling of production for the Boroks, and they failed to repay the debts within the stipulated time. The immigrant moneylenders and traders caught the Boroks in a debt trap of loan capital. Failure to pay interest within the stipulated period enabled permanent possession of the mortgaged lands by the moneylenders. Instead of settled cultivation giving prosperity to the Borok farmers, they found themselves victims of the moneylending system (Das Gupta 1991: 2113). The entire process led to alienation of the Boroks from their own lands, which further led to their general pauperization (Bhattacharyya 1989: 114). 
The condition of the Boroks worsened with the handling of 'Reserved Areas' in the state. The Government of Tripura prohibited large-scale jhuming since 1952 and restricted the customary rights of the Boroks and their free movement in the forest (Chakravarty 1994: 121). Even very little wetland is left for the Boroks to practice settled cultivation (Mukherjee and Singh 1982: 321). The government policy deprived the Boroks of their sources of livelihood, as they were not provided with a viable alternative to improve their condition (Das Gupta 1993: 309).

As a measure to check alienation of the Boroks, a special provision was included in the Land Revenue and Land Reforms Act, 1960. Technically the Act imposed restrictions on transfer of land from Boroks to non-tribals. Section 187 of the Act provided that

no transfer of land by a person who is a member of a Scheduled Tribe to a person who is not a member of such tribe, shall be valid unless the transfer is made with the prior permission of the Collector in writing. ${ }^{2}$

However, this Act was inadequate to prevent the transfer of Borok lands to the non-tribals. There were rooms for administrative manipulation embedded in the Act. By avoiding all the legal impediments, the immigrants began to purchase lands from the Boroks through higher rate and Benami deeds. For instance, if the value of a plot of land among the Boroks is 5,000 rupees, a non-tribal buyer offers a sum of 10,000 rupees. Consequently, the Borok sells the land to the non-tribal under a fictitious tribal name in paper. It is evident from such Benami deeds that the motive of the non-tribal immigrants is to occupy the Borok land by all means (Debbarma 1994: 3).

Although the Land Reforms Act, 1960, prohibited transfer of land to the non-tribals without prior permission of the government, in practice, due to its ineffective implementation, indiscriminate transfer of land from the Boroks to the non-tribals took place in contravention of the legal provisions (Datta 1980: 105-23). In a block level survey of indebtedness and alienation of land conducted by the Directorate of Tribal Research, Tripura Government, Agartala in 1974, it was found that indebtedness was directly and positively correlated with alienation of Boroks' land (Government of Tripura 1974). In most cases it was revealed that heavy load of indebtedness, particularly after drought years of 1965 and 1972, forced the Boroks to sacrifice most of their lands.

The Land Reforms Act 1960 could not prevent the transfer of Borok lands to the non-tribals. The Act was amended in 1974, which provided 
for the restoration of all Borok lands transferred on or after January 1969 , in contravention of the Act, to the transferor or his successorin-interest (Datta 1980: 119). By keeping the lands transferred before 1 January 1969 outside the scope of the Land Reforms Act, legal recognition was given to the transfer of lands made before that date. The Tripura Land Reforms (Third Amendment) Act 1975 contains the provision that 'if any non-tribal people intends to sell land within 42 Tashils and 133 villages specified in the Act, then the members of the Scheduled Tribe shall have the preferential right to purchase such land' (Datta 1980: 120). However, in practice, there is hardly any record of non-tribal community selling land to the Boroks. At the same time, the Boroks being economically much backward than their counterparts are not in a position to buy back land from the non-tribal immigrants.

Notwithstanding the several Land Reforms Acts passed by the Government of Tripura since 1960, the plight of the Boroks with regard to the illegally transferred lands could not be minimized at all. Though the law may provide some provision of protection, the fact is that the rural Boroks are generally poor, illiterate and have no capacity to access and knowledge about judicial redressal alternatives. It is appropriate to quote one of the observations and reports submitted by the Dinesh Singh Committee constituted by the Government of India to suggest measures for restoration of peace and normalcy in Tripura after the violence of June 1980. It says:

Two Features if this Tripura Land Revenue and Land Reforms Act caused dissatisfaction . . . Firstly, with regard to the choice of the end of 1968 as cut off point, the Acts virtually legalized the transfer of Boroks' lands that had taken place before January 1969. Secondly, the progress of restoration has been lamentably tardy. It received some impetus in 1978 part and has again languished thereafter. Out of nearly 100000 petitions received only 4300 have been disposed off in the petitioners' favour and just 7700 acres of lands have been actually restored till March 31, 1980.

(Bhattacharyya 1989: 116-7)

Though the above observation seems to reveal the restoration of Borok land, in reality it was not completely materialized. The Boroks continue to remain alienated from their own land.

The question of land alienation of the Boroks and its restoration has all along been pertinent in the context of the political scenario of Tripura. This issue received importance in the ideologies of various sociopolitical organizations of the indigenous peoples of the state, like the 
Tripura Upajati Juba Samity (TUJS) and Tripura National Volunteers (TNV). One of the main demands of these two organizations was the complete restoration of illegally alienated lands. However, the TUJS failed to achieve this objective when the party was in power during the coalition government in the state for a complete term of five years in 1988. On the contrary, the TNV was persistent on the question of land alienation and its restoration. As a result, the issue was incorporated in the TNV accord of tripartite agreement signed on 12 August 1988. As per this Memorandum of Settlement (MoS), Section 3:6 contains the following agreed resolutions:

1 Review of rejected applications for restoration of Boroks' land under the Tripura Land Revenue and Land Reforms Act, 1960

2 Effective implementation of the law for restoration

3 Stringent measures to prevent any fresh alienation ${ }^{3}$

Though the MoS was signed by a tripartite agreement between the TNV, the Government of Tripura and the Union Government, restoration of lands to the Boroks has not yet been implemented. Subsequently, TNV has threatened the government with renewed agitation in case the accord is not respected. The surrendered members of the TNV even declared that they would again go back to armed struggle if the provisions of the TNV accord were not fully implemented. Renewed demand for implementation of several Land Revenue and Land Reforms Acts has received wide range of support from TNV, TUJS, regional political parties, Tripura Students' Federation (TSF) and all sections of the Borok society.

The Government of Tripura came under pressure from various sections of the Borok society in 1994-95. CPI (M)-led Front Government in Tripura under the leadership of Borok Chief Minister Dasarath Debbarma initiated certain measures to implement the restoration of alienated lands to the Boroks. The Left Front Government passed the Tripura Land Revenue and Land Reforms (Sixth Amendment) Bill 1994 and declared 1994-95 as the year of land reforms. This bill aims at reinforcement of all provisions of Land Revenue and Land Reforms Acts of 1960, 1974 (as amended), 1975 (as amended) and 1982 (as amended) particularly relating to the restoration of lands to the Boroks. It also incorporated the provision of prevention of re-transfer of restored lands to the non-tribal people. ${ }^{4}$ The Act provides the provision to safeguard the interest of the indigenous peoples who otherwise had become victims due to the massive influx of refugees. As per the provisions of the Act, the government initiated to implement the law 
to restore all the alienated lands to the Boroks from the non-tribal people. In many areas the non-tribal people who possessed illegally transferred lands were issued notice and order to return the lands back to the original Borok landowners.

However, the bill faced great opposition from the non-tribal communities even before its implementation in the state. ${ }^{5}$ They were determined not to return the lands back to the Boroks irrespective the legal directives. A regional political party, Amara Bengali, strongly reacted against the bill. This phenomenon created ethnic tension between the Boroks and the non-tribals and led to several clashes in different parts of the state. It is reported that the non-tribals were organizing themselves to protest against the implementation of the Land Revenue and Land reforms Acts 1994. However, such a strong opposition is possible only in a state like Tripura because of the imbalance in demographic composition.

Following these developments, restoration of land-related tension was mounting high at Teliamura area in West Tripura following the massacre of six members of a non-tribal family on 29 April 1994. As the people of Thangsai in Teliamura area of West Tripura district became panicky and insecure after the incident, the state government had to take measures to establish confidence among the people, and security forces were kept in close vigil. The massacre occurred within a week of the state government's declaration of 1994-95 as the year of land reforms, which indicates opposition to the law relating to restoration of the Boroks' land. ${ }^{6}$ The ethnic tension had forced the Tripura government to issue an order of special alert to all the police stations, subdivisional and district heads of police to maintain a maximum vigil on the prevailing situation and take measures to prevent any communal violence in the state. As the tension was mounting high, the then Chief Minister Dasarath Debbarma, through telecast message on 9 May 1994, appealed to the people of different communities to maintain peace and communal harmony in the state. According to the director general of police, the situation at that point of time in the state was extremely serious and was reminiscent of the 1980 riot. $^{7}$

The problems arising out of land alienation and its restoration is due to the negligence of the Government of Tripura to implement several Land Revenue and Land Reforms Acts. If the Land Reform Acts passed since 1960 are not implemented fully and sincerely, the future of the Borok peoples and their economy cannot be safeguarded. A fivemember TNV political party delegation led by its president, B. K. Hrangkhawl, met the then Chief Minister Dasarath Debbarma on 10 May 1995 and submitted a memorandum containing five-point charter of 
demands. The memorandum included the demand of deportation of 'foreign nationals' and physical restoration of alienated lands, both of which were included in the provisions of the tripartite TNV accord signed on 12 August 1988. The TNV meanwhile had threatened to paralyse the entire state if its demands are not conceded and fulfilled on time. ${ }^{8}$ It is quite clear that alienation of the Boroks' land and its restoration assume a significant political dimension. There is a need for a government with a strong political will to resolve such an ongoing problem in the state. If the issue of restoration of land is not tackled properly on time, it appears that ethnic conflict and communal disharmony may aggravate in the days to come.

The Government of Tripura faces a stiff challenge to stop land alienation of the Boroks as this directs causal linkages with the ongoing socio-economic problems and ethnic conflicts. But the question remains if the government is willing to resolve the problem or is only wary of majoritarian electoral interests. Such a concern has hardly appeared in the imagination of the dominant political class in the state. In the face of impending crisis of land alienation, it has to be said that the sooner the process is initiated the better it will be for the people and the state. Any approach towards this should recognize that simply making legislations after legislations is not going to take much way forward if not guided by a strong will to uphold the rights and historicity of the indigenous people. One way of overcoming the crisis could be through educating the opposing masses with right sense of understanding the issue. Second, creation of a viable alternative is extremely important for those who would give back the lands, for they too need security and alternate source of livelihood. Third, there is a need to create economic opportunity for all sections of the Borok people without any political favour. Such initiatives will certainly instil a proper understanding and good will among the people of the state, which will perhaps ensure a better Tripura ahead.

\section{Notes}

1 This chapter was first published in Eastern Quarterly, 4(2): 101-11, 2007.

2 Tripura Land Revenue and Land Reforms Act of 1960 (No. 43 of 1960), Government of Tripura.

3 'Memorandum of Settlement of TNV', 12 August 1988, New Delhi.

4 See Tripura Land Revenue and Land Reforms (Sixth Amendment) Bill 1994' (Tripura Bill No. 4, 1994).

5 Based on observation and interview with one of the officials of the Land Revenue Department, Government of Tripura on 13 July 1995. Also see Bhowmik (1994: 2) and Choudhuri (1995: 2). 
6 Reference D/h®TPA, TLM-P.S. Case No. 76/94, U/S 148/49/302 and IPC and 27 Arms Act, West Hawaibari, 29 April 1994. Also 'Rajye Ain Shrinkholar Abonoti Jati Sangat Bridir Ashanka', The Dainik Sambad, (Agartala), 1 May 1994: 1; and 'Tension Prevails in Tripura', The Meghalaya Guardian, (Shillong), 3 May 1994: 1.

7 DGP's Alert Circular Wireless Message No. C.41(1)/PHQ/92/13991-14034, cited in 'Raijye Prai 1980 Saler Anurup Parishthiti Srishthi Hayeshe: DG's Shikriti', The Dainik Sambad, (Agartala), 10 May 1994: 1 and 7; and 'Red Alert in Tripura', The Meghalaya Guardian, (Shillong), 11 May 1994: 1.

8 A Memorandum by TNV, Agartala, 9 May 1995 submitted to the chief minister of Twipra. Also see 'TNV Warns Government', The Sentinel, (Guwahati), 11 May 1995.

\section{References}

Adhikari, O. S. 1982. The Problem of Indebtedness among the Tribals in Sadar Sub-Division of Tripura. Agartala: A Government of Tripura Publication, Department of Welfare for Scheduled Tribes.

Baroah, Debo Prasad. 1984. 'Silent Civilian Invasion: India's Danger in the Northeast', in B. L. Abbi (ed.), Northeast Region: Problems and Prospects of Development. Chandigarh: Centre for Research for Rural and Industrial Development.

Bhattacharyya, Gayatri. 1988. Refugee Rehabilitation and Its Impact on Tripura's Economy. New Delhi: Omsons Publications.

Bhattacharyya, S. R. 1989. Tribal Insurgency in Tripura: A Study in Exploration of Causes. New Delhi: Inter-India Publications.

Bhattacharyya, Suchintya. 1991. Genesis of Tribal Extremism in Tripura. New Delhi: Gian Publishing House.

Bhowmik, Bhupen Dutta. 1994. 'Tripura Bhoomi Ainer Shustha Sangshudhoni Bill 1994 Pratyahar Karte hobe. Noile Dakishuddha Mansa Bisarjon, Kintu Keno?', The Dainik Sambad, a Bengali Daily (Agartala), 3, 4, 5 and 6 May.

Chakravarty, Mahadev. 1994. 'Land in Tripura: The Tenurial System and Transfer', in J. B. Bhattachahrjee (ed.), Studies in the Economic History of Northeast India. New Delhi: Har Anand Publications.

Choudhuri, Badal. 1995. 'Bhoomi Sanstha Sangshudhani Bill - Prakrita o Aingata Abastha', The Syandan Patrika, a Bengali Daily (Agartala), 8 June.

Das Gupta, Malabika. 1991. 'Land Alienation among Tripura Tribals', The Economic and Political Weekly, 26(36), 7 September.

Das Gupta, Malabika. 1993. 'Regionalism and Separatist Forces in Tripura', in B. Pakem (ed.), Regionalism in India with Special Reference to Northeast India. New Delhi: Har Anand Publications.

Das Gupta, Malabika. 1994. 'Continuity and Change in Tribal Societies: A Study of Economic Aspects of Tribal Jhumia Society in Tripura', in Milton S. Sangma (ed.), Essays on Northeast India. New Delhi: Indus.

Datta, Narendra Chandra. 1980. 'Land Reforms', in Jagadis Chaudhuri (ed.), Tripura: The Land and Its People. New Delhi: Leeladevi Publications. 
Debbarma, Harinath. 1994. 'Indigenous Peoples' Self-Determination, SelfGovernment', a paper presented in the woskshop by Khasi Students Union (KSU), at NEHU Campus, Shillong, 9-11 April.

Government of Tripura. 1974. Indebtedness and Land Alienation Survey of Tribal Family under Mohanpur Block, Vol. 1, Part I, II and III. Agartala: Bulletin of the Directorate of Tribal Research.

Misra, Bani Prasanna. 1976. Socio-Economic Adjustments of Tribals. New Delhi: People's Publishing House.

Mukherjee, Bhabanand and K. S. Singh. 1982. 'Tribal Movements in Tripura', in K. S. Singh (ed.), Tribal Movements in India, Vol. 1. New Delhi: Manohar Publications. 
$\because$ Taylor \& Francis

http://taylorandfrancis.com 
Part V

Migration and ethnicity 
$\because$ Taylor \& Francis

http://taylorandfrancis.com 


\title{
10 Illegal Bangladeshi migration into the Northeast
}

\author{
Policy making, politics \\ and road blocks ${ }^{1}$
}

\section{Bibhu Prasad Routray}

Little unanimity exists on the extent of illegal migration of Bangladeshi nationals into India's Northeast. However, some convergence of views on the impact of such population movement on demography, economy and shrinking resources in the region is noticeable. Irrespective of the divided opinions on the commitment of the ruling regimes to deal with such illegal migrants and the feasibility of the measures adopted to stop the influx, there is a unanimity of sorts among the different stakeholders that such migration, unless stopped, could destabilize the fragile region even further. The issue of continuing influx of foreigners also highlights the intricacies of policy making, the specific role of actors, enablers and the external influences facilitating or inhibiting formulation of a coherent policy.

The chapter attempts to critically analyse official policy making with regard to dealing with illegal migration from Bangladesh into the Northeast. It analyses the role of the different actors in the policy making architecture, examines the push and pull factors and the impact ability of the peripheral actors in the decision making apparatus. While the chapter makes cursory reference to other states of the Northeast, the bulk of the analysis pertains only to the state of Assam. The chapter also focuses mostly on the official policies on migration, especially that of the Congress Party-led governments in the state as well in New Delhi and makes a brief reference to the Bharatiya Janata Party (BJP)-led National Democratic Alliance (NDA) government in New Delhi's position on the issue.

The chapter argues that the official policy dealing with illegal migration from Bangladesh is based on the premise that a complete halt to migration is a desirable yet unachievable goal to pursue. Hence, political prudence and electoral expediency leads the ruling regimes in New Delhi as well as Assam to use the migrants as a source to gain political strength. As a result, the policy making with regard to migration 


\section{Bibhu Prasad Routray}

while investing in the gradual strengthening of the infrastructure on the Indo-Bangladesh border directed at preventing further migration and also in mechanisms to identify such illegal foreigners, does little in terms of deporting them back to Bangladesh. The chapter further argues that this policy, which has been critiqued by the communitybased organizations and also has been the source of periodic upheavals/ riots in states like Assam, has been provided with a soft landing by a popular acceptance of migration as a fait accompli in Assam. As a result, demands and periodic upheavals demanding the identification and deportation of the migrants coexist with a political as well as economic expediency to benefit from their presence.

The chapter is divided into four sections. The first section provides a brief overview of the impact of migration on Assam. The second section examines the important pillars of policy making with regard to the problem of illegal influx. The third section examines the weakness and inability of the secondary actors to influence policy making. The last section evaluates and sums up the findings.

\section{The impact}

Bangladeshi migrants trickled into the Northeast, primarily through Assam's porous borders, prior to India's independence. The movement continued following the partition of the subcontinent into India and Pakistan in 1947, after the creation of Bangladesh in 1971 and thereafter. They have been alleged to have taken away jobs, occupied land and changed the demography of the state's districts. While statistics on the jobs taken away and land occupied by the migrants are not available, the increase in the Muslim population in some of the districts in the state is cited in support of the claim of the unceasing migration from Bangladesh.

What is apparent from the cited official data on undivided districts in Assam is that the Muslim population (presumably due to the population influx from Bangladesh) has risen consistently over the decades. Other sources, however, point at a more alarming rise in the Muslim population. For example, a report submitted by Lt. Gen. Srinivas Kumar Sinha, who served as Assam's governor between 1997 and 2003, had said that the Muslim population of Assam rose by 77.42 per cent between 1971 and 1991, compared to 41.89 per cent for the Hindus. The comparative pan-India increase in the Muslim population during that period was 55.04 per cent. The report had prophesized that except in Sibsagar district the indigenous Assamese people would not find themselves at home in Assam. It further warned that if the 
Table 10.1 Variation of Muslim population in Assam from 1941 to 2001 (in \%)

\begin{tabular}{lrrrrrr}
\hline Undivided district & 1941 & 1951 & 1961 & 1971 & $1991^{*}$ & 2001 \\
\hline Lakhimpur & 4.98 & 4.66 & 5.64 & 4.59 & 5.96 & 6.52 \\
Sibsagar & 4.82 & 5.82 & 5.83 & 5.27 & 6.36 & 6.95 \\
Nowgong & 33.76 & 34.18 & 33.74 & 31.32 & 35.77 & 38.42 \\
Kamrup & 29.07 & 29.29 & 29.36 & 31.33 & 32.87 & 34.91 \\
Darrang & 16.42 & 17.03 & 19.35 & 16.19 & 22.22 & 25.20 \\
Goalpara & 46.23 & 42.94 & 43.32 & 42.25 & 46.91 & 51.31 \\
Cachar & 42.48 & 38.49 & 39.19 & 39.88 & 43.02 & 45.47 \\
Total & 25.72 & 24.68 & 25.26 & $\mathbf{2 4 . 5 6}$ & $\mathbf{2 8 . 4 3}$ & $\mathbf{3 0 . 9 2}$ \\
\hline
\end{tabular}

*No census took place for Assam in 1981.

Source: White paper on Foreigners' Issue, Home and Political Department, Government of Assam, 20 October 2012, p. 45.

present trends are not arrested, the indigenous people of Assam would be reduced to a minority and there may, in course of time, be a demand for the merger of Muslim-dominated bordering districts with Bangladesh' (Raghavan 2007).

On 28 August 2000, an affidavit filed by the Assam government stated:

There are three districts in Assam which have borders with Bangladesh, viz. Karimganj, Cachar and Dhubri. All India percentage of decadal increase in population during 1981-1991 is 23.85 percent whereas the border districts of Assam, namely, Karimganj, shows decadal increase of 42.08 percent, Cachar district 47.59 percent, and Dhubri district 56.57 percent. From the above it can be assumed that the infiltration of foreigners from Bangladesh contributed significantly to the sharp increase of population in Assam.

(Phukan 2012)

Similarly, the Gauhati High Court in July 2008 said that 'Bangladeshis would soon become kingmakers in Assam and that the State government had failed to solve the problem of illegal migration'. ${ }^{2}$ Further, in 2008, the Parliamentary Standing Committee on Home Affairs said in its report that the 'large presence of illegal Bangladeshi immigrants poses a grave threat to the internal security'. This is in contrary to the previous Congress government in Assam which continuously claimed that migration from Bangladesh has stopped.

The increase of Muslim population has also been cited as the reason for many of the riots between different indigenous tribes and 


\section{Bibhu Prasad Routray}

Muslims in the state. Starting with the 1983 Nellie massacre, in which the Lalung tribals attacked Bangladeshi Muslim immigrants in Nagaon district resulting in the deaths of at least 2,191 people, riots have claimed lives and produced a large number of internally displaced people in various districts of the state. In July and August 2012, Muslims and the Bodo tribals clashed in four districts of Assam in which ' 77 people lost their lives, 5367 houses were burnt and 47,936 families had been affected. Men, women and children from 244 villages filled in the 340 temporary relief camps'. ${ }^{3}$ Prior to that, in 2008, a similar communal flare-up resulted in the loss of fifty-five lives and displacement of 200,000 people. The reasons of such regular clashes have been attributed to migration, pressures on land and shrinking resources.

\section{Congress policy: Pillars on which it rests}

Amid the pulls and pressures of decision making between the primary and secondary actors and the other stakeholders, four critical pillars of the official policy with regard to migration are discernible. These pillars, while explaining the constraints of policy making, also provide a peep into the labyrinth of strategic thinking behind particular decisions, processes of bargaining between the actors involved and external influences that shape official decisions.

\section{Absurdity of a zero-influx regime}

Rates of success of governments worldwide to stop illegal migration through an array of technological, infrastructural, legal and bilateral or regional cooperative mechanisms have been unsatisfactory. Whereas the United States has struggled to stop immigration from Mexico even after investing huge sums on strengthening the border control mechanisms, conflicts in Asia and Africa have pushed millions of people away from the badlands to Australia and the European nations. Only a fraction of these people have been legal immigrants. In this background, to assume that the Indian government would be successful in establishing a zero-influx regime along the complex 4,096.7 km IndoBangladesh border ${ }^{4}$ appears, from a policy making point of view, an unachievable goal to pursue.

Such realization has been seconded by expert opinions, recommending methods other than border fencing to deal with migration. Among such advices which have received maximum attention is the 'work permit system', which would allow Bangladeshis to be legally employed 
in India. Experts believe that the work permit system would directly address the illegality of migration and the related components which

drive[] the related economy underground, placing it in the hands of organised criminals, corrupt officials and unscrupulous politicians who can exploit the vote banks it creates. It also deprives the central and state governments of sources of revenue they would have enjoyed had migrant economy been above-ground.

(Pai 2012)

Experts believe that the work permits can transform the nature of migration by encouraging high-skilled migrants and allowing lowskilled seasonal migrants a pathway to return to Bangladesh. 'With porous borders, there is no way migration can be checked and this will be accentuated with environmental refugees. At best, one can ensure illegal migration becomes legal, instead of wishing the problem away' (Debroy 2010). The move has faced opposition from various sections within the Northeast and outside. These stakeholders point at the absurdity of legalizing Bangladeshi labour in India, where millions are unemployed. Political parties within the Northeast fear that the influx of additional migrants will threaten social equilibrium in the region. Such local opposition has militated against the acceptance of the unfeasibility of fencing as an instrument to stop migration, lest this be construed as a policy that promotes influx. Thus, no regime either in New Delhi or Assam has ever highlighted the limitation of pursuing this approach.

In 2001, a Group of Ministers (GoM) on national security reforms in the National Democratic Alliance (NDA) government, under the chairmanship of L. K. Advani, had recommended a work permit system 'to curb illegal migration and to begin this with Bangladesh and Myanmar nationals' (Pai 2012). While the NDA government's acquiescence to a work permit system appeared a pragmatic way out of the influx quagmire, the United Progressive Alliance (UPA) government headed by the Congress Party in New Delhi and the Congress Partyled coalition government in Assam appeared to opt for a fencingcentric system to deal with the problem. With the present BJP regime in Assam who have won the public mandate on the issue of this much influx, much is expected to come in 2017-18.

The UPA government did not have a known position on the work permit system. It also shared a similar scepticism in the effectiveness in the border fencing mechanism. Speaking in the Lok Sabha in September 2012, then Minority Affairs Minister Salman Khurshid said that 
Table 10.2 Progress in fencing the Indo-Bangladesh border (length in km)

\begin{tabular}{|c|c|c|c|c|c|c|}
\hline \multirow{2}{*}{$\begin{array}{l}\text { Name of } \\
\text { State }\end{array}$} & \multicolumn{2}{|c|}{ Phase I: 1986-2000 } & \multicolumn{2}{|c|}{ Phase II: 2000-2012 } & \multicolumn{2}{|c|}{ Total (Phase I + II) } \\
\hline & Sanctioned & Completed & Sanctioned & Completed & Sanctioned & Completed \\
\hline West Bengal & 507 & 507 & 1021 & 712 & 1528 & $1,219.00$ \\
\hline Assam & 152.31 & 149.29 & 77.72 & 72.27 & 230.03 & 221.56 \\
\hline Meghalaya & 198.06 & 198.06 & 272.17 & 182.00 & 470.23 & 380.06 \\
\hline Tripura & - & - & 856 & 730.50 & 856 & 730.50 \\
\hline Mizoram & - & - & 352.33 & 184.00 & 352.33 & 184.00 \\
\hline Total & 857.37 & 854.35 & $2,579.22$ & $1,880.77$ & $3,436.59$ & $2,734.73$ \\
\hline
\end{tabular}

Source: Fencing and Floodlighting of Borders, Union Ministry of Home Affairs, Government of India. http://mha.nic.in/hindi/sites/upload_files/mhahindi/files/pdf/BM_ Fence(E).pdf.

the government does not have specific details about the magnitude of illegal migration from Bangladesh to India as it takes place clandestinely. He accepted that the migrants manage to 'infiltrate into the country despite checks and control' at the international border. ${ }^{5}$ In the same month, Minister of State for Home Affairs Mullappally Ramachandran, while replying to a question on the estimated number of illegal Bangladeshi migrants in Assam, provided a detailed rationale. He said:

There are reports of illegal infiltration/immigration of Bangladeshi nationals who manage to infiltrate into the country in spite of checks and control at the international border, particularly through few patches where fencing is not feasible due to difficult terrain and riverine areas. As this activity takes place clandestinely, no specific details are available about the magnitude of this illegal migrants staying in India including North Eastern States as well as in Assam. ${ }^{6}$

Such official admission appeared to have been guided by the opinions of the border guarding forces. In one of the rare occasions of admission of the limits of the fencing, Director General of the Border Security Force (BSF) U. K. Bansal said in August 2012,

In this year 15,000 Bangladeshis have been pushed back. But the border is complex that I can't say with confidence that there is zero entrance through the border from Bangladesh. Complete sealing of the border with Bangladesh is not easy without great human hardship. 
As a result, the policy of fencing appears to be continuing as a measure only to deter and not prevent influx.

\section{Identification and deportation snags}

The problem of identifying the immigrants and deporting them back to Bangladesh has been frequently cited as the limitations of pursuing a proactive policy on migrants. The achievements of the governments in Assam - both Congress and the opposition Asom Gana Parishad (AGP) - in this regard remained far from satisfactory. The subsequent section in the chapter will deal with this aspect. However, one of the frequent justifications for its below-par achievements in deporting the migrants provided by the Congress government has been the lack of cooperation from Bangladesh.

This narrative of Bangladesh's reluctance to taking the immigrants back, however, appears to be merely anecdotal and unsubstantiated. The response of the Ministry of Home Affairs in the Lok Sabha indicates that Dhaka does not have an official policy in this regard. For example, on 22 May 2012, in response to a question 'Whether the Government of Bangladesh has officially refused to acknowledge the illegal migration of Bangladeshis into India', Minister of State for Home Affairs Ramachandran answered in the negative. ${ }^{7}$ Further, the fact that BSF has managed to deport a number of illegal migrants to Bangladesh in the past years further goes against the narrative of Dhaka's refusal to acknowledge migration and its opposition to accepting the deported migrants.

\section{Politics over migrants}

The Congress Party, while maintaining a 'tough' position on migration, also professes to protect the genuine Muslim citizens of India from being harassed and deported after being falsely accused of being illegal migrants. However, the measures to protect the Indian Muslims from harassment through legislations have also amounted to creating barriers in identifying and deporting the migrants themselves. This has fuelled the suspicion of 'vote bank politics' being played by the Congress.

Experts agree that the Illegal Migrants (Determination by Tribunals) [IMDT] Act, enacted in 1983 remained, till its 2005 annulment, one of the most lopsided pieces of legislations that deterred processes for identification and deportation of the illegal migrants. The Congress party, however, not only remained an avowed supporter of the IMDT 
Act, but initiated a range of measures to bring the Act back through the back channel after its repeal. In an affidavit filed on 8 August 2001, the Congress government in Assam maintained that 'the IMDT Act is constitutional and there is no question of either repeal or striking down of the Act' (Phukan 2012). Three years later, in November 2004, the UPA government in New Delhi too filed an affidavit, revoking the one filed by the previous NDA regime. The new affidavit stated that on reconsideration the central government had taken a decision to retain the IMDT Act in Assam.

In 2005, the Supreme Court struck off the Act calling it 'the biggest barrier to deportation'. A three-judge bench of the Supreme Court pointed out that the Act created 'innumerable and insurmountable difficulties' in identification and deportation of illegal migrants. The bench noted that though enquiries were initiated in 310,759 cases under the IMDT Act, only 10,015 persons were declared illegal migrants and only 1,481 illegal migrants were physically expelled up to 30 April 2000. ${ }^{8}$ Again in 2006, the Supreme Court defrocked the UPA government's attempts to bring back the scrapped IMDT Act through the back door. ${ }^{9}$ It struck down an Assam-specific notification issued under the Foreigners' Act that put the onus of proving a person a foreigner on the complainant.

In this background, the 2009 statement of then Home Minister P. Chidambaram appeared to be a rethink of the Congress policy on migrants. Chidambaram said during an interview,

If he is a Bangladeshi he has no business to come to India unless he has a valid visa. He has no business to live here unless he has a resident permit, and no business to work here if he has no work permit.

(Choudhury and Bhattacharjee 2009)

However, the statement had been made in the immediate aftermath of the 30 October 2008 serial explosions in Assam which claimed seventy-seven lives and left about 300 people injured. The preliminary suspicion of the intelligence agencies had been directed at the Bangladesh terrorist outfits like the Harkat-ul Jihadi-al Islami Bangladesh (HuJI-B). However, with the passage of time the Congress appeared to have reverted to its old position.

Political statements during communal flare-ups in Assam, between indigenous tribal groups and Muslim populations, provide opportunities to different actors to reiterate their stand on the migrants. The 2008 riots between the Adivasis and the Muslims and the 2012 
riots between the Bodos and the Muslims were two such occasions. Whereas the BJP, the AGP and the Bodo organizations termed the flare-ups as violence between the Indians and the Bangladeshi foreigners, the Congress party continued to describe the Muslim victims of the riots as 'settlers'. Its position remained unchanged even after the media reports ${ }^{10}$ indicated that about 500 Muslim victims of the riots staying in different relief camps in Dhubri district had gone missing and were suspected to have crossed over to Bangladesh after authorities started verifying antecedents of the victims.

\section{Narrative of declining influx}

The fourth pillar of then Congress government's policy on migration was based on a questionable narrative of drastic reduction in the level of migration. Irrespective of the significant rise in Muslim population in the state vis-à-vis the Hindus, both then state government and then UPA government at the Centre maintained that the level of influx from Bangladesh has sufficiently declined. Then Chief Minister of Assam Tarun Gogoi, a known protagonist of the 'significant decline in the influx' theory, insisted that the problem of illegal migrants 'is not as grave as many would like the outside world to believe' (Anurag 2012). During a media interview after the communal flare-up in Bodoland districts in July-August 2012, he said,

I have all along been saying that migration is on the decline. Where does migration take place? Where there is ample job opportunity, where there is land that is available. Today, land availability is not there. Earlier, why did they come? Today, [that is] why they do not come?

(Varadarajan 2012)

Then Congress government's denial has finally led to electoral defeat of the party in the state assembly election in 2016 where BJP got an absolute majority.

\section{Frailty of the other players}

Notwithstanding the anti-migrant stand of the political parties like the BJP and the AGP and the vocal student organizations like All Assam Students Union (AASU), their ability to influence policy of then Congress government has remained vastly limited. The AASU, in particular, has organized intermittent anti-migrant movements in the state. 


\section{Bibhu Prasad Routray}

It has carried out a periodic statewide Short Message Service (SMS) campaign asking the Assamese population to refrain from employing Bangladeshis as labourers. Both the BJP and the AGP have periodically accused the Congress party of being pro-migrant. However, apart from transitory value, the overall domination of the Congress Party in the state assembly, uninterrupted since 2001, has limited the ability of the opposition to influence policy making. With the BJP in power now, coming years will be crucial in terms of carving the roadmaps to delivering the promises on which it gained public sympathy.

First, as pointed out in the earlier section, in spite of their known anti-migrant position, the achievement of the AGP in its tenure as the ruling party in the state and the BJP as the government in New Delhi in identifying and deporting the illegal migrants remained fairly obscure. The AGP was in power in Assam on two occasions in 1985 to 1990 and again during 1996 to 2001, headed by its leader Prafulla Kumar Mahanta. The AGP was also a junior partner in the BJPled NDA regime which served as the ruling coalition in New Delhi between 1998 and 2004. Table 10.3 demonstrates that even with a favourable political climate and anti-migrant agenda, the number of migrants identified and deported during the AGP and the NDA rule was hardly significant. Although the number of cases referred to the IMDT tribunals appeared to have increased substantially during their tenure, the number of people declared as foreigners remained miniscule. Also, the actual number of deportations, subsequent to such declaration, remained fairly low.

The Congress Party has used this data both to underline the 'genuine' difficulty in identifying and deporting migrants and to dispel the accusation of it being pro-migrants. Then Chief Minister Tarun Gogoi's following statement provides a critique of the AGP's achievements:

Table 10.3 Identification and deportation of illegal migrants

\begin{tabular}{lrlllc}
\hline Period & $\begin{array}{l}\text { Cases } \\
\text { referred }\end{array}$ & $\begin{array}{l}\text { Cases } \\
\text { disposed }\end{array}$ & $\begin{array}{l}\text { Cases } \\
\text { pending }\end{array}$ & $\begin{array}{l}\text { No. of persons } \\
\text { declared as } \\
\text { foreigners }\end{array}$ & $\begin{array}{l}\text { No. of } \\
\text { deportations }\end{array}$ \\
\hline $1985-90$ & 22,682 & 6,486 & 16,196 & 6,724 & 521 \\
$1991-95$ & 3,488 & 7,335 & 12,349 & 2,577 & 792 \\
$1996-2000$ & 17,693 & 4,420 & 25,552 & 902 & 179 \\
2001 to & 68,998 & 5,780 & 88,770 & 2,643 & 55 \\
$\begin{array}{l}\text { July 2005 } \\
\text { Total }\end{array}$ & $\mathbf{1 1 2 , 7 9 1}$ & $\mathbf{2 4 , 0 2 1}$ & $\mathbf{8 8 , 7 7 0}$ & $\mathbf{1 2 , 8 4 6}$ & $\mathbf{1 , 5 4 7}$ \\
\hline
\end{tabular}

Source: White paper on Foreigners' Issue, op.cit., p. 18. 
'When the AGP was in power and they had a chance to prove they were different. They could have registered cases [against foreigners living here]. Why did they not do it?' (Varadarajan 2012).

Second, the abhorrence towards the migrants at the popular level appears to have been overshadowed by the economic utility. It is a wellaccepted fact that Bangladeshis are employed as low-paid labourers in states like Assam, Nagaland, Meghalaya and Manipur. The thriving service sector and the real estate boom in the Northeastern region has produced a great demand for labour. Compared to the unskilled labourers from other Indian states, the Bangladeshis come cheap and provide a fiscal rationale for employment. As a result, to shun the migrants completely is not a viable proposition either for the construction industry, business houses or individual households. The AASU's SMS campaign against the migrants, in this context, has limited acceptability. Tarun Gogoi emphasized the point during an interview.

To construct your house, to buy chicken, you are dealing with migrants. Now they are all foreigners and they are engaging them! Those who are agitating on this issue, whether AGP or BJP leaders, their pandals, their houses were also constructed by them. . . . In the peak [of the anti-foreigners agitation], I myself saw the AGP building was constructed by them, those who they allege are illegal migrants. We do not say [this].

(Varadarajan 2012)

Third, the somewhat constrained acceptance of the migrants is further reflected in the statement of the insurgency movement that arose out of the anti-foreigners agitation in Assam in the 1980s and also in literary organizations with wide appeal in the Assamese society. The United Liberation Front of Asom (ULFA), in the early 1990s, asked the Assamese population to recognize the contribution of the Bangladeshi population to the native society. While the ULFA's change of position was the result of its relocation into Bangladesh, even the premier literary organization Assam Sahitya Sabha (ASS) appeared to toe a similar line in 2002. In its special annual session on 11 February 2002, ASS President Homen Borgohain declared that the Assamese Muslims of East Bengal origin are an integral part of greater Assamese society. Noting that 'immigrants' constitute a fourth of Assam's total population, the ASS president urged for reconciliation between the various communities in the state (Routray 2002).

It can thus be argued that the seemingly pro-migrant policies of the then Congress government are an extension of the tolerance of the 
Assamese society towards the migrants. Migration appears to have been fairly well accepted as a fait accompli by the Assamese population. The economic sense of employing the migrants coupled with the failure of successive regimes to identify and deport them has ensured their economic integration with the Assamese society. The social integration, though, remains an incomplete project.

\section{Policy under the NDA government}

Cross-border migration is high on the agenda of the NDA government. It was one of the major poll issues before it came to power in 2014. During the electioneering Narendra Modi promised to cleanse the country of all illegal Bangladeshi migrants. In a way, the NDA regime tends to believe that fencing and proactive policy can indeed end the problem of illegal migration. However, the problem has continued unabated. In the first eight months of 2015, the Border Security Force intercepted 1,731 Bangladeshi nationals trying to cross over to India. In October 2015, the Cabinet Committee on Security (CCS) cleared infrastructure projects worth 4,400 crore rupees for the Bangladesh border that included around $200 \mathrm{~km}$ of fencing along the border and $400 \mathrm{~km}$ border roads (Singh 2015). The CCS also gave an extension to the border fencing project till 2019 as the March 2014 target could not be met due to various issues like land acquisition, forest clearance, rough terrain and public protest. In May 2015, Union Home Minister Rajnath Singh had written to the respective chief ministers of states sharing border with Bangladesh asking them to expedite land acquisition so that fencing could be completed in these states. In January 2016, Singh announced that construction of the barbed-wire fence along the Assam stretch of the Indo-Bangladesh border would be completed by the end of 2016. 'There will be no dearth of funds for this. Moreover, certain gaps that exist in the already installed fence will also be filled up soon', Singh said (Kashyap 2016).

\section{Conclusion}

With the passage of time, policy making with regard to illegal migration continues to grow more complex. While in its earlier phase, it required simple determination of the regime to cleanse the land of most foreigners, the protraction of the problem now negates the effectiveness of any such simplistic endeavour. The political weight of the migrants and the inclination of the regimes to exploit that in a highly polarized milieu, precludes the possibility of any future scenario where 
the presence of the migrants can be controlled and is as per the terms laid down by the state.

As emphasized earlier, while illegal migration can certainly be deterred, its complete prevention is an unrealizable objective. Within this narrow window of opportunity, governments need to strive to control the presence of the foreigners on India's soil. Amid several suggestions that have been provided, one that recognizes both the pregnable nature of any border control mechanism and the economic utility of the migrants appears to be most useful. As Sanjoy Hazarika opines,

We need to follow the system already in place in Meghalaya, where immigrants are only allowed to work and not own land or property. At the same time, they will not be given voting rights so that politicians cannot exploit the situation. This will also help solve the immigrants' problems as they will be able to earn a livelihood.

(Pednekar 2012)

Whether the NDA regime, known mostly for its anti-migrant stand and repeated assertions, can garner the political will and strength to work towards such a scenario and mobilize support within the region to that effect would remain something to watch out for.

\section{Notes}

1 This is a revised version of the paper titled 'Illegal Bangladeshi Migration into the Northeast: Policy Making, Politics and Hurdles', Eastern Quarterly, 7(3\&4): 90-103, 2011.

2 This statement was made during the judgment in the case involving Mohammad Kamruddin alias Kamaluddin in July 2008. Fifty-two-yearold Kamaluddin, holding a Pakistani passport was believed to have entered Assam through Bangladesh. He not only lived in Moirajhar village in Nagaon district long enough to father six kids, but went on to contest the State Assembly elections in 1996 from Jamunamukh constituency. Kamaluddin had been deported to Bangladesh twice but returned with little difficulty to his wife Dilwara Begum. See Routray (2012: 64-66), http://issuu.com/ newsline/docs/e-mag_geo_sep_12/65. Accessed on 31 October 2012.

3 Statement of Home Minister in Rajya Sabha on Recent Violence in Assam, Press Information Bureau, Government of India, 9 August 2012. http:// pib.nic.in/newsite/PrintRelease .aspx? relid=85875. Accessed on 31 October 2012.

4 The complexity of the border is narrated in a handout of the Union Ministry of Home Affairs. It reads, 'The entire stretch consists of plain, riverine, hilly/jungle and with hardly any natural obstacles. The area is heavily populated, and the cultivation is carried out till the last inch of the border at many stretches'. See Management of Indo-Bangladesh Border, Union 
Ministry of Home Affairs, Government of India. http://mha.nic.in/pdfs/ BM_MAN-IN-BANG(E).pdf. Accessed on 4 November 2012.

5 'No Details about Magnitude of Illegal Migration from Bangladesh, Says Government', Economic Times, 6 September 2012. http://articles.economic times.indiatimes.com/2012-09-06/news/33650226_1_illegal-migration-ille gal-migrants-assam-chief-minister. Accessed on 31 October 2012.

6 Minister of State for Home Affairs, Mullappally Ramachandran, Answer to Unstarred Question No. 3792, Lok Sabha, Indian Parliament, 4 September 2012.

7 Mullappally Ramachandran, Minister of State for Home Affairs, Government of India, answer to Unstarred Question No. 7435, dated 22 May 2012 by Chandrakant Bhaurao Khaire.

8 'IMDT Act Is the Biggest Barrier to Deportation, Says Supreme Court', The Hindu, 14 July 2005. www.hindu.com/2005/07/14/stories/200507140 5551200.htm. Accessed on 4 November 2012.

9 'Apex Court Bars Back-Door Entry of IMDT Act', Economic Times, 6 December 2006. http://articles.economictimes.indiatimes.com/2006-1206/news/27459228_1_illegal-immigrants-imdt-act-tribunals. Accessed on 23 October 2012.

10 '500 Inmates in Assam Camps Flee to Bangladesh Fearing Verification', Indian Express, 12 September 2012. www.indianexpress.com/news/500inmates-in-assam-camps-flee-to-bangladesh-fearing-verification/1001 705/. Accessed on 2 October 2012.

\section{References}

Anurag, K. 2012. 'Infiltration Not the Biggest Issue in Assam: Gogoi', Rediff, 20 October. www.rediff.com/news/report/infiltration-not-the-biggest-issuein-assam-gogoi/20121020.htm. Accessed on 5 November 2012.

Choudhury, Sunetra and Kishalay Bhattacharjee. 2009. 'Congress Changes Stance on Bangladeshis', NDTV, 13 January. http://ndtv.com/convergence/ ndtv/story.aspx?id=NEWEN20090079926\&ch $=633674792148370000$. Accessed on 31 October 2012.

Debroy, Bibek. 2010. 'Work Permits for Bangladesh', Indian Express, 3 December.

Kashyap, Samudra Gupta. 2016. 'Bangladesh Border Fence in Assam to Be Completed This Year: Rajnath Singh', Indian Express, 4 January. http:// indianexpress.com/article/india/india-news-india/rajnath-singh-promisesto-complete-bangladesh-border-fence-by-year-end/. Accessed on 28 April 2016.

Pai, Nitin. 2012. 'Fixing the Migration "Problem”', Business Standard, 30 July. Pednekar, Puja. 2012. 'Land Alienation at the Root, Say Experts', Daily News \& Analyses, 8 October. www.dnaindia.com/mumbai/report_land-alienation-atthe-root-say-experts_1750047. Accessed on 6 November 2012.

Phukan, Abir. 2012. 'Price of Inaction', Frontline, 29(16), 11-24 August. www. frontlineonnet.com/fl2916/stories/20120824291601700.htm. Accessed on 12 October 2012. 
Raghavan, B. S. 2007. 'The Killing Fields of Assam', Hindu Businessline, 15 August. www.thehindubusinessline.com/todays-paper/tp-opinion/article166 6479.ece. Accessed on 31 October 2012.

Routray, Bibhu Prasad. 2002. 'The Healing Wounds of Migration in Assam', IPCS Article No. 714, 13 March. www.ipcs.org/article/military/the-healingwounds-of-migration-in-assam-714.html. Accessed on 3 November 2012.

Routray, Bibhu Prasad. 2012. 'Migrants or Settlers?', Geopolitics, 3(4): 64-6, September.

Singh, I. P. 2012. 'Can't Assure Zero Entrance through Bangladesh Border: BSF Director General', Times of India, 29 August. http://articles.timesofin dia.indiatimes.com/2012-08-29/india/33475262_1_punjab-frontier-bsf-dgbsf-director. Accessed on 28 October 2012.

Singh, Vijaita. 2015. 'India Plans Big Project Along Bangladesh Border', The Hindu, 14 October. www.thehindu.com/news/national/india-plans-bigproject-along-bangladesh-border/article7758328.ece. Accessed on 28 April 2016.

Varadarajan, Siddharth. 2012. 'Migration in Assam Is on the Decline', The Hindu, 10 September. www.thehindu.com/opinion/interview/article387 8211.ece. Accessed on 30 October 2012. 


\section{Employment, unemployment, job aspiration and migration \\ Some reflections of Tangkhul migrants to Delhi ${ }^{1}$}

\section{Reimeingam Marchang}

Unemployment denotes a condition of joblessness and the existence of a reserve labour time available for utilization. The unemployed are out of work full-time and are seeking/available for work. But the terms seeking/available for work are hard to define. A person may be available for work next week, or tomorrow, but not today (Sinclair 1987: 1). The widespread prevalence of educated unemployment is attributed to the too literary nature of education and limited formal employment opportunities. Educated unemployed are those persons who have attained an educational level of secondary and above, and attained age of fifteen years or above and are seeking/ available for work (GoI 2011). Young people who had prolonged their studies for a longer period were more likely to have higher aspirations. Young people have become more ambitious and better qualified, while their employment opportunities have narrowed (Roberts 1985: 131). Moreover, there has been a 'widespread and persistent upgrading of minimum hiring standards in India' (Blaug, Layard and Woodhall 1969: 5). This suggests that the better educated must, after varying periods of unemployment during which aspirations are scaled downward, take jobs requiring lower levels of education (Todaro 1991: 339).

The young job seekers adapt to the nature of the labour market faced by them and adjust their aspirations and work preferences over a period of time. An individual's job preference is influenced by income expectation, location of proposed employment, nature and status of the job, short-term and long-term prospects (Marga 1974: 19) or levels of pay and travelling distance for employment (Roberts 1985: 135). The unemployment rate falls as the person grows older due to the increase in economic responsibility. Normally the youth who are educated can remain unemployed by depending on family income. Puttaswamaiah ascertained that educated unemployment is 
presumably a consequence of the general impression among the public that investment in education by an individual should yield a return in terms of remunerative job, search for a job suited to the particular type of education received and decline in acceptance of job other than office jobs (Puttaswamaiah 1977: 100-1).

Migrant, according to the Census of India, is a person if the place of birth (POB) or place of last residence (POLR) is different from the place of enumeration. A person is considered as a migrant by $\mathrm{POB}$ if the place in which the person is enumerated during the census is other than the person's POB. And a person is considered as migrant by POLR if the place in which the person is enumerated during the census is other than the person's place of immediate last residence. Migrants defined on the basis of POB or POLR are called the lifetime migrants because the time of their move is not known (Visaria 1980: 2). Migration is to 'achieve maximum individual satisfaction through obtaining better employment or wage or security or environment' (Santhapparaj 1996: 269). Meanwhile, numerous studies in Britain have found that the propensity to migrate increases with rising educational qualifications (as cited in Cote 1997: 56).

The chapter analyses the issues concerning employment, unemployment, job aspiration and migration from Manipur to Delhi in recent decades. Though migration by unemployed youths from the Northeast to the metropolis is taking place on a much larger scale, I have confined myself to a particular ethnic group from Manipur into the city of Delhi. This makes the study more focused at the micro level.

\section{Data sources and methodology}

The secondary data from Directorate General of Employment and Training (DGET), National Sample Survey (NSS) and Indian Census is used for validation by using primary data on Tangkhul migrants from Ukhrul district of Manipur to the national capital Delhi. In order to understand the formal employment opportunities and constraints the scenario of organized employment, where most of the educated people sought for jobs - covering public and private sectors using DGET data - are examined for Manipur by comparing with the national pattern and trend. Unemployment, usual principal status (UPS), is analysed for Manipur in relation with the national average based on NSS data from 1993-94 onwards. To some extent an attempt is made to link the study of unemployment with migration phenomenon from Manipur to the National Capital Region (NCR) of Delhi based on the available census data since 1981 . 
The primary data was collected from a survey, conducted by this author, using structured and semi-structured questionnaires in 2007. A stratified and simple random sampling technique was adopted in selecting the sample. The sample population is taken from twenty villages of origin from Ukhrul district on the basis of their population size in Delhi based on the census of Tangkhul Katamnao Long Delhi (TKLD) ${ }^{2}$ during 2004-05. According to TKLD census, Tangkhuls have migrated from ninety-nine villages from the Ukhrul district to Delhi. These villages are categorized into three groups for sample selection such as large, medium and small on the basis of their population size in Delhi. For the present study, fifteen villages in the large segment population and five villages from medium population were drawn randomly and are being taken up. With the help of contact addresses given in the TKLD census, a comprehensive survey was conducted covering 323 respondents. It also ascertained the 'newcomers' (newly arrived Tangkhuls in Delhi) with the help of 'old timers' (older Tangkhuls in Delhi) of the sample villages. And during the survey it was observed that some of the migrants had already left Delhi.

\section{Employment in organized sector}

Organized employment generation capacity would address the problem of unemployment particularly among the educated whose aspiration is acquiring a formal and decent salaried job. The burgeoning educated unemployment in Manipur is due to the stagnant organized employment growth. Employment generation in the organized sector has slightly declined from 0.83 lakh in 2002 to 0.79 lakh in 2012, mainly due to decline of employment in the public sector. In contrast, the country's organized employment has increased due to the rise of employment in the private sector during the same period. In 2012, about 96 per cent of the employed in the organized sector in Manipur were working in the public sector and the remaining 4 per cent were in the private sector (Table 11.1), whereas in India, the private sector is increasingly engaging in generating and providing employment opportunities.

Downsizing of government job is responsible for the decline of public sector employment. Concurrently, the rapid growth of private sector has offshoot the performance of private sector employment generation. Private sector contributed as large as 40 per cent of the organized employment in 2012 in the country, against 4 per cent private sector employment in the state. In Manipur, as in the country, less than a quarter of the organized employment was females. This is associated with the prevalence of higher educated unemployment among the females, as discussed 
Table 11.1 Distribution (\%) of employment in organized sector in Manipur/ India

\begin{tabular}{|c|c|c|c|c|c|c|c|}
\hline \multirow{2}{*}{$\begin{array}{l}\text { Statel } \\
\text { Country }\end{array}$} & \multirow[t]{2}{*}{ Sector } & \multicolumn{2}{|l|}{ All } & \multicolumn{2}{|l|}{ Females } & \multicolumn{2}{|c|}{ Females $\%$ All } \\
\hline & & 2002 & 2012 & 2002 & 2012 & 2002 & 2012 \\
\hline \multirow[t]{3}{*}{ Manipur } & Public & 96.7 & 96.2 & 94.8 & 96.6 & 22.7 & 24.2 \\
\hline & Private & 3.3 & 3.8 & 5.2 & 3.4 & 37.0 & 21.3 \\
\hline & Total & $(0.83)$ & $(0.79)$ & $(0.19)$ & $(0.19)$ & 23.2 & 24.1 \\
\hline \multirow[t]{3}{*}{ India* } & Public & 69.0 & 59.5 & 58.5 & 52.1 & 15.4 & 17.9 \\
\hline & Private & 31.0 & 40.5 & 41.5 & 47.9 & 24.3 & 24.2 \\
\hline & Total & $(272.06)$ & $(295.79)$ & $(49.35)$ & $(60.54)$ & 18.1 & 20.5 \\
\hline
\end{tabular}

Notes: Figures in the parentheses are number in lakh. 'Employment Market Information Programme is being implemented in all the States and Union Territories of the country except Arunachal Pradesh, Sikkim, Dadra \& Nagar Haveli and Lakshadweep. The programme could not be extended to these States/UTs so far due to administrative reasons' (Ministry of Labour and Employment 2015: 2).

*India excludes these four States/UTs.

Sources: For 2002 from www.indiastat.com/table/labourandworkforce/380987/employ mentinorganisedsector/18526/293412/data.aspx. Accessed on 9 April 2015; and for 2012 from Ministry of Labour and Employment (2015).

later, as they aspire for formal employment like their counterpart males. Interestingly, female employment in the organized sector has showed an improvement particularly in the public sector.

In Manipur, government jobs including central, state, quasi-central, quasi-state and local bodies have slightly declined from 0.78 lakh in 2004 to 0.77 lakh in 2012. Central government, state government and state government quasi-jobs have declined as the shares of these shows a declining trend in the state over the same period (Table 11.2). However, jobs in central government quasi and local bodies slightly improved. Concerning private sector employment, larger establishments were stagnant; however, smaller establishments showed an improvement over the years. For the country, government jobs have declined across the branches. Further, organized employment in Manipur is not growing at par with other states of India, which is evident from the declining share of employment in organized sector. Manipur contributes 0.30 per cent in the total organized employment in the country in 2004 that has declined to 0.27 per cent in 2012. It is a disturbing situation in the labour market in the state where educated people who are aspiring for formal organized sector jobs are increasingly growing. This situation stimulates the educated people to migrate outside the state such as Delhi to fulfil their job aspirations. 
Table 11.2 Branch-wise distribution (\%) of employment in organized sector in Manipur/India

\begin{tabular}{|c|c|c|c|c|c|c|}
\hline \multirow[t]{2}{*}{ Branch } & \multicolumn{2}{|c|}{ Manipur } & \multicolumn{2}{|l|}{ India* } & \multicolumn{2}{|c|}{ Manipur \% India } \\
\hline & 2004 & 2012 & 2004 & 2012 & 2004 & 2012 \\
\hline Central Govt & 5.6 & 5.0 & 11.4 & 8.5 & 0.15 & 0.16 \\
\hline State Govt & 76.4 & 76.3 & 27.3 & 24.3 & 0.86 & 0.85 \\
\hline $\begin{array}{l}\text { Central Govt } \\
\text { Quasi }\end{array}$ & 5.2 & 6.3 & 12.5 & 11.7 & 0.13 & 0.14 \\
\hline $\begin{array}{l}\text { State Govt } \\
\text { Quasi }\end{array}$ & 4.2 & 3.8 & 9.5 & 7.9 & 0.13 & 0.13 \\
\hline Local Bodies & 4.9 & 5.0 & 8.0 & 7.1 & 0.19 & 0.19 \\
\hline Larger Ests & 2.5 & 2.5 & 27.4 & 36.2 & 0.03 & 0.02 \\
\hline Smaller Ests & 0.7 & 1.3 & 3.8 & 4.2 & 0.06 & 0.08 \\
\hline Total & $(0.81)$ & $(0.79)$ & $(264.43)$ & $(295.79)$ & 0.30 & 0.27 \\
\hline
\end{tabular}

Notes: Figures in the parentheses are number in lakh. 'Employment Market Information Programme is being implemented in all the States and Union Territories of the country except Arunachal Pradesh, Sikkim, Dadra \& Nagar Haveli and Lakshadweep. The programme could not be extended to these States/UTs so far due to administrative reasons' (Ministry of Labour and Employment 2015: 2).

*India excludes these four States/UTs. Establishments (Essts) employing twenty-five or more persons are categorized as larger establishments and those employing 10-24 persons are termed as smaller establishments (http://dget.nic.in/upload/uploadfiles/files/ publication/CHAPTER1.pdf, p. 3).

Sources: For 2004 from www.indiastat.com/labourandworkforce/380987/employment/ 85/employmentinorganisedsector/18526/stats.aspx and for 2012 from Ministry of Labour and Employment (2015).

\section{Unemployment and job aspiration}

In spite of several efforts, in a labour surplus economy like India many people remain unemployed and continue to search or to be available for employment. Some may be chronically unemployed and some intermittently unemployed due to seasonal fluctuations in the labour market (GoI 1997: 129). Any change in the condition of business, transport and industry reflects to urban employment level. Agricultural unemployment is the major problem in rural areas. The problem of unemployment is more severe in urban areas as the rate of unemployment was considerably higher in urban than rural areas in Manipur, following the national pattern, for both genders throughout the period. This is due to a large participation in economic activities as part-time workers, particularly in agriculture sector in rural areas. Unemployment problem is more severe in urban areas due to rise in educated people and migration from rural to urban areas for 
non-agricultural jobs. The dominance of organized sector for employment where the normal entry age for jobs is in the mid-twenties resulted in more unemployment among the urban people. Furthermore, Hazra has pointed out that 'it is the failure of the organized sector to absorb labour at a significantly increased rate which is one major reason for the persistence of various types of unemployment within the organised sector' (Suzan 1991: 40).

In Manipur the problem of unemployment has hit harder in rural areas as the rate of unemployment has gradually increased from 1.9 per cent during 1993-94 to 4.2 per cent during 2009-10 for rural males. It has also increased for rural females to a similar extent. In urban areas, it has increased from 1993-94 to 1999-2000; however, it considerably declined thereafter particularly for females, as presented in Table 11.3.

At the national average, the rate hovers around 2 per cent for rural males throughout the period. For rural females, it has increased gradually till 2004-05, however, slightly declined in the following period. In urban areas, it has declined from 4.5 per cent in 1993-94 to 3 per cent in 2009-10 for males. Similarly, for urban females, it has declined by about one percentage point during the same period. In general, unemployment has declined in the recent period particularly in urban areas. In the 1990s, unemployment problem was less severe for females as compared to males; however, it has emerged that females faced more problem of unemployment in the recent years in rural areas of Manipur following the national pattern. In urban areas, at the national

Table 11.3 UPS unemployment rates (\%) and educated unemployment rates for $15+$ years $(\%)$ in Manipur/India

\begin{tabular}{|c|c|c|c|c|c|c|c|c|c|}
\hline \multirow{3}{*}{$\begin{array}{l}\text { Statel } \\
\text { country }\end{array}$} & \multirow[t]{3}{*}{ Year } & \multicolumn{4}{|c|}{ Unemployment rates } & \multicolumn{4}{|c|}{ Educated unemployment rates } \\
\hline & & \multicolumn{2}{|c|}{ Rural } & \multicolumn{2}{|c|}{ Urban } & \multicolumn{2}{|l|}{ Rural } & \multicolumn{2}{|c|}{ Urban } \\
\hline & & Male & Female & Male & Female & Male & Female & Male & Female \\
\hline \multirow[t]{4}{*}{ Manipur } & 1993-94 & 1.9 & 1.1 & 5.3 & 4.4 & 6.5 & 6.1 & 10.2 & 10.1 \\
\hline & 1999-2000 & 2.4 & 2.5 & 7.4 & 10.3 & 6.3 & 13.1 & 11.4 & 19.3 \\
\hline & 2004-05 & 2.0 & 1.2 & 5.3 & 8.2 & 6.5 & 8.6 & 8.5 & 14.6 \\
\hline & 2009-10 & 4.2 & 4.4 & 5.2 & 4.6 & 6.8 & 15.3 & 6.3 & 7.2 \\
\hline \multirow[t]{4}{*}{ India } & 1993-94 & 2.0 & 1.4 & 4.5 & 8.2 & 8.8 & 24.9 & 6.9 & 20.6 \\
\hline & 1999-2000 & 2.1 & 1.5 & 4.8 & 7.1 & 6.8 & 20.4 & 6.6 & 16.3 \\
\hline & 2004-05 & 2.1 & 3.1 & 4.4 & 9.1 & 5.9 & 23.1 & 6.0 & 19.4 \\
\hline & 2009-10 & 1.9 & 2.4 & 3.0 & 7.0 & 4.1 & 15.7 & 3.8 & 13.9 \\
\hline
\end{tabular}

Source: NSSO (1997, 2001, 2006 and 2011). 
level, unemployment problem continues to be more severe for females than males as the rate continues to be considerably higher for females. Manipur also follows the national pattern from 1999-2000 up to 2004-05; however, it folds back to the 1990s pattern of lesser severity of unemployment problem for females as compared to the males in 2009-10. It is due to the increase in outmigration towards big cities like Delhi where opportunities are considered abundant.

Concurrently, students contesting in educational system and their aspirations have increased. The longer stay in what may be called the educational contest, due to the rising income of parents, has resulted in a considerable increase in the proportion of educated. According to a report of National Sample Survey Organisation (NSSO) 2004-05, a little more than 18 per cent of the rural people, against about 36 per cent in urban areas, had completed secondary and above educational level. Despite the rapidly rising literacy rate, a majority of the literate remained uneducated particularly in rural areas resulting in unemployment due to non-employability or non-availability of job. Nevertheless, people are voluntarily unemployed due to their higher aspiration and preference of salaried job and place of work. The limitation of employment generation in the organized sector creates the problem of educated unemployment. As Parthasarathy and Nirmala commented, the 'educated seek employment mainly in the public/private organized sector' (Parthasarathy and Nirmala 2000: 691). This is true in the case of Manipur where the educated set targets and aspire for jobs - mostly secured government jobs. Gumber has also remarked that the 'educated persons look for specific kinds of employment opportunities and remain unemployed till they get such work' (Gumber 2000: 659).

The problem of educated unemployment originated from the system of education and the rapidly changing employment structure. According to Puttaswamaiah, the "theoretical bias in Indian educational system results in most of our educated job-seekers having very little aptitude and technical qualifications for various types of works' (1977: 100). However, in recent times, the system has been reoriented and restructured to some extent as the economy demands. Yet, the system is of much speculation that schools have 'failed to build bridges with employers' and have 'failed to produce youngsters who are employable' (Watson 1983: 6). Significantly, NSS data shows that educated unemployment rate was more or less stable at about 7 per cent for the rural males of Manipur throughout the period. In case of rural females, it has increased considerably in the 1990s indicating the rate of outmigration and employment generation in the state is unable to meet the ever-rising demand for job. However, to some extent the 
state was relieved from the problem of female educated unemployment problem as the rate declined to 8.6 per cent during 2004-05. The situation worsens in the following period as it considerably increased to 15.3 per cent. Its increase is due to the slow employment generation and increase in seeking formal jobs as the level of education increases besides an increase in the agriculture density.

In Manipur the problem of educated unemployment was more severe in urban areas till 2004-05, which is against the national pattern. Later, it became milder in urban areas as the rate shows considerably lower in urban areas for females in particular. In the 1990s, it has increased; however, later it has rapidly declined in urban areas due to the result of outmigration in search of jobs among the educated, as their aspiration does not fit in the existing labour market reality in Manipur. To an extent, the problem of urban educated unemployment is a spillover effect of the same from rural areas. The decline in the rate is because after spells of unemployment the educated unemployed after experiencing greater difficulty in finding the aspired job is often 'obliged to trade down and accept second or third best job' (Roberts 1985: 135).

In India, remarkably, the educated unemployment rate has declined throughout the period for males in both the areas. Large private investors were attracted in the period of economic reform in the 1990s, which boosted the economy through employment generations in the country. The rate also declined in the 1990s; however, it increased in the latter period for females. It has declined considerably in the recent period in both the rural and urban areas partially due to the implementation of various central programmes and schemes of employment. The problem is more severe in rural areas particularly among females with a high prevalence of unemployment rates due to restriction in migration. The concentration of formal jobs in urban areas, which are mostly sought and aspired by the educated, also attributed to the situation. Formal jobs in rural areas are generally very limited. The situation highlights the preference and aspiration of formal jobs that arises due to increase in educational level. In addition, it is attributed by the sizable return of migrants to their rural origin after they failed to get job in urban areas, withdrawal of financial support by their family or return for social obligation like marriage as they grow older. Return migration flow is generated when a person in general and workers in particular who have just migrated are extremely likely to move back to their original location (George 2005: 319).

During 2009-10, unemployment problem in Manipur is more severe than national level for males in both the urban and rural areas. 


\section{Reimeingam Marchang}

This situation arises perceivably due to a sizable number of return migrants to their native state amidst a growing number of unemployed among the non-migrants. Unemployment problem can be reduced by increasing seats in higher educational institution; create, support and promote self-employment; or promote migration. According to Parasuraman (1989: 114-16), the 'nature of formal schooling in India is not particularly job-oriented and hence more and more educated end up unemployed'. In Manipur like in any developing nation, 'each worsening of the employment situation calls forth an increased demand for more formal education at all levels' (Todaro 1991: 339). For the Indian educational system is envisaged to restructure towards a job-oriented system. The educated unemployed mostly seek for a specific kind of job particularly in organized sector unlike the general unemployed. In order to reduce the problem of unemployment, the unemployed should try to fit in or accept the available job rather than waiting for a particular job which are limited and time-consuming. The educated unemployment rate was considerably higher than the general unemployment rates for Manipur as well as India for both the genders in both the areas. Parthasarathy and Nirmala ascertained that the 'educated seek employment mainly in the public/private organized sector' (Parthasarathy and Nirmala 2000: 691).

Employment opportunities are booming in specific regions due to the increased inflow of capital markets as the country's economy becomes stronger and stabilizes. In the process the tendency to migrate or transfer labour from the less developed regions such as Manipur towards big cities like Delhi in search of jobs has increased. In recent years 'new employment opportunities are coming up in selective sectors and in a few regions/urban centres' (Kundu 2007: 353). The economy of Manipur should be stabilized and developed along with a plan for greater employment generation by creating a conducive environment for private investors.

However, a majority of the unemployed still aspire for the so-called government job as they consider it as the real and only job which gives economic security and social status. Dignity of work needs to be safeguarded and promoted across all social and economic class, while contractual and casual work has increased even in the government sector. Government does create jobs but far lesser than the rapidly increasing supply of labour. Arguably, private sector employees are more efficient and productive than the government counterparts. Disinvestment of public holdings is a valid example. Arguably, large numbers of government sector employees in Manipur are a 'slack' and corrupted where their contribution to the state income is negligible. As 
a consequence the state is developing at the pace of a snail resulting to slow employment generation, which rendered people unemployed and induced to migrate from the state in search of aspired employment corresponding to their educational qualifications. Ironically, the Government of Manipur provides a majority of the formal jobs, as discussed earlier, partially due to the existing unfavourable socio-political problems, whereas private investors are averting the risk to establish their business.

\section{Migration from Manipur}

Migration from Manipur is increasing over the years in order to maximize one's economic and social wellbeing. Faggian and McCann stated that 'people migrate to maximise welfare' (2006: 480). This is true in our case study. The prevailing unfavourable social, economic as well as political conditions of the state acted as the push factors of migration. According to the Census of India, in 1981 a total number of 787 migrants defined by POLR with all-duration of residence have migrated from Manipur to Delhi. This number has increased to 1,266 in the following decade, and then further increased to 5,481 in 2001. The 2011 census data, which was not released till mid-2016, revealed a significant increase of migrants from the state to Delhi due to the improvement in the levels of education and income apart from improvement in social networking and the systems of information, communication and transport. The opening up of new employment opportunities due to industrial growth, inflow of capital, investment growth, market expansion in diversified economic activities and other economic growth drivers in the national capital region Delhi acted as the pull factors. Migration is rapidly growing even from the remote areas due to the increase in access of communication technology creating a phenomenon of chain migration. Chain migration can be defined as that movement in which prospective migrants learn of opportunities, are provided with transportation, and have initial accommodation and employment arrangements by means of primary social relationships with previous migrants (MacDonald and MacDonald 1964: 82). In addition, like other people of North Eastern states, having a pleasant nature of hospitality and positive attitude towards job, being dutiful to their assigned job and having decent accent of English facilitate people of Manipur in getting a job in hospitality services, shopping malls or customer care services. The tendency to migrate is greater for males than females as the sex ratio of migrants was low at 748 in 2001. Migrants from Manipur, by POLR with duration of residence of $0-9$ years, to Delhi were mostly 
Table 11.4 Distribution (\%) of reasons of migration for migrants (by POLR with all-duration of residence) from Manipur to Delhi (NCT)

\begin{tabular}{|c|c|c|c|c|c|c|}
\hline \multirow[t]{2}{*}{ Year } & \multicolumn{2}{|c|}{ Work/employment } & \multicolumn{2}{|c|}{ Education } & \multicolumn{2}{|l|}{ Others } \\
\hline & Males & Females & Males & Females & Males & Females \\
\hline 1981 & 24.2 & 5.9 & 34.3 & 8.8 & 41.5 & 85.3 \\
\hline 1991 & 37.9 & 7.1 & 27.8 & 12.5 & 34.4 & 80.4 \\
\hline 2001 & 37.7 & 10.2 & 32.5 & 21.2 & 29.8 & 68.7 \\
\hline
\end{tabular}

Note: Movement for economic reasons such as setting up of shops, starting of business, etc. were included in the category 'others' in 1981; however, 'business' was separately categorized in 1991 and 2001. Thus, for comparability the category 'business' of 1991 and 2001 was club bed together in 'others'. Others in the present analysis includes marriage, move after birth, moved with household, natural calamities, movement due to retirement, movement for economic reasons such as setting up of shops, starting of business, etc. (business of 1991 and 2001), and all other reasons for migration not covered by work/employment and education. A total migrant is the sum of migrants for employment, education and others.

Source: Census of India (1981, 1991, 2001).

youth in the age group of 15-29 years at 64 per cent (against 30 per cent of youth in the total population in Manipur) in 2001. Employment and education were the main reasons for migration among the migrants (by POLR with all-duration of residence) from the state particularly for the males (Table 11.4).

Migration for employment and education has increased for both the genders over the years. The trend implies that the rising unemployment partially acts as the cause for migration. People from Manipur tend to migrate to Delhi as the system of education, and the job opportunities are enormous in and around Delhi. The process continues in the form of 'repeat' migration. This form of migration is generated when the migrants are likely to move onward to still other locations (George 2005: 319). Interestingly, many people across all communities from the state are venturing into various types of businesses and generate some employment avenues in Delhi in recent times.

\section{Aspiration of Tangkhul migrants to Delhi}

Tangkhuls, mostly youth, are increasingly migrating from the Ukhrul district of Manipur to Delhi. There is a growing number of educated youth in the district, who constitute about 30 per cent of the district population. Lack of adequate educational infrastructures and problems of growing unemployment at home has driven many to choose 
Delhi for their career and jobs. To them, Delhi is the centre that facilitates better educational system and employment opportunities. About 96 per cent of the migrants fall in the age group of 15-29 years. They mostly migrated after the completion of at least the matriculate exam. The process of migration was largely a chain migration because most of them already have their relatives or at least known persons in Delhi who provide basic requirements and facilitate in finding accommodation, admission or even a job at the time of migrating to Delhi. Family members, relatives and friends who have previously migrated may provide information about their present locations to persons residing in their former place of residence. Former migrants may also provide temporary food and shelter and ease the social transition. Such cases have been studied and proven elsewhere also.

Most of the migrants were recent migrants who have come in recent years for education and jobs. Only few of them were found married and the rest were living in rented houses either with their family members or relatives. They later stayed with their family members/relatives for easy social networks and lower financial costs of living. Most of them studied arts followed by science, commerce and vocational subjects. The majority of them graduated in degree courses in humanities and social sciences that do not give easy placements for jobs. One of their main aspirations is to get a government job after degree courses. Therefore, most males after completing their education continue to stay back in Delhi and prepare for civil service and other competitive examinations.

The male workers largely are found working in the business process outsourcing (BPO) sector (call centres), which fetches a relatively higher salary for fresh graduates. Females who are mostly in their late teens and early twenties migrated specifically for employment after completing their higher secondary education, this indicates that females do not continue to study, but seek employment at a younger age (compared to males) due to either domestic economic pressures or their reluctance to pursue higher studies. They mostly work in private shops, hotels, restaurants, parlours and the like, constituting about 62 per cent of the workforce. It is also interesting to notice that there is a sea change in the concept of jobs among the Tangkhul females. They work in retail shops, malls, hotels, restaurants, front desk private offices or in the BPO sector. It was also evident that females make a profound contribution by financing their siblings' educational expenses. Female graduates are mostly employed in call centres indicating that increase in educational level enables them to meet their aspirations in terms of earning. 
The work participation rate was about 48 per cent for females against a lower rate of about 31 per cent for males. This difference is due to variation in the flexibility in choosing jobs, reluctance to continue after secondary education, different aspirations for government jobs and domestic and individual economic pressures. It portrays a loosening notion of dependence on males, a narrowing down of gap in earning and demonstrating capabilities. It exhibits the neglected value of household works performed in terms of money value. The females who worked in the above sectors are found financing their siblings' education and preparation for civil service and other competitive examinations. However, the high workforce participation rate (WPR) of females does not suggest there was a male child preference for education because it was evident that the sex ratio of Tangkhul students in Delhi was high. It was due to the prevalence of a high unemployment rate among the males.

The problem of unemployment was more severe for the males as the rate of unemployment, measured between the ratio of persons seeking/available for work among the nonworkers (unemployed) and the labour force (workers plus unemployed), was prevailing at about 40 per cent against about 18 per cent for females. It is due to high preference, expectation and aspiration of jobs. The question of employability due to too general educational background is the other reason. They prefer employment in public sector, which will give a sense of permanency and security, with about 46 per cent private sector than self-employment. Most of them are seeking employment for more than half a year, suggesting the difficulty in getting a job due to tougher competition. The above condition suggests an approach of education to a professional and job-oriented education.

Many of the employed were unsatisfied with their present job; about 34 per cent of the employed were seeking new jobs because they consider that their present work is not remunerative enough, unpleasant working hours and mainly due to the desire for a permanent government job. Amidst the existing labour problems, the Tangkhul society recognizes a government job as a real and only job, which gives economic security apart from gaining social status. Undoubtedly, migration from the district is due to the problem of unemployment in Manipur, which could be validated as most of the employed people opined that they were willing to transfer to Manipur if the employment opportunities are given there. In addition, a study by Lakshminarayana ascertained that migrants 'wait for an opportunity to come back to their home state, even for a lesser salary' (Lakshminarayana 1985: 83). 


\section{Conclusion}

Organized sector employment that is mostly state government employment has shrunk, resulting in an alarming educated unemployment problem in Manipur. As a consequence, an educated unemployed is increasingly migrating to metropolizes like Delhi in search of better employment opportunities. The availability of wide range of formal and informal sectors for salaried jobs, both in public and private sectors, pull these migrants. This is due to inadequate employment opportunities in Manipur and rising job aspirations in terms of secured government jobs. The high prevalence of educated unemployed amidst the increasing job aspirations and limited job opportunities in the state apart from social or political unrest are the major factors that push them to migrate. Unemployment problem is mitigated by outmigration from Manipur especially among the Tangkhuls. However, migration is not favourable in the area of migration destination because it raises the problem of unemployment in it. Generally, an increase in educational attainment raises the aspiration of the young educated unemployed, while there emerges a narrowing down of employment opportunities and upgrading of minimum hiring standards. As a result, the unemployed scale down their job preferences and aspirations, and adjust to accept jobs of lower grade irrespective of the sector of employment. The rising level of educational attainment has raised the propensity to migrate. Migrants are mostly young, educated, unmarried and optimistic, who are in search of better opportunities. The student migrants after completion of their studies continue to seek employment either through appearing in competitive examinations or work in the private sector due to financial pressure. The problem of educated unemployment, among the Tangkhuls, is that most of them opt for educational streams that are not job-oriented or professional. Among the Tangkhul workers, a majority of the males work in call centres against the majority of the females working in the hospitality sector, malls and parlours. The level of unemployment is acute for males as they aspire and seek for permanent and secured government jobs through competitive examinations which requires a longer time. Employment level is considerably higher for the females when compared to the males, although a patriarchal social system prevails in the region. This shows the complexity of relationship between the available job avenues and individual aspirations.

\section{Notes}

1 This is a revised version of the paper titled 'Unemployment, Job Aspiration and Migration: A Case Study of Tangkhul Migrants to Delhi', Eastern Quarterly, 7(3\&4): 128-39, 2011. 


\section{Reimeingam Marchang}

2 One of the Naga student bodies, of the Tangkhul Naga community who predominantly hail from Ukhrul district, is the Tangkhul Student Union Delhi. It conducts a census covering only Tangkhuls in National Capital Region Delhi to record a basic socio-economic profile with irregular intervals.

\section{References}

Blaug, Mark, Richard Layard and Maureen Woodhall. 1969. The Causes of Graduate Unemployment in India. London: Penguin Press.

Census of India. 1981. Registrar General and Census Commissioner of India. Delhi: Ministry of Home Affairs.

Census of India. 1991. Registrar General and Census Commissioner of India. Delhi: Ministry of Home Affairs.

Census of India. 2001. Registrar General and Census Commissioner of India. Delhi: Ministry of Home Affairs.

Cote, Guy L. 1997. 'Socio-Economic Attainment, Regional Disparities, and Internal Migration', European Sociological Review, 13(1).

Faggian, Alessandra and Philip McCann. 2006. 'Human Capital Flows and Regional Knowledge Assets: A Simultaneous Equation Approach', Oxford Economic Papers, 52.

George, Borjas J. 2005. Labor Economics. New York: McGraw-Hill.

Gumber, Anil. 2000. 'Correlates of Unemployment among the Rural Youth in India: An Inter State Analysis', The Indian Journal of Labour Economics, 43(4).

Kundu, Amitabh. 2007. 'Mobility of Population', in Kaushik Basu (ed.), The Oxford Companion to Economics in India. New Delhi: Oxford University Press.

Lakshminarayana, H. D. 1985. College Youth: Challenge and Response. New Delhi: Mittal Publications.

MacDonald, John S. and Leatrice D. MacDonald. 1964. 'Chain Migration Ethnic Neighborhood Formation and Social Networks', The Milbank Memorial Fund Quarterly, 42(1), January.

Marga. 1974. Youth, Land and Employment. Colombo: Marga Publication.

Ministry of Labour and Employment. 2015. Employment Review 2012. Delhi: Ministry of Labour and Employment.

NSSO. 1997. Employment and Unemployment in India 1993-94 (Report No. 409). Delhi: MOSPI.

NSSO. 2001. Employment and Unemployment Situation in India 1999-2000 (Report No.458). Delhi: MOSPI.

NSSO. 2006. Employment and Unemployment Situation in India 2004-05 (Report No.515). Delhi: MOSPI.

NSSO. 2011. Employment and Unemployment Situation in India 2009-10 (Report No. 537). Delhi: MOSPI.

Parasuraman, S. 1989. 'Education, Employment and Training: An Exploration into the Present and Future Position of Youth in India', in P. S. Nair, Murli 
Dhar Vemuri and Faujdar Ram (eds.). Indian Youth: A Profile. New Delhi: Mittal Publications.

Parthasarathy, G. and K. A. Nirmala. 2000. 'Employment and Unemployment of Youth', The Indian Journal of Labour Economics, 43(4).

Puttaswamaiah, K. 1977. Unemployment in India: Policy for Manpower. New Delhi: Oxford and IBH Publishing Co.

Roberts, Kenneth. 1985. Youth and Leisure. London: George Allen and Unwin Ltd.

Santhapparaj, A. Solucis. 1996. 'Job Search and Earnings of Migrants in Urban Labour Market: A Study of Madurai Metropolis', The Indian Journal of Labour Economics, 39(2).

Sinclair, Peter. 1987. Unemployment: Economic Theory and Evidence. New York: Basil Blackwell Ltd.

Suzan, Hazra. 1991. 'Employment in India's Organised Sector', Social Scientist, 19(7).

Todaro, Michael P. 1991. Economic Development in the Third World. New Delhi: Orient Longman.

Visaria, Pravin. 1980. 'The Level and Pattern of Economic Activity by Migration Status in India', Demography India, 9(1\&2).

Watson, Keith (ed.). 1983. Youth, Education and Employment - International Perspectives. London: Croom Helm. 
$\because$ Taylor \& Francis

http://taylorandfrancis.com 


\section{Part VI \\ Federal politics}


$\because$ Taylor \& Francis

http://taylorandfrancis.com 


\title{
12 Salvaging autonomy in India's Northeast
}

\author{
Beyond the Sixth Schedule way ${ }^{1}$
}

\author{
Kham Khan Suan Hausing
}

The Sixth Schedule is one of India's ingenious constitutional ways of recognizing the virtues of asymmetry which are prevalent in a plural socio-cultural setting. A product of entrenched tradition of isolation and contingent 'special' treatment, it was originally devised to provide a simple and inexpensive administrative set-up for the erstwhile tribal areas of Assam. Thus, autonomy couched in this schema is a contrivance to provide a sense of self-rule within the framework of a shared rule. Self-rule under this schema is intended to be a 'development catalyst' for this part of the country. However, this is seen to be problematic on the contention that 'self-rule' leverages 'separatist' demand, that is, separate 'statehood'/homeland'. This demand, in turn, was considered to have endangered the 'unity and integrity' of the State of Assam.

As a matter of fact in less than a decade of making the Autonomous District Councils (hereinafter ADCs) work under the framework of the Sixth Schedule, the hill tribes were convinced that they were substantially inadequate to protect and preserve their land, custom, tradition and identity. Based on these grounds, a demand had been made to carve out a separate Hill State within Assam ever since the 1960s, which culminated into the reorganization of the entire Northeast in 1971 (Suan 2002).

Even as a separate Hill State demand mobilized hill leaders against plains-based Assamese leaders, antagonists of the Sixth Schedule began to see in it the seeds of distrust between the hills and plains on the one hand, and on hills' separatism on the other. The seeds of distrust were exacerbated especially in a situation where the Sixth Schedule is placed under dual control of the union and the State. ${ }^{2}$ This arrangement conceptually engenders a 'split-institutional' identity. Under this rubric, the Sixth Schedule draws its identity and sustenance from the 
executive fiat of the union at the first level, and at the second level it largely depends on the State for functional purposes.

The first identity has the potential of extending elements of centralized rule to an already unitary system. In a way it amplifies the scope of having a centralizing effect on the ongoing decentralization agenda; hence autonomous arrangements have the propensity to 're-concentrate at the centre' (Bogdanor 1997: 65-87). The second identity has often been cited as an instance to erode the efficacy of autonomy arrangement per se as it advocates uninhibited dependence of the hill communities on the State, which is seen to be controlled by the majority plains people. In other words, it has the potential to redefine, as it were, the political relations between the plains and hills communities.

This chapter examines the underpinnings of autonomy enshrined in the Sixth Schedule of India's Constitution. It begins with the thesis that the onerous task of salvaging autonomy can be attempted by locating the perceived failure of the provision - starting from catering to autonomy demands and aspirations of the hill (tribal) areas of the erstwhile Assam to the very ideational premise of the Sixth Schedule.

The organization and functions of ADCs dovetailed by the Schedule are at best managerial, principally envisioned as they were, as integral parts of a benign paternalist control regime. This is discussed under the rubric of the power versus knowledge solution debate, ${ }^{3}$ which informs this premise. The chapter then examines the issue of institutionalizing autonomy demands of disparate tribal groups within a State. It argues that entrenchment of autonomy and demands for greater autonomy may not necessarily be construed as a halfway house to Statehood (Suan 2002). The real challenge of the unity and integrity of the State, it contended, would emanate from the ability/inability of the State to innovate ideas and institutions which can accommodate and democratically transform 'separatist' demands into support networks of India's federal system.

\section{Benign paternalism as managerialism: Locating the power versus knowledge solution debate ${ }^{4}$}

It is a truism that the ideational premise which underpins the Sixth Schedule of India's Constitution privileges paternal control of the state. It posits a civilizational burden on the post-colonial state to manage, as it were, the developmental affairs of the tribal communities in line with the dominant mainstream development model.

Central to this idea is the naïve assumption that the tribal 'others' for whom the administrative arrangement is considered are essentially 
seen as lacking a sense of order and organization. They are perceived to be susceptible to the 'wiles of the moneylenders'. This perception is aroused because of their traditional barter economy which was considered awfully unequal to the modern monetized economy. As a corollary, the prescribed antidote to this is paternal control of the state which privileges the 'individual' citizen over the 'community'. Hence, as B. K. Roy Burman reminded us, the erosion of the community per se and concomitant decadence of its identity and rights are embedded in the very concept of the autonomy envisioned by the Sixth Schedule (Roy Burman 1998: 81-114). I shall discuss the implication of this conceptual flaw in the next section.

Right from the onset of colonialism in the Indian subcontinent, resolving the tussle between the rights and identity of the tribal communities in order to maintain their autonomous 'societal culture' ${ }^{5}$ has been a nagging constitutional conundrum. So is the case with the post-colonial state's project to maintain its unity and integrity.

The institutional mechanism to recognize and protect antecedent autonomous 'societal culture' in the forms of the 'Inner Line Regulation' (1873), 'Scheduled District' (1874), 'Backward Tract' (1919), and the 'Partially Excluded and Excluded Areas' (1935) spawned special and asymmetrical demands. In fact, the terms of enquiry of the Bordoloi Committee, ${ }^{6}$ constituted by the Constituent Assembly on 27 February 1947, were 'to report on a scheme of administration for the tribal and excluded areas" ${ }^{7}$ which would help in 'reconciling the hill peoples' demand for political autonomy with the Assam government's drive to integrate them with the plains' (Chaube 1999: 100). The Report submitted by this Committee was thoroughly debated in the Constituent Assembly during 5-7 September 1949.

The Constituent Assembly Debates (hereinafter CAD) provided moments of interplay between the development and security paradigms which echoed in the power versus knowledge solution approaches spelt out in the course of the debates. For one thing the demands of the hill tribes to maintain separate autonomous 'societal culture' was considered to be the outcome of economic backwardness. This can be rectified, it is contended, by evolving holistic development programmes so they can be brought in line with the mainstream culture and development. Second, demands of such nature are considered to have a direct bearing on the security and thereby on the unity and integrity of the state. This development-security paradigm which heavily informed the CAD got sprinkled in the power versus knowledge solutions we have just mentioned. A careful perusal of the CAD would convincingly prove this point. The concern for security and development was 
so palpable that a member of the Constituent Assembly saw in the proposed Sixth Schedule an 'old separatist tendency'. This member contended that if the Sixth Schedule were to be enshrined in India's Constitution it would leverage not only 'misrule' or 'a primitive rule' but also culminate in the creation of 'Tribalstan' or a 'Communistan'. 8 The power solution approach emanated from this concern. It posits national interests above the so-called provincial autonomy. Brajeshwar Prasad, participating in the debate, minced no words and made his views explicitly clear when he said:

Therefore, Sir, is it right, is it safe, is it strategically desirable, is it militarily in the interests of the government of India, is it politically advisable that the administration of such a vast tract of land should be left in the hands of provincial government, especially in a province where there is no element of political stability? Sir, I love this country more than provincial autonomy. ${ }^{9}$

He went further saying, 'to vest wide political powers into the hands of tribes is the surest method of inviting chaos, anarchy and disorder throughout the length and breadth of this country'. ${ }^{10}$ In a similar tone another member, Rohini Kumar Chaudhuri, vigorously put forward this view when he said: 'If you want to keep them separate, they will combine with Tibet, they will combine with Burma, they will never combine with the rest of India'. ${ }^{11} \mathrm{He}$ underlined the fear of entirely losing the whole of tribal areas on lack of information. Forcefully stressing the policy of assimilation, he thus said: 'We want to assimilate the tribal people; we were not given that opportunity so far'. ${ }^{12}$

A critical appraisal of the context of the debate is in order here. To be sure, the long standing internal instability of Assam which is characterized by conflicts between the Ahoms and the Assamese, the Bengalis and the Muslims and the Mongoloid races alike enlarged the scope of subversive activities across porous borders with China, Tibet, Burma and Pakistan. Hence, any talk of self-determination or for that matter autonomous 'societal culture' was considered inopportune. In fact, the gory images of partition overshadowed the CAD climate so much so that the very word 'self-determination' or 'autonomy' became suspect.

The outright approach of assimilation was, however, considered inimical and insensitive to the unique and distinct 'life-world' of the tribes. Moreover, the overriding concerns for dominant mainstream development and security ignore the fundamental question of tribal self-rule/autonomy. This is done by virtue of relegating their basic aspirations to the background. In other words, the issue of self-rule or 
autonomy was considered to be adjunct to development and security. Hence, the so-called 'State within a State' demand during the 1960s should be seen as an attempt to reverse these priorities.

A counter approach to this, referred to earlier as the knowledge solution, sought to take tribe sensitivities into account and deal them with understanding. Rev. J.J.M. Nichols Roy aptly encapsulated this when he said, 'Sir, the first principle for bringing about a feeling of reconciliation between people who are estranged from one another is that one must place himself in the place of another' ${ }^{13}$ According to him, 'advancement comes by a process of assimilation of a higher culture, higher mode of thinking and not by force'. ${ }^{14}$ Jaipal Singh was more persuasive when he said:

I would appeal to members to be generous in what they say about the tribal people, to be generous to them and not think as if they were enemies of India . . . I am very optimistic about the future of Assam, particularly if the Sixth Schedule, even with all its shortcomings, is operated, in a spirit of accommodation and in the real desire to serve the hill people of Assam, as our compatriots, and as people whom we want to come into our fold, as people whom we will not let go out of our fold and for whom we will make any amount of sacrifice so that they remain with us. ${ }^{15}$

Furthermore, the knowledge solution allays the fear of 'misrule' or 'primitive rule' which is posited by the power solution. To quote Gopinath Bordoloi, the chairman of the Bordoloi Committee: 'What is necessary for good government is already there'. ${ }^{16}$ This approach was endorsed by B. R. Ambedkar. He contended that unlike the tribe in other areas, those in Assam have 'distinct and unique laws of inheritance, of marriage and customs'. ${ }^{17}$ Eventually this approach culminated into an ad hoc asymmetric federal arrangement in order to protect the tribes until they 'acquire some capacity for judgment' ${ }^{18}$

\section{Institutionalizing autonomy: A halfway house to statehood?}

A careful reading of the Constituent Assembly debates shows that ADCs as envisaged by the Sixth Schedule were an afterthought to the earlier 'assimilationist' approach - an approach that some Constituent Assembly members have unabashedly championed. Not strangely enough, issues of development and security continue to inform and precede the substantive question of autonomy till today. 


\section{2}

Precisely speaking, ADCs are basically intended to give selfmanagement rights in matters pertaining to, inter alia, marriage, social customs, culture, land, religion and tradition. ${ }^{19}$ The legislation of the State would not normally be effective until it is discussed by the tribes' representatives and thereafter consented to by the governor. Protagonists of State autonomy consider this approach as an instance to clip the wings of the legislative powers of the State.

Studies on ADC's legislation, however, prove otherwise. The Commission on the Hill Areas of Assam headed by H. V. Patashkar (hereinafter the Patashkar Commission) and appointed by the Government of India in 1965, for example, concluded that none of the five ADCs in the erstwhile tribal hill areas except the Mizo Hills passed any significant legislation. ${ }^{20}$ Even in the latter's case, the Commission contended that insignificant tribal laws pertaining to custom, land, marriage and tradition were passed. Another study discerns a regular pattern of superseding 'community ownership' of land and property by encouraging private property since 1979 (Barbora 2005: 196-215). This, it contended, is facilitated by the propensity of ADCs and the village chiefs to play into the hands of vested propertied class. When friendly party dominates the executive council of ADCs, it opens up space for political manipulation as the ADC members and the chiefs are known for their political affiliations (Barbora 2005: 207).

Structurally, too, the Sixth Schedule is considered to give leverage to non-democratic forces since it is based upon two institutional bedrocks having contrasting loyalties. First, the village authority(ies) or village council under the leadership of the village chief(s), which is based on kinship relations; and second, the district council(s), which is based on territorial loyalty and, which in turn operates according to the principle of democratic citizenship. ${ }^{21}$

The sustenance of the first kind of institutional bedrock implies legitimizing 'non-democratic forces' as the head of the village authorities/ councils. For instance, the village chief is more often than not hereditary and is based on lineage. The second institutional bedrock implies the extension of single-line administration which flows from the union to the State and thereafter to the district(s) and finally to the village levels. By giving the power of 'filter mechanism' to the governor, who is simultaneously the representative of the union executive and head of the State, it establishes a cascading linkage between the three levels of government, namely the union, State and sub-State/district. This extension of State's power to the grassroots has the potential to override extant traditional self-governing institutions. It is interesting here to note the dissatisfaction shown by the tribes, particularly the 
Khasis, for superimposing the district councils' authority over their chiefs/systems when the Patashkar Commission team visited Shillong. Owing to their continued perception of the chiefs as the custodians of community identity and rights, the Khasis demanded the reversal of the said authority. ${ }^{22}$

Anxieties of this nature are apparent in the face of Paragraph 12A to the Sixth Schedule inserted by the Assam Reorganisation (Meghalaya) Act, 1969 and the North-Eastern Areas (Reorganisation) Act, 1971 (Passah 1998: 109-15). Specifically applicable to the State of Meghalaya, it gives precedence to the laws made by the State legislature over those of ADCs in case they overlap. In fact, paragraph 15 explicitly makes it clear that autonomous institutions and the ensuing laws, regulations, organizations and functions would have to conform to the overriding consideration of 'order' and 'safety' of India, and, for that matter, the State at the ground level. Towards this end, paragraph 16 empowers the governor to wield a sword of Damocles, as he or she has the power to either dissolve or suspend the $\mathrm{ADC}(\mathrm{s})$ in light of the findings submitted by an enquiry commission (Paragraph 14) that he or she may duly appoint. This reinforces a double hierarchical responsibility of ADCs towards the union and the State and superimposes a split identity on the ADCs. Cascading linkages contrived in such an autonomy schema confounded the problem of fixing responsibility, the onus for which often lies not on the union but on the State.

It is also pertinent to note the bleak performance of the Sixth Schedule provisions in the financial domain. ADCs are empowered to mobilize their own resources by investing them with the power to collect taxes and levies on land, schools, buildings, market place and so forth. They are also statutorily assured of financial grant from the union via Article 275(1), which would, in turn, supplement their income and resources. It is disheartening to note, however, that ADCs could not satisfactorily mobilize their own resources which were, at best, limited. For example, the Patashkar Commission found that from 1960-61 to 1964-65 forest accounted for the bulk of ADCs' income contributing 69.6 per cent to Mikir Hills, 67.03 per cent to United Khasi and Jaintia Hills (UKJH), 53.62 per cent to North Cachar Hills, 51.01 per cent to Mizo Hills and 38.45 per cent to the Garo Hills. The contribution of land revenue was significantly poor accounting respectively to $20.91,4.8,7.19,33.87$ and 23.29 per cent. The contribution from the market varied from 0.63 per cent in Mizo Hills to 25.94 per cent in North Cachar Hills. ${ }^{23}$

The thesis of non-viability of a 'State within a State' in a situation of economic insufficiency seemed to be buttressed by the mismatch 
in terms of receipts and expenditure of the five ADCs. The gross mismatch could somehow be bridged by grants-in-aid made by the union government, which until 1961 stood at merely 40 crore rupees. ADCs are notorious for incurring massive non-developmental expenditure which eats up their vitals. The Patashkar Commission pointed out that during 1960-61 and 1964-65 the proportion of expenditure on staff vis-à-vis establishment to their own resources, excluding grants-in-aid received from the union, has been abnormally high. The Mizo Hills topped the list with a whopping 99 per cent, followed by UKJH ( 63 per cent), NC Hills (57 per cent), Mikir Hills (44 per cent) and Garo Hills (32 per cent)..${ }^{24}$ On the contrary, the proportion of development expenditure to their internal resources was awfully insufficient. Garo Hills which topped the list could spare only 19 per cent, followed by UKJH ( 8 per cent), Mikir Hills (16 per cent) and NC Hills ( 3 per cent) for the corresponding period. Consequently, Mizo Hills had to totally rely on union grants to fund development expenditure of ADCs. ${ }^{25}$

ADCs are also plagued by opaque financial management. Although Paragraph 7 of the Sixth Schedule provides district funds for ADCs, no uniform rules could be passed. The system continued to be plagued even more by the absence of internal scrutiny mechanism, leave alone external scrutiny. ${ }^{26}$

To cut it short, it is plausible to say that autonomy envisaged by the Sixth Schedule is still in its nascent stage; it has never been able to take off. Although it is a welcome instrument of decentralizing powers and recognizing the rights of tribal self-rule, the lackadaisical operationalization of the schema estranged disparate tribal groups within Assam.

The All Party Hill Leaders' Conference (APHLC) bid to establish a separate hill State and the Mizo movement for 'Greater Mizoram' during the 1960s, within the erstwhile State of Assam, were both glaring examples of this. While the Assam Language Bill, 1960 and the disastrous management of the Mautam Famine of 1959 (by the Assam government) were respectively the immediate catalyst of the movements, deep-rooted dissatisfaction over 'step-motherly treatment' which was meted out to the ADCs by the State was cited as the chief cause of their unrest or 'separatist demands' (Bhaumik and Bhattacharya 2005: 216-41). ${ }^{27}$ Hence the desire to live on 'equal terms', with their selfsustaining autonomous 'societal culture' remaining unaffected by the long arm of State's intervention and regulation, informed these demands. In a way, it was an attempt to reverse the precedence of the State over the community. This attempt was successfully managed by innovative asymmetric federal innovations. Creation of an autonomous State (via Article 244A) and later on full-fledged Statehood granted 
to Meghalaya and Mizoram were the outcome of this very attempt. They, in turn, consolidated ethnic principle as a basis for creation of a State in India, the trend of which was set by the creation of Nagaland in 1962 (Arora 1995: 71-104).

Paragraph 2(2) of the Sixth Schedule, in its attempt to preserve and protect minority rights and identities, provides for the establishment of regional councils for minority tribes within ADCs, if at all they demand the same. Unwittingly it implants a time bomb within the ADCs. This is borne out by ongoing attempts by the Hmars and Paites, among others, to establish regional councils/ADCs in Mizoram. The Lai (Pawi), Mara (Lakher) and Chakmas had to undertake almost two decades of persistent struggle to upgrade their regional councils into ADCs in Mizoram. This was interspersed by the State government's bid to dissolve and disband the erstwhile Chakma Regional Council on the ground that they are not an indigenous tribe but refugees. Instances of such kinds provide opportunities to redefine and deepen grassroots democracy and at the same time recast the contours of majority-minority relations within a State. They may not, however, be seen a halfway house to statehood.

\section{Salvaging autonomy: Beyond development catalyst model}

From the foregoing discussion it is clear that autonomy enshrined in the Sixth Schedule provides institutional mechanisms to preserve and protect tribals' autonomous 'societal culture'. Being hedged in by the institutional paraphernalia of union and State control, it has never been able to take off in the true sense of the word. Soon after its operationalization, it got enmeshed in a paradoxical situation where the State became the 'main culprit' in denying 'full autonomy' to ADCs. This engendered 'separatist' demands, which were, in turn, considered inimical to the State's project of development and security. The concern for these issues are understandable but not to the extent of suspecting autonomy demands having territorial underpinnings. There is an urgent imperative to salvage autonomy from this predicament. This can be done, in my considered view, on the following grounds:

1 Since autonomy in the form of ADCs under the Sixth Schedule is basically a contrivance to bring about greater democratization and decentralization, it would continue to generate autonomy demands from minority tribal groups within ADCs or elsewhere. To deny autonomy on the ground that it is incompatible with 
the development-security paradigm is to contain democracy/ democratization or flog a dead horse. The 'unity, security and integrity' of the State is best preserved by guaranteeing autonomy, not the denial of it.

2 A way out could possibly be to revisit the grounds for granting autonomy. This is premised upon an assumption that the present policy frame of autonomy vis-à-vis ADCs engenders a precarious regime of tribe recognition whose axis is vaguely defined in Article 342 (such as social backwardness and geographical isolation) and opens up space for populist measures. Take for example, the quick-fire solution adopted by Assam government in August 2005 wherein barely within five months of the formation of an un-enumerated plains tribe's Committee, that is Thengal Kachari Autonomous Demand Committee (TKADC), Autonomous Council Bill for the same was passed. That this demand was made in Titabor (near Jorhat in Upper Assam), the 'homeland and heartland' of TKADC which also happened to be the constituency of the chief minister, Tarun Gogoi, made the issue more riveting (Prabhakara 2005a: 95-7, 2005b: 35-9). This and similar demands by Sonowal Kachari and Deori tribes were subsequently accommodated, which increased the number of autonomous councils for the plains tribes of Assam from the existing three - Mising, Rabha, Tiwa - to six. The Bodos, another plain tribe, have its own ADCs under the ambit of the Sixth Schedule.

3 Finally, ways and means of incorporating local democratic institutions as recommended by the National Commission to Review the Working of the Constitution (2002) must be evolved. ${ }^{28} \mathrm{~A}$ bottom-up autonomy model which would privilege communities' rights and identities must be devised. This would look beyond the state-centric 'top-down' autonomy model envisaged by the Sixth Schedule.

\section{Notes}

1 This is a revised version of the paper titled 'Salvaging Autonomy in India's Northeast: Beyond the Sixth Schedule Way', Eastern Quarterly, 4(1): $5-16,2007$. I have since used my name in full after the publication of this piece as Kham Khan Suan Hausing. I gratefully acknowledge technical help from my elder brother Tual Khan Lal, and friends, L. Lam Khan Piang, Thangkhanlal Ngaihte and Kamkhenthang Guite in the preparation of this chapter.

2 I shall employ 's' in the lower case while referring to the 'state' to imply the modern nation state in a general sense and ' $S$ ' in the upper case when I use it to refer to the component unit of the Union of India. 
3 I shall use the term power versus knowledge solutions in the mould of what Jaipal Singh, a member of India's Constituent Assembly, reckoned with as 'two solutions' bequeathed by the 'learned Ambassador in Moscow'. See the Constituent Assembly debates in Savyasaachi (1998: 129).

4 The following section is largely drawn from my MPhil dissertation, 2002, chapter 3.

5 I borrowed the term 'societal culture' from Will Kymlicka who used it to denote 'a territorially concentrated culture, centred on a shared language'. It involves, as he says, 'a common language and social institutions, rather than common religious beliefs, family customs, or personal lifestyles'. See Kymlicka (2001: 25).

6 The Bordoloi Committee is also known as the Sub-Committee on the North-East Frontier (Assam) Tribal and Excluded Areas. It was one of the sub-committees formed under the Constituent Assembly of India's Advisory Committee on the Rights of Citizens, Minorities and Tribal and Excluded Areas. See Rao (1967: 684).

7 See Bordoloi Committee Report, Rao (1967: 708).

8 Kuladhar Chaliha (from Assam) in CAD (Savyasaachi 1998).

9 CAD, p. 115.

10 Ibid., p. 120.

11 Ibid., p. 127.

12 Ibid.

13 Ibid., p. 133.

14 Ibid., p. 136.

15 Ibid., p. 131 (emphasis mine).

16 Ibid., p. 123.

17 Ibid., p. 139.

18 Lakhsmi Narain Sahu in CAD, ibid., p. 129.

19 See paragraph 3 of the 'Sixth Schedule', Constitution of India: 151-64, 1996.

20 See Government of India (1965).

21 For related discussion, see Chaube (1990: 15-25).

22 See GoI Report (1965: 18-19).

23 Ibid., p. 83.

24 Ibid., p. 84.

25 Ibid., p. 85.

26 Ibid., p. 77.

27 For related discussion, see Lalthangliana (1994: 174-88).

28 Government of India (2002).

\section{References}

Arora, Balveer. 1995. 'Adapting Federalism to India: Multilevel and Asymmetrical Innovations', in Balveer Arora and Douglas V. Verney (eds.), Multiple Identities in a Single State: Indian Federalism in Comparative Perspective. New Delhi: Konark.

Barbora, Sanjay. 2005. 'Autonomy in the Northeast: The Frontiers of Centralised Politics', in Ranabir Samaddar (ed.), The Politics of Autonomy: Indian Experiences. New Delhi: Sage Publications. 


\section{Kham Khan Suan Hausing}

Bhaumik, Subir and Jayenta Bhattacharya. 2005. 'Autonomy in the Northeast: The Hills of Tripura and Mizoram', in Ranabir Samaddar (eds.), The Politics of Autonomy: Indian Experiences. New Delhi: Sage Publications.

Bogdanor, Vernon. 1997. 'Forms of Autonomy and the Protection of Minorities', Daedelus, 126(2), Spring.

Chaube, S. K. 1973/1999. Hill Politics in Northeast India. New Delhi: Orient Longman.

Chaube, S. K. 1990. 'Tribal Societies and the Problem of Nation-Building', in B. Pakem (ed.), Nationality, Ethnicity and Cultural Identity in North-East India. New Delhi: Omsons Publications.

Government of India. 1965. Report: The Commission on the Hill Areas of Assam. Ministry of Home Affairs.

Government of India. 1996. Constitution of India (as amended up to 1 June 1996). Ministry of Law, Justice and Company Affairs.

Government of India. 2002. Report: National Commission to Review the Working of the Constitution, Consultation Paper, Book II, Vol. 2. Ministry of Law (online edition).

Kymlicka, Will. 2001. Politics in the Vernacular: Nationalism, Multiculturalism, and Citizenship. Oxford: Oxford University Press.

Lalthangliana. 1994. 'Mizo National Front Movement', in R. N. Prasad (ed.), Autonomy Movements in Mizoram. New Delhi: Vikas.

Passah, P. M. 1998. 'The Working of the Jaintia Hills Autonomous District Council', in M. N. Karna, L. S. Gassah and C. J. Thomas (eds.), Power to the People in Meghalaya (Sixth Schedule and the 73rd Amendment). New Delhi: Regency Publications.

Prabhakara, M. S. 2005a. 'Manufacturing Identities?', Frontline, 22(20), 7 October.

Prabhakara, M. S. 2005b. 'In the Name of Tribal Identities', Frontline, 22(24), 2 December.

Rao, B. Shiva. 1967. Framing of India's Constitution, Vol. 3. New Delhi: Indian Institute of Public Administration.

Roy Burman, B. K. 1998. 'Constitutional Framework for Tribal Autonomy with Special Reference to North-East India', in Manis Kumar Raha and Aloke Kumar Ghosh (eds.), North-East India: The Human Interface. New Delhi: Gyan Publications.

Savyasaachi. 1998. Tribal Forest-Dwellers and Self-Rule: The Constituent Assembly Debates on the Fifth and the Sixth Schedules. New Delhi: Indian Social Institute.

Suan, H. Kham Khan. 2002. 'Special Status of the North-East in Indian Federalism'. Unpublished M.Phil. dissertation, Jawaharlal Nehru University. 


\title{
13 Autonomy for tribal communities in India
}

\section{A study of the Northeastern states $^{1}$}

\author{
M. Amarjeet Singh
}

The population of tribes (officially designated as Scheduled Tribes) constitutes about 27.25 per cent of the total population of the Northeastern states of India. ${ }^{2}$ There are affirmative polices for their welfare in the form of reservations in public employment, political representation and education. Different laws were introduced by the British government for the administration of the hill areas of former province of Assam as well as the former princely states of Manipur and Tripura, respectively. The Bengal Eastern Frontier Regulation, 1873 was enforced to the districts of Kamrup, Darrang, Nowgong, Sibsagar, Lakhimpur (Garo Hills), Khasi and Jaintia Hills, Naga Hills and Cachar to prohibit

all [citizens of India or any class of such citizens] or any persons residing in or passing through such districts from going from beyond such line without a pass under the hand and seal of the chief executive officer of such district or of such other officer as he may authorize to grant such pass; and the [State Government] may, from time to time, cancel or vary such prohibition.

(BEFR 1873)

Subsequently, Lushai Hills, Naga Hills, Garo Hills, North Cachar Hills, the British portion of Khasi and Jaintia Hills, Lakhimpur Frontier Tract, Balipara Frontier Tract and Sadiya Frontier Tract were declared as the 'Backward Tracts' by the Government of India Act, 1919. Since 1937, all the Backward Tracts were designated as the 'Excluded' and 'Partially Excluded' areas by the Government of India Act, 1935, which placed them directly under the Governor of Assam, not to the provincial government. The excluded areas included Naga Hills, Lushai Hills, North Cachar Hills and Northeast Frontier (Sadiya, Balipara and Lakhimpur) Tracts; and the Partially Excluded Areas covered Garo Hills, Mikir Hills and Khasi-Jaintia Hills. 
Under the Rules for the Management of the State of Manipur, 1916,

the hill tribes [of Manipur] are administered by the President [of the Darbar (the highest court) who was an Indian Civil Service (ICS) Officer] assisted by one or more officers on His Highness's behalf in accordance with rules approved by the Government of Assam but His Highness shall be consulted in all matters of importance and the Political Agent, in consultation with the President shall give effect to His Highness's wishes so far as is consistent with the orders of the Government of Assam. If the Political Agent is unable to agree His Highness's proposals, the matter shall, if His Highness so wishes be referred to the Government of Assam.

Likewise, with the appointment of the Political Agent by the British government, the authority of the Maharaja of Tripura was effectively curtailed.

When the independence of India was approaching, some tribes, including Nagas, were apprehensive of remaining with India and hence expressed their keenness to remain independent. The matter was extensively discussed by the five-member sub-committee (the Northeast Frontier Tribal and Excluded Areas Committee) appointed by the Constituent Assembly in February 1947 with the then premier of Assam, Gopinath Bordoloi, as its chairman. In its July 1947 report, the Committee noted 'the anxiety of the hill people about their land and fears of exploitation by the more advanced people, especially the money lenders because of which control of immigration was desired' (KHADC 2015). On 6 September 1949, Gopinath Bordoloi made the following observations while reporting to the Constituent Assembly:

Now I want to place before you the background in which this draft had to be formulated. It is not unknown to you that the rule of the British Government and the activities of the foreign Missions always went together. These areas were formerly entirely excluded areas in the sense that none from the plains could go there and contact them. That was the position till August 15, 1947, when India became independent. The foreign rulers till then had in these areas power to send out of the place anyone they desired within 24 hours. Again, Sir, some of these areas were war zones. During the war, the then rulers and officers developed in the minds of these tribal people a sense of separation and isolation and gave them assurances that at the end of the war they will be independent States managing their affairs in their own way. They were led to believe that the entire hill areas would be constituted 
into a province and put under some irresponsible Governor. You might possibly have read in the papers that plans were hatched in England in which the ex-Governors of Assam evidently took part, to create a sort of a Kingdom over there. ${ }^{3}$

Bordoloi had voiced strong disapproval of the special treatment being given to the hill areas by the colonial officials. At the same time he was also fully aware of the apprehensions of the tribes towards the more advanced people of the plain areas. We shall not ignore significant contribution of the colonial intervention in the transformation of the hill people. Nonetheless, in the case of the relationship between the hill people and the Assam government, they neither understand nor trust each other.

The issue raised by the Bordoloi-led sub-committee was deliberated among those involved in the drafting of the constitution who finally decided to include a special provision for the administration of the hill areas of Assam known as the Sixth Schedule. ${ }^{4}$ It authorizes the formation of a district council for each autonomous district with elected councils. The council shall comprise a general council consisting of both elected and nominated members (councillors) and an executive council, whose members shall be elected from among the members of the general council to carry out its executive functions. The elected members shall be elected on the basis of adult franchise and the nominated ones shall be appointed by the governor of the state. The council shall hold office for a period of five years. The council shall exercise limited authority to an area, which can be further subdivided into territorial constituencies. The area is known as the autonomous district. The council shall exercise limited legislative, judicial, executive and financial powers on specified subjects allocated by Assam government including the management of non-reserved forests; to establish, construct and manage primary schools, dispensaries, markets, cattle pounds, ferries, fisheries, roads, road transport and waterways; the use of any canal or watercourse for the purpose of agriculture; the regulation of the practice of jhum or other forms of shifting cultivation; the establishment of village or town committees or councils and their powers; any other matter relating to village or town administration, including village or town police and public health and sanitation; the appointment or succession of chiefs or headmen; and the inheritance of property; collect land revenue and impose tax. ${ }^{5}$ Thus the original purpose of the Sixth Schedule

is aimed at protection of tribal areas and interests, by constitutionally mandating district or regional local self government 
institutions for them. These institutions are entrusted with the twin task of protecting tribal culture and customs and undertake development tasks for them.

(GoI 2006: 16)

At the time of its inception in 1952, the Sixth Schedule was meant for the hill tribes ${ }^{6}$ of Assam (the plain tribes were not included) and divided the hill areas into (1) United Khasi-Jaintia Hills District (excluded Shillong), Garo Hills, Lushai (Mizo) Hills, Mikir Hills, Naga Hills and North Cachar Hills; and (2) North Frontier Tracts and Naga Tribal Area. ${ }^{7}$ Areas considered relatively backward in the former 'Excluded' and 'Partially Excluded' areas were called the 'tribal areas'. The Special Sub-committee of the Minorities Advisory Committee looked after the tribes inhabiting the plain areas such as Bodos, Misings, Lalung, Sonowal, Deori and Tiwas.

Four district councils were constituted in 1952, of North Cachar, Dima Hasao, Garo Hills and United Khasi-Jaintia Hills. Naga Hills did not accept it and boycotted the first general election held in the country in 1951. This marked the beginning of the first real armed challenge against India.

\section{Trouble with limited autonomy}

Few years after district councils were constituted the country was reorganized on linguistic grounds by the State Reorganisation Act, 1956 into fourteen states and six union territories. The perception of what was in the best interests of national security was also prone to change over time. In 1960, barely four years after the reorganization, the state of Bombay was bifurcated into Maharashtra and Gujarat. At the time of the reorganization it was believed that Assam, Manipur and Tripura should not be divided. But the pressures from various groups saw Assam being divided several times. In 1963, the Nagas got the state of Nagaland carved out of Assam in response to the secessionist insurgency. Assam was further divided in 1972 to create the states of Meghalaya, Mizoram and Arunachal Pradesh (Singh and Pani 2012: 121-40).

In neighbouring Tripura, an autonomous region, comprising an area of about 7,132 $\mathrm{km}^{2}$ or 68 per cent of Tripura's land, was constituted under the Tripura Tribal Areas Autonomous District Council Act of 1979. The first election was held in 1982. In 1985, it was brought under the Sixth Schedule with the primary aim of redressing the grievances responsible for the secessionist insurgency. Its formation was 
opposed by some Bengali-speaking people leading to the formation of an insurgent group called the Amra Bengali. A bloody ethnic riot broke out in 1980 killing many people.

Since the latter part of the 1960s, the Bodos started a campaign for recognition of their mother tongue and script for the purpose of education. Once it was recognized as an associate official language, ${ }^{8}$ the movement for a separate state started. The movement was suspended after the signing of an agreement in 1993 with the government (the Centre and the Assam government) to constitute an autonomous region within Assam. It promised to offer limited home rule powers to the autonomous region granted by the state government. The council consisted of a general council of elected and nominated members and an executive council.

However, the delay in the demarcation of its administration boundary in time and an intense infighting among the local political leaders eventually caused utter disappointment among the people leading to the revival of another movement for a separate state since 1995. The movement was spearheaded by a new insurgent group, the Bodo Liberation Tigers. In 2003, their movement came to an end as the insurgent leadership signed another agreement with the government for the purpose of granting limited political autonomy by constituting an autonomous region within Assam under the Sixth Schedule. The region is now technically known as the Bodoland Territorial Areas District comprising of four contiguous districts of Kokrajhar, Baska, Udalguri and Chirang. It is governed by the Bodoland Territorial Council with forty elected and six nominated members and a twelve-member executive council. The council has legislative, executive and financial powers granted by the Assam government under the provisions of the Sixth Schedule in respect of over forty subjects, such as cottage industries, forests, cultural affairs, irrigation and the like. ${ }^{9}$ Subsequently, the former insurgent leaders became active in local politics through their political party, the Bodoland People's Front. It had won two successive elections of the council. Some of its nominees have been elected to the state legislative assembly and the Lok Sabha (the lower house of India's parliament), respectively. Thus, altogether six districts of Assam (Karbi Anglong, North Cachar Hills, Kokrajhar, Udalguri, Chirang and Baksa) constitute the Sixth Schedule areas. It was however opposed by the non-Bodo people who have already mobilized under the Sanmilita Janagosthiya Sangram Samiti, condemning the government policy of imposing an 'ex-parte settlement' upon them and wanted exclusion of villages with more than 50 per cent non-Bodo 
population from Bodoland Territorial Areas District. One of its main functionaries made the following observations:

The Centre had amended the Sixth Schedule of the Constitution and created BTC [Bodoland Territorial Council] to end violence in the area but it has not helped the people. Instead, non-Bodos, comprising 80 per cent of the total population, have been continuously attacked, displaced and even killed by people having support from those in power in the council. Non-Bodos are forced to pay extortion money and those refusing to do so are attacked and killed frequently. ${ }^{10}$

In 1972, the Mizo hills district became the union territory of Mizoram along three district councils of the Lai, Mara and Chakma. Further, the entire Meghalaya, except Shillong town, constitute the Sixth Schedule areas. Autonomy to the hill areas of Tripura and Bodoland in Assam were granted in response to the insurgency movement. The original purpose of Sixth Schedule was significantly diluted after the reorganization of Assam in 1972 to create Mizoram and Meghalaya. There are now tribal areas within the tribal areas as there are district councils in Mizoram and Meghalaya. In the case of Meghalaya, the tribes who are the rulers of the district councils are also the rulers of the state.

\section{More trouble with limited autonomy}

In order to prevent further reorganization of Assam, six more autonomous councils were constituted by separate legislations of the state legislative assembly: for Mising (headquartered at Dhemaji), Rabha (at Goalpara), Tiwa (at Marigaon), Deori (at Lakhimpur), Sonowal (at Dibrugarh) and Thengal Kachari (at Titabor) under different legislations of the legislative assembly of the state. It was done without proper planning and hence existed without proper functioning for many years.

Manipur presents a rather more complex political problem than other Northeastern states. Geographically Manipur is made up of the hill and the plain (valley). It is inhabited by people broadly classified into Meiteis, Meitei-Muslims, Nagas and Kukis. The last two are concentrated in the hill areas, while others are mostly concentrated in the plain areas. The Nagas and Kukis are officially recognized into twenty-nine Scheduled Tribes. Since Meiteis and Meitei-Muslims are considered more advanced people they are not recognized as Scheduled Tribes, and further they are also restricted by law to purchase and 
own real estate and other land in the hill areas while Nagas and Kukis can buy and own land anywhere in the state.

Their political aspirations are at loggerheads over the political future of Manipur. On one side, the Meiteis want a country of Manipur with full sovereignty, and on the other, both Nagas and Kukis are in favour of the reorganization of Manipur into three parts so that they can control certain territories outside Manipur. In order to grant limited home rule powers to the hill areas, the Indian Parliament enacted the Manipur (Hill Areas) District Councils Act, 1971. Accordingly the hill region is divided into six autonomous districts each having a district council (eighteen elected and two nominated members). The elected members are elected on the basis of adult franchise from the territorial constituencies of the district. Six district councils were constituted in 1972. Each council has limited executive and financial powers. The executive powers are the construction and maintenance of roads, bridges and other public buildings; the establishment, maintenance and management of primary schools, dispensaries, markets and fairs; the supply, storage and control of water for agricultural purpose; the preservation, protection and improvement of livestock and prevention of animal disease, public health and sanitation; the management of any forest not being a reserved forest; the regulation of the practice of jhum or other form of shifting cultivation and the like. Although the district council does not have legislative powers but it can recommend legislations on certain matters concerning Scheduled Tribes such as the appointment or succession of chiefs, inheritance of property, marriage and divorce and social custom. The council's financial powers include levying taxes on profession, trades and employment; on animals, vehicles and boats; on the entry of goods into the market for sale; on the maintenance of schools, dispensaries or roads and the like. Although the first elections were held in 1973, all the district councils were superseded by the state government and finally revived in 2010 . But the Nagas and the Kukis are in favour of more autonomy either under the Sixth Schedule or separation from Manipur.

\section{Inherent weaknesses and urge for more autonomy}

One of the inherent weaknesses since their inception has been the conflict between the district council and the state government. The district council cannot function smoothly without the cooperation of the state government, failing to do so, the latter can always act as spoiler. The prospect of good coordination is high if the same political party rules both the state and district councils. The district councils 
are autonomous body which 'is not outside the state government' and 'it has to work within the framework of the state government itself' (Bhuyan 1989: 221-33). The district councils are in favour of direct funding from the Centre and timely release of the funds. They alleged that the erratic release of funds affected development works undertaken by them. On the other the state government also accused them for inefficiency. There were instances in Meghalaya in which the salaries of primary school teachers were not paid regularly due to the non-receipt of funds from the state government since the latter withheld the funds on the charge that the Khasi Hills council indulged in corrupt practices and failed to comply with prescribed procedures (Nongbri 2001: 1-14). Further, in 2011, the Bodoland Territorial Council lodged a complaint before the Planning Commission (now NITI Aayog) against the state government for lack of transparency in fund allocation and demanded that the Planning Commission should earmark the funds to be released to the Council every year while finalizing the state's plan. In Mizoram, it was learned that the state government 'continues to undertake works in respect of the same devolved function, without consulting the council' (GoI 2006: 84-5). Even the 'schools continue to be constructed by the state government without reference to the council, to whom the subject matter of primary education is devolved' (GoI 2006: 85). Districts councils in Meghalaya are 'unnecessary and expensive, rendered redundant' after the creation of Meghalaya covering the entire area of district councils (GoI 2006: 54). Some call the institution of district council as 'lamb duck institution'. ${ }^{11}$

Second, the principle of nomination of members have been misused for 'narrow' gains since the state government has the final authority and they were nominated who would support the party in power (Tuolor 2013: 408-18). Thus, the state government indulged in 'the king making process in the council' (Bhuyan 1989: 224) by using the nominated members. Even the officials were not keen to be posted in the district council.

Third, the elections were not held within the time frame. Therefore some councils were compelled to be run by the nominated members. For example, the Mising Autonomous Council was constituted in 1995 , but it was functioning with the nominated members. The election was held in October 2013. In the course of a debate in the Lok Sabha, veteran Karbi politician, Jayanta Rongpi stated:

I have the experience of heading such Autonomous Hill Council for seven long years ... With that experience I can say that the Sixth Schedule has failed in India since 1952. . . There are five 
inherent weaknesses . . . One of the basic problems . . is that the funding from the Government of India is through the State Government. Most of the State Governments are burdened with overdraft problem. So, the funds meant for the tribal areas do not reach the tribal Autonomous Councils ... The second issue is the personnel, the bureaucracy. There should be a separate cadre for the tribal Autonomous Councils. If you post the same cadre officers to the tribal areas, then nobody will go there ... They treat the tribal areas, the interior areas, the hill areas as a dumping ground, as a punishment to the officers. No good officer will go there. ... The next is the elections. It is at the whims of the State Government whether they will hold the election or not. If the Council is ruled by an Opposition Party, then they will not hold election. So, after five years it will go directly under the Governor's rule. That means it will indirectly be ruled by the Ruling Party in the State . . . Regarding nominated members, I would say that you have said that you are giving grass-root level democracy, an Autonomous Council, to the tribal's. . . . We have the experience of Karbi Anglong. There are four nominated members and these four nominated members become instruments at the hands of the State Government to destabilise the Opposition-ruled Autonomous Council ... It was the reason that in the 1950s and 1960s, repeatedly Garo Hills Autonomous Councils, Khasi Hills Autonomous Councils and Jaintia Hills Autonomous Councils were destabilised by the then Government of Assam, with the help of these nominated members. ${ }^{12}$

Fourth, there is no geographical contiguity in the councils outside the Sixth Schedule areas of Assam. The territories of these councils consisted of both core villages and satellite villages with no geographical contiguity. For instance, the Thengal Kachari Council comprises about 264 villages spread over as much as five districts. Of these, about 120 villages are in Thengal and the others are satellite villages in other districts. Likewise, the Mising Council comprises 231 villages, of which 127 are in the core area and 104 in the satellite area. In these areas the Panchayati Raj institutions also exist. Thus, there are three authorities operating in parallel in these areas (GoI 2006: 16).

Fifth, the district councils wanted powers over additional subjects and direct funding from the Centre. Most of the councils have been campaigning for separate states. Several Bodo organizations ${ }^{13}$ have already revived the statehood movement. Why is it so? The Maraland Democratic Front wanted the division of Mizoram to facilitate the 
formation of a union territory because the Sixth Schedule 'is unable to safeguard and promote' their interests because of the interference by the state government. The party cautioned that 'practically, the autonomous district councils in Mizoram are functioning as one of the state departments'. Since the Sixth Schedule was amended to confer more powers and functions to the Bodoland Territorial Council, other councils also wanted powers over additional subjects.

In my view the original mandate and purpose of Sixth Schedule was aimed at preventing the possible breakup of Assam into smaller states, but that did not succeed. Naga Hills and Tuensang became the state of Nagaland in 1963 and United Khasi-Jaintia Hills District, Garo Hills District and Lushai (Mizo) Hills District were separated from Assam to facilitate the formation of the states of Meghalaya and Mizoram. This happened soon after the councils were created. In this way, the experiment of political autonomy became subject to increasing balkanization of Assam. This was followed by the demand for the formation of an autonomous state of North Cachar Hills and Karbi Anglong under the provision of the Article 244-A which was spearheaded by the Autonomous State Demand Committee and other students' associations of the districts. ${ }^{14}$ They signed an agreement with the chief minister of Assam in 1995 to grant more powers to the councils of Karbi Anglong and North Cachar under the Sixth Schedule. It was however limited to mere administrative changes and hence not a significant one. ${ }^{15}$ In due course of time the protagonists of the new state have lost their appeal.

It is now clear that the real concern is not about development but the urge for more political power. The demand for limited political autonomy under the Sixth Schedule/other legislations is mostly made by those ethnic groups whose mother tongue is not the official language of the state in which they reside. ${ }^{16}$ They occupy more or less a contiguous area which is comparatively less developed and are mostly recognized as the Scheduled Tribes. Since they are politically subordinate in the state they reside their chances of becoming chief minister are remote (except in Manipur and Tripura where a Naga and a Borok had occupied the post). The situation is different in Meghalaya where except the Shillong municipal area, the entire state constitutes the Sixth Schedule area. The experiment of this form of political autonomy has led to the creation of new states or the demand for a new state. Further, the formation of autonomous regions under different legislation, as in Assam or Manipur, is undoubtedly an attempt to prevent the division of the existing states. Such autonomy offers an alternate political arrangement in lieu of a new state. 


\section{Conclusion}

The Sixth Schedule was stipulated with a view to turn the former state of Assam into a happy home of tribes and non-tribes alike. However, the Assamese assertion of their linguistic claims over others created a psychosis among the tribes and other non-tribes that they had no future in Assam. The increasing divide between the dominating Assamese and tribes continued unabated and it contributed to the dissection of the united state of Assam in spite of the existence of the Sixth Schedule. These developments have largely shaped the future political regrouping in Assam and other Northeastern states.

It may not be out of context to note that stipulation of the district councils has largely been interpreted by different tribes as an ad hoc arrangement between district councils and statehood. And they have come to believe that the district councils could be negotiated for the statehood in the times to come. They have the impression that adequate share of political power is a necessary condition for retaining their cultural identity and, more so, for their all-round development. Such aspirations are not only reasonable but also legitimate. But it starts facing rough weather once the aspirations for cultural identity and development get necessarily connected with exclusive administrative boundaries for 'self-governance'. Given the nature and magnitude of ethnic diversity of Assam and other Northeastern states, not only of the plurality but also of shared geographical and cultural spaces among these communities, such a demand calls for serious reflection of viability. In other words, granting of autonomy based on ethnic identities and exclusive divides has not gone well. In fact, it aggravates the appetite for such aggressive postures. The leadership has to be convinced that isolated existence will not be administratively and financially viable in the long run.

\section{Notes}

1 This is a substantially revised and rewritten version (with a slightly different perspective) of the paper titled 'Tribal Autonomy in Assam: Problems and Prospects', Eastern Quarterly, 4(1): 27-35, 2007.

2 The population of Scheduled Tribes constitutes about 124 lakh out of the total population of 455 lakh of the Northeastern states as per Census 2011. See Government of India (2013).

3 Constituent Assembly Debates (Proceedings), Vol. IX, 6 September 1949.

4 Now, this is no longer confined to Assam alone.

5 The powers and functions vary from one council to another.

6 Different tribes have been officially recognized as Scheduled Tribes owing to their social and economic backwardness and hence enjoy the benefits 
of reservations in political representation, jobs, education and welfare programmes.

7 The first set of areas now comprises the present-day Meghalaya, Mizoram, Nagaland and parts of Assam, and the second set comprises Arunachal Pradesh and a portion of Nagaland.

8 Each state in India can enact their official language. The Bodo language has been an associate official language of Assam for specific purposes. It has also been recognized as the official language of Bodoland Territorial Areas District.

9 The Bodoland Territorial Council consists of forty-six members of whom forty shall be elected on the basis of adult suffrage, of whom thirty shall be reserved for the Scheduled Tribes, five for non-tribal communities, five open for all communities and the remaining six shall be nominated by the governor of Assam.

10 'Non-Bodos Move Patnaik - Token Fast to Demand Exclusion from BTAD \& Safety', The Telegraph, 26 November 2013.

11 Some tribal organizations termed district council as 'lame-duck institution' with no real power to ensure the development of the backward areas. See 'Tripura Tribals' Party to Protest for Separate State', Tripurainfo, 10 October 2013.

12 Lok Sabha, Consideration and Passing of the Sixth Schedule to the Constitution (Amendment) Bill, 2003 Moved by Shri I. D. Swamy on 1st August 2003 (Bill Passed), 1 August 2003.

13 All Bodo Students' Union, United Democratic People's Front, People's Joint Action Committee for Bodoland Movement and Bodoland People's Progressive Front.

14 The United Mikir and North Cachar Hills District came under the provision of the Sixth Schedule in 1952. In 1976, the North Cachar Hills were carved out as a separate district, while the Mikir Hills were renamed Karbi Anglong.

15 See Office Memorandum (HAD. No. 57/95/316) Hill Areas Department, Government of Assam, Dispur, dated 31 December 1996.

16 There are already three autonomous regions in Meghalaya for which both the Khasis and Garos almost equally share the governance of the state.

\section{References}

Amarjeet Singh, M. and Narendar Pani. 2012. 'Territories Beyond Geography: An Alternative Approach to the Demands for New States in India', Commonwealth \& Comparative Politics, 50(1).

The Bengal Eastern Frontier Regulation. 1873, 27 August 1873.

Bhuyan, B. C. 1989. 'District Council and the State Government: Karbi Anglong District Council and the Government of Assam', The Indian Journal of Political Science, 50(2), April-June.

Government of India. 2006. Planning for the Sixth Schedule Areas, Report of the Expert Committee. New Delhi: Ministry of Panchayat Raj.

Government of India. 2013. Demographic Status of Scheduled Tribe Population of India. New Delhi: Ministry of Tribal Affairs. 
KHADC. 2015. Framing of the Sixth Schedule. Shillong: Khasi Hills Autonomous District Council.

Nongbri, Tiplut. 2001. 'Democracy, Gender and Tribes: A Critical Appraisal of India's Constitutional Policies', Indian Anthropologist, 3(12).

Tuolor, Robert. 2013. 'Autonomous District Councils and Tribal Development in Northeast India: A Critical Analysis', International Journal of Advancements in Research \& Technology, 2(7). 
$\because$ Taylor \& Francis

http://taylorandfrancis.com 


\section{Part VII}

\section{Locating civil society}


$\because$ Taylor \& Francis

http://taylorandfrancis.com 


\title{
14 Fast forward or living in a permanent state of nature? ${ }^{1}$
}

\author{
Samir Kumar Das
}

\section{An anthropology for John Locke}

While explaining what it means for 'men' to leave state of nature and join a political or civil society, John Locke observes:

Wherever therefore any number of men are so united into one society as to quit everyone his executive power of the law of nature, and to resign it to the public, there and there only is a political or civil society. And this is done wherever any number of men, in the state of nature, enter into society to make one people, one body politic under one supreme government: or else anyone joins himself to and incorporates with any government already made. For hereby he authorizes the society, or which is all one, the legislative thereof, to make laws for him as the public good of the society will require, to the execution whereof his own assistance (as to his own decrees) is due.

(Locke in Barker ed. 1978/1960: 51-2)

Significantly for Locke, political or civil society represents the coming into existence of 'one people, one body politic, under one supreme government'. Good political theory might turn out to be bad anthropology. Locke does not tell us how individuals while coming together to form 'one people' represent many other things than being a mere sum total of all such individual authorizations. While it is true that 'reason' demands that reparation is done only 'in proportion to one's transgression' in the state of nature, such factors as 'self-love', 'boundless extravagancy of one's will' and so forth violate the principle of proportionality and reparative justice. Locke does not feel it necessary to explain why people will recognize their own frailties as underlined by him in a state of nature and opt for the kind of political or civil 
society that will take care of the evil of disproportionality - unless they share their common experiences, already constitute themselves into 'one people' and get to know a measure of what such factors as self-love and boundless extravagancy could do to them and how their 'comfort, safety, peaceful living and security' are jeopardized in it. It is still not clear why those who benefit from the disproportion and are far less sagacious to appreciate the necessity of making contract in the collective interest would at all be interested in being a part of the body politic - unless there comes into existence a society that exerts pressure on them. Their prior constitution into one people makes it possible for them to transcend these factors and make the constitution of the body politic possible in the first place. In simple terms, although Locke does not explicitly recognize it, it is obvious that the constitution of the political or civil society is necessarily enveloped in the constitution of the otherwise self-aggrandizing individuals into 'one people'.

Besides, the collective power that the political or civil society constitutes through the relinquishment of the individual right to punish the offenders in the state of nature protects the individual against the threats both from within and without. But who are those who pose a threat from without? They are certainly those who do not form any part of this 'one people'. They must have either remained caught within the state of nature for whatever reasons or have formed another people. If, as Locke too concedes, 'any number' of individuals could form what he calls 'one people, one body politic under one supreme government', then one may rightly ask why this body will not engulf the entire world and eventually lead to the formation of what Kant might call 'World Republic'. While peoples remain divided despite that all of them face the problem of disproportionality - as anthropological evidences bear out, they have the potential of coming under one World Republic. There is theoretically no reason why they should continue to remain divided between all very different 'peoples' and political and civil societies.

\section{One body politic, many peoples}

Historically state and nation do not always fit: while a state may contain many peoples - 'people-nations', as French theorists would describe them - the same one 'people' may remain dispersed between more than one body politic or state. India's Northeast represents a classic scenario of both these historical trends. State territory, in other words, contains many groups of people who do not constitute part of the 'one people' that is known as the Indian nation or more accurately, constitute many such peoples ('nations' and 'nationalities' as they 
prefer to characterize them) on their own with their separate collective will to autonomous statehood. Many of them demand some degree of autonomy within the Indian Union, while some of them refuse to form part of the body politic. In other words, they perceive themselves as being drawn into the body politic without being given the freedom of exercising their choice. It is the same story of denial of freedom, as many of the insurgents maintain, that has been repeated whether in Manipur, Assam, Tripura, Mizoram or Nagaland. What is at issue in these cases is not so much that the collective power that got formed in 1947 fails in delivering what it was expected to - technically known as 'breach of contract' - but very much that they do not identify them with it inasmuch as they do not consider themselves as part of that 'one people' on whom the collective power is supposed to bestow. Locke's theory cannot account for the anthropology of diversity that keeps 'one people' from another - a situation that invests us with the freedom of not only making the choice for any and every body politic that delivers what is expected of it as per Locke, but also the freedom of choosing between a whole range of bodies politic or states - providing 'comfort, safety, peaceful living and security' to all irrespective of our peoplehood with - let us presume - the same level of performance and efficiency. While Locke implicitly accepts diversity as a given reality, it is inexplicable why he does not attempt to theorize the role of people's identity in making and unmaking the contract.

Those who refuse to be part of 'one people' are then left with two mutually distinct options: voice and exit. Many of the insurgents in the Northeast are now in a ceasefire mode and are involved in renegotiating the terms of their incorporation into the established body politic. The demand for renegotiation is voiced through such phrases as 'special federal relationship with the government', 'integration of Nagainhabited areas', the issue of 'sovereignty of Assam' and so forth.

There are still others who are sought to be pushed out of the body politic precisely because no demand for renegotiation is entertained from them. They are thrown back into the 'state of nature'. While I had the occasion of writing on voice elsewhere, in this chapter I propose to confine myself to a discussion of exit, that is to say, what happens when groups of people are governed by the 'law of nature' rather than the rules of 'political or civil society' and how this turns into a governmental technology in the neoliberal age. One has to recall that the colonial rulers too realized the limits of their 'civilizing mission' and seemed to have made a distinction between two groups of people: the subjects who deserved to be ruled and the 'primitives and the savages' who were too 'wild' to be subjected under any settled rule 


\section{Samir Kumar Das}

and administration and from whom the 'subjects' were to be protected by organizing 'punitive raids' and 'military expeditions'. Such colonial and post-colonial instrumentalities as Tribal Belts and Blocs, Inner Line Regulation, Inner Line Permit, Excluded and Partially Excluded Areas, Sixth Schedule, Customary Laws and Traditional Institutions and so forth will have to be viewed in this light. Basically, all these taken together represent an attempt at keeping certain groups of people from the general administration of what Locke would call 'political or civil society'. Governing parts of the Northeast continue to be anchored in the same rhetoric of insulation from the mainland.

\section{The natural way}

It is an irony that the time-honoured policy of pushing hordes of people in the Northeast outside the domain of the body politic corresponds with the present-day neoliberal policy of minimizing the role of the state and this - as Foucault tells us - marks the rise of a particular mode of governmental power. As he argues:

One is not paying enough attention, too many things escape one's control, too many areas lack regulation and supervision, there's not enough order and administration. In short, one is governing too little. Polizeiwissenschaft is the form taken by the principle of the reason of state, and it is in a 'completely natural way' as it were, that it attends to the problems of population, which ought to be the largest and most active possible - for the strength of the state. Health, birthrate, sanitation find an important place in it, therefore, without any problem.

(Foucault 1994:74)

Exit from what Locke calls 'political and civil society' also marks a throwback into the 'law of nature' in a strange sense of the term. Certainly this trend towards governing the region with the 'law of nature' has been intensified by a heavy dose of such neoliberal policies as have been announced in recent years through such packages as 'Look East' and 'Northeast: Vision 2020'. The central idea is to develop the region as rapidly as possible in a way that not only the region catches up with the rest of the country and thus makes good the 'lost' time but development automatically takes care of some of the chronic problems of governance afflicting the Northeast. It is argued, for instance, that once development takes off and creates employment opportunities, the unemployed youth of the region will be absorbed in gainful 
employment, thereby turning away from insurgency - sarcastically called as the 'only booming industry' in a region which has no history of industrialization. The new thrust of the proposed policies has been to shed the responsibility of development from the state and shift it to private entrepreneurs so that accountability and transparency - two grand watchwords of governance - can be ensured. I read these policy statements more as documents on developing governance than governing development from what Nehru fondly called 'commanding heights' of the economy and through state fiat. The idea is to expose the Northeast to the market forces that are expected to serve as mechanisms ('invisible hand' in Adam Smith's famous language) for correcting the 'distortions' that continue to stand in the way to development of the region. As a result, the proposed policies recognize the importance of regulating, if not completely turning off the free flow of state funds for development so that these do not get siphoned away and are not remobilized for fuelling insurgencies.

\section{Permanent state of nature}

Locke was clear in explaining why men thought it imperative to leave the state of nature and enter into the political or civil society. Since there is no collective agency to enforce it, individuals by virtue of being 'self-loving' and 'boundlessly extravagant' are bound to commit excesses. A collective security system in the form of one supreme government or state is the only guarantee against any injustice, that is to say, any disproportionality that might occur between violations of the natural law and the private and individual attempts at seeking reparations and justice.

Locke was trying to reconcile the imperative of justice with that of individual will and volition in the sense that the individual too thinks that the collective power that is thus formed acts on his behalf and executes his will while providing collective security among other things. The non-state actors too set up their own apparatuses and function like para-states in areas where the political or civil societal rules are yet to make much headway. These non-state actors collect taxes, punish the 'offenders', ban showing of Hindi movies, enforce prohibition, impose dress codes, maintain law and order in their respective areas, 'protect' the members of their community from the 'enemies' and so forth. In short, there is hardly any single collective agency in these areas that is capable of exercising its monopoly over the legitimate instruments of violence. It resembles an anarchic situation where there is 'war of all against all'. State is only one of the many such agencies. 
In the absence of any substantial identification with the established body politic or the state, the latter is viewed predominantly as an external agency exercising force and coercion with impunity. Reparations by the state under such circumstance are bound to trigger what Locke would call disproportionality. That the draconian Armed Forces Special Powers Act (1958) has remained in force in the Northeast for the past sixty years - despite vociferous protests particularly in Manipur and Nagaland - is only one of the many examples of how parts of the region are pushed into a re-inscribed state of nature where disproportionality of the state and other non-state armed groups replaces that of the 'self-loving' and 'extravagant' individuals. Locke does not seem to envisage the fact that the state of nature may become unbearable not only because of the 'self-loving' and 'extravagant' individuals, but also because of the armed syndicates at war amongst themselves. While Locke believes that perversion of the state of nature results from individual excesses, the one that now has set in, in the region and elsewhere - wherever the states have 'failed' - is marked by mutually fighting syndicates with rivalling claims to guardianship over people's security. Most of India's Northeast is governed by the law of nature and not by the rules of 'one' political or civil society. The liberal fiction of creating a political or civil society is made possible by quarantining it from what Locke considers as threats to it and keeping the threats at bay, perpetually in a state of nature. Thus, state of nature and political or civil society are not two phases in the history of state formation; they presuppose and are implicated in each other.

\section{Nation-rebuilding}

As the state of nature reinforces and expands itself - thanks to the neoliberal policies coming into force, that 'one people' - the nation closes in on itself and shrinks further and further within it simultaneously pushing the vast congeries of peoples into a re-inscribed state of nature. The Indian state seems to have followed the twin policy of confining the sources of insecurity to some carefully marked-out zones so that the interior of the nation is kept safe from the contagion outside and then governing these zones of insecurity by way of making exceptions to the country's constitution and law of the land, that is to say, the rules of political or civil society. This brings into existence an insuperable divide within India between those who are governed by the rules of political or civil society and those who remain under what I prefer to call the re-inscribed law of nature.

The earlier project of building the Indian nation in the Northeast by way of allowing parts of the region to renegotiate the terms of their 
incorporation into the established body politic was evident particularly from the mid-1980s through the early1990s when both the central and state governments kept on signing accords with organizations claiming to represent a variety of disgruntled ethnic communities. This obviously raised high expectations that the state for once seemed to have been poised up for brave, new experimentations with its political institutions. The accord-signing spree gradually ended with a whimper. Exit becomes the only means of governing them.

Unlike the nationalism of the post-independence years when the promise of legal equality leveled off the high and the low, between the Brahmins and the Shudras, between the Tamils and the Nagas and involved a certain profanation of the nation's interior, nationalism in the new millennium constitutes what Benedict Anderson in an address calls 'a sacred space' to be kept safe from the threats of the profane particularly from within. The enemy within is much more dangerous than the one without. The emphasis on connecting the region to the 'powerhouse' economies of Southeast Asia, as I have argued, is likely to benefit the rest of India more than, if not, at the cost of the region, and exacerbate interethnic conflicts and violence - thereby sharpening further the divide. Only a little of India's trade with the Southeast Asian countries is conducted on the surface across the Northeast. While the policy facilitates the movement of goods and services, it is not meant for facilitating similar movements of ethnic cousins across the borders and their reunification. The market has no compunction for those who are of no use for it. The market has become the new mantra of Indian nationalism in the Northeast if not in the rest of the country.

\section{The low politics of nature}

Is the state of nature then a condition of the jungle? For Locke, the state of nature has a law that is either already known or potentially knowable to all. Although this law exists more as a set of ethical principles than as an explicitly written code backed by agreed-upon sanctions, people living in that state have no problem in discerning what it is, that is to say, what the ethical principles are that they ought to live by. But the state of nature lacks the collective means of implementing them. The anarchy that plagues it emanates from the disproportionality that occurs only at the level of implementation.

By contrast, the present-day re-inscription of the state of nature in parts of the Northeast implies that the state and non-state actors are involved in a permanent 'war of all against all' and hardly share anything in common about what these principles are. Unlike that of 


\section{Samir Kumar Das}

Locke, a re-inscribed state of nature has no consensus in this regard. The state and non-state actors implement the ethical principles that are peculiar to themselves. It resembles a condition in which people are subject to all different systems of law running parallel to each other including that of the state - pay 'taxes' to more than one agency, hold driving licenses issued by many of them. Elsewhere, I designated the phenomenon as sub-territoriality.

If this is what the high politics of the state of nature represents with its syndicates making rivalling claims to guardianship over people's security and therefore embroiled in a deadly yet enduring battle for supremacy, then at a much lower level - at the level of village, locality or neighbourhood - social life consists in living in the society and therefore living with others without having to be involved in conflicts. The very imperative of living with others makes us realize our fallible nature, negotiate and compromise with others, cross the boundaries laid down by its high politics. A lot of our social life is about how we cross these boundaries on an everyday basis sometimes under grave threat from the high politics and make it possible for all of us to share the same space. Social life is far less rigorous and demanding than what the 'armed guardians' of the law of nature would have us believe. Our acceptance of the other does not mean that we adopt or even lend moral approval to what they do. I call it the moral moment. Social life in the Northeast survives not because of any breakthrough in the ongoing series of official peace processes in which state and the nonstate actors are involved in negotiations, but because of these hundreds of the unofficial micro-processes that make social life possible without acquiring any visibility. It is this low politics of peace-making and conflict resolution that makes state of nature bearable for those who live in it.

The key to success of our political or civil society lies in the fact that groups of people are permanently thrown into a state of nature. The more 'we' change, the more 'they' remain the same.

\section{Note}

1 This article was first published in Eastern Quarterly, 6(3): 87-94, 2010.

\section{References}

Barker, Ernest (ed.). 1978/1960. Social Contract: Essays Locke Hume Rousseau. London: Oxford University Press.

Foucault, Michel. 1994. 'The Birth of Biopolitics', in Paul Rabinow (ed.), Ethics: Essential Works of Foucault 1954-1984, Vol. 1. London: Penguin. 


\section{Civil society and democracy \\ Absence of the sovereign in Northeast India ${ }^{1}$}

\section{Kakchingtabam Naresh Sharma}

In a representative democracy, citizens' participation in electoral politics legitimates the sovereignty of the state. Citizens also engage with different institutions and organizations to influence and control the representative political institutions. These different institutions and organizations become the core of the space that lies outside the state, family and economy. Though given different meanings and definitions, the space has been conceptualized as 'civil society'. Historically, civil society emerged when individuals possessing the 'natural right to life, liberty and estate come together, sign a contract' and constitute a common public authority. And the common public authority guarantees these rights to its citizen through law. Protection of rights symbolizes the condition for the existence of a democratic space (Mahajan 1999: 118). For Hegel, civil society was the 'realm of instrumental relations between atomized and isolated individuals and is distinct from family and the state' (Khilnani 2001: 23).

In this chapter I am using the idea of 'civil society' as the space of 'organized life that is voluntary, self generating, self supporting, autonomous from the state, and bound by the legal order or set of shared rules' (Diamond 1994: 5). Of late, civil society is being promoted by academicians, politicians, governments and aid donors as a medium for the consolidation of democracy. India is no exception to this phenomenon. In the context of Northeast India, the regime which oversees democratic governance has a tinge of authoritarianism. This raises the question: Which form of institutions or organization is compatible with democracy? Do they contribute to the welfare of citizens in achieving the goals of social justice? And most importantly, does the civil society which is being promoted actually consolidate democracy or authoritarianism. The chapter shall engage these questions by (1) locating the state of democratic governance in the region, (2) understanding civil society in the region in its functional elements and juxtaposing 
it against democratic ethos, and (3) locating the 'sovereign individual' between civil society and democratic institutional practices.

\section{Liberal to illiberal democracy}

Kohli has observed that democracy has been established with firm roots in India and has been consolidated over a period of time. Among the processes that have contributed to this phenomenon is the introduction of a successful federal system. The system has been able to accommodate some of the contentious ethnic/nationalist conflicts in India involving Tamils, Sikhs and Muslim Kashmiris (Kohli 2009: 21). This notion stems from the perspective that different nationalisms were resolved in the constituent assembly debate and by the reorganization of states on a linguistic basis. The validity of such an observation is contestable in the light of the presence of plethora of issues in Northeast India that directly subvert the core ideas of democracy. I shall try to highlight these challenges to democracy in three broad areas.

First, nationalist struggles by the Nagas, Manipuris and Assamese have challenged the very foundation of democratic Indian polity. On one hand, the over decade-old negotiation between the Government of India (GoI) and Naga leaders has not been able to solve the issue of Naga nationalism. On the other hand, Manipuris and Assamese nationalists have not agreed to get into a negotiation with the GoI if it is to be held under the framework of the Indian constitution. The representatives of these nationalist struggles reject the constitution and argue that they were not a party to the original contract (Das 2010: 232-62). Hence, there are claims and counter-claims on the validity and finality of the constitution.

Second, related to the above, Indian political elites understand the issue purely from a perspective of law and order. Policy analysts argue that the issue can be dealt by 'overhauling the security structure . . . greater deployment of security forces and by implementing emergency laws' (Das 2010: 237). For counter-insurgency operation, a threetier structure called the 'Unified Command' was created in Assam in January 1997. Under the 'operational group', para-military and police forces were kept under the operational command of the army. This leads to the creation of a state within the state where the axis of decision making resides in the Home Ministry of India and effectively shuts out the elected representatives of the state in the decision making process (Baruah 2005: 63). Further, counter-insurgency operations are conducted under the Armed Forces Special Powers Act, 1958 (AFSPA). Clause 6 of the Act 'elevates the military arm of the executive above 
judicial and legislative scrutiny' (Akoijam SARAI: 489). The long-term impact of undermining of constitutionally established institutions for a democratic order is underscored by Pratap Bhanu Mehta as 'institutional forms matter in society because they are the only contrivances we have to mediate matters of truth'. He further comments, 'otherwise the test of truth will simply be what any individual can declaim loudly' (Mehta 2010). The subversion of constitutionally guaranteed principles by the state and enactment of acts like AFSPA are unconstitutional, undemocratic and also an act of 'disguised war' by the Government of India (Akoijam and Tarunkumar 2005: 5-19). Through this Act, rights and liberties are suspended or abrogated. The Act further demoralizes the sovereign individuals and has broken the promise of democracy where the legitimacy of the government is based on the contract among the sovereign individuals.

Third, most parts of Northeast India are characterized by ineffective, unaccountable and corrupt governments. The TII-CMS India Corruption Study 2007 and 2008 found that Assam and Nagaland have an alarming rate of corruption. The study described Meghalaya and Sikkim as very highly corrupt states and Arunachal Pradesh and Manipur as highly corrupt states, while Mizoram and Tripura were found to have moderate levels of corruption. Besides, the process of selection of beneficiaries for the public distribution system was perceived as corrupt by 43 per cent of respondents. Interestingly, the survey also found that bribes are being given not to gain any personal benefits for unlawful activities but rather for services legally guaranteed to the citizens through the public institutions. For example, respondents (36 per cent) averred that bribes had to be paid for getting a bed in the hospital, and also for availing diagnostic service and for medicine. The same goes for getting a new electricity connection or rectifying a faulty meter (45 per cent). People also have to give money for installation and maintenance of hand pumps, repair of water pipe and regularization of unauthorized connection (52 per cent), and police are paid for filing a complaint and for issuing of character certificate ( 77 per cent). Further, perception of corruption and ineffectiveness of the grievance redressal mechanisms lead to distrust of the government formed by the transfer of rights through democratic elections. It 'undermines the long established rule of liberal democracy that any individual that is affected by a decision should have an equal opportunity to affect the decision' (Warren 2002: 678). Importantly, 'democracy has not been able to eliminate the invisible powers of the executives that escape public accountability' (Warren 2002: 677). This only leads to diminishing expectations from democracy. 
Given the governments' transgressions against norms and spirit of democracy, the claim of successful consolidation of democracy in the country does not carry conviction. Hereabout, the role of civil society becomes critical because democracy rests on the consent of the governed. It is critical also because intrinsically 'civil society can perform the function of containing the powers of democratic governments by checking their potential abuses and violations of the law and subjecting them to public scrutiny' (Diamond 1994: 7). Further, they can 'supplement the political parties in stimulating political efficacy and skills of democratic citizens, and promoting an appreciation of the obligations as well the rights of democratic citizenship' (Diamond 1994: 8).

The political elites, executives and the policy analysts respond to the crisis as a crisis of 'lack of development' (Biswas 2008: 178-88). It is considered that 'troubled by history and geo-politics, the Northeast has remained one of the most backward regions of the country' (MDoNER 2008: 2) and economic development will inevitably lead to building of democracy fairly and quickly. The 'North Eastern Region: Vision 2020' document sings the same tune when it points to the ambitious vision of the people of the region to move out of backwardness. Within these contexts, civil society is being promoted in the region as a necessity to 'bridge the gap between expectations and performance by ... fostering creative and collaborative partnership with civil society ... to induct people into the planning and implementation process in a participatory mode' (MDoNER 2008: 39) 'with institutional mechanism designed for modern development and service delivery' (MDoNER 2008: 27).

Even if it is agreed that all the democratic institutions cannot function effectively and efficiently in the desired way, we cannot undermine the fact that a 'modern political democracy is a system of governance in which rulers are held accountable for their actions in the public realm by citizens' (Schmitter 1991: 76). And 'the political process is one where the organs of the state interact with members of the civil society in their individual capacities or as members of the associations' (Chatterjee 2004). In a modern democratic state, the locus of sovereignty rests with the people. There lies an inseparable relationship between the civil society and the state. Yet, in the present crisis as also in the mode of promotion of civil society, citizens in Northeast India appears to have lost the right to be part of the sovereign thereby reducing them to the status of a 'population'. The change in status hints to the transition of democratic form of government to an authoritarian one. Thus the form of democracy that exists in Northeast India can be better expressed as 'illiberal democracy' (Zakaria 1997: 22-43). 


\section{Nature of civil society}

In a society where community life plays an important role in shaping the thinking of an individual, there also exists a particular type of 'self' that does not consider his or her interest as pre-given or predefined. This 'self' is embedded in the community and also lives in the realm of public life. The duality of the 'self' gives rise to organizations where individuals come together for the community - Gemeinschaft and also to promote self-interest compatible with the larger public good - Gesellschaft. However, for the purpose of the chapter both Gemeinschaft and Gesellschaft shall be seen from the prism of their functions. Broadly, civil society bodies existing in the region can be broken down into five categories.

First, agent of the state. These organizations play the role of an extended agent of the government and perform the functions of nurturing and taking care of the population. They work in the area of health, particularly in prevention of HIV/AIDS, in protection of the environment, child care and so forth. For example, there are forty-nine organizations working for the prevention of HIV/AIDS in Imphal alone. They intervene to spread general awareness and take up advocacy for infected people. ${ }^{2}$ Further, in the environmental sector, organizations like Assam Science Society, Science Teachers Forum, Manipur and so forth impart environmental education to school teachers, conduct surveys on environment and so on. Others like Manipur Voluntary Health Organization and Manipur Mahila Kalyan Samiti and Voluntary Health Association of Tripura work for the welfare of the children within the parameters prescribed by the governments. Here, the role of civil society is to produce civility in the voluntary activities necessary for the successful implementation of the prescribed development activities. Such approach emphasizes the positive aspect of association for governance. Seen from the perspective of participation of citizens in the democratic functioning, though not as equal partner in the politics, they legally take part in the implementation of government policies.

Second, the civic organizations. These are generally rights-based organizations and they try to limit or check the functions of the state. These organizations maintain certain amount of autonomy from the organs of the government and try to bring a responsive and accountable government such as Human Rights Alert (HRA), Manipur, Naga Peoples Movement for Human Rights (NPMHR), Manab Adhikar Sangram Samiti (MASS) and Manipur Chanura Leishem Marup. Human Rights Alert has been helping the victims of human rights abuse by the military and police personnel in filing of First Information Report (FIR) 


\section{Kakchingtabam Naresh Sharma}

in the police stations. The organization provides legal aid to victims. Similarly, NPMHR undertakes different programs including awareness and education on human rights, capacity building, monitoring and intervention, campaign and advocacy, networking, documentation and dissemination and legal challenges and assistance. NPMHR has also taken up relief work for victims of rights violations. ${ }^{3}$ Such acts of keeping an eye on the aberrations of the organs of the government is also taken up by Manipur Chanura Leishem Marup by invoking the Right to Information Act in cases concerning the use of public office for private gain, that is corruption. Members of the organization help people in the filing of Right to Information (RTI) applications and in bringing the offenders to the notice of concerned officials thereby helping the victims in getting justice. Since these organizations do not reject the rule of law, they do not undermine the democratic authority of the state or try to act as a competitor of the state. They, in a way, act as a facilitator in the promotion of democracy.

Third, identity-based organizations. Organizations of this nature are influenced by identity politics and try to articulate the interest of specific identities or communities. Naga Hoho, All Manipur Clubs Organisations (AMUCO), United Committee Manipur (UCM), Kuki Inn Manipur are some examples that can be put within this category. Their roles and functions can be best seen in crisis like the economic blockade of Manipur for fifty-two days in 2005 and sixty-four days in 2010. The blockade was called by the groups that espouse the interest of Nagas against the perceived injustices of Government of Manipur with their whole ire being directed against the Meitei community. It is argued that Government of Manipur is a government of the Meitei community and the interests of Nagas are not properly represented in the government. The Meitei community was left to fend for themselves (Kamei 2010). Here, the point is not about the validity of the claims but about the fact that organizations representing these different communities did not engage with each other to find a solution to the problem; instead they kept themselves busy in blaming each other for the crisis. Due to the entrenchment of politics of identity in the everyday life, the tradition of Itao or Ita sanaba ${ }^{4}$ between different communities became a part of history. Due to these factors, they failed to develop democratic attributes of tolerance, moderation, willingness to compromise and respect for opposing viewpoints. Hence, identity-based "vigorous associational life acts as a serious constraint in bringing peace as the engagement between the communities is weak in associational forms of engagements and everyday forms of engagement' (Varshney 2001: 363). 
Fourth, the path finders. Such organizations make an attempt to create channels for articulation, aggregation and representation of interests beyond the political parties. Besides the presence of ethnic nationalist struggle against New Delhi, there also exists a zone of conflict between communities at different layers in the region. The outcome of these conflicts is hegemonic and homogenizing claims over truth and absence of peace. To counter these contesting claims some organizations such as Senior Citizens for Society (SCS), Manipur had 'urged the government of India to initiate a process of political dialogue with the major insurgent groups operating in the state without any pre-condition to avoid further deterioration of the situation'. ${ }^{5}$ Yet, there has not been a substantive response from the Government of India. Likewise, People's Consultative Group (PCG) of Assam tried to initiate peace dialogue between the Government of India and United Liberation Front of Asom (ULFA). However, after holding thirteen rounds of talks with the Government of India to prepare the groundwork for the start of a dialogue, PCG withdrew itself from the process. The reason for the failure was the insistence of the government to hold talks directly with the leaders of ULFA and the demand of ULFA to halt military operations while the PCG and Government of India were finalizing the terms of engagement. As the Government of India's history of peace initiatives in the country shows, they enter into the dialogue process only when they are sure that they can dictate the terms and content of the dialogue. This is reflected in the words of the Indian Army Chief J. J. Singh: 'the Army has been given an assignment to perform. If we can compel them to come to the negotiating table and abjure violence, the peace process and prosperity will come back in the region' ${ }^{6}$ Preference for military over democratic means reduces civil society to the role of pressure group. Albeit, they try to promote democracy by reducing the armed conflict, thereby secure the rights and freedom of the citizens.

Fifth, vigil organizations. These organizations take the role of vigilantes to achieve certain public goods in the society. They generally operate in small geographical areas, more specifically in the vicinity of their locality. Organizations like Leikai Clubs, Meira Paibis, and Naga Mothers Association (NMA) engaged themselves with activities aimed at improving the quality of life in the community. For example, Leikai Clubs engaged themselves in activities to ensure cleanliness, proper water and electricity supply, maintenance of library and act as a platform to discuss issues that affect the day-to-day activities of the locality. ${ }^{7}$ Meira Paibi and NMA are engaged in banning of liquor and other illegal drugs so that society may lead a healthy life. These organizations try to achieve certain levels of 'social good' by collectively 
deciding what is good for the society. Such an active and vigorous form of civil society promotes democracy by involving themselves in collective decision making and setting the political agenda.

In their functioning, the organizations and institutions try to achieve common social or political good and to effectively check the unwarranted and irresponsible behaviour of the state. Or it can be said that they act as a stimuli in strengthening the democratic principles. Civil society initiatives to protect the rights of the citizens show the presence of democratic political practices which legitimates the government and the state system.

\section{The slippery imagination}

In a representative democracy, sovereignty is transferred from the people to the state and its rulers. Protecting the sovereignty is not only the responsibility of the democratic state but also that of the civil society. However, in their intoxication with the 'brown men's burden' of civilizing the backward people, political elites and policy experts have defined and promoted civil society through an Act of the government. The Manipur Municipality Community Participation Bill, 2010 is a classic example. It defines civil society as:

any non-government organization or association or persons, established, constituted, or registered under any law for the time being in force and working for social welfare, and includes any community based organization, professional institution and civic, health educational, social or cultural body or any trade or industrial organization and such other association or body as the state may decide. ${ }^{8}$

This understanding of civil society is that any organizations or institutions shall abide by the constitution and follow the laws of the land. Their validity as a civil society and even their functions shall be decided by the government. And the functions range from

mobilizing voluntary labour and donation by way of goods or money for social welfare programme, to providing assistance in the implementation of developmental schemes and ensuring people's participation in the voluntary activities necessary for the successful implementation of the development activities. ${ }^{9}$

But imagining civil society as an implementing agency or agent of the state negates interaction between the citizens and organs of the 
government to ascertain the desire and needs of people in matters that have a direct bearing on their lives. While the instrumental conception of civil society might help in effecting the state's preferred outcomes, it also depoliticizes, sacralizes and bureaucratizes the civil society (Jenkins 2002: 250-68). This has undermined 'the expansion of social equity and liberty and ... democratizing of state institutions' (quoted in Flyvbjerg 1998: 211). Unconsciously, those 'agents of the state' have contributed in the consolidation of an authoritarian regime. By defining through an Act, the government has used civil society as a tool of the state for the production of labour in its relationship between the government and the individuals, thus resulting in a new set of socioeconomic relationship.

This is the art of governing by emphasizing on individual relationship with 'wealth, resources, means of subsistence, the territory with its specific qualities, climate, irrigation . . f famine, epidemics and death, and so on' (Foucault 1994: 210) for 'the common good'. But, when the art of governing insists on securing 'the common good', it marks the 'end of sovereignty', because 'end of sovereignty' refers to 'state of affairs where all the subjects without exception obey the laws, accomplish the tasks expected of them, practice the trade to which they are assigned and respect the established order' (Foucault 1994: 210). Michel Foucault observed, 'in actual sense the end of sovereignty is the exercise of sovereignty' (Foucault 1994: 210).

It is important to note the relationship between the laws that are 'in operation' in the region and the organs of the government and the form of civil society that is being promoted. The operational existence of an executive state - manifested in laws operated under the command of an executive, the dwindling primacy of the legislature and the distortion of civil society into a bureaucratic institution - reinforces the principles of an authoritarian regime. This has affirmed the argument that inhabitants of Northeast India are not citizens in its true sense; rather they are the 'population' that needs to be controlled. This has delegitimized the freedom and rights of the citizens of the Northeast as these issues were never treated as a crisis of democracy. This begs the question: where does one locate the sovereign individual in the civil society for the functioning of a democratic state?

\section{Conclusion}

The model of democracy that exists in Northeast India (which I have termed an 'illiberal democracy') seeks to control the people by denying the rights of a 'sovereign individual'. As has been pointed out above, 
the protection of rights symbolizes the condition for the existence of democratic state. The question of protection arises because the democratic state is formed by the transfer of rights by sovereign individuals. So, democracy can only be consolidated when the government has the consent of the citizens. This consent is expressed through activities and involvement of sovereign individuals in the realm of engagement with the organs of the government and in shaping the political agenda through their collective decisions. The civil society that is being promoted in the region is about effectiveness in the delivery of services.

To make the claim of 'consolidation of democracy' meaningful, one of the fundamental tenets of democracy - 'the rights' - should be respected. This should be the primary criteria in the promotion of the civil society. Respecting such a principle will lead to political institutionalization. Democratic citizenship can acquire its sheen only when the laws and institutional mechanism that is not in harmony with democratic ethos are discarded. Believing in the democratic ethos can produce a vibrant civil society where the 'sovereign individual' experiences rights to life, freedom and liberty. The promotion of just one particular model of civil society and operationalization of undemocratic laws and institutional mechanisms in Northeast India would amount to saying 'Obey, but argue as much as you want and about what you want' (Chakrabarty 2002: 81).

\section{Notes}

1 This chapter was first published in Eastern Quarterly, 6(3): 106-15, 2010. The author acknowledges the comments and insights of Laishram Bidhanchandra Singh. The limitations and mistakes that creep in the chapter solely lie with the author.

2 www.cicmanipur.nic.in/html/aids_ngo.asp

3 www.npmhr.org

4 This is a traditional form of friendship that exists between the Meeteis and neighbouring communities at personal level. However, it should be noted that this was a practice accepted as a community discourse beyond the bounds of cultural and ethnic rules and regulation. The practice shows a space for developing fraternity among communities beyond the community/ ethnic identities.

5 'Manipur Senior Citizens for Political Dialogue', Hindustan Times, 11 February 2010. www.hindustantimes.com/Manipur-senior-citizens-for-politicaldialogue/Article1-507606.aspx. Accessed on 10 July 2010.

6 These events are well documented in Samir Kumar Das, Conflict and Peace in Northeast India: The Role of Civil Society, Policy Studies 42, Washington: East West Center, 2007, and in Samir Kumar Das, 'Peace Sans Democracy? A Study of Peace Accords in the Northeast India', in Sanjib Baruah (ed.), Beyond Counter Insurgency: Breaking the Impasses, New Delhi: Oxford University Press, 2010. 
7 For detailed study on the activities of Leikai Club refer Ningthoujam Irina, 'Leikai-Club in The Contemporary Meitei Society', 2010. http://manipur online.com. Accessed on 22 November 2010.

8 The Manipur Municipality Community Participation Bill, 2010, p. 2 (emphasis added).

9 Ibid., p. 3.

\section{References}

Akoijam, A. Bimol. Undated. 'Another 9/11', SARAI Reader 05, Bare Act. www.sarai.net/publications/readers/05-bare-acts. Accessed on 10 August 2010.

Akoijam, A. Bimol and Th. Tarunkumar. 2005. 'Armed Forces (Special Powers) Act 1958: Disguised War \& Its Subversions', Eastern Quarterly, 3(1).

Baruah, Sanjib. 2005. Durable Disorder: Understanding the Politics of Northeast India. New Delhi: Oxford University Press.

Biswas, Pransenjit. 2008. 'Post-Development, Democratic Discourse and Dissensus: A Critique of Vision 2020', Eastern Quarterly, 4(3\&4).

Chakrabarty, Dipesh. 2002. Habitation of Modernity. New Delhi: Permanent Black.

Chatterjee, Partha. 2004. Politics of the Governed. New Delhi: Permanent Black.

Das, Samir Kumar. 2007. Conflict and Peace in Northeast India: The Role of Civil Society, Policy Studies 42. Washington: East West Center.

Das, Samir Kumar. 2010. 'Peace Sans Democracy? A Study of Peace Accords in the Northeast India', in Sanjib Baruah (ed.), Beyond Counter Insurgency: Breaking the Impasses. New Delhi: Oxford University Press.

Diamond, Larry. 1994. 'Rethinking Civil Society: Toward Democratic Consolidation', Journal of Democracy, 5(3).

Flyvbjerg, Bent. 1998. 'Habermas and Foucault: Thinkers for Civil Society?', British Journal of Sociology, 49(2).

Foucault, Micheal. 1994. 'Governmentality', in P. Rabinow (Series Editor) and J. D. Faubion (Volume Editor), Essential Works of Foucault: Power, Vol. 3. New York: New York Press.

Jenkins, Rob. 2002. 'Mistaking Governance for Politics: Foreign Aid, Democracy and the Construction of Civil Society', in S. Khilnani and S. Kaviraj (eds.), Civil Society: History and Possibilities. New Delhi: Cambridge Publication.

Kamei, N. 2010. 'Manipur Economic Blockade: The Reasons from Naga Viewpoint', Mizoram Express, 18 June. http://mizoramexpress.com/index.php/ 2010/06/manipur-economic-blockade-the-reasons/. Accessed on 20 June 2010.

Khilnani, Sunil. 2001. 'The Development of Civil Society', in S. Kaviraj and S. Khilnani (eds.), Civil Society: Histories and Possibilities. New Delhi: Cambridge Publication.

Kohli, Atul. 2009. Democracy and Development. New Delhi: Oxford University Press.

Mahajan, Gurpreet. 1999. 'Civil Society and Its Avatars: What Happens to Freedom and Democracy', Economic and Political Weekly, 34(20). 


\section{Kakchingtabam Naresh Sharma}

Mehta, Prarap Bhanu. 2010. 'Beware the Single Brush', Indian Express, 23 October.

Ministry for the Development of Northeast Region. 2008. North Eastern Region: Vision 2020.

Schmitter, Philippe C. 1991. 'What Democracy Is ... and Is Not', Journal of Democracy, 2(3).

Varshney, Ashutosh. 2001. 'Ethnic Conflict and Civil Society: India and Beyond', World Politics, 53(3).

Warren, Mark E. 2002. 'What Can Democratic Participation Mean Today', Political Theory, 30(5).

Zakaria, Farid. 1997. 'The Rise of Illiberal Democracies', Foreign Affairs, 77(6). 


\title{
16 Pang-Sau or redeeming India's Northeast from impoverished constitutionalisms
}

\author{
After-life of an essay ${ }^{1}$
}

\section{Prasenjit Biswas}

\section{The transnational gaze}

This essay originally published in Eastern Quarterly now acquires a new life, as India's Northeast has witnessed an irredeemable corporate and statist attempt at blueprints of economic development built on extractive natural resource-based mining. Recent debate on Uranium Corporation of India's tender to mine uranium in Meghalaya has brought back serious ethical and political concerns. The idea of eminent domain versus Sixth Schedule autonomy of the tribal communities on natural resources only reached an incompletely theorizable (dis)agreement. ${ }^{2}$ The debate is: can the eminent domain principle override the right over natural resources of the tribal communities (particularly in the Sixth Schedule areas)? The debate is taken to a larger level by bringing in the issue of free, prior and informed consent (FPIC) that is required for setting up any project by the state and/ or by the private corporations involving transfer of ownership over natural and cultural resources of tribes and other indigenous communities. ${ }^{3}$ Due process required for eminent domain is interpreted in a much-watered-down manner by financial and industrial corporations to undermine cultural rights of peoples by speaking of consultations with all potentially displaced persons and payment of monetary compensation by the extractive industries in the context of resource rich Northeastern India. ${ }^{4}$ Often the due process is shortened by a complete abrogation of procedural rights of the indigenous peoples (Hudson 2010: 1280-327). Often inadequate procedural protections within Sixth Schedule need to be made up by devising legal and extra-legal measures. ${ }^{5}$

The recent incident of police atrocities on Tawang anti-dam activists and the rush of the government in implementing mega-projects shows a novel tendency of expropriation of community resources by elites from other parts of India, who are supported by the state at 


\section{Prasenjit Biswas}

the local level. Move toward Act East Policy centres upon less and less of environmental and social impact concerns, as Memoranda of Understanding (MoUs) and No Objection Certificates (NOCs) are reduced to mere formality. The new hydrocarbon policy, auctioning of oilwells, commercialization of minerals and huge infrastructure projects attest to the fact that the economic and geographical space of Northeast India is reduced to a mere corridor. Rampant trading of natural resources as part of the Act East Policy lacks any visionary social policy that can secure land, resources and employment along with sustainable cultural and political rights of the people. In a sense, greater central and transnational expropriation of resources will only add to dilution of already existing protective mechanisms and will generate stronger divisive reactions. Instead of a normative framework of recognition of cultural and political rights, neoconservative demands for politics of distinction and exclusion will be perpetuated for an apparent protection of community against outsiders and thereby effectively diluting land laws, which is of primary importance for keeping the communities safe and stable on their own territory.

The whole situation could be theorized in terms of incomplete theorization of (dis)agreements as what Rawls had called 'an agreement on political principles', as part of 'overlapping consensus' is never achieved in the context of Northeast India. Judgements that underlie convictions about opening up the Northeast to transnational economic activity cannot justify the demands for changing land laws and diluting provisions of tribal autonomy and hence leaves a yawning gap between one policy and another. The 'local pockets of coherence' offered by incompletely theorized (dis)agreements address concerns of cultural and political rights raised by the civil society.

\section{Reinventing of the ethnic}

The recent interpretations of the Indian Constitution that privilege 'national security' over the rights of people in determining their own choices has produced severe stress in democratic politics in India's Northeast. The apparent demise of regionalism from the sphere of governance and electoral politics has only added force to a normative superiority of centralized decision-making and supervisions in matters of public interest. The assumption that a corrupt ethnic elite that leads any regional or national political outfits acts only as directed by the Centre gained considerable ground at the cost of credibility of civil society formations, although such formations actually dominate everyday politics. 
Often major insurgent outfits bank on such civil society collectivities to legitimize their otherwise counterintuitive acts, while the more Weberian Indian state, lying on the other side, blinkers at the rationality of such assertions at different public bodies. One needs to understand this phenomenal implosion of public spaces to articulate the language of 'responsible dissent' through the agency of 'civil society'.

To begin with, the old debate on the nature of 'political society' being the mediating forum between 'state' and 'civil society' needs to be drawn out in the context of deliberative practices that bulwark of law in India's Northeast is supervenient upon. The context of such rule is 'plural' in its form, as it emanates from constitutionally embedded forms of instituitionalism to an intersection between ethnoscape, financescape and mediascape that turns constitutional rule into a near cosmopolitan biopower. Disembedded forms of institutionalism produce a ground for narratives of economic growth couched in terms of reference of a host of financial institutions, starting from the World Bank to the Reserve Bank of India. Projects like trans-Asian highways, border trade and profit turnover from public sector and private sector are redistributed by such an institutional and biopower nexus. Such a hypereconomic hyperbole can hardly hide the fact that agricultural land grabbing and commercialization of natural resources has not only dwindled the productive base of the Northeast's economy, but it has alienated the productive populace from land, forest, river and the communitarian labour process. Financial institutions created a situation of dependency on the finished goods market at the cost of productive labour and ecology-based economy. The role of civil society here emerges in rediscovering the lost balance between finance and ecology. It articulates opposition to destruction of natural landscapes that affect livelihood and productive activity of the common masses. One example will make it clear. Recently, the Lotha Hoho, the highest social body of the Lotha tribe, filed a Public Interest Litigation (PIL) against leasing out oilfields in Wokha district of Nagaland, to which the Gauhati High Court has issued a stay order in 2015.

The other aspect of plurality of contexts that arise from intersection between ethnic, finance and mediascapes attempts to replace the lived reality of peoples by creating 'virtual neighbourhoods' that recreate pasts and imagine new homelands opening up the cartographically enclosed space of the nationstate. As such imaginary and 'virtual neighbourhoods' affect the public spaces in more than one way, it gives rise to a series of cultural crafting: from an imagined Korean-Chinese descent to becoming one of the lost tribes of the Old Testament. Civil society bodies here redescribe their definition of 'self' and 'other' as it 
moves from a myth-symbol complex to sentient relationship of dominance that positions oneself vis-à-vis an Other. ${ }^{6}$ To a very large extent civil society bodies mobilize public memory by reference to sensible, visible and memorable structures, images, built-up places and other such artefacts. In a cognizable sense, the 'virtual' and the 'real' crisscross in this intersecting spaces of ethnic, finance and mediascapes in India's Northeast.

This brings us to understand two vital components of emerging public spaces in India's Northeast: one, disembedded forms of institutionalism; and the second, the virtual neighbourhood of Southeast Asia and the West. Both of these affect the social relations in two different and contrary ways: the former alienates and the latter helps reconfiguration of public spaces in a deep psychological way. The social and cultural engineering produced by these two simultaneous alienating and reconfiguring influences shape the 'political society' of India's Northeast. I have elsewhere characterized the formation of political society in two distinct ways: first, by a reconstruction of the realm of the sensible, and second, by a de-materialization of 'forms of life'.7 Both these descriptions are based on the nature of construction and participation in politics, which is participation in the 'contraries' of life. One of the good examples of such a participation in the contraries of life is the ongoing participation of Sammilita Jatiya Abhibartan (a Citizen's Forum for Peace) in Assam in the peace parleys between the state and the insurgents. The forum is often decried as an impediment for the respective goals and objectives both by the state and the insurgents. To both the contending parties, the forum looks like the 'agent' of the other side. In the same vein, any intervention from a civil society group risks such a scurrilous description of an 'agent'. Those who assume a dark womb for such civil society groups as 'sympathizers and overground spokesmen' of the despicable members of the UGs, they cannot fathom the need for an interstitial space between the state and the insurgent beyond what conforms to the powers that be. This experience is not only peculiar to Assam, but found in almost all the conflict-torn places in the region.

At a normative plane, the participation of civil society groups in politics resists two distinct frameworks of understanding the phenomenon of insurgency in India's Northeast. The first one that considers all ethnocentric nationalist assertions as a by-product of some kind of retrograde relapse into primordialism of a confessional kind gets challenged by such civil society initiatives that expose limits inherent to any form of political patronage that only brings out universalisticrepublican issues of rights. For example, Apunba Lup's questioning 
of the presence of the Armed Forces Special Powers Act exposed the limits of liberal constitutionalism. The second notion about civil society groups as narrowly ethnocentric gets problematized as questions of propriety of the liberal state are raised in democratic movements propelled by civil society groups. While none of these groups takes part in the 'politics of recognition' played by the state in a certain way, they do not and cannot afford to clash with their counterparts in other societies, just as the state does it in the context of counter-insurgency or otherwise. The larger context of absence of check and balance on the use of force by the state, as in the case of Special Operation Teams (SOTs) in Manipur, Salwa Judum in Chhattisgarh or secret killings in Assam gets obfuscated in undermining civil society group's resistance for it speaks in the name of community. So the question remains as an open question: When and where does a civil society group get narrowly ethnocentric? Does it necessarily speak in the name of a community when the interests of communities clash with each other?

\section{The negotiable 'state'}

Civil society groups position themselves in the in-between space between state and citizens or peoples. Depending on the specific configuration of power centres of the state and its attendant machinery, the civil society can act as a source of resistance. Between the increased aptitude of resistance and increased domination by the state and the market, the civil society of the Northeast arises as a diverse and plural source of voices that resist the designs of dominance. ${ }^{8}$ This diversity and plurality of the civil society resists the indissociable institutional base of the state by way of resisting statist abstractions that arise from 'structural relations' that sustain the state. Such abstractions are prefigured in cacophony of discursive productions by the civil society groups that produce a patchwork of interpretive repertoire that is available with them when they argue for a social cause (Wetherell and Potter 1992: 56).

This interpretive repertoire includes an empathic and passionate mobilization of events and histories that turns inward and reclaims 'roots' in terms of local and situated agents, spread across communities and boundaries between them. The small dramas and fine detail of social problems, especially at its lower depths, instead of the embedded power of the institutions produce a discursive frame that allows an independent articulation as an outside of the well-defined power relations between the state and the society. Such a possibility of discursive framing recaptures the alienated subjects of the modern state 
who experience the intrusive character of power over their rightful existence. It is by this experience and its articulation in claims of rights the subjects also realizes their freedom in the very frame of 'negative universality' of the modern state. ${ }^{9}$

The 'negative universality' of the modern state produces its ripples in the life-world of its subjects who remain as its outside, while the inside of the modern state attempts to construe a 'society' in itself. This experience with the state assumes its manifold representation in an engaged belonging to the society, which in itself, cannot affect a return to the alienated subjectivity of flesh and blood subject. The experience of a liberal state in terms of its disalienating effects gets limited to asking for a 'proper representation' in an official space. ${ }^{10}$ This mode of representation assumes that one needs to live not just in a self-enclosed locale, but move outside of one's self in order to allow a representation that reproduces the ensemble of social relations that define cultures and communities. Such an ensemble certainly includes instances of resistance that is built from within. For example, the event of celebration of a decade of Sharmila's fast has been foiled by denial of permission by the state. Activists from all over India who came to participate in a festival to celebrate Sharmila's unique fast for repealing the Armed Forces Special Powers Act,1958 had to sulk under police coming in their way. ${ }^{11}$ This is a typical case of an already shrunk democratic space that the state refuses to open up.

Another very contemporary 'official representation' of India's Northeast is the invitation to Shillong Chamber Choir (SCC) group, who won a national award in a very popular TV show to perform at Rashtrapati Bhavan on the occasion of the state dinner of US President Barack Obama. The spirit of inclusion within the mainstream Indian nationalist discourse gets its much-needed legitimation from such an act of invitation that grants it a lot of acceptability as a benevolent master. This is also a part of the programmatic agenda of filling up the gaps in the representation of India's Northeast by the pervasive authority of the Indian state. The question that one would ask is, does this ameliorate the pathology of survival in India's Northeast by altering the frame of perception? The content of the experience of being treated as an Other gets newly determined by the ontic sense of representation, which is further determined by the specific social totality structuring our 'transcendental' horizon of understanding oneself as an Other. ${ }^{12}$ The representation of SCC turns out to be the other side of the true story of the cultures of cruelty in the theatre of everyday life. The everyday life counts here more than the aesthetic of statist representation. 
The question is, how does civil society set its face against the manipulation of their sensibilia? How does it resist and collaborate with the predicament that it is presented with? In the context of civil society of India's Northeast, for a proper theory of its sustenance, a set of objectives that could be made acceptable to the larger goals of development and electoral politics, which mostly are neoliberal concepts of 'gains' that enrich a powerful section of the state and economy are continuously propagated in order to silence any voice of dissent. The recent example is rationalization of Armed Forces Special Powers Act by the 'strategic thinkers' of the state to stave off the demand for its repeal. Such a defence of the 'unjust' fits into the agenda of electoral politics and development as the discourse of democracy allows for a legitimate monopoly of violence of the state. Recent declaration by Irom Sharmila to break her fast and contest elections in 2017 shows how the civil society faces political constraints and how it tries to cope with such constraints. The other event that exemplifies the idea of demonstrating 'gains' is the defence of large river dams by the Assam and Arunachal governments in the name of power generation that sidesteps the massive environmental degradation in the downstream of rivers such as Ronganadi, Borak, Subansiri, Mapithal and many others. The attempt to get legitimacy in the civil society becomes the primary site of political rationalization of the objectives framed by keeping in mind the 'gains' by the specific coterie of power. While civil society is (dis) informed in a tactical manner, the purported aim of such rationalization lies in strengthening the interests of big business, political mafioso and the already manipulated and bought up intelligentsia. The extent to which this supportive bulwark can operate depends on the extent to which it can influence the civil society.

\section{We, the people}

The multitude of civil society bodies and their individuation carrying a warrant of sanity and responsibility presents the new face of India's Northeast. Each of these bodies speaks of their peculiar experiences in terms of their belonging to a site, event or community - the very language of which is shaped by demand for legitimation. Such a demand is like a 'categorical imperative' that resists any universalization of specificity of suffering in the discursive politics of experience. The politics of experiencing the suffering and the guilt, the failure to redeem oneself and the more than prejudicial attempt to disclose select part of that experience to Others gives rise to an interruption to the stream of experience that is left 'inarticulable' and 'inexpressible'. The 
uncanny aspect of this politics of revealing to others what is painful and self-debasing is an inverted foundationalism of culture and history in which one is supposed to be rooted. Such grounding and articulation of 'roots' in flesh, blood and tears allows a great degree of freedom in evolving an alternative to the dominant discourse, which remains as the mainstay of the contribution made by civil society bodies in the Northeast. In a strong sense, civil society gets re-territorialized in its juridical self-understanding without throwing up new sets of political and moral universals. The only way one can capture this moment of self-definition and a consequent return to the non-universal political subjectivity of suffering is by way of moving beyond the realm of its necessary production as plural or singular identity within the space of the nationstate.

The civil societies of India's Northeast portray a great imaginative potential in pursuing such an agenda of justice. The potential arises from 'an unstructured, or rudimentarily structured and relatively undifferentiated community' that presents itself as the actor in a situation of defending and pursuing the rights of the oppressed and the marginalized. The question is, to what extent such moves by the civil societies have room to manoeuvre the state and the market that turn them toward self-empowerment as well as to seeking a certain kind of safeguard from these powerful institutions against which they raise their voice and mobilize the public. Civil society bodies in India's Northeast prove themselves to be the forbearers of sustaining the domain of collective action in a democratic manner that gives them greater moral strength than the repressive organs of the state. The state puts up a proxy fight against self-empowered and activated civil society bodies using legal and political means. One would rather identify a democratic constraint in the workings of both the state and the civil society bodies, as both these kinds of entities, in the ultimate analysis attempts to prove their democratic credentials in constitutional terms. In a sense both these kinds of entities are constitutional status quo antists without subscribing an agenda of transformation. One may say that 'social engineering' and reproduction of an originary harmony between the state and the civil society remains as its mainstay. In a strong sense, the political society is not the necessary outlet for the civil society action and its programmes, it is rather a restoration of an originary harmony that is the proper placement of both the state and the civil society in a relational space of procedural adjudication of claims.

In effect, such institutions at the local level have taken care of the aspirations of the ethnic elites, while quite ironically, it left open the 
scope of increased dissent to any central government-led programme of social engineering. Indeed civil society bodies articulate what lies beyond the governmental mechanism, that is, the issues of the life-world.

The life-world issues involve, very interestingly, historical and cultural issues such as living an authentic life according to norms and values that have evolved within the ambit of a community who occupy a place in the earth as 'descendents of miracles and solitudes', whose life and world is mis-represented by some nominalized reproduction of signifiers by the nationstate. ${ }^{13}$ From the perspective of the nationstate, the myth-symbol complex that is articulated in real practices and performances by ethnic, tribal and other cultural communities of India's Northeast has never become a part of the metalanguage of Indian culture and nationhood. This metalanguage in which the Indian nation constructs itself leaves its marks and scars of exclusion on almost every 'community' from India's Northeast. Civil society bodies use the space of the life-world as a space of recovery of their lost self, but it cannot be entirely free from contestation and difference with the other. One observes here a politics of boundary maintenance that arise from quite a paradoxical form of exclusivism as well as an attempt to make oneself a part of the dominant national narrative by way of talking of 'lesser known freedom fighters' from among the tribes of India's Northeast. This is how the set pattern of dominant national narrative imposes itself sixty-three years after independence in India's Northeast as the National Council of Educational Research and Training (NCERT) textbooks get reoriented to include 'history' of the Northeast. The civil society bodies can find this 'inclusionary exclusion' as an umbrage cast by the state on the authenticity of life-world narratives. From a theoretical position one can say that the inner-worldly moorings of local culture could now be strategically subsumed under the national narrative within which the self-visualization of ethnic and tribal groups of Northeast India can be organized, albeit, not in unproblematic ways. The problematique of such a subsumption lies in its trans-coding of local histories into qualifiers of assimilation, as the tribal and ethnic self is idealized as the embodiment of the 'unity in diversity'.

\section{Assimilation of contraries}

The foregoing process of assimilative pan-national identification with the local and the different throws up a new challenge to the resistance activism of the civil society bodies. The challenge is that how such 
activism can separate the Lockean-Rawlsean presence of the state as collaborator and arbiter of questions of right from demands and voice of the people at the level of experience, although they can be easily separated at the level of conceptualization. The state can lay a thick 'veil of ignorance' that neutralizes the radical potential of a supposed agenda of transformation. The return to political subjectivity via the life-world has to confront the production of objective claims of justice and fairness by invoking a sense of authenticity that is different and yet not exclusivist. This can be realized in finding friends and supporters to causes at the national and international level, that is, from the national and global civil society. ${ }^{14}$ The recent campaign for withdrawal of the Armed Forces Special Powers Act brought together civil rights groups of Northeast and rest of India, as also the campaign against big river dams in the Northeast found support of many an environmentalist groups from all over India and South and Southeast Asia. For the first time, issues of these kind that have definite repercussions and reflections on the functioning of a supposedly democratic state and issues that affect India's peripheries have found occupied a larger space of public discourse. Claims of autonomy and freedom of political and cultural expression outside the mainstream of India's ruling coterie that arise from the peripheries such as Northeast India alters the self-perception of India's mainstream, although it will take a longer time before such talks are merely dismissed as a show of disloyalty to India.

What happens in the realm of culture and interpersonal and intercommunity relations between the Northeast and the mainstream India has its queer ripples in the fields of politics and economy as well. The so-called Look East Policy objectifies a look on India's Northeast. Is it how one looks at oneself or at one's other? Does this look as an Other allow a 'moral economy' to function? The invisible hand of the market forces in extracting all the natural resources from India's Northeast with its surplus transporting trans-Asian highways and waterways converting the Northeast into a 'corridor' to Southeast Asia turn it into a residue of national and trans-national capital. Are the civil society bodies from the Northeast ready to encounter such an offensive of the capital? They have to write a useful account of self-understanding for this very process of subjectivation and objectification. This requires a necessary construction of a more inclusive democratic space by the civil society bodies themselves by identification with innovative methods of resistance at the epistemological plane. ${ }^{15}$ This innovation has to break out of the vicious cycle of violence-counterviolence, as such a cycle only produces a dichotomy between the self and the other. Civil society 
bodies need to break their self-enclosed cultural and ethnic exclusivity by yielding place to the Other and when such a process of reconstruction is on, it would be possible to reaffirm the normative presence of the civil society as a 'regulator' that is far more extensive than the juridical state. The juridical state is itself regulated by powerful corporate and political coterie and hence such a regulated state needs to be further regulated in acts that amount to subjectivation and objectification of peoples. Can civil society of India's Northeast play the role of the regulator of the regulated? Can civil society bodies of Northeast India argue a good case for laws against the state in order to uphold inviolability of all forms of human rights as well as to contain the regimes of impunity that the constitutional state allows without any remorse? The imminent figure of 'statelessness' in a borderless Northeast calls for augmenting the Constitution of India with a better sense of legal and moral pluralism that allows responsible dissent a rightful place.

\section{Notes}

1 This is a revised version of the paper titled 'Pang-Sau or Redeeming India's Northeast from Impoverished Constitutionalisms', Eastern Quarterly, 6(3): 95-105, 2010.

2 After-life of this essay is based on a notion of incompletely theorized (dis) agreement that operates at a low or intermediate level of abstraction. Such (dis)agreements work through intense disagreement on both what is right and what is good. See Macedo (1999: 130-3).

3 In the United Nations Office of the High Commissioner for Human Rights (OHCHR) document issued on FIPC in September 2013, it is stated that the Committee on Economic, Social and Cultural Rights (CESC) in its comment 21 expanded the scope of cultural rights by asking for return or restitution of land, territories and resources traditionally used and enjoyed by indigenous communities if these are taken without FPIC.

4 One can draw a parallel here in terms of what World Bank President Mr. James Wolfensohn said about FPIC that it cannot be operationalized in most cases and hence what could be done best is compensation to be given to all the potentially displaced persons. See Kirsch (2014).

5 Recent instruction of the Government of Meghalaya (July 2016) to Uranium Corporation of India Limited (UCIL) to keep in abeyance its tender for extraction of uranium is an example of such a measure to stop uranium mining.

6 The memory of a birthplace such as Somdal in NSCN (I-M) General Secretary Th. Muivah's recent attempt to visit Manipur, or the Ahom ampitheater or cremation tombs in Sibasagar district of Assam, are some examples of embodied history and its reproduction.

7 First Dr. Thingnam Kishan Memorial Lecture entitled, 'Beyond the Trapping of the Ethnic: Ethics and the Political', delivered on 28 June 2010 at Imphal. 
8 Such resistance against the dominance involves delivering social good, empowering citizens, struggling against violation of human rights and raising of social issues.

9 The 'negative universality' of the modern state lies in negation of the nonconforming and disparate particulars.

10 One could mention here a recent demand made by Ms. Agatha Sangma, one of the MPs from India's Northeast about mentioning the contribution of India's Northeast in history books published by NCERT. She indeed mentioned names of freedom fighters such as 'Moje Riba, U Tirot Singh, Pa Togan Nengmingza, Haipu Jadonang, Rani Gaidailiu, Ropuiliani' and many others, who deserve a rightful place in the history books meant for children so that people of India are aware of the history of peoples of the Northeast region. See The Shillong Times, 26 October 2010, p. 3.

11 Details available in The Telegraph, Northeast, 6 November 2010, pp. 15, 17.

12 The dichotomy of being an Other as a signifier of artistic perfection as in the case of Shillong Chamber Choir presenting a musical item before Barack Obama is creating otherness in proximity, while it signifies the representation of the Other as distinguishable from who organizes such signifiers and their representational repertoire. See Paul Ricoeur, Oneself as Another, Cambridge: Cambridge University Press, 1997.

13 Various national museums represent cultural artefacts and attires of various tribes of India's Northeast as a piece of art. Such representations most often make terrible mistakes, for example, Asomiya Mekhla is worn by a Naga women figurine in the National Museum of Calcutta.

14 A very interesting case of such alliance is the division in the national opinion when a three-month blockade of all the arterial roads to Manipur was conducted by Naga civil society groups. While the National Centre for Human Rights supported the cause behind the blockade by rearticulating the Naga demand for historical rights, the Asian Human Rights Commission (AHRC) critiqued the action by Naga groups saying that neither the blockade nor the claim of territory by Naga groups are justifiable. A little differently, the National Alliance for Peoples' Movements has supported the cause of resistance to large river dams in Northeast in a major way by connecting itself with every civil society initiatives and campaigns from Northeast India.

15 Epistemological resistance is an idea that can resist an offensive act by the dominant by formulating an alternative. It can as well fight anti-intellectualism of one's own community. See Smith (2009: 84-5).

\section{References}

Hudson, D. Zacahary. 2010. 'Eminent Domain Due Process', The Yale Law Journal, 119(6).

Kirsch, Stuart. 2014. Mining Capitalism: The Relationship between Corporations and Their Critics. California: University of California Press.

Macedo, Stephen (ed.). 1999. Deliberative Politics: Essays on Democracy and Disagreement. New York and Oxford: Oxford University Press.

Ricoeur, Paul. 1997. Oneself as Another. Cambridge: Cambridge University Press. The Shillong Times, 26 October 2010. 
Smith, Paul Chaat. 2009. Everything You Know about Indians Is Wrong. Minneapolis: University of Minnesota Press.

The Telegraph, Northeast, 6 November 2010.

Wetherell, M. and J. Potter. 1992. Mapping the Language of Racism: Discourse and the Legitimation of Exploitation. New York: Harvester and Wheatsheaf. 
$\because$ Taylor \& Francis

http://taylorandfrancis.com 


\section{Part VIII}

\section{Tradition and modernity}


$\because$ Taylor \& Francis

http://taylorandfrancis.com 


\title{
17 Colonial modernity and plight of the receiving communities ${ }^{1}$
}

\author{
Bhagat Oinam
}

\section{The problem}

With several studies being conducted on the facets of modernity and its overarching impact on the erstwhile-colonized world (of the receiving communities), the problems of modernity seem to be fairly addressed. However, one area of its impact that still calls for further investigation is the engagements among the receiving communities in the "postcolonial' scenario. Colonialism is supposed to be over and any enquiry on it seems to be a study of the past. But its impact is far from being over. What Ashis Nandy calls 'intimate enemy' within still seems to exist amongst the colonized world - with different sets of players and perhaps with different rules of the game.

Receiving communities are those societies who conceive of themselves as a 'people' in the face of colonial forces' onslaught. These communities as manifest are a product of colonialism with little choice of their own. It is through historical exigencies - of political, economic and cultural influences/impositions - that receiving communities start wearing the garb of a receiver of knowledge and values. There are two major characteristics of the receiving communities, one that has historically emerged and the other structurally developed. First, those receiving communities, who free themselves from the political dominance of Europe's colonial rule during the middle of the twentieth century attempt to colonize the lesser receiving communities to its fold thus extending the colonial legacy through a neo-colonial mode of operation. Due to this historical unfolding of colonial modernity, there is the emergence of hierarchies within the receiving communities. Second, 'receiving community' does not carry a logically fixed representation. A community can both be a receiver and a giver. It is through different perspectives and discourses that a community becomes a receiver at one point in time and giver at another. 
Today, the dialogue between tradition and modernity is not so much between two entities qualified as 'modern' and 'traditional', but about multiple contestations within the traditional societies that got deeply influenced by the modern values. The contest in our time depicts a tale of negotiation among the receiving communities, much more complicated and disguised. Multiple layers of negotiation take place; one, a receiving community negotiates intra-community between the modern values with the traditional, and two, different communities negotiate and contest among themselves with both the modern and traditional values (horizontally as well as vertically). The assumption that participants in a dialogue are 'equally powerful' seems to be wrongly construed since dialogue mostly turns out to be between unequal power centres. Most often, instead of being engaged in dialogue, these communities enter into contestations.

In the face of a desired dialogue, what is generally missed out is the inseparable nature of two valued systems termed as 'traditional' and 'modern'. Operation of values based on the two systems is historically conditioned. The space that the two occupy within the receiving communities is historically twined that cannot be displaced, yet are constantly in surge with contest and adaptation. With the world turning global, projection of 'tradition' in purity is an illusion, so is an unchanging modernity having an essence ${ }^{2}$ a myth.

The multiple forms of crises briefly introduced above are linked with how the receiving communities are positioned as receivers. Import of modernity along with colonialism has created existential and intellectual anguish among the elites of the receiving communities. While at few historical moments, response of these elites was of accommodation and assimilation, at others it was of protest and denial - these responses as marked by politics of the time. As mentioned above, negotiation on power and control is not merely between the receiver and the giver, but also among the receivers, some among them playing the role of neo-colonizer. The way, at times, the Indian state operates with a neo-colonialist attitude towards its marginal communities (on development and security, for instance) serves as a case in point. The marginal communities are not homogenous either, and do not show similar forms of response to the forces of modernity. While variation in response depends largely on several historical and social factors, the role of collective consciousness and subjective interventions must serve as significant causal factor. ${ }^{3}$ The contest of modernity and tradition is not about two phenomena in alterity, ${ }^{4}$ but of negotiation within the self (singular/collective) for a space of identity and assertion. 
For Northeast India, it is of continually wearing a garb of a 'receiver'. The 'bundles of contradictions' that colonialism brought during the first half of the nineteenth century has created fractured self/selves with several ideational and ideological divides. A longing to discover or invent a 'past', through which the self could be recovered, not merely for functional deliberation but for providing a paradigmatic account of the community self, has become a daunting task of the receiving communities today. The social and political movements in the region in the last six decades show the dilemmas and challenges faced by these communities between an undesired present, a projected future, and an imagined past.

This chapter is an indicator, not in the sense of measuring a standard, but hinting at a possible alternate methodology for studying the marginal communities. Its engagement, more than the interpretation of events, is of enacting a discursive framework. While historical narratives of the Northeast have brought out rich information about kings, communities and their rules, these have remained partial with many communities being absent in these narratives. The challenge is of ensuring autonomy, representation and connectivity that would mark the future of Northeast India's narratives. When modern values come into contact with traditional worldviews and ways of life, these not only generate conflicts but also set up new discourses to deal with the conflicts. As a case study, a representative study of Manipur is made here to reveal some complexities that arise in the interface.

\section{Modernity by proxy, colonialism by content}

Modernity's entry into Northeast India was by proxy. Entry of science, technology and education took a pace that suited the colonial rule. This is true of many parts of the country, Bengal could be a classic case (Chatterjee 1993). But on the contrary, freedom of expression, human rights and right to self-determination, which were the gift of modernity to the West, did not quite figure in the modernity project in the colonized world. Difficulty is not so much about the critique that modernity 'while being rational within its confine, refused to be rational about other traditions of knowledge' (Nandy 1983/2002: 2-3). The programme was equally harsh with its own traditional values in the then Europe. It was by breaking the cultural foundation of the medieval Europe that modernity as a way of life emerged. A more significant issue is tied to the hypocrisy with which colonialism operated its modernist programme in the colonized world. It was inconsistent 
to the stages experienced in Europe, and was driven by imperial design in the colonized world.

Modernity was packaged with many other forces that were inherently opposed to its own programme. Take for instance, the Church. It was against the Church and institutionalized Christendom that Enlightenment programme stood its ground. But the two antithetical poles most often mingled well in the colonial frame of operation. As much as Hume saw 'reason as the slave of passion' (Hume 1978), modernity in the colonized world became a tool for exploiting the receiving communities. Modernist rationality was selectively used to serve the colonial interests, consequences of which are the contradictions that emerged. The contradictions that constituted colonialism not only made it internally unstable but also made scattered selves out of the receiving community. This experiential aspect of the receiving communities is articulated by Nandy in the idea of 'intimate enemy' (1983/2002). Interestingly, this trend of experiencing in scattered forms is witnessed among the ethnic communities of the Northeast, too. Perhaps the difference lies in the mode of self-articulation. For instance, strong impact of Christian missionary teaching is visible where preconversion state is 'revealed' as a state of barbarism, of 'hunting down heads as trophy'. 5 This idea of a 'once savage self' is unfortunately internalized by many elderly Naga intellectuals. Contrary to such a perception contemporary political discourse of the Nagas tells a contrary tale: of their unique history, of village republic and of their having lived independently from time immemorial. The idea of a village republic and the ability for self-governance demand certain maturity of running a collective life. Different domains of the same self discover its past so varyingly that accepting contrary narrations becomes a major task. It is manifestation of a deeper crisis that colonialism imparted, and continues to be internalized and carried forward by the colonized mind.

Another well-known 'divide and rule' policy that led to the creation of two nations in the subcontinent was also used in the region. More than the religious identity, ethnicity was used, resulting in the emergence of ethnic politics that have overarchingly prevailed over all other discourses in the region. Seed of structural conflict in the region was sown by this divide and rule policy. Manipur can be shown as a case in point. Administrative division of this erstwhile kingdom into hills and valley, and altering the boundary of the state to serve colonial interests, created drastic changes not only in the socio-cultural lives of the people but also affected inter-community harmony. While a new king was installed to look after the administration of the valley, 
hills indirectly came under the direct control of the British. By installing a puppet king the colonial power freed itself of the day-to-day administrative responsibility, though the British political agent took major political decisions by proxy. Subsequent policies introduced in the valley showed naked economic exploitation at different layers of administration. The British did not interfere much with the village administration of the communities in the hills except for a few additions like introduction of lambus. ${ }^{6}$ Hills were left as a fertile ground for evangelizing activities though there are instances of conflicts where the British administration found the missionary activities going against the colonial interest. Administration also had to intervene over conflicting interests of different missionary groups. For instance, an understanding was reached between the Baptists and Presbyterians to mark respective jurisdiction of operation. The entry of the missionaries in the hills enabled influence on the cultural/spiritual domain of the hill people leading to a clear divide between the hills and the valley. ${ }^{7}$ Since the administrative division made the valley and the hills two segments in the material domain, entry of Christianity in the hills sharpened the division in the cultural domain. It made the division between the two segments complete. Formalization of categories like Naga and Kuki, ${ }^{8}$ even though for administrative purposes, later helped in consolidation of identity in the cultural domain. Identity politics in Northeast India is a gift of colonial modernity.

In contrast to the hills, the target of the British in the Manipur valley was to have control over the material domain. Though administrative changes were in the field of revenue, trade and economy in general, its impact was indirectly felt in the cultural domain too. The shift from the Lallup to the Patta system ${ }^{9}$ enabled the British to control the revenue of the state. In order to enhance trade, a cartable road was developed from Moreh to Dimapur amidst several resistances. In fact, British interest in Manipur, in addition to creating a buffer state, was marked by need for a free trade route between Burma and British-India. Colonial administration also brought about a more structured form of economy. These changes led to 'dual government' that was witnessed in Bengal during 1757-64. The British enjoyed all the power without responsibility while the king was given responsibility without economic power. This compelled the king to look for revenue in the cultural domain. New taxation such as Chandan-senkhai, Mangba-sengba ${ }^{10}$ was introduced to increase royal exchequer, which in turn led to consolidation of orthodox Brahmanism in the valley. Never before in the history of Manipur was untouchability witnessed as during the colonial period. This is against the background that Hinduism arrived at Manipur 
during the sixteenth century. The episode is blown out of proportion by few observers and interest groups that Meiteis practiced untouchability against the hill communities. Much more than the hill communities, it was the Meitei subjects, particularly the marginalized and the underprivileged, who suffered the most. Emergence of Sanamahi movement ${ }^{11}$ as a protest against such atrocities, which later contested the control of the cultural space, serves as an important historical marker.

What has been witnessed as a whole is several contradictions with which colonialism operated. While the British administration projected an image of a benevolent master bringing about transformation in each sphere of life, modernity has been selectively used. Though modernity's characterization lies in the primacy of reason and self-criticism that operates in each sphere of human endeavour, either towards capturing the knowledge about the physical or the life-worlds, or understanding the intricacies of human reality, the same does not get reflected in the lives of the people in the region. This is an area where not only the colonial rule failed, but the present 'liberated' state is yet to gain success.

\section{Making and remaking of narratives}

The need for highlighting the idea of a 'past' as part of reclaiming tradition is as much a post-colonial project as had been part of the anti-colonial movement in the country. Though this project articulates a memory of a traditional past as a counterpoint to modernity, it also ideationally accepts the 'discovery' (often creation!) of a cultural force. Methodologically, any form of assertion is always made from the present, so much so a statement about the past and the future. Accordingly any statement about a tradition is made from the prism of the present even if conceived as continuous. Our past is not a naked past; it is brought in memory 'dressed' in one way or the other. Each time one looks back from one's present, the memory is clad differently based on the present-site where one is located. The past does not remain independent in isolation in some pure form. All that we know or claim to know is about what we perceive. And what we perceive is through a prism already construed and formalized. Tradition (as a continuity from the past) is perceived through a prism, and is neither divorced from the present nor from a desired future. And this prism could be the 'prism of modernity'. More importantly, what we perceive as a past (in tradition) is a projection - an imagined past!

Some of the contemporary movements on preserving tradition should be seen in the light of the above articulation. Many protest 
movements witnessed in Manipur in recent past in the name of preserving traditional values and heritage - such as 'script movement' and 'traditional dress code for girl students' - have very little traditional values associated. Such an image of a tradition incorporates the modern political ideas such as 'right to culture', 'civil disobedience and courting arrest', 'language and script as vehicle for inculcating nationalism' etc. Even the idea of a denial of Westernization or Indianization has already incorporated the image of that which they wish to deny. Though images of a past heritage are projected, these images are not only modern in character but also equally possess a mode of agitation. For instance, take the writings of Atom Bapu Sharma, Wahengbam Yumjao Singh, Asangbam Miniketan Singh and many others who engaged in the process of discovering the past of the Manipuris that was close to Vedic lineage. Migration of Kiratas was shown to bring the Meiteis closer to Vedic Bharata. The other group, Meitei Marup, completely rejects such a narration of the Hinduized Meiteis seeing it as concocted myth. Kangjiya Gopal's book Adungeigi Kangleipak Manipur Natte (Then Kangleipak is not Mahabharata's Manipur) rejects the myth of locating the present Manipur (Kangleipak) in the Mahabharata. This has also been acknowledged by well-known historians like R. C. Mazumdar (1968). While the two hold opposing positions, both look for traces of the past through the discourse of modernism. Linearity in modern historiography guides their perceptions that both fall back on constructing a long past heritage, a 2,000year history. More than the validity or invalidity of the narration, what is important is the mode of narration - of construing a tradition from modernist perspective. The anxiety of the nationalist poet Bankim Chandra Chattopadhyay that 'India does not have history and must have one' turns out to be a historical experience of the receiving communities as a whole. Anxiety of having a genuine tradition arises in the receiving communities due to its encounter with a fairly complex 'bundles of contradictions', which colonialism brought. The dilemma and the anguish are not confined to the academia alone but also visibly witnessed in the day-to-day life-world of the receiving communities. Complexity and paradoxes do not stop the ongoing journey of life. We continue to live with these bundles of contradictions.

Discovery of a tradition among these communities is more about manifestation of anxiety of a scattered self. The experience of Bengal as illustrated by Partha Chatterjee highlights a more generic form fairly applicable to various receiving communities, going outside the bound of Bengal. It is important to see how receiving communities articulate their own assertion in the face of a colonizing force. Explaining the 
experience of the colonized Bengal and the subsequent self-assertion, Chatterjee articulates that the failure at the material domain led to the resurgence at the spiritual (Chatterjee 1993: 26). Defeat from the colonial rule gave birth to this new programme. The resurgence specifically tends to look towards a past. The nationalist movement in Bengal, in an effort to reject colonial rule, started looking at superior image of the natives in their pre-colonial time. Siraj-ud-daula, for instance, became the hero and Mir Zafar a villain in Bengali theatre and plays. Apart from the recovery, the attempt was also a search for an alternate space. What came quite natural was a political space in the cultural/spiritual domain. This was projected to counter the British onslaught that had already overtaken the receiving communities in the material domain (Chatterjee 1993: 26). Discovery of Ramakrishna in the Bengali middle class (Chatterjee 1993: 36-7) enabling assertion of middle-class hegemony in Bengal was a case in point. Similar trend is being observed in Manipur during the first half of the twentieth century through educated Manipuri middle class, who, from their education in Bengal, brought the spirit of nationalism. Introduction of print technology, inception of civil society bodies like Nikhil Manipuri Maha Sabha and so forth were manifestations of the trend. The trend continued in the growth of Manipuri theatre. It was through proscenium theatre of 1950s and 1960s that Yubaraj Takendrajit Singh and General Thangal became the hero of Manipur (much later their assassination), and King Surchandra and Prince Pakasana as villains, quite like the binary of historical figures of Bengal. ${ }^{12}$ What is important is the construction of a past based on the projected future. Experience of Manipur in the post-1891 colonial rule highlights the dilemmas of a receiving community. Manipuris, unable to reconcile with the defeat in the Anglo-Manipuri War of 1891 (Singh 1998), looked for areas where the natives' supremacy could be recovered. Loss in the war meant loss of control over military, political administration and economy. This led the traditional Manipuri elites take recourse to the private domain. British were projected as impure and the 'dirty other'. There had been cases where houses entered by the British officials were destroyed and new houses built (Allen 1905: 61). These were collectively sanctioned and performed. It was a fight, more a protest, to a dominant power. It was not a direct fight as the domain of operation of the two were different - the military-administrative versus the cultural. It was a judicious and selective move by the traditional elites not to directly confront the British yet register their supremacy differently. Responses to modernity show a complex phenomenon than a homogenous archetype. Differences in the responses of these communities 
were shaped not only by the varying administrative policies of the colonial rule but also by the dynamics of power struggle among the receiving groups. In fact, complexity is shown by the varied and multilayered character of these responses. Manipur, for instance, showed an interesting trend of elite formation. First were the traditional Brahmins and royal clans who still carry the legacy of a pre-colonial state authority. The feudal classes were not very cordial, if not hostile, to the British. Slowly, this class was co-opted by the new state, took to English and Bengali education, and led to the formation of new elites. Some members of this class with the addition of a few other sections of the society formed the new group - the middle class. This group was mostly educated at places like Sylhet, Dacca and (then) Calcutta. The emerging new elites were progressive, but used traditional idioms to register and propagate their political aims. They were the brands of middle class 'intelligentsia' as witnessed elsewhere in India. A case of Hijam Irabot could throw light into the trend and exceptions. ${ }^{13}$ The third group emerged out of an existential crisis of being left out, took contrary positions to the ones held by other elite groups. This traditionalist Meitei Marup (Pre-Hindu Sanamahi sect) took to indigenous pre-Vaisnava values and lifestyle (e.g. Naoriya Phulo). Impressions of the trend still find traces in many civil society organizations like Meetei Erol Eyek Loinasilol Apunba Lup (MEELAL), Umang lai Kanba Apunba Lup (UKAL) and so forth. One also observes through the functioning of these groups multiple narratives often conflicting than complimenting. Today contradicting narratives seem to have become a trend than exception. This can be witnessed between different communities - the Meiteis and the Nagas in Manipur, the Bodos and caste-Assamese in Assam, Mizos and Bru in Mizoram. Similar is the case found in Meghalaya where the Bengalis and the Assamese struggle to get a place in the historical narrative of the state, which tends to selectively erase certain past memories involving their origin in the state. While the Assamese, Bengalis and Manipuris (particularly Meiteis) are also being accused of denying possible politico-cultural space to other communities in the region in their long-drawn historical narratives, the new trend by the protesting communities to carve a space for themselves through new political narratives/arrangements deny than supplement the existing narratives. At the end, it turns out to be a contest for the control of power among different receiving communities. But it is important to note that the contesting narratives among these communities are factored, more than the struggle for power, by a deep-rooted internal tussle between the traditional values and colonial-modernist interventions. 


\section{A footnote to historiography}

The highlight of these narratives is that each goes on 'totalizing' not only the goal but also the narration. Each act excludes or hegemonizes the other act, so much so are the goals (as 'totality') ${ }^{14}$ mutually exclusive or oppressive. In principle, two totalities cannot be realized simultaneously. The contrary would mean that a narration has more than one 'totality'. This creates the fear of having split personality. The projection of the Nagas in Manipur narrating an alternative totalization and totality (of Naga identity) is with the presupposition that there is more than one nation in the present state of Manipur. The totality is of an independent Naga inhabited land. Another version of 'totality', largely held by the majority Meiteis, is seeing the entire people of the state as one nation in evolution. It seems that both the ideas cannot coexist; the two look contradictory. Interestingly both the narratives are deeply influenced by modernist narratives while both communities are still culturally rooted to their cultural life-worlds.

A careful study will reveal that totalizations have deeper philosophical underpinning. Sartre's formulation that 'totalising present is conditioned by totalised and totalising past of the process of human development' could serve as a point for reflection. Totalization projects a 'cultured' man (including illiterate societies) who totalizes through centuries of history, through experience (Sartre 1960/1982: 54). In fact, each act of totalization projects a long trace of historical origin of the people. The often-used phrase in these narratives is 'from time immemorial'. Through the phrase, legitimacy is sought for a narrative to become historical. Two options clearly emerge: one, whether to see multiple totalizations and totalities as prelude to smaller nation states, or two, that these are the voices of a fractured self. The problem is not only unique to the state of Manipur. This is witnessed at every level of political discourse, whether one looks at Northeast India as a whole or the Indian nation state as one. Perhaps the answer lies in seeing the two as component of a historical dialectics! These contradictory narratives, if seen as product of historicity, the answer shall lie in dialogue and negotiation. And a hope for a synthetic narrative!

To conclude, understanding the plural character of Northeast India shall fulfil the task of discursively articulating social realities in the region. Such an effort will not only be comprehensive in capturing the region through connecting narratives, but also overcome the limitations of exclusivist narratives. The present political crises in the region are largely because of the gap that exists in our knowledge of the other. It is the lack of what Ricoeur calls 'pairing' (paarung) of individuals' temporal fields, which form a historical field of experience that 
correlates gaps in our perception of the surrounding. ${ }^{15}$ It is not merely about non-Northeasterner not understanding the Northeast but about Northeasterner not understanding his own surroundings and the fellow ethnos. Stereotypes still exist within the region itself.

The stereotypes largely rest on our inability to negotiate the traditional values and ways of life with modernist worldviews and vocabulary (that comes with institutional powers). For instance, communities' over emphasis on modernist values of self-determination and autonomy at times underplay the significance of certain traditional practices of kinship, inter-community connections (performed through cultural narratives and actual living). Two communities, Meitei and Tangkhul, represent best the examples stated here. At the larger plane, challenge is of drawing a comprehensive history of the region fulfilling democratic representation and traditional values and ways of life. This is not to denounce the already existing narratives. Chronicles, such as Buronji, Cheitharol Kumbaba, Rajmamala and so forth will continue to have their own significance in forming narratives of few larger communities. But there is need to be critical of the narratives that project a mere imaginative fantasy ${ }^{16}$ without pairing. It needs to be clearly shown that arrival of modernity in the package of colonialism shaped the consciousness of the communities in a particular direction. History writing here has performed some limiting jobs. It was the colonial rule that paved structural changes to almost all the communities in the region. Northeast was physically bridged and spiritually scattered by the British colonial power. A narrative that comprehends the historical fields of experiences of the region with shared narratives seem to be the most reasonable approach to understand the region of its past and future, through an 'accommodative' present. Unless such a project is materialized, the fear of living with 'intimate enemy' will remain!

\section{Notes}

1 This is a revised version of the paper 'Receiving Communities: The Encounter with Modernity', Eastern Quarterly, 3(2): 86-96, 2005.

2 Essentializing modernity is to make it (as an idea and process/act) stagnant which would be self-contradictory. Modernity characteristically is self-critiquing, and its goal lies in the act/process. It is in our performing the rational act(s) that modernity is envisaged and accomplished.

3 Collingwood's 'free and deliberate act of a conscious and responsible agent' as a historical cause needs a special highlight. See Collingwood (1940/1962: 290).

4 Alterity is about 'those' outside the self. But what is outside is not free from the actor who is 'inside'. The conception goes closer to the ideas of Levinas where the outside gets meaning through the inside. See Smith (2005).

5 Reference is to the so-called practice of headhunting. 


\section{Bhagat Oinam}

6 Roles of Lambus were traditionally the intermediary between the king and the tribal chieftains. The same post was retained by the British administration that engaged them for collecting taxes from the villages in the hills.

7 This phenomenon has been well articulated by Kh. Bijoykumar Singh seeing this as repercussion of a politics of religious conversion and religious identity formations (Hinduism and Christianity). See K. B. Singh (2017). But the author has not addressed to the conflicts between Nagas and Kukis in 1990s, who are both Christians. Such ethnic conflicts need to be explained beyond the yardstick of religious difference.

8 Gangmumei Kamei (then Kabui) highlights 'common place' of origin of several tribes who are now clubbed within the category of the 'Naga'. But the physical representation of the term is fairly complicated now. Before the advent of the British, the term 'Naga' as known to the Assamese was confined to few tribes inhabiting the hill ranges south of the Brahmaputra valley. During the post-colonial period, many tribes of Kuki-Chin linguistic group (like Anals and Chiru) started identifying themselves as 'Naga'. Though the term was formalized by the colonial administration, later it got internalized during the post-colonial period. The strength of identity formation does not seem to lie in linguistic or historical tracing of origin of a term. Rather, it seems to lie in political engagement of the term. Naga identity formation is a clear example of this practice. To continue the debate, see Kabui (1995: 21-5).

9 Lallup is a form of military, administrative and civil services rendered by the subjects to the state. The subject in lieu of his service is entitled to hold land for cultivation. The practice was abolished to bring in patta system which enabled the British to have direct control of the revenue. See N. J. Singh (1992: 29-30), N. L. Singh (1998: 29-30) and K. B. Singh (2017).

10 Chandan-senkhai was a form of taxation against the use of chandan as tilak on the Vaisnava population. Mangba-sengba was the purification fee paid by those ostracized as impure either by the king, king's brother, or the Brahmin. Purification fees varied depending upon the nature of the declaration. New forms of taxation made the king increasingly unpopular, but substantive revenue could be gathered through these ill practices. See N. J. Singh (1992), N. L. Singh (1998) and K. B. Singh (2017).

11 Sanamahi movement aims at reviving the indigenous religious and cultural practices of pre-Vaisnava Meiteis. See Sairem (2017).

12 Much of what has happened in Manipur in the middle of the twentieth century has close resonance with what happened in Bengal. I see this as historical trend of receiving communities' encounter with colonial modernity. What Partha Chatterjee saw of Bengal experience with theatre is what happened later in Manipur in a gap of nearly fifty years or so. In fact, modern theatre practice in Manipur started only with the influence of Bengali theatre. Starting from Manipur Dramatic Union (where Hijam Irabot used to perform), Rupmahal and Aryan Theatre, and later with Kanhailal, Ratan Thiyam and Lokendra Arambam - all have been deeply influenced by the theatre movement in Bengal.

13 Leaders like Hijam Irabot, who were co-opted by the king, did not succumb to the pressure but genuinely worked for the people. He stood for the modernization of economy, social reforms and justice that shook the existing feudal structure. He believed that rectifying the evils of Hinduism could 
regenerate Meitei society. Activities of such middle class leaders were influenced by the dominant ideology of Indian freedom struggle. For instance, Irabot interacted with many leaders of Indian freedom struggle in Sylhet and Cachar. See Yambem (1976: 327) and K. M. Singh (1989: 153-4).

14 For Sartre, 'totality' and 'totalization' refer to goal of praxis and act of praxis respectively. Human praxis is narrating and asserting about oneself, which is about creating history. The difference between the two is that totality is totalized and the totalization totalizes itself. While the former is projected as 'become', the latter is 'becoming', which suggests that it is locating in time and, as such, totalizes itself. So totalization as an act in the present encompasses the past acts as well as the future goal. If history is totalization which temporalizes itself, culture is itself temporalizing and temporalized totalization. Although one totalizes individually, one's culture cannot be treated as mere subjective accumulation of knowledge as 'my own', but is conceived as specific participation in interiority in the objective culture. See Sartre (1960/1982: 53-6).

15 Paul Ricoeur sees 'imagination' as an individual action. Each individual imagines independently in isolation that creates a flux. It is through the idea of 'pairing' that one temporal flux accompanies another. This leads to a higher order temporality that categorizes isolated events and actions. The formulation largely explains intersubjective understanding of imagination as an act of constructing history. However, it remains to be seen how far it successfully explains inter-community understanding of imagination. See Ricoeur (1994: 127).

16 To illustrate the point, take the case of Meities as descendents of mythic figures of the Mahabharata. Such attempts are manifestation of a desperate self to equate with an imagined superior race and tradition.

\section{References}

Allen, B. C. 1905. Assam District Gazetteer: Naga Hills and Manipur, Vol. 9, Part 2. Calcutta: Baptist Mission Press.

Chatterjee, Partha. 1993. The Nation and Its Fragments. New Delhi: Oxford University Press.

Collingwood, R. G. 1940/1962. An Essay on Metaphysics. Oxford: The Clarendon Press.

Hume, David. 1978. A Treatise of Human Nature, ed. L. A. Selby-Bigge. Oxford: Clarendon Press.

Kabui, Gangmumei. 1995. 'Genesis of the Ethnoses of Manipur', in NaoremSanajaoba (ed.), Manipur: Past and Present, Vol. 3. New Delhi: Mittal Publications.

Mazumdar, R. C. 1968. 'Expansion of Arianization beyond Bengal', in Atom Bapu Memorial Lecture. Imphal.

Nandy, Ashis. 1983/2002. The Intimate Enemy. New Delhi: Oxford University Press.

Ricoeur, Paul. 1994. 'Imagination in Discourse and in Action', in Gillian Robinson and John Rundell (eds.), Rethinking Imagination: Culture and Creativity. London and New York: Routledge. 


\section{Bhagat Oinam}

Sairem, Nilabir. 2017. 'Sanamahi Religion', in S. Shyamkishore Singh and Bhagat Oinam (eds.), Perspectives in Manipuri Culture. New Delhi: CSC.

Sartre, J. P. 1960/1982. Critique of Dialectical Reason, trans. Alan SheridanSmith and ed. Jonathan Rée. London: Verso and NLB.

Singh, Karam Manimohan. 1989. Hijam Irabot Singh and Political Movements in Manipur. New Delhi: R. B. Publishing Corporation.

Singh, Khuraijam Bijoykumar. 2017. 'Political Economy of Religious Conversion in Manipur', in S. Shyamkishore Singh and Bhagat Oinam (eds.), Perspectives on Manipuri Culture. New Delhi: CSC.

Singh, N. Joykumar. 1992. Social Movements in Manipur. New Delhi: Mittal Publications.

Singh, N. Lokendra. 1998. Unquiet Valley. New Delhi: Mittal Publications.

Smith, Michael B. 2005. Towards the Outside: Concepts and Themes in Emmanuel Levinas. Pittsburgh, PA: Duquesne University Press.

Yambem, Sanamani. 1976. 'Nupi Lan: Women's Agitation, 1939', Economic and Political Weekly, 11(8), 21 February. 


\title{
18 In the name of a flyover Development, resistance, politics $^{1}$
}

\author{
Yengkhom Jilangamba
}

The lone flyover in Manipur has been in existence now for the last ten years. This structure, the construction of which took longer than anticipated, has seen many controversies. There was a public debate justifying, challenging, opposing the construction of the flyover. This essay was written in the midst of that public debate in which varied opinions were expressed.

Much has happened, insofar as 'developmental' works are concerned in Manipur, since this episode. Driven by global capital trans-Asian highways, trans-Asian railways, construction of dams, privatization of water, electricity, health and education have all become realities. Those who supported the flyover, as a means to solve the traffic problem in Imphal, and as a symbol of development, may find further solace that thanks to Asian Developmental Bank, Greater Imphal may very soon see a Ring Road! Manipur today has an international airport. Imphal has a number of fancy restaurants, expensive hotels, and showrooms for foreign consumer items, opulent private residences, and farmhouses. In the meantime, the buildings of the Khwairamband Keithel have been inaugurated and partially destroyed by an earthquake.

Societally, it seems that many more people from Manipur are migrating out seeking livelihood, better education and healthcare needs and in turn many more people are arriving, returning to Manipur for short-term as well as long-term residence. Now that Imphal has been deemed a smart city, it seems poised to be upgraded to a futuristic city. The Bir Tikendrajit flyover was thought of as the inaugural emblem to this hyper-modern Imphal which would usher in a new age in Manipur.

And yet, Manipur has one of the lowest per capita income in the country and high urban unemployment, especially among the youth. More than one-third of Manipur's population lives below the poverty line, and this is one of the highest in India. It has also seen further devastation of the agricultural sector, driven by infrastructural 
development - urbanization, construction of schools, brick kilns, and expansion in cash crops, use of chemicals, plantation of bio-fuels. The transformation in agriculture has also coincided with intensive mechanization. In effect, this has produced a transformation of the rhythm of rural life-world, associated primarily with the production process by the rural workforce. This has meant that even as there is an increasing interest in rurality through art, folk songs, artefacts, the very rural that these items seek to represent is no longer available. The disappearance of the rural life-world, in my view, is not disconnected from the processes that make the rural visible merely as artefacts.

There is a forceful march towards an extractive economy in the form of explorations for natural gas, oil and so forth. In this context, it is important to remember that some of the old problems such as the close affinity between militarization and developmental works still persist. This foundational linkage between development and militarism is visible at many sites such as the forceful manner in which the capital/capitol project has been carried out, the expansion of the Tulihal airport; the readiness with which the armed forces are deployed in Loktak, Mapithel, Tipaimukh.

The rechristening of Look East Policy to Act East Policy is a clear indication of the urgency and the determination with which the prime motor of these changes has been pushed through. In this, Manipur has been promised to be turned into a gateway.

The flyover since its inauguration has continued to be a witness to many political events that have rocked Manipur. The flyover has been immortalized through the BT Road 'fake encounter' ever since the Tehelka magazine report of the 23 July 2009 incident in which the Manipur police commandos shot dead Sanjit and Rabina. In fact, the flyover could not have had a more ominous beginning. On the day of its inauguration, the then Chief Minister Okram Ibobi Singh collapsed on stage after ending his speech with the nationalistic salute of Jai Hind. In the sphere of electoral politics, the long reign of Ibobi is finally over, but ironically, the change in electoral politics has also meant that the two most powerful men today - the chief minister and the deputy chief minister of Manipur were once his close affiliates.

At the time when the debate unfolded over the flyover, many were still hopeful of changing the course of these developments. The intensification of these state-capital driven changes has also seen resistance by peoples in various forms of protests, and they are continuing. One may still find resonance of the points made in this essay more than a decade ago. 


\section{Issues}

The flyover at the heart of Imphal city has snarled up much controversy in the recent times. This flyover has come to represent an intriguing encounter of electoral politics, developmental rhetoric, politico-aesthetic, sectional interests and 'nationalist' politics of various kinds. Situated at the heart of the capital of Manipur on the Bir Tikendrajit Road, cutting beside the historical emblems of the Ima Keithel, Mapal Kangjeibung, then throws out in front of the Kangla fort, the present flyover measuring $600 \mathrm{~m}$ is what would represent a modernity counterpoised with tradition even in its spatial distribution. The everydayness ${ }^{2}$ of the flyover seems to have been turned into an episodic event, or rather by making it as the need of the 'everyday', concealing the ideological baggage, the construction of the flyover has been represented and rendered.

It is in examining the imagination of the new cityscape in Imphal that we find the (un)realized dreams and realities of the situation in Manipur; the flyover has to be located within a larger politics.

Understanding the landscape that is going to give a 'modern' taste and texture allows for a possibility to interrogate the cityscape as located within a natural and social environment, with a history of its own intercepted with the other changes and continuities that generate as constitutive elements of the entity as a living whole. And let it be made clear at the beginning that the flyover in Manipur as a part of a larger urban-building is power - both for and about; besides signifying or symbolizing power relations, 'it is an instrument of cultural power, perhaps even an agent of power that is (or frequently represents itself as) independent of human intentions' (Mitchell 1994: 1-2). The urban as the centre of concentrated state power has been enmeshed with diverse issues and politics in Manipur and there is a need to look at the changing urban space in Imphal to uncover the implanted ideologies, as a social structure with its localized meaning and not only for its forms, not as 'the dead, the fixed, the undialectical, the immobile' (Foucault 1980: 70).

\section{Symbolic capital and/or symbols of capital}

Once the assumption of assessing the form of a social formation has been understood within a scale that measures the material, scientific, technological developments, it is not a difficult task to seek for manufactured artefacts, which could symbolize the 'civilisational hierarchy' of the society. Along with an emphasis on the materiality of a society 
as a marker of civilization in modern worldview, is a strong emphasis on 'tools and cannons and conceptions of time and space' (Adas 1990: 68 ) as means of classifying the hierarchy of civilization. By making a conquest of time only perceivable in the form of a unilinear, progressive chronology, the evolutionist impinge on progress is established. For any society to reach civilization it has to follow and be a part of this ladder; every stage being a station from where the possibility of both promotion and demotion is open. Once these values are inherited and internalized, 'bringing home' those artefacts as representatives big, tall buildings, flyovers, mega-hydro projects, big dams, shopping plazas - is a means of entering modernity; these structures become the legible signs. It's a reorganization of space as a layout of the representative element of the time.

City development in the modern world has been imagined to be only possible within the paradigm, which embraces the 'huge, machine, hierarchical, centralized city with a vengeance' (Scott 1998: 104). In the new imagination of a city the magnitude itself is a statement, which is planned to have a visual shock as a form; the gratification or acknowledgement of that impact is made possible only when physically distant from the site. It may be added that the distance, which is needed to appreciate and have a proper vision of totality of the new city, is both metaphorical and physical. If one stands, except on a neighbouring hill or a high building, one would not be able to have a complete vision of the whole structure of the flyover in Imphal. It is in being able to produce this impossibility of having a clear picture of the whole structure that a new aesthete would be created, along with the symbolic power that it would carry.

Moreover, in the gigantic imagination of a city in modern developmental paradigm, it is inherent that the socio-economically weaker sections of the society would be displaced. For them what would replace their earlier habitat is made to be seen only with that blurring vision of estranged distance. As a result of a new form of relations that is involved in the production process, the powerless would be alienated from being able to participate in the celebration of a symbol of power. It is not merely the aesthetic of appreciation, which calls for a movement away from the site of the object of the gaze but simultaneously with the process of constructing these monumental structures, there is withering away of intimacy between the onlooker and the object. Those who do not own automobiles, say rickshaw pullers and the cyclists, would not experience the 'joy-ride' that their richer comrades would benefit from. Psychologically also, the possibility of an intimate relationship between the two is sapped, merely by the size. 


\section{Modern traditions}

The case in Manipur, however, seems to go beyond the debate on the modern form of development. There is an overshadowing of packaging the modern forms of urban development in a smart marriage with an invocation of the traditional. Or rather, it is by slotting modernity in the 'tradition' (a larger practice which has already seeped in the psyche of the people) that the flyover is a reflection of more than the structure. The new politico-aesthetics is stuffed in the imaginative ordering of space of Imphal by demolishing the old remnants. However, within the process of making a nation it is a collective feeling of being ancient, from a location of 'time immemorial' past that holds together the romantic celebration about the past and a call to make a beginning. Kangla is sought to stand as a reminder of the 'glorious past' and by constructing the flyover just next to it is a reflection of a 'national' self-assertion.

Moreover, modernity needs aesthetics of the past, manufactured in the present, without which its contrast and progress would have no meaning. It is by maintaining the strained relationship between an illusionary forward march away from the past and an elusive artefact from the past that modernity thrives. Obstructing the sight of the Kangla fort as a result of the construction of the flyover in front of the fort, the epitome of history and power in the imagination of Manipur, symbolizes the triumph of technology and modernity over the uninhabited trace of the past. ${ }^{3}$ This contradiction between a vision that looks at the site of Kangla as a trace from the past and its erasure from visual presence is allowed when history is woken up from its slumber only when it serves an immediate goal in gaining power, as a legitimizing motif for political contingency. From the issue over the more authentic script to the question of the boundary of the state, politics in the name of the past has been about possession. The complexities of the past, the heterogeneity of social relationships, customs and institutions have been subdued as manifestations of factional political gains. When dogmatism in the present political consciousness seeks its legitimacy from the past, the past is turned into monochrome. In fact, it generates a refusal to look into past, except as a rendering in the name of the past. The selective and opportunistic nature of mobilizing history is visibly obvious. Kangla has been seen as the site of history whereas Ima Keithel and other sites of the Khwairamband Keithel have been made to go down under the sprite of the flyover. The composite organic linkages have been sapped, in a process which chooses history as artefacts. One way to understand this selective appropriation of history could be to 
see how the former is the centre of power whereas the latter is a site of the public. Since all those who are in support (or partially opposing!) of the flyover are struggling to maintain a share of power, their choice of the site to be 'preserved' and memorialized has to be a symbol of power from the past.

The simultaneity of the two at the same locale is a manifestation of a society in transit, waiting for a coherence of vision, conflicting within the self of the two mentalscapes of making a beginning. One self is for the enigmatic past, the harmony of nature, the glory of the past, which seeks to tell a history of a moment to cherish. But at the same time, the other half of the self is enamoured by an imagined future, breaking the shackles of the past and acquiring into the mainstream of modern life. Here, science, technology, and industrialization, the flyover through which this is supposed to be reflected, would be the only way to usher nationalistically imagined community(ies) in Manipur into the age of the future. For a society which has not witnessed these modern forms of flamboyance in the urban cityscape, 'domesticating' the signs of progress is a way of asserting power for a society that is bitten by a consciousness of being modern.

The Manipuri society occupies a site of anxious space in a self-narrative of civilizational scale, which has come down from colonial enterprise of anthropological classification. Since there has been an industry of 'autoethnography', it creates a conflict of self-representation. Over the last few decades with more information flow (through cable TV, soap operas, MTV types, internet etc.); different cultural systems have been imbibed to be more modern and civilized. Since more people are moving away from the geographical confines of the state to other areas, they have witnessed various forms of social formations. Amongst those myriads of experiences, what is interesting is how an evolutionary model of civilization/modernization has been imbibed as the narrative of progress. As a result of the experiences in which they are still looked down upon for being 'inferior', as 'tribal', there is an impetus to prove of their being modern in their forms of attitude, fashion, language and so forth. What used to be inflected as a personal affair could now be transposed as a collective cultural practice by investing in the symbolic capital of modernity, for instance the flyover. It is in participating within the frame which has been set for them that a hope of deflection is inserted. These 'developmental' artefacts, by impersonating as symbols of 'progress', seek to conceal the hardship of the individual or the internal conflicts of the collective. The imagination and fascination of the big structures sanctions to compensate for the loss of the self because of modernization and a compromise for the problems faced 
in the everyday. It glosses over the inherent repercussions of human suffering in the name of 'greater common good'.

The form of the 'developmental' projects is closely related to the way in which the purpose and the beneficiaries are visualized. For a newly enriched middle class in Manipur, which has a close relationship with state power, with enough economic resources, who owns automobiles (largely second-hand), they feel a need for convenience as well as to bolster their image through representations in the form of an amplified socio-cultural order. Constructing more 'modern' indicators like the flyover becomes a marker of being 'civilised' when encountering their compatriots from the same class in different regions.

\section{Modernity set apart}

There is certainly a need to distinguish between the big, gigantic monuments of the earlier times in history and the modern forms of big monuments. The former is a celebration and marking of institutional power - monarchical, or other forms of state power whereas the latter is marked by a culture in which the big becomes a form of expressing progress, scientific development by implicating power in its structural organization of modern society - a symbolic capital. The 'pre-modern' forms of structure is the embodiment of the power, in the sense of the individual and the institution clubbed into one, whereas the modern forms of structures seek their legitimacy from the discourse, which legitimizes and makes them legible.

Within a 'democratic' social structure there is the difficulty of proposing the mega-structures as an embodiment of institutionalindividuals. The only possible means to utter them as a part of the self is to represent them in the vocabulary of development, progress and science. But it is the privileged sections, whose socio-economic standing in the society are implicated in the mythification of celebrating these structures that have given rationale and legitimacy to be bought by others as the paradigm of imagining development. The unrealized dream of attributing a structure as personification of the individual in modern society to demonstrate power creates a restructuring of denominating meaning to those structures. Instead of presenting it as an individual's exposition, there is a pretension of collective sharing of being a part of the powerful community. So, one can have the names of eminent personalities as the individuals who inaugurated the structures, not as somebody who built it. From a concentrated demonstration of power there is a seeming transference of the possibility of a sharing of power; for a common individual by accepting it as a 
manifestation of development, it elects and legitimizes the continuance of that power; she or he imagines being a part of the larger collective that has created the structure.

One point of difference that could be noted in the pre-modern artefacts of the institutional-individuals in some of the famous examples, which are known always in association with the individual, and the case of historical monuments like Kangla is that Kangla, for the modern Manipur represents a trace, or rather a symbol of the imagined 'glorious past'. Ima Keithel is understood and meaningful without its historical context; by decontextualizing the site from its historical locale and by inscribing it as a representative of 'the grand old days', its meaning and value is made intelligible. It becomes a symbol of pride for those populations who would believe in its ahistorical significance, which is getting more momentum within a narrative of nation-making.

\section{Lack of fit}

It is an irony that the cash starved Government in Manipur which does not have the money to give its employees the monthly salary in time is planning the mega-project of constructing the flyover in the middle of the capital along with other major changes as a part of urban renovation. Put the flyover within a context where there are not even the basic necessities of drinking water supply, electricity, proper road (forget public transport system)! What is conspicuous in the development paradigms that are employed in places like Manipur is that the material and production process of industrialization have not changed substantially whereas the cultural import has changed drastically.

There is a misfit between the materiality and the paraphernalia of the 'superstructure'. This is a classic case of what I would call 'floating culture syndrome', without any base to anchor. The creation of the 'modern secular temples' of development in the industrialized societies, especially in the West, was a part-cause/part-effect of a particular form of economic organization in the society. These big structures are not just an appendage to industrialization, especially in the post-World War II Western countries; it rallied round in creating the condition for such monolithic vision of progress. In the context of the flyover in Manipur it has been transformed into a force that has a relationship with the changing socio-economic configuration - the nexus between contractors, builders, bureaucrats, politicians, in fact all those who want a share in the package of the money that has been pumped in the name of developing the state, in order to buy off a section of the 
society by the Indian state against the opposition by the people. What has happened in the nonindustrialized societies like Manipur is that the aesthetics of those societies has been imbibed without any major change in the means of production of the society.

The construction of the present flyover, recreation of the site of Ima Keithel and other 'infrastructural constructions' have to be seen within the structure of change in the realm of economic transformations raging in Manipur. The coming of the new edifices is a part of the already ongoing process of changing the site of market places in Imphal, for example Moreh market, and more prominently, the new fascination of the mega-shopping malls, which could be seen in its crude, shoddily imitated forms already in Imphal, for instance, Gambhir Singh Shopping Complex. The flyover, imagined within a new economy, is rationalized as a solution, whereas what is happening is creating more problems so that it could generate a mood to seek for more 'solutions'. We cannot but notice that the flyover as a 'solution' has to be seen within a policy of the state government that does not have any public transport system in the state. It's a part of a new economic force that has seeped into Manipur. Super markets have already been constructed at the outlying areas of the Imphal market area. In fact, if the outlandish plans of building more flyovers in Imphal go unopposed (the present flyover is the beginning of a series of planned flyovers), perhaps, Imphal would be a 'floating' mofussil town.

The 'rootlessness' of the new change has produced its own inherent anxiety manifested in various forms. The misfit between the material and the cultural change has seen its repercussions in the debates and banning of cultural artefacts, especially on the dresses of women and school children. The anxiety of loss, an erosion of 'tradition' erupts because what has been happening as a changing process is neither natural nor from within, but at the same time it has not been engineered by some powerful alien force. The way in which it has developed is a result of being at the zone of interface - politically, culturally, historically and geographically. The misfit that has come into being could be witnessed in various forms. On the one hand, there is a 'dehistoricisation' of the sensibility of the past; on the other hand, because of the erasure of this sensibility there is an investment to seek for symbolic representation of those expunged past.

One could, perhaps, visualize the situation in Manipur in a more allegorical form of a religious order. The 'political' class of the state has been propitiating the godly figure at the centre in order to gain benefits, and not making them angry by following the dictates. Since the revenue of the state is not generated from the people through taxes 
and other means but rather through the 'gifts of grants' from the central authority, the accountability of those who are in power in the state towards its people weighs less than towards the source of income. Because the state is the major source of employment without any other source, its importance in the running of the society is also heightened as a structure of monopolized power. If this is one face of the divine spirit of the Indian state, it makes its appearance in the form of the devil as well - the armed forces running the daily organization of the society. In a sense, the cultural manifestation in Manipur is what could be described as fetishism of commodity culture, manufactured though the power of the state. Capital does not operate merely in its obvious manifestations of industry; the power of capital is to command. ${ }^{4}$

\section{Who is protesting?}

Contained by the hegemony of a developmental paradigm, even the voices of opposition is sought to be located and regulated inside the system. As a result, even while opposing the flyover by asserting to change one 'traditional' script over another in the plaque that records the name of the individual who inaugurates, it exposits a claim to seize power by evoking 'tradition'. The first premise of a challenge to do away with these monuments is absent. Once these monuments stand to symbolize progress, development, by asserting for a particular script against the other, it brags about the 'historical' people with their own history of a literate culture. It is a ploy in which the modern is made meaningful, only in juxtaposition with the 'traditional', which is allowed within the politics of an imagination propelled by process(es) of nation-making in Manipur. In contending to historicize, it participates within the logic of a narrative of allocating written script as a marker of civilized people against those who do not have.

It has been much criticized by now that these development gimmicks are not merely arbitrary but in fact they serve an ideological impetus, which attempts to create a society according to a universalized logic. ${ }^{5}$ It has already been challenged that the rules of development followed in the capitalist countries of the West and the Soviet Union are not the only solvents for a better future of material imagination. This model of development is observable for their notoriety in being centralized, top-down, undemocratic and anti-people consequences. ${ }^{6}$

In fact it is an irony that those 'futuristic looking', 'forward marching' 'rationalistic' modernists, who would detach themselves at the mention of history/past and those who celebrate on the mention of 'tradition', 'time immemorial' are married in the flyover under construction 
in Imphal. The poetical affinity of the two marches along with the political recruitment of motifs to prove to others of being a modern nation. Architecturally, the two symbols would have a sharing of the consistent spatiality, in the middle of the centre of power as signatures of the politico-aesthetic imagination of Manipur. The physical conjugality of the two is more than metaphorical. When Kangla, which of late has been a site of Meitei nationalist pride, goes along with the flyover, it will demolish the sense of historical existence. ${ }^{7}$ Moreover, it is also clearly visible that this project of urban renovation is a very Greater Imphal centric enterprise (forget valley centric!).

The flyover is a reminder of reverberation that tries to rebuild the much criticized and highly problematic junk of developmental logic in the backyard of a country which is engrossed in a dream to gain a superpower status in the global strategic politics. The internalization of the rhetoric has reached to such an extension that those who oppose the flyover have been targeted as 'non-progressive', 'anti-development', 'conservative' and 'close-minded'. In times like this the need to change the way we would march in future seems very urgent.

\section{Notes}

1 This chapter is a recast form, with an introduction, of the paper titled "The 'Priestly' State: Flyover Development, Politico-Aesthetics, Protests in Manipur”, Eastern Quarterly, 3(2): 107-116, 2005.

2 I am using the term not as the mundane, repetitiveness of the daily, but as a practice of ideological structure. See Lefebvre (1984).

3 For an analysis which argues for the triumph of Enlightenment symptom of reason, science in colonial India, see Prakash (2000).

4 The 'modern world' is a society of what Henri Lefebvre calls a 'bureaucratically controlled consumption'; the system of its operation to control and conform the individual consumers lies in its ability to transmit a sense of fear - 'fear of being out of fashion, of not being young and attractive being odd, out of it, the subtle terrors through which advertising motivates'. See Philip Wander, 'Introduction to the Transaction Edition', in Henri Lefebvre, Everyday Life in the Modern World, translated by Sacha Rabinovitch (London and New York: Continuum), 2002, p. viii.

5 For a passionate and engaging critique against the high-modern obsession with the megalomaniacal 'developmental' projects in India, especially concerning the Sardar Sarovar Dam, see Arundhati Roy, 'The Greater Common Good', Outlook, 24 May 1999. Development, despite being a discourse of rational planning, has an inherent limitation because of the impossibility to locate the 'external' agency in its execution, since the supposed external body is already implicated in the configuration of power. See Mitchell (2002).

6 From a sense of despair of humans vis-à-vis nature's unmanageable power, it gave way to European condescension of the capability to 'possess' nature 


\section{Yengkhom Jilangamba}

as the marker of civilization, distinct from 'savagery', in the light of industrialization. For an account of the ways in which science and technology became very dominant in the way the Europeans started looking at the outside world, see Adas (1990). Because of an inability to come out of the state of a colonized mind, most of the developmental paradigms in the 'Third World' have been following the scientific-industrial model, with a commitment to heavy industrialization, big and centralized mega-projects as the only model for economic and social construction, without considering whether it suits the environment, thus, blocking the search for a more viable alternative.

7 I am not pleading for a celebration of the 'harmonious' past against an intruding modern state. It is an attempt to rethink the given universal and critique the system, which produces, circulates and consumes a rule of 'totalitarian' rule and monopolized violence.

\section{References}

Adas, Michael. 1990. Machines as the Measure of Men: Science, Technology, and Ideologies of Western Dominance. New Delhi: Oxford University Press. Foucault, Michel. 1980. Power/Knowledge: Selected Interviews and Other Writings, 1973-1977, ed. and trans. Colin Gordon. New York: Pantheon.

Lefebvre, Henri. 1984. Everyday Life in the Modern World, trans. Sacha Rabinovitch. New Brunswick: Transaction Books.

Mitchell, Timothy. 2002. Rule of Experts: Egypt, Techno-Politics, Modernity. Berkeley: University of California Press.

Mitchell, W.J.T. 1994. 'Introduction', in W.J.T. Mitchell (ed.), Landscape and Power. Chicago and London: The University of Chicago Press.

Prakash, Gyan. 2000. Another Reason: Science and the Imagination of Modern India. New Delhi: Oxford University Press.

Scott, James C. 1998. Seeing Like a State: How Certain Schemes to Improve the Human Condition Have Failed. New Haven and London: Yale University Press. 


\section{Part IX}

\section{Popular culture}


$\because$ Taylor \& Francis

http://taylorandfrancis.com 


\title{
19 Music, body and sexuality in Bihu songs of Assam ${ }^{1}$
}

\author{
Utpola Borah
}

At the advent of spring when nature changes its colour and wears her glorious attire, the people of Assam welcome their most cheerful and joyous festival Bohag Bihu or Rongali Bihu. Literally the term 'Bohag' means the first month of the Assamese New Year. 'Rangali' meaning festival of colour and the suffix 'Bihu' is both genre and the festival in large. Held annually (between mid-April and mid-May), Rangali Bihu and the month of Bohag are the beginning of the new agricultural cycle and mark the Assamese New Year. Pastoral singing and dancing dominate the Bohag or Rangali Bihu celebration with great enthusiasm amongst the people.

Primarily a festival of rural folks and performed in a lonely place or on the river bank, Bohag Bihu reached the status of national festival of Assam under the patronage of the legendary Ahom monarchs (1228-1836). The Ahoms are the Shan group of Mongolian invaders. They entered the Brahmaputra valley in the beginning of the thirteenth century from the Upper Burma and ruled Assam for more than six hundred years. Bihu became a public performance. An amusement palace, known as the 'Rangghar', or 'house of amousment', was built at the Rupahipathar near Sibsagar (the royal capital of the Ahom kingdom) for the members of the royal court to experience Bihu performances. The neo-Vaisnavite movement of Sankardeva (1449-1559) influenced Bihu songs and dance, in which wild jubilant expression became blended with prayer and invocations for the welfare of the family and community.

In the early part of the twentieth century Bohag Bihu songs were designated as a 'vulgar tradition,' because of its erotic overtones by certain factions within the elites and inteligensia of Assam. However, in 1952 Bohag Bihu performances were brought to Guwahati, the present capital of Assam, and performed on stage under the banner of Guwahati Bihu Xanmilan (a formal Bihu function). Crossing the 
barriers of caste, creed, community, tribes and even religion, Bohag Bihu today is not just a secular festival; it has given oneness to the multi-ethnic and poly-cultural region of Assam. It has become a national identity of the Assamese.

To understand the nature of music, body and sexuality in Bihu songs, I will describe the types of Bihu performances, including Rati Bihu song and Bongeet (Bonghoxa) below.

Bohag Bibu performances can be divided in two broad categories: Xamajuwa Bihu (community performance) and Mukoli Bibu (free performance). Husori, a community performance, is performed only by males of all age groups, for the purpose of seeking blessing on the New Year. It is a custom for Husori band to first sing and dance in the village Namghar (Vaisnavite community prayer hall) and then visit every household. The songs of Husori performance are ritualistic and carry social appeal. The Husori dance is a ring or circle dance, where dancers move their body with a graceful gesture.

The Mukoli Bihu is an affair of youthful expression of various moods, such as love, separation and union. Mukoli Bihu has various events according to gender, space and age groups of the participants. They are Deka Bihu, Bon Bihu for adolescent boys, Gabharo Bihu or Jeng Bihu for maidens, Chuwali Bihu for pre-puberty girls, Maiki Bihu or Buwari Bihu for married women and Aitar Bihu for elderly women. Every village has different rules and regulation of Bihu performances and to certain extent it also applies as per caste and community. In some areas of Sibsagar and Dibrugarh districts young males are dressed as female dancer to perform Bihu dance. In these villages, maidens are not allowed to dance together with men - only young girls (pre-puberty) dance and sing Bihu during the day within the village premises. In general in higher class Ahoms and Kalitas the dancing of marriageable girls takes place in private, or inside a house or shed, and men are not allowed to watch it. These restrictions are probably imposed by Hinduism, and are well in keeping with Hindu ideas of women's modesty and behaviour (Thomson 1948: 55-56). Jeng or Gabharu Bihu and Maiki or Buwari Bihu are entirely women's performances, held mostly in the afternoon in an open area away from their home. Dry branches are planted as fence to mark a space for the performance and also to prevent men. The following song is an example of women Bihu performance:

Bihure birina pate, xamonia/gabharu chuwali nace jume jume/sotor Bihu lagiche gat

Birina grass of Bihu/Oh dear friend/young girls dance in clusters/ they have had a touch of Sotor Bihu 
The young maidens express their feeling of joy and love in spring, yearning for her beloved, enjoy singing and dancing with friends. In some cases, newly wedded daughters-in-law also join the maidens while going to fetch water from the nearby river or pond. In Maiki or Buwari Bihu, women get together during afternoon after completing their day-to-day activities and perform Bihu in nearby field. These women express various moods of marital life through the songs, and some time even having a young lover boy as the following song describes.

Khabor mane gol bagihah ejoni/subabo nuwaro theng/jabor mane gole piliga dekaloi/batate bagorir jeng

I felt like eating a white duck/I cannot chew its legs/I felt like going to a young lad/but on the way are thorns of the plum

\section{Rati Bihu or Bihu at night}

One of the prominent events of Mukoli Bihu performance is Rati Bihu performance. The Rati Bihu was performed in the month of Sot (midMarch to mid-April) for a month, exactly before the month of Bohag. It is also popularly called as 'Sotor Bihu'. In the month of Sot, the soil hardens up and is not fit for agriculture. So the village folks invoke the weather god's blessing by performing Bihu dance and song by beating drums. For the farmer community, this performance is a marriage between thunderclouds and mother earth. Rati Bihu starts at nightfall and continues till midnight or early morning. The performance was held in the countryside, under the shadow of a Banyan/any big tree or on river bank or in a lonely paddy field.

Rati Bihu was performed only by the youth; both boys and girls were accompanied by two elderly men as guardians, known as Deka Bora (for boys) and Gabharu Bora (for girls). Specially, the Gabharu Bora was responsible for bringing and leaving the girls from home like their own father. The performances were conducted under their guidance in a common area, but separately for boys and girls. Usually, no audiences were allowed to witness the Rati Bihu performances. The songs are erotic in nature and free from all kinds of inhibitions in expressing love. The language of these songs are colloquial Assamese, but is saturated with deep sincerity. The bonding of love is well brought out in a song like this:

Piriti nabhage piriti nichige/piriti najay au pari/jimame khuwaba ximane mere khaba/piriti premare jari 
Love does not break/love does not die/love is the string of attachment/the more you twine it the more it gets twined/love is the thread of attachment

Rati Bihu uses a call and response form. It begins with an invocation, and as the night falls expression of the songs goes deeper in meaning. Rati Bihu performances are accompanied by musical instruments such as dhol (drum), pepa (buffalo hornpipe), gogona (Jew's harp), xutuli (ocarina), toka (bamboo clapper). Since both performances go side by side, there are times when while singing Bihu songs or playing $d h o l$, pepa and so forth, boys use the occasions to attract the girls with their talents. Sometimes, even to win heart of one girl, several men compete to show their superiority by singing Bihu song, playing drum or the hornpipe. While exchanging their feeling through songs, if by chance a man gets a hint that the young lady whom he likes is responding, then they can propose each other by exchanging gifts the following day, or later during the month. Usually man brings a Kapau flower (a spring orchid which also symbolizes a male sexual organ) for decorating her hair and the young lady brings a Bihuwan (a traditional white towel with red border) woven by her. The entire process of exchange of feelings happens in hiding from their fellow performers. Since physical relationship without marriage is not allowed in the Assamese society, most often they get married in the month of Bohag. For most of the rural Assamese people, Bohag Bihu is an occasion to choose a life partner - during this season the majority of elopements occur, especially in villages of Upper Assam.

\section{Kumalia kakalti ciya ai maina/kulalia kakalti ciyaltumi kumaliya maino kumaliyalpati jao bahagot biya}

Your tender waist is slim, dear/your tender waist is slim/you are tender/I am tender/come let's marry this Bohag, dear

In the case of elopement, it is customary to legalize the matches by securing consent from the Gaon panchayat (village court) and offering a feast to the community. To avoid forestalling the relationship, which violates societal norms, the young men and women of the same village are not encouraged to dance together.

Rati Bihu performance was very popular until few centuries ago, however, with the colonial interruption of the British during India's independent movement; the colonial army used to hunt freedom fighters in the villages or nearby forests, and often punishment was meted 
out to innocent youth celebrating Bihu at night. Today Rati Bihu is rarely performed confined to few villages in the Sibsagar and Dibrugarh districts of Assam.

In the following paragraphs, I will examine lyrics of some of the Rati Bihu songs and Bongeet or Bonghoxa songs connected to agricultural activities. The Rati Bihu song represents the joy of love, hunger for companionship or yearning and the wounds caused by separation and frustration. In the following song, youthfulness is justified in various ways and love is attributed divine origin:

Prathame isware prithibi srajile/lagate carajile jiwa/sejan isware piriti karilelamiba nakarim kiya

God created the world/and he created the creatures/the same God created love/why should not we love my dear

The colour red, which is colour of fertility, appears frequently in Bihu songs. Usually, female dancers wear muga silk (golden silk) in mekhelachadar (long skirt and shawl worn around the skirt), woven with red motif, which women weave on their loom.

\section{Bongeet or Bonghoxa}

Another variety of love songs, which are sung throughout the year by mainly the youth are Bongeet or Bonghoxa, which literally means 'songs of the wild'. According to folklorist Lila Gogoi, 'Bonghoxa or Bongeet is passionate lyrical outburst of young unfitted lovers exploring the own unknown depths of their hearts. These expressions become fruitful during spring with the awakening of nature and with the rhythm of Bihu music' (Gogoi 1987: 76-77).

These are sung mostly by young men while grazing cattle in the forest. Other than these songs, there are also love songs connected to agricultural activities sung by the young men while ploughing or sowing in the field, as well as songs specifically for young women, performed while planting, reaping in the field or weaving or spinning on the loom. These compositions are unique and have raw physical expression, for example:

If you were cucumber/I would have chewed you up. ...

I dreamt of you last night/my hand was on your breast. . . .

My body has been burning like mustard seeds in fire/since I saw you at the river bank. ... 


\section{Music}

The Bihu songs and Bongeet are kind of communication of feeling between youths. The Bihu songs are commonly composed in couplets of four lines and often sung antiphonally. The antiphonal character of these songs is evident when a young man sings a song and then begins to beat his drum while his opposite, the female, dances. While the female sings and dances, her partner plays on his drum. Usually, Bihu songs are sung by one person while other takes up the refrain and plays on their instruments. They are spontaneous in creation; dance movements are closely associated with the music, and the song's meters undergird the rhythmic movements. Bihu songs are mainly restricted to a high-pitch scale (sung in the higher registers of the vocal range). These songs require an extremely skilful and unusual manner of vocalization. The musical refrain consists of syllables like bohona, lahari, chenai, ohoi, haioi, hey (meaning dear or beloved etc.) and so forth, which are functionally important for making the performance more exciting and maintaining the meteoric structure of the rhythm. Different types of melodic patterns are used in a performance, but generally a particular performance contains repetitions of the same melody (except in the case of singing competitions).

Bihu songs are transmitted through oral tradition by imitating master to pupil, friends to friends, sometime even from parents and relatives and currently from recorded music. Since they are transmitted orally, the rendering of songs varies from place to place and even popular songs also change in to different tunes or lyrics according to their need.

\section{Body and sexuality}

The expression of the body and sexuality in Bihu songs are well described in both lyrics and dance. Bihu songs are ostensibly symbolic, where a woman's body is often the important subject right from attaining puberty to youthful body. The beauty of women is always compared with nature, like her face with full moon, breasts with budding flower or ripe oranges, arms with lotus buds and so forth.

Buku bahal kari kakal ciya kari/tomar man xuwani nailtomar ai kakalti atkaiye lahilkhojat hali jail jai

With your broad bosom and thin waist/none is your equal in beauty/your waist is so slim/it sways as you walk 
Comparing to women's body, there are very few songs describing the masculinity:

Bahar agaloi caino pathiyalo/bah kodali pon/cenaitir phalalai caino pathiyalo/jene purnimare jon

I caste my glance at the bamboo clumps/to see which one is the straight/I caste my glance at my lover/he is as it were the moon is full

Unlike some of the other Indian springtime love songs, the nature of Rati Bihu songs is also as mating calls. The male and female physical union is explained in the following songs:

Gaje pani khale haiyange daiyangelghorai pani khale raildhane pani khale piriti nijarat/thiya garat khopani lai

The elephant drunk anyway it liked/the horse drunk standing/my lover drunk the spring of love/by planting his feet on the steep bank

Tomare tinikhani amar tinikhani/chakahani kaporar jap/tomar tinikhani lowa bachi bachi/kukurai diche hi dak

Yours three and mine three/six cloths made up our fold/pick out your three/listen, the cock is crowing

Kukura kukura agjati kukuralbhukuwai marime tok/rati naupuwatei kiya dake dili/dhane eri jay mok

Oh, you cock, outcaste cock/I would kill you with a blow/it is hardly dawn and you crow out/my darling has to leave me

The union of men and women often happens during Rati Bihu performance, while dancing at night a few couples might disappear in the dark to fulfil their desire of being together. Other than that, it also takes place when lovers meet in the lonely field or in the forest in different time of the year. The most important point to note is that these songs are restricted only to Rati Bihu event and never sung in the public performances.

Bihu dance is a group dance, in which the percussions also sing while keeping the rhythmic patterns. The solo playing of the hornpipe is an invitation for the female dancers to join, following which the male dancers begin to move around them in circle. Then, the males and females will dance together or break into parallel lines. There are certain fixed patterns with sexual connotations. The female dancer at first keeps her hands on her hips and then sways her waist in a circle, 
gradually opening and pushing out the pelvic region as well as the breasts. While making these gestures she takes short steps and moves laterally both to her left and right and also forward and backward in a line. The male dancer exhibits the same gestures but in slightly more vigorous form. In some places young men dance opening out their knees and raising both hands upwards, in a froglike expression. There are also variations in dance steps from place to place, but the basic patterns are more or less consistent in every village.

There are specific musical rhythms for moving parts of the body. In the sound of hornpipe, the female dancer bends her upper body, keeping her hands in her waist or hips, gracefully pushing out the pelvic region as well as the breasts in a circular motion and then gradually shifts from a seated to a standing position, while looking gazing in each direction. The drummer is the leader, and he moves continuously in and around the female dancers and pairs with a particular female dancer by closely bending his body towards her. This kind of male and female pairing gesture is also common with other instrumentalists (who play the flute, gogona and xutuli). Dancers change their rhythmic movements according to the drum patterns. At times, female dancers whirl around, stretching both hands like birds, soaring with the rhythm. When a song ends, the drummer concludes with a series of uniform beats, culminating in a final single articulation, which terminates the dance.

\section{Conclusion}

Bihu song and dances are two major factors of Bohag Bihu festival. It is a fertility festival, and the major objective is to have abundant crops. In order to achieve this and make the earth fertile, erotic songs and dances are performed. According to an ancient Assamese belief, if young boys and girls perform dance and songs with sexual connotations during the spring in paddy fields, then the earth will be fertilized and will yield abundant crops. The fundamental reality of Bohag Bihu song and dance is attuned with reproductive and matrimonial stream of human life. For a good harvest, the land should be fertile and the bullocks healthy. The cattle play a vital role for the fertility of the entire village, and the first day of Bohag is dedicated to the cattle welfare. A good harvest and the emotional and sexual desire of youth and marriage are fundamental concerns to a traditional agrarian society, constituting both functional and philosophical dimensions of social existence. Bohag Bihu is a clear example, in both practice and symbolism, of an agricultural society and its values. Though primarily a song and dance performance, it exemplifies the basic characteristic of Assamese culture and society. 


\section{Note}

1 This chapter was first published in Eastern Quarterly, 5(4): 164-74, 2009.

\section{References}

Gogoi, Lila. 1987. Bihu eti samiksha, A Critical Survey on Various Aspects of Bihu Festival. Guwahati: Granthapeeth.

Thomson, R. C. Muirhead. 1948. Assam Valley: Beliefs and Customs of the Assamese Hindus. London: Luzac \& Company Ltd.

\section{Additional Reading}

Barua, Avay. 1989. Bihu Janakristir Baishistha: A Critical Study of Bihu. Guwahati: Student Store.

Barua, Prafulla. 1965. Fundamental of Assamese Culture. Guwahati: P. C. Barua.

Basu, Nirmal Kumar. 1970. Assam in Ahom Age: 1228-1826. Calcutta: Sanskrit Pustak Bhandar.

Biswas, Hemanga. 1990. Lok-Sangit Samiksha. Nalbari: Journal Emporium.

Borah, Utpola. 1998. 'A Study of Bihu Songs of Assam with Special Reference to Its Musical Contents'. Unpublished Ph.D. Thesis. University of Delhi.

Borah, Utpola. 2005. Bihu Festival of Assam: Music, Dance \& Performance. New Delhi: B. R. Rythms.

Das, Prabin Chandra, Birendranath Datta and Nabin Chandra Sarma. 1994. A Handbook of Folklore Material of North-East India. Guwahati: Anundoram Borooah Institute of Language, Art and Culture.

Gogoi, Lila. 1992. Asamiya lok sahityar ruperekha, Folk Literature of Assam. Dibrugarh: Student's Emporium.

Goswami, Prafulladatta. 1966. The Springtime Bihu of Assam: A Socio-Cultural Study. Guwahati: Lawyer's Bookstall.

Goswami, Prafulladutta. 1988. Bohag Bihu of Assam and Bihu Songs. Guwahati: Publication Board of Assam.

Goswami, Prafulladutta. 1995. Festivals of Assam. Guwahati: Anundoram Borooah Institute of Language, Art \& Culture.

Hazarika, Bhupen. Undated. Bo'hag mathu ati ritu nahay (Spring Is Not Just a Season). Dibrugarh: Bani Mandir. 


\title{
20 Problematizing cultural appropriation \\ Tangkhul folk-blues and socio-political aspirations ${ }^{1}$
}

\author{
Dhiren A. Sadokpam
}

The concept of culture for a society in transition can be understood by its own members in numerous ways. There was a time when modernity or modern culture was better understood by juxtaposing it in complete contrast to tradition or traditional culture. With the 'giver' of modern institutions and the 'receiver' ${ }^{2}$ having contrasting, if not 'non-reconcilable' understanding of what was or is being transacted, the generation of meanings has multifarious, if not fused, layers. Be it politics or economy, these fused layers find resonance in the everyday cultural articulation of political aspirations of a society, making it even more difficult to understand them from the conventional positionality of the 'binaries' like classic versus folk, modern versus tradition, art versus craft and so forth. This chapter seeks to understand cultural articulation of socio-political aspirations not from a hierarchical binary positioning but by problematizing the notion of cultural appropriation in a milieu of cross-cultural setting. The attempt at problematization of cultural appropriation is done through a reading of a new genre of Tangkhul popular music epitomized by the works of Rewben Mashangva, an artiste from the hills of Ukhrul, Manipur.

Polemical debates over cultural appropriation in the last few decades of the twentieth century have centred on the notions of 'dominance and subservience', more specifically on how a dominant group took over the creative forms, themes and practices of lesser known group and made the best use to define the dominant culture's own cultural products and artefacts. The emergence of the concept of 'cultural appropriation' was a result of the post-colonial critique of Western expansionism. The earlier phase of the debate talked about the notion of 'class appropriation' and 'cultural colonialism' while the later debates made an attempt at establishing an uneasy combination of these two notions. Class appropriation here meant the phenomenon of dominant class possessing the right to define what is the official 
'high culture' of a society or community. This phenomenon was identified early on but not by people armed with the notions mentioned above. Early twentieth-century New Negro and Harlem Renaissance writers in the United States not only identified the issue but also had to engage with the emergent trend of understanding African American folk traditions. Cultural appropriation came to acquire negative connotations like exploitation and dominance. In recent times, what some critics call cultural appropriation has also been understood in a more neutral sense as 'influence' or some even have elevated it to 'postmodern hybridity' with some degree of positive connotation (Drabble and Stringer 2007: 167).

The exercise of going back to how the notion of cultural appropriation in the West came about is not to set a non-flexible foundation to our understanding of the same. The associative perception of the notion would still indicate a process under which the cultures of less powerful groups are being appropriated by the dominant group not only to maintain the status quo but also to perpetuate the ideological power base of an order. Then how do we understand the phenomenon of appropriation of 'subservient' group whose creative forms, themes and practices exist, as it were, in a state of continual flux of either recognition or indifference to other cultural patterns? Can the relationship still exist without cultural appropriation as distinct from economic and political appropriation? Or how does one culturally articulate the political and ecological settings of the place where his or her group exists? To what effect have cultural encounters shaped the new modes of expression? These are some of the questions this chapter will seek to address by setting out to examine the life and works of 'the father of Tangkhul folk-blues' and a popular cultural icon, Rewben Mashangva.

\section{From the tumultuous hills: The popular understanding}

Rewben Mashangva, the musician, composer and researcher, is generally considered to be the leading torchbearer of the new generation of tribal folk music for many years now. He was born to Shangphai Mashangva (father) and Lasengla Mashangva (mother) in a small village called Choithar in the Ukhrul district of Manipur. He did not have the benefit of a 'musical environment' in his childhood as is understood in contemporary times, save for the sound of bamboo instrument called 'Talla' that his father occasionally played. Rewben dropped out of school after his tenth standard and decided to venture into adulthood trying his hands at odd jobs around his ancestral home. Years 
later, he married Happy Mashangva and raised three daughters and a son. They are now settled at Nagaram, Imphal. It is said that Rewben was influenced by the great American balladeer Bob Dylan ${ }^{3}$ and the inimitable Rastafarian and reggae icon Bob Marley (Hebdige 1987). In an article published by the New York Times in June $2008,{ }^{4}$ Rewben recalled how he was initiated into the music and songs of Dylan when a friend came over to his place with an album of the singer/songwriter, how it struck him that most of Dylan's songs were 'so relevant' to the landscape he grew up in, and how he acquired his first guitar at the age of fifteen. The guitar was brought to him by a trader from across the border in Burma (Myanmar). He grew up listening to Western music and learning about the same through the only link - the communication medium of the poor in many developing countries, the transistor radio.

A brief scrutiny of the man and his work reveals that the sociocultural and political milieu he grew up in had given him a unique place in the world of popular music in the Northeast. And the so-called influences do not matter much now. In an interview to a representative of the Manipuri portal E-Pao.net in 2008, ${ }^{5}$ Rewben said his first encounter with Western music was when he became part of community singing for the church. He attended no formal music education save for the times spent with church choirs and Christian fellowships in the villages. In a characteristic style, he auto identifies 'himself' in a song called 'My Land and People', ${ }^{6}$

\section{Ob! I was born and brought up}

Here I am, Here I am,

Here I am Ob! The son of this land....

The 'son of this land'/soil strain in the song is good enough base to construct a mental canvas large enough to accommodate the imagery of the man and his times. Perhaps this also explains why he has made painstaking efforts in researching and discovering indigenous musical instruments, promoting them and drawing the attention of the new generation to their roots in the backdrop of other popular musical forms.

\section{Articulation through creative roots}

Rewben is the principal exponent of 'Hao music'. He has not only rediscovered and reinvented the variegated and rich folk traditions of the Tangkhuls but also refashioned tribal musical instruments to 
suit the Western tonal scale. Rewben is also credited for the amplification and customizing of the Tingtelia, a fiddle-like traditional stringed instrument. Rewben experimented for almost a decade with the original Tingtelia so as to enable him to create a distinct sound that goes harmoniously with the modern acoustic and electric guitar and harmonica. The other instruments which accompany his 'Hao music' include Yankahui, a long bamboo flute, and a yak horn played with a mallet, apart from an assortment of modern and traditional percussions. Rewben has released two seminal music albums called Naga Folk Blues and Creation apart from lesser known ones. It is only to be expected that a man who has been so much in love with the rich folk traditions will also sing songs celebrating 'life and beauty'. Many of his songs pay tribute to the beauty and grace of the feminine body at par with nature's abundant bounty. The most prominent of his compositions, 'Chonkhom Philava', has also been the most popular with people who do not even understand the language of the lyric. The unforgettable lilt of the composition is befittingly matched by a numinous lyric. Some parts of the lyric translated into English go like this:

\section{The freshness of youth like the black thorn flower blooms . . . \\ Lady Chonkhom is the princess of the mountains ... \\ She looks like a fairy, an angel... \\ Her dress - like the tail of a wild peaben ...7}

When he sings of the feminine beauty, Rewben simply cannot be oblivious of the fading green hills, invoking not only a sense of nostalgia for its mystical appeal but also an awareness of the fragility of the ecological settings of the land where he was born:

I walk along this red country road...
And those deep green vales just yonder me...
When the deep red sun just hit the ground...
I stood there like a child...
Watching the birds heading home...
Under this deep red burning sky...8

This Tangkhul folk and blues balladeer might be home-grown, but he drinks deeply of life and savours both the joys and travails. What is even more interesting, he has given himself the apostolic mission of popularizing his brand of music - reviving the age-old traditional folk music. Rewben is aware that the current crop of young musicians in the region thinks that modern Western music is the only path to being 
a successful musician. He however opines that they can become complete musicians only when they learn about their roots and realize that they cannot treat folk music as outdated. ${ }^{9}$

Commenting on his experimental music, Rewben thinks that once anyone masters the given traditional folk musical roots, it is easy to fit in the elements into Western music or add Western elements to the folk. Most music compositions of Rewben have the guitar sounds replaced by sound of folk instruments or folk instruments' sound supporting and supplementing other sounds produced by modern instruments. It is a creative fusion of sounds deeply rooted in the many folk traditions of his tribe. Rewben has been sharing experiences with great musicians of the Northeast like Rudy Wallang of Soulmate, Meghalaya, Momocha Laishram, the master percussionist, Imphal Talkies and the Howlers and Mangangsana, the famous Pena (indigenous folk fiddle) artist of Manipur. Rewben had also participated in several music fusion projects. Through platforms like the annual Roots Festival ${ }^{10}$ and Imphal Music Project, he has shared music space and performed and interacted with international artists too. $\mathrm{He}$ is part of the Folk Art and Cultural Guild (FACG), Manipur and has taken part in many kaleidoscopic cultural shows and festivals in and outside the state.

\section{Rooted in nature and politics}

As Rewben creates milestones with his experimental music, he acknowledges the insights he has gained from his interactions with the vanishing tribe of traditional folk crooners in his community. He remembers fondly how he trudged to remote villages in Ukhrul district looking for enlightening interactions with the traditional folk singers. Each of these interactions had enhanced his understanding of folk arts and instruments. Rewben remembers folk experts Shamphang of Nungshang village, Akhothing of Phungyar, Shimeingam Shinglei and Stephen Angkang who had all imparted rich insights on different folk art forms and the use of indigenous musical instruments to him. While researching for over a decade on the traditional folk instruments he uses now, he had also inadvertently re-discovered the delicate relation between the people and bamboo which can unmistakably be called the green gold for the Northeast region due to the fact that the livelihood of most communities in the region entirely depended on the rich varieties of bamboo grown here. The plant provides not only construction materials for human shelter and other handicraft products but also food and musical instruments. 
Perhaps, it is Rewben's uncanny knack of understanding the relation between music and nature that has made his mission so vibrant and arresting. He has gained copious amount of knowledge on human being's harmonious as well as destructive relations with the land, forests and animals and the associative values attached to these very relations. Right from his first music album produced by the Naga Cultural Development Society in 1999, his passion and love for the 'ecology' has been unmistakably evident. While longing for a 'Green Green Home', he is also disturbed by the wanton destruction of the forest land and calls for an awakening 'To save our land from vanishing'. Rewben sings:

Like a romantic man I just stood there...

Smelling the mild sweet fragrance...

Dying to hold the flirting wind...

If I should die may it be here...

Under this deep red burning sky...

I don't want to lay my head... .

under some strange foreign sky...

Set me free, set me free...

Where I belong...

Under this deep red burning sky...

May be I'm just a real great fool... .

Or may be I'm a real dreamer ... .

Just beholding the empty sky...

When you're busy loading your guns ...

Slaughtering the wild beasts that you make...

I need a land of love and peace... .

Under this deep red burning sky. ${ }^{11}$

With such lyrics and a sound so distinct, yet popular, one is free to make an attempt at portraying the 'man' and what he represents. Listening to Rewben's kind of music does not entail a perfect understanding of the intrinsic politics of poetics which make subtle presence in all his songs, lyrics and the sound. Unlike many who believe in just showcasing talents to the mass without even enabling themselves and others to know that there is a 'twine' that binds all forms of sounds with nature and society, Rewben has gone ahead to give an unequivocal statement that human-made 'amplified sound' can harmoniously exist with nature while representing turmoil. Through his interactions with the aged and experienced folk artists, Rewben has not only revived passion and interest in the age-old tradition but also created 
an innovative space for himself. If Rewben has received high accolades for his experimental folk music from the critics, he should also be credited for that innovation and introduction of the folk to the youth.

\section{Encounter and appropriation of unique kind}

The descriptive attributes of Rewben Mashangva would have us believe that his creative expressions are just the representation/reflection of the socio-political turmoil that has engulfed the entire Northeast of India. With claims and counter-claims and associated political polyphony to the very idea of nationhood, community and territoriality, his works have to be placed against them. The popular belief that Northeast tribes are natural born musicians has been attributed to the region's deep-rooted 'folk and oral' tradition. While this is partially true, one should remember that the effect as it is experienced now has a history of appropriation, amalgamation and counter-appropriation. The introduction and spread of Western music is as old as the encounter with British colonial expansion and the evangelical missions of the Christians since 1894. The subsequent organized programmes of the Christian missionaries from Europe and America in the region led to the introduction of the English language, hymns and gospel music to the so-called primitive sensibilities. Even as Western and Indian musical senses prevailed, the post-colonial history of the region saw political violence of sorts quite unimagined by world watchers then. Remote corners and tiny pockets populated by ethnic groups began asserting for the right to self-determination in variegated hues. Yet, quixotically, the region where Rewben grew up had some kind of affectation for the colonial past, quite akin to what David Lal Zou calls 'Raj Nostalgia'. ${ }^{12}$ Unlike some urban pockets in the Northeast, many areas have not yet been saturated by Hindi film music or the popular culture of mainstream India. The advent of Christianity and English education in the region too has not been able to convert all Christians of the region into complete consumers of products representing Western popular culture or music in the conventional sense. Numerous rock music bands modelled on the European and the American ones have mushroomed in major cities and towns of the Northeast. That some of them are now ready to experiment with the 'form and content' on their own terms are good enough indicators that popular music in the region is in for a state of transformation.

Despite evidence of 'influence' of Western popular culture, can one just describe the phenomenon like that of Rewben's as 'postmodern 
hybridity?' That would be the easiest way to engage with his works if one decides to avoid the inconvenience of a deeper scrutiny. As addressed in the beginning of this chapter, the idea of cultural appropriation normally indicates a process under which the cultures of less powerful groups are being appropriated by the dominant group. Going by this understanding, Rewben's music has been appropriated by the state not explicitly in terms of enhancing the 'dominance' but implicitly in terms of recognizing the socio-political content of his 'craft'. In such a scenario, who transmits a message of opposite 'ideational' polarities? The Government of Manipur had conferred the State Kala Akademi Award on Rewben in 2005 for his works. Earlier, he had been honoured with the title of 'guru' under Guru Shisya Parampara Scheme of 2004-2005 by the Ministry of Culture, Government of India. ${ }^{13}$ Both events carry shades of the appropriation of the creative forms, themes and practices of 'subservient' groups àla the appropriation of minority black music by the white elites in the West.

A case in point is how jazz, ragtime, be-bop, rhythm and blues, and other musical genres whose roots primarily are linked to African culture have been explicitly appropriated by upper middle class whites whose 'ideology' is not much different from the one backed by the state in the United States. ${ }^{14}$ In Rewben's case, the state or the majority culture it represents may not have 'ulterior economic' interests as in the United States where the market for popular music culture is eminently large besides the 'ideologically' backed culture of creating and selling 'stereotypes'. In such a situation, the production of a popular culture like the one initiated by Rewben Mashangva can be understood in terms of 'multiple exposures' to world cultures without reproducing them. In some sense, this can be seen as a case of counter-appropriation. The interpretation of Rewben's work should vary from the conventional or traditional interpretation of the 'folk'. This process offers the possibility of the emergence of new insights into what has been understood as 'preservation of folk tradition' by emphasizing on the contextual differences. The 'aspirational' values reflected in the work have not undergone a qualitative change with the change in the relationship between the artiste and state patronage. But like all creative expressions, whether the temporality of the current pattern of relationship takes a different turn or it remains the same needs to be observed with an intent gaze. For the time being, one can for sure make an attempt at understanding the politics of 'cultural appropriation' beyond the binary of 'dominance and subservience'. 


\section{Notes}

1 This is a revised version of the paper 'Problematizing Cultural Appropriation: Tangkhul Folk-Blues and Socio-Political Aspirations', Eastern Quarterly, 5(4): 175-84, 2009.

2 Northeast India seems to be wearing a permanent garb of a 'receiver' owing to the 'bundles of contradictions' that the colonial rule brought during the first half of the nineteenth century. This has created fractured selves with several ideational and ideological divides. For more details, see Oinam (2005).

3 Considered to be the inspiration behind all the protest singers during the Civil Rights movement in the United States and post America's misadventure in Vietnam. Bob Dylan (b. Robert Allen Zimmerman)is a singer-songwriter whose lyrics have been critically assessed by poets and academics.

4 A report by Somini Sengupta published by the New York Times, 23 June 2008. Online version can be read at www.nytimes.com/2008/06/23/arts/ music/23dylan.html. Accessed on 12 August 2009.

5 A recording of the interview in 2008 by E-Pao.net is with the author in two compact discs. The author had co-written a profile of Rewben Mashangva for the same portal based on this interview and other sources.

6 Lyric by Ahao Horam featuring Baby Alvina Gonson from one of his music albums called Tantivy, 1999.

7 See a documentary on Tangkhul folk music called Anthology produced and hosted by Rewben Mashangva in late 1990s.

8 From the song 'Deep Red Burning Sky', from the music album Tantivy, 1999.

9 Interview with E-Pao.net representative in 2008.

10 'Roots Festival' began in the year 2003 as an initiative of Springboard Surprises, Shillong, Meghalaya, India. It is a musical collaborative effort featuring local, regional and international artists. Now the Roots Festival tours Assam, Arunachal, Manipur, Meghalaya, Mizoram and Nagaland in India's Northeast. Its stated objectives include, the spread the message of peace and brotherhood, to inspire the youth, to uplift culture, to provide a platform for constructive, creative expression and collaboration, to educate and inform and to promote eco, cultural and sustainable tourism in the region.

11 Deep Red Burning Sky from the music album Tantivy, 1999.

12 David Lal Zou, a former research scholar from Queen's University Belfast, in a paper presentation titled 'Raj Nostalgia against Nationalist Hegemony in Northeast India' talked about how tribes in Northeast India were more responsive to the public works undertaken by British colonial authorities in comparison to programmes and policies of post-colonial India. The talk was delivered as part of MRF special seminar series in August 2009.

13 For more read Donny Meisnam Luwang, 'Guru Rewben Mashangva: King of Naga Folk Blues', www.epao.net/epSubPageExtractor.asp?src=features. Profile_of_Manipuri_Personalities.Donny_Luwang.Rewben_Mashangba_ Folk, webcasted at e-pao.net on 15 October 2009.

14 For more on the issue, see, Julie L. Lemley, 'Critique of Appropriation of Black Culture by White Suburban Youth', 23 April 2007. http://grad. mnsu.edu/research/urc/journal/URC2007journal/Lemley.pdf. Accessed on 10 November 2009. 


\section{References}

Drabble, Margaret and Jenny Stringer. 2007. Oxford Concise English Literature, 3rd edn. New York: Oxford University Press.

Hebdige, Dick. 1987. Cut ' $n$ ' Mix: Culture Identity and Caribbean Music. New York: Routledge.

Oinam, Bhagat. 2005. 'Receiving Communities: The Encounter with Modernity', Eastern Quarterly, 3(2). 


\title{
21 Poetic discourse in the songs of Tapta ${ }^{1}$
}

\author{
Usham Rojio
}

The current chapter is an attempt to examine certain aspects of the Manipuri popular songs - particularly that of Tapta, pseudonym of Loukrakpam Jayenta, as a text of social dissent. Let me share some considerations that have guided my explorations in this chapter. First, though I listen to and enjoy Tapta's songs extensively, I am interested chiefly in the problem of how protest songs function in their setting; what they mean, not so much to the scholar or cultivated audience, but to those who sing them and listen to them in their natural habitat. Second, the chapter seeks to look at Tapta's song as a text of social dissent.

Tapta refreshes the field of cultural studies and modernism because his performance is the axis of so many media which critical orthodoxy used to segregate. The success of his art depends wholly upon such a confluence. Discourse analysis has served to remind us that reading is not confined to the letter or field of letters. The text is still one of the elements in the chain of interconnected media that represents Tapta's act. Tapta's art humbles the status of the text as it richly rewards anyone who decides to reflect on the texts that have emerged from his recordings and performing activities. I am not prepared to argue that the interrelation of music, word and gesture makes it invalid to judge rock music and lyrics qualitatively, or what a literary critic might find bad poetry can be turned into a great art with the assistance of flair musicianship and electricity.

Tapta has gone through a number of musical styling changes: topical and political songs; symbolic and expressionist songs ranging from folk to Hindustani classical to rock ' $n$ ' roll, folk rock in genre. This mixed genre reflects the plurality and complexity of Manipur society as a whole. Music is a language, a language that becomes significant not only by cultural initiating, but also through bodily and emotional responses. Tapta can be studied more through his song writing ability 
than through his prowess as a singer. His lyrics, which are subversive, make his songs unique and thought-provoking.

I have listened to the sessions of Tapta several times now, but still the intensity of his screaming is overwhelming. When I listen to the tape recordings for the first time, I am tempted to ask: why don't they comfort him? As I listen on to the rest of the tape, it seems to herald a singular capability of Tapta - to play and to communicate. From this vantage point, the second question pops up: is it significant that they don't (comfort him)?

Cries and screams are a type of expression that perhaps is the most pure semiotic expressions we can think of. The screams normally occur in situations where strong emotions are involved and it is connected with strong feelings of pain, anger, grief or anxiety, but sometimes also with strong feelings of joy and relief. The scream is the most powerful dramatic expression of distress.

\section{Lyrics, music and screams}

The power of Tapta's lyrics and screams can be judged from the reception of the same at the popular as well as the discerning levels. Some called him the 'protest singer from the protest land' and others termed him a 'radical reformist'. ${ }^{2}$ However people may brand his kind of music, one aspect is clear: that he is deeply swayed by the social, political and economic insecurity and turmoil in Manipur and his understanding of the political processes in the state is overtly expressed in his lyrics. Tapta has always reacted to the insensibility of the state and hegemonic political games of the central government that caused the bloody uprising of 18 June 2001 through his songs. Blatantly, Tapta's PRUCK series and 1958 are clear depiction of the discontent that the people of the state have over the political insensitivity of New Delhi. 'Eigee Abok' (My Grandma), 'Revolution', 'Neihatpikhraba' (Oppressed), 'Umaibi' (Eagle), 'Thabaton' and 'Meira' (Torch) from Abok series are remarkable political songs about the human rights violations and political turmoil, particularly in Manipur and Northeast India in general. Tapta's album 1958 and many other songs from other albums can be texts of discourse study of the draconian act called Armed Forces Special Powers Act, 1958. John Lewis's statement 'a singing army is a winning army' is archetypical.

Social dissent becomes a force in his lyrics and his fundamental purpose of music is social protest. The lyrics of songs are reflections of our culture. Through these words we can see ourselves and our younger generation, in a new light. Popular lyrics sometimes challenge firmly 
held beliefs. These same lyrics can also help us examine our common social heritage as well as specific events in Manipur history. Some songs are highly philosophical, stressing universal human concerns about war, freedom, equality, brotherhood, love and justice. Many popular songs, however, relate directly to specific historical events (murders, massacre, protests, tsunami and conflicts) or to continuing social and financial problems (economic instability, corruption and irresponsible political leaders) that evoke strong public feelings. Although it may seem obvious that some songs are retelling of folktales (like Pebet, Lai Khutsangbi), Tapta's narratives and sources are more ubiquitous, brief and often political; and continue to trouble our imagination and intellect. The characters from these tales are translated into a story setting that is suitable for a four to five-minute vocal recitation. Once converted, the story is told - not by a loving grandparent, a mother, a father or a babysitter, but by a commercial recording artist. These narratives are altogether different texts inviting plurality of reading.

His lyrics are restricted to generational conflict. For the adolescent, his music is opposed to the 'romantic' compositions preferred by parents. Using narrative styles, the songs document many of the areas of discord in Manipur in emotionally charged terminology while stressing the notion that, unless the people became aware and involved, the problem would continue. The following lyrics from the track Problem is illustrative:

Problem tana thallaba punsiselpotthapham khanghandraba punsise/chaneinana hingliba punsise/chamamnana hinglakliba punsise/kanana karigi thokhanbano?/kari maramdagi thokhanbano?

Life, full of problem/restless life,/living a jumbled life,/living a mystified life/who is responsible?/Why it happens?.

Some music critics might object and question the use of mixed genres to communicate social protest. But that would be missing the trees for the woods. For Tapta's mixed genres must be analysed in terms of how effective is the packaging in imbuing popular songs with sociopolitical messages.

\section{Popular music in social movements}

Social movements arise not only in response to conditions of inequality or injustice but, more importantly, because of changing definitions of these conditions. Those involved must recognize and define their plight as an injustice, and one that is intolerable to live with, rather 
than just passing it off as a result of luck or a cruel twist of fate. In addition, participants in such a movement must come to believe that 'an alleviation of these intolerable conditions is possible and that their efforts will be important in obtaining the desired changes in political and social conditions' (Wilson 1973: 195). Music and popular songs can play an important role in this process of symbolic redefinition and the creation of a social ideology for social movements. Parenthetically, there are symbolic aspects of the music of most protest movements that help to both define ideology and develop solidarity that are not contained strictly in the lyrics of the songs themselves.

The musical forms chosen by protest musicians usually involve elements drawn from the traditional music of the oppressed group. These elements usually involve the use of traditional melodies, transformed by the use of new lyrics, but which are recognised by most participants as deriving from the people's music.

(Lewis 1973: 37)

Thus, familiar forms of musical structure may be used, such as rhythm patterns or traditional instruments that are a part of the specific cultural heritage of the oppressed group, to symbolically define the music as that of the people. One clear example of this in Tapta is his track Problem, where he initially begins his song with a rhythm of folk dance of Kabui, a dash of Manipuri sankirtan and then shifting to a popular Hindustani classical as filler.

In considering the presentation and performance of protest songs, one has to take note of the ritual nature of music, and the effect of this ritual in creating feelings of identification and solidarity in the audience. As Randall Collins (1992: 28) has already pointed out that 'once an individual has been brought into the sphere of a movement's activities, the use of music in gatherings can, unquestionably, reinforce the feelings of communal belonging and social solidarity'. This function of emotionally charging the interests of group members is more effectively done via music than it is via speeches, pamphlets or other rational, language-based means. Thus, as Emile Durkheim (1965) suggested in the context of religion, musical events can provide the sorts of emotional, euphoric, vitalizing and integrative experiences that more rationalistic appeals cannot. This function of music is

doubly important in the context of social movements, when one considers the high proportion of the non-literate in most oppressed population, for whom rational, language-based arguments are, 
at the most, non-effective and, at the least, totally inappropriate means of communication.

Thus, in summary, music is an especially unique and effective force in mobilizing the oppressed population. The function and social effect of popular music has drawn considerable attention. In juxtaposition, an increasing number of writers have come to see popular music as an opinion formation device. Reisman in treating popular songs polarizes listeners into a majority and a minority. The latter unit is one in which certain socially rebellious themes are encapsulated' (Reisman 1954: 441).

Some critics hold that protest songs appeal to only a small segment of the so-called Big Sound audience. In juxtaposition, an increasing number of writers have come to see popular music as an opinion formation device. The Beatles, particularly, have been described as 'hypnotizing' and 'brainwashing' American teenagers (Noevel 1965). A handful of social scientists have portrayed popular music as evocative of a new 'social ethic' while at the same time rejecting the 'old order'. A cursory examination of these discussions finds much disagreement upon the socio-political effect of popular music. One interpretation sees popular songs as a form of 'background noise', which has little meaning if examined as a total entity. 'It would have understood that the specific study of forms does not in any way contradict the necessary principles of totality and History'. 'This is the case with mythology: it is a part both of semiology inasmuch as it is a formal science and of ideology as it is a history of science: it studies ideas-in-form' (Barthes 1982: 96-7). In sum, the impact of socio-political songs appear somewhere between the Reisman position and the position that art must be 'a cry for justice' in the Brechtian tradition. Given the novelty of this area of research, there is still many problems, both qualitative and quantitative, to be resolved.

\section{Music and symbolic order}

Tapta's screams fit into the tonality of his music. He relates to the musical phrases, and fills in the pauses when screaming. Tapta's screams in the pauses in a turn-taking manner that is characteristic of the musical interplay as well as the dialogue. We could say that this is a demonstration of his capabilities for protocol conversation. Turn-taking is often regarded as the most basic organization of all human communication. In musical interplay there is also usually an alternation 
between simultaneous playing and turn-taking. I would call this wonderful game of turn-taking in Tapta's songs as a successful dramatic monologue. Foregrounding the aggression and rhetorical power of the speaker has thus tended to allow the effacement of the second-person addressee in favour of exploring the complex political turmoil in the region. Like in dramatic monologue, there is an intra-textual aesthetic communication which shifts into an extra-textual public communication, or, I could say, into an inter-textual public communication.

When this interplay is transcribed to musical notes, it looks like a real composition. I must however admit that I find it difficult to hear this pitch relationship that suggests that Tapta's screams relate to the tonal key of the music. Another question concerning this is whether this musical interaction is possible only because of his skills for creating the music so that his scream fits into the music. However, the important issue here is not whether this observation or analysis is correct or not, but what significance his screams has as musical interaction and make it a part of the music. At this point, we should ask how such a dominant semiotic aspect as the scream affects the musical expression. Kristeva (1994: 63) argues that the semiotic modality in language 'gives music to literature'. She further asserts that without the semiotic, or when the semiotic is weak, language lacks life, and becomes empty words (Kristeva 1994: 63). The opposite, a language without the symbolic would be chaos, if not psychosis (Kristeva 1994: 65). The semiotic creates the nuances and turns opposites into differences. Screams are also otherwise used in music to create a strong musical expression, for example in hard-rock music screaming is part of the musical conventions. Does Tapta's screaming widen his potential for musical expressions in a similar way? Paradoxically when he screams his dynamic and tonal spectrum broadens. Although some critics argued that Tapta's expressions have some aspects that could be understood as the germ of a symbolic. It is his presence that provides the structure and that connects this expression to a music-cultural world.

When we speak about a symbolic aspect in music this can be related to an exclusive musical symbolic order, or to the symbolic order that constitutes all languages, as the Swedish culture researcher Johan Fornäs (1995: 171) suggests:

Symbolic orders thus exist within as well as beside the verbal mode. Music and images are no diffuse flows that are given shape and meaning only by the presence of words. They also elaborate logical and meaningful structures even though these differ from the verbal ones. 
A musical symbolic order is the set of conventions and rules that constitutes a musical genre. The symbolic order is, according to Kristeva, the overall structural and constituting set of rules that determines the categorization of objects into language. The subject has to be posited in the symbolic to make use of the language for expression and communication. The symbolic order is the most fundamental aspect of the organization of society and languages. It is a concept that refers to the categorizing of objects into language.

It is obvious that music does not always have an evidently denoting function such as in verbal languages. But totally neglecting the denoting aspects of musical meaning would be, in my opinion, a correspondingly great mistake. Musical codes have meaning, and sometimes the meaning would be shared by people who participate in the same musical-cultural society. Other times the meaning is related to private memories and experiences of people or incidents. But again, due to the dominance of the semiotic modality in music, the meaning will always be ambiguous. The symbolic aspects in the musical interplay by Tapta must mainly be related to musical conventions, to a musical symbolic order. He improvises according to certain rules that are typical of a musical genre which he himself cannot define. He improvises in a tonality; he presents a rhythmic and melodic theme, and develops this theme as expected in this tradition through augmentation and through harmonic and instrumentation variations.

In the poetic language, the semiotic is always dominating, always cynical and domineering. But in the way it is performed it has a character that matches Tapta's temper. Tapta plays consequently 'on top' of the pulse. This 'on top' creates an uneasy and intense mood that has a body correlation; it is similar to the heart's changes with excitement. Tapta's excitement is audible in the music. Tapta's tempo is the semiotic expression, but is, at the same time, deeply rooted in the symbolic. When the intensity increases, there is 'a strident voice, amplified or natural, which screams to the deaf who can hear and the blind who can see'. ${ }^{3}$ Simultaneously this vocalizing is connected to a high degree of excitement, as in football matches or in sexual intercourse.

Tapta's excitement is symbolic, but the symbolic meaning, suggested by musical conventions, is transgressed by the semiotic. These aspects of emotional harmonizing exemplify the semiotic in the music. But the symbolic is never threatened by total destruction. In this way the music is a poetic language. Placing his screams in a musical-cultural world, they achieve a place for him in the symbolic order. 


\section{Poetic language: A revolutionary force}

We have called this musical interaction a poetic discourse, which implies that it is rendered revolutionary. According to Kristeva (1994), the poetic discourse or the poetic language is a sort of communication which is characterized by a strong semiotic aspect. This semiotic modality in poetic language transgresses the symbolic, but never destroys it, to communicate these aspects or feeling that is otherwise unspeakable:

Poetic mimesis maintains and transgresses thetic unity by making it undergo a kind of anamnesis, by introducing into the thetic position a stream of semiotic drives and making it signify. This telescoping of the symbolic and the semiotic pluralizes signification or denotation: it pluralizes the thetic doxy. Mimesis and poetic language do not therefore disavow the thetic; instead they go through its truth (signification, denotation) to tell the 'truth' about it.

(Kristeva 1994: 60)

It is this transgression of the symbolic, of the thetic, that provokes change if not revolution. The expressions of the unspeakable threaten the language and the symbolic order from inside. Suddenly a chair is not a chair any more, the significance of the words becomes ambiguous, or less important, and instead the experience of the words depends on the rhythms, the intonation, on the semiotic flow in the language. And furthermore the poetic discourse questions the subjectivity, the subject positional in the language, in a manner that affects the common roles of a sender and a receiver, and interferes with asymmetries of the therapist-client relationship. The signifying process of the poetic discourse must include an emphatic kind of understanding that makes the communication to a mutual process of meaning making. When the language between us is poetic, there has to be two subjects communicating. Kristeva calls this emphatic understanding love (Kristeva 1987: 59). In these ways, poetic practices can provoke changes not only in the subject, but also in the language and in the society.

When Tapta achieves a position in the symbolic, this means that it is possible for him to express himself in a way that other people will understand. When Tapta's scream becomes part of a musical communication, he experiences that some aspects of his inner life have become sharable in social communication, but it's equally important that this interaction gives him a position in a broader musical-cultural community. 
He is from this moment capable of music making. This is the first step towards a music-cultural membership. Such a membership is often seen as an important aspect of identity that people regard musical activities as a way of performing our identities, our sense of ourselves.

To participate in a musical interplay from such a point of view be seen as a way of creating an identity. According to common conventions of musical participation, Tapta does not have an inevitable place in a music-cultural community. Nor do I have any intentions of changing the musical or cultural politics through my work with a local musician called Tapta. But this musical interplay and many other musical interactions are questioning traditional conventions in Manipuri culture about masculinity and about the abilities required to participate in musical interplay. Tapta has taught us much about how to include children and adults with severe communicational problems and disabilities in musical interplay. Later on, other bands in Manipur like Eastern Dark, Phunga and Imphal Talkies, though in different stratum and different aesthetic, have used this musical interaction in their works concerning integration of disabled people into musical communities, as a way to provide a social network for clients who are threatened by isolation.

Therefore, music can be understood as a reformative movement in music pedagogy. This movement has influenced the policy of music education, towards less elitism, towards more valuation of popular music, and towards valuation of the musical experience before traditional aesthetic valuation. In this regard, music therapy has really been revolutionary, and has contributed to changes in musical politics. So my answer to my initial questions is that it is indeed significant that they did not comfort Tapta in a usual manner, but let his screams be part in the music. Tapta's screams are a reminder of a human need to be communicative; perhaps not as famous as Bob Dylan's scream but certainly a revolutionary force when it comes to music.

\section{Notes}

1 This is a revised version of the paper 'Poetic Discourse in the Songs of Tapta', Eastern Quarterly, 5(4): 154-63, 2009.

2 'The Power of Words', http://taptamusic.com/biography.htm\#7. Accessed on 5 January 2008.

3 Analysis.http://taptamusic.com/analysis_contemp_manipur.htm. Accessed on 5 January 2008.

\section{References}

Barthes, Roland. 1982. 'Myth Today', in A Barthes Reader. New York: Hill and Wang. 
Collins, Randall. 1992. Sociological Insight. New York: Oxford University Press.

Durkheim, Emile. 1965/1995. The Elementary Forms of Religious Life. New York: The Free Press.

Fornäs, Johan. 1995. Cultural Theory and Late Modernity. London: Sage Publications.

Kristeva, Julia. 1987. Tales of Love. New York: Columbia University Press.

Kristeva, Julia. 1994. Revolution in Poetic Language. New York: Columbia University Press.

Lewis, George H. 1973. 'Social Protest and Self Awareness in Black Popular Music', in Popular Music and Society. New York: Oxford University Press.

Lewis, George H. 1985. 'The Role of Music in Popular Social Movements', International Review of the Aesthetics and Sociology of Music, 16(2).

Noevel, David A. 1965. Communism, Hypnotism, and the Beatles. Tulsa: Christian Crusade Publications.

Reisman, David. 1954. Individualism Reconsidered. New York: Free Press.

Wilson, John. 1973. Introduction to Social Movements. Boston: Basic Book. 
$\because$ Taylor \& Francis

http://taylorandfrancis.com 


\section{Part X}

\section{Literary trends}


$\because$ Taylor \& Francis

http://taylorandfrancis.com 


\title{
22 Manipuri literature in history ${ }^{1}$
}

\author{
Thingnam Kishan Singh
}

Over centuries, the people inhabiting what is presently called Manipur experienced numerous upheavals as a result of clashes with different cultures and powers. Known as Kathe to the Burmese, Meklee to the Assamese, Mooglie to the Cacharies, Cassey to the Shans, the people of this ancient Asiatic Kingdom, have witnessed three major epochmaking encounters in the vicissitudes of its history. Based on these encounters, the chapter seeks to scrutinize certain aspects of Manipuri literature as it unfolds during the travails of its growth and development, and its engagements with the changing realities.

Even though Manipur's contact with Hinduism can be traced to King Charairongba's reign in the seventeenth century, it was King Pamheiba's ascension to the throne in 1709 that saw the brutal imposition of Hinduism. The ensuing clash between the indigenous Meetei faith and the alien Hindu faith was essentially an encounter between two traditional cultures and worldviews. The second has been the encounter with the Western civilization vis-à-vis the British conquest of Manipur in 1891 though its contact with the British was established much earlier. The impact of the encounter with the British immediately followed by the two world wars brought about a massive change in the collective experience and consciousness reflected in terms of cultural values being rendered more open, liberal, equalitarian and humanistic. The second encounter also brought far-reaching political changes in the wake of the swelling tide of decolonization that swept Asia, Africa and Latin America. Manipur eventually became free from British control in 1947 and remained a sovereign democratic state till its 'integration' with the newly independent state of India on 15 October 1949. The third encounter comes with this contact with India (as the nation state). It presents a queer picture of an encounter with another not too dissimilar entity. ${ }^{2}$ With its own logic, the society and culture of this ancient Asiatic land has experienced the dynamics of these encounters. 


\section{Thingnam Kishan Singh}

Though these three phases of historical encounters set the background upon which cultural manifestations and literary creations are witnessed, the chapter picks up specific trends of literary creations and practices. These specific trends have been mapped cutting across historicity and socio-cultural dynamics. The sections marked out are not based on a generic theme, rather these are based on the significant but varied themes. The narrative may be seen as segmented reading of the literary history of Manipur. This is merely a humble attempt to illustrate an otherwise a large corpus of works in Manipuri language running through centuries.

\section{Peculiar keepers of the oral tradition}

Manipuri literature till the seventeenth century has been said to constitute its early period. Ritual songs and hymns composed before the advent of the Manipuri script ${ }^{3}$ form part of the corpus of the literature of the early period. These songs and hymns are not treated as folk songs or part of folklore as they were not widespread amongst the people. Neither were they handed orally through successive generations. They were confined to a certain erudite section of performers whose performances were limited to 'particular ceremonial functions, ritual observance and festive occasions' (Singh, Manihar 1996: 12).

The manuscript Panthoibi-Khongkul gives an account of the religious and social festival known as the 'Lai Haraoba' where the Khaba community paid homage to the deity Nongpok Ningthou and his consort Panthoibi. This festival, believed by scholars to be part of the cosmological theory of creation in Meetei myth, is a repository of numerous songs. Significant among these Lai Haraoba songs found in Panthoibi Khongkul are the 'Ougri', 'Khencho', 'Anoirol' and 'Lairemma Paosa'. 'Ougri' and 'Khencho' are much more archaic in diction and steep in historical allusions. 'Ougri' is also mentioned in the manuscript Laisra Pham as a coronation song on the occasion of the ascension of Nongda Lairen Pakhangba in AD 33. The royal chronicle known as Cheitharol Kumbaba begins with Nongda Lairen Pakhangba's ascension to the throne in AD 33.

Another manuscript titled Naothingkhong Phambal Kaba refers to the 'Ougri' as an important aspect of Meetei culture and tradition. The lines of the first part of 'Ougri' comprise of six syllables each while those in the second part comprise of eight syllables. Noted for its cadentic quality, 'Khencho' remains an obscure and unintelligible literary piece to the modern generation. Still considered as one of the most important component of the Lai Haraoba festival, this immensely rhythmic 
song is characterized by its archaic diction. It consists of lines of six syllables each. 'Lairemma Paosa' and 'Anoirol' are based on the theme of love. Diction appears to be comparatively simple in these songs with a lyrical flow created through alliteration and rhythm. Another song associated with the festival is the 'Hijan Hirao', a long narrative poem extremely lyrical and sentimental. Some other prominent songs associated with rituals are 'Ahonglon', 'Yakeiba', 'Pakhangba Langyensei', 'Langmailon' and 'Kumdamsei'. 'Ahonglon' is important as it is mentioned in the manuscript Loyumba Sinyen, a written codification of laws and customs dating back to the twelfth century.

Another important aspect of the literature of the early period was the treatment of heroism. Rivalry and clashes between the clans resulted in the development of martial skills. Bravery and courage remained central to the numerous conflicts that created a martial culture. It dominates the spirit of the society till the late nineteenth century. Anonymous writers ${ }^{4}$ of the early period dealt with the saga of heroism in numerous works like Chengleiron, Tutenglon, Numit Kappa, Thawanthaba Hiran, Chainarol and Nongsamei. Chengleiron stands as one of the earliest known text in Manipuri literature whose style has been widely followed. Opening with a dedication to the patron king, the lyrics are meant to be recited or sung. It is a narrative that spans three generation of kings of the Chenglei clan. Interesting narrations are found in Numit Kappa, an allegory with a strong political overtone which still commands a wide practicality in today's Manipur where there are inter and intra ethnic clashes over power.

\section{The first note of realism}

However, the first work to register the note of realism is Thawanthaba Hiran, a tragedy based on a crime story. Departing drastically from the legendary nature of stories in the other works, it was based on historical events. Closely aligned with history, it grapples with the violent and bloody conflicts between the Khuman and the Meetei clans. The horrific violence that characterized the work makes it distinct. Chainarol is an account of combats based on the feuds of the clans. There are twenty-seven stories based on real-life incidents.

Besides the numerous literary tracts on the cult of heroism and bravery, the theme of romance and love found abundant expression in the literature of this period. We find works, which can be classified as pure fiction in clear distinction from those fictions based on historical realities. Many of these fictions were based on mythical legends. Nungpan Ponpi Luwaopa narrates the romantic saga of Luwang 
Prince Luwaopa and Koubru Namoinee, the adopted daughter of the Koubru King. Myth and legend fuse together with divine intervention playing an important role in the narrative. After a series of mishaps and ordeals, the two lovers are finally united. Fate emerges as the overarching power dominating human lives in the tragic story of Naothingkhong Phambal Kaba. Human actions and human characters are helpless in the sweeping changes brought by the elements of fate and destiny.

Panthoibi Khongkul is one of the most valued literary works in Manipuri. It is, perhaps, the most, critically assessed work of Manipuri literature of the early period. As the title suggests, the story deals with the trail or footsteps left by Panthoibi after she leaves the house of her husband. As per this text, Panthoibi is the epitome of freedom, which makes her distinct and ahead of her time. Panthoibi, the Meetei princess, is described as a maiden of rare beauty. Eagerly sought by many powerful kings and princes, she is portrayed as an extremely independent character. Her spirit is symbolic of a natural zest for life. Spurning many proposals for marriage, she is finally persuaded to marry Taram Khoinucha, the Khaba prince born of Khaba Sokchrongba, king of the Khaba dynasty and the queen Teknga. With great pomp and grandeur, the bride was received in her new household. However, Panthoibi still retained her zest for freedom and independence. She never took to married life as a married woman was meant to. Instead of keeping indoors, she roamed the countryside alone. It was fate, which took her to a chance meeting with Angoupa Kainou Chingsompa, the lord of the Langmai hills. Instantly they were attracted to each other. The love-struck couple decided to break all traditional social barriers by running away. Angoupa wanted to take her to his land. After some dramatic twists and turns, the lovers finally managed to elope. The Khaba warriors led by their king pursued the fleeing couple but eventually failed to capture them. Thus united, the two lovers were received by the Langmai people with dance and music.

\section{The epics of the seven incarnations}

Apart from several other works based on the theme of love, mention may be made of the literature coming from the Moirang region of Manipur. A civilization situated on the magnificent Loktak Lake, the culture of the Moirang clan has been noted. Numerous manuscripts of the Moirang region dwell on the theme of love. One of the most popular stories refers to the seven pairs of lovers who are regarded as incarnations of the same souls in different generations or ages. The 
seven cycles are ${ }^{5}$ Akongjamba (hero) and Phouoibi (heroine); Henjunaha (hero) and Leima Lairuklembi (heroine); Khuyol Haoba (hero) and Yaithing Konu (heroine); Kadeng Thangjahanba (hero) and Tonu Laijinglembi (heroine); Ura Naha Khongjomba (hero) and Pidonnu (heroine); Wanglen Pungdingheiba (hero) and Sappa Chanu Silheibi (heroine); Khamba (hero) and Thoibi (heroine).

Even though the development of this literature in its written form may be traced to the twelfth century, the oral tradition had existed much earlier as indicated clearly by the chronicles. The literary tradition that prevailed till the encounter with Hinduism was rooted in the indigenous script, language, culture and social milieu. A pertinent aspect of this literature of the early period is its distinct character unmarked by any traces of outside influence. This remained a characteristic feature till the dawn of the eighteenth century (Singh, Manihar 1996: 105-6).

\section{Culture by diktat}

The close of the seventeenth century and the beginning of the eighteenth century mark a turning point in the history of Manipur. The year 1709 witnessed the ascension of Pamheiba to the throne after the death of his father King Charairongba. Rechristening himself as Maharaja Garibniwaz, he issued a diktat pronouncing Hinduism as the new religion of Manipur under the influence of the proselytizing Bengali Vaisnavite, Shantidas Goswami. This act engendered an upheaval with colossal implications for a society's identity. Opposition and resistance to this autocratic move to obliterate the traditional faith and culture were brutally repressed. The king and his mentor left no stone unturned to erase traces of the indigenous faith. Places of worship were destroyed, worship of traditional and local ancestral deities, traditional rituals and rites, including Lai Haraoba festivals, were immediately banned. Burial of the dead was replaced by cremation. Along with the imposition of Hinduism, the manuscripts and texts in the indigenous script were confiscated and burnt in full public view. Use of the indigenous script was replaced by the Bengali script.

Shantidas Goswami composed an entirely different chronicle in Bengali known as Vijay Panchali, which was a deliberate attempt to efface the history of the people. It projected the land as Manipur of (the Hindu epic) Mahabarata and traced the lineage and genealogy of the first King of Manipur to Chandrabhanu, whose daughter Chitrangada was married to Arjuna, the great Pandava archer. Brabrubahana was the son born of this wedlock. His son Yavistha was 


\section{Thingnam Kishan Singh}

then identified with Nongda Lairen Pakhangba who first ascended the throne in Kangla in AD 33. Imported art forms like the Natya Sankirtan actively encouraged by the royal power gained popularity. Corruption in language became the order of the day as the elite and aristocratic class got increasing exposure to Indo-Aryan languages like Sanskrit and Bengali. Manipuri vocabulary witnessed introduction of many new words from these languages.

\section{The great translation enterprise}

Literature as a social entity conditioned by historico-political, material circumstances naturally did not remain unaffected by these drastic changes. Restrictions on the practice of the indigenous faith and widespread patronage of the newly imported alien faith saw a marked rise in the influence of literatures of Indo-Aryan languages, especially Sanskrit and Bengali. Apart from the changes that can be seen in the formalistic domain of writing, thematic engagements were heavily influenced by the new religion. The two Hindu epics, the Ramayana and Mahabarata, came to assume a central space in the Manipuri literature of the period.

Garibniwaz patronized one Kshema Singh Moiramba to compose the Ramayana in Manipuri. Five young scholars were engaged in the project, namely Pramananda Nongyai Khumanthem, Mukundaram Khoisnam, Laxmi Narayan Soiba, Ramcharan Nongthomba and Lakhmi Narayan Saikhuba. Parikshit, a part of the Mahabharata was translated by one of the king's Vaisnavite teacher, Gopaldas. Virat Santhuplon was another work from the Mahabharata produced by crown prince Nabananda. He engaged two eminent writers, Wahengbam Madhabram and Mayengbam Brindavan, to produce this work.

In the sphere of fiction, contact with Indian culture brought about new trends in terms of theme and narration. Mention can be made of Wahengbam Madhabram's Sanamanik, Dhruba Charit, Ananda Pukhrambam's Dhananjoy Laibu Ningba, the anonymous Rupaban and Lalananda Das's Bhakta Gunamrita. Translation of the Bhagavad Gita is also a notable feature of this period. Repressed and marginalized writers who retained the traditional indigenous faith also worked hard, in the face of severe constraints, to produce remarkable literary works anonymously. Several manuscripts written during the period extolled the need to protect and nurture the indigenous faith and culture of the pre-Hindu period. A text known as Sanamahi Laikan stands out distinctly with its rich historical, legendary and mythological references woven in an intricate narrative pattern. Many critics 
have noted the poetic quality of this work. The other great works of this strand are Khagemba Langjei, Sanamahei Laibui and Chingoiron.

\section{Encounter with British colonial power}

The close of the nineteenth century marks another significant turning point in the history of Manipur. British victory in the Anglo-Manipuri War of 1891 brought the land under British control. This marked a long chapter of foreign rule, the second in Manipur's history since the Burmese occupied it during 1819-1826 in what has come to be known as Chabi Taret Khuntakpa (Seven Years' Devastation). The British were not only responsible for introducing a new administrative system but also other things like new roads, new judicial system, new modes of trade, schools based on Western system of education and so forth. Apart from the technological changes, the British also made inroads in the social landscape of the land with their religion. Christian missionaries played a crucial role in proselytizing the non-Meetei people living in the hills.

The literary domain paradoxically failed to capture the long British colonial interlude. Instead, mainstream Manipuri consciousness continued to be steeped in Vaisnavite Hinduism and the rhapsodical art forms it spawned like Sankirtan and Raslila. There was a lull in creative and critical efforts in the field of writing as dance and music enthralled and captivated the collective mindset. An important literary personality of this transition period, Haodijamba Chaitanya, published four significant works - Khamba Thoibigi Warini (1899), Khagi Ngamba (1900), Takhel Ngamba (1902) and Chingthangkhomba (1902). But these works are traditional in essence. Except for the first one, which is based on the romantic saga of Khamba, the orphan, and Thoibi, the princess of Moirang, the remaining three are based on three great kings of Manipur. Engagement with the changing realities generated by the thrust of modernity did not take long to emerge.

\section{The triumvirate usher in modernity}

The literary landscape witnessed a dramatic upheaval in the early part of the twentieth century with the entry of three overarching figures Khwairakpam Chaoba, Lamabam Kamal and Hijam Anganghal. New consciousness shaped by forces of modernity, imprinted clearly in their works, herald the advent of modern Manipuri literature. Their works made a lasting impact on the collective Manipuri consciousness by interrogating many assumptions and notions of received ideas and 


\section{8}

practices. Their literary works celebrated the richness of their culture, language and history as well as passionately foreshadowed a resurgent literature written in the grass-roots Manipuri language with an explicit attempt to foreground its strength and vitality marked their writings. Their versatility made them foray into different genres - poetry, drama, novel, short story, essay, epic and criticism. Rightly called the founding fathers of modern Manipuri literature they paved the path of modern sensibility in literary expression.

A serious poet, Chaoba never fails to use a word with optimum effect. His collection of poems Thainagi Leirang (The Flower of the Ancient Time) (1933) bears the hallmark of powerful use of language. In prose, too, he was equally prolific. His prose work Chhatra Macha was prescribed by Calcutta University in 1924. The historical novel Labanga Lata (1940) also remains as a work of distinction.

As a poet, Kamal laments the debility and neglect of our rich heritage. He calls forth a vision to reinvigorate the rich traditional culture. Influenced by Western Romanticism, his appeal for nature's beauty and harmony is striking. As a novelist, Kamal is credited for giving Manipuri literature one of its great classics, Madhabi (1930), a story of love and sacrifice.

Hijam Angahal, in spite of poverty compelling him to drop out of school at an early age, gave Manipuri literature some of its most remarkable poems and novels. Of his works, Shingel Indu stands out along with Khamba Thoibi Seireng (Khamba Thoibi Poem), his magnum opus. His lone novel Jahera has continued to exercise a grip on the minds of the people till today. Based on a love story between a Muslim girl and a Meetei boy, it has remained popular. This is a reflection of the existing cultural distance in terms of conjugal relationship between the Meiteis and the Meitei Pangals (Muslims). This is the socio-textual reading of a tradition in the literature. His plays Thabal Chongbi, Nimai Sanyas, Ibemma and Poktabi performed by the Manipur Dramatic Union makes him a rare genius gifted with great literary skill and imagination. Other literary figures like Hawaibam Nabadwipchandra, Asangbam Minaketan and R. K. Shitaljit made significant impact on the Manipuri literary landscape.

\section{The unsung giant of Manipuri literature}

Hijam Irabot emerges as a towering personality whose overarching presence was felt in almost all aspects of life and consciousness in contemporary Manipur. His radical vision and activities left an indelible mark in the collective psyche of the Manipuris. Apart from being 
the most charismatic and visionary leader in contemporary political history of Manipur, his contribution to Manipur literature has been immense. A pervasive legacy of marginalizing and obscuring this great personality from the Manipuri mainstream consciousness in the interest of the prevailing power structures - from the colonial and feudal period till today - can be seen clearly. Hailed as the first truly modern poet of Manipur, many of his works were published posthumously. Some have not been published even today (Soyam 1996).

A pioneer in different spheres of life, Hijam Irabot was the first to start a literary journal in Manipuri. Titled Meitei Chanu (Meitei woman), the first volume appeared in 1922 with contributions from great poets like Kamal. His early work titled Seidam Seireng (1924), a collection of poems, was prescribed as a text for schools in Manipur. He wrote the first travelogue in Manipur titled Mandalay Khongchat (A journey to Mandalay). As a radical revolutionary leader spearheading organized resistance against feudalism and British imperialism, he steadfastly refused to be daunted by imprisonment, deportation, banishment and exile.

An interface between Irabot and history took place during his imprisonment in Sylhet Jail (now in Bangladesh) in 1941 (Soyam 1997: 9). It resulted in the production of some of the finest poems in Manipuri literature. Titled Imagi Pujah (The Worship of Mother) (Hijam 1987/2005), the poems Irabot wrote during his imprisonment in Sylhet were published posthumously only in 1987. A first glance at these poems immediately strikes the reader with its profound engagement with varied themes like identity, nationhood, patriotism, struggle against injustice, emancipation of the exploited etc. His poems in this collection (Imagi Pujah) attempt to capture a historical picture of Manipur since the pre-colonial era to the grim realities of contemporary Manipur. A commonly held view amongst critics of Manipur literature is that if Irabot's poetry were published during the colonial period, it would have made substantial impact on the revolutionary politics of the day (Soyam 1997; Singh, Nilakanta 1996; Biswas 1996; Singh 1998).

After World War II Manipuri literature saw a new trend, with playwrights like Haobam Tomba and Sarangthem Bormani drawing deeply on the rich ballads and legends associated with Moirang. Tama Salon Saphaba, Pidonnu, Thainagi Leirang, Sajik Thaba and Thaja Thaba by Tomba, and Kege Lamja, Tonnu Laijinglembi, Nura Santhalembi and Haorang Leisang Saphabi by Bormani are notable works. G. C. Tongbra is another literary figure whose plays created ripples in the literary landscape. With his first published work Mani Mamou, he went on 
depicting the ironies of life in its various shades and colours. A. Minaketan and R. K. Shitaljit are the new voices of post-war sensibilities in Manipuri poetry (Thokchom 2005; Hemchandra 2005).

\section{New theme song: Hegemony and resistance}

The rapidly changing political configurations after the Second World War era vis-à-vis the swelling tide of decolonization marks a new signpost in Manipur's history, too. The British Union Jack was replaced with the Manipuri national flag in 1947 at Kangla, the historical seat of power in Manipur, marking the end of colonial rule and the beginning of a free independent Manipur. But this ancient Asiatic Kingdom newly transformed into a democratic political structure in the post-colonial period was 'merged' with the newly independent state of India on 15 October 1949 in pursuance of the Treaty of Accession. This crucial encounter with India has produced highly conflicting tendencies in terms of explicit moves to impose a homogenizing framework operating at every level of existence - social, political, cultural, legal, economic and so forth.

Contest at the political level with the emergence of armed resistance movements fighting against the 'merger' with India has created the articulation of a conflict at various levels of existence. Elangbam Nilkanta's first published poem 'Manipur' (1949) raises fundamental questions that foretell the shape of things to come:

\section{O Mother Manipur, one day your children will trace you \\ Like Dushyanta with eyes bathed in tears, But by that time where shall they find you? Where shall they find you?}

(Singh, Manihar 1996: 256)

Intensification of armed struggle in Manipur has made profound impact on contemporary literature (Hemchandra 2005). Poetry has plunged deep into this conflict and notable poets like Laishram Samarendra, Yumlembam Ibomcha, Thangjam Ibopishak and Shri Biren explore the sordid reality informed, shaped and distorted by the conflict. Ibopishak's collection of poems Apaiba Thawai (The Wandering Soul) (1969) has been hailed by critics as a trendsetter for a new wave of poetry that grapples with the rising tide of conflicts emerging from the crucial encounter in 1949. A growing sense of dissent and anger at the degeneration in society can be discerned clearly. Shri Biren's Tollaba Shadugi Wakhal (Thought of the Wretched Animal) (1970) 
aptly captures the decadence that has eroded the social fabric. Yumlembam Ibomcha's Shingnaba (The Challenge) (1974) written with two other poets, documents the extreme note of anger in contemporary Manipuri society. R. K. Bhubhansana's 'Marup Ani' (Two Friends) in his collection titled Mei Mamgera Budhi Mamgera (Whether the Light Is Out or the Mind Is) expresses the stark and sordid reality of life under draconian laws like the Armed Forces Special Powers Act, 1958.

Women poets have attempted to scrutinize contemporary life and society in a radical tone. Questions of identity, freedom and status figure prominently in many of these poets whose female sensibilities offer another dimension of social analysis and critique. Memchoubi's Androgi Mei (The Fire of Andro), Borkanya's Mongphamgi Meenok (Laughter of the Grave) and Pukhrambam Urmila's Ashibagi Mara$k t a$ (In the Midst of the Dead) are notable works that capture the stark social realities. Different genres like drama, novel and short story share similar concerns. In theatre, mention can be made of writers like Arambam Somorendra, Brajachand Khundrakpam and Kanhailal, whose literary engagements are shot through with stark social realities. In novels, mention can be made of writers like M. K. Binodini, Aribam Chitreshwar, Elangbam Sonamani, Aramban Biren, Loitongbam Pacha Meitei, B. M. Maishnamba, Hijam Guna and M. Borkanya. The short story has emerged as a powerful mode of literary expression with writers like M. K. Binodini, N. Kunjamohon, Khumanthem Prakash, Shri Biren, Hijam Guno and others.

\section{Notes}

1 This chapter was first published in Eastern Quarterly, 3(2): 128-38, 2005.

2 Similarity was in terms of the fact that both were two new nation states engaging into the same path towards modernization.

3 Historical research provides evidence of the advent of the Manipuri script at the close of the twelfth century.

4 Anonymity was primarily because of a particular practice in the traditional social system where the place of individual agency is given least prominence as against the collective. The royal chronicle Cheitharol Kumbaba, for instance, does not highlight the authorship of the chroniclers. It is similar to the different Vyasas whose names do not figure in writing the Mahabharata.

5 There is also another list of nine incarnations. This is given below in sequence of their appearances: (1) Henjunaha (hero) - Thongnang Lairoulembi (heroine); (2) Shamba Naha Lamnganba (hero) - Khamnu Yaidingkonu (heroine); (3) Wanglen Pungdinhanba (hero) - Chakpa Yainu Phishaheibi (heroine); (4) Nganba (hero) - Shangloulembi (heroine); (5) Khoyon haoba (hero) Yaithing konu (heroine); (6) Akongjamba (hero) - Leima Phouoibi (Phoiding Nura Athoibi) (heroine); (7) Khamba (hero) - Thoibi (heroine); (8) Kadeng Thangjahanba (hero) - Tonu Laijinglembi (heroine); (9) Ura Nahakhongjomba (hero) - Pidongnu (heroine). See for details Sarangthem (2003: 4). 


\section{Thingnam Kishan Singh}

\section{References}

Biswas, Hemango. 1996. 'Irawat Singh: The Artist in Arms', Ningshing Chephong, Imphal.

Hemchandra, K. 2005. 'Houjiki Manipur Sahityagi Khongchat Sheireng', Seminar paper of Manipuri Sahitya Parishad, Imphal.

Hijam, Irabot. 1987/2005. Imagi Pujah. Imphal: Irabot Leirak Phonba Lup (Imphal: Langol publications reprint).

Sarangthem, Bormani. 2003. Moirang Shaiyon, 3rd edn. Imphal: S. Boramani. Shri, Biren. 1970. Tollaba Shadugi Wa (Story of the Wretched Animal). Imphal: Sri Biren.

Shri, Biren. 2011. Sri Biren's Poems, trans. Jodha Chandra Sanasam. Imphal: Cultural Forum Manipur.

Singh, Ch. Manihar. 1996. A History of Manipuri Literature. New Delhi: Sahitya Akademi.

Singh, E. Nilakanta. 1996. 'Irabot and Social and Cultural Awakening in Manipur', Ningshing Chephong, Imphal.

Singh, L. Damodar. 1998. 'Irabot gi kavital: Anouba yening Hunbagi Lambida', in Ritu. Imphal: Manipur Sahitya Parishad.

Singh, Yumlembam Ibomcha, Thangjam Ibopishak, and Ranjit W. 1974. Shingnaba (The Challenge), Vol. II. Imphal: V.I. Publications.

Soyam, Chatradhari. 1996. Hijam Irabot. Imphal: Soyam Publication.

Soyam, Lokendrajit. 1997. 'Irabot Ki Seireng', in Ritu. Imphal: Manipur Sahitya Parishad.

Thangjam, Ibopishak. 1969. Apaiba Thawai (Wandering Soul). Imphal: Naharol Sahitya Premi Samiti.

Thokchom, Ibohanbi. 2005. 'Manipurda houjiki Manipuri sahitya-wari macha', Seminar paper of Manipuri Sahitya Parishad, Imphal. 


\title{
23 The origin and development of Mizo literature ${ }^{1}$
}

\author{
Laltluangliana Khiangte
}

\section{The milieu}

Mizos live in the Northeastern part of India, sandwiched by Myanmar in the east, Bangladesh in the south and the state of Assam in the north. In their legendary parchment, the forefathers of the Mizos claimed that they had recorded something in black and white, which however was eaten up by a stray hungry dog since it was carelessly kept in the porch. So there was no writing that can be read before the advent of the British in the last part of the nineteenth century. The language has been codified by the two pioneer missionaries, namely Sap-upa (Rev. Dr. F. W. Savidge) and Pu-Buanga (Rev. J. H. Lorrain), who had landed in a small hamlet near Sairang by the bank of the river Tlawng in the chilly winter of 11 January 1894 . Since they did not have any servant, they were considered as sap vakvai (wandering white men) and they were not considered as those authoritative British who came to the land before them. Since they had been familiar with Mizo language from the book prepared by Thomas Herbert Lewin (1839-1916), they began making full form of Mizo alphabet before preaching any of the good news.

It was twenty years before they arrived on the land. Lewin, the then deputy commissioner of Chittagong Hill Tracts, whom the Mizos dearly called as Thangliana, had written so many Mizo words and published a few informative books. In one of his books named A Colloquial Exercise in the Lushai Dialect of the Dzo or Kuki Language with Vocabularies and Popular Tales, published in 1874, he had written a good number of Mizo words including three folk tales of the tribe. It seems that this book is the first-ever written document on the Lushai (Mizo) language. It may be a little presumptuous to claim the existence of any Mizo literature prior to that year, that is 1874 . Thangliana wrote several books that include Progressive Exercises in Lushai Grammar 
(London), The Hill Tracts of Chittagong and Dwellers Therein (Calcutta 1869), Wild Races of South Eastern India (London 1870) and A Fly on the Wheel (London 1912). In 1884, Assistant Surgeon Brojo Nath Shaha, a civil medical officer of Chittagong, published an important book called Grammar of the Lushai Language. However, this particular book could not be found for reference.

Commenting on these pioneering written works, Lorrain wrote that he and his colleague Savidge found them extremely useful in their early efforts to learn words and phrases, but neither of them pretended to suggest a mode of literation which could be taught to the Lushais. Lorrain further pointed out in his introductory note:

It therefore, fell to our lot to reduce the language to writing in such a way that our system could be readily adopted by the people themselves. For this purpose we chose the simple Roman script, with a phonetic form of spelling based on the well-known Hunterian system, and this, with slight emendations adopted since, is still used through-out the tribe with eminently satisfactory results.

Besides these two books, one British officer C. A. Soppith compiled Rangkhol-Kuki-Lushai Grammar (1885) and a few other material of relevant subject had also been published. All these efforts paved the way towards more systematic efforts by the missionaries.

\section{Prose works/theology/textbooks and so forth}

Looking back the formation period, the two pioneering missionaries of London-based Arthington Mission, Lorrain and Savidge left to the Mizos valuable documents during their first four years stay (1894-97) in Mizoram. The first known book in Mizo called Mizo zir tirna Bu (A Lushai Primer) was published on 22 October 1895. Then they revised as Zirtanbu (Primer) and then Zawhna leb Chhanna (Questions and Answers) in 1896. They prepared textbooks for elementary schools from which beginners made their effort to learn reading and writing.

Then they put earnest effort to the translation of the Bible. They started with the Gospel of St. Luke on 21 August 1895, followed by the Gospel of St. John and then the Acts. First of all, they started with the translation of St. Luke 15: 11-32 into Lushai (Dulien dialect, as recorded by them), the parable of Jesus Christ about the Prodigal Son and the first copy was sent to their friend Parteous on 5 February 1896. The two gospels were published by the British and Foreign Bible 
Society in 1898. Again, the year 1898 saw the publication of Lorrain's great work, Grammar and Dictionary of the Lushai Language by the Assam government.

Other important written works like Mizo leh Vai Thon Thu of 1898, as collected and printed by Tarmita (J. Shakepear); translation of the Gospel of Luke from the Bible by Pu Buanga and Sapupa, which they started on 1 August 1896; Gospel of John translated and published by British and Foreign Bible Society in 1898; Acts of the Apostles published in 1899 and the first Christian hymn book (Hla bu) printed in 1899 were among the first few books that Mizos had in hand before the turn of the twenty-first century.

The Welsh missionaries (namely Zosaphluia, D. E. Jones and Zosapthara, Edwin Rowlands) had taken up the difficult task of teaching, preaching, translating, writing, composing and compiling books after the pioneering missionaries Savidge and Lorrain left in 1897. They found that the publication of Christian literature helped to convey the message of Christianity to the Mizos. So with the help of some early Khasi Christians who were working in the government offices and the first group of Mizo literates, the missionaries could produce a number of literatures within a short period of time. Besides, those publications mentioned earlier, a school textbook called Zirtirbu Thar (New Primer) was compiled in 1899. It contains moral and religious lessons and some articles on general knowledge. With the help of early educated Christians of the tribe, several textbooks and other relevant books were written, translated and prepared in a published form by the missionaries during 1900-1930.

\section{Translations/journals/history and so forth}

Following the publication of various textbooks for schools and the Bible in Mizo, a good number of translated Christian hymns were published, which the new literates appreciated with all their hearts. Then came the Mizo version of The Pilgrim's Progress (1910) translated by the Chuautera, and The Story of the Bible (1909) translated by the Challiana, which remained two of the most readable books, apart from the Bible, among Mizo literature for a long time.

Having been exposed to the world of literature, the need for publication of things common and secular was soon felt. The first Mizo journal of a sort called Mizo Chanchin Laishuih (The Highlander's News) was published in 1898, most probably in the month of July. It was a handwritten cyclostyled tabloid. It featured local news of different villages, folk tales of the tribe and conveyed the orders of the 
government to various chiefs. It was a miracle for most people that something can be read from the white sheet of paper.

A monthly journal Mizo leh Vai Chanchin Lehkhabu was published by the then superintendent of Lushai Hills, J. Shakespear, in November 1902. Interestingly, contributors to this journal were the first educated Mizos (three chiefs) who were held in high esteem by the people. Then came the Kristian Tlangau, edited by R. Dala, a monthly mouthpiece of the Presbyterian Church Mission from Aizawl, which has been published without any break since October 1911 till today.

Other magazines are Sipai Tlangau by the Salvation Army from 1931; Tlawmngaibna in 1934 by the 'Rover Scout' group of Baptist Mission Serkawn; Kohbran Beng, a monthly newspaper by Baptist Mission Lunglei started in 1947; LSA Chanchinbu by Lushai Student Association started in September 1938 (later renamed MZP Chanchinbu); Tun Hapta Kar Chanchin started in September 1939 by Liankhuma; the first known daily newspaper of Mizoram - Ni tin Chanchin by D. C. McCall in 1939; Zoram Thupuan started on 6 December 1947 by the United Mizo Freedom Organization; Mizo Arsi started in 1948 by H. K. Bawihchhuaka to benefit Mizo Union Party. Apart from these, religious books, travelogues, prose, essays and stories were also published before 1950. Several dailies, biweeklies, fortnightlies and monthly magazines have been circulated within and outside Mizoram. In 2001-02, there were fifty-eight approved newspapers according to Statistical Handbook 2002, Directorate of Economics and Statistics.

Many other newspapers and journals have come up since then. Amongst those, the ones that have contributed most to the development of Mizo literature are those of the old MZP Chanchinbu (a publication of Mizo Students Union), Meichher (a publication of Adult Education Wing) and Thu leh hla, a mouthpiece of the Mizo Academy of Letters.

Apart from the contributions of the church and other organizations, the first important individual work is the History of Mizos by the Pastor Liangkhaia, which he completed in 1926. It is a competition manuscript with which he won the first prize in the first-ever writing competition held in the land. The book was published in two volumes. The first part of Mizo Chanchin (Mizo History) was published in 1938 and the second part in 1947. Apart from this book, Liangkhaia had written and published over thirty books and also contributed over 100 articles to different journals before his death in 1979 . He has undoubtedly made great contribution in the field of sacred hymn, poetry and prose writing. In addition, he had translated twelve books 
of the English Bible into the Mizo language within two years (1947-49), as he was rightly engaged as the first full-time literature worker by the Presbyterian Church of Mizoram.

\section{Hymns/songs/poems and so forth}

With the coming of the gospel in the hills, the first two missionaries translated and re-composed a few Christian hymns/songs from 1894 onwards. With the help of the new converts, several hymns were translated by the missionaries one after another. Amongst them, the literary works of Zosapthara (Edwin Rowlands) was commendable for his tireless efforts for the preparations of school textbooks, Christian guidebooks and in the production of sacred hymns. He has almost 100 songs/poems to his credit.

Many composition of Christian literature appeared right from the turn of the twentieth century from the hands of early Christians and that of missionaries. When we look at it closely, Awithang-pa and Elder Thanga started composing poems and songs in the beginning of the twenty-first century, followed by the Liangkhaia. This trend was followed by hymn writers like L. Siamliana, R. L. Kamlala, Hrawva and Damhauhva.

Three poet-cum-songwriters, namely L. Biakliana, Kaphleia and Lalzuithanga, appeared in the scene in 1930s. They were all novelists as well. Laltanpuia, V. Hawla, Romani and others started composing songs in the 1930s. In the southern part of Mizoram, song writers like Lalmama, Liandala, Chhuana, Rokunga Khiangte, F. Rokima, Nuchhungi and others contributed a great deal. From 1940s, several poets, song writer, hymn writers like P. S. Chawngthu, Rokunga, L. Z. Sailo and others began their compositions. Literary compositions like poems that are not designed to be sung appeared rather late. K. C. Lalvunga, James Dokhuma, Lalthangfala Sailo, R. L. Thanmawia, Laltluangliana Khiangte, Lalzuahliana, Mafaa Hauhnar and many others contributed in the enrichment of Mizo secular poetry and devotional songs.

\section{Novel/short story/novelette and so forth}

A study of the contemporary Mizo literature reveals considerable maturity and depth from 1930s onwards as poets and writers have been producing works of lasting value on secular subjects. The first Mizo novel, Hawilopari, was written by L. Biakliana (1918-41) and appeared in the year 1936. The same novelist wrote a short story called Lali in 1937. The third Mizo novel, Chhingpuii, a romantic 
tragedy, was written by Kaphleia in 1939. The two pioneer novelists L. Biakliana and Kaphleia wrote and circulated weekly news namely Chhura Chanchin while suffering as tuberculosis patients in Durtlang Hospital. Chronologically speaking, these three novels were the only novels written before 1940 .

Then, the ghostly fictions, Thlabrang and Phira leb Ngurthanpari were written by Lalzuithanga, son of Chawnghnuaia. He was a romantic tragedian born on 16 April 1916 and died on 28 September 1950. Lalzuithanga also wrote a number of other short stories, namely, Aukhawk Lasi, Khawfing Chat, Eng dan nge ni, Eng nge Pawi? These were already printed in a book form.

C. Khuma (Challiankhuma), an army officer serving in Burma, wrote the tragic love story called Maymyo Sanapui in 1946. It was published by the Burma Lushai Association in 1950. This tragedy was perhaps the first Mizo fiction ever printed and published outside Mizoram. The author has also written other short stories like Hmangaih thiamna, Fahrah nun, Phu loh Zunleng and Chbingkhual Lungdi.

One of the most popular novels, Thla hleinga Zan, was written by James Dokhuma. He has written a number of fictions, namely Good Bye Lushai Brigade, Rinawmin, Irrawaday Luikamah, Tumpangchal nge Saithangpuii, Hmangaihna Thuchah, Kymoto Synora, Silaimu ngaihawm and other books. In 1977, Khawlkungi wrote the Christian love story called Zawlpala Thlan tlang, winning a story-writing competition organized by Central Kristian Thalai Pawl. She also wrote a number of other stories like A Tlai lutuk ta, Sangi Rinawmna, Fabrah Nun, Pasal Dubthlan and so on, and she happened to be a playwright as well.

An Indian foreign service officer and a former Indian ambassador, K. C. Lalvunga, also known as Zikpuii-pa, wrote novels like C.C. Coy No. 27, Silvarthangi, Hostel Awmtu, Kraws bulah chuan and Nunna Kawng Thuampuiah. Zikpuii-pa was also a well-known essayist and poet.

A number of fictional works appeared in the 1980s and 1990s. Lalengmawia Ralte wrote about seven fictions and C. Laizawna also wrote more than ten novels. Other novelists like Lalhriata (Khualzin Nula), H. Lallungmuana (Ram leb I tan chauh and Hmangaih Zoramthangi) and C. Remtluanga (Fate Nu Atan, etc.), Khawlkungi (Zawlpala thlan tlang etc.), L. Z. Sailo (Winner of Book of the Year award, Runlum Nuthai and others), Lalhmingliana Saiawi (Lungrang Laiawrha etc.), H. Lalngurliani (Winner of Book of the Year award) and many others made valuable contributions to Mizo literature. There are as many as 500 (approx.) novels and short stories that have been preserved in printed form till today. 


\section{Drama/short play/morality plays and so forth}

The root of the Mizo drama began with the celebration of the grandest Christian festival in the land, that is Christmas. The missionaries and a few native speakers celebrated Christmas Day in 1903 by entertaining children and giving them a special feast. It later turned out to be a yearly activity. In 1912, Christmas Day was celebrated in most of the villages with a grand feast. That Christmas Day will be remembered in the history of Mizo drama, because in the evening of this very day, the first-ever dramatic performance was held in the small thatched-roofed theatre of Thakthing Veng. With the initiative of the missionaries, the most successful function of variety show was conducted for the first time.

The first Mizo dramatic performances had strong moral content. The effect of the religious teaching was great. It closed the early Christmas entertainments in the Church. The immediate result was the emergence of secular drama. About this time, Ch. Pasena (18931961), who had a diploma in education from London, came back to Aizawl in 1925. In those days, the people were strongly attracted to the Puja variety show of Bengali babus at Babutlang (officer's complex) and the Nataak (live performance) of 1st Assam Rifles Regiment at Drill Shed in Aizawl. The time was ripe for theatrical revival, which had faded as a result of spiritual awakening. Pasena came forward to stir up the latent dramatic instinct of the people. His participation in the dramatic art suited the time, for he was a free mixer with all sorts of people. Pasena was trusted by the natives; also an advantage for foreigners who come to Mizoram. Between 1925 and 1933, Pasena prepared and directed six extempore dramatic performances, which were staged in Sikulpui Hall, the popular name for Boys' Middle English School at Mission Veng, Aizawl. All these dramas were enacted not only for entertainment but also for moral lessons. His first dramatic show, Heroda Chawimawina (King Herod's Glory), a tragedy, was staged in 1925 at Sikulpui Hall by the actors of Mission Veng.

There were several other dramatists like Lalkailuia, Chawngzika, Lalzuithanga, Lalmama, L. Biakliana and Lalhmuaka who made good contribution to the development of Mizo drama. The flowering period arrived with the publication of Sangi Inleng by Lalthangfala Sailo (b. 1933) in the early part of 1960s. L. F. Sailo has written and published almost ten plays, some of which has been prescribed as texts in the school and degree level courses. A recipient of Sangeet Natak Akademi Award 2007, Sailo made a good contribution to Mizo drama since 1959. 
The writer of this chapter (Laltluangliana Khiangte, an Awardee of Padma Shri in Literature in 2006) may be considered as one of the major playwrights who made contributions for the development of Mizo drama in a variety of ways. As a playwright, he has written more than thirty plays, of which seventeen are published in different volumes. His first play, Thupha ka rawn chawie (1982) was written and staged in Shillong. Out of his seventeen plays published so far, Pasaltha Khuangchera (a collection of three plays) has been awarded the Book of the Year 1997, that is the book was chosen as the best out of 115 books newly published in 1997. His other play, Lalnu Ropuiliani has won the first prize in the state-level drama writing competition in 1990, organized by the Art \& Culture Department, Government of Mizoram. One of his plays, Chanchintha Meichher (1993) was used as an official script of drama that had been staged in every village of Mizoram as one item of celebration in the Gospel Centenary in 1994. Some of his plays have been translated and acted in Hindi and broadcasted in Delhi Doordarshan and other channels. He has also been awarded the Distinguished Playwright Award, Rastriya Lok Bhasha Samman and Bharat Adivasi Samman for his valuable contributions, especially in the field of drama.

There are several other playwrights who had contributed a great deal to the field. Playwrights like Lalhmuaka (1915-2001), H. Lalsiama (1909-83), Khawlkungi (b. 1927), James Dokhuma (19322007), K. Saibela (b. 1936), Liansailova (b. 1949), Lalsangzuala (b. 1951), H.K.R. Lalbiakliana, C. Laizawna and some younger dramatists made commendable contributions to the development of Mizo drama. According to my record, by the end of the twentieth century and the close of the second millennium, over 150 plays have been published in the Mizo language. So, there is a good scope of research in the field of drama, an opportunity to improve and enrich Mizo literature through making use of various dramatic performances.

\section{Essay/articles/critical writings/research works and so forth}

If we turn our attention to other prose writings, like essays, critical and research works, the contribution of essayists like Kaphleia, C. Thuamluaia, Zikpuii-pa, J. Malsawma, Siamkima Khawlhring, James Dokhuma, Dengchhuana, Darchhawna, Laltluangliana Khiangte and so forth may be considered for critical examination. Then comes critical writing in the form of book review and literary criticism. Research scholars of Mizo language and literature have now explored the wide 
ranges and prospects of research field for younger research scholars, students and outside investigators. Mizo scholars, writers and journalists are continuously publishing essays and articles in various journals and books. It will not be inappropriate to conclude that the Mizo prose work is increasing in a large scale through hundreds of newspapers, bulletins and magazines published fortnightly, monthly, biannually and annually. And the Mizos may possibly be considered to be one of the richest in having a variety of newspapers, journals and magazines viewed in proportion to the population of the region.

\section{Concluding note}

No sufficient justice can be done to describe the spurt of literature, which has come up in the recent years without a full-length study. Suffice it to say, that the literary award given to the Liangkhaia, the multifaceted prolific writer, by the Mizo Academy of Letters in 1979, and Padma Shri Award to James Dokhuma on literature (1985) by the president of India, confirms that, given the opportunity and necessary patronage, the door is open now for massive development of Mizo literature. At present, as many as ten writers (James Dokhuma 1985, Nuchhungi 1986, Khawlkungi 1987, R. K. Lalhluna 1989, R. Vanlawma 1998, Lalsangzuali Sailo 1998, P. S. Chawngthu 1999, Darchhawna 2005, Laltluangliana Khiangte 2006, L. Z. Sailo 2007) bagged the Padma Award in literature, and eight writers (Liangkhaia 1979, James Dokhuma 1985, P. S. Chawngthu 1992, K. C. Lalvunga 1995, Khawlkungi 1998, J. Malsawma 2001, Darchhawna 2004, B. Lalthangliana 2007) have been awarded the Academy Award in literature, and this may be considered as the highest state award in the field of language and literature.

The greatest impediment to the growth of Mizo literature is lack of fund for printing of books in a large scale. In the small community of the Mizos, the number of books that can be sold is very small. Publication of a literary work, unless it happens to be a text book or supported by the government or church body, is a losing proposition which no individual writer can afford. There is, at the moment a great interest in the development of literature, which is evident from the number of manuscripts and cyclostyled copies lying with individual writers. If only there could be an agency of the government that could assist in the publication of works of literary value, it would be a monumental contribution for the growth of Mizo literature and the society. The Mizoram Publication Board Bill, 1993, has been quite effective ensuring the publication of more than 200 new books with 75 per cent assistance given by the board. 


\section{Laltluangliana Khiangte}

In spite of all these problems, the Mizo Academy of Letters, knowing the increasing number of published works in various genres of literature, started selecting 'The Book of the Year' since 1989. The best book in Mizo language and literature was awarded Book of the Year Award, a small cash incentive and a citation of honour. It is clear from the record that the Mizo literature has been greatly developed and a large number of books (100 to 200) are published every year. Today, the Mizos have a good number of poems, plays, essays, novels, articles, critical reviews and other prose works which are to be translated into different languages of the world and to be circulated outside the state of Mizoram.

\section{Note}

1 This chapter was first published in Eastern Quarterly, 5(1): 24-33, 2008.

\section{References}

Grierson, G. A. 1930. Linguistic Survey of India, Vol. 3, Parts 1, 2 and 3. Calcutta: Office of the Superintendent of the Government Printing, India. Also glossary and books on Mizo history, culture, and other materials \& unpublished manuscripts of L.T.L. Library \& Archives, B-43, Mission Veng, Aizawl, Mizoram.

Hminga, C. L. 1987. The Life and Witness of the Churches in Mizoram. Lunglei: The Literature Committee, Baptist Church of Mizoram.

Khiangte, Laltluangliana. 1993a. Lehkhabu Ramtiam. Aizawl: L.T.L. Publications. Khiangte, Laltluangliana. 1993b. Mizo Drama: Origin, Development \& Themes. New Delhi: Cosmo Publications.

Khiangte, Laltluangliana. 1995. Thublaril: Literary Trends \& History of Mizo Literature. Aizawl.

Khiangte, Laltluangliana. 1996/2007. Biakliana Robawm. Aizawl: L.T.L. Publications.

Khiangte, Laltluangliana. 2002. Mizo Songs and Folk Tales. New Delhi: Sahitya Akademi.

Liangkhaia. 1948. 'Origin of the Mizo', in Mizo Chanchin, Part - I. Aizawl: Zoram Printing Press.

Lorrain, James Herbert. 1983. 'Introduction', in Dictionary of the Lushai (Language). Calcutta: The Asiatic Society.

Thanmawia, R. L. 1998. Mizo Poetry. Aizawl: Din Din Heaven Publication. Tlanghmingthanga. 1994. Zorimawi-Music: Ministry of the Mizos. Aizawl: L.T.L. Publications. 


\section{Differing resistances}

\section{Mediating the Naga struggle in Easterine Iralu's A Terrible Matriarchy and Temsula Ao's These Hills Called Home ${ }^{1}$}

\section{Ashley Tellis}

Why should literature have anything to do with conflict? Isn't literature a safe haven outside of conflict, a space where we experience aesthetic pleasure and to which we take recourse precisely not to have to deal with the conflicts of our day-to-day lives? These are the sort of questions that face the literary critic (and indeed the literary writer) when she wishes to negotiate political conflict in her writing. The questions are, of course, premised upon a certain conception of the literary and a certain theory of the aesthetic. Those are not the premises of this investigation. It is my firm belief that the literary often helps in understanding the question of conflict - its impasses and its possibilities - much better than most other modes of articulation.

In being singular and unverifiable ${ }^{2}$ in the way in which sociological or historical data is not, it takes a leap of faith to enter the world of the literary, one has to surrender oneself to the written word and one emerges with a sense of what causes conflict and how conflict is experienced and resolved or not resolved with a perspective that political and historical analysis rarely offers. Literature offers us access to the psyche often simply denied in the straitjacketed world of social and political analysis. As Jacqueline Rose puts it in the preface to her extraordinary collection of literary essays, The Last Resistance (Rose 2007: xi):

The other is literature whose power to subvert the status quo receives new urgency when the dominant clichés and deceptions of statehood, whether here and in the US or in Israel, have reached new and mind-numbing heights.

Rose's 'here' is the UK, but it could well apply to India whose deceptions of statehood are nowhere more obvious than in the 'Northeast'. 3 


\section{Ashley Tellis}

Further, her first (of which literature is the other) term is psychoanalysis with 'its ability to uncover truths that would remain hidden, and to unsettle the most rigid forms of identity as they play themselves out across the stage of political life' (Rose 2007: xi). Through looking at two fictional texts by Naga writers Temsula Ao and Easterine Iralu, I want to see the roles that literature plays in mediating the conflict in Nagaland, keeping in mind the de-romanticization of literature that Rose effects through psychoanalysis.

Literature may be resistant, but it is not normatively so. It could well be resistant in the psychoanalytic sense, which Rose describes as: 'For Freud [...] resistance was a psychic reality that blocked the passage of the psyche into freedom. One of the mind's best defences, it cuts subjects off from the pain and mess of the inner life' (Rose 2007: 5). Not all literature is subversive, then, and Easterine Iralu's A Terrible Matriarchy is an example of that. Even though its ostensible object across 314 pages is the inner world of its central protagonist, Dielieno, it is an inner world that shows an unrelenting resistance to the 'pain and mess' of the political realities in which it inheres. This is effected through a curious gendering of the text. The text is saturated in a women's world, where the protagonist is trapped; the Naga political world is almost completely denied entry through the dense gendering of its world. All the violence of the context is displaced onto the violence of a dominating matriarchal figure in the form of the grandmother, with whom young Dielieno is sent to live, and this is the only violence that the adult Dielieno also reads.

The temptation to read this resistance to the political violence of the outside as an act of subversion of the male world of politics on the part of a female author is untenable given the loving and complex detail in which each male character is etched and the few moments when the Naga political world is allowed to seep into the narrative. By contrast, the few moments when the women characters are given complexity are devoid of any compassion. Thus the resistance is not just a blocking of the pain of the public violence of the Naga context; it is also a resistance to an exploration of the private pain wreaked upon the protagonist in the context of the family. In both spaces, men are let off the hook and women are held responsible. Iralu not only resists engaging with the Naga political text, she also resists an engagement with Naga patriarchy.

The private, familial world in A Terrible Matriarchy is full of soothing men and menacing or menaced women (the few menacing men are aberrations who need to be domesticated); the political world is full of brutalized men and uncomprehending women, traumatized by 
their incomprehension and incapable of any political analysis of it, let alone a sense that their trauma is being caused by the brutalized men displacing anger at the Indian state or at Naga hierarchy upon them; unable also to see how they inflict violence upon each other based on age and access to power, let alone be capable of forging any sense of solidarity with each other. Resistance in Iralu's text, far from being subversive, shores up the Indian state and buttresses patriarchy.

The novel is built by a slow process of accruing detail. We follow the vision of a young girl left at her grandmother's by her parents who documents in painstaking detail the oppressive regime of this brutal woman and the minutiae of day-to-day life at home, school and home again. The tediousness of this life is matched only by the excruciatingly descriptive prose which is remarkably literalist and invariant, and, consequently, serves no purpose apart from ethnographically fleshing out a certain exotic context for the reader. ${ }^{5}$ The political world outside enters A Terrible Matriarchy only as late as page 173 and leaves just as suddenly. Reference is made to recruits to the Naga army and their arrest and torture at the hands of the Indian army. The fear on the part of the father and the elder, more responsible brother, Leto, is that Vini, Dielieno's tempestuous and alcoholic brother, has been one of the boys involved. Dielieno, the narrative protagonist claims that she

knew what they were talking about. It was the new recruits in the Naga Army who had been captured. The boys in our class would talk about it endlessly, saying they would join up when they were old enough. There were boys as young as seventeen in the Naga Army.

(atm 173)

Reference is then made to Vechoi, a Chokri Naga from Phek town, whose father had been killed by the Indian army, whose village had been attacked by the Indian army, the men killed, the women raped to teach the Nagas a lesson. Dieleno adds: 'Bulie and I made a pact to join the Naga army when we grew up and vowed to avenge Vechoi's father' (atm 174-75). Bulie is Dielieno's other brother who is portrayed as mentally somewhat slow, firmly located in his body, strong of body and good with his hands. Nowhere is he endowed with any politics except in this adolescent moment. This is exactly the case with Dielieno as well. She has not talked about politics at all in the preceding 172 pages and will not do so again. Further, Leto is contrasted with Vini, as the responsible brother, seeking government employment, avoid alcohol and bad company (read militant company) and leads a stable domestic 


\section{Ashley Tellis}

life, unlike Vini, who dies brutally of his alcoholism, repentant and remorseful. Also, the stress on the youth of the Naga Army recruits (Army moves from being capitalized to having a small 'a') suggests that it is a foolish, headstrong enterprise, that these are misguided, testosterone-ridden, rebellious youth.

The only other moment when the Naga political context enters the scene is the bitter moment of confrontation between the good and bad brother before the bad brother dies. Vini explodes in a sudden burst of politically articulate rage:

Do you know how frustrating it is to be a Naga and live with the fear of being shot all the time? Do you know what it does to your insides when you hear about the people being tortured and killed by the army and you can't do anything about it? And then, along comes this smart alec who thinks it is alright to stop fighting for freedom, to stop being men and be sitting at an office desk, having sold your identity away for a bundle of money. You didn't know that Rocky's father was killed by the Indian army, did you?

(atm 247)

Though Vini is ostensibly speaking about Naga politicians who have sold out this indictment could just as easily be of his brother who has a desk job and has become a stooge of the Indian government. Masculinity is invoked and again the implication is that Leto is impotent and has forgotten what it is to be a Naga man. Vini goes on to explain that he drinks because of this bottled political rage in him:

I didn't start out drinking because of that reason but now that I have been drinking for some years, I feel the futility of stopping because things are going from bad to worse. Leto, haven't you heard that they killed Lato's mother? Put a gun into her mouth and shot her dead after they had raped her. Do you know that when Lato went to avenge his mother they beat him until he was half-dead and then they released him? And no one could do anything to help him, certainly not the government. Tell me, Leto, what is the use of trying to live life well?

(atm 247)

Leto has no answer but to invoke God and peace and Vini's privatized world of wife and child as antidote to this political impasse and as reason to live a reasonable life. Vini soon dies of his alcoholism, Christian and repentant, so the implicit argument is that the political rebel in 
Nagaland is the mindless alcoholic, whose thwarted masculinity leads to violence on women and children, even though the alcoholism is precisely because he can do nothing to the violences visited upon women and children by the Indian army that he as a Naga man cannot tolerate. He is opposed to men (like Leto) who have been domesticated and schooled into Indian citizenship and nationality, into proper, Christian manhood which is not violent but paternalist and protective to women and passive and hopeful in prayer in their relationship to the Indian state, which is not a relation of confrontation.

These are the only two moments ${ }^{6}$ that rupture the seamless narrative of female oppression at the hands of the grandmother, which continues even after her death in the form of hauntings, the gossipy women on whom the novel ends, who are shunned in favour of the good women who marry, reproduce, stand by their husbands, no matter what, and never gossip. Bad femininity is gossipy (the village gossips, the prostitutes) and oppressive (the grandmother) and good femininity is passive, silently suffering and bearing oppression with Christian stoicism and even compassion (the mother, Bano, Dielieno, Nisano, Vimenuo).

Iralu's infantilizing of the Naga political struggle and her subsumption of Naga political anger into a larger domesticating discourse of Christianity, family values and government job security is paralleled by her upholding of male values and female subservience. At no point does she allow her female protagonist to seriously question Naga patriarchy, try to understand why and how the grandmother's oppression can be seen as her attempt to have some power in patriarchy, to wonder why the mother is so invested in her sons and is almost entirely uncaring about her daughter, to reflect upon the biases in the treatment of the prostitutes and the village gossips or indeed to have any political opinion, or ambition of any kind, outside of relational positions in the family or community bound by kinship and religion.

By contrast, Ao locates all her stories in These Hills Called Home: Stories from a War Zone very clearly in the early part of the Naga movement and reads roughly the same period quite differently. However, this does not mean that her mode is politically obvious in any way. Despite the combative subtitle to the book, she states in her Introduction, entitled 'Lest We Forget', that she does not see the stories as being about 'historical facts' or justice or justification but opts instead for a universalizing 'We all suffer in conflict' and 'There are no winners' mode. ${ }^{7}$ She appears to posit the Naga as traditional, placid and rural and the conflict with the Indian state involving the Nagas having disabled themselves and damaged their psyches. 


\section{Ashley Tellis}

Nevertheless, the stories themselves can be read as militating against this framework and offering a stringent political critique not just of the Indian state, and specifically the Indian army, but also of Naga patriarchy. Sanjay Barbora, in an otherwise laudatory review of the book, points to a problem he perceives at the heart of Ao's fiction when he writes that the timelessness and the lack of particularity in the stories give them a universality that is: 'both liberating and (somewhat unfortunately) subject to self-censorship. The vague references to political positions and positioning of people as victims of circumstances beyond their comprehension are somewhat misleading'. As a result, Barbora adds 'one is left with a nagging doubt that one half of the story is missing' (Barbora 2006).

Yet it is my contention that not all Ao's characters are victims, if any of them are victims at all. Indeed, many of them are subversive in remarkable ways - fooling the Indian state by disguising militants, singing even as she is brutally raped by the army, living courageously with babies out of wedlock - and almost all of them resist the Indian state.

Further, Ao's own characterization of her fiction and the opaque and departicularized surface of her writing notwithstanding, it is possible, I contend, to read the opacity as containing a reservoir of sublimated anger that is, precisely through its particular fictionality, very politically productive and her departicularization in terms of ethnic and political as a poetics that not only resists the ethnicizing impulses of the Indian state vis-à-vis Nagaland and the 'Northeast' as a whole but also allows for the articulation of a collective politics that offers a way out of the impasses and internecine battles of the current Naga political situation.

A detailed study of the modes of her writing - her creation of narrative suspense in each story, her articulation of internal difference through a subtle critique the logic of gender relations and of community, her use of figures and figurations of marginality, e.g. the mentally challenged, the illegitimate, the physically challenged - offer us a nuanced understanding of the processes by which politics is transmuted in art. Given space constraints, I will be able to look closely at only one story, though each of her stories offer multiple possibilities of resistance and critique in the subversive way that Rose signalled literature having the potential of earlier. All of Ao's stories are written from within psyches engaging with political violence of various kinds and while they also are in a literalist prose, they $\mathrm{do}^{8}$ not shy from exploring the constitutive contradictions of the human psyche. They disarmingly, almost imperceptibly, enter the layered nature of violence across 
the sites of family, community, state and nation and do not dwell on external description. They do not allow the reader the luxury of surveying a scene or painting a picture. Instead the bare prose draws the reader immediately into the vortex of what is usually a turbulent scene masked by the serenity of the prose. Both male and female characters are portrayed with a psychic depth through techniques that mask their own capacities and modes of reach. While in some stories, Ao gives in to the explicatory aside or the bald political statement or explanation, the stories work best when she simply tells the story and the subtlest, smallest detail takes on a metaphorical significance and resonance that overtakes the story or throws it into sharp relief.

In 'An Old Man Remembers', the protagonist Imtisashi, like many of the male protagonists in these stories, is scarred by physical and psychic wounds that will not go away. He was part of the Naga Underground Army in the 1950s along with his best mate Imlikokba, with whose death the story opens. He has a bad leg, suffers traumatic dreams from which he wakes screaming and he is cold and tired. A question from his grandson who has come over - 'Grandfather, is it true that you and grandfather Imli killed many people when you were in the jungle?' (THCH 92) triggers a long account of his time in the underground army because he comes to realize that he has to give this young boy a sense of his history and that 'the bad things' do not go away when one does not talk about them.

Two moments stand out in the story of Imli and Sashi for the way in which they infect the reading of the story and make it work at levels that are unimaginably more complex than political commentary. Both are moments from childhood. One is when he describes to his grandson how once, hiding, as children, they saw a naked woman, her breasts bouncing, the dark of her pubic region, in awestruck wonder, as she passed with a bunch of other women. The other is when they used the birdcalls to send messages to each other as children in the adult context of revealing themselves to the villagers and not being taken for the enemy and killed. They try and there is no sound returned to them. Then:

'I'll give it a last try', Imli said and taking a deep breath let out another whoop. The strength and tone of that sound was so deep that I thought his lungs had burst because he collapsed even as the last note left his body. I slipped to his side to see if he was all right and tried to raise him from the ground where he lay in a heap. Seconds after I reached him, there was an answering whoop followed by a long twittering echo. 
These two moments, the first one returns at the end of the story, say more than the grisly accounts of ambushes in the jungle. The old man cannot recall the incident of the naked woman as man-talk with his grandson; it is displaced, or so the narrator says, by another 'area of darkness' that he had always wished away. The shock of the sexual, the mystery and the wonderment of it actually resonates with the shock, mystery and wonderment of the jungle experience. The exchange of birdcalls in childhood eases into an adult political strategy that saves their lives. Narrating this history releases the monstrous protagonist from a sense of his own monstrosity into the placid relationship with the early morning landscape on which the story ends. The old man does not give his grandson any message or moral. This is what he tells his grandson:

I do not know if what I have just told you answers your question or makes you understand your reason for asking it. But there is nothing more I can add. You have to make what you can from what I have tried to tell you.

It is not an exorcising of the political so much as a coming to terms with it. Ao's protagonists have to live with their histories. Her violators are haunted by what they perpetrate; her victims become part of the legacy of the landscape. But whether violator or victim, no one is allowed to escape history. People are either compromised by it or refuse to compromise with it. It is clear where Ao's politics lies but it is not easy to describe her politics. Her own broadly humanist account of it fails in the face of the stories. What her stories enunciate, the quality of resistance they offer in the telling of the stories of a people who built their history out of suffering almost beyond endurance, is a resistance with no easy lessons to offer, no quick redemptions; hers is a literature with as many dark areas as there are areas of illumination, which is the stuff of our political engagement with the world.

\section{Notes}

1 This chapter was first published in Eastern Quarterly, 5(1): 34-42, 2008.

2 I borrow these terms from Gayatri Chakravorty Spivak, who, therefore, describes reading literature as 'suspending oneself into the text of the other' and 'striving for a response from the distant other, without guarantees'. See Spivak (2007: 23).

3 There is a growing body of very powerful work on this subject. See, for example, Sanjib Baruah, India Against Itself: Assam and the Politics of Nationality, New Delhi: Oxford University Press, 1999; also Sanjib Baruah, 
Durable Disorder: Understanding the Politics of Northeast India, New Delhi: Oxford University Press, 2005. I am aware that the term 'Northeast' is homogenizing and problematic, but I use it here as shorthand for the Indian state's attitude to all the states in the region.

4 Easterine Iralu, A Terrible Matriarchy. New Delhi: Zubaan, 2007. Henceforth, atm and all citations will be in-text ones.

5 Indeed there is much to be said for the way Iralu milks the Naga context for what clearly seems to be a foreign audience. Iralu is based in Norway; Zubaan speaks on the back page biography of her travelling widely and having 'spoken extensively on the idea of self-exile, on writing in another country, on Naga literature and on the conflict-torn state of Nagaland'. The politics of such a self-description (it is apparent Iralu endorses this writing of her self) begs several questions that are beyond the scope of this chapter. Suffice it to say that the "conflict-ridden state of Nagaland barely appears in the novel which is an entirely privatized world domesticities, alternately lovingly detailed and horrifyingly oppressive.

6 The only exception is when Dielieno's mother invokes her own memories, as a young woman, of the Japanese occupation of Nagaland but that episode is recounted quite differently through a gendered vision of human kindness from friends in adversity, a shocked response to the violence of war and the brutal surprise of a sexual advance made by a German spy thwarted by a yelping dog and child, 'magical and unreal' stories as Dielieno recalls them (atm, 184-87).

7 Temsula Ao, These Hills Called Home: Stories from a War Zone, New Delhi: Zubaan, 2006. Henceforth, THCH and all citations will be in-text ones.

8 In 'The Jungle Major', a Naga woman defends her husband who is part of the underground, covers up for him and saves his life, braving village ridicule (she is beautiful; he ugly) and suspicion and turns her apparent disadvantages into advantages; in 'Soaba', a woman and a mentally challenged figure bond in opposition to the deranged masculinity of a surrendered militant; in 'The Last Song', a woman continues to sing a hymn in her haunting voice even as she is being raped by army officials; in 'The Curfew Man', a man made to become a government informer loses both his legs but gains freedom from that treacherous role, aided by his hard-working and hard-nosed wife; 'The Night' and The 'Pot Maker' offer delicate but razor-sharp critiques of Naga patriarchy; 'Shadows' and 'A New Chapter' explore the psychic effects of treachery, violence, political compromise. Both men and women are portrayed with a keen sense of the faultlines of their subjectivities, all levels family, community, state, nation - are critiqued interrelationally and Ao somehow simultaneously manages to distance her narrative voice from any implication in the scene, presenting them as tableaux, almost as parables, in keeping with the oral, story-telling Ao Naga mode from which she borrows and which, as an academic, she has researched and written about.

\section{References}

Ao, Temsula. 2006. These Hills Called Home: Stories from a War Zone. New Delhi: Zubaan. 
342 Ashley Tellis

Barbora, Sanjay. 2006. 'Book Review: Reading Temsula Ao', The Morung Express, 12 September.

Baruah, Sanjib. 1999. India against Itself: Assam and the Politics of Nationality. New Delhi: Oxford University Press.

Baruah, Sanjib. 2005. Durable Disorder: Understanding the Politics of Northeast India. New Delhi: Oxford University Press.

Iralu, Easterine. 2007. A Terrible Matriarchy. New Delhi: Zubaan.

Rose, Jacqueline. 2007. 'Preface', in The Last Resistance. London: Verso.

Spivak, Gayatri Chakravorty. 2007. 'Righting Wrongs - 2002: Accessing Democracy among the Aboriginals', in Other Asias. London: Blackwell. 


\section{Part XI}

Women and gender 
$\because$ Taylor \& Francis

http://taylorandfrancis.com 


\title{
25 The politics of gendered resistance
}

\author{
Body and agency ${ }^{1}$
}

\author{
Sukalpa Bhattacharjee
}

Contemporary resistance movements in general and women's movements in particular unfold different modes of constructions of resistant subjectivities. Women as individuals in some cases and women as collectives constitute an alter/native 'multitude' which allows for 'the living alternative that grows within Empire' (Hardt and Negri 2000). Women as a socially and politically excluded group must rethink and reorder the patriarchal notions of femininity which justifies their exclusion and 'represent it in their own terms' (Deleuze 1994: 117). Social and political patriarchy creates a power structure that inflicts bio-power over disempowered gendered subjects. Therefore women must articulate their bio-politics by resisting social and political subversion and by seeking autonomy from it (Foucault 1998). Gendered selves and collectives are an extensionally determined form of subjectivity that assumes 'living flesh' (Hardt and Negri 2004: 100) as a necessary precondition for singularity of its lived body of difference. Reordering of the feminine as mentioned above happens through resistance to bio-political organization of relations of production that creates altered and transformed spaces of the new sovereign subjects of gendered identities. The differential relations of power through altered spaces of relations of production throws up gendered identities as an expanded form of social being that produces 'in excess of' (Hardt and Negri 2004: 192) every traditional political-economic measure of value. Negri suggested that gender as an element of the expanding sense of commons break the duality between 'private' and 'public' by creating 'communication' through its singularity of 'production of common'. This is how the resistance of the victims and the struggles that they undertake recast the notion of what is 'social' and what is 'political'. We can read into such political reordering of the feminine through a few gendered resistance movements in India's Northeast and the construction of their agency. 
But we also have to consider the methodological problem of constituting women as a category primarily because 'woman' is not a homogenous category. Besides, such a categorization and the discussion that emerges from such categories enters various levels of shifting contexts - 'starting from the widest conceptual level, through institutional level right down to the interpersonal one' (Moitra 2002). At the conceptual level one has to contest the hegemony of male reason, which resists subjective engagements with issues of individual experiences particularly of women. At the institutional level women are often constructed as subjects/objects/agents of investigation and research where there is a 'sifting of facts', 'manipulation of data' to construct a form of reality that will serve the object of getting somebody's story right. Again at the interpersonal level any discourse on women requires a structure of analysis 'the correct' position to which all other positions are required to converge. Such an exercise introduces the problem of agency as speaking about women is always a speaking to or speaking with on the one hand and speaking from or speaking for on the other. A distinguishing feature of speaking to is the prominence of the speaker while both speaker and listener enter into a shared language game ossifying language into meaning. Speaking with generates an anxiety of insufficient information both for the speaker and the listener. So there is an absence of authority as both acknowledge that the reality construed is only a partial one. It is in speaking from and speaking for women that one's intervention is complicated by one's own social and ideological position apart from the methodological risk of putting words into the mouth of one's respondents. A greater difficulty lies in relating the ideological to the experiential, i.e. of relating various symbolic constructs to the lives and actions of women. An intervention through an unstructured methodology (if binaries such as Male:Reason/Female:Unreason constitute the mainstream rationality paradigm) and weaving a history of the lives of women through scattered narratives have been conceived as a kind of disjunction in patriarchal politics and philosophy. Therefore speaking for women is also speaking from a woman's perspective which creates a subversion of the duality between male and female universes of discourse, deconstructing the duality with the goal of altering women's exclusion from paradigmatic male discourses of politics and philosophy.

Feminist thinkers like Hélène Cixous have offered alternatives of speaking and writing beyond male prescriptions. Writing as breaking silences and writing as inscription of the self constitutes both a writing on paper and writing on the body which Cixous has termed as 'Écriture féminine' (Cixous 1975). Such inscriptions inspire the idea of an/ 
other history and alternative democracy which could redeem women from the phallocratic descriptions of binaries of the male/female constitution. This idea of an alternative paradigm of writing oneself into the democratic space has been instrumental in constructing certain types of subjectivities in certain categories of women who either internalized the offered models by her male counterpart or celebrated a self-reflexivity, creating alternative mediums of expression. Judith Butler (1990) explains how femininity and masculinity become, broadly, bodily styles which our bodies incorporate to yield a gendered subjectivity. Butler's performative account of the female body in Gender Trouble in the 1990s has offered immense performative possibilities of the body. Following Butler, Elizabeth Grosz also insists on 'the irreducible specificity of women's bodies, the bodies of all women, independent of class, race and history' (Grosz 1994: 207). Contesting Lacan, Luce Irigaray challenges the notion of the female 'lack' and argues for the need to reconstruct an inter-connected imaginary and symbolic of the female body which is livable and positive for women (Irigaray 1985). Prior to the seventeenth century the dominant view of the body was homological; male body was described as perfect and complete and female body was interpreted as lack. Subsequently, the culture of the body was shaped by discourses of the medical body vis-à-vis the sociological construction of the gendered body. In the mid-twenties the medical body also got grafted into the realm of cultural representation and therefore the gendered body became a representational tool. The female body became a text for the articulation of patriarchal desires and politics.

The maintenance of patriarchal ideology in society and politics requires production of certain spaces as gendered spaces because space is an instrument of thought and action which enacts the struggle over power between genders (Gerard 2001). It is the politics of spatial distribution and usage that determines its power. The (under) representation of women's body and experiences in social, political and institutional spatial structures constitutes the basis for gendered exploitation and violence. The assignment of gendered spaces in society and politics is nuanced with meanings and ideologies, which also tend to shape and condition women's sense of her(self). It is therefore important to examine the ideological distribution of bodies in space and the metaphorical appropriation of the gendered body reflected in contemporary social and political discourses and counter-discourses. Gendered spaces are constructed through the operation of patriarchal ideologies in social and cultural realms and through state-sponsored political propaganda in art, public images and media. This is more 
poignant in situation of armed conflicts and draconian Acts. However, women have appropriated patriarchal ideologies by creating spaces of their own, within which they construct and negotiate their identities making gendered space a culturally and materially embedded repertoire of the appropriate gender roles that create frames. (Bazylevych 2010: 1). A gendered space is therefore the intersection of knowledge and action that is political, ideological and embedded in the existing mode of production (Lefebvre 1991; Gal and Kligman 2000). There is a 'discursive hypernormalization' from direct meaning of gender specific actions to the repetition of public discourse in everyday lives at work, on the street and in public places, of how everyday practices make stereotypical metaphors easily recognizable and hypernormalize them. Nation-states construct and use sets of images and practices to confirm their authority and legitimacy and issues of gendered identity and experience is caught at the critical nexus of these images, their representations and practices. (Yurchak 2008: 9-10). Echoing Foucault's idea of space as a tool for 'thought and action' Lefebvre argues that space is not only a 'means of production', but also 'a means of control' (1991: 10, 26). Lefebvre argues that space problematizes subversive knowledge and as an intersection of different agencies; 'it points up the antagonism between a knowledge which serves power and a form of knowing which refuses to acknowledge power' (1991: 10). Lefebvre differs with Foucault on the idea of power as embedded in force (bio-power), rather power for him is political in nature and spatial representation includes its representation of the political. Gendered space perceives gender as an ideology of what it means to be a man or a woman in a given society, institutionalized by the state; 'gender is socially and culturally produced ideas about male-female difference, power, and inequality that structure the reproduction of these differences in the institutionalized practices of society'. (Gal and Kligman 2000: 4). Edward Said (1994: 56) argues how notions of fixities constitute stereotypes which are imagined and carefully orchestrated. Homi Bhabha also considers 'fixity as the sign of cultural/historical/racial difference in the discourse of colonialism, which is a paradoxical mode of representation: it connotes rigidity and an unchanging order as well as disorder, degeneracy and daemonic repetition' (Bhabha 1994: 66). Gendered discourses as counter discourses interrogate male hegemony, overtly or covertly in everyday practices, together with iconic images and public discourses and seek to legitimize existing gendered spaces. They reinforce and reproduce the brackets within which women and men construct and contest their identities. Recent critical theories suggest the notion of sexual identity as the compulsory repetition of 
culturally prescribed codes or what Bourdieu (1993: 201-10) refers to as 'habitus', where to think, feel and act, one is conditioned and influenced by a defined set of images, languages and social practices and without questioning we embody these gendered actions as 'logic of practice'.

The assigned social and political positioning of women in the public discourses of Indian Nationalism and the demarcation of the 'home' and the 'world' for the female subject would elaborate this point. This assigned positioning of women in the visible and invisible spaces is also seen in armed conflict and Insurgency in Northeast India. Gender is culturally constructed to justify that men and women inhabit two worlds: one of projection that is artificial, abstract and male; the other is of protection that is sensual, informal and female. Our material, social and moral life also extends this justification to control and ghettoize female actions and experiences. The history of Western philosophy not only binarizes mind and body but also necessarily hierarchizes the two according to value. According to traditional Western philosophical discourses on dualisms, mind is superior to body and therefore men are associated with rational minds while women are associated with bodies. Patriarchal oppression is justified in connecting women much more closely to the body and, through this identification, restricting women's social and economic roles in biological terms (Grosz 1994: 14). It is therefore an imperative to see how women appropriate this notion and provide for an alternative discourse of the body, thereby grounding body as agency in libratory ethics and politics. One way to overcome the mind-body dualism is to construct a libratory theory of embodied subjectivity by combining Merleau-Ponty's and Foucault's ideas. Gendered focus on embodiment bases itself in Merleau-Ponty's phenomenology of lived experience as fundamentally embodied and in Foucault's analyses of bodies as thoroughly 'inscripted' and constructed by power relations. While there is a problem in coming to a common ground based on Merleau-Ponty's (1958) phenomenological approach and Foucault's poststructuralist position, one common ground is that both reject the Cartesian dualism. Merleau-Ponty's claim for an embodied subjectivity centres on the claim that there is an intentional subject with agency, a position which, according to some theorists is contrary to Foucault's account of discursively constituted bodies which lack both subjectivity and intentionality, and hence cannot possess agency. However, both of these positions are central to the notion of a self-reflexive embodied subjectivity which can appropriate oppression inherent in patriarchal ideology. It would be useful to theorize body as agency drawing on both 
Foucault's position (Foucault 1980), that power directly impacts bodies materially and Merleau-Ponty's notion that bodies are themselves subjects that can respond to and interact with their world (Crossley 1996). An examination of relationship between discourse and the 'subject' is one of the central problematique of these two positions. Is the subject simply an 'effect' of discourse or does the exclusion of the subject from discourse disclose the constitutive possibilities of agency?

Gendered interpretation of contemporary movements has shown that body has not only been a 'weapon of the weak' but a critical site for articulating resistance to oppressive structures. Contemporary discourses on the relationship between sexual violence and the political economy of war needs to be reconstructed on the basis of the politics of gendered distribution and exploitation of female bodies in space. Leatherman (2011: 41) posits the concept of a 'runaway norm' that permits the shattering of traditional limits on violence and the legitimizing of crossing of several types of limits with regard to 'the type of violence' and 'the intended targets of violence'. Hypermasculinity and warring masculinities create insecurities for women particularly in cases of physical dislocation. As Leatherman notes, 'the bodies of women, girls, and sometimes men may be the last lootable goods' (156). Dominance among competing hypermasculine groups need violence to be inscribed on women's body in one sense and gang rape is used as a form of male bonding in another sense. The ways in which female body is controlled and gendered is socially constructed. A sense of her female self is created in the interaction between signs/symbols, concepts and therefore oppressive patriarchal ideologies need to be destabilized and deconstructed in order to recreate an autonomous gendered space.

Feminist standpoint theories have tried to establish the relation between identity and experience but such an identity gets further problematized, as different subjects experience differently, particularly their bodily experience as conditioned by race, caste, culture and economic positions. Women also have to unlearn all the social strictures imposed on them and learn anew the method of being reflexively critical in order to re-define their own body. In doing so she learns to become a 'subject-self' whose knowledge of her body can be used as an instrument of protest, resistance and transformation. However, women's experiences as liberative resources can be constructed only from a critical feminist perspective that seeks liberation and transformation, with a proper appreciation for the multiple spaces/identities and intersections that women find ourselves in, without falling into the trap of gendered, 'feminine' stereotypes. As mentioned by Schüssler Fiorenza 
(2001), the female body bears the markers of her own community as well as the fears and suspicions against her community. Her given identity determines the parameters of her freedom and also makes her a target when the 'other' community wants to teach her community a lesson. In both instances the statements the body is used to make is not in the woman's control. Her body is used to make statements about her caste, class and communal honour. In cases of group clashes a woman's body becomes the site of contestation over honour and the inscription of power. For example, women victimized during Partition or in the Godhra Riots were targeted simply for carrying the marks of religious/communal identity on their bodies.

An engagement of such a kind with the lives and histories of women particularly of South Asian communities involves a multilayered inquiry and intervention because of the invisibility of women in dominant discourses of power and politics. This is also because of the absence of recorded histories on women. South Asian women have frequently been conceptualized in colonial, academic and post-colonial studies more as objects of description. This has led to a monolithic and pathological description of South Asian women particularly by Western academics. An increasing growth of texts that 'sought to give voice' to the South-Asian women reinforced the stereotypes of sati and other oriental images to feed the Western need to sympathize with 'these helpless creatures'. Therefore a balanced reading into the histories and lives of women as subjects of the South-Asian social and historical forces would have to take into account the interactions of capitalism, racism and patriarchy' (Puwar and Raghuram 2003), vis-à-vis an attention to the personal experiences of women as it was experienced by them. The interplay and contradiction between the images and the reality of gender identity in South Asia continues to raise concerns of representation. Further, in attempting a study of this kind specifically in the context of Northeast India one finds that in the contemporary scene, the gendered impacts of armed conflict and political violence has been ignored or generalized. Women in fact occupy a number of roles and create different fates for themselves, as conflict situation is also a site of potential change. An analysis of women's roles and the inclusion of women working in conflict situations reveal that women are not only fighters and/or victims, but also negotiators in post-conflict futures. A critical examination of women's participation in formal and informal peace-building activities shows that in most cases women are excluded from formal peace negotiations. Such high-level negotiations are identified as male domains (Gardam and Charlesworth 2000) which means that they also employ discourses and practices that are closer to men's 


\section{Sukalpa Bhattacharjee}

reality than to women's. Nevertheless, women are demonstrated to play an influential role through their work in grassroots organizations working for peace and reconciliation. From within these organizations, women constantly challenge the authorities and other members of society with demands for peace, non-discrimination, accountability, recognition of human rights and so forth. While always positioned on the margins, these organizations show their ability to mobilize large numbers of women, and to translate individual grievances into legitimate social concerns. Moreover, many of them play a significant role in building a new culture of peace at the local level by organizing peace education and community-based reconciliation and social reconstruction activities. It is a political imperative to note how women have appropriated conflict and violence from a marginalized position in the transitory phase of the nineteenth and twentieth centuries amidst social and political dislocations caused by Partition and the logic of statist violence legitimized by the post-colonial nation state. Political realism constructs a violent and anarchical picture of the Northeast India without taking into account the ways in which the non-state actors influence and are influenced in turn by those developments. Women not only experience the politics of 'betrayal and resistance' in such moments through direct acts of violence on them by the perpetrators but also play active roles in addressing such conflicts. We have several examples of the roles played by women in the conflict situation in India's Northeast. Many women's organizations of Northeast India like the Naga Mothers' Association and the Mizo Women's Federation have been on a collaborative project either with the state actors or the ones opposing it (Bhattacharjee 2002). These organizations along with the Meira Paibis of Manipur display a unique gesture of intervention where individual mothers address the community as social mothers thus enlarging the space of tradition-specific roles.

Now I will briefly dwell on narratives which represent the construction of resistant subjectivities and the enactment of resistance through (female) bodies. The first two cases are based on realistic political narratives of Manipur while the third captures a moment of the violence on the female body through a fictional narrative and how a woman uses her body as agency. The fictional here has been employed to link the symbolic with the imaginary. I would like to argue that women exhibit unique ways of constituting their subjectivities for speaking and writing themselves into existence, in appropriation to dominant discourses of power. Although it is the socio-cultural context which in large measure enables each person to reach an understanding/ perception/definition of herself, every person is reflexive and has the 
potential to modify definitions of herself given by the social context. Perhaps this is the nature of 'internal capabilities' (Nussbaum 2000: 84 ) which allow women to participate in the common good. The modification of perception about the self by the other is based on personal experiences if the latter is at variance with the socially given definitions; the subject may modify them and thus create a self-fashioned subjectivity. Subjectivity therefore constitutes a point of intersection, an area in which an individual's gendered performance is worked upon by the structures and categories of the outside world. This space of subjectivity is neither exclusively determined by forces and structures in the outside world, nor it is purely the product of a free, intentional rationality. This is perhaps how women and the subalterns have always been able to create a space of creativity even under the most oppressive and fascist structures, away from the gaze of the oppressors.

An unique agency of intervention can be seen in the Meira Peibis of the Manipur valley, known as torchbearers, who have a direct program of action on social issues like drugs and alcohol and these women as 'multitude' have changed the face of political protest by using their 'body as weapon' (Butalia 2004). The Manipur valley has turned into field of overt social and political struggle where women often have had to invent different ways of speaking for themselves. In speaking for themselves, women have made use of their body, their phanek (Manipuri traditional attire worn by women) and their whole being to stand as a distinct subjectivity of their own. Many of the observers recorded, how women hung phanek and stood beside it in order to protest killing of a pregnant women and an ex-activist called Sanjit. That the police often crossed the hanging line of Phanek in order to disperse protesting group of women brought out the livid picture of a desperately repressive state in Imphal West district in the month of July-August $2009 .^{2}$ The question that needs to be asked here is, why is it that women require to make themselves visible by way of articulating through body and its extended representational artefacts such as the phaneks? One possible answer to this question lies in the inseparability of body and subjectivity that finds an inevitable expression in any condition of repression, as an attempt to separate body and all its extensions into an act is to agree with the repressive state that it can separate women's body from their being. A statement such as 'naked body is the perfect icon of [...] political rightlessness' that links 'political vulnerability' and 'physical vulnerability' (Vajpeyi 2009: 40) is a 'horrific' (Asad 2007) response to situations of 'terror' by the state. Such an understanding forbears an elimination of women's subjectivity, as any act of protest involves an irony that turns annihilation of 
women's sense of being against itself. Protest, be it through nude representation of the body or be it a symbolic mode of representation of the self through the hanging of the phanek, evolves through a complicated act of immanent connection between body and being as well as a transcendent act of 'intruding' into the space of the aggressor, the violent State. One possibly needs to re-learn this new language of protest from the Manipuri Women's movement, as they bring alive the voice of the dead with the counter-production of women's essential being that symbolizes an affirmation of life over socially and politically determined decline of continuous existence as such (Adorno 1973: 370). Women's voice and the enactment of their protest in the public space constitutes an interconnection between the self and the Other, which is an inalienable ontology for women's subjectivity. This inalienable ontology presents itself through an enactive and performative agency that establishes the link between body and being in the lived experience of the body. Lived experience of the body is how the subjectivity of the body-subject constitutes her world. This is also a moment of transition from the gross experiential everyday to an autonomous assignment of meaning and subjectivity to one's public self. Such a transition is available in the course of women's movement in Manipur. The basic point is that the assumed dichotomy between the private/public, self/ other, proximate/distant is resolved in the 'work-like' actualization of 'performative agency' of the body of the women that contextualizes itself in developing a 'counter-concept of self' that takes performance at the limit of an action. This counter-concept is presented in the daring naked protest by 'Apunba Lup' before Kangla fort on 15 July 2004 against the Indian Army who violated the body and being of Manorama Devi and who executed the Armed Forces Special Power Act (AFSPA) in Manipur.

Another presentation of the counter-concept of self is written through her body by Irom Sharmila, the iron lady of Manipur. One can draw here a useful comparison between Sharmila's act of countering the repression of the state by trans-figuring herself in the domain of collective suffering and Apunba Lup's protest in the public domain. Sharmila's continued act of fasting and her being forced to eat through her nose by her captors projects the impossibility of living in Manipur, which is as good as being robbed of one's appetite and in a greater sense staying alive only in flesh and blood. Sharmila projects the state of being robbed of being in her continued 'staying alive' to express the phenomenon of socially determined decline of continuous existence. A distinction between the self that passively suffers to tell us story about the evil that rides over and a self that encounters 
suffering by overcoming consequences of suffering tells us a different story of suffering in me for the other. Sharmila's suffering is an act of becoming one with existence, as it goes beyond what suffering could inflict. Sharmila stays alive for in an enactive, receptive and performative mode that affirms a bodily presence more passive than experience in order to transform her suffering body into a body and being beyond the binaries of repression. This is a body that states, narrates and describes itself in which Sharmila's being can take part, a body that encounters every experience of repression beyond the concept of repression. Many still understand Sharmila's protest through fasting in an instrumental sense by calling 'body as a weapon' (Mehrotra 2009: 100), a deadly cliché that needs to be relinquished. Sharmila's fasting does not make us of body in an equipmental sense, it rather overcomes the 'repressive' binary between aggressor and victim by turning consequences of repression against itself. Body here plays a multidimensional role. By an apparent suffering of the body, Sharmila turns her bodily victimhood against the 'subjection' that suffering inflicts. She transcends 'suffering' by 'participating' in that subjected body, which now not only is her but also has the affect of bearing the suffering of others. Her imprisoned, incarcerated and monitored body in the hospital-prison is a social body that now belongs to the domain of every other suffering self in which Sharmila can participate.

The moot problem in this debate about women's agency and subjection is the play between an open display of effects of power versus a strategy of transcendence from power. The play comes as an event in the subjection by centres of power. This difference is presented in the difference between Sharmila's act and the act of the women before Kangla Fort which are manifestations of two forms of subjectivities that women constitute with their bodies on the face of a coercive power structure.

It would be interesting to highlight the symbolic and political significance of the bodily resistance in the political narratives cited above, by making a comparative analysis with a real-life fictional narrative by Mahasweta Devi, set in the background of this naxal movement, which has been translated by Gayatri Chakravorty (2002). In 1967 in West Bengal there was a peasant rebellion in the northern part of West Bengal. Draupadi Mehjen and her husband Dulna Mehjen are part of this movement against corrupt landlords, police and army officials. The fact that Draupadi is called Dopdi, as she is a tribal woman who cannot pronounce her own Sanskrit name Draupadi, lends a subaltern perspective to her identity which could be further interpreted against the backdrop of 'resistance from below'. Dulna and Dopdi along with 
others in the movement are on the run from the army which is combing the area to arrest them for the murder of a landlord and for the burning of police stations. The army official tasked with apprehending them is called Senanayak and he has spent some years analysing the guerrilla warfare of this group that Dopdi belonged to and was plotting strategies to capture them. While on the run in the forest Dulna, Dopti's husband shot by the army is spotted drinking water from a river and so Senanayak leaves Dulna's corpse as bait to lure Dopdi. But Dopdi does not give in and she along with other fugitives are still on the run. However, Dopdi on her return to the forest camp from the town where she'd gone to collect information about the army activities from her informant, is trapped and captured by the army. She is taken to the army camp and questioned. When Senanayak's dinner time approaches he leaves after saying, 'Make her. Do the needful'.

Dopti does not know what has happened to her as she lost consciousness and when she regained her senses she felt her arms and legs tied to four posts. She looks down at bleeding body and understands that she has been 'made up' perfectly. She sees her breasts were bitten raw, the nipples torn as she tries to remember how many had 'made her' but only remembers that after counting seven rapists she had turned unconscious. Tears of shame and indignity trickle down her eyes as rape is not only a physical violence but a violation of human dignity and bodily integrity, which gives one a sense of being human. But it is not yet over and a guard jumps at her and the process of 'making her' starts over again. In the morning a guard asks her to wash up and go to Senanayak's tent and gives her a cloth to cover herself. She pushes away the water and tears the cloth. She goes out of the tent to meet Senanayak under whose order her body was spread-eagled all night. This is the moment of her resolution to appropriate notions of masculinity and the shame associated with female body. She refuses to enact the stereotypical feminine shame by covering her wounded body. She walks towards the Senanayak, naked in the bright sunlight with her head held high and stands before the Senanayak naked, her body matted with dry blood. She comes closer standing with hands on her hips. She laughs and says,

You asked them to make me, don't you want to see how they made me?' He asks, 'where are her clothes' and the guard answers 'Won't put them on sir'. Draupadi's black body comes even closer. She shakes with an indomitable laughter that he cannot understand. Her lips bleed as she laughs. She asks in a voice that is as terrifying and sharp, 'What is the use of clothes? You can strip me, 
but how can you clothe me again? Are you a man?' She spits a bloody gob at him and says, 'There isn't a man here that I should be ashamed. I will not let you put my cloth on me. What more can you do? Come on, 'kounter' me, come on, 'kounter' me. Draupadi pushes Senanayak with her two mangled breasts, and for the first time Senanayak is afraid to stand before an unarmed target, terribly afraid. Dopdi refuses to let her body be clothed again. She transforms the definition of a 'man' and masculinity. She asks, 'Are you a man? You can strip me but how can you clothe me again?'

This is the most powerful section of Mahasweta Devi's text as it projects the agency of the dispossessed in its most combative stance. Dopti in Devi's text, in many ways appears to be the forerunner of the 'Manorama Mothers' as they are popularly called all over the world, who also challenged masculine power by standing naked in broad daylight, in front of the Kangla Fort shouting -'Indian Army Rape Us'. This resonates Dopti's challenging voice - 'Are you a man? You can strip me but how can you clothe me again?' The Army had picked up Manorama and dumped her body in the dead of the night but the Manorama Mothers walked naked in broad daylight. Naked bodies that are supposed to be symbols of vulnerability - political and physical - are ironically reproduced by the Manorama Mothers' constituting an act of protest which creates its meaning through the irony it reproduces. The inherent connection between body and being coupled with the body 'intruding' into the space of the aggressor, make the Manipuri women's act a unique protest, performed by using the body as agency.

Sharmila's participation in her own act of turning suffering against itself can be contrasted with the naked protest of women on 15 July 2004. The protest brings into picture an Agambenian state of 'suspension of sovereignty' (Agamben 2005). The enactment of AFSPA in Manipur and its subjection of female bodies are brought in the 'open' by the unique and historic protest. When protestors bring posters such as 'Manipur under Siege' it not only speaks of suspension of every democratic political right, but it also means that the disused rights of people of Manipur is now in the 'open' in the Agambenian sense. Agamben defined 'open' in the sense of disconcealment of the acts of taking hostage, repression and subjection, which according to him is biopower in display. When such a disconcealment comes in the open, all its constituents such as body goes 'outside of being'. Women's protests in their naked body for the first time brings it in the open 
how statist violence has already subjected the body of the women in the state of Manipur. Biopower discloses itself in the open with all its subjected constituents, women's body being the signifier of such subjection. Women's protest before Kangla Fort is one form of recovery of the being in the subjected body, an affirmation of subjectivity against the repressive apparatus of the State.

Therefore, the incarcerated body of Sharmila has been simultaneously a site for writing her protest as well as it is a site for reaffirming an identity beyond the stereotypical construction of gender roles in society. The case of women protesting outside Kangla fort is inscribing/ writing resistance with/on the body and presenting it in the public domain, while in the case of Sharmila, the body is used for reversing such a process of inscription. Sharmila instead inscribes her act of resistance through fasting on the body of the state. Her defiance and resistance on the one hand makes a mockery of statist power, while on the other hand she poses a moral threat to the state putting her life at stake. In order to free her body and her being from the coercive rules of the state, she must make her incarcerated and suffering body a site of transcendence for her as well as for others.

\section{Notes}

1 This is a substantially revised version of the paper 'Gendered Constructions of Identity in Northeast India', Eastern Quarterly, 5(2\&3): 104-14, 2008.

2 'These clothes save our honour. But we are bringing them out to express our outrage at the endless fake encounter killings', Th. Anita, Convenor of the Khurai Joint Action Committee formed against the killing of Ch. Sanjit, said. This is reported in The Telegraph, Kolkata, 14 August 2009 in The Northeast Page by Khelen Thokchom.

\section{References}

Adorno, Theodor. 1973. Negative Dialectics, trans. E. B. Ashton. New York: Continuum.

Agamben, Georgio. 2005. The State of Exception. Chicago: University of Chicago Press.

Asad, Talal. 2007. 'Thinking about "Just War"', The Huffington Post, 17 July. Bazylevych, Maryna. 2010. 'Public Images, Political Art, and Gendered Spaces: Construction of Gendered Space in Socialist and Post-Socialist Ukraine', Journal of Contemporary Anthropology, 1(1).

Bhabha, Homi K. 1994. The Location of Culture. London: Routledge.

Bhattacharjee, Sukalpa. 2002. 'State, Insurgency and (Wo)man's Human Rights: Two Cases From North-East India', in R. Dhamala and S. Bhattacharjee (eds.), Human Rights and Insurgency: The NE India. New Delhi: Shipra Publications. 
Bourdieu, Pierre. 1993. 'The Historical Genesis of a Pure Aesthetic', in The Field of Cultural Production: Essays on Art \& Literature. Cambridge, MA: Polity Press.

Butalia, Urvashi. 2004. 'The Body as Weapon', China/View From the South, Issue 371, September.

Butler, Judith. 1990. Gender Trouble, Feminism and the Subversion of Identity. London: Routledge.

Cixous, Hélène. 1975. 'The Laugh of the Medusa', Signs, 1(4), trans. Keith Cohen and Paula Cohen (1976), 875-93.

Crossley, N. 1996. 'Body-Subject/Body-Power: Agency, Inscription and Control in Foucault and Merleau-Ponty', Body \& Society, 2(2).

Deleuze, G. 1994. Difference and Repetition. London: The Athlone Press.

Devi, Mahasweta. 2002. Breast Stories, trans. Gayatri Chakravorty Spivak. Calcutta: Seagull Books.

Fiorenza, Schüssler Elisabeth. 2001. Wisdom Ways. New York: Orbis Books.

Foucault, Michel, 1980. 'Body/Power', in C. Gordon (ed.), Michel Foucault: Power/Knowledge Selected Interviews and Other Writings (1972-1977). UK: The Harvester Press.

Gal, S. and G. Kligman. 2000. The Politics of Gender after Socialism. Princeton: Princeton University Press.

Gardam, J. and H. Charlesworth. 2000. 'Protection of Women in Armed Conflict', Human Rights Quarterly, 22(2000): 148-66.

Gerard, Rey A. Lico. 2001. 'Architecture and Sexuality: The Politics of Gendered Space', Humanities Diliman, 2(1), January-June.

Grosz, Elizabeth. 1994. Volatile Bodies: Toward a Corporeal Feminism. Bloomington: Indiana University Press; and Sydney: Allen and Unwin.

Hardt, Michael and Antonio Negri. 2000. Empire. Cambridge, MA: Harvard University Press.

Hardt, Michael and Antonio Negri. 2004. Multitude: War and Democracy in the Age of Empire. New York: The Penguin Press.

Irigaray, Luce. 1985. Speculum of the Other Women, trans. G. C. Gill. Ithaca: Cornell University Press.

Leatherman, Janie L. 2011. Sexual Violence and Armed Conflict. Malden, MA: Polity Press.

Lefebvre, Henri. 1991. The Production of Space. Oxford: Blackwell Press.

Mehrotra, Deepti Priya. 2009. Burning Bright: Irom Sharmila and the Struggle for Peace in Manipur. New Delhi: Penguin.

Merleau-Ponty, Maurice. 1958. Phenomenology of Perception, trans. Colin Smith. London and New York: Routledge.

Moitra, Shefali. 2002. Feminist Thought: Androcentrism, Communication and Objectivity. Kolkata: Jadavpur University, Centre of Advanced Study in Philosophy.

Nussbaum, Martha C. 2000. Women and Development: The Capabilities Approach. New Delhi: Kali for Women.

Puwar, Nirmal and Parvati Raghuram. 2003. '(Dis)locating South Asian Women in the Academy', in Nirmal Puwar and Parvati Raghuram (eds.), South Asian Women in the Diaspora. Oxford: Berg. 
Said, Edward W. 1994. Culture and Imperialism. New York: Alfred A. Knopf. Thokchom, Khelen. 2009. 'The Northeast Page', The Telegraph, Kolkata, 14 August.

Vajpeyi, Ananya. 2009. 'Resenting the Indian State: For a New Political Practice in the Northeast', in Sanjib Baruah (ed.), Beyond Counter-Insurgency: Breaking the Impasse in Northeast India. New Delhi: Oxford University Press.

Yurchak, Alexei. 2008. 'Postsocialist Studies, Cultures of Parody and American Stiob’, Anthropology News, 49(8). 


\title{
26 'We have got things to say' Beyond the nationalizing narrative of the Bodoland movement $^{1}$
}

\author{
Amrapali Basumatary
}

Like most of the sub-nationalist and ethnic revivalist movements, the Bodoland Movement has been associated with ideas of autonomy, liberation and revolution. Struggling to move beyond the historical experience of staying in the margins of the existing political and territorial structure of the state of Assam, the Bodos have sought to reconstruct their history and taken recourse to an organized, often armed assertion of themselves as a separate 'nation'.

The attempt, here, is to trace how a people's struggle for nationhood and autonomy, with its own mapping of demography and territory, assumes 'oneness' as an essence for its victory. It is imperative to look at the Bodoland process, which is based on the articulation of its own exclusive 'distinctness', and bears a complex relationship with all those unarticulated identities that are still on the edge of political visibility. Since any contested identity cannot emerge without suppressing its own internal voices, which are potentially different or often contradictory, for the 'sake' of its unity and strength as a monolithic politic community, Bodos cannot be different in this regard. However, without contesting the Bodo aspirations for a separate nationhood, it is worthwhile to look at and analyse the politics of their struggle in terms of how it categorizes and constructs the Bodo identity within the trajectory of imagining themselves as 'one people one nation'. Further, this article would also attempt to produce some of the 'suppressed', 'different' and 'ignored' voices which pose a challenge to the seemingly unified, coherent and singular voice of the Bodoland movement, through presentation of narratives from Bodo women, who were in the forefront of women's participation in the autonomy movement since the 1980s. The focus is limited largely to the period between 1986 and 1998.

The period from 1986 to 1998 , which spans the peak moment in the history of the Bodo people's struggle for nationhood and autonomy, 


\section{Amrapali Basumatary}

has been looked at more closely. This period becomes important in terms of the offensive strategies adopted by the dominant forces of the Bodoland movement, which also witnessed the occurrence of most violent events in the history of ethnic rivalry and nationality claims. It is interesting to identify the processes of writing and telling history of the movement, how the dominant voice attempts at distinguishing itself, in all glorificatory terms, as 'totally free' of gender-based violence, despite upholding patriarchal values of uniformity, suppression and silencing. The Bodo society is a fairly Hinduized and patriarchal one, even though its women enjoy a fairly equal share in property and have relative autonomy and freedom as compared to the non-tribal Hindu communities within the country. The high moral claims of the Bodoland movement needs to be questioned on the bases of the discrepancies arising out of its claims and actual politics that they did during the movement.

\section{Boro Haari, Geder Haari: A brief history of Bodoland movement}

The phrase 'Bodo Haari, Geder Haari', crudely translated, means 'Bodo people/race, great people/race'. 'Boro' is the popular term for Bodo and 'Haari' means race. It is a statement as well as a claim. The phrase connotes the Bodo people's claim as the 'original autochthones' of Assam, borrowed from the colonial body of knowledge production, and thereby the Master race, which has been thrown to the margins of history dominated by the "caste-Hindu Assamese'2 with its cunning and exclusive control over economy, administration and history. The Bodo people's claim of being the 'original autochthones' of Assam is largely based on the colonial historiography of the nineteenth and early twentieth centuries. Having no written histories of its own, it relied much on what the colonial administration, linguists, evangelists and anthropologists had written. This process of retrieval of a constructed history from the colonial body of knowledge also arises from the processes of delimitation by Assamese historiographies in the post-colonial era.

In the post-colonial Assam the history writings are largely focused on the composite 'we-ness' of Assamese identity, subsuming all the 'tribal' communities within the state of Assam. Thus, history of a composite Assam more often than not becomes the history of the mainstream Assamese society, that is, a non-tribal history. For instance, in the 1960s the Government of Assam initiated a voluminous project of recording the political history of colonial Assam, headed by none other than eminent historian like H. K. Barpujari, which resulted in the publication 
of The Political History of Assam in three volumes. ${ }^{3}$ Despite the Plain Tribal ${ }^{4}$ playing an important role in the political processes of Assam during the freedom movement, reference to political role of the Bodos is restricted to minimal three lines in the three volumes. Most of the writings on social and cultural history of Assam also merely reiterate what administrator-historian Edward Gait wrote about the Bodos in his A History of Assam published in 1905 (Barua 1969).

However, the modern Bodo people's dependence on colonial historiography is not uncritical one. The popular history-writing criticizes both colonial and post-colonial writings of 'consign[ing] the Bodos the past but not to history, they became the subject of anthropology but not history'. It is further claimed that 'subversion of Bodo history began with the Bodos themselves, they allowed others to give them names and divide and sub-divide them into different groups', and are compared to the Aborigines of Australia,

where Europeans constructed a clever history of the country by giving the impression to the world that the aborigines were mere artefacts of the human past. The Brahmans in Assam indulged in wholesale conversion of the Bodo rulers and then left nothing behind but little inscriptions on copperplates as if to facilitate future Aryan historians to practice a cult of forgetfulness and disremembering.

(Pegu 2004)

The Bodo community in the wake of experiencing the prolonged and historical domination in the hands of the caste-Hindu Assamese people raised the question of 'Bodos are not Assamese' (Baruah 1999) and challenged the Assamese chauvinism since the early phase of the second half of the twentieth century. Though the history of resistance goes back much before that period, ${ }^{5}$ it is imperative to place the Bodo issue in the context of post-colonial period when the problem of its identity vis-à-vis the claims of a composite we-ness of the Assamese becomes more prominently visible and oppressive. The processes of unequal terms of assimilation into the composite Assamese identity in the post-colonial era, of all the 'tribal' communities in Assam indiscriminately affecting these 'tribal' communities in every manner possible, led to the formation of an alternative imagination which would not only protect but also develop the aspirations and ethnic identity of these communities. With this broader imagination of a united 'tribal identity', the Plains Tribal Council of Assam (PTCA), a political party largely under the leadership of the Bodos, was formed in 1967, which 
asserted the constituent communities' aspiration for a separate 'homeland' called Udayachal, within the Indian Union, but separate from Assam, articulated in the nature of a union territory. The Bodos constituted the largest component of this visionary platform. But it was only in 1987, with the formation of All Bodo Students' Union (ABSU)-Bodo Peoples' Action Committee (BPAC) alliance, that the younger leaders of the community were able to mobilize a large mass of the Bodo people to push forward the struggle for an 'exclusivist' ${ }^{6}$ separate state for the Bodos, called the Bodoland, in the northern banks of the river Brahmaputra.

This shift in the Assam Plains Tribal politics witnessed the transformation of a composite tribal struggle to a Bodo-centric movement of identity assertion, wherein the ABSU and BPAC became the dominant voice of the Bodos as a separate nation, which ironically gets articulated on the lines of the All Assam Students' Union (AASU). This was also the time when the All Assam Tribal Women's Federation (AATWWF) was formed. Alongside these civil society groups and political bodies, this period also witnessed the formation of armed groups like the Bodoland Liberation Tiger (BLT) and National Democratic Front of Bodoland (NDFB) who were constantly at war with each other. The formation of the latter organizations created more feelings of resistance and antagonism as well as fear amongst the people, both Bodos and non-Bodos. Widespread killings, abduction and extortions marred the movement itself, thereby pushing it into the thresholds of stagnancy, counter-terrorism and militarization of the entire region for more than a decade.

\section{Producing the Bodo nation}

The Bodo struggle under the leadership of ABSU evoked a new era of making 'revolutionary' efforts of clearing the historical lag in terms of economic, political and social progress of the community. This historical effort consolidated into imagining the community as 'a nation', of which the young Bodo men and women would be the architects. There was large-scale awareness about the 'specialty' and the 'beauty' of the tribe's language, culture, tradition and history itself. ${ }^{7}$ The movement created a new vocabulary of articulating its sentiments and desires and thereby the roles that members of the community would play were more 'clearly' outlined. The entire mass of Bodo students and youth were called upon to participate and lead the struggle. The women were specially called upon to get out of their homes and join the struggle for nationhood. 
The timing of ABSU taking over the leadership of the Bodo movement from 1987 has complex relationships with the 'Assam agitation' led by the All Assam Students Union (AASU) demanding detection and eviction of foreigners from the state and a greater autonomy. The Bodo youth participated in this movement. After the singing of Assam Accord in 1985, they realized that the new government formed by Asom Gana Parishad (AGP) formed by the leadership of AASU was not much different from the earlier ones insofar as the Bodos were concerned. Amongst a list of ninety-two demands formed by the ABSU, three major political issues could be pointed out: (1) formation of a separate state named Bodoland on the north bank of the Brahmaputra, (2) establishment of autonomous district councils in the tribal dominant areas on the south bank of the Brahmaputra and (3) incorporation of the Bodo Kacharis of Karbi Anglong in the Sixth Schedule of the Indian Constitution (George 1994: 880). The Bodo movement under ABSU had witnessed the strategy of eviction and restriction against foreigners, which necessitated the sharpening of Bodo identity as well as a militant opposition against the 'other'.

The paradigmatic shift towards becoming 'modern' was necessitated by the Bodo historical experience of discrimination and marginalization in the hands of caste-Hindu Assamese society. The struggle armed itself with issues of development, enlightenment, empowerment and reformation in order to wriggle out of the historical stagnancy perpetrated through strategic alienation of the 'tribals' from every level of progress.

'Divide Assam Fifty Fifty' - the slogan that marked the crescendo of Bodo demand for a separate homeland - did not produce a direct violent confrontation with the dominant caste-Hindu Assamese. The movement's assertion of the Bodos being the original autochthones in the past legitimized the political claim to the territory in contemporary times. Whether the goals would be an independent sovereignty of the Bodos or an autonomous unit within the Indian Union, the demand for 'homeland' was the hallmark of the movement. The Bodoland movement based primarily on a feeling of victimhood and carried out through the articulation of being a 'master race', not being the only movement with a similar claim on the same land, came in collusion with other political movements. The politics of identity assertion, through the processes of a homogenizing community along with definite territorial claims resulted in violent confrontations with other groups having similar demands.

In the shared memory of the community, they have been subjected to unimaginable atrocities by police and para-military forces of the 
state, in their legitimate fight for reclaiming what is their birthright. The conflict and the consequent repression witnessed during the Bodo movement is precipitated by the relationship of the former with Assam and India and their political configuration. 'The increasingly violent politics of a Bodo homeland bring to sharp focus the contradictions at the heart of the projects surrounding nations, nationalities, and homelands. That the Assamese sub-national narrative should be so violent[ly] contested just as it challenges the pan-Indian narrative lends both political and theoretical poignancy to the Bodo case' (Baruah 1999: 174). From time to time, police and military forces have carried out a spree of raids and indulged in violence like lootings, physical torture, rapes and other forms of sexual violence easily meted out on the men and women of the community. This process strongly highlights the way in which the community becomes identified as a totalistic and monolithic category of insurgent elements. These designs of suppression orchestrated by the state power are easily recorded in the memories of the public. In the act of remembering and recollecting the history of the movement, these facts of armed repression accentuate the Bodo people's sense of collectiveness as a unified 'nation'.

\section{From thy ribs was I born?}

Nations are premised on the ideal unity between all its component members who are called upon to serve it. Nations provide 'identity' beyond the self, a sense of belongingness and connectedness (Eisenstein 2000). A conventionally patriarchal society, the Bodos in its struggle for political and economic autonomy, ascribe historically unprecedented importance to women as bearers and mothers of the community. Thereby women come to be actively visible in the process of nation making. The first organization of Bodo women, AATWWF, was formed in 1986, in the context of 'the injustice and human rights violation committed by the police force upon the Bodo women during the movement period' (ABSU 2001). The ABSU states that gender bias is not known in Bodo society and ascribes an international status by comparing the rise of the Bodo women in an organized form to the feminist movement in the world (ABSU 2001). ${ }^{8}$ What do women say?

The women's organisation was formed purely as a wing to provide moral support to the cause of Bodoland as desired by the ABSU. It was never designed to be an independent political body like the ABSU. ${ }^{9}$

In my experience as an active woman activist in the Bodoland Movement, I personally felt the lack of economic freedom of the 
Women's organisation ... it was difficult for us women to execute our work; it limited our mobility because they (ABSU) did not allow us to find our own resources. There can be no movement and mobility without money. In the peak period of the Movement we did not face any economic crisis, it was an easy situation. ${ }^{10}$

Since 1984, when I was still in B.A., I have been a volunteer and supporter of ABSU . . . U.N. Brahma explained to us about the need to sensitise women in every socio-economic and political spheres ... Sansuma issued a letter telling us to call people to construct a women's organisation. AATWWF was formally formed on 14th July 1986, in the meeting held in Debargaon Higher Secondary School. There we adopted the resolution to work on every front in the society except the political sphere. We were more concerned with issues of rape, police and army atrocities and other social evils like alcoholism. ABSU and AATWF were always closely knit, and Bodofa Upen is our maker; without him nothing would have been possible. ${ }^{11}$

The above extracts, taken from the narratives of three different Bodo women who were all activists and leaders of the women's organization during the peak of the movement in the 1980s and 1990s, complement each other as far as the genesis of the first Bodo Women's organization, namely, the AATWWF, is concerned. The role of this organization is largely defined - a supportive one and subordinate in status, analogous to the status of women in society in general. These voices oscillate between factual statement, frustration regarding lack of autonomy and celebration of their roles determined primarily by the men of the 'nation'. The role specified for the women and their organization reiterates the reality of existing nations as a male project; thus Bodo women also, like elsewhere in the world bearing histories of conflicts and wars involving ethnicities and nations, become spontaneous subjects of a nation which 'has largely been constructed as a heteromale project, and imagined as a brotherhood' (Anderson 1991). They are summoned and empowered willingly to bear the responsibility of the community's aspirations for freedom and autonomy.

Hailed as essential for the movement and progress of the society, the Bodo women were 'asked' to organize typically as gendered actors who would be

involved in creating awareness among the women. [we] mobilized the women into consciousness and trained them to retaliate and resist police atrocities during sudden raids. After much hard work and mass mobilization [we] got legal justice for the victims 
[state armed forces], though in some cases some of the criminals escaped ... [we] mobilized all our women to learn to ride bicycles. It started at a time when [we] were not able to use public conveyances. The police atrocities were very nasty. [We] taught the women to wear panties . . . an automatic environment of organized fight was built up. And [we] used to deal in secret works. [Our] training was not very technical. It was more in terms of creating awareness among the common people to be self sufficient. Women were trained to use first aid for wounded cadres of the ABSU and Volunteer Force and for victims of police atrocities. There was no such training before the Movement. ${ }^{12}$

In this reminiscent narrative, the women cadres of AATWWF and ABWWF (All Bodo Women's Welfare Federation) ${ }^{13}$ fulfilled those jobs which could not be done by men, since the men are largely relegated to underground and hiding from the state forces, leaving the women to manage the house and the society in their absence. Women thus adorned the role of protectors of men. The gendered process of nation making also empower the women of the community, often times creating a room for role reversals, women are temporarily masculinized as men are feminized by the forces they are fighting against.

There is one positive aspect of the Movement, despite the patriarchal structure that has largely defined the Movement. Bodo women were liberated, at large. It was the Movement which provided and opportunity and space to the women to get modernised and liberate themselves from their closed houses. Simple things like learning to wear underwear so that while running or fleeing in cases of confrontation with the police or paramilitary forces, they would not be exposed if they fell down; this allowed them to run faster and more confidently, thus not having to think about their modesty alongside concern for their lives and the cause. ${ }^{14}$

Women came out of their houses and homes. There was equality in terms of gender-wise division of work. We tried to rescue womenfolk from social hazards like the practice of women working as maids. We were into social reform and we tried to bring back the maids from their masters. We advised and tried to make our people more disciplined. We asked them to observe strict monogamy so that married women are not exploited, in that way we assured them security and their rights as women. ${ }^{15}$

My decision to join the Movement as an active member was met with disapproval from my family. My father slapped me ... 
they felt that I would bring shame to the family and they almost harassed me. But as I explained they understood and compromised. I felt a sense of liberation to make that decision and work for the nation ... . During these times, the standard of education developed; people were reading and studying; the number of graduates was huge. ${ }^{16}$

These women are simultaneously empowered and modernized as they rise to serve the nation, whereas paradoxically they conform to and reproduce the very elements which are the primary bases of their secondary status and subjugation in the society. At one level the nation demanded women's participation out of their homes and at another level, women were also left to fight with basic patriarchal values, starting from their homes. The young unmarried women who became full time activists had the added responsibility of maintaining moral discipline, sacrifice and sexual parsimony as demanded by the nation and prescribed by the men. The ABWWF served as the main agents of social control and reform, spearheading a rigid regime of dress codes for women, marriage and sexual conduct in the Bodo nation's attempt to sanitize its society.

The men had a clear policy of how they could bring brides from other clans, tribes and races because it would increase the size of our population. The women were not allowed to go out of the community in marriage. That was of course a very selfish point of view of the men, they should be equally loyal like us women. these restrictions were important only to the extent that these sustain us since we are just a growing race. ${ }^{17}$

As markers of nation, women lose their own identity and are reduced to the function of political signifiers because of, as termed by Judith Butler, their 'phantasmatic investment and phantasmatic promise' (Eisenstein 2000). During the peak period of the movement when all activism was directed towards fulfilment of the cause, women cadres did not particularly think that there was gender discrimination. However, in the post-movement phase, when these interviews were being conducted, retrospection unearthed grave contradictions and discontinuities in the way men ran the whole show.

In my experience as a cadre, I feel that it was easier to work in the early phases of the Movement as per the given social structure. When we started working, a sense of individuality arose in me. 
Today, in the context of larger politics, I feel a sense of discrimination against we women ... today they question our talent, our aptitude and we are never given priority ... We were guided by males, I realise, earlier also ... When the Movement is over and revolution has calmed down, the patriarchal notions of the men are exposed. We never realised it before. The Bodo leaders, after Upen Brahma, why have they not preferred women as leaders and shareholders of power? . . . Earlier also, in every AATWWF meeting, an ABSU member was always present. ABSU always had the final word. Even in formulating the new Constitution of the BTC, we had to fight for the equal share in designing it. ... They looked at us just as messengers and did not give us any cadre status. We agreed silently ... The men even used violent and biased language against some women who seemed to oppose or question their decisions. ${ }^{18}$

The speaker, unmarried woman who devoted her whole youth and life to the nation, through the prism of resentment, memory and individual understanding, provides a sharp critique of the movement. Despite its rhetoric of equality for all who partake in the 'national project', nation remains, like other feminized entities - emphatically, historically and globally - the property of men (Mayer 2000). Empowered and uncomfortable subjects of both patriarchy and thereby nation, these women's voices question, often indirectly, the very structure of patriarchy which define the nation, rendering hollow the rhetoric of equality and democracy, exposing the tall claim of internal unity amongst the aspiring population. Women are 'absented from the fraternity which is masculine' (Eisenstein 2000).

\section{Identity politics and violence: Silencing gender discourse}

The relationship between ethnic-based identity formation and territorial claims is almost gruesomely rendered simple through its deployment of gender by the logic of masculine aggression that operates within the nationalist ideology. The archetypal construction of 'a woman' is repeated again and again in this blatant play of ethnic rivalry. A woman's life and body is simultaneously marked with her identity of belonging to 'other' ethnic category as well as her non-identity as a woman, which legitimizes the logic of her being both raped and killed: 'How can one expect these boys to stay off from sexual violence in an opportune situation like that' ${ }^{19}$ is an implicit indication of sexual violence and rape of women as an aspect of the riots. In this situation, 
women of each community involved in the riots have experienced not only the fear of being killed and displaced, but also of being raped and sexually abused. Thus, their difference as women also marks their differences of experiences of fear and trauma perpetrated by men of the 'other' community.

The issue of suffering and displacement during the riots that affected thousands of people across both the communities stands as the starkest testimony of the Bodoland project and its politics. As Brahma, who witnessed the 1996 Bodo-Santhali riots ${ }^{20}$ recalls, 'Those days were so frightening. Why and how it happened does not make any sense'. ${ }^{21}$ Whether this woman fails to or ignores to establish a causal connection between the movement and the riots in her personal narrative, the gaps and silences in her narrative fills itself under the generalized description of 'bad time' that 'displaced' so many. Standing outside the structure of formal politics of the movement, with which she does not identify at all, she narrates how she and her villagers had experienced fear and apprehensions of termination of life during the riots. Her recollection of the riots occurs in terms of both 'the time' of and the 'incidents' that happened during the riots. With her narrative travelling in and out of objective and emotional recollections, her spontaneous perspective filtered with the passage of time, allows us to witness the riots from an alternative point of view. She remembers how the faces of 'those' boys frightened her as they came looking for a Santhali girl who lived in her neighbour's house: 'They all had red clothes tied around their forehead and they seethed to be in a state of mad fury and frenzy'. ${ }^{22}$ She had tried to misguide the boys as she sensed the ensuing danger. Her remembrance of this incident is interspersed with a strong sense of regret in not being able to finally save that 'lovely' girl from those boys who were inflicted with 'queer madness'. Despite the (girl's) landlady's pleading with the boys, they 'took' her away and was never heard of after that day. As she recalls, 'The girl had completely become a Bodo - in her language, her dress and her ways'. Yet they took the innocent girl away to be murdered, because she was a Santhali by birth, and violated because she was a woman.

In the riots, like any other instances of warfare or political terror, the instruments with which the body has been abused in order to violate, avenge and break the spirit of the other community has tended to be gender differentiated and, in the case of women, to be sexualized. Thus, rapes have always been part of the male war strategy: dominating, humiliating, conquering and destroying the 'other' and the hatred and violence are crystallized in rape. In contrast to these experiences of women in general, and as individuals, the dominant and the male 
narratives of the event is once again silent about the women of the 'other' as special targets of the violence. Both at the formal and the discursive level, men of Santhali and Adivasi ${ }^{23}$ communities have been vocal about how the Bodos have 'raped and killed' Santhali women: 'There have been ample instances of our women being violated and killed by the Bodos. I can even give you reports and data about it. You can also go through my newspaper cuttings' ${ }^{24}$ The Bodo dominant discourse uses the same terminology against their 'enemies'. But both the groups of men claim that men of their respective communities have never indulged in these crimes. The question then is - who committed these crimes? The answer will likely be a volley of mutual allegations rooted in the patriarchal narratives articulated by both the communities. On the other hand, the All Bodo Women's Welfare Federation $(A B W W F)$ is almost categorical about the riots being free of any sexualized violence: 'Nothing of that sort happened. Maybe, there were some stray instances, but we have not got any reports of any such violence. It was a tragic event in our history, through'. ${ }^{25}$

The commonplace accounts of men and women of both the communities are uniform to the extent of locating the beginnings of the riots: 'It all began with the murder of three women whose dead bodies were found in a rotten state in the forests near Satyapur'26 is the common sense embedded in the minds and memories of the people. The more marginalized men and women concern themselves with memories of fear and trauma inflicted upon them by the attackers. On a very experiential level, the displaced Santhali women are 'ignorant' and mostly maintain a distance from the necessity of analysing the cause and are generally seen as accepting of 'their' men's analysis and information; since for women, men remain the chief and mostly the only source of information about these 'political' events and processes.

In a more politically constructed narrative of the Adivasis, the riot discourse, while unable or strategically conscious of avoiding the personal narratives, show the necessity of bringing up issues of sexual exploitation perpetrated on their women. There is a felt need of politically remembering, telling and circulating 'facts' about these incidents with the 'Bodo' as 'other nation' emphasized. In his construction of a history of the Adivasis in the area, an Adivasi leader tells how 'cases like rapes and murders were numerous during the 1998 riots. Women and children were worst sufferers. Such violence is always part of the society. Further, some people have witnessed molestations and rapes. It was the season of cultivation and most of these crimes happened in the paddy fields. So they were less visible'. ${ }^{27}$ Apart from establishing women and children as chosen subjects of violence, his narrative is not 
different from what Bodo men and dominant Bodo discourse would say about the Adivasis. Where the credibility of some incidents is real, cannot be doubted, they are also embedded in the political scenario of the riots.

In the most direct way, the most ordinary voice of a most ordinary woman lays bare the problem of nation and masculine tendency of war-mongering. Women, embedded in their historical experience of male subjugation remain outside the fraternal order which fundamentally defines the nation as it exists today. Their location in patriarchy and nation necessarily make anti-national out of them, notwithstanding the problematic agency that women adopt to reinforce the heterosexual hierarchies in the making of a nation.

The situation was dire - BLT on one side and the military on the other. Both ways, the sense of 'here they come again' never left our minds as evening approached everyday ... What is the need for a nation? Why cannot things remain as they are? Why do people need and are made to suffer? People should coexist in harmony ... Today after all the promises and dreams told, nothing has changed in our lives. We do not feel anything great . . . The cadres used to walk about well armed. I have no hard feelings against them but these sights would automatically create an atmosphere of fear. ... So many lives are lost and young people's lives were ruined. Why young people? The community itself was disrupted with the feelings of fear and suspicion. ${ }^{28}$

\section{Notes}

1 This is a substantially revised version of the paper 'Fashioning of Identities: Nationalising Narrative of the Bodoland Movement', Eastern Quarterly, 4(2): 112-22, 2007, with more emphasis on gender questions. Several arguments have been taken from my other articles published in Journal of Social Studies, Dhaka 2007, and SEPHIS, Centre for Studies in Social Sciences, Kolkata 2008.

2 The term 'caste-Hindu Assamese', here, implies the Sanskritized, high-caste, Assamese-speaking Hindus who "enjoyed a "superior" culture by virtue of their background of Sanskritic civilization' and who dominate the political, social and economic scenario within Assam. See Pegu (2004: 4).

$3 \mathrm{My}$ reference to these volumes is from the second edition published in 1999.

4 'Plains Tribal' refers to the tribal communities residing in the plains of Lower Assam. During the Bodo movement, the term referred to the collectives of politically conscious Plains Tribes, who organized themselves to fight against the all-round exploitation by the 'Assamese' under the broad banner of Plains Tribal Council of Assam in 1967. 
5 The Bodo people's consciousness, and apprehension of their marginal situation, was articulated by the beginning of the twentieth century. The Kachari Jubok Sanmiloni and the Boro Jubok Sanmiloni submitted a memorandum to the Simon Commission demanding recognition of the Boro as distinct and independent society separate from the Hindu society. See 'A Brief History of the Boro People', www.geocities.com/ndfb2001/ history.htm.

6 The term is used to refer the progression of the Assam Plain Tribal movement for autonomy and political recognition, initially articulated in terms of a larger tribal solidarity, which got crystallized into a predominantly Bodo assertion of its identity in exclusive terms.

7 The language issue is crucial in the Bodoland movement. Founded in 1952, Bodo Sahitya Sabha is the vanguard of Bodo language and literature. See www.bodoland.org/sahitya.htm.

8 ABSU, notwithstanding its nomenclature, stopped inducting women as its cadres eventually as ABWWF came to be seen as the space for women.

9 Dwi Brahma (name changed), former office bearer of ABWWF. Interview July 2005.

10 Mrs. Narzinari (name changed), former office bearer of ABWWF. Interview July 2005.

11 B. Baglary, former office bearer of ABWWF. Interview July 2005.

12 Mithu B, (name changed), former office bearer of ABWWF. Interview July 2005.

13 AATWWF was later on changed into ABWWF, marking the political transition from an inclusive plains' tribal movement to markedly Bodo movement.

14 Dwi Brahma (name changed), former office bearer of ABWWF. Interview July 2005.

15 Mithu B, (name changed), former office bearer of ABWWF. Interview July 2005.

16 B. Baglary, former office bearer of ABWWF. Interview July 2005.

17 Mithu B, (name changed), former office bearer of ABWWF. Interview July 2005.

18 Ibid.

19 Brinda Brahma. Ordinary cultivator and single woman. Interview July 2005.

20 There were two major phases of violent conflict between the Bodos and the Santhalis in 1996 and 1998, especially in the Kokrajhar District. The Santhalis and other non-Bodo groups allege these riots as Bodo attempt at ethnic cleansing to prove their majority for claiming autonomy, while the Bodos see it as arising out of Santhali provocation.

21 Brinda Brahma. Ordinary cultivator and single woman. Interview July 2005.

22 Ibid.

23 The term 'Adivasi' has been used in this chapter in the popular sense in which the tea garden 'tribal' population is perceived in Assam. The Santhali, one of the Adivasi sub-tribes, were brought to Assam during the nineteenth century under colonialism largely from the Chotanagpur region as tea labourers. The riots did not affect the other Adivasi groups like the Mundas and the Oraons. The riots were exclusively between the Bodos and the Santhalis. 
24 Ms. Hasda is a Santhali woman displaced during the 1996 Bodo-Santhali conflict.

25 Rozey (name changed), former member of ABWWF.

26 Different local narratives claim different ethnic identities of these three murdered women, many say they were Bodo women and some maintain they were actually Nepali who were projected as Bodos. The dead bodies of these three murdered women were found in the forest a few days before the Bodo-Santhal riots broke out in 1996.

27 Justin Lakra, an activist and leader of the Munda (a constituent community of the Adivasis) community who has been at the forefront of counter Bodoland movement, especially by the Adivasis.

28 Brinda Brahma, an ordinary cultivator and single woman. Interview, July 2005.

\section{References}

All Bodo Students Union. 2001. Bodoland Movement (1986-2001): A Dream and Reality. Guwahati: Saraighat Offset Press.

Anderson, Benedict. 1991. Imagined Communities: Reflections on the Origin and Spread of Nationalism. London and New York: Verso.

Barua, B. K. 1969. A Cultural History of Assam. Guwahati: Lawyers Book Stall.

Baruah, Sanjib. 1999. India against Itself: Assam and the Politics of Nationality. New Delhi: Oxford University Press.

Eisenstein, Zillah. 2000. 'Writing Bodies on the Nation for the Globe', in Sita Ranchod-Nilsson and Mary Ann Tetreault (eds.), Women, States, and Nationalism: At Home in the Nation? London and New York: Routledge.

Endle, Sidney. 1911/1993 reprint. The Kacharis. New Delhi: Cosmo Publications. George, Sudhir Jacob. 1994. 'The Bodo Movement in Assam: Unrest to Accord', Asian Survey, 34(10), October.

Mayer, Tamar. 2000. 'Gender Ironies of Nationalism: Setting the Stage', in Tamar Mayer (ed.), Gender Ironies of Nationalism: Sexing the Nation. London: Routledge.

Pegu, Jadav. 2004. Reclaiming Identity: A Discourse on Bodo History. Kokrajhar: Jwngsar Narzary. 
$\because$ Taylor \& Francis

http://taylorandfrancis.com 
Part XII

State and development policies 
$\because$ Taylor \& Francis

http://taylorandfrancis.com 


\title{
27 Building Northeastern futures, looking East ${ }^{1}$
}

\author{
B. G. Verghese
}

The increasing participation of the voters in the electoral politics of the Northeastern region of India suggests that people in the Northeast seek peace and orderly development and believe that there is a viable alternative to the gun. Not all in the region may agree; but a lot of others are, perhaps, redefining their sense of what constitutes self-determination. None will deny that alienation, neglect and errors of judgement, often real, sometimes imagined, have given cause for frustration, anger and militancy. However, change is in the air with the dawning realization that there is a significant opportunity cost of delay and that past lags and lapses can only be overcome by building the future.

Until independence, 'Greater' Assam incorporated most of the Northeast, barring the princely states of Manipur and Tripura. This was among the most globalized parts of India and Assam ranked high in terms of relative development and income levels. World War II rudely ended the political isolation of what were hitherto remote frontier regions while partition severed national and external connectivity by land and water. This created the large and rich but virtually landlocked geo-strategic area that makes up the Northeast.

A look at the map tells us why the region is called the Northeast. This is not an insult, nor a derogation of identity or status as sometimes believed, but a logical and convenient geographical expression of/for a collective entity. For purposes of planning, development and strategic thinking, the Northeast is more than the eight member states that now make up the Northeast Council. It necessarily encompasses all the territories lying beyond the Siliguri neck, including North Bengal and the Darjeeling-Gorkha Hills Area. This is where Southeast Asia begins, racially Mongoloid and an ethno-cultural and bio-geographical bridge to the lands and fast-growing economies lying to the north and east. 
To ignore geography is to fail to understand history and the opportunities that beckon.

The entire critical infrastructure that links India to the Northeast the railway, national highway, oil pipeline, multiple telecommunication conduits, and power transmission lines - run through the Siliguri neck, a narrow corridor $22 \mathrm{~km}$ wide sandwiched between Nepal and Bangladesh and in close proximity to Tibet/China and Bhutan. A breakdown, bandh or interruption anywhere along any part of this funnel has a critical impact on supplies, prices, security and the wellbeing of millions. No unit in the Northeast can prudently disregard this geo-political reality. So while each state is free to shape its own development and progress, there is a certain compulsion for the component units to march together or suffer separately. This provides the inherent rationale for the North Eastern Council (NEC), which is not intended in any way to curtail or minimize local identities but rather to facilitate and maximize realization of the potential and wellbeing of the constituent units.

Another truism that merits greater appreciation is that peace and development go hand in hand. Indeed, a World Bank study establishes a significant correlation between pockets of unemployment and poverty, and unrest and militancy. The end of isolation of the hitherto remote hills that ring the Brahmaputra and Barak valleys has induced change from subsistence and barter to a monetized, market economy. This has both bewildered and confused many who believe in traditional organic modes of living, even as it has started a process of modernization and challenged imagination and aspirations. Traditional mores and institutions have been relegated or abandoned but what has replaced them has often been unsuitable or exclusive, thus creating new hierarchies and an emerging feudalism. No wonder the restless and discontented fall prey to adventurism and subversion. Development, even if equitable and sustainable, is admittedly no panacea for every social and political ill; but it can sometimes also trigger negative tendencies that can and must be corrected.

Although the Northeast enjoys the largest volume of subventions from the Centre, it remains a natural resource rich region inhabited by poor people. Its Human Development Index (HDI) indices rank among the lowest on the national scale, with Assam at the bottom of the heap. This is particularly disturbing. Assam by its size and location is the region's prime anchor for stability and engine for growth or must otherwise be a drag. Today Assam, like the region as a whole, is deficient in essential food items leading it to import from other parts of the country. 
A study done by the National Institute for Public Finance and Policy, New Delhi, has estimated that if the national growth rate is to be assumed at 9 per cent over the next two to three Plans, then the Northeastern states will need to grow even faster at around 12 per cent per annum (maybe 13 per cent for Assam) if the region is to catch up with the rest of the country in terms of per capita income and basic social indices by 2020 . This represents a huge challenge. If not met, disparities between the Northeast and the rest of the country will only widen. Closing the gap will not be easy but is doable and will require the Centre to underwrite correspondingly larger investments in the region, with basic needs and infrastructure taking priority.

One of the major infrastructural buildup lies in meeting the challenges and combating the frequent floods that has led to agricultural depression and food crises in Assam. If the state practices a largely mono-crop, low risk subsistence agriculture, it is because of the devastation caused by the annual floods. Inundation cannot be altogether avoided but can be mitigated and better managed. Embankments are no more a sufficient answer, with bed aggradation and continuing erosion occurring not merely on account of a shrinking jhum cycle but also because of a variety of development and construction activities.

To moderate floods, storages can be constructed in Arunachal Pradesh that can also generate electricity and augment low season flows to improve navigation. This solution, first mapped out by the Brahmaputra Board, has run up against opposition from Arunachal Pradesh, which fears submersion and displacement and would rather limit itself to run of the river projects. Such schemes are unobjectionable in themselves, but would entail sacrificing a significant amount of power and do little for flood moderation and navigation. Smaller dams could offer an intermediate solution but would preclude optimal energy generation and other benefits.

It has been argued by some that displacement by submersion in terms of persons per unit of benefit is likely to be relatively low in Arunachal in view of its very sparse population. But this becomes less tenable where tribal communities are small, sometimes numbering just hundreds or a few thousands, and the ratio of displacement or loss of homeland to inundation is proportionately large. Such human and cultural costs, apart from ecological and livelihood losses, should certainly be sought to be minimized, if not avoided as far as possible. However, rational cost-benefit analyses and computer simulation models could suggest options, trade-offs and appropriate compensatory mechanisms that leave everybody better off at the end of the day. 
There is also greater public awareness and higher standards are being set within stronger legal frameworks. Further, concepts of resettlement and rehabilitation have vastly improved and are being more closely monitored. The terms of compensation have undergone qualitative and quantitative transformation with project-affected families being made stakeholders through equity ownership, annuities and participation in the future stream of benefits. This then could result in informed consent and better guaranteed outcomes.

A practical and mutually beneficial trade-off between Arunachal and Assam and a fair deal for those displaced seems possible, given imaginative initiatives. The idea of tripartite Trusteeship Zones (TZs) can be initiated, in disputed areas between Assam and Arunachal with central interventions, for the next 30-50 years and to utilize them for the development of essential infrastructure such as railheads, airstrips, communication hubs, warehouses, cold storages, entrepots, training centres, growth poles and other investments (such as cement plants, workshops). All these are necessary to build larger projects in the hills and to convert hydroelectricity into value-added products and jobs before 'surplus' power is fed into the grid for consumption elsewhere. The availability of power, water supply, rail, road, air and even water connectivity, markets, banks, health and educational facilities, hotels and so forth and, above all, unencumbered flat lands in these TZs, render them well suited to being developed as Special Industrial Development Zones with SEZ-type incentives for an initial period of time to attract investment. The proposed 3,000 MW Dibang multipurpose project in the Luhit region, whose foundation stone was just recently laid by then Prime Minister Dr. Manmohan Singh, could well spawn such a TZ.

Such an arrangement would be attractive to all sides. Arunachal would gain from a new land-for-land model of development, exchanging relatively narrow valleys that get submerged for flat lands in the plains that are ideally suited for large investments and employment generation. Displaced communities could be offered housing-cumtraining-cum-employment benefits in the TZ if so desired (apart from compensation) or in situ through area development of the upper catchment.

Hill areas are naturally disadvantaged because of their difficult terrain. This also compels suboptimal land use patterns and unsustainable cultivation in the face of reducing jhum cycles and precludes more sustainable land use for horticulture, plantations and even cultural or eco-tourism in the absence of market access. Dams therefore serve a most valuable role in opening up remote regions for area development. 
Under new compacts that can be negotiated, communities facing submergence or displacement should be able to benefit from provision of basic services and other social and economic development deriving from investments made by duly constituted upper catchment area development authorities funded with resources earmarked for mandated catchment area development, reservoir fishery and tourism and new land use development.

All of these would provide opportunity for those who would prefer not to go to TZs. Additional funding could come from normal development and poverty alleviation budgets marshalled to implement area development programmes. There is no reason why poverty alleviation schemes, R\&R and realization of the Millennium Development Goals, all of which are mandated, should be seen as separate or parallel projects. The bottleneck is not resources but imagination and management and technical capability, which, in the case of horticulture and plantations, could come from public-private-community partnerships with corporate collaboration. As it is, host states are now entitled to receive an enhanced quantum of 13 per cent free power from hydro projects a small part of which could surely be earmarked for area development programmes. Since utilization of this power in scattered hamlets in the neighbourhood may not be cost-effective on account of long and difficult transmission leads and line losses, it would be more appropriate to apportion a small part of the commuted value of 'free power' to develop local, stand-alone mini, micro and non-conventional systems of energy generation of which solar, water turbines and bio-fuels could be some. This could light and heat hamlets and power small gadgets and motors for local industry and processing units.

The new plantation/horticulture economy would be a far cry from the old tea estates or gardens but would compromise smallholders, organized in cooperatives or community enterprises and/or linked to corporates that could provide the necessary technical guidance, inputs and undertake all subsequent grading, processing, branding and marketing operations on a profit sharing basis. As it is, smallholder tea growers in Arunachal are selling leaf to neighbouring tea factories across the border in Assam to mutual benefit. In a competitive, globalizing world, economies of scale matter.

Trusteeship Zones could also be set up linked to the proposed Tipaimukh project, to benefit Mizoram, Manipur and Assam, and to the Bairabi, Turial and Tuvai projects in Mizoram. Meghalaya and Assam could work out similar project-related TZs (in disputed border strips) linked to water resources and mineral (coal, limestone, uranium) development. There are objections to many of these projects 
but they are not incapable of resolution given transparency and a clear understanding.

The TZ concept could give a tremendous fillip to investment and industrialization in Assam not merely for local consumption but for export to the rest of the country and beyond. Small and medium industries would gain impetus from market buoyancy induced by a surge in agriculture. This apart, Assam could gain from market development and consolidation in a variety of ways. The military and para-military formations, including the Border Roads Organization and even the police in the Northeast, together with their families, possibly number a million or more persons. These are up-market consumers for a variety of stores and supplies - canned foods and juices, boots, Olive Green (OG) and other uniform material, belts, badges, haversacks, water bottles, webbing, mosquito nets, parachute cloth, bandages, sleeping bags, blankets, a range of everyday medicines - which largely or almost entirely come from outside, assisted by transport subsidies. Why should not many of these items be manufactured locally? This would entail negotiating contracts with the defence authorities with fixed delivery schedules and quality assurance, following trial production runs.

These production and trading arrangements will automatically generate the need for developing connectivity in a big way. There is an already reasonably good civil air service in the region. However, few know or recall that the Northeast enjoyed far superior air connectivity in the 1950s than today as a number of private carriers operated Dakotas (aircraft) from wartime airstrips as no-frill air taxi services ferrying civil and military personnel and stores. These carriers provided an elaborate and extensive air supply service to maintain the civil and security establishments and the local population throughout the hill region through free drops and para-drops in designated drop zone (DZ) areas, supplemented by landings at high-altitude air strips. This role was subsequently taken over by the Indian Air Force (IAF), which conducts a considerable air supply mission even to this day.

It would make a great deal of sense to repatriate much or entire air supply mission to private carriers who should be permitted to fly small passenger-cum-cargo aircraft. The military contract would provide them with a guaranteed base load that would take care of overheads and render regional air-taxi operations viable. The paucity and unreliability of air connectivity to and within the Northeast at present represents a failure of national civil aviation policy, retarding development and integration in a vulnerable and strategic part of the country.

Railway development is moving forward with further BG conversion, line extensions and the construction of some key bridges. A large 
road development programme is under way, especially to connect neglected border regions as in Arunachal, where a major east-west corridor is proposed, and to bring more state capitals nearer railheads if not on the railway map. New airports have been commissioned and several derelict airstrips are being revived and upgraded to cater to a regional air service. The waterways too are being improved and extended and these are likely to develop faster were multi-modal transportation systems and roll-on/roll-off containerized truck services to be encouraged.

The proposed 1,500 MW capacity Tipaimukh project would be the creation of extensive new waterways reaching deep into remote parts of Manipur and Mizoram and could stimulate employment and income generation through industrialization with the assured energy it provides. The Bairabi project could do the same for Mizoram. The stimulus such projects can give the economy by opening up vast neglected regions, given attractive $R \& R$ and compensation packages as proposed, has not been adequately appreciated.

There are also imaginative ways to promote peace and reconciliation and ecological restoration. The $15 \mathrm{MW}$ Gomti power project in Tripura was built over thirty-five years ago when the state badly needed electricity and had no other source. The Gomti dam, however, displaced 45,000 tribal families from about 45,000 acres of farmland in the prosperous Dumbar bowl. The towns (read Bengalis) benefited from the power whereas the tribals were resettled in the surrounding hills and resumed jhumming, which they had given up, aggravating erosion and siltation of the reservoir. This sparked tribal-Bengali tensions that gave rise to insurgency while shrinkage of the reservoir over time steadily reduced generation capacity to around no more than 7 MW of firm power. Meanwhile the state developed alternative energy resources from local gas finds and has recently started work on a further $750 \mathrm{MW}$ gas-fired thermal station that will make Gomti power redundant. The Gomti project has by now been fully amortized and were the dam to be decommissioned and the reservoir drained, energy supplies would not be affected whereas the originally displaced tribal families would be enabled to return to settled cultivation in the now highly fertile reservoir bed and the eroded hills restored to forest. Such a measure would bolster Tripura's farm economy, assist reconciliation between the uprooted tribals and the Bengali population and strike a powerful blow for peace and development whose repercussions would be felt throughout the Northeast.

Many other innovations and initiatives come to mind. The 'rathole' mining to win coal from narrow seams burrowed into shallow 
outcrops, practiced in parts of Meghalaya is hazardous, wasteful, ecologically harmful and exploitative. Since the land is privately or communally owned these mines were not nationalized and are operated locally outside the ambit of any regulatory framework. A powerful mafia controls the trade and much of the coal is smuggled into Bangladesh or sent down to Guwahati. It should surely be possible to request the NE Coalfields Ltd, a public sector unit (PSU), or any other consultant to survey the reserves and formulate a scientific work plan with proper conservation and safety measures that the owners could then be helped to manage. Everybody could gain. Anxieties over progressive degradation of the Loktak Lake and its unique eco-system can be similarly addressed jointly by the Loktak Hydel Project and local communities.

The Northeast cannot be isolated from its external neighbourhood and hence the relevance of Looking (Acting?) 'East' at Bangladesh, Myanmar, Tibet/China, Bhutan and eastern Nepal. For long after independence some of the region's external boundaries were virtually closed for a variety of reasons. Since then, political relations, once strained, have improved and the climate is favourable for resumed and expanded contacts and exchanges. In the absence of a border policy, large frontier tracts were left undeveloped as wilderness areas in the misguided belief that this would constitute a protective security barrier against inimical forces from the other side. This bizarre assumption has at last been discarded though old mindsets remain and fears are still expressed about dangers from subversive elements, drug peddlers, arms merchants, smugglers and other undesirables. This too is slowly changing.

Instead of feeling peripheral and looking inwards, the Northeast could acquire an important new centrality looking outwards. It could and should be the gateway and land bridge not only to its immediate external neighbourhood but also to Inner Asia and Southeast Asia that lie beyond. This is the logic of ideas like BIMSTEC, the MekongGanga Association, the Bangladesh-(Southwest) China-(Northeast) India-Myanmar (BCIM) Forum or so-called Kunming Initiative. These entities are unexceptionable but are each of them huge in extent and population.

None of them has really taken off because of official dithering to some extent but largely on account of the singular failure to put trade facilitation measures in place. In their absence, bureaucratic hurdles enhance transaction costs and compel resort to corrupt practices or smuggling, which entail loss of revenue and the growth of mafia syndicates. This has been the sad story of Moreh, which has become a 
gateway for licensed smuggling and has lost out to its Myanmarese counterpart, Tamu. India built a first class highway from Kalewa on the Chindwin at a ferry crossing to Mandalay in 2000 in order to promote trade with Myanmar and through it with Southeast Asia and China. But there was absolutely no follow through. This has been the story on the main Indo-Bangladesh trade corridor at Benapole-Petrapole and along the Indo-Nepal border. There is even today no motor vehicles agreement that permits through movement of trucks across the Myanmar or Bangladesh border. This necessitates transshipment, delays, losses, pilferage and higher overheads. Additionally, in many parts of the Northeast, the underground and criminal gangs impose levies and taxes.

Trade facilitation is therefore of paramount importance if the Look East Policy (LEP) is to translate into trade, investments and prosperity. Perhaps the best way to begin would be to take up smaller and more manageable trans-border growth triangles or two-country growth poles. Thus, Tripura and Mizoram could pair off with Chittagong, the Chittagong Hill Tracts and Cox's Bazar or even add on the adjacent Chin Hills and Rakhine coast of Myanmar to constitute a growth triangle. Similar arrangements could be made elsewhere to resolve the last-mile problem of connectivity, by building a bridge, immigration and customs post, telephone line, bank and whatever else it takes to facilitate movement and exchange. Once these bridgeheads are consolidated with the necessary infrastructure in place, further expansion will be more easily possible, embracing larger territorial units and a wider range of goods and services.

The Guwahati international airport and air cargo terminal was completed quiet some years ago but has been languishing for lack of coordinated action to forge the necessary linkages and loops. This is utterly absurd and shows a total lack of forethought. The Kaladan corridor now proposed as an inter-modal road-cum-waterway link from Southern Mizoram to Sitwe port along the Kaladan river could meet the same fate without forward planning and the execution of linked developments.

Implementation of the LEP should not make the Northeast a mere transit route but a destination and a point of origin and destination for merchandise and services. For this to happen, the Northeast must generate the investments, manufactures and services of the kind discussed earlier, starting with connectivity. Such a policy also implies a commitment to expanding regional cooperation and not merely paying lip service to that ideal. Relations with Bangladesh are probably most critical as the Northeast needs transit to end its isolation from 
the Indian heartland and must cooperate with it for optimal development of its vast water resources. Bhutan, being landlocked, is dependent on close cooperation with the Northeast and West Bengal. The reopening of the Nathu La trade route holds out interesting possibilities even if the Stilwell Road takes time to be meaningfully restored. Cooperation with China is also important for receiving adequate and timely river discharge readings for harnessing the Brahmaputra and mitigating floods and debris-dam outbursts, especially in the context of climate change.

A number of scare stories have appeared about possible Chinese diversion of the Brahmaputra northwards to the Gobi desert and the Beijing region, with devastating consequences for the lower transHimalaya riparians. This is highly exaggerated and bears little relationship to the hydrology, topography and consequent pumping involved in such flights of fancy. The first point to be noted is that the Brahmaputra is only formed around Sadiya and that any diversion structure the Chinese might build would be on the Tsang-po, which becomes the Siang or Dihang after it enters Arunachal. The massive 2,500 m drop in the Brahmaputra U-bend has an estimated potential of 48,000 to $54,000 \mathrm{MW}$ according to a Japanese map study. The notion that this energy could take care of the pumping load to send the waters north $2,000 \mathrm{~km}$ north is fallacious as all that energy would be utilized just to pump the water back up to the head of the drop. Some water may legitimately be used in Tibet or diverted, but nothing enough to 'dry up' the river. In any event, about 70 per cent of the flow of the 'Brahmaputra' system as a whole originates south of the Himalaya.

It would perhaps be more purposeful for India to propose to China that the two countries consider a collaborative study to harness the potential of the U-bend as a joint or regional venture with international support as a contribution towards combating climate change through generation of clean hydro-power.

Development of the 3,000 MW Chindwin cascade, starting with the Tamanthi project, east of Phek, Nagaland, is something India and Myanmar have been discussing. Should this fructify, surplus power from Tamanthi is proposed to be transmitted to Nagaland, thus laying the groundwork for what could become a larger SAARC-ASEAN grid into which U-Bend power could also feed.

The Northeast will require bold thinking about utilizing what are largely community land rights for rapid development. Arunachal has announced a bold initiative in this regard. Cadastral surveys need to be extended and expedited and measures taken to prevent the commodification of community lands through a process of appropriation (akin 
to the English enclosure system) and benami alienation to outsiders, including Bangladeshis and Nepalese. Abandoned jhum lands could be diverted to horticulture and plantations to both ecological and economic advantage, unless imaginative agro-forestry programmes like Nagaland's NEPED are pursued. Land banks could be built up and whole communities made stakeholders in future development. Meghalaya had some years ago sought to develop the concept of 'tribal interest' as an adaptive alternative to the notion of 'public purpose'.

Another and possibly more tricky issue could be labour. The Northeast has depended on outside labour for development as witnessed by the pattern of recruitment to the Border Roads Organisation and other large enterprises. At another level, certain skills are in short supply and will require to be procured from outside until these are sufficiently developed within the region. The in-migration of labour over the years, whether foreign or India, has inflamed local sentiments on grounds of its demographic, cultural and political impact. The answer is not to keep out migrant labour but to manage its political and social fallout differently.

Thus, for the rest, workers from the Indian heartland, could be electorally registered in one or two large 'general' non-territorial constituencies irrespective of where they live. Thus, they would not be disenfranchised but would equally not influence voting critically in a large number of constituencies as is the case at present, especially with regard to tea garden labour. Non-territorial constituencies are constitutionally recognized as in the graduates' constituency that forms part of the electoral college for upper chambers in the states.

Finally, one needs to think of revamping administrative structures, adapting traditional institutions where possible. The successful communalization programme in Nagaland offers a good example. A simpler, single-line administration with dedicated officers oriented to the field rather than the secretariat is required on the model of the hastily abandoned Indian Frontier Administrative Service cadre that was somewhat hastily abolished around 1970.

The Northeast Council (NEC) needs overhaul in terms of its charter and powers. This is hopefully under way. An empowered Northeast Water Resources Authority under the NEC would be a sound replacement for the moribund Brahmaputra Board.

There is no reason why Northeast tribal residents should not begin paying income tax, the proceeds of which could for a while be earmarked for development purposes in their own states.

It is also time for the system of Inner Line permits and Restricted Area Permits to be withdrawn. They have served their purpose. A 
process of national citizenship certification together with the compulsory registration of births, marriages and deaths within a defined time horizon would be far more purposeful.

When the NEC was first constituted, the security adviser for the region (the inspector general of the Assam Rifles) was made integral to the scheme. Over the years, this official has virtually got detached from the NEC and reports directly to the Home Ministry. This is unobjectionable but there is good reason to have this officer report concurrently to the chairman of the NEC and be his security adviser. Peace and security are two sides of the same coin and must go hand in hand. Even the rehabilitation and reorientation of surrendered militants requires civil collaboration in terms of retraining, counselling and employment if these elements are not to lapse back into militancy or crime. The MEA and Commerce Ministry should be represented in the NEC and officials of the latter in those Union Ministries.

Much else can be said about developing tourism, improving education, encouraging IT with broadband connectivity, developing sports

and music, in which the Northeast has tremendous potential, and so on. But all these are well known and well understood. The region and the individual states have to get their act together. Ultimately it is Northeasterners who must take responsibility.

While lamenting those things that may not have gone well in the Northeast, the region can boast of many success stories of orderly change. The stage appears now to be reasonably well set for a major thrust forward. Things are changing and there is ground for cautious optimism. Development and opening up to its neighbours could provide impetus for the next stage.

\section{Note}

1 This chapter was first published in Eastern Quarterly, 4(3\&4): 157-68, 2007-08. 


\title{
28 Preparing the Northeastern economy for the future ${ }^{1}$
}

\author{
Gulshan Sachdeva
}

The Northeastern region of India is known for its ethnic, linguistic and cultural richness and diversity. It comprises the states of Arunachal Pradesh, Assam, Manipur, Meghalaya, Mizoram, Nagaland, Sikkim and Tripura, with about 8 per cent of the country's geographical area and about 4 per cent of its population. Their combined contribution to the national economy is around 2 per cent. The economic literature on the region broadly discusses its unique economic institutions economic backwardness and failure of economic policies in the region (Srivastava 2000, 2002). The 'mainstream' economic literature on the Northeast generally argues its economy in the context of a 'neglect' theory. It has also been frequently suggested that to end this neglect, massive developmental assistance from the central government is required, which in due course would also end discontent, insurgency and terrorism in the region. This chapter argues, instead, that failure of economic strategy for the region is not because of any so-called economic neglect but because of wrong assumptions and inappropriate economic policy framework, which have created an unbalanced economy and destroyed the basic institutions of market economy.

\section{Northeast in Indian planning}

During the colonial period, the institutions and infrastructure in India were mainly developed to serve colonial interests (Bhardwaj 1982). In the initial years of planning after independence, regional economic development was still not really on agenda. The emphasis was on concentration of limited resources on those areas and regions, which could give maximum returns to tackle the problems of food security and heavy dependence on imports for capital goods. Very little attempt was made at regional desegregation of national planning. Emphasis on industrialization during the second plan led to some industrial regions. 
Although some problem regions like Damodar valley, refugee rehabilitation and so forth were identified, they were not part of any regional development strategy. Till that time, states of the Northeast were not discussed as a 'problem' region, as per capita income of Assam was among the top few states.

In the Third Five Year Plan, the concept of balanced regional development was discussed in detail. The policies through which the balanced regional development was supposed to be achieved were selection of industrial location (both for public and private sector), use of large projects as nuclei of regional growth, technological development, education and training and labour mobility. It was asserted that 'from the decisions regarding location of projects in the public sector which has been reached so far, it is apparent that there will be a fair measure of dispersal and various regions will have significant share in industrial development' (Third Five Year Plan 148). Despite these policy pronouncements, the Third Plan document also noted that

the level of development depends to a considerable extent on the availability of competent administrative and technical personnel and on the growth of a class of small and medium sized entrepreneurs. ... Attention should be given to these aspects of development, for they point to handicaps which cannot be removed merely by providing resources to an under-developed region.

(Third Five Year Plan 151, emphasis added)

This was an important observation, which was ignored in later plan documents. Overall, the thinking was that

development of regions and the national economy as a whole have to be viewed as parts of single process. . . Excessive emphasis on the problems of particular regions and attempts to plan for their development without relating their needs to the requirements of the national economy have to be guarded against, for in the final analysis, it is as integral parts of the country that different regions can best hope to realize their full potential for growth.

(Third Five Year Plan 153)

The Fourth Plan outlined that 'differences in development between State and State arise out of variations in activity in the three sectors cooperative, private and public'. It was argued that in the cooperative and private sector, actions of the central government could influence very little. In the state sector, it was outlined that directions in which 
the Centre can help are: (1) allocation of Central assistance; (2) location of Central projects; and (3) adjustments in procedures and policies of national financial and other institutions. Apart from weightage given to backward states in the allocation of central assistance, programme for small farmers, marginal farmers, drought-prone areas, dry areas, tribal areas and industrially backward areas were taken up. The planning commission also issued guidelines for the formulation of district plans. Despite these steps there was a sense of frustration in the Fifth Plan when it said that in the reduction of regional imbalances 'the measure taken so far have not had any appreciable impact' (Fourth Five Year Plan 55). It argued that 'there has been an unfortunate tendency to define the needed efforts merely in terms of financial magnitudes. Organisational and institutional aspects of the resource development problem of the backward regions have not been attended to' (emphasis added) (ibid.).

Northeast as a region started figuring prominently in planning literature from the early 1970s, particularly after the reorganization of states in the region. The establishment of the North Eastern Council (NEC) in 1972 was acceptance of the fact that this region needed special institutions and incentives for development. In the Sixth Five Year Plan, under the sub-plan approach, greater emphasis was placed on Special Tribal Plan, Hill Area schemes and the programmes handled by the North Eastern Council (Sixth Five Year Plan 273). Contrary to the Third Plan, where it was argued that the central government cannot influence much the private sector initiatives in backward areas, under the Sixth Plan, central policies were also designed 'to provide incentives to private entrepreneurs through schemes of concessional finance, seed/margin money scheme, central investment subsidies scheme, tax reliefs, specific interest subsidies for engineer entrepreneurs and so on' (ibid. 276). These policies were in addition to resource transfers and public sector programmes.

One of the main objectives of the Seventh Plan was also the 'adoption of effective promotional measures to raise the productivity and incomes of the poorer sections of the population, poorer regions and poorer States' (Seventh Five Year Plan, Vol. I). The plan also emphasized the need for decentralization of planning and development administration below the state level, particularly in the context of agricultural and rural development programmes. It urged the states to take steps towards four important aspects of a decentralized district level planning setup. These were (1) effecting functional decentralization, (2) effecting financial decentralization, (3) the establishment of appropriate planning mechanism at the district level and (4) establishment 
of appropriate budgeting and re-appropriation procedures (Seventh Five Year Plan, Volume II). In the Eighth and Ninth Five Year Plans, there were very little direct references to the problems of the regions. In both these plans, Northeastern states were discussed broadly within the category of Special Area Development Plans like Hill Area Development Plan (HADP), NEC and so forth (Eighth Five Year Plan, Volume II). One of the major concerns of the Mid-Term Appraisal of the Ninth Plan as well as the Tenth Five Year Plan was that of widening regional disparities.

While emphasizing the importance of balanced development for all states, the Tenth Plan document included a statewise breakup of the broad developmental targets, including targets for growth rates and social development. For the first time a separate volume on state plans was included. The document declares that

the adoption of planning and a strategy of State-led industrialization was intended to lead to a more balanced growth in the country. It was expected that, over time, inter-State disparities would be minimized. Plans and policies were designed to provide more investments to the relatively backward areas. Nevertheless, socioeconomic variations across States continue to exist today.

(Tenth Five Year Plan, Vol. III: 1)

It further said that some of regional imbalances have narrowed down, but most have grown over time.

To tackle the problem, it was argued that the emphasis would be on effectiveness, quality and reforms and not so much on volumes of investment alone. According to the document, the 'core element in the Planning Commission's strategy towards reducing regional disparities would be the targeting of less developed areas with provisions of funds for capital investments and innovative delivery mechanisms linked to institutional reforms' (ibid. 124). For the first time a special portion of the document deals with Northeastern States. According to the Tenth Five Year Plan

the trauma of partition, political evolution and insurgency combined with the geographical location, transport bottlenecks, natural calamities, etc. have hindered the progress of the Northeast, and the region has experienced relatively slower economic growth compared to the rest of the country. Most of the Northeastern States joined the planned development process later than many other States.

(ibid. 91) 
The plan documents outline the special measures initiated by the central government like the special PM packages, NEC, non-lapsable central pool of resources, Department of Development of the Northeast etc.

The Eleventh Five Year Plan argued that it is the collective endeavour of the central and state governments to form appropriate polices for the region. The plan document emphasized connectivity (road, rail, air, inland waterways, telecommunications) as the key area for the development of NER. In addition, it was recognized that economic activities will be generated through interaction with neighbouring countries (Eleventh Five Year Plan 2008a: 151-64). The 12th Five Year Plan noted that 'larger plan investments and focus on infrastructure development has helped growth in this region'. It further stressed however that 'continued emphasis on the development of physical and social infrastructure must continue so that the region can become strong, confident, and capable of engaging with external market' (Twelfth Five Year Plan 2013: 332-4).

\section{Empirical studies on regional disparities}

A lot of research has been conducted in India on the inter-regional convergence or divergence in incomes of different states. Many scholars have found that there has been marked reduction in income differentials in state domestic product (SDP) growth rates. At least they have noticed a tendency for convergence. Another group of scholars have found widening regional disparities amongst Indian states or they have found noticeable tendency for divergence. ${ }^{2}$ Although the bourgeoning literature on regional disparities in India is useful to appreciate the problem, it is not enough to understand the problems of the Northeast. These studies provide little information on the Northeast as almost all these studies have ignored smaller Northeastern states due to lack of relevant data. In many studies even Assam is missing.

\section{Understanding economic policy framework for the Northeast}

The above analysis shows that the policies of regional development provide some scattered information about the Northeast. Although, many of the recent government documents do provide some special mentions of the Northeast, they are still not part of any coherent strategy. They also do not clearly mention any linkages or diversions from the earlier policies. 
It seems that due to special constitutional arrangements, historical background as well as geographical location, ${ }^{3}$ the central government has been trying to integrate the Northeast region with the national economy through certain policy framework. It has accepted the right of the tribals to retain their way of life and identity and has sought to integrate them through democratic means into the federal frame of the Constitution of India. The policy framework for the region so far is guided by a combination of political economy and culture. The main focus of the political economy approach is on the relations between the state and the economy. Therefore, in this approach, the role of the bureaucratic state arrangements is strongly emphasized. The cultural approach, however, focuses on the socially constructed character of economic organization where the economic system is a product of the social order.

As a result of this combined approach, the importance of the bureaucratic arrangements in the process of economic development has been unduly exaggerated. Besides, wherever possible, an attempt has been made by policy makers to work through the unique social and cultural institutions existing in the region instead of imposing new institutions. This special approach has been adjusted with the central governments' policies of a regional planning development model. The major assumption of regional planning is that it would permit the transfer of surplus generated in one region to another. This mechanism was expected to increase aggregate national efficiency through optimum resource allocation.

Further, to protect tribal interests, policies of less interference with the cultural traditions and customs of the tribal people are being followed and additional political and administrative framework has been provided for the region. Under the Sixth Schedule of the Constitution, the concept of Autonomous District Councils has been applied (Sharma 1998). The councils are responsible for looking after the social, economic and minor criminal and civil matters of the tribal people. More specifically these councils are empowered to make laws with respect to: (1) land, (2) forest, (3) watercourse, (4) shifting cultivation, (5) establishment of village and town and its administration, (6) appointment of, or succession to chiefs or headmen, (7) inheritance of property and (8) marriage and divorce and matters relating to any other social customs.

Restrictions have been imposed on the rights of citizens of other states as well as nontribals from the same state acquiring landed property in some parts of the Northeast. The regulation of Inner Line Permit prohibits entry of outsiders into Arunachal Pradesh, Mizoram 
and Nagaland without a permit, and debars a non-native to acquire any interest in land or the produce of land. Tribal belts and blocks have been constituted in the plains areas to prevent land alienation from tribals there.

Under the influence of this policy, various schemes for the development of infrastructure and economy of the Northeast region have been formulated. The schemes include the formation of the Northeastern Council, Hill Area Development Projects and sub-plans, Tribal Area sub-plan, and Tribal Development Agency Projects to name only a few. In addition, Northeast states have been declared as Special Category States; they get central assistance on the basis of 90 per cent grant and 10 per cent loan. Some public sector units have also been set up in the region. The policies of industrial licensing, concessional finance and investment subsidy, growth centres, as well as freight equalization of some major industrial inputs have also been used towards economic development. Under the announcement made by the then Indian Prime Minister Mr Deve Gowda in October 1996, all developmental ministries and departments of the central government have been directed to earmark at least 10 per cent of their annual budget for the programmes in the Northeast. In case any central government ministry failed to achieve this target, the unutilized 10 per cent portion is pooled in the non-lapsable central pool of resources, which will be re utilized to finance developmental projects in the Northeast. Creation of a separate department and then a Ministry for the Development of North Eastern Region (MDoNER) was another new initiative by the government. In 2008, the union government came out with a Vision 2020 for the region. The vision document argues that to reach per capita average by 2020, the region has to grow close to 13 per cent per year (GoI $2008 \mathrm{~b})$. In addition, the critical non-economic parameters required to reach required growth included good governance, improved law and order and diplomatic initiatives with the neighbouring countries. ${ }^{4}$

\section{Economic outcome and development trends}

The development strategy followed by the centre and state governments has created an unbalanced economy in the Northeast. There are differences among the states of the region with respect to their resource endowments, levels of industrialization as well as infrastructural facilities. On the whole, all these economies are underdeveloped agrarian societies with very weak industrial sectors and inflated service sectors. The share of agriculture although declined, is still much higher than the national average. The industrial sector has mainly 
developed around tea, oil, timber (TOT) in Assam, and mining, saw mills and plywood factories in other parts of the region. State sponsored industrialization - whether sugar mills, jute mills, paper mills or food processing - has not been successful. Small-scale industries have also not been viable, and there is large scale industrial sickness in this region. Despite changes, the economy of the region remains primarily agricultural. The full potential of this sector has not been exploited. Primitive farm practices of slash and burn (jhum) shifting cultivation in many of the hills and mainly single crop traditional farming in the plains continue. As a result, the region is not even able to produce adequate food grains to feed its population. Since neither agriculture nor industry has taken off, the pressure for employment is on the service sector (government service). As a result, this sector has expanded disproportionately. Because of low economic activity, the states of the region have resource deficit. Of these limited resources a large portion is spent mainly to maintain the service sector.

The regional average growth rates in the 1980s were slightly lower than the national economy. During this period except Assam, all other economies in the region grew at higher growth rates than the national economy. Growth was close to national economy even in the case of Assam. In the post-liberalization phase during the 1990s, while the national economy was growing fast after initial contraction, overall Northeastern economy had slowed down. As a result, the gap between national growth rates and regional growth rates further widened. Assam, the largest economy of the region was in a very critical state, both in agriculture and industry. In the decade of 1980s, the average rate of growth of Assam was more than 4 per cent. In the 1990s, growth in Assam was much lower. Except Arunachal, the hill economies did not show much difference in growth rates during the decade of the 1990s. Tripura economy, however, was growing fast even in the 1990s. Overall, as a result of these trends the gap between the Northeast and the national economy widened in the 1990s.

As many of the central and state government policies started showing results in the last two decades, the growth in the region has improved. One of the major factors has also been agriculture sector in Assam. For some time, there has been some rethinking on the development pattern followed in the Northeast. It has been realized for quite some time that this kind of development pattern will not be able to face the forces of liberalization and globalization, unless some serious radical policies are implemented. For that civil society in the region has been engaged in serious debate about different alternatives and their 
Table 28.1 Economic growth in the Northeast, 1992-2017

\begin{tabular}{llllll}
\hline & $\begin{array}{l}8 \text { FYP } \\
(1992-97)\end{array}$ & $\begin{array}{l}9 \text { FYP } \\
(1997-2001)\end{array}$ & $\begin{array}{l}\text { 10 FYP } \\
(2002-06)\end{array}$ & $\begin{array}{l}\text { 11 FYP } \\
(2007-11)\end{array}$ & $\begin{array}{l}\text { 12 FYP } \\
\text { (2012-17) } \\
\text { Target }\end{array}$ \\
\hline Arunachal & 5.0 & 6.6 & 6.2 & 8.5 & 8.5 \\
Assam & 2.8 & 1.8 & 5.0 & 6.8 & 7.0 \\
Manipur & 3.7 & 4.7 & 5.7 & 6.2 & 6.5 \\
Meghalaya & 4.0 & 7.2 & 6.7 & 7.8 & 8.0 \\
Mizoram & - & 5.7 & 5.9 & 10.8 & 9.0 \\
Nagaland & 7.2 & 6.5 & 7.4 & 6.2 & 7.0 \\
Sikkim & 4.6 & 6.6 & 7.7 & 22.8 & 8.0 \\
Tripura & 6.7 & 9.4 & 6.9 & 8.9 & 8.2 \\
India & 7.5 & 5.5 & 7.8 & 8.0 & 8.0 \\
\hline
\end{tabular}

Source: Twelfth Five Year Plan, Volume 1 (New Delhi, Planning Commission, 2013).

implications. The central government took many initiatives, particularly from the mid-1990s. After seeing difficult economic conditions, state governments from the region also initiated many measures to attract private investment. As a result of combination of factors, economic performance improved significantly since the early 2000, particularly in Assam (Table 28.1). Although economic growth in the region has improved, it still has to tackle many of the fundamental issues which continue to affect its performance. Information under the new statistical series starting from 2004-05 shows that there has been definite improvement in economic performance in the region. Still, experience of the past one decade show that two important economies, namely Assam and Manipur, continue to underperform (Table 28.2).

\section{Demystifying Northeast and preparing for the future}

'Complex, mysterious, unique', the region continues to be referred in these terms in academic, media and policy circles. Indeed, the region's history, geography, ethnic composition and culture have given it a distinctive character. And selective academic research on disparate subjects like tribal customs, community ownership, gender equations etc., has generated interest. Even the central government deals with these states as Special Category States. Although, over the years, the region has undergone tremendous changes but certain stereotypes have remained. For most people in policy circles, media and academia, it still remains a tribal, neglected, backward, insurgency prone remote frontier. The time has come to question some myths surrounding the 


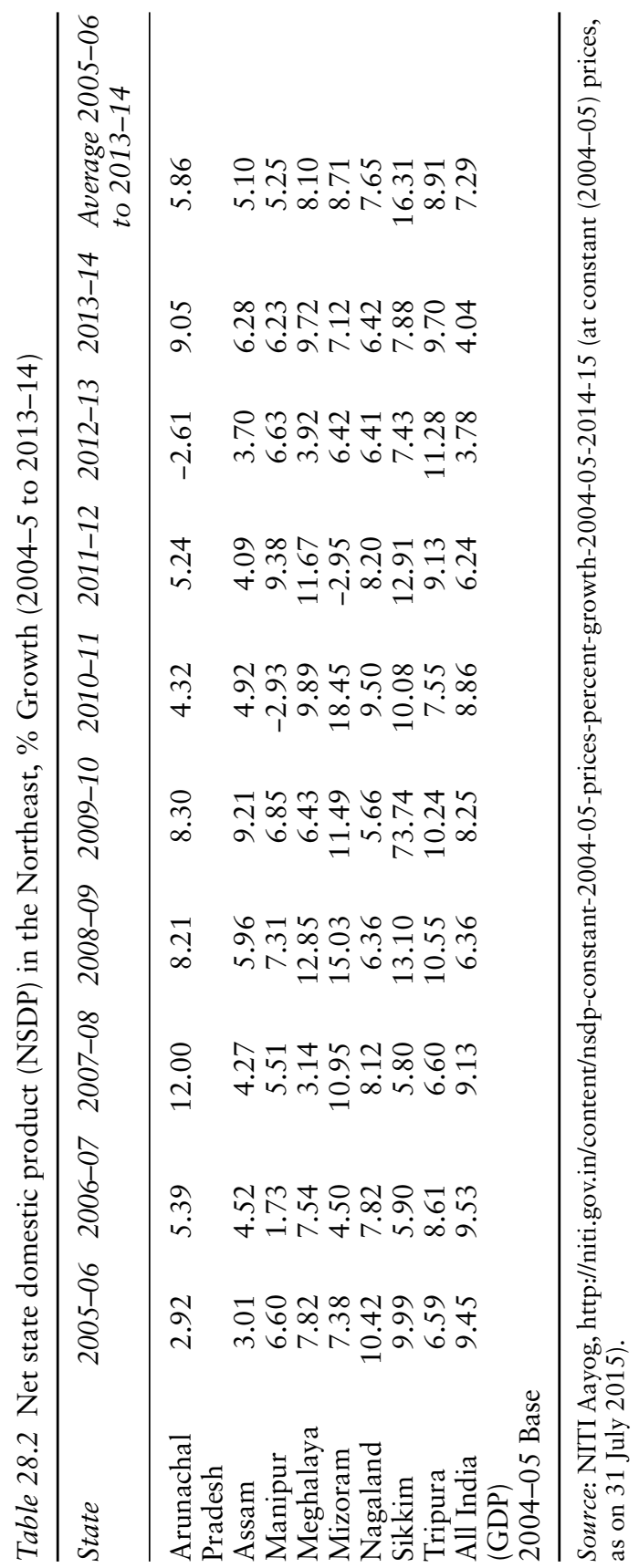


region. This will help in creating a meaningful ground for future policy framing.

Any discussion regarding the region starts with its tribal nature. It is almost unanimously accepted as a tribal region. Surprisingly, facts on the ground are totally different. According to 2011 census, only about 27 per cent of the population of the region is tribal (out of a total 45.5 million population in the region, the Scheduled Tribe population is about 12.4 million)..$^{5}$ It is always emphasized that in the four states - Mizoram, Meghalaya, Nagaland and Arunachal Pradesh tribals are in majority. But tribal majority in these states does not make the whole region tribal. Moreover, in today's Northeast, tribals are not 'headhunters'; on the contrary, a large number of them are educated and have adopted Western dress and modes of living. It would be misleading to equate them with marginalized tribals in other parts of the country. The policy of protective discrimination for 'Scheduled Tribes' in the region raises serious questions of justice, and equality for the non-tribal population (Baruah 2003). As Sanjib Baruah argues, this kind of policy 'effectively compromises the constitutional right to free movement of Indian citizens' (Baruah 2005: 51). Moreover, rigid barriers - which aim at restricting outside penetration - are contrary to the processes of contemporary globalization (Sachdeva 2000). In these circumstances, it would be more productive and useful if we start treating Northeastern economic problems in a normal way rather than in a 'special tribal way'. First, the region is not a 'tribal region' and second, 'special solutions' have created more problems than solving it.

Second, the myth about 'neglect' of the region needs to be seriously examined. There is obviously some neglect of the Northeast in Delhi politics and national media. There could also be some knowledge deficit. But most vocal writings and speeches regarding 'neglect theory' often cite economic figures to show the neglect. There could be any other kind of neglect but the facts about devolution and transfers of resources from the Centre reveal entirely a different story. Between 1990-91 and 2002-03, the region received about 108,504 crore rupees from the Centre. A portion of that money is also given back to the central government as repayment on loans and interest payments. Still, the cumulative net devolution from the Centre to the Northeast for the period between 1990-91 and 2002-03 is about 92,000 crore rupees. Only grant portion to the region during these thirteen years is about 65,000 crore rupees (Sachdeva 2004: 53-63). So the lack of development could not be because of shortage of funds. In fact, as economist and Congress leader Jairam Ramesh has recently argued that this kind of public expenditure has become very much part of the 
problem of the Northeast (Ramesh 2005). In fact, a significant portion of development funding actually ends up in the hands of underground groups.

Third, the importance of high literacy levels in the Northeast should not be over emphasized. Although the region has done well in education due to several socio-historical factors, but there lies underneath some serious problems - that of imbalance. Results of 2011 census indicate that despite some pockets of high literacy the combined literacy rate in the region is 73.7 per cent, which is slightly below the national average. Even in the neighbouring West Bengal, the literary rate is 77 per cent. ${ }^{6}$ Low literacy rates in Arunachal Pradesh and Assam are responsible for this. There is, however, significant improvement between 2001 and 2011. According to 2001 census, thirty-five out of seventytwo districts of the region recorded literacy levels below national average. Even high literacy rates in other districts were accompanied by low educational levels due to high dropout and low standards. Active student politics and the culture of bandhs in the region have created havoc with the education system. There are enough teachers in the region but many of them are not trained. According to sixth National Council of Educational Research and Training (NCERT) survey, only 45 per cent of total school teachers in the region are trained. The corresponding figure for the national level was about 87 per cent. The situation was particularly bad in Assam and Nagaland where only about 30 per cent teachers at the secondary and higher secondary levels were trained. Latest figures from the Ministry of Human Resource Development also indicate that except Manipur, all the states in the region has high gross dropout rates at all stages. Even in a state like Mizoram, which has almost 90 per cent literacy, about 76 per cent students could not complete high school (Annual Report 2004-05: 262).

Another factor is that major parts of the region face labour scarcity. This is perhaps one of the main reasons for the failure of various labour intensive government schemes like animal husbandry, Jawahar Rozgar Yozana and so forth. Despite all the talk of outside invasion, labour (both skilled and unskilled) is a big problem with the possible exception of Brahmaputra valley and Tripura. Already outside labour (mainly from Bangladesh, Myanmar, Nepal and other parts of India) is a crucial factor in both agricultural as well as non-agricultural activities. With any increase in economic activities, the problem of labour shortage is expected to be aggravated. Unless the inner line restricted areas' are opened for outside labours, economic development is going to suffer. Or worse, it would be an open invitation to illegal Bangladeshi immigrants. 
Another standard argument is its disadvantageous geographical situation. This has been argued in writings as one of the main stumbling block for its economic development. The region shares less than 1 per cent of its borders with the rest of the country, and the rest with Bhutan, Bangladesh, Myanmar and China. For the most part this international border has been artificially created. The result has been the elimination of the region's trade, commerce and other linkages which existed in the pre-partition days. This locational disadvantage could be converted into a boon as these states are very close to the dynamic Southeast and East Asian economies. It is imperative to develop coherent policy thinking in this area. The reason being that there is not only a failure of the economic policy framework in the region but also a weakness of country's foreign policy which had ignored Southeast Asia for a long time. So far the major border trade activity of the region with Bangladesh and Myanmar has been 'unauthorised trade'. China is an important player in the border trade even though its trading activities are mainly through Myanmar. The major policy issue, therefore, would be to synchronize these realities into Indian trade policies. But first of all the region should start producing globally competitive products. Otherwise the region would be a transit point of goods which may create further discontent.

\section{Conclusion}

In conclusion, the failure of economic strategy for the region is not because of any so-called economic neglect but because of wrong assumptions and inappropriate socio-economic policy framework, which have created an unbalanced economy and destroyed the basic institutions of market economy. There is no 'land market' as twothirds of the land area is under community or clan ownership. There are restrictions on labour movement due to inner line regulations in Arunachal Pradesh, Nagaland and Mizoram. And, of course, there is no investment climate due to law and order situation and attitude towards outsiders. We need to demystify the region, create basic institutions of market economy and start working towards linking the region with dynamic Asian economies.

In a liberalized economy, any new policy has to be based on some kind of market oriented approach. This framework should concentrate more on economic factors and less on political and cultural factors. The economic factors include labour cost, comparative advantages, technology, efficiency and returns on investment. In a market economy environment, the inefficient economic processes (jhum) and barriers 
to market entry (inner line regulations, restricted area permits, trading licensees, existing land tenure policies in hilly areas etc.) will clearly make an economic difference.

Although market forces will play a greater role, the state institutions will have to be geared up for the new task. The stimulus to expansion at the national level is likely to run up against supply bottlenecks due to insufficient infrastructure, entrepreneurship, business supporting institutions as well as the insurgency, which prevails in many parts of the region. This is where the state would have to play a role, specifically the state governments. Therefore, there is an urgent need to reappraise the role of the central as well as the state governments in developing the region with the right degree and intensity in the context of a decentralized liberal economy. The central government will play the role of a facilitator rather than a promoter of development. The actual action regarding land policies, inner line regulations, law and order, and above all, changes in attitude towards investors (read outsiders) will have to begin at the state level.

\section{Notes}

1 This is a revised version of the paper 'Preparing the Northeastern Economy for the Future', Eastern Quarterly, 3(3): 183-95, 2005.

2 This literature survey has been well documented in Shetty (2003).

3 Some of these special historical and geographical aspects of the region as well as background of special constitutional arrangements are nicely summarized by L. P. Singh. See his 'Problem', 1990, No. 336.

4 For detail see North Eastern Region: Vision 2020.

5 Demographic Status of Scheduled Tribe Population and its Distribution. Ministry of Tribal Affairs, Government of India. http://tribal.nic.in/WriteRe adData/userfiles/file/Section\%20Table/Section1Table.pdf

$6 \mathrm{http}: / /$ censusindia.gov.in/2011-prov-results/data_files/india/Final_ PPT_2011_chapter6.pdf

\section{References}

Baruah, Sanjib. 2003. 'Protective Discrimination and Crisis of Citizenship in North-East India', Economic and Political Weekly, 26 April.

Baruah, Sanjib. 2005. Durable Disorder: Understanding the Politics of Northeast India. New Delhi: Oxford University Press.

Bhardwaj, Krishna. 1982. 'Regional Differentiation in India: A Note', Economic and Political Weekly, April.

Government of India. 1961. Third Five Year Plan. New Delhi: Planning Commission.

Government of India. 1970. Fourth Five Year Plan. New Delhi: Planning Commission. 
Government of India. 2005. Annual Report 2004-05. New Delhi: Ministry of Human Resource Development.

Government of India. 2008a. Eleventh Five Year Plan 2007-2011, Vol. 1. New Delhi: Planning Commission.

Government of India. 2008b. North Eastern Region: Vision 2020. New Delhi: Ministry of Development of North Eastern Region. www.mdoner.gov.in/ sites/default/files/silo2_content/ner_vision/Vision_2020.pdf

Government of India. 2013. Twelfth Five Year Plan, Vol. 1. New Delhi: Planning Commission.

Government of India. 1981. Sixth Five Year Plan. New Delhi: Planning Commission.

Government of India. 1985. Seventh Five Year Plan, Vol. 1. New Delhi: Planning Commission. www.planningcommission.nic.in/plans/planrel/fiveyr/default.html

Government of India. 1985. Seventh Five Year Plan, Vol. 2. New Delhi: Planning Commission. www.planningcommission.nic.in/plans/planrel/fiveyr/default.html

Government of India. 1992. Eighth Five Year Plan, Vol. 2. New Delhi: Planning Commission. www.planningcommission.nic.in/plans/planrel/fiveyr/default.html

Government of India. 2002. Tenth Five Year Plan, Vol. 3. New Delhi: Planning Commission.

Ramesh, Jairam. 2005. 'Northeast India in New Asia', Seminar, 550, June.

Sachdeva, Gulshan. 2000. Economy of the Northeast, Policy, Present Conditions and Future Possibilities. New Delhi: Konark Publishers.

Sachdeva, Gulshan. 2004. 'Fiscal Governance in the Northeast', Dialogue Quarterly, 5(4): 53-63.

Sharma, Arvind K. 1998. 'District Councils in the North-East', in T. N. Chaturvedi (ed.), Fifty Years of Indian Administration: Retrospect and Prospect. New Delhi: Indian Institute of Public Administration.

Shetty, S. L. 2003. 'Growth of SDP and Structural Changes in State Economies: Interstate Comparison', Economic and Political Weekly, 6 December.

Singh, L. P. 1990. " "Problem" in "The North-East: A Symposium on the Problem of a Neglected People \& Region”, Seminar, 336.

Srivastava, Nirankar. 2000. Survey of Research in Economics on Northeast India 1970-1990. New Delhi: Regency Publications/ICSSR-NERC.

Srivastava, Nirankar. 2002. Northeast India: A Bibliography. New Delhi: Teen Murti Museum and Library. 


\title{
29 Critiquing the development intervention in the Northeast ${ }^{1}$
}

\author{
Amar Yumnam
}

The approach of the Government of India (GoI) to the development needs of the Northeastern region (NER) has been well-summarized by the High Level Commission, popularly known as the Shukla Commission, thus:

The Northeast tends to be seen as a distant post, some kind of land's end. Yet it was until recently a crossroads and a bridge to Southeast and East Asia, with its great rivers ending in ocean terminals ... the Northeast must be enabled to grow at its own pace and in accordance with its own genius. It cannot be treated merely as a resource region, market dump and transit yard. There is a strong resentment over what is seen as an earlier phase of 'colonial exploitation' in which wealth was extracted for others' enrichment. Such a path of development is not advocated.

(GoI 1997: 2-3)

The lack of or level of development the NER, particularly Manipur, has reached would be evident from the other chapters in this volume. My concern in this chapter would be to appreciate the basic impacts the policies purportedly meant for development have had on other aspects instead of fostering development. ${ }^{2}$ My fundamental argument in this chapter is to show how the various policies have rather led to nurturing and fostering political competition rather than economic competition. Further territorial security rather than peoples' security has been the driving principle. In the process, country rode over the nation.

\section{The macro-foundations}

Before we come to the micro-foundations and the approaches adopted specifically for the region, it would be in place how the regional 
development policy has evolved in India during the period before 1991. ${ }^{3}$ Though there are several well-known writings on the aspect of regional balance (Myrdal, Hirschman and Williamson), ${ }^{4}$ my concern here, however, is with the policy approaches as reflected in the Plan and policy documents of the GoI.

The First Five Year Plan of India was on a rush order basis. Its main aim was to stabilize and rehabilitate the economy from the devastating effects of the Second World War and the partition of the country. ${ }^{5}$ The basic thrust behind the Plan was that "without a substantial increase in the production of food and raw materials needed for industry it would be impossible to sustain a higher tempo of industrial development' (GoI 1952: 44). The Plan recognized that the 'excessive concentration of industries brings in its wake certain economic and social disadvantages and a wider diffusion of industry is desirable from this larger point of view. Further, if industrial development in the country is to proceed rapidly and in a balanced manner, increasingly greater attention will have to be paid to the development of those states and regions which have so far remained backward' (ibid. 442). This understanding, however, could not be translated into action as the Plan remained essentially a rehabilitation plan and the share of industry in the total outlay was low. The development of industries in India was, till 1991, mainly regulated by the Industries (Development and Regulation) Act, 1951. The First Schedule of this Act gives a detailed list of the industries which are to be under the control of the central government. ${ }^{6}$ In 1954, the Indian Parliament passed a resolution that the basic aim of economic policy should be a socialistic pattern of society. Two years later, the GoI came out with the Industrial Policy Resolution 1956a, which had continued to be the guiding principle of India's industrialization policy. This Policy Resolution notes:

In order that industrialization may benefit the economy of the country as a whole, it is important that disparities in levels of development between different regions should be progressively reduced. ... Only by securing a balanced and coordinated development of the industrial and the agricultural economy in each region, can the entire country attain higher standards of living.

It was in this background that the Second Five Year Plan was formulated. Though it talked of progressive reduction of regional disparities, it essentially remained a plan for the promotion of basic industries and labour intensive consumer industries. It emphasized rapid industrialization and diversification of the economy as the core of development. 
But 'if industrialization is to be rapid enough the country must aim at developing basic industries and industries which make the machines needed for further development' (GoI 1956b: 25). It continues:

Investment in basic industries creates demands for consumer goods, but it does not enlarge the supply of consumer goods in the short run; nor does it directly absorb any large quantities of labour. A balanced pattern of industrialization, therefore, requires a well organised effort to utilise labour for increasing the much needed consumer goods in a manner which economises the use of capital.

(GoI 1956b: 25)

But we all are aware of what happened to the Second Plan which was abandoned midway.

From the angle of regional development policy as well as from the basic thrust of this chapter, what are of utmost relevance are the developments during the Third and Fourth Five Year Plans. For the first time, the Third Five Year Plan approached the problem of industrialization from the wider perspective of balanced regional development, and devoted an entire chapter on it. It pointed out:

There are many examples both of countries and of regions within a country in which, with limited development in industry, an appreciable rise in living standards has been achieved through the fuller utilisation of local natural and human resources. There are also instances of areas around massive projects where no great impact on the levels of living of the people is to be observed. Apart from the basic and capital goods industries and other large industries, there are other industries whose possibilities need to be fully explored such as labour intensive industries of the traditional type, small scale industries of modern type, agricultural processing industries, forest industries, assembly operations, and recreational industries. Each region should endeavour to identify, plan for and promote industries which are specially suited to its conditions and for which it can provide relatively greater facilities.

(GoI 1961: 143)

This Plan proposed the setting up of 'industrial development areas' in backward regions where 'basic facilities like power, water and communications are to be provided, and factory sites developed and offered for sale or on long lease to prospective entrepreneurs' (GoI 1961: 149). It also put forward the concept of large projects as regional growth 
nuclei. It recognized that balanced regional development involved the preferential treatment of backward regions in the location of training facilities for engineers craftsmen etc., training programs to facilitate labour mobility and engendering the growth of small and medium entrepreneurs. It also gave importance to dispersal of small-scale industries. But most of the various comprehensive statements made by the Third Plan on balanced regional development 'remained a mere charter of intentions' (Sundaram 1978: 78).

By the end of the Third Five Year Plan, it was admitted that in terms of regional development, there has been a natural tendency for new enterprises and investments to gravitate towards the already overcrowded metropolitan areas because they are better endowed with economic and social infrastructure. Not enough has been done to restrain this process. While a certain measure of dispersal has been achieved, a much larger effort is necessary to bring about greater dispersal of industrial activity' (GoI 1970: 11). The necessity of specific policy instruments designed exclusively to promote industrial development in backward areas was recognized during this period. The committee of the National Development Council (NDC) decided in its meeting on 13 September 1968 to set up two working groups, one dealing with the identification of backward areas and another with the incentives for starting new industries in backward areas. ${ }^{7}$ The first one dealing with the identification of backward areas is commonly known as the Pande Working Group and the second dealing with the incentives as the Wanchoo Working Group depending on the names of the Chairpersons of the groups. These two working groups were set up by the Planning Commission in pursuance of the NDC resolution. The Pande Working Group submitted its report on 'Identification of Backward Areas' in February 1969 and the Wanchoo Working Group on 'Fiscal and Financial Incentives for Starting Industries in Backward Areas' in April 1969. Whereas the criteria suggested by these two working groups for identification of backwardness and provision of financial and fiscal incentives might be of little relevance here, I must hasten to add that both the groups put emphasis on identification of backwardness at the state or union territory levels. This orientation of the two groups proved to be absolutely consequential for the issue whether it was political competition or economic competition at the countrywide level to be fostered. The basic thrust of the two groups to identify backwardness at the state or union territory levels and to devise incentives accordingly did not meet the political desires of the larger and economically already more powerful states. ${ }^{8}$ These larger and powerful states started their own political mobilizations before the 
recommendations of the two reports were converted into policy. The politically as well as economically weaker states like Manipur, Nagaland, Mizoram and so forth were in no position to match the weight of their larger and stronger counterparts in other parts of the country. The two reports were finally put for consideration in the meeting of the NDC in September 1969. The two main decisions taken in this meeting are quite significant.

1 Concessions to be offered by credit and financial institutions for financing industries in backward areas should be available to all the backward areas in all the states and union territories. When time comes for decisions, the larger states, both economically and politically, could easily prevail their options over the economically and politically smaller ones; and

2 The criteria to be adopted for identification of industrially backward districts may be settled by the Planning Commission in consultation with the state governments and the financial institutions in the background of the recommendations of the two working groups. When it comes to investments, the economically and politically larger states would definitely satisfy the requirements of the financial institutions better than the economically and politically smaller ones. This static perspective, however, completely ignores the dynamic requirements of building a pluralistic nation almost the size of a subcontinent with absolutely diverse geographic $^{9}$ and institutional ${ }^{10}$ needs of development interventions. To put it another way, the heterogeneity in culture, demography and geography was swept under the carpet under a very paternalistic approach of taking care and not enhancing capability for development. ${ }^{11}$

The turnaround was now complete. And it has yet remained more or less there only. The messages emerging from the entire process were as follows:

1 The backwardness of states like Manipur was to be treated on par with the backwardness of some districts in Maharashtra, Gujarat and so forth. This, as mentioned above, would satisfy the immediate static principles of economic optimization, but not the long term dynamic needs of fostering a nationwide economic strength and competition; and

2 Whatever the longer-term economic compulsions, the ultimate decision would be based on political weights and political aims 
driven by short run static arguments. The needs of economically and politically smaller states like Manipur could naturally not fulfil the static principles of optimization better than the larger states.

Such a message for political competition ${ }^{12}$ rather than equipping for economic competition on equal footing has had its deleterious impact on the psyches of the larger population of backward states like Manipur - states weak both economically and politically in terms of the national decision making structure. This has completely disoriented the perspective of the political class in the region as well. For the last four decades or so, the one basis on which the political leaders in the NER have been requesting funds is the need to fight insurgency. This serves the twin purpose of catering to the political orientation of national decision making and stunting the economic articulation of the population in the region. This overall macro perspective of the GoI was accompanied by other national approaches towards the region and region's own weaknesses, which together have played havoc with the development process of the region. Let us now turn to these.

\section{The initial conditions and sustained approaches}

The initial conditions in 1951, when the planning process was started in the country, were absolutely non-convergent between the NER and the country in general. ${ }^{13}$ The British left the country in general with a rich endowment of able administrators, while just the opposite was the case for the region. ${ }^{14}$ It was in such a context that the regional administration was left in the hands of lower calibre bureaucrats serving time in the distant post. These definitely lacked acquaintance of the regional realities and commitment to the region.

Second, the British introduced and exposed the mainland India to quite a few modernizing elements like the industrial culture and respect for rules. This synchronized with the pioneering efforts of Indian industrialists of Jamshedji Tata's genre.

Besides, the importance of planning for economic development was fairly well understood by a few to begin with and spread horizontally to the educated elite in the case of mainland India (Myrdal vol. II 1968: 712). But this definitely was not the case in the region as the movement for mass education is fundamentally a post-1950 phenomenon in the region.

Given these initial conditions, it would be easily evident that the NER in the 1950s just could not articulate its own development future (Yumnam 2004; Sarma 2005a: 1-20; Sarma 2005b). It was during 


\section{Amar Yumnam}

this period that the GoI evolved and adopted an approach towards the region, which has fundamentally remained the same till today (Yumnam 2004). The GoI adopted an approach founded on two edifices. The first edifice was one of non-interference into the traditional socioeconomic structure of the region. The second was national security perspective. Since the NER could not articulate itself its own development future and given the low level of understanding and appreciation of the region among the policy makers in Delhi, the surest shortcut to policy was one based on security. ${ }^{15}$ So security emerged as the guiding principle for all policy interventions, development or otherwise, in the region. The security principle, or rather the insecurity of the GOI, drove it to adopt the Armed Forces Special Powers Act (Assam and Manipur) way back in 1958 when there was hardly any insurgency in the region. The GOI could never get rid of its insecurity and abandon the security principle even when it belatedly realized that the NER needed a development agency for transformation. As a result, when the North Eastern Council (which should have been there in 1958 instead of the Armed Forces Special Powers Act) was established in the early 1970s, it was placed under the Home Ministry. But the Home Ministry could never evolve a development strategy for the region as it is neither competent nor oriented for such a task. This politicization of economic issues had reached its height with the requirement of certificates from the Home Ministry for the provincial government to get funds sanctioned from the Ministry of Finance.

\section{The result}

The concatenation of the above three crucial factors - basing national policy for regional development on political weights, region's inability to articulate its own development agenda and the Gol's approach of basing policies towards the region on security principle - has stunted the evolution of a spontaneous economic awareness in the region, has kept the people of the region occupied in tackling the transitory political issues and has thus kept them away from articulating any kind of economic agenda for mutual cooperation and competition. This has further had the unfortunate impact on three counts:

1 Since no common economic agenda has emerged, it was not costly for any group to articulate its own political agenda as it would involve no economic cost to the group. This is how fractionalization has intensified in the region with definitely deleterious implications for both region and nation. ${ }^{16}$ Since no common economic 
framework has emerged, the dichotomy between the hill economy and the economy of the plains has intensified. Examining the road infrastructure situation of Manipur, an international team of experts, which included the present author, observed in 1999: 'One can easily deduce from the district-wise road-density figures the kind of transport bottlenecks being faced in the hilly areas. Superimpose this on the difficult terrain of the hills and the problem is really enormous. This makes the hill economy a much more costlier one as compared to the valley economy, and, in turn, serves as a double constraint on development. First, because of the low level of economic activity in the hills, real wages are low there, and second, due to higher transport costs, prices are higher in the hills' (Government of Manipur 1999: 3-27). What is most unfortunate for all of us is that such problems do not get highlighted or articulated by any group. This scenario is to be appreciated from various angles. First, there is the divergence of ethnic groups in the region, and this internally homogeneous and heterogeneous (cf. Pons-Vignon and Lecomte 2004) with each other population is settled in more or less spatially contiguous and homogeneous areas. Second, not only is there non-emergence of a common economic frame and interdependent growth, but also there is the issue of growth slowdown in the region during the 1970s and 1980s; and

2 As a result all the social organizations in the region are now involved in political competition and political one-upmanship rather than articulating the developmental needs of the general population. This has had the even more unfortunate effect of politicizing the all-important event of decennial census. The trend now is each ethnic group (majority of the many groups) trying to over enumerate its own population in the census as a means to get more out of any intervention. This is seen more among smaller ethnic groups in their efforts to establish a politically equal playing capacity vis-à-vis larger ethnic groups. Such a trend has emerged because a feature of deciding on economic matters on the basis of political weightage rather than economic compulsions has been made inherent in most of our significant development interventions. This has had second round impact of each group articulating, as no economic cost is involved, to have a separate and autonomous administrative unit as that is seen as the only means for any advancement whatsoever. In other words, the dominant articulations in the region are now particular community-centric or specific area-centric. The casualties naturally have been the articulation of an economic agenda, and the 
building up of a region-wide and across-the-communities articulation for development.

3 The state - as represented whether by the provincial government or by the union government - has never been a credible institution. ${ }^{17}$ Increasing resort by the state and even non-state agents to rule of state law rather than rule of law has been the lived experience of the people since 1949. Due to the enforcement of rule of state law rather than rule of law, each ethnic group was force-mobilized to be always on alert to protect itself and reduce the damages from the brutalities of the enforcement of rule of state law. Now we have before us these realities: (1) the sociological reality of noninclusive society; (2) the economic reality of non-inclusive growth and growth slowdown; and (3) the political reality of lack of credibility of the state. As a result of the interplay of the above factors the various groups, particularly the smaller groups, did not visualize any economic benefit from identifying with and working for the larger macro-economy of Manipur. Now these above are necessary and sufficient conditions for the ethnic-based articulations and mobilizations to surface as well as gain momentum in a multi-ethnic society like Manipur's. The primordial identity now becomes the only identity for rallying around for political and economic reasons as well. In other words, the primordial identity has become the instrumental variable for all articulations political, sociological and economic. Unfortunately for Manipur, the use of this identity has been made even more convenient and forceful by the districting process in the state. ${ }^{18}$

\section{The challenge}

The challenge now before the regional governments and the GoI is to work in tandem and vigorously for generating an atmosphere of economic competition ${ }^{19}$ in the region. If we are not able to do so in less than a decade, the region's future as well as the nation's future in the region is at stake. This is more so with so many hurdles to be crossed before the region faces the opening up to East and Southeast Asia head-on. Besides the hometruths as mentioned by Atul Sarma (Sarma 2005b), there are so many scientific and technological truths to be addressed without any loss of time. Unless something definitive is done for fostering economic competition through appropriate investment intervention in right earnest, even the censuses in the coming decades would be even more unreliable. The regional economy is now 
marked by (1) diversification of consumption without strengthening any production and productivity base; and (2) absolute lack of a common economic characteristic with each spatial (hills, valley and what not) economy remaining as local economies ${ }^{20}$ rather than as components of a larger regional or provincial economy fit for emergence into an atmosphere of economic competition to replace the articulations for fractionalization. This is the moment for absolute strengthening of all the institutions of governance, education and legality for fostering rule of law culture, enhancing social capability, cultivating a new credibility of the state and all these in a contextual way. Contextualization of the interventions is paramount now as time is of the essence. The historical juncture now is of the Generation $\mathrm{Y}$ with accumulated state failures.

\section{Notes}

1 This is a revised version of the paper 'Development Intervention in the Northeast: A Critique', Eastern Quarterly, 3(3): 196-205, 2005.

2 Whereas the Manipur's merger with India in 1949 was expected to establish and strengthen the foundations for development in the province, it has not even been able to sustain the bases created by the British, and capitalize on the massive social capital mobilized during 1950s to mid-1960s. Cf. Acemoglu et al. 2001 (91): 1369-1402.

3 This dividing line of 1991 is used for practically the very issue of regional balance has been taken out of the agenda with the adoption of structural adjustment programs in this year whereby planning has been put to the backburner, and privatization and liberalization are now the guiding principles of any economic policy.

4 See Myrdal (1973); Hirschman (1958); Williamson (1965: 3-45). More recently, there have emerged a strong revival of regional studies with diverse approaches. Some of these are Maskell et al.(1998), Rosser (2011), Nijkamp and Siedschlag (2011) and Kanbur and Venables (2005).

5 This attempt to address the adverse partition effects were confined to those felt in the northwestern and eastern parts of the country, but the absolutely deleterious economic impact on the NER went unnoticed. In other words, it was as if India ended with West Bengal on the Eastern Frontier.

6 This list is so detailed as to cover the entire gamut of industries. Nonetheless, Section 25 of the Act provides for the delegation of power to the state government or other bodies by a notified order of the central government.

7 This is the most significant occasion in India's balanced regional development planning attempts for the fallouts of the reports of these two groups shaped the politicking for funds in the subsequent periods.

8 In the Indian democratic system, the constitution of the representatives in the Parliament (in both lower and upper houses) - Lok Sabha and Rajya Sabha - is fundamentally of the representatives of the larger states necessarily. Thus when financial bills are discussed and developmental allocation decisions are adopted the priority of these states become predominant. 
9 On this see, Krugman (1991) (99): 483-499;Fujita, Krugman and Venables (1999); Fujita and Thisse (2002); Henderson (1988); Sachs, Gallup and Mellinger (1998); Mellinger, Sachs and Gallup (2000); Sachs (2005). See also 'My main conclusion [is] that societies developed differently on different continents because of differences in continental environments, not in human biology' by Diamond (2003).

10 See in this context, North and Thomas (1973), wherein they present the efficiency view of institutions; and North 1981 wherein the efficiency view is abandoned but the continuation of inefficient institutions cannot be explained. Also see North (1990). There is a subtle change or rather widening of view in North in Understanding the Process of Economic Change, 2005. Also see Greif (2006); Guo (2006); Coleman (1988), reprinted in Dasgupta and Serageldin (2000). Also see, Dasgupta and Serageldin (1990); Sabatini (2006); Putnam, Leonardi and Nanetti (1993).

11 For an extensive discussion on this issue, see Yumnam (2009).

12 The political competition I have in mind is not the one of competition through the electoral process which can be good both for democracy and development. What I have in mind is the articulation of every issue on political grounds for political reasons and without in any case reflecting the economic situation of the places and people. Cf. Besley, Persson and Sturm (2005).

13 It would be rewarding to see the various differences in initial conditions between the countries of South Asia and the Western countries on the eve of their industrial revolution given by Myrdal(1968).

14 W. Arthur Lewis writes: 'In the first place, planning requires a strong, competent and incorrupt administration', 1969: 121. Such a requirement is all the more for a region where the people are not yet attuned to modern attitudes of risk-taking and profit-making through investment in activities that add to the aggregate product.

15 It has fundamentally remained as security of territory and boundary with no scope allowed for security of people. This is despite the global experience of only people ensuring security of a country/nation rather than by military.

16 The literature on fractionalization is by now fairly rich. See, for instance Bates (1999); Tan (2005).

17 On a general perspective on this, see Borner, Brunetti and Weder (1995).

18 For a longer commentary on this, see Amar Yumnam, From Political to Economic Agenda: A Sustainable Development Future for Manipur, 2006. SSRN: https://ssrn.com/abstract=2696121 or http://dx.doi.org/10.2139/ ssrn.2696121

19 As compared to the political competition I have mentioned, which has a zero-sum nature inherent in it, the economic competition I have in mind is the one usually employed by economists. This kind of economic competition would be based on value-addition activities and in the first best case would be a win-win one. Even in the second-best cases, there would always be options for corrective mechanisms and the areas for state intervention would be spelt out on the basis of economic arguments, and not on the basis of ethnic-centric or specific area centric political articulations.

20 The level of interaction of local economies, despite the potential and real free mobility of labour and other factors, is such that the overall interdependence within the region/sub-region spaces and population do not decide the overall economic fate of the internally homogeneous and externally heterogeneous population (groups) and spaces. 


\section{References}

Acemoglu, D. S., S. Johnson and J. A. Robinson. 2001. 'The Colonial Origins of Comparative Development: An Empirical Investigation', American Economic Review, 91.

Bates, Robert H. 1999. 'Ethnicity, Capital Formation and Conflict', CID Working Paper 27, Harvard University.

Besley, Timothy, Torsten Persson and Daniel Sturm. 2005. 'Political Competition and Economic Performance: Theory and Evidence from the United States', Working Paper 11484, NBER.

Borner, Silvio, Aymo Brunetti and Beatrice Weder. 1995. Political Credibility and Economic Development. St. Martin's Press.

Coleman, James S. 1988. 'Social Capital in the Creation of Human Capital', American Journal of Sociology, 94: S95-S120.

Dasgupta, Partha and Ismail Serageldin (eds.). 1990. Foundations of Social Theory. Massachusetts and London: Balknap Press.

Dasgupta, Partha and Ismail Serageldin (eds.). 2000. Social Capital: A Multifaceted Perspective. Washington, DC: World Bank.

Diamond, Jared. 2003. Guns, Germs, and Steel: The Fates of Human Societies. New York and London: Norton.

Fujita, Masahisa, Paul Krugman and Anthony Venables. 1999. The Spatial Economy: Cities, Regions and International Trade. Cambridge, MA: MIT Press.

Fujita, Masahisa and Jacques-Francois Thisse. 2002. Economics of Agglomeration: Cities, Industrial Location, and Regional Growth. Cambridge: Cambridge University Press.

Government of India. 1952. First Five Year Plan. New Delhi: Planning Commission.

Government of India. 1956a. 'Industrial Policy Resolution'. New Delhi: Planning Commission.

Government of India. 1956b. Second Five Year Plan. New Delhi: Planning Commission.

Government of India. 1961. Third Five Year Plan. New Delhi: Planning Commission.

Government of India. 1970. Fourth Five Year Plan. New Delhi: Planning Commission.

Government of India. 1997. Transforming the Northeast: Tackling Backlog in Basic Minimum Services and Infrastructural Needs. New Delhi: Planning Commission.

Government of Manipur. 1999. 'Strategic Options Study', Project Coordinating Consultancy Services, World Bank Study.

Greif, Avner. 2006. Institutions and the Path to the Modern Economy: Lessons from Medieval Trade. New Jersey: Cambridge University Press.

Guo, Rongxing. 2006. Cultural Influences on Economic Analysis: Theory and Empirical Evidence. Basingstoke and New York: Palgrave Macmillan.

Henderson, J. Vernon. 1988. Urban Development: Theory, Fact and Illusion. Oxford: Oxford University Press. 


\section{Amar Yumnam}

Hirschman, Albert O. 1958. The Strategy of Economic Development, Chapter 10. New Haven and London: Yale University Press.

Kanbur, Ravi and Anthony J. Venables (eds.). 2005. Spatial Inequality and Development. Oxford: Oxford University Press.

Krugman, Paul R. 1991. 'Increasing Returns and Economic Geography', Journal of Political Economy, 99.

Lewis, W. Arthur. 1969. Principles of Economic Planning. London: Allen and Unwin.

Maskell, Peter, Heikki Eskelinen, Ingjaldur Hannibalsson et al. 1998. Competitiveness, Localised Learning and Regional Development: Specialisation and Prosperity in Small Open Economies. New York and London: Routledge.

Mellinger, Andrew, Jeffrey D. Sachs and John L. Gallup. 2000. 'Climate, Coastal Proximity, and Development', in Gordon Clark, Maryann P. Feldman and Meric S. Gertler (eds.), The Oxford Handbook of Economic Geography. Oxford: Oxford University Press.

Myrdal, Gunnar. 1968. Asian Drama, 3 vols. New York: Pantheon.

Myrdal, Gunnar. 1973. Economic Theory and Underdeveloped Regions, Chapter 3. Bombay: Vora.

Nijkamp, Peter and Iulia Siedschlag (eds.). 2011. Innovation, Growth and Competitiveness Dynamic Regions in the Knowledge-Based World Economy. New York, Dordrecht, Heidelberg and London: Springer.

North, Douglas C. 1981. Structure and Change in Economic History. New York: Norton.

North, Douglas C. 1990. Institutions, Institutional Change and Economic Performance: Political Economy of Institutions and Decisions. Cambridge: Cambridge University Press.

North, Douglas C. 2005. Understanding the Process of Economic Change. Princeton: Princeton University Press.

North, Douglas C. and Robert P. Thomas. 1973. The Rise of the Western World. Cambridge: Cambridge University Press.

Pons-Vignon, Nicolas and Henri-Bernard Solignac Lecomte. 2004. 'Land, Violent Conflict and Development', Working Paper No. 233, OECD Development Centre.

Putnam, Robert D., R. Leonardi and R. Nanetti. 1993. Making Democracy Work: Civic Traditions in Modern Italy. Princeton, NJ: Princeton University Press.

Rosser, J. Barkley. 2011. Complex Evolutionary Dynamics in Urban-Regional and Ecologic-Economic Systems: From Catastrophe to Chaos and Beyond. New York, Dordrecht, Heidelberg and London: Springer.

Sabatini, Fabio. 2006. The Empirics of Social Capital and Economic Development. http://ssrn.com/abstract=879712. Accessed on January 2006.

Sachs, Jeffrey D. 2005. The End of Poverty: Economic Possibilities of Our Time. Penguin.

Sachs, Jeffrey D., John Luke Gallup and Andrew Mellinger. 1998. 'Geography and Economic Development', Annual World Bank Conference on Development Economics. 
Sarma, Atul. 2005a. 'Why the Northeastern States Continue to Decelerate?', Man and Society, Spring.

Sarma, Atul. 2005b. 'Northeast as Gateway to Southeast Asia: Big Dream and Home Truths', Presidential Address, Seventh Annual Conference of North Eastern Economic Association, Itanagar, 21 October.

Sundaram, K. V. 1978. 'Some Recent Trends in Regional Development Planning in India', in R. P. Misra and D. V. Urs (eds.), Regional Planning and National Development. New Delhi: Vikas.

Tan, C. M. 2005. 'No One True Path: Uncovering the Interplay between Geography, Institutions, and Fractionalization in Economic Development. Tufts University, Dept. of Economics Working Paper No. 2005-12.

Williamson, Jeffrey G. 1965. 'Regional Inequality and the Process of National Development: A Description of the Patterns', Economic Development and Cultural Change, 13.

Yumnam, Amar. 2004. 'Regional Cooperation and Development: Strategy for Development in a Conflict Zone', Paper read at the National Seminar on 'Towards a New Asia: Transnationalism and Northeast India', organized by the Centre for Northeast India, South and Southeast Asia Studies, OKD Institute of Social Change and Development, Guwahati, 10-11 September. Yumnam, Amar. 2009. 'Northeast: Time to Move from Generalist Nash Equilibrium to Specialist Equilibrium', Presidential Address to North Eastern Economic Association 11th Annual Conference, Guwahati, India, 18 December. SSRN: https://ssrn.com/abstract=1526982 or http://dx.doi.org/10.2139/ssrn. 1526982 
$\because$ Taylor \& Francis

http://taylorandfrancis.com 


\section{Part XIII}

\section{Critiques of development discourse}


$\because$ Taylor \& Francis

http://taylorandfrancis.com 


\title{
30 Understanding underdevelopment State of economy in the Northeast ${ }^{1}$
}

\author{
Thingnam Kishan Singh
}

In contemporary times, many polemical debates have revolved around the concept of development. What necessarily constitutes development or the parameters of development still eludes the public discourse. As human beings organized themselves into communities and societies with characteristic features of production based on the surrounding environment, understanding the centrality of production that sustains human life becomes all the more imperative. Modes of production therefore are necessarily correlates of modes of development. Change in the mode of production inevitably conditions the nature, scope and impact of development.

Development debates vis-à-vis the Northeast generate complex and polarized positions. What has perhaps been postulated as 'complex' conspicuously underlines the marginality of these very debates. Purported complexity of the issue has been an overarching articulation amongst the policy makers in New Delhi. At the outset, it is important to note that conceptualizing the region as a compact entity is not without problems. Given the historical evolution of the region as an entity in terms of the geographic, political, economic and social space it occupies, modern understanding of the region apart from its historicocultural configurations is intertwined with colonial geography and historiography. Since British colonialism took roots in Bengal in the mid-eighteenth century, a systematic attempt to explore the 'frontier' of Bengal remained a concern for the colonial administration. During those days the 'frontier region' of Bengal was loaded with imaginations important for the 'empire' (Mackanzie 1884).

\section{Foundations of underdevelopment}

Rivalry among European powers over colonial expansion led the British to concentrate initially on mainland India with the coastal regions 
perceived as strategic both in terms of economics and politics in line with its maritime framework. However as colonial expansion proliferated across the length and breadth of the Asian continent, increased and intensified competition between the English, French and Dutch in Southeast Asia had repercussions in this otherwise 'wild' region marked by 'inhospitable terrain' with mountains, deep gorges, ridges, hills and villages. Consolidation of colonial domination in mainland India along with expansionist threat posed by the French in IndoChina led the British transform their exploration of the region to the perpetration of the colonizing process. By the nineteenth century, the British colonial authorities in India grew extremely conscious of the strategic importance of the region. Since the outbreak of the AngloBurmese war in 1626, the British Raj made a conspicuous attempt to expand eastwards. Assam was the first casualty as the British soon overran the fertile Brahmaputra and Surma valleys. With the signing of the Treaty of Yandaboo in 1826, Manipur also became an important entity for the British. This colonial momentum triggered a series of events leading to far-reaching changes in the region. It was crucial for the British to incorporate the region in its colonial domain so as to open the vital alternative land transit route to Burma and Thailand, which eventually became part of the British overseas empire.

With the extension of colonial domination to the kingdom of Ahom in the first half of the nineteenth century, a gradual process set into motion with the subjugation of the 'wild tribes' in the hills of the region - Lotha Nagas in 1875, Angami Nagas in 1878-80, Ao Nagas in 1889 and Lushais in 1871 . The colonial geography replete with colonial cartography systematically organized administration of the region to facilitate economic exploitation. Territoriality of the empire inscribed in colonial geography was thereby responsible for constructing the dynamics of a political economy marked in terms of an idea articulated as a region. Transformation of the whole region into a frontier apparatus of the colonial possession in India led the British to extend their influence and domination over the entire region. Inscribed in this colonial geography was the visualization of the region as a frontier area for their prized possession known as 'the jewel in the British crown' (Reid 1942).

The colonial apparatus explored the necessity of exploiting the immense resources of the region. Plundering of the resources in the Brahmaputra and Surma valleys got underway as the British realized that it could add substantially to their coffer. In the process, Assam witnessed a kind of colonial domination more intense than other parts of the region (Guha 1991). Ever since the first half of the nineteenth century the Lakhimpur district in Assam witnessed frantic settlement 
programmes undertaken by the British to exploit the tea potential. Tea bushes were discovered in the area, which was then sparsely populated. As a cash crop tea was responsible for systematic and organized expansion of the plantation economy; British capital found profitable investment. Vast tracts of uninhabited land throughout the Brahmaputra valley were soon reclaimed and acquired through meticulously crafted land reform policies meant to subserve the interests of the colonial power. 'Tea mania' led to unchecked expansion of tea plantations with easy access to land dexterously dispossessing the indigenous population. Speculative aspect associated with this mad rush for land for tea plantations undermined and affected productivity in the region. Massive surplus thus extracted from the plantations were exported outside the region to different parts of mainland India and elsewhere in Europe (Ahmad and Biswas 2004). Colonial economies thereby created foundations for underdevelopment in the region.

\section{Birth of dependency}

The neighbouring areas were marked as the Northeast Frontier Agency (NEFA) with substantially lesser interest taken by the colonial authority (Edney 1997). Leaving the difficult adjoining upper ridges of the mountainous NEFA, the other areas witnessed the introduction of a monetized economy hitherto unfamiliar before. Traditional trade carried on under an equitable exchange system suffered immediate rupture as a system of unequal exchange based on cheap manufactured consumer items flooded the hill areas. A penchant for the new items grew alongside the rapid strides made by cultural encroachment as the tribes became increasingly dependent on imported commodities. The merchant class of Marwaris and Bengalis from mainland India subserving the interest of the colonizers were also introduced to facilitate monetization of tribal economy in the region. This merchant class introduced opium and carried on a brisk trade with far reaching consequences for the people in the hills as they were made to trade natural products like timbers and rubber for opium. Dependency thus grew amongst the tribes for manufactured commodities from outside and along with consumption of opium destroyed the traditional economy and depleted traditional resource base (Ahmad and Biswas 2004: 52). Integration of the economy of the region into the world capitalist system through the mechanics of colonial imperialism led to its transformation into a peripheral underdeveloped economy.

Even as India started to embark on the process of industrialization during the later half of the colonial period due to concomitant 


\section{6}

Thingnam Kishan Singh

and corollary efforts of the British and the emerging Indian capitalist class transformed from its feudal base - there was a conspicuous absence of similar developments in the Northeast. British colonial policy of visualizing the region as a frontier largely contributed to the undermining of any production based effort. Colonial interests in the region were served incredibly well by the Indian merchant class who exported the surplus of the region. The smooth running colonial economy through the facilitating role played by these class who extracted and exported surplus could not afford jeopardization as far as any substantive attempts to develop the industrial potential of the region was concerned. Mention may be made of the surreptitious role played by the Marwaris who in their extraction and export dynamics created artificial scarcity of rice in Manipur in 1939 - caused the fierce women's agitation also called Nupilan or literally translated as 'Second Women's War' (Singh 2006). Close survey of the economic undercurrents in the region since the British colonial intrusion reveals the steady emergence of the region's economy as a peripheral capitalist economy vis-à-vis its integration into the world capitalist system during the colonial period. It was essentially during this period that the economy of the Northeast underwent a transition from its various pre-capitalist social formations to a quasi-capitalist organization of productive forces. It can therefore be argued that such a transition was not a result of strictly chronological features. The region's historical development and progress of its mode of production have not yet had the necessary material base nor the time required to transform itself successfully into a capitalist system. What happened was the thwarting of the region's potential to transform its productive forces in order to evolve a truly meaningful development framework of its own. Instead, it witnessed the introduction of an economics that benefited the colonizers and the mercantile class of outsiders comprising of Marwaris and Bengalis. Traditional resource base and economic modes in the tribal areas were ravaged with their integration into the colonial economy. Destruction of the fragile tribal economy and subsequent emergence of a new base for creation of a modern economy based on colonial exploitation characterized the hill areas in the Northeast.

\section{Transformation, obliteration and underdevelopment}

In the area marked as NEFA, traditional economic arrangements like the posha through which the tribal people levied taxes on material goods of the plains people rapidly eroded as a result of the introduction of a monetized capitalist economy. The tribal in the hills were soon 
deprived of the right to levy and collect taxes. Due to ruptures created by the market economy - distribution, circulation and exchange of products between the hills and plains differed immensely (Mishra 1983). These transformations were instrumental in converting the region into a peripheral economy replete with the system of uneven trade. Obliteration of the traditional barriers that gradually led to the influx of immigrants introduced as a part of the colonial class to facilitate the transformations through an intermediary class discouraged local entrepreneurship (Ahmad and Biswas 2004: 53). Enjoying patronage of the colonial authorities and superior financial and material resources and networking relations these absentee interests soon controlled the entire economic landscape of the region. Colonial policies surreptitiously made rapid inroads to increase dependency of the tribes on unequal trade with the emerging commercial class to subserve the interest of exerting pressure to extract concessions for colonial expansion (Sikadar 1982). End of British colonial domination in the subcontinent in the post-Second World War era did not produce any pathbreaking changes as the region continued to reel under similar conditions in the face of an external market, now in the form of the mainland India market and its emergent national capitalist class (Mohapatra 2002: 24).

Integration of the Northeast with India - starting with the 'merger' of Assam, Manipur and Tripura in 1949 - failed to produce the dynamics of a successful transformation in terms of economic development. Mere semblance of a socialist pattern through indicative centralized planning over the last five and a half decades miserably failed to generate development and transform the region's backward and underdeveloped economy. Reasons are not far to seek. As decolonization dawned in the post-war years, it remained imperative for the newly decolonized to choose between two modes of development - the capitalist and the socialist. India's capitalist logic of development evident in its indicative planning and mixed economy with massive deficit financing of the private sector by the state concentrated and confined development in certain industrialized metropolitan pockets. It has been widely argued that the Indian state perpetuated the legacy of colonial economy with the capitalist mode of production in the post-British period as a result of the alliance and collaboration between western metropolitan capital and the indigenous capitalist class (Patnaik 1999).

The Indian capitalist class located in the industrialized locations in the mainland had already made significant inroads in the colonial economy during British rule. British departure did not entail a similar picture as far as Western capital was concerned. Western capital 
still had immensely high stakes in India. It was the successor Indian state that became instrumental in propelling capitalist development by evolving complex strategies for achieving growth of capitalism in India (Bhambri 1998: 6). Mobilization of resources on a large-scale investment and the resultant high capital-output ratio reveal the logic of capitalist contradictions. Capital driven development was concentrated in certain specific locations in mainland India while the Northeast as a region continued to suffer from a perpetuation of the logic of underdevelopment. Development issues per se in the Northeast continue to reflect the structural inequalities of patterns of economic relationship with both the global capitalist system and the newly emerged Indian capitalist system. State intervention in the post-integration period has been directed from the top. It is an explicit superstructural intervention without a firm base transformation.

\section{Reading the Northeast}

Development debates on the Northeast in mainstream Indian intellectual discourse has so far been to show the need for a top-to-bottom approach. Economic backwardness in the region has been seen and analysed through the lens of an a priori integrationist model over zealously and fervently working towards the creation of a monolithic discourse. Insularity has been a characteristic hallmark of these analyses on the region's economic standing as the basic issue of production was conspicuously overlooked. Beyond the stereotyped premises of 'neglect' or massive allocation of funds through central assistance, serious study of the region's productive management is yet to be seen. The core issue of production engaging different aspects of production sectors and potential has largely remained on the margins of development debates. Economic development sans production issue can only generate haphazard polices which in turn will eventually render multimillion economic packages and central assistance lopsided and meaningless. Underdevelopment of productive forces in the region is something that needs a detailed analysis to understand the failures behind the much hyped economic policies and packages designed in the power corridors of New Delhi.

Failure of economic policies and packages in the Northeast can be perceived strikingly clear from a cursory glance at some of the basic indices commonly used to measure the state of economic and social development. The per capita net state domestic product of the constituent states of the region indicates a dismal picture of disparity in comparison with the all India average. When India's gross domestic 
product was growing at an average over 6 per cent in real terms, economies of the region were growing at a lesser rate during 1992-99. Net state domestic product (NSDP) of the seven states of the region has shown a marked decline over the years. Decline in the annual average growth rate of NSDP has been ascribed to the increase in dependent accumulation in the region (Ahmad and Biswas 2004: 63). Even as GDP is known to hide many things, a low NSDP is not considered congenial for improving the living conditions of the people. With a primarily agrarian-based economy that still caters to subsistence production rooted in obsolete methods of farming, the unmechanized and uncommercial nature of agriculture in the region is a sector on which more than 70 per cent of the population depends upon. Population engaged in agricultural activities for livelihood constitutes the majority showing intense disparity with the all India average. High dependence on an otherwise primitive agriculture based on subsistence level of production indicates the nature of the underdeveloped economy of the region. Increasing pressure on land as a result of population growth compounded by the quantum leap through massive influx of immigrants from Bihar, Bengal, Orissa, Rajasthan, Punjab, Bangladesh and Nepal and recent trends in the wake of globalization triggered liberalization transforming cultivation configurations from food crops to cash crops contribute to significant increase in dependency. Increasing trends of displacement of rural cultivators as a result of haphazard urbanization without concomitant creation of productive base have been widely noticed. Dependency is aggravated and exacerbated in the face of decreasing production levels in agriculture, which ironically constitute the mainstay of the region's economy. Studies conducted on production in the primary sector have shown how a traditionally surplus exporting economy like Manipur - even during and after British colonial occupation - has been transformed into a net importer. Rice as the staple food grain cultivated in Manipur always reached surplus production levels with subsequent export of the surplus. However, ever since Manipur's 'integration' into India in the post British period, alarming decrease in production levels has been noticed with its subsequent transformation into a rice importing state where 20 per cent of its requirement is imported from mainland India (Singh 2005).

Despite the polemics surrounding the use of per capita income as an important indicator in assessing poverty and economic backwardness, its limitations notwithstanding, it is however generally true that people in areas with low per capita do not live well. The per capita picture in India reveals striking disparities with the states in the Northeast displaying pathetic levels. Generally speaking, a cursory glance at basic 
statistics speaks volumes for increasing dependency of the region. Per capita income in Assam in 1950-51 was found to be 4 per cent above the all India average marking it as one of the most prosperous states in the entire eastern belt. However, decades of centralized planning have led to a drastic fall showing it at 41 per cent below the all India average in 1998-99 at current prices and 45 per cent below the all India average at $1980-81$ prices. While per capita income at 1980 prices grew by 40 per cent for all India during 1980-90, Assam grew by only 20 per cent. When all India growth rate of per capita was 37 per cent during 1980-1998 in Assam it grew by just 10 per cent (GoI 2002). Similar picture prevails in the other states of the region.

Majority of the population in the region still live below the poverty line. Mass poverty as an acute problem is complementary to income inequalities. Estimate based on the study by a Planning Commission Group headed by Lakdawala gives a figure of 36.5 per cent of the total population of the region living below the poverty line. Using the Human Poverty Index (HPI), a composite index frame on the basis of deprivation in economic, educational and health sectors all equally and proportionally given due weightage, the Northeast region represents a dismal picture in both the urban and rural areas. Drawing the comparable data of 1981 and 1991, there is an insignificant or marginal improvement in Assam, Arunachal Pradesh and Mizoram while the other states have significantly declined rapidly (National Human Development Report 2001).

In states like Manipur all the districts fall under the category of 'No Industry District' by all India standards (Sharma 2006). Virtual absence of industrial infrastructure, compelling the region to depend only on the primary sector of production, even after five decades of centralized Indian economic planning conspicuously narrates the saga of underdevelopment. Starting with the Second Five Year Plan, more widely known as the Mahalanobis Plan for intense industrialization in India, economic planning has never relegated the importance of creating industrial base to modernize the economy. However, in the Northeast increasing deindustrialization presents a different story altogether (Singh 2005). Sheer absence of industrial development and production units in the secondary sector indicate the persisting peripheral status of the region's economy. Increasing dependency marks the economy of the region with heavy imports of consumer and non-consumer commodities from the mainland which in turn virtually make it impossible for the region to carve a path for economic self-reliance. It has been estimated by the Shukla Commission that over 2,500 crore rupees' worth of consumer items are imported from mainland India annually. 
Glaring instances of dependency are provided when Assam, the most 'industrialized' state in the region, imports 74 per cent of its milk product, 98 per cent of its meat requirements and 94 per cent of its eggs from outside the region. In spite of adequate rainfall and natural abundance of water resources, the state imports half of its fish requirements from outside (Ahmad and Biswas 2004: 56). Manipur, traditionally self-sufficient in fish production with a large variety (Brown 1873), today imports more than three fourths of its requirement from outside, the bulk coming all the way from Andhra Pradesh. A predominantly rural Manipur has to import nearly all its egg and poultry requirements from a distant Andhra Pradesh. The fledging poultry sector in the state catering mostly to meat production is also filled with incongruous terms of trade where one- to seven-day-old chicks are flown in by air, supplemented by all the feed items right from the initial to the consumption stage coming from states like Orissa and West Bengal. This anomaly renders it impossible for local entrepreneurs to successfully develop a self-reliant poultry. It has also been noticed that the low credit-deposit ratio in the region leads to the transfer of 5,000 core rupees annually to other regions for investment by the banking sector. Lopsided and haphazard development policies detach the issue of production from development. Thwarting of local productive forces and failure to develop productive base tend to increase dependency on the mainland. Transformation of the region into a market for manufactured goods from mainland India went hand and hand with increasing underdevelopment in spite of sheer abundance of prime resources like oil, timber, tea, gas, limestone and other forest resources.

\section{Underdevelopment entrenched}

The predominant feature of underdevelopment, evident in the conspicuous absence of industrial and production base in the region, has been conveniently ignored in mainstream development debates. Uneven and unequal regimes of exchanges seen so far ironically subserves the interests of capital elsewhere representing the legacy of underdevelopment of a region considered a frontier in so many ways. Even since the British colonial period, the oil-bearing area in Assam has seen a meticulous exploitation of this precious resource (Edney 1997). The British knew of the existence of oil in the hills of upper Assam as early as 1825 and identified the oil bearing belt which runs from the extreme northeast of Assam to the eastern border of the Brahmaputra and Surma valley. Drilling of oil commenced in 1866 and 1865. The British company McKellop Steward and Company drilled 
many shallow wells near Makum during 1866-68. Soon it led to the discovery of Digboi oilfields, the biggest oilfield in the subcontinent. Annually it raises about 4 lakh tonnes of crude oil. Situated $30 \mathrm{~km}$ away from Digboi is the Naharkatiya oilfield discovered by Assam Oil Company, an Indian Government undertaking, in 1955. Naharkatiya is the second largest oilfield in India with oil reserves estimated to be about 5 million tonnes. Bappapung, Hansan pung, Hugirijan and Moran, located about $40 \mathrm{~km}$ southwest of Digboi, are also important oilfields. Mention may be made of the fact that quest for oil formed an important part of the colonial enterprise in the region.

Post-British oil industry never witnessed any radical departure, as Indian state monopoly was the only significant replacement that never really percolated to the basic foundation of the region's underdeveloped economy. It remains a sector existing to meet demands elsewhere on unequal terms of exchange. Set up in 1901, the Digboi refinery has not grown in terms of installed capacity even as it continues to be the main and the most important supplier of crude refined elsewhere. Its installed capacity is a mere 5.20 lakh tones. The Noonmati refinery near Guahati under the Indian state-owned Indian Oil Corporation (IOC) with an installed capacity of just 8.8 lakh tones and the Bongaigan refinery set up in 1978 west of Guwahati with a capacity of 10 lakh tones stand in marked contrast with the Baruni refining in Bihar, a non-oil producing area, set up in collaboration with USSR. Production in the refinery began in 1964 with a refining capacity of 33 lakh tones, the rider being its total crude receipt from the oilfields in Assam.

The logic of ruthless plundering of the resources without proportionate returns to the people of the region can be substantiated by the sheer discriminatory rates of revenues between the Centre and states. A cursory glance at the revenue sharing rates speaks volumes for the nature of resource plundering. The royalty Assam got for its oil during the mid-eighties witnessed a marginal increase from 325 rupees per tonne to its current rate at 632 rupees per tonne in comparison to the Centre's earning at an average dividend of 2,623 rupees per tonne. It is equally distressing to learn that two third of Assam's crude oil is transported outside the region for refining. In the midst of widespread demand for an optimum capacity refinery to refine its crude Assam got a toy refinery at Numaligarh (Ahmad and Biswas 2004: 235).

The tea industry in Assam also experienced similar patterns of extraction and exploitation. Even since discovery of tea by the British, a mad rush for plantation culture proliferated with tremendous growth of tea estates. Departure of the British eventually saw the exit of European companies with subsequent increase in the number of 
estates. Statistics reveal the rise of tea estates from 785 with an acreage of 155,674 ha producing $150,370,000 \mathrm{~kg}$ in 1951 to more than 848 tea estates with an acreage of 236,811 ha producing $402,947,000 \mathrm{~kg}$ in 1993 (Nag 2006). Drain of profit in the tea industry is also colossal. Figures indicate that Assam produced an average of 250 million $\mathrm{kg}$ annually during 1962-1999 at international price estimate of US $\$ 2.50$. However, it is distressing to learn that the tea companies, almost all of them owned by outsiders, have invested almost nothing in the state from this staggering amount. These are ample evidence of the ways in which the resources of the Northeast are drained out and transformed into sources of profit elsewhere in whole, simultaneously unleashing a chain of exploitation networks shifting the development outputs from the region.

Forest resources have also been similarly plundered and exploited ruthlessly. Assam, Arunachal Pradesh, Nagaland, Meghalaya and Manipur have suffered the consequences of mindless and ruthless logging and lumbering business catering to commercial interests of outsiders. With the erosion of traditional indigenous modes of replenishment and afforestation in these traditionally forest based economies along with the displacement of tribal population as a result of forest laws enacted in the distant power corridors of New Delhi, the region has witnessed an upheaval in the face of the state exercising absolute monopoly of control. The nature of ruthless plundering and exploitation can be comprehended by the virtual absence of any substantial forest based industry in the region except for the odd miniscule saw mills and a few paper mills in Assam. Timber from the region feed the plywood industries in West Bengal, Delhi, Uttar Pradesh, Haryana and so forth. The finished products find their way in the domestic and international markets. In typical peripheralization fashion, the region still performs the role of a supplier of primary products to feed the industries located elsewhere in different parts of mainland India. Paper, plywood and other forest-based products like paper gum, resin, lac and all rubber items have to be imported thereby displaying the classic modus operandi of transforming the region into a monocultural economy. Diversification that can be brought about only with substantial industrialization is nowhere on the horizon. The nature of development policies therefore has not all addressed the basic and fundamental issue of production in the region. If production and modes of production in the region remain confined to the monoculture level where the region only acts as a supplier of primary products in these three sectors, oil, timber and tea - development discourse will remain lopsided and haphazard. Development therefore should necessarily 
address production and generation of productive base in the region. Only when the region emerges as a strong producing base rooted in using the resources available for the benefit of its people, development semantics will assume a holistic nature. It will enable the region to utilize its resources meaningfully and erase dependency.

\section{Note}

1 This chapter was first published in Eastern Quarterly, 4(3\&4): 189-200, 2007-08.

\section{References}

Ahmad, Raiful and Prasenjit Biswas. 2004. Political Underdevelopment of Northeast India. New Delhi: Akansha Publishing House.

Bhambri, C. P. 1998. Politics in India 1947-1987. New Delhi: Vikas.

Brown, R. 1873. Statistical Account of the Native State of Manipur and the Hill Territory under Its Rule. Calcutta: Office of the Superintendent of Government Printing.

Edney, M. H. 1997. Mapping an Empire: The Geographical Construction of British India 1765-1843. Chicago: Chicago University Press.

Government of India. 2001. National Human Development Report. New Delhi: Planning Commission.

Government of India. 2002. Assam Development Report, 2002. New Delhi: Planning Commission.

Guha, Amalendu. 1991. Medieval and Early Colonial Assam: Society, Polity, and Economy. Calcutta: Centre for Studies in Social Sciences.

Mackanzie, Alexander. 1884. History of the Relations of the Government with the Hill Tribes of the North-East Frontier of Bengal. Calcutta: Superintendent of Printing.

Mishra, S. N. 1983. 'Arunachal's Tribal Economic Formations and Their Dissolution', Economic and Political Weekly, 18(43), 22 October.

Mohapatra, A. C. 2002. 'Development and Underdevelopment in the Northeast Region: Search for a Paradigm', in Bimal J. Deb (ed.), Development Priorities in Northeast India. New Delhi: Concept Publications.

Nag, Sajal. 2006. 'Land, Migrants, Hegemony: The Politics of Demography in Northeast India', in David R. Syiemlieh et al. (eds.), Challenges of Development. New Delhi: Regency Publications.

Patnaik, Prabhat. 1999. Whatever Happened to Imperialism and Other Essays. New Delhi: Tulika.

Reid, Robert. 1942. History of the Frontier Areas Bordering on Assam from 1883-1941. Shillong: Government Publication.

Sharma, Hanjabam Isworchandra. 2006. 'India's Look East Policy and Manipur's Economy: A Critical Scrutiny', Alternative Perspectives, 1(4). 
Sikadar, S. 1982. 'Tribalism vs Colonialism British Capitalistic Intervention and Transformation of Primitive Economy of Arunachal Pradesh in Nineteenth Century', Social Scientist, 10 (115), 15-31 December.

Singh, Chongtham Priyoranjan. 2005. 'Manipur's Economy: Historical Roots and Structural Evolution', Eastern Quarterly, 3(3).

Singh, Karam Manimohon. 2006. Nupi Lan (Women's War of Manipur). Imphal: KPD. 


\section{Re-imagining the Northeast in India, again}

Did geography sidestep history in Vision (2020)? ${ }^{1}$

\section{Rohan D'Souza}

In a previous incarnation of this chapter in 2007, I had somewhat smugly concluded on reading an advance draft chapter of the Vision 2020 document that India's Northeast ${ }^{2}$ was being re-imagined as a 'development deficit' in a formulaic way. My claim - much inspired by the subversive scholarly turn widely referred to as post development ${ }^{3}-$ was that the authors of Vision 2020 failed to grasp the challenge of 'historical difference' (social, cultural and ecological heterogeneity). Consequently, Vision 2020, I argued, pretty much ended up advocating for the wholesome 'economic assimilation' of the Northeast region within 'mainstream' India through 'dispossession, enclosure and displacement' (D’Souza 2007-08: 207-17).

\section{Problematizing Vision 2020}

This very same advance chapter draft of the Vision 2020 document titled 'Peace, Progress and Prosperity in the North Eastern Region', however, was republished in 2008 as part of a substantial report brought out by the Ministry of Development of North Eastern Region and the North Eastern Council. ${ }^{4}$ The three-volume Vision 2020 since its publication has unsurprisingly evoked considerable academic interest and still remains one of the most comprehensive efforts in recent times that both analyses the Northeast region for its contemporary development challenges and confidently prescribes pathways for achieving positive economic and governance outcomes. Given that the idea of economic development is a much fraught subject in itself, it is no surprise that Vision 2020 has invited scrutiny and criticism from a broad spectrum of thinkers and observers.

Sanjib Baruah, amongst the foremost scholars on India's Northeast, in a recent deliberation on the Vision 2020 astutely counsels us that 'to ask whether development succeeds or fails is to fall into the trap 
of the imaginary of development' (Baruah 2017: 50). In effect, Baruah believes that Vision 2020 as a 'transition narrative' - a document that scripts radical social, cultural and economic change - should not be judged only over whether it can achieve what it considers to be transformational possibilities in India's Northeast. Rather, the document knocks on many other conceptual doors as well. Notably, the need to reflect on who possess what kind of agency for effecting what kinds of change: is it the expert and her or his world of neat numbers or would it be a surprise produced through interaction, opposition and negotiation between social and political pressures from above and below?

The creative energies of the people and communities of the Northeast, Baruah claims, must be understood as being able to go much beyond the 'development imaginary' of the expert. In other words, in their daily calculations and from within their everyday worlds these ordinary folk can and will draw upon a vast reservoir of practices, memories, livelihood strategies and environmental pasts to forge outcomes that will inevitably shape a political economy of surprises rather than the linear realization of statistically informed policies. History will shape geographical possibility rather than geography dominating the region's history. Vision 2020, thus, as a development master text, Baruah suggests, must also be analysed for what it fails to place within its frame of reference, besides serving as a blueprint for how things should unfold for realizing development and economic growth outcomes in the Northeast (Baruah 2017: 45-67).

In part, Baruah's strategy to read Vision 2020 'against the grain' follows from his earlier writings and it helps us here to recall some of them. In Durable Disorder, Baruah underlines how the idea of development takes on an entirely different slant in the state of Arunachal Pradesh.

The developmentalist path that Arunachal has embarked upon is neither the result of a choice made by policy makers about what is best for the well being of the people of Arunachal, nor is it evidence of the inevitability of 'progress' and 'civilization'. Rather, it is the intended and unintended consequence of the Indian state's efforts to assert control over this frontier space and to make it a 'normal' part of India's national space.

(Baruah 2007/2005: 35-6)

Development discourse as a project for 'nationalizing space', in other words, frames Arunachal Pradesh principally as an extension of the Indian state's geo-political imperative rather than the means 
for unleashing the region's own historical and cultural possibilities. Baruah, in fact, follows this assessment with an equally provocative and illuminating discussion on India's 'Look East Policy' (which is now rechristened as the 'Act East Policy'). Here, he suggests that the Indian government in this newest policy imagining aims to transform the Northeast region - through rail and road infrastructure - into a land bridge that then physically connects the Indian Gangetic plains with Southeast Asia. That is, the Northeast is going to be built up in steel and cement to help it overcome its perceived geographical 'landlocked' isolation rather than drawing upon its historical multiplicities and possibilities: notably by ignoring the mountainous region's links with much of Asia that was forged when it was on the 'southern trails of the Silk Road during ancient and medieval times' (Baruah 2007/2005: 214).

Engaging thus with some of Baruah's insights, one is given the strong impression that India's Northeast is discursively imagined and re-imagined time and time again by Indian policy makers and the political officialdom as a geographical space rather than as a historically created place. But before I explain what it means to argue that geography imposes on history and that space overwhelms place, it bears mentioning that Baruah's understanding finds resonance amongst other thinkers as well. In particular, one should highlight the recent scholarship of Duncan McDuie-Ra, whose fine-grained ethnographic accounts on India's Northeast reveals to us how fraught the intellectual, policy and political terrain over development has become. His conclusions, in a recent essay bluntly state:

Development in the Northeast region is driven by national security imperatives and the dominance of national security ensures that development priorities are centrally orchestrated and involve securing the Northeast and integrating it into the national economy through resource extraction and road building, and the cultivation of a loyal elite rewarded in the political structures of statehood and the legitimacy of the Sixth Schedule... The perception that the region's people are 'backward' and in need of 'modernising' enables the highly centralised, paternalistic approach of the Indian Government to drive the development agenda and at the same time ensure that national security imperatives are met.

(McDuie-Ra 2008: 203)

Both Baruah and McDuie-Ra, in effect, argue that development initiatives in India's Northeast do not entirely originate from within the 
region nor are they exclusively aimed at addressing the aspirational challenges of its people. Rather, ideas and plans under the rubric of development are formulated and then despatched from the central government based in New Delhi; who, in turn, are driven by the their own anxieties about security and the need to address larger geopolitical calculations for the region. In other words, the Northeast does not act but is acted upon and the terrain for manoeuvre for the people in the Northeast is reduced to one of compliance, negotiation or subversion. The Vision 2020 document, however, wants to fix this. At the outset itself, it is stated that the 'empowerment of the people' is to be achieved by 'maximizing self-governance and participatory development through grass-roots planning' (Vision 2020 vol. I: 4). Which, by any estimate, is no easy task. More so given what Vision 2020 outlines as the economic, social and demographic profile of the Northeast:

The eight states located in India's north-east cover an area of $2,62,179$ sq. $\mathrm{km}$. constituting 7.9 per cent of the country's total geographical area, but have only 39 million people or about 3.8 per cent of the total population of the country (2001 census). Over 68 per cent of the population of the region lives in the state of Assam alone. The density of population varies from 13 per sq. $\mathrm{km}$. in Arunachal Pradesh to 340 per sq. km. in Assam. The predominantly hilly terrain in all the states except Assam is host to an overwhelming proportion of tribal population ranging from 19.3 per cent in Assam to 94.5 per cent in Mizoram. The region has over 160 scheduled tribes and over 400 other tribal and subtribal communities and groups. It is predominantly rural with over 84 per cent of the population living in the countryside.

(Vision 2020 vol. I: 5)

The strategy for enabling development despite the above mentioned social and ecological complexity is fleshed out in vol. II of Vision 2020. The plan is to bring about inclusive growth through inclusive governance' by initiating the 'devolution of functions, finances and functionaries to representative institutions of local self-government', which in turn would operate with the 'principle of subsidiarity' - meaning that 'anything which can be done at a lower level should be done at that level and no higher level' (Vision 2020 vol. II: 11). In sum, at least in theoretical terms, the effort of the Vision 2020 enthusiasts seems to be to endow meaningful agency to the stakeholder and the development beneficiary, so that decision-making truly flows from the bottom up. 


\section{But what do the people want?}

A sense of what it means to listen to the 'voices of the people' for development is indicated in the strikingly innovative 'Public Hearings' exercises that were carried out during the draft stage of the Vision 2020 document. In vol. III, it is noted that twelve Public Hearings were held at different locations within the Northeast with the recorded minutes of these meetings being listed in Annexure 16 of Vision 2020 (vol. III: 254-93). At Silchar (Assam), for example, about 110 people attended the hearing and those that spoke included journalists, NGO workers, retired government officials, academicians and even a member of the legislative assembly (Vision 2020 vol. III: 255). Similarly, in Imphal (Manipur) over 200 participants attended, which included the chief minister and other ministers from his cabinet.

These exercises, moreover, seem to have thrown up a fascinating set of perceptions and concerns by the assembled 'publics'. In a hearing at Itanagar (Arunachal Pradesh), Dr. I. K. Barthakur, one of the Northeast Council members, informs the meeting that following a 40,000 household survey across the Northeast region there was an 'overwhelming response' for 'developing Agriculture \& its Allied sectors' (Vision 2020 vol. III: 279). At the Pasighat (Arunachal Pradesh) hearing, a suggestion was made for transforming governance by creating 'a secure, responsive and market-friendly environment'. At Dibrugarh (Assam), about 225 concerned citizens put forward a range of opinions on corruption, employment, health, education, sanitation, infiltration and a somewhat puzzling suggestion by one Professor Horen Gogoi who felt that 'efforts need to be made for the Assamese people to learn to work' (Vision 2020 vol. III: 277). At Agartala (Tripura) besides demands for better road and railway links with Bangladesh, there was also a demand for 'Air connectivity within the region' along with an academy for training pilots. In the same list there was also mention that the marriage age for girls in many places was as low as thirteen and there was need 'to increase this' (Vision 2020 vol. III: 286). At Imphal, a teacher, T. Vunglallian, concluded, perhaps with a touch of irony, that 'India should adopt the policy of looking to the East and for the NER (Northeast Region) to look to the West'. Dr. Rosemary Dzuvichu (President, Nagaland University Teachers' Association) at the Hearing in Kohima (Nagaland) felt that 'academicians in general' were not 'properly consulted' in preparing the document and that the 'aspirations of the people should not be put in the appendix but should form the core of the document' (Vision 2020 vol. III: 270). On a different note, however, in the same Hearing, the Rev. Dr. V. K. Nuh of 
the Baptist Church 'lamented the lack of economic growth in the NER in spite of having $40 \%$ of the country's hydro-electric power potential, $53 \%$ of tea product and $26 \%$ of forest product' (Vision 2020 vol. III: 270 ).

The above does seem to strongly suggest that the Public Hearings might have been very colourful events: filled with contradictory voices, striking claims, long speeches and inconclusive endings. The Vision 2020, however, though thus stirred by opposing opinions and messy realities remained unshaken when drawing out the larger governance implications when the people have spoken:

People of the region have an ambitious vision: by 2020, they aspire to see their region emerge peaceful, strong, confident, and ready to engage with the global economy ... They want to banish poverty and illiteracy and ensure that every family in the region has the opportunity to live a healthy and secure life with dignity and self-respect. Moving away from the dependency syndrome, people in the region would like to acquire the capability and selfconfidence to shape their own destinies. They would like to enjoy their freedoms - freedom from hunger and poverty, the freedom to exercise choice in their avocations, income-earning and spending decisions, and political, economic and social freedoms without fear. They would like to enjoy peace and achieve sustainable progress and prosperity.

(Vision 2020 vol. I: 3, italics mine)

This grand declaration, that signals such a sweeping urgency for social and economic betterment, carries not only an obvious seduction and appeal but could have been arrived at, I suspect, even without the dense discussions from the Public Hearings. More pointedly, however, the term their region is more than a silent physical backdrop to the innumerable back and forth at the Hearings. The use of the term region, in fact, acts to 'perform' and underwrite all discussions in the Hearings so that geography can firmly hold and contain within a sprawling physical setting of mountains, valleys, hills and plains the overflow of particularistic identities such as the Naga, Kuki, Bodo, $A k a$ or Nyishi (to name but a very few of the ' 160 scheduled tribes and over 400 other tribal and sub-tribal communities and groups'). Put differently, the inhabitants of the Northeast are essentially defined by a shared geography. The region as space is thus privileged over time - comprising messy histories of differences, cultures, places and 


\section{Rohan D'Souza}

dissimilar pasts. In a sense, once again, the Vision 2020 document reaffirms, even if almost absentmindedly, an earlier insight of Sanjib Baruah that India's Northeast, as a category, was a 'hurried exercise in political engineering'; wherein the region by being so overwhelmingly enumerated and described as a geographical location often obscures its 'historical or cultural memory' (Baruah 2007/2005: 4-5).

\section{Aspiration and the quest for equivalence}

Is it possible to assemble a conceptual world entirely shorn of historical imaginings? Here we must recall Arjun Appadurai's instructive essay on the 'Capacity to Aspire', in which he directs us to reflect on the sharp differences in the treatment of notions such as culture and development in the fields of anthropology and economics (Appadurai 2013). In most anthropological studies, Appadurai points out; culture has been generally viewed as 'one or other kind of pastness - the keywords here are habit, custom, heritage and tradition'. Development, on the other hand, has usually been seen, in 'terms of the future plans, goals, hopes, targets'. For anthropologists, thus, the idea of the future remains somewhat alien to many descriptions of culture, while economics with its keenness to quantify and discuss wants, needs and expectations 'has become the science of the future'. In other words, Appadurai explains 'the cultural actor is a person of and from the past, and the economic actor a person of the future' (Appadurai 2013: 180)

The Vision 2020 document clearly is future-facing with its commitment to reveal the Northeast region primarily in the technical language of economic development and growth. Vol. II and III of the Vision 2020 are almost saturated with statistical tables and data-sets that sum up surveys, lists, a range of classificatory schemas, taxonomies, and censuses. Some sampling of the tables, for example, are on the distribution of handlooms in the Northeast between 1995 and 1996, the ratio of mineral production to geographic area, statistics on forestry and fishing, growth rates of agriculture (1993-94 to 2002-03), number of local bodies in the region, share of services in the net domestic product (1993-2003) and even a list on the incipient sick units in small-scale industry (2001-02).

Creating a world through numbers, Appadurai explains in another path breaking essay, however, goes much beyond the mere quantification of phenomena. Numbers and their tabulation, for him, can and should be measured or drawn up against political contexts and how they are inserted within knowledge regimes shaped by power. For colonial India, in particular, Appadurai argues that the manner in 
which the British generated numbers and statistics served as much to address a range of 'justificatory' protocols for knowledge making as they became a means for 'disciplining' their colonial subjects. That is, numbers, howsoever collected and howsoever flawed in their understanding of social and cultural realities, were served up as subject matter for intense internal debates within the British administration over issues of classification and policy before they were deployed to inform 'bureaucratic practices and styles' for control (Appadurai 1996: 114-35). What, however, is also critically pointed out in the essay, is that

numbers permitted comparison between kinds of places and people that were otherwise different, that they were concise ways of conveying large bodies of information, and that they served as a short form for capturing and appropriating otherwise recalcitrant features of the social and human landscape.

(Appadurai 1996: 120)

Another critical aspect of the power of enumeration, for Appadurai was how mute numbers could represent social groups as being 'unyoked' from their complex and localized situations. Such that with bland statistical tabulation the 'huge diversity of castes, sects, tribes, and other practical groupings' in British India could be 'untethered' from the specificities of their physical and social settings (Appadurai 1996: 127).

These insights of Appadurai, in fact, do inform our discussion as they give fresh meaning to the many statistically generated equivalences and comparisons that liberally pepper Vision 2020. In particular, I could argue that there is a steady dissolution or obscuring of the Northeast region as a 'place bearing landscape' by detailed statistical information posed in terms of geographical contrasts - the systematic comparison of averages between the Northeast region and all India facts. In vol. II, thus, we see the full play of this striking format of mute numbers deployed to rhetorically eliminate place and install space or by getting geography to sidestep history:

In 2001, 23.13 per cent of the total terrorist incidences in India took place alone in this region, which increased to 28 per cent in 2005 and further to 29.4 per cent in 2006 . . . Assam shows the highest number of civilians killed due to terrorist violence, which was around 11 per cent of the total civilians killed in India in 2001 due to terrorism.

(Vision 2020, vol. II: 279) 
That Internet usage is low in the Northeast is clear from the insignificant number of connections in NER, being a low 15,303 in 2002 , just 0.48 per cent of the total number in the country [India]. This increased in 2003 but was still less than 1 per cent $(0.88$ per cent) of the total [in India].

(Vision 2020, vol. II: 179)

Meat production per head for the NER is higher than the national average. The dependency on milk 'imports' is high because cattle is used primarily for meat production rather than for milk, there is low buffalo per head ratio (0.02 compared to the national average of 0.09 ), and low milk productivity of cattle in the region.

(Vision 2020, vol. II: 58)

Agricultural systems remain predominantly traditional. The landto-person ratio for the NE region (0.68 hectares/person) is much higher than the national average $(0.32$ hectares/person), with Arunachal Pradesh having the highest ratio ( 8.63 hectares/person) and Assam the lowest ( 0.29 hectares/person).

(Vision 2020, vol. II: 42)

Agriculture is the mainstay of the economies of the northeast. This sector accounted for close to 30 per cent of the region's NSDP in 2002-03, and is a major source of employment and livelihood for around 80 per cent of the population. However agricultural growth has been uneven across regions and crops. NER continues to be a net importer of food grains. In spite of covering 8.8 per cent of the country's total geographical area, NER produces only 1.5 per cent of the country's total food grain production.

(Vision 2020, vol. II: 39)

Economic Poverty (EP) of the region, as per the estimates of the Planning Commission, is 19.1 per cent, as against 28.5 per cent in the country as a whole, and is being reduced at a faster rate in NER as compared to the all-India average.

(Vision 2020, vol. II: 27)

The above is a mere sprinkling from the more weighty data and fact based interpretations that are advanced throughout Vision 2020 - a typical format for texts that deal with development and economic growth. But the constant contrast drawn between the Northeast region (NER) and the all India country averages clashes with and 
collides against another perhaps unintended narrative: the idea of 'historical difference' which altogether escapes the power of quantification, equivalence and comparison. One refers here to the often times passionate debates that animated the making of India's official policy towards the 'tribes' in what was then known as the North Eastern Frontier Agency (NEFA, today's Arunachal Pradesh). Many Indian administrators, academics and political leaders in the decades of the 1940s and 1950s, in fact, hotly questioned whether these tribes and communities were to be kept 'isolated' from the Indian mainstream.

One of the most striking voices on the subject, in fact, was that of the Oxford educated and self-trained anthropologist Verrier Elwin (1902-64). Elwin briefly served as tribal affairs advisor to the Indian government in NEFA and for quite a while his views carried much weight even with Prime Minister Nehru. In an absorbing biography on Elwin, Ramachandra Guha tells us that in the decades following India's independence in 1947 the central government was largely conflicted about its role in the near inaccessible mountains and hill ecologies of the Northeast region. And it was amidst this lack of official clarity that Elwin's ideas, strong beliefs and opinions, drawn from his many years of living with tribes in central and now Northeast India, acquired considerable academic, polemic and even political persuasion. More so after the publication of his much celebrated A Philosophy for NEFA (1957) in which the leitmotif of the book could be summed up in the term ' make haste slowly' (Guha 2014: 264). That is to say, the full force of modernity in the form of industrialization and economic growth had to be greatly tempered in the Northeast region because 'if the tribals move too fast', Elwin argued, 'they tend to move downwards' (Guha 2014: 264).

Elwin's pleas for restraint and going slow, however, ran afoul of an equally powerful set of opinion makers who with equal vigour argued that his tribal worldview amounted to a celebration of primitivism and was inevitably about turning the much disempowered tribe into objects for display in museums. Elwin nonetheless, before his untimely death in 1964, energetically responded to many of his critics by constantly fine-tuning and giving much nuance to his initial claims. Guha sums up Elwin's careful but firm conceptual navigation in which he ended up rejecting the extremes of isolation and assimilation by formulating instead a 'Middle Way, the way of integration' (Guha 2014: 263). The middle way was further explained by Elwin in his A Philosophy of NEFA as trying to resolve the puzzle of 'how to bring the blessings and advantages of modern medicine, agriculture and education to them, without destroying the rare and precious values of tribal life'. ${ }^{5}$ 
In several ways one could still argue perhaps that the tensions over 'assimilation versus integration' continue to play out in the manner India's Northeast is often framed and discussed in many official and popular forums. The Vision 2020 document, in fact, also appears to twist awkwardly on this fault-line of sorts. One cannot help but note, for example, that despite the technical and objective tone of the document with its surfeit of statistics and averages to explain 'backwardness and the lack of prosperity in the NER', Vision 2020 nonetheless acknowledges that:

The quest for ethnic and regional identity, nationalism, and ideological motivations have fomented a climate of insurgency in several parts of the North Eastern region, which has led to political fragmentation of the region; the climate has been further fuelled by with the slow pace of development. The difficult terrain, dense forest cover and open borders with Myanmar and Bangladesh have provided a congenial environment for this.

(Vision 2020 vol. I: 6)

In effect, place based identities and recalcitrant or 'difficult' ecologies can congeal to amplify corrosive politics, furious opposition and disagreement. The Vision 2020 document, thus, much as it sees salvation and hope in needed development for the NER, it also acknowledges that not only is a dense social world interwoven into the landscapes but that these thick cultural clots might not be reached only by economic means.

But, of course, it can also correctly be argued that too much is being made of the Vision 2020 document by non-economists in the social sciences: after all Vision 2020 is a mere text, a wish list, a cautious road map for change and above all else a qualified exercise for generating economic foresight. On the other hand - and this is the crux of this chapter's question - did the document despite its alluring claims for objectivity through data and fact end up re-asserting through its analyses, rhetoric and narrative style that the NER story can be understood within the biography of India's development quest? Put differently, did the region's pasts, histories and imaginations play out on the surfaces of its geography or the reverse that the very geography of the NER has been constituted by its pasts, histories and imagination? This is, I argue, a critical distinction that ends up posing the problem of development and economic growth differently: either we accept a geography that is intimately woven into and shaped by the turns of history rather than a history that was enacted on the passive stage 
of geography. What follows is of course the inevitable question: how does history matter for developing the NER?

\section{Experiencing the past}

Before moving onto the final section, it is important that I state my preference for treating the idea of history as a dialogue between the present and the past. ${ }^{6}$ This E. H. Carrian sense of history becomes particularly helpful for this chapter, I believe, as it prevents the past being warped by the pursuit for an ahistorical essentialized authentic moment. Instead, the past can be more meaningfully grasped as never fully escaping the taint of the ideological present. Two other qualifications also follow. First, my effort here is to discuss how a recent mood in histories on India's Northeast tend to increasingly emphasize the interpenetration of the geographic and the historical. That is history and geography co-constitute rather than exist as separate domains during period of change and transformation. Second, this effort, given the limitations of space, will be indicative rather than comprehensive.

In sum, I wish to suggest that by thus reviewing some of the relevant claims in four recent monographs dealing with histories of the Northeast region that Vision 2020 has been somewhat blindsided (no pun intended) in failing to grasp how critical history was to constituting the region's geographic peculiarities and processes for identity formation, leave alone trying to redeem it through development and economic growth.

Bengt Karlsson, a much-celebrated Swedish anthropologist, in his monograph Unruly Hills (2011), which studies the ethnic communities in the state of Meghalaya points out how in pre-modern or precolonial times the hills and plains in the region were woven into a single resource bloc. The inhabitants comprising the Jaintias, Garos, and Khasis were marked by being relatively egalitarian social groupings and were characterized by chiefdoms, headmanships, clan loyalties, village decision-making bodies, and lineage-based hierarchies. A reasonably elaborate and complex social world that Karlsson is also keen to suggest which depended greatly on mobility between the hill and plain ecologies. The transformative moment, however, was initiated with the coming of British colonialism in the middle of the nineteenth century. Karlsson flags, in particular, three significant colonial initiatives: (1) the political and administrative separation of the hill ecologies from that of the plains, (2) the strengthening of male control over decision-making and (3) the introduction of private property in land. Whilst these colonial interventions were never entirely fully 
realized, the entry of the modern Indian state in the latter half of the twentieth century only resulted in the further intensification of such modernizing process. Leading inevitably, Karlsson tells us, to the further erosion in Meghalaya of the community based institutions for managing local resources (Karlsson 2011).

There is a somewhat similar pattern that is discernible in Joy L. K. Pachuau's elegantly written monograph on the Mizos. In Being Mizo (2014), Pachuau tells us that not only is the notion of the Mizo as a distinct identity fairly recent in history but that, significantly as well, the strong association between identity and territoriality is equally novel for the region. Prior to the emergence of British colonial rule in the Lushai hills (mountain range spanning today's Mizoram and Tripura), Pachuau explains that a number of groups headed by chiefs crisscrossed the valleys, plains and hills as part of their livelihood strategies and cultural understanding of these landscapes. But as the British began to consolidate their sway over the hills by the early decades of the twentieth century, the idea of the 'fixed boundary' and the introduction of standard time was obsessively pursued as critical organizing principles for modern administration. To quote Pachuau:

the struggle between the colonialists and the indigenous can be seen as a contestation between an identity founded on territory and territoriality and an identity founded on movement, which made the forcible 'rooting' of a people to a fixed space even more significant. (Pachuau 2014: 101)

Sanghamitra Misra's much-celebrated Becoming a Borderland (2011) further deepens our understanding of how certain landscapes and people in the NER were rendered separate and marginal by a slew of British colonial and modernizing impulses, beginning in the nineteenth century. What is Goalpara in today's Assam Valley, she points out, was in the Mughal period (sixteenth to seventeenth centuries) peopled by a range of mobile communities who shared cultural and historical ties with Bhutan, Tibet, Cooch Behar and parts of Bengal and Assam. While social, economic and political transformations had been shaping Goalpara complex histories through time, the introduction of absolute private property in land by the British inaugurated an unprecedented rupture in decisively sundering the intricate relationships and interdependencies between plain and hill ecologies. In time, much of Goalpara's social plurality and economic mobility was substantially inflected and altered by the spatial imagination of colonialism and the "heartland' political sensibilities of the modern state (Misra 2011: 196-7). 
The historian Gunnel Cederlof in her insightful sweeping study of India's Northeast from the early British colonial period, perhaps best explains how colonial modernity profoundly reconstituted the region's geography and its communities (Cederlof 2014: 44-78). In a chapter titled 'Making "Natural" Boundaries', we are told that kingdoms and chieftainships perceived geo-political boundaries very differently from the early colonial officials. For one, to most of the indigenous grouping a 'political boundary' was treated as a 'set of points, like ghats [steps leading to a riverfront] at narrow places where rivers flowed from the hills into the plains. Marking out territorial claims meant fortifying strategic strongholds such as heights or river bifurcations, or exercising authority by taxing market places'. For the British, on the other hand, marking a boundary meant connecting dots or points with lines that enclosed territory and usually made manifest in 'red ink on cartographic sheets' (Cederlof 2014: 49). In part, this sharp difference in how political geographies were viewed lay in the critical role of mobility for indigenous livelihood and cultural strategies. Cederlof, in fact, quotes David Ludden's persuasive conclusions from his study of Sylhet (now Bangladesh) to throw light on the immense sociological and economic consequences following the steady triumph of the cartographic boundary in the region:

It decisively ended an 'old order' of fluidity and vagueness in which land use, commerce, and culture existed in mobile geographies and people [sic] were beyond the reach of state authority ... the 'boundary's' modernity came with its subordination of all geographies to that of the state.

(Cederlof 2014: 51)

From attempting something equivalent to a conceptual hop, jump and skip exercise through four well-argued and rigorously researched monographs, it becomes clearer that any meaningfully understanding of India's Northeast requires one to see it as being co-constituted by the simultaneous play of its history and geography. In effect, to treat them as separate domains or turn geography into a passive context to the loud voice of history is to impoverish or diminish the richness of insight and analysis. ${ }^{7}$

\section{Concluding remarks}

The Vision 2020 document, to reiterate, is undoubtedly one of the most comprehensive efforts in recent decades that set out to map a pathway 
of solutions for the NER's many economic, social and political challenges. And, not unexpectedly, any intellectual ambition positioned at such a scale would perforce invite meaningful academic scrutiny and careful evaluation. This chapter should be considered as merely one such attempt with the further caveat that any criticism, howsoever withering, does not necessarily set the grounds for the complete dismissal or disavowal of the document as being a very substantial and detailed exercise. Nonetheless, Vision 2020 I argue rests on certain premises and principles that might weaken its capacity to solve or sort out precisely those challenges that it appeared most confident of addressing: in particular, I point out that Vision 2020 by getting the geography of NER to sidestep its own history might misread a range of realities on the ground. This claim is significantly borne out by what appears to me to be the main historical hinge of the Vision 2020 document:

Troubled by history and geo-politics, the Northeast has remained one of the most backward regions of the country. The trauma of partition in 1947 not only took the region backwards by at least a quarter of a century, but also placed hurdles on future economic progress. It isolated the region, sealed both land and sea routes for commerce and trade, and severed access to traditional markets and the gateway to the East and South-East Asia - the Chittagong port in East Bengal (now Bangladesh). It distanced the approach to the rest of India by confining connectivity to a narrow $27-\mathrm{km}-$ wide Siliguri corridor, making it a 'remote land' and constraining access for movement of goods and people.

(Vision 2020 vol. I: 2, italics mine)

As a cursory reading of the four monographs cited in the previous section suggests, the NER of today was radically reconstituted in terms of its sociology, geography, economy and politics following the emergence and steady consolidation of British colonialism, the introduction of modernizing impulses under conditions of external domination and the dramatic re-articulation of the relationships between territory and identity. To therefore simply hold the partition of 1947 as a defining moment is not just flawed history but causes us to totally misread a range of critical social, cultural and political relationships that shape and continue to animate the NER.

Whilst these monographs, it must also be added as a further qualification, survey and offer a picture of change only in relatively few zones within the sprawling region of the NER, their conceptual implications are nonetheless compelling: that geography and history are 
co-constituted. And since the pasts never quite disappear even as the people of the NER seem to have embraced the full force of the modern, those distant imaginations and memories, it would be perhaps be only correct to assume, still have the potential of reviving under new circumstances and as plots in new narratives. The authors of Vision 2020 might yet be surprised, again.

\section{Notes}

1 This chapter is a substantially revised version of the article titled 'Making Backwardness: How to Imagine the Northeast as a Development Deficit' Eastern Quarterly, 4(3\&4): 207-17, 2007-08.

2 India's Northeast region currently refers to the states of Assam, Meghalaya, Mizoram, Tripura, Sikkim, Nagaland, Manipur and Arunachal Pradesh.

3 On post-development, see Escobar (1995); Rahnema and Bawtree (1997); Crush (1995); Sachs (2000/1997); Deb (2009). Also see for an excellent summary and discussion McGregor (2009: 1688-1702).

4 North Eastern Region: Vision 2020. Henceforth Vision 2020.

5 A Philosophy of NEFA, cited in Guha (2014: 263).

6 It is but obvious that I draw this claim from Carr (1964/1961). For an engaged discussion on E. H. Carr, see Evans (1999).

7 Ideally, I should have offered a broad and telling discussion of the growing importance of environmental history writing on the Northeast. Notably, the writings of Saikia (2011) and Sharma (2011). While I clearly stand guilty of omission, my argument in this essay however was to highlight geography as a political and territorial quality rather than an ecological one.

\section{References}

Appadurai, Arjun. 1996. Modernity at Large: Cultural Dimensions of Globalization. Minnesota: University of Minnesota.

Appadurai, Arjun. 2013. The Future as Cultural Fact: Essays on the Global Condition. Verso Books.

Baruah, Sanjib. 2007/2005. Durable Disorder: Understanding the Politics of Northeast India. New Delhi: Oxford University Press.

Baruah, Sanjib. 2017. 'India and its Northeast: Another Big Push without a Take-Off', in Amit Baishya and Yamin Saikia (eds.), Northeast India: A Place of Relations, Cambridge, New York, Delhi: Cambridge University Press: 45-67.

Carr, E. H. 1964/1961. What Is History? London: Penguin.

Cederlof, Gunnel. 2014. Founding an Empire on India's North-Eastern Frontiers (1790-1840): Climate, Commerce, Polity. New Delhi: Oxford University Press.

Crush, Jonathan (ed.). 1995. Power of Development. London and New York: Routledge.

Deb, Debal. 2009. Beyond Developmentalism: Constructing Inclusive Freedom and Sustainability. New Delhi: Danish Books. 
D'Souza, Rohan. 2008. 'Making Backwardness: How to Imagine the Northeast as a Development Deficit', Eastern Quarterly, 4(III \& IV): 207-17.

Escobar, Arturo. 1995. Encountering Development: The Making and Unmaking of the Third World. New Jersey: Princeton University Press.

Evans, Richard J. 1999. In Defence of History. New York and London: W. W. Norton \& Company.

Guha, Ramachandra. 2014. Savaging the Civilized: Verrier Elwin, His Tribals and India. Haryana: Allen Lane.

Karlsson, B. G. 2011. Unruly Hills: Nature and Nation in India's Northeast. New Delhi: Orient BlackSwan \& Social Science Press.

McDuie-Ra, Duncan. 2008. 'Between National Security and Ethno-Nationalism: The Regional Politics of Development in Northeast India', Journal of South Asian Development, 3(2): 185-210.

McGregor, Andrew. 2009. 'New Possibilities? Shifts in Post-Development Theory and Practice', Geography Compass, 3(5).

Misra, Sanghamitra. 2011. Becoming a Borderland: The Politics of Space and Identity in Colonial Northeastern India. New Delhi: Routledge.

Pachuau, Joy L. K. 2014. Being Mizo: Identity and Belonging in Northeast India. New Delhi: Oxford University Press.

Rahnema, Majid and Victoria Bawtree (eds.). 1997. The Post-Development Reader. London, New Jersey, Halifax, Nova Scotia and Cape Town: Zed Books, University Press Ltd., Fernwood Publishing.

Sachs, Wolgang (ed.). 2000/1997. The Development Dictionary: A Guide to Knowledge as Power. Hyderabad: Orient BlackSwan.

Saikia, Arup Jyoti. 2011. Forests and Ecological History of Assam (18262000). New Delhi: Oxford University Press.

Sharma, Jayeeta. 2011. Empire's Garden: Assam and the Making of India. Duke: Duke University Press.

Vision 2020: North Eastern Region, Vol. I, II and III. 2008. Government of India, New Delhi: Ministry of Development of North Eastern Region \& North Eastern Council. 


\title{
32 Post-development, democratic discourse and dissensus
}

\section{A critique of Vision $2020^{1}$}

\author{
Prasenjit Biswas
}

The essentially contestable ideas of 'development' and 'democracy' come to a global construction of social and economic realities, a kind of epistemic and cultural grounding into a representative discourse that follows a strategic path of choice and action. Such contestable ideas strategically become part and parcel of archaeology of power and self-identity. Given this entrapment of development discourse, the nationstate of India with its expansive market relations give rise to 'peripheries' marked by sharp differences with what can be called 'mainstream'. The difference can be contextualized in terms of a periphery such as Northeast India that gets represented in the mainstream by its 'lack' of development. Mainstream developmental agenda defines the 'lack' in terms of what is lacking in a region such as the Northeast. Looked from a different angle, the lack that Northeast apparently has can also be defined by what the developmental agenda itself lacks. This whole idea of 'lack' is not simply a negative idea, it is rather a complex outcome of developmental practices that ensues from the mainstream. The so-called shared experience of development between mainstream and periphery turns out to be a hierarchical flow of material and financial resources that assumes a centrist pattern. One understands the structuring of the centre-periphery relationship between the national mainstream and the Northeast around a bipolar 'exchange relation':2 (1) the existing embrace with marginality that struggles for sustaining an indigenous notion of wellbeing within the present institutional order governed by dominant ideological, economic and political rationality; and (2) the possibility of affirmation of difference by way of transforming the existing institutions of political economy. Both these poles of the exchange relation can be experienced from the ground of developmental processes as well as from the echelons of institutions. The chapter aims at critiquing this in-built 
polarity of developmental process that often reduces everything to a measurement of 'lack'.

The significant question that arises here is the very concept of 'development' and its 'lack'. As development happens in a hierarchy of actors starting from state/corporate to grassroot participants, can the lack of development be attributed to choices of those actors or to the outcomes that follow from such choices? Can the 'lack' be overcome by way of gross utilization of natural, mineral and water resources of the region? It implies the promotion of private accumulation and extractive surplus by the corporate in and out of the region. Such a policy of accumulation is prompted by the statist and corporate policy of 'maximum' utilization of the unutilized resources of the region. The rapid creation of a natural resource market in the region as an outcome of the policy of the governments at the Centre depletes the resource bases of communities living in the region. This doctrine of development issues from 'gap-filling', 'raising' or 'ameliorating' that create not just another gap/lack for the future, but causes irredeemable gaps within its constitutive elements like 'resource' and 'benefits'. This can be further grasped from the emphasis on the shift towards a service economy that simultaneously bases itself on material resources and at the same time converts it to the immaterial forms of production.

\section{Post-development blues}

The very context of Northeast India interrogates the intellectual and moral conformity with dominant paradigms of development. It invites us to explore and examine some of the significant critical issues raised by post-development thinkers. According to them, the possibility of noncapital non-surplus aspects of production and distribution excluded from the pale of capital is simultaneously a call for its inclusion as well as a recovery of the notion of wellbeing that constitutes an authentic way of life. The context of the Northeast, in its possibilities of being an area of plural 'modes of production' throws up immense challenge to the hegemony of development institutions. The challenge is post-hoc and twofold: developmental strategies and praxis fall far short of an active realization of capacity building and the effect of development introduce an element of conflict and discord between livelihood, resource and achievements. The source of such a challenge lies in the life-world of many of the communities and their relationship with others.

To conceive of the simultaneous coexistence of a variety of modes of production and their interrelations, one needs to take a post-structuralist position of 'relations of substitution and play' that such modes enter into. 
The interplay between 'domestic', 'intermediary' and 'capitalist' modes of production create the condition for 'dependence' of the region on the dominant mode of production. The primary sector of the region portrays the presence of 'domestic' mode of production, while the other two 'modes' arise only in collusion with each other. In fact, both the intermediary and capitalist modes enjoy a hierarchically higher status by keeping the 'domestic mode' under their service and control. In effect, there is only a backward extension of the capitalist market in the Northeast of India (Ahmed and Biswas 2004: 84). This implores a few possible outcomes: one, market extracts surplus out of primary resources, two, the consumption of finished goods requires a class of intermediaries who can generate 'market surpluses' through the money economy, three, for maintenance of dependency of the domestic and intermediary on the capitalist market, there is only a benign substitution of the one mode by another and four, the networks of capital merely reproduce those coexisting modes of production in their concrete spatial and social relations. The question that can be raised here is, in what ways can the nexus between capital and existing modes of production be broken?

Existing developmental models never attempt to break the nexus. Rather they reinforce the nexus through the channels of economy and politics. Developmental programmes that are based upon investment and profit-seeking enact itself on the presupposition of an existing nexus between capital and modes of production and hence it merely plays the role of a cosmetic without changing the 'production relations'. It merely strengthens the relations of production and reproduction by establishing a continuum between investment and accumulation through a given mode of development. To substantiate the point, let me quote two versions of a document here. The first one is called 'Peace, Progress and Prosperity in the North Eastern Region: Vision 2020', vol.1, 11 September 2007, which in a chapter entitled, 'A People Based Approach to Development' reads the following:

A development vision for the Northeast region (NER) of the country must focus on improving economic condition for the poorest, through the creation of economic growth opportunities. With about two-thirds of the population ekeing out an existence from subsistence farming, the growth will require a structural change in the region's economy over the next twenty years or so. The historical trajectory of all subsistence economies shows that this structural change must involve a shift in employment opportunities from agricultural to the industrial and service sectors. (Government of India 2008: 1) 
This so-called vision of development proposes to develop 'comparative advantages' and exploit it through trading by way of creation of markets, which is nothing but a proposition of shift from agricultural to cash-crop farming and creation of a small-scale low labour-intensive service sector. But how such a shift brings in a 'structural change' is not spelt out except an assertion such as, 'A common market in the region would crucially depend not only on the production of goods and services, but on the effective and efficient distribution of these' (Ibid 2008: Section III overview). This idea of developing a market mechanism and a shift from primary sector to tertiary sector does not alter the concrete spatial and social relations that manifest in the 'exchange relation' between the mainstream market and the periphery. It rather reproduces the internal processes of balancing and adjusting various sectors of production within the framework of capitalist mode of production. Further the idea of accumulation based on investment as expressed in 'market-based economy' in the Vision 2020 reproduces 'capitalist relations of reproduction' by affirming that decision of production must be based on 'comparative advantage', which lies, as per the document, in untapped natural resource endowment of NER and 'geographical contiguity' of the region with Southeast and East Asia. Both these sources of advantage, needless to say, are conceived keeping in mind the possibility of extracting natural resources and supplying them to the world economy across borders to Southeast and East. To drift the attention of resource endowed communities of Northeast from the processes of extraction, the document talks of 'industry' and 'service sector', although there is no real advantage in these sectors. The idea of a prospective service sector that can thwart the social and economic cost of natural resource extraction is what the document envisions in next two decades. Such a possibility of a blooming service sector at the edges of an extractive economy is the neoliberal assumption of the document that talks of 'participation' by people of NER in a globalized 'outside', the economy of Southeast and East. The 'outside' now constitutes the Centre, the East Asian hub, beyond the national boundaries that stands out as the goal of a regional integration of Northeast Indian economy with the Greater Mekong Region (GMR).

Much of this neoliberal fad gets a clearer exposition in the second version of the same document entitled the same, but dated December 2007. On the issue of comparative advantage, it goes here to the specifics:

[T] he rich resource endowment of the region can be harnessed to improve the living conditions of the people only when the sectors having comparative advantage are identified and enabling 
conditions created for investment promotion in these sectors. The focus on agro-processing industries, modernization and development of sericulture, investments in manufacturing units based on the resources available in the region, harnessing the large hydroelectric power generation potential and focus on developing services such as tourism will help to accelerate development and create productive employment opportunities.

(Ibid: $3-4)$

Notwithstanding the fad of 'investment promotio' and a bubonic mix up between agriculture and industry, hydropower and tourism, the Vision retained its originary patronizing tone and tenor of talking above the shoulders of people, for whom this document is crafted. Read this ogling paragraph:

The quest for ethnic and regional identity and nationalism, and ideo-logical motivations have fomented a climate of insurgency in several parts of the Northeastern region, which has led to political fragmentation of the region; the climate has been further fuelled by dissatisfaction with hegemonic domination and frustration with the slow pace of develop-ment. The difficult terrain, dense forest cover and open borders with Myanmar and Bangladesh have provided a congenial environment for this.

(Ibid: 6)

The paragraph began indeed with a much humbler statement about the 'enormity of understanding the region' that ends up blaming the ongoing social movements that often took the path of armed resistance, which, according to the document, made use of 'dense forest covers and open border with Myanmar' as well. The paragraph makes light of 'hegemony' and dissatisfaction with it, as if it would change the scene by an enumeration of palliatives that will satisfy the 'dissatisfied' people. The document that appreciated the natural resource advantage of Northeast, now deplores the 'dense forest cover', which incidentally grew over centuries because of an active human-nature symbiosis as ingrained in the life-world of many of these bordering communities and tribes. If development is a matter of outlook and attitude at a fundamental level, the revised draft exhibits an attitude of condescension, which actually constitutes the neoliberal strategy of blaming the deprived and the underdeveloped for their state of being. The document applies the discursive strategy of 'consensus building' for the already existing hegemonic economic strategies by enlisting support from a section of the society through the means of 'public hearing'. 
The voices of support and dissent find a place only at the 'end' of the text and the text remains silent about how it culled all these diverse and variegated public opinions in finalizing the document.

\section{Rethinking the democratic discourse}

Post-development theorists have pointed out that 'consensus building' over development measures through public discourse has been the most important strategy for providing 'alternatives to development' (Pieterse 2000: 175-91). In the context of Northeast India, the neoliberal frame of development propounded in terms of market relations advance an idea of 'substitution' of modes of production without changing the 'production relations'. The idea of substitution works not as a replacement but as an introduction to a new mode. For example, substitution of shifting agriculture by settled agriculture, agriculture by horticulture and other such cosmetic measures are provided as 'alternative' to the existing cultures of cultivation. The alternative is supposed to be higher, better and advanced, instead of being an alternative to such 'developed' method of production. This emphasis on the 'developed alternative' leads to the rationality of 'realising the vision' in terms of a 'new strategy' (Vision 2020: 17-9 of the revised Vision) that identifies 'deficits' 3 in physical terms. Post-developmentalists point out that the absence of any exercise of agency on the part of people themselves marks how the developmental strategy condones itself from enabling the agency of people. This absence of reciprocity between strategic thinkers and the people for whom it is thought out gets compounded with a reductionist notion of 'people' understood from an already determined set of priorities. Here this is reflected in the guiding statement that brings out the real motive behind the document,

Given the large number of stakeholders, the variety of groups demanding various concessions, and the international dimension mired in diplomatic tangles, various issues need to be addressed delicately, using both the carrot and the stick.

(Ibid: 19-20)

The strategy of using 'carrot and stick' is how the document spills the beans of 'paradigm shift in development strategy'. Such a strategy is a bleak adage of an already existing mainstream perception of the people of the Northeast as 'other'. In terms of post-development theory, the practice of non-conformism on the part of the Subjects 
of development strategies, especially any strand of resistance, is often coerced. ${ }^{4}$ The ideas of such coercion, albeit, is represented in the form of a discursive choice, as the document chooses to speak in an avantgarde subtitle, 'Harnessing resources for the benefit of the people' for its subjects,

The people would like to see the large river systems converted into a source of prosperity, and mineral wealth used to create opportunities to increase employment and incomes. They would like to harness the vast hydroelectric energy potential and use the comparative advantage to expand economic activities in the region. They would like to see that the global public goods they provide through the vast forest cover is recognised and given adequate compensation.

(Ibid: 14)

The carrot of 'cash value' of natural resources is weaved with the mincemeat of 'compensation' for all the euphemistic global public good that the region possesses in the un-spoilt and pristine state of nature. Apart from what the post-developmental thinkers conceived as the indignity of speaking for others', the passage is also an example of re-articulation of the relationship between the mainstream and periphery such that in the sphere of economic transactions, the dominant can speak for its Subjects. It is also very interesting to note that the voice of guardianship in matters of economic decisions is an assumed authority that takes over by recognizing the existing global good by paying 'compensation' to those who lose their rights and voices. The agenda of 'giving adequate compensation' is an alchemy of words bolstered by the hidden stick that seeks to decide to 'convert large river systems' into a source of prosperity. This is an implicit expression of construction of large river dams and displacement of people by paying them compensation - a reenactment of the Narmada experiment by an experienced Indian state.

The Vision in its dissoluteness of senses uncovers the most inaccessible of all resources, the very normative core of communities of the Northeast into an open fragment of a flow of globalized circuit of cash, to which it hasn't opened itself up. This gives the vision a temporalized frame of opening up the closures of its immediate context, but it leads us to an exceeding of the context by a logic of incapacity for coming to terms with the life-world of peoples. The blindness of the Vision is purveyed in this dangling prose of otherness,

An important part of capacity building is increasing awareness in the rest of the country about people in the NER, and within 
the region itself through increased social interaction. This would require promotion of sports and cultural exchanges within the Northeastern region as also between the region and the rest of the country. The rich cultural heritage of the region can be capitalised on by engaging the youth in creative activities while promoting a two-way understanding with the rest of the country. Organising annual music and dance carnivals in different parts of the NER with competitions at the district, state and regional levels would increase youth involvement in creative activities. These events could become important tourist attractions, with national and international participation, which, with good publicity should attract a large number of tourists, who can be ferried through chartered flights.

(Ibid: 27)

This is an articulation of building up cultural capital and feeding it into a circulating global economy. But how these extraordinary and specific cultural resources can be sustained within a trajectory of cashcontract-tourist economy without 'commoditification' is the moot question that Post-development thinkers ask for. The Vision continuously curbs and transmutes the existing forms of social and cultural practices of the region to fit them to the economistic drill, which is a return to a Hobbesian notion of 'order'. ${ }^{5}$ How such an order is given a content in the Vision is an ideological ploy, whereby, the relationship between NER and Southeast and East Asia is given a phantasmal description in terms of fly-by-night trading and connectivity. The idea of 'geographical contiguity' with the ADB-built trans-Asian road, rail and air connectivity now replaces the old nationalist myth of 'Integration' and substitutes it with a signifier of 'regional economic integration' through bodies like BIMSTEC. The transnational fantasy simultaneously uses the cultural symbols and practices for sustaining the global connectivity, while at the same time, it reduces cultural values and artefacts to a mere instrument of circulation of capital.

The experiment called 'integration of Greater Mekong Region' into the East Asian economy by sheer force of transport, infrastructure and cash is borrowed in the Vision document by way of eulogizing the growth of the GMR, while it remained conspicuously silent about the ongoing 'drain of resources' from NER to the larger mainstream market. The returns accrued to public investments in the form of flight of capital from the region poses the greatest challenge to the framework of development proposed by the Vision, as such investments in natural, human and other resources actually lead to a quick flight of capital from NER. The significant aspect of this flight lies in incursion 
of non-capital that exists in the region in the form of cultural resources as well in the form of natural resources. It has its parallel in the functioning of various modes of production, especially in the subsumption of the domestic mode of production by the capitalist mode that now attempts to establish 'connectivity' with the Asian economy. Such connectivity ensures the partnership role of the NER in the flight paths of capital, even though it may exist only as a corridor between India and Southeast, while it seeks to join the connected networks of trans-Asian pathways through its capillary geographical contiguity with Myanmar and Bay of Bengal. What waits on this serpentine connectivity is the reduction of NER into a mere node in the already surrounded by China sea and surface routes. It won't be an apocalypse of sort if NER gets to encounter the dragon before the rest of India wakes up in the flutter of its flashing tail.

\section{Dissensus}

This entire 'consensus building' discourse of vision places emphasis on 'responsive governance' by maximizing self-governance and generation of resources. On the face of it, such an exercise is part of a strategy of inclusion that plays the truant's tune in an orchestra of global capital. This certainly has an experiential dimension. Various accounts of this experience begin from the affirmation of being different and being an other to the mainframe project of nationalist hegemony. The otherness is not self-ascribed, but it is the by-product of the relationship between the misrecognized cultural particularity of various ethnic and cultural identities of the NER and the dominant discourse of national identity. The misrecognition is confronted by social identities from below, the phenomenon of which is entirely misrecognized by the Vision in following terms,

underdevelopment is caused by insurgency and terrorism and therefore all developmental efforts will be in vain, unless political volatility is controlled simultaneously. Thus, the development vision for the NER should focus on the primary requirements of safety and security in these states. However, there is an alternative view which maintains that insurgency is the cause of underdevelopment, in which case the vision would be to hasten the pace of development to solve the problems of insurgency in the long run. However, the causality runs both ways. That is, insurgency and unemployment resulting from poor economic development feed on each other. Thus, poor economic performance results in insurgency and hence 
the solution of insurgency lies in the achievement of rapid economic progress of the region. If this can be taken as a legitimate position then perhaps one need not worry too much about the insurgency, which would be solved by achieving faster growth.

(Ibid: 30)

Needless to say that the Vision establishes a causal nexus between insurgency and underdevelopment as an economistic subterfuge for the 'vicious cycle' between investment, growth and poverty. Further it confuses between reasons and causes in the realm of social phenomena. Apart from these methodological short-circuits, the Vision tom-toms economic growth as a solution to Insurgency. That there are greater cultural and social reasons for affirmation of self-identity against the hegemony of a unified Vision is completely obliterated from this narrow perspective on economic development.

The Vision does not build up on critical scholarship on the link between insurgency and underdevelopment. In a sense, the Vision promotes certain stereotypical ideas about Northeast through its economistic vision that fails to recognize the lived experiences of people. The binary between development/underdevelopment, insurgency/peace, governance/terrorism are deployed without any context-sensitivity in order to formulate a god's-eye-point-of-view that reduces multiple possibilities of meaning of social action to a pre-ordained discourse of economic growth. The Vision does not celebrate the inner creativity of the people of Northeast in their concrete social and economic practices and turns a blind eye on these practices. This is purging out of values and beliefs from the realm of rational calculation, the basis of which lies in ideological domination and in the colonizing function of technical-manipulative and objective knowledge. The Vision merely cites the 'evidences' to confirm its hypothetical take on problems faced by Northeast as a region. It contextualizes the idea of 'interest' of development, in which People are supposed to partake as a fait accompli. The word 'Vision' here is more like a game plan or a blueprint for operationalizing a structured scheme of thought, the body of which merely seeks a confirmation of all its tailor-made inferences by way of fitting the 'facts of life' into the premises of a derivative discourse.

This is not first of its kind that the Vision gives a subsidiary role to the agency and choice of self-representing collectives, but this has been the mainstay of subversion of political meaning within socioeconomic interests. If the realm of the political is taken to be the terrain in which the so-called interests are contested and the notion of autonomy is re-constituted. How this contest of meanings is subverted by the 
hegemony of global political economy is represented in the Vision by way of appropriation of different voices. Let me cite an instance from the Vision. In one of the public hearings held in Nagaland, Rosemary Dzuvichu termed the document to be 'patronizing' (Ibid: 270), while Sanjeeb Kakoty suggested 'social audit' (Ibid: 266) for the projects implemented under the Vision. The document attempts to reverse such critical difference that not only positions the critics outside the discursive frame of the Vision, but such criticisms express the stifled truth and re-establish the connection with reality.

As the Vision suggested a transition from primary to tertiary sector of production, it charts a course of passage from material to immaterial forms of production. But this passage in the periphery of Northeast region has to follow the mode of production of global capital, which is to carve a margin to the global network of production. From the perspective of integrating NER into the global market, the immaterial kind of production in the form of symbolic-analytical functions carried out by financial brokers, for example, cannot happen in an autonomous manner. What the Vision formulates is the changed role of the Northeast into a collaborator of globalization that begins with changes in physical aspects of connectivity and infrastructure to be followed by an abstract collaboration by material labour. Such a process ensures compatibility between hierarchical network of capital and the immaterial form of labour, which can be embedded in the physical infrastructure. The social-symbolic function of distinct ethnic cultures shall merely remain as one of the incomplete constituent of material labour, but it can't survive for long in the virtual networks of global capital.

\section{Notes}

1 This chapter was first published in Eastern Quarterly, 4(3\&4): 178-88, 2007-08.

2 'Exchange relation' is a relation of commodity-exchange that involves the matrix of social relations between tribes/communities/ethnic identities and the dominant institutional forms. Exchange relation assumes the form of social relations by way of converting it into rules of commodity exchange.

3 The deficits identified by Vision are fivefold: 'a basic needs deficit; an infrastructure deficit; a resource deficit; and a two-way deficit of understanding with the rest of the country. To this should be added the governance deficit'.

4 The process of victimization through 'development agenda' is theorized by Escobar, following Focault, in the notion of a struggle to reconstruct the connection between truth and reality. See Escobar (1995: 223).

5 Hobbesian notion of order emanates from the will of the ruler as the only unified will that the community can have - a will that is deemed to be better and superior to the disorder emanating from the state of nature that threatens the order of the society. For a full discussion on Hobbes, see Laclau (1996: 62). 


\section{References}

Ahmed, Rafiul and Prasenjit Biswas. 2004. Political Economy of Underdevelopment of North-East India. New Delhi: Akansha.

Escobar, Arturo. 1995. Encountering Development: The Making and Unmaking of the Third World. Princeton: Princeton University Press.

Government of India. 2008. North Eastern Region: Vision 2020, Vol. I, II and III. New Delhi: Ministry of Development of North Eastern Region \& North Eastern Council.

Laclau, Ernesto. 1996. Emancipations. London: Verso Books.

Pieterse, Jan Nederveen. 2000. 'After Post Development', Third World Quarterly, 21. 


\section{Index}

action programme 131

administrative arrangement 13,188

administrative manipulation 143

administrative structures 389

AFSPA/Armed Forces (Special Powers)

Act 19, 30, 37-8, 46-7, 55-64,

74-5, 78, 122, 224-5, 354, 357

alcoholism 336, 337, 367

anti-migrant agenda 162

antiphonal character 284

armed opposition groups 19, 41-2, 45, 47, 49, 132, 136

Assamese identity 20, 362-3

Autonomous District Councils 16, 187, 208, 365, 396

autonomy $7,16-17,19,21,30,33$, $84,92,95,98,100,107,113,116$, 130, 187-9, 190-6, 199, 202-5, 208-9, 217, 227, 235-6, 244, 253, 261, 345, 361-2, 365, 366-7, 462

bamboo instrument 289

Bangladesh 11, 12, 14, 20, 91, 132, 139, 140, 153-64, 319, 323, 380, 386-7, 389, 402-3, 429, 440, 446, 449, 450, 457

Bangladesh war 91

Bihu 21, 279-86

Bodoland movement 22, 361-2, 365-6 body politic $20,215,216,217,218$, 220, 221

border fencing 156-7, 164

Border Security Force/BSF 60, 158-9, 164

Bordoloi Committee 189, 191

Borok people 139, 141-2, 146-7 breach of contract 217

bundles of contradictions 253, 257

ceasefire agreements 41,46

centralized decision making 236

chain migration 177,179

Christian literature 325, 327

Church 31, 35, 47, 100, 104, 105, 254, $290,326,327,329,331,441$

civic nationalism 95, 105-7, 109

civilizational unity 97

civil society $3-4,7-8,13,21,38-9$, $47,128,136,215-20,222-4$, 226-7, 229-32, 236-9, 241-5, 258-9, 364, 398

colonial interruption 282

colonialism $15,83,115,136,189$, 251-4, 256-7, 261, 288, 348, 423, 447-8, 450

colonial modernity 21, 251, 255

colonial polity 130

common public authority 223

communal disharmony 147

communism 118

community ownership 192, 399

composite culture 29, 30

conflictual growth 128,135

consolidation of democracy 223, 226, 232

constitutional arrangement 396

constitutional monarchy 116

context-sensitivity 462

cosmetic federalism 45

cultural appropriation 288-9, 295

cultural identity 84, 209

cultural studies 298 
degree of autonomy 217

democracy 12, 16, 39, 50, 62, 69,

78, 79, 117, 195, 196, 207, 223, 224, 225, 226, 228, 229, 230,

$231,232,241,347,370,453$

democratic rights $38,58,59,60,63,69$

demography $153,154,361,410$

deportation 91, 147, 154, 159, 160, 162,319

development 39, 44-5, 83-6, 88-91,

$95-8,104,109,122,129,132-7$,

142, 146, 187-96, 202, 206, 208-9,

218-19, 226-7, 230, 235, 241, 252,

260, 265-72, 274, 275, 293, 311,

$313,315,323,326,329-31,352$,

$365,377,379-85,387-98,401-4$

development catalyst 187,195

development challenges 19, 436

development frontier 132, 134

dissenting nationalism 114, 119, 123

dominant political class 147

dramatic monologue 303

ecological settings 289,291

ecology based economy 237

efficacy of autonomy 188

elitist historiography 83

employment 18, 22, 78, 85-7, 141, 163, 168-81, 199, 205, 218-19, $236,265,274,335,380,382,385$, 390, 398, 440, 444, 455, 457, 459, 461

ethnic insurgencies 95, 128

ethnic minority 29

ethnic polarization 87

ethno-national ideologies 127

exclusive homelands 121

experimental music 292

extractive economy 266, 456

extra-judicial killings 34

extra-textual 303

flyover $21,265-75$

folk rock 298

forward policy 59,62

frontier areas 100

gender 172, 176, 178, 280, 334, 338, 345, 347-51, 353, 358, 362, 366, $368-71,399$ gendered actors 367

gendered body 347

gendered process of nation making 368

gendered resistance 22,345

gendered space $347,348,350$

geo-body 130

global capital 265, 428, 461, 463

grievance redressal mechanism 225

guerrilla warfare 41,356

hao music $290-1$

hegemonic space 115

higher aspirations 168

Hill Area Development Projects 397

historical consciousness 113-14

history writing $261,362-3$

holistic development 189

humanitarian norms 57, 61

human rights $7,12,19,29,32-6$, 38-9, 227-8, 245, 253, 299, 352, 366

Human Rights Alert (HRA) 227

identification 96, 154, 159-60, 220, 243-4, 301, 349, 409-10

identity $3,4,7,10,11,15-17,20,58$, $84,86,89,92,104-5,122,128$, 139-40, 187-9, 193, 209, 217, 228, 242, 252, 254-5, 260, 280, $306,315,319,321,334,336,348$, 350-1, 355, 358, 361-6, 369-70, $379,396,414,446-8,450,453$, 457, 461-2

identity politics $10,228,255,370$

illegal migrants $153,158-63$

impunity $19,56-7,63,78,220,245$

Indian government $32,42,44-6$, 101-3, 108-9, 130, 156, 336, 432

Indian national movement 83,98 indigenous people 139-45, 147, 155, 235

individual authorization 215

Indo-mongoloid groups 86,89

influx of immigrations 427

instrument of accession 42

interconnected media 298

inter-textual 303

Kuki-Chin 132-3 
lack of development 226, 401, 453, 454

land alienation 134, 139, 141, 144-7, 397

land laws 236

Land Reforms Act 143-6

law 19-20, 30-2, 34, 39, 42, 46, 53, 56-9, 64-5, 69-70, 72, 74, 76, 78-9, 102, 117-18, 144-6, 191-3, 198-9, 204, 215, 217-24, 226, 228, 230-2, 236-7, 245-6, 313, 321, 396-7, 403-4, 414-15, 433

literary tradition 22,315

lived experience 121, 349, 354, 414, 462

Look East Policy 19, 23, 132, 135 , 244, 266, 387, 438

Loukrakpam Jayenta 298

Manab Adhikar Sangram Samiti (MASS) 227

Manipur (Hill Areas) District Councils Act 205

Manipur Chanura Leishem Marup 227-8

Manipuri literature 22, 311-14, 316-19

market forces 219, 244, 404

martial law 59

masculinity $285,306,336-7,347$, $350,356-7$

Memorandum of Settlement 48, 145 merger agreement 117

militancy 47, 49, 83, 102, 379-80, 390

military civic 56

minority 19, 29-30, 72, 140, 142, $155,195,295,302$

minority rights 195

missionaries 6, 22, 87, 99-100, 255, 294, 317, 323-5, 327, 329

mistaken identity 58

Mizo Peace Accord 48

mode of literation 324

modernism 257, 298

modernity 4, 15-18, 21, 114, 136, 251-6, 258, 261, 267-71, 288, 317, 445,449

multi-nationality 84, 95, 97-8, 109

musical instruments 282, 290, 292 musical interplay 302, 304, 306

music pedagogy 306

mythic beliefs 130

Naga army 335-6

Naga Club 100

Naga-inhabited areas 45, 99-100, 102, 104, 106, 109

Naga movement 98, 102-4, 106-8, 337

Naga Peoples Movement for Human Rights (NPMHR) 227

national question $20,59,97,103$

national security $5,11-12,18,30$, 58-9, 62, 71-2, 132, 137, 157, 202, 236, 412, 438

National Security Act 59

National Volunteers 145

nationhood 56, 64, 83, 113, 115, 121 , 129, 132, 243, 294, 319, 361, 364

North Eastern Council 397

North East Frontier Agency 34, 425

old separatist tendency 190

organised life 223

organised sector 173

Panchayati Raj 207

Pan Manipur Youth League 119

participatory mode 226

patriarchy $22,334-5,337-8,345$,

$351,370,373$

performative agency 354

Phizo, Angami Zapu 43, 101, 103, 109

pluralism 127, 245

plurality of reading 300

polarized milieu 164

policy intervention 412

policy of assimilation 190

political aspirations $49,90-1,132$, 205, 288

political dominance 251

political economy 22, 23, 350, 396, 424, 437, 453, 463

political elites $129,224,226,230$

political patronage 238

political songs 298-9, 302

political violence 19, 21-2, 294, 334, 338,351

politics of identity 228,365 
popular lyrics 299

post-colonial instrumentalities 218

postmodern hybridity 289,295

power and politics 351

Prevention of Seditious Meetings

Act 59

Prevention of Terrorism Activities

Act 59

princely state $98,116,140,199,379$

private sector $169,170,171,176$, 180, 181, 237, 392, 393, 427

productive base $237,426,429,431$, 434

productivity $139,393,415,425,444$

protest singer 299

psychology of pain 60

public feeling 300

public-private-community

partnership 383

radical reformist 299

receiving communities $17,21,251-4$, 257-9

Reddy Committee 50

reformative movement 306

regional disparities 394-5, 407

reparative justice 215

reserved areas 142-3

resistance $12,20-2,45,49,91,95$, $102,109,115-16,119,132,136$, 239, 240, 243-4, 255, 265-6, 315, 319-20, 333-5, 338, 340, 345, 350, $352,355,358,363-4,457,459$

resistance movement 20,95, 109, 320, 345

resource plundering 432

responsible dissent 237, 245

Rewben Mashangva 288-9, 294-5

ritual celebration 131

scattered selves 254

scream 299, 302-6, 339

self-appropriation 129

self-determination $5,18,21,30,61$, $95,98,107,141,190,253,261$, 294, 379

self-governance $209,254,439,461$

service delivery 226

sexual identity 348 sexuality $21,279-80,284$

sexual violence $350,366,370$

Shillong Accord 43, 103

shrinking resources 43, 153, 156

Simon Commission 100

Sixth Schedule 21, 101, 187-96,

201-9, 218, 235, 365, 396, 438

social dissent 298-9

social protest $299-300$

sovereignty $21,30,62,64,107,108$,

$117,129,130,205,217,223$,

$226,230,231,357,365$

special federal relationship 45, 217

state of exception 20,59

stereotypes $261,295,348,350-1,399$

sub-nationalism 84

supranational consciousness 98

Supreme Court 32, 37-8, 56, 63-4,

$75,77,160$

symbolic and expressionist songs 298

Tapta 298-306

tea plantation $87,99,425$

territorialization 129,132

text 3, 6, 22, 298-300, 313-16, 319,

$329,331,334-5,347,351,357$,

$437,444,446,458$

tradition and identity 187

tradition and modernity $15,17,18$, 21,252

transfer of ownership 235

translations 325

tribal areas $115,187,188,190,201$, 202, 204, 207, 393, 426

Tribal Area sub-plan 397

tribal autonomy 236

Tribal Development Agency Projects 397

tribal laws 192; exteriority 9, 11,

$15-16$; interiority 11,15

trusteeship zones $382-3$

unbalanced economy 391, 397, 403

undemocratic laws 232

underdevelopment 23, 423, 425-6, 428, 430-1, 461-2

unemployment $22,168-70,172-6$,

$178,180-1,265,380,461$

uninhibited dependence 188 
United National Liberation Front 119, 122, 127

Unlawful Activities Prevention Act 59

Uranium Corporation of India 235

victimhood 355,365

virtues of asymmetry 187
Vision 2020 218, 226, 397, 436-7, 439-44, 446-7, 449-51, 453, $455-6,458$

war on people 59

women's organization 367

work permits 157 